
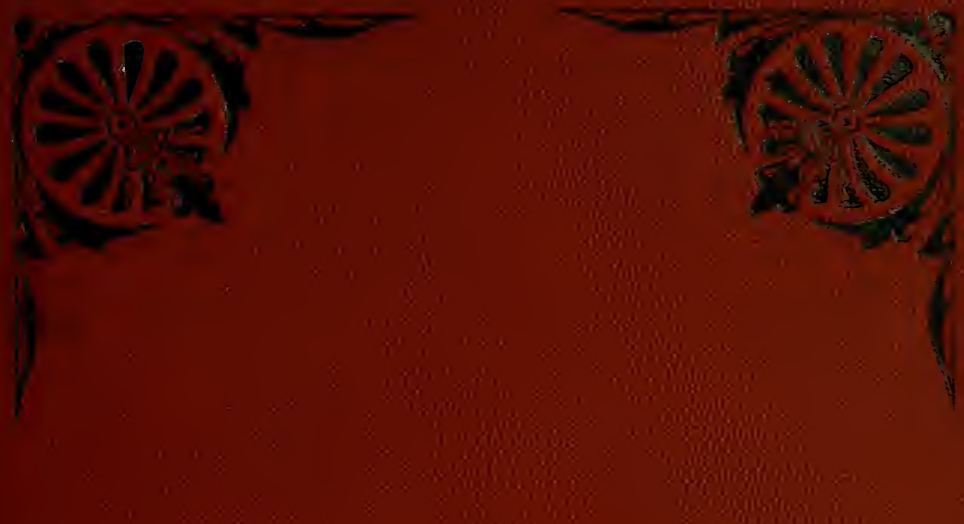


\section{I B R A $\mathrm{Y}$}

OF THE:

Theological Seminary, PRINCETON, N. J.

Cirse

sthelf

Booli

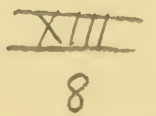






INSECTIVOROUS PLANTS. 


\section{BY THE SAME AUTHOR.}

ON TIIE ORIGIN OF SPECIES BY MEANS OF NATURAL SElection; or, The Preservation of Favored Races in the Struggle for Life. New and revised edition. 12mo. Cloth. 450 pages. Price, $\$ 2.00$.

TIIE DESCENT OF MAN, AND SELECTION IN RELATION TO SEX. With Illustrations. New edition, revised and augmented. 12mo. Cloth. 704 pages. Price, $\$ 3.00$.

A NATURALIST'S VOYAGE ROUND THE TORLD; or, A JOURNAL of Researches into the Natural History and Geology of tie Countries visited during the Voyage of H. M. S. Beagle, under the command of Captain FitzRoy, R. N. 12mo. Cloth. 530 pages. Price, $\$ 2.00$.

THE EXPRESSION OF THE EMOTIONS IN MAN AND ANIMALS. With Photographic and other Illustrations. 12mo. Cloth. Price, $\$ 3.00$.

THE THEORY OF DESCENT, AND DARWINISM. By Prof. Oscar Schmid, University of Strasburg. 12mo. Cloth. Price, $\$ 1.50$. 


\title{
INSECTIVOROUS PLANTS.
}

By CHARLES DARIVIN, M.A., F.R.S., ETC.

\author{
WITH ILLUSTRATIONS.
}

\section{- NEW YORK: \\ D. APPLETON AND COMPANY, 549 AND 55I BROADWAY. 1875 .}





\section{CONTENTS.}

\section{CHAPTER I.}

Drosera rotundifolia, or the Comnon Sun-Dew.

Number of insects captured - Description of the leaves and their appendages or tentacles - Preliminary sketch of the action of the various parts, and of the manner in which insects are captured - Duration of the inflection of the tentacles - Nature of the secretion - Manner in which insects are carried to the centre of the leaf - Evidence that the glands have the power of absorption - Small size of

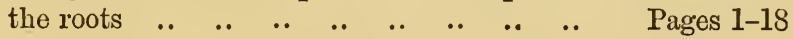

\section{CHAPTER II.}

The Movements of the Tentacles from the Contact of - SOLID BoDIEs.

Inflection of the exterior tentacles owing to the glands of the disc being excited by repeated touches, or by objects left in contact with them - Difference in the action of bodies yielding and not yielding soluble nitrogenous matter - Inflection of the exterior tentacles directly caused by objects left in contact with their glands - Periods of commencing inflection and of subsequent re-expansion - Extreme minuteness of the particles causing inflection-Action under waterInflection of the exterior tentacles when their glands are excited by repeated touches - Falling drops of water do not $\begin{array}{lllllllll}\text { cause inflection .. } & . . & . . & . & . . & . . & . . & . . & 19-37\end{array}$ 


\section{CHAPTER III.}

Aggregation of the Protoplasir within the Cells of the Tentacles.

Nature of the contents of the cells before aggregation - Various causes which excite aggregation - The process commences within the glands and travels down the tentacles - Description of the aggregated masses and of their spontaneous movements - Currents of protoplasm along the walls of the cells - Action of carbonate of ammonia - The granules in the protoplasm which flows along the walls coalesce with the central masses - Minuteness of the quantity of carbonate of ammonia causing aggregation-Action of other salts of ammonia - Of other substances, organic fluids, \&c.-Of water - Of heat - Redissolution of the aggregated masses Proximate causes of the aggregation of the protoplasm Summary and concluding remarks - Supplementary observations on aggregation in the roots of plants .. $\quad$ Pages 33-65

\section{CHAPTER IV.}

\section{The Effects of Heat on the Leaves.}

Nature of the experiments - Effects of boiling water - Warm water causes rapid inflection - Water at a higher temperature does not cause immediate inflection, but does not kill the leaves, as shown by their subsequent re-expansion and by the aggregation of the protoplasm - A still higher temperature kills the leaves and coagulates the albuminous

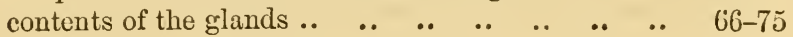

\section{CHAPTER V.}

\section{The Effects of Non-xitrogenous and Nitrogenous Organic Fluids on the Leaves.}

Non-nitrogenous fluids - Solutions of gum arabic - Sugar Starch-Diluted alcohol-Olive oil-Infusion and decoction of tea-Nitrogenous fluids - Milk - Urine - Liquid albumen - Infusion of raw meat - Impure mucus - Saliva - Solution of isinglass - Difference in the action of these two sets of fluids - Decoction of green peas - Decoction and infusion of cabbage - Decoction of grass leaves 76-8t 


\section{CHAPTER VI.}

The Digestive Power of the Secretion of Drosera.

The secretion rendered acid by the direct and indirect excitement of the glands - Nature of the acid - Digestible substances - Albumen, its digestion arrested by alkalies, recommences by the addition of an acid - Meat - Fibrin Syntonin - Areolar tissue - Cartilage - Fibro-cartilage Bone-Enamel and dentine - Phosphate of lime - Fibrous basis of bone-Gelatine - Chondrin - Milk, casein and cheese - Gluten - Legumin - Pollen - Globulin - Hæmatin -Indigestible substances - Epidermic productions - Fibroelastic tissue - Mrucin - Pepsin - Urea - Chitine - Cellulose - Gun-cotton-Chlorophyll - Fat and oil - Starch - Action of the secretion on living seeds - Summary and concluding $\begin{array}{lllllllllll}\text { remarks } & . & . & . & . & . & . . & . . & . . & . & \text { Pagies } 85-135\end{array}$

\section{CHAPTER VII.}

\section{The Effects of Salts of Amionia.}

Manner of performing the experiments - Action of distilled water in comparison with the solutions-Carbonate of ammonia, absorbed by the roots - The vapour absorbed by the glands - Drops on the disc-Minute drops applied to separate glands - Leaves immersed in weak solutionsMinuteness of the doses which induce aggregation of the protoplasin - Nitrate of ammonia, analogous experiments with - Phosphate of ammonia, analogous experiments with - Other salts of ammonia - Summary and concluding remarks on the action of salts of ammonia .. $\quad . \quad \cdot 136-173$

\section{CHAPTER VIII.}

The Effects of variods other Salts, and Acids, on the LEAVES.

Salts of sodium, potassium, and other alkaline, earthy, and metallic salts - Summary on the action of these salts Various acids - Summary on their action ... .. $\quad$ 174-198 


\section{CHAPTER IX.}

The Effects of certain Alkaloid Poisons, other SubstaNCES AND VAPOURS.

Strychnine, salts of - Quinine, sulphate of, does not soon arrest the movement of the protoplasm-Other salts of quinine - Digitaline - Nicotine - Atropine - Veratrine Colchicine - Theine - Curare - Morphia - Hyoscyamus Poison of the cobra, apparently accelerates the movements of the protoplasm - Camphor, a powerful stimulant, its vapour narcotic - Certain essential oils excite movement Glycerine - Water and certain solutions retard or prevent the subsequent action of phosphate of ammonia-Alcohol innocuous, its vapour narcotic and poisonous-Chloroform. sulphuric and nitric ether, their stimulant, poisonous, and narcotic power - Carbonic acid narcotic, not quickly poisonous - Concluding remarks $\quad$. $\quad$.. $\quad$.. Pages 199-228

\section{CHAPTER X.}

On the Sensitiveness of the Leaves, and on the Lines of Transmission of the Motor Impulse.

Glands and summits of the tentacles alone sensitive - Transmission of the motor impulse down the pedicels of the tentacles, and across the blade of the leaf - Aggregation of the protoplasm, a reflex action-First discharge of the motor impulse sudden-Direction of the movements of the tentacles - Motor impulse transmitted through the cellular tissue - Mechanism of the movements - Nature of the motor impulse - Re-expansion of the tentacles .. 229-261

\section{CHAPTER XI.}

Recapitulation of tile Chief Obsenvations on

Dirosera rotundifolis. 


\section{CHAPTER XII.}

On the Structure and Movements of sone other SPECIES of Drosera.

Drosera anglica-Drosera intermedia-Drosera capensis-Drosera spathulata-Drosera filiformis -Drosera binata-Concluding.

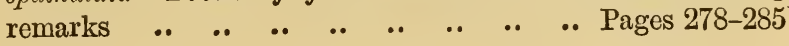

\section{CHAPTER XIII.}

\section{Dionea MUSCIPULA.}

Structure of the leaves - Sensitiveness of the filaments - Rapid movement of the lobes caused by irritation of the filamentsGlands, their power of secretion-Slow movement caused by the absorption of animal matter-Evidence of absorption from the aggregated condition of the glands-Digestive power of the secretion-Action of chloroform, ether, and hydrocyanic acid-The manner in which insects are captured - Use of the marginal spikes - Kinds of insects captured The transmission of the motor impulse and mechanism of the movements - Re-expansion of the lobes $\quad . \quad 286-320$

\section{CHAPTER XIV.}

\section{Aldrovanda vesicolosa.}

Captures crustaceans - Structure of the leaves in comparison with those of Dionæa-Absorption by the glands, by the quadrifid processes, and points on the infolded margins Aldrovanda vesiculosa, var. australis - Captures prey Absorption of animal matter-Aldrovanda vesiculosa, var. verticillata_Concluding remarks ..

\section{CHAPTER XV.}

Drosophyllum - Roridula - Byblis - Glandular Hairs of other Plants-Concluding Remarks on the Droseracee.

Drosophyllum-Structure of leaves-Nature of the secretionManner of catching insects-Power of absorption-Digestion of animal substances-Summary on Drosophyllum-Roridula - Byblis - Glandular hairs of other plants, their power of absorption - Saxifraga - Primula - Pelargonium - EricaMirabilis - Nicotiana - Summary on glandular hairs - Con-

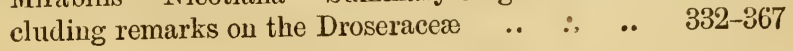




\section{CHAPTER XVI.}

\section{Pinguicula.}

Pinguicula vulgaris - Structure of leaves - Number of insects and other objects caught-Movement of the margins of the leaves - Uses of this movement - Secretion, digestion, and absorption - Action of the secretion on various animal and vegetable substances - The effects of substances not containing soluble nitrogenous matter on the glands-Pinguicula grandiflora - Pinguicula lusitanica, catches insects - Movement of the leaves, secretion and digestion .. Pages 368-394

\section{CHAPTER XVII.}

\section{UTRICULARIA.}

Utricularia neglecta - Structure of the bladder-The uses of the several parts - Number of imprisoned animals - Manner of capture - The bladders cannot digest animal matter, but absorb the products of its decay-Experiments on the absorption of certain fluids by the quadrifid processes Absorption by the glands - Summary of the observation on absorption-Development of the bladders - Etricularia vulgaris-Utricularia minor-Utriculuria clandestina 395-430

\section{CHAPTER XVIII.}

\section{Utricularia (continued).}

Utricularia montana-Description of the bladders on the subterranean rhizomes - Prey captured by the bladders of plants under culture and in a state of nature-Absorption by the quadrifid processes and glands - Tubers serving as reservoirs for water - Various other species of Utricularia Polypompholyx - Genlisea, different nature of the trap for capturing prey - Diversitied methods by which plants are

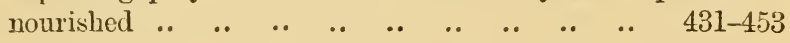




\title{
INSECTIVOROUS PLANTS.
}

\author{
CHAPTER I. \\ Diosera rotundifolia, or the cominon Sun-dew.
}

Number of insects captured-Description of the leaves and their appendages or tentacles - Preliminary sketch of the action of the various parts, and of the manner in which insects are capturedDuration of the inflection of the tentacles - Nature of the secretion-MIanner in which insects are carried to the centre of the leaf - Evidence that the glands have the power of absorptionSmall size of the roots.

During the summer of 1860 , I was surprised by finding how large a number of insects were caught by the leaves of the common sun-dew (Drosera rotundifolia) on a heath in Sussex. I had heard that insects were thus caught, but knew nothing further on the subject.* I

* As Dr. Nitschke has giren ('Bot. Zeitung,' 1860, p. 229) the bibliography of Drosera, I need not here go into details. Most of the notices published before 1860 are brief and unimportant. The oldest paper seems to have been one of the most valuable, namely, by Dr. Roth, in 1782 . There is also an interesting though short account of the habits of Drosera by Dr. Milde, in the 'Bot. Zeitung,' 1852, p. 5t0. In 1855, in the ' $\mathrm{An}$ nales des Sc. nat. bot?' tom. iii. pp. 297 and 304, MMI. Gronland and Trécul each published papers, with figures, on the structure of the leaves; but MI. Trécul went so far as to doubt whether they possessed any power of movement. Dr. Nitschke's papers in the 'Bot. Zeitung' for 1860 and 1861 are by far the most important ones which have been published, both on the habits and structure of this plant; and I shall frequently have occasion to quote from them. His discussions on several points, for instance on the transmission of an excitement from one part of the leaf to another, are excellent. On Dec. 11, 1862, Mr. $J$. Scott read a paper before the Botauical Society of Edinburgh, 
gathered by chance a dozen plants, bearing fifty-six fully expanded leaves, and on thirty-one of these dead insects or remnants of them adhered; and, no doubt, many more would have been caught afterwards by these same leaves, and still more by those as yet not expanded. On one plant all six leaves had caught their prey; and on several plants very many leaves had canght more than a single insect. On one large leaf I found the remains of thirteen distinct insects. Flies (Diptera) are captured much oftener than other insects. The largest kind which I have seen caught was a small butterfly (Crnonympha pamphilus); but the Rev. H. M. Wilkinson informs me that he found a large living dragon-fly with its body firmly held by two leaves. As this plant is extremely common in some districts, the number of insects thus annually slaughtered must be prodigious. Many plants cause the death of insects, for instance the sticky buds of the horse-chestnut (Esculus hippocastanum), without thereby receiving, as far as we can perceive, any advantage; but it was soon evident that Drosera was

which was published in the Gardener's Chronicle,' 1863, p. 30. Mr. Scott shows that gentle irritátion of the hairs, as well as insects placed on the dise of the leaf, cause the hairs to bend inwards. Mr. A. W. Bennett also gave another interesting account of the morements of the leaves before the British Association for 18\%3. In this same year Dr. Warming published an essay, in which he describes the structure of the so-ealled hairs, entitler, "Sur la Différence entre les Trichomes," \&c., extracted from the proceedings of the Soc. d'Hist. Nat. de Copenhague. I shall also have occasion hereafter to refer to a paper by Mrs. Treat, of New Jersey, on some American species of Drosera. Dr. Burdon Sanderson delivered a lecture on Dionzea, before the Royal Institution (published in 'Nature,' June 14, 1874), in which a short account of my observations on the power of true digestion possessed by Drosera and Diunæa first appeared. Prof. Asa Gray has done good service by calling attention to Drosera, and to other plants having similar habits, in 'The Nation' (1874, pp. 261 and 232), and in otber publications. Dr. Hooker, also, in his important adkress on Carnivorous Plants (Brit. Assoc., Belfast, 1874), has given a history of the subjeet. 
excellently adapted for the special purpose of catching insects, so that the subject seemed well worthy of investigation.

The results have proved highly remarkable; the more important ones being-firstly, the extraordinary

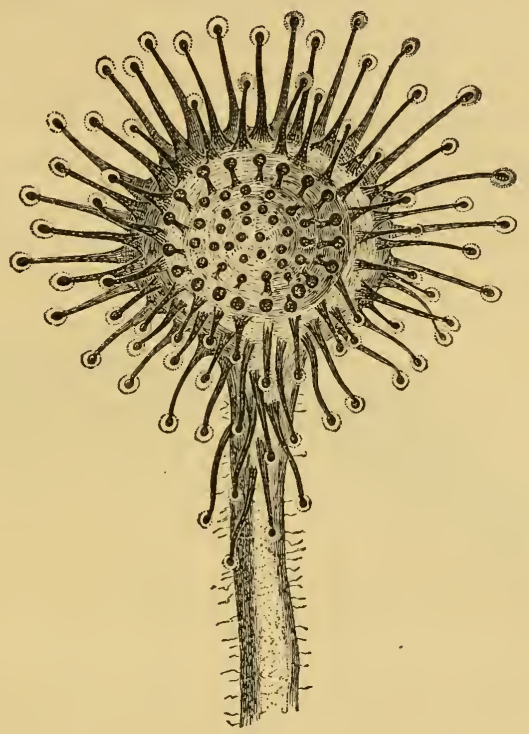

Fig. 1.*

(Drosera rotundifolia.)

Leaf viewed from above; enlarged four times.

sensitiveness of the glands to slight pressure and to minute doses of certain nitrogenous fluids, as shown by the movements of the so-called hairs or tentacles;

* The drawings of Drosera and Dionæa, given in this work, were made for me by my son George Darwin; those of Aldrovanda, and of the several spccies of Utri- cularia, by my son Francis. They have been excellently reproduced on wood by Mr. Cooper, 188 Strand. 
secondly, the power possessed by the leaves of rendering soluble or digesting nitrogenous substances, and of afterwards absorbing them; thirdly, the changes which take place within the cells of the tentacles, when the glands are excited in various ways.

It is necessary, in the first place, to describe briefly the plant. It bears from two or three to five or six leares, generally extended more or less horizontally, but sometimes standing vertically upwards. The shape and general appearance of a leaf is shown, as seen from above, in fig. 1, and as seen laterally, in fig. 2 . The leares are commonly a little broader than long,

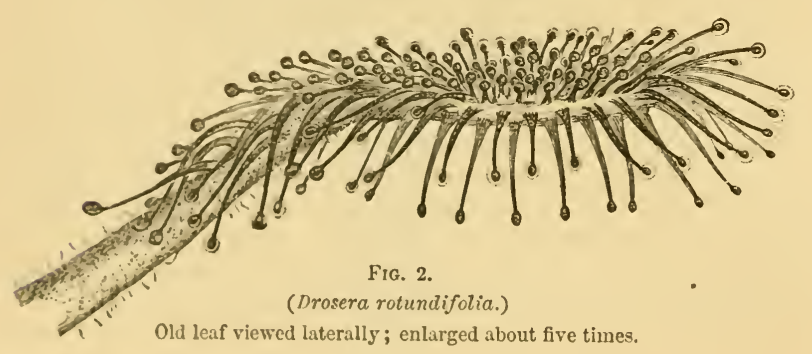

lut this was not the case in the one here figured. The whole upper surface is covered with gland-bearing filaments, or tentacles, as I shall call them, from their manner of acting. The glands were counted on thirtyone leaves, but many of these were of unusually large size, and the average number was 192 ; the greatest number being 260), and the least 130. The glands are each surrounded by large drops of extremely viseid secretion, which, glittering in the sun, have given rise 10 the plint's poetical name of the sun-dew.

The tentacles on the central part of the leaf or disc are sliort and stand upright, and their pediecls are green. Towards the margin they become longer and longer and more inclined 
outwards, with their pedicels of a purple colour. Those on the extreme margin project in the same plane with the leaf, or more commonly (see fig. 2) are considerably reflexed. A few tentacles spiing from the base of the footstalk or petiole, and these are the longest of all, being sometimes nearly $\frac{1}{4}$ of an inch in length. On a leaf bearing altogether 252 tentacles, the short ones on the disc, having green pedicels, were in number to the longer submarginal and marginal tentacles, having purple pedicels, as nine to sixteen.

A tentacle consists of a thin, straight, hair-like pedicel, carrying a gland on the summit. The pedicel is somewhat flattened, and is formed of several rows of elongated cells, filled with purple fluid or granular matter.* There is, however, a narrow zone close beneath the glands of the longer tentacles, and a broader zone near their bases, of a green tint. Spiral vessels, accompanied by simple vascular tissue, branch off from the vascular bundles in the blade of the leaf, and run up all the tentacles into the glands.

Several eminent physiologists have discussed the homological nature of these appendages or tentacles, that is, whether they ought to be considered as hairs (trichomes) or prolongations of the leaf. Nitschke has shown that they include all the elements proper to the blade of a leaf; and the fact of their including vascular tissue was formerly thought to prove that they were prolongations of the leaf, but it is now known that ressels sometimes enter true hairs. $t$ The power of movement which they possess is a strong argument against their being viewed as hairs. The conclusion which seems to me the most probable will be given in Chap. XV., namely that they existed primordially as glandular hairs, or mere epidermic formations, and that their upper part should still be so considered; but that their lower

* According to Nitschke ('Bot. Zeitung,' 1861, p. 22t) the purple fluid results from the metamorphosis of chlorophyll. Mr. Sorby examined the colouring matter with the spectroscope, and informs me that it consists of the commonest species of erythrophyll, " which is often met with in leaves with low vitality, and in parts, like the petioles, which carry on leaf-functions in a very imperfect manuer. All that can be said, therefore, is that the hairs (or tentacles) are coloured like parts of a leaf which do not fulfil their proper office."

$\dagger$ Dr. Nitschke has discussed this subject in 'Bot. Zeitung,' 1861 , p. 241, \&c. See also Ur. Warming ('Sur la Différence entre les 'Trichomes,' \&c., 1873, who gives references to various publications. See also Gronland and 'Trécul, 'Annal. des Sc. nat. bot.' (4th series), tom. iii. 1555 , pp. 297 and 303. 
part, which alone is capable of movement, consists of a prolongation of the leaf; the spiral ressels being extended from this to the uppermost part. We shall hereafter see that the terminal tentacles of the divided leaves of Roridula are still in an intermediate condition.

The glands, with the exception of those borne by the extreme

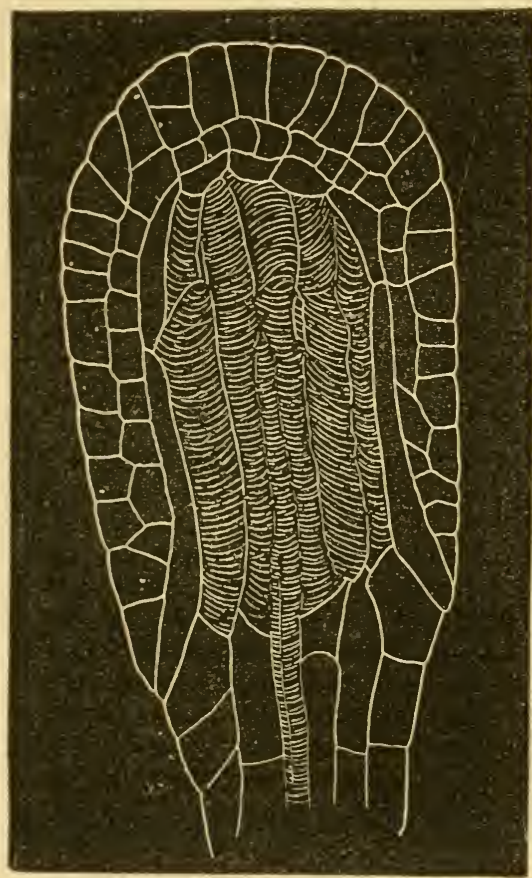

Frg. 3.

(Drosera rotundifolia.)

longitudinal section of a gland; greatly magnitied. From Dr. Warwing.

margiual tentacles, aro oral, and of nearly uniform size, viz. about $\frac{4}{500}$ of an inch in length. Their strueture is remarkable, and their functions complex, for they secrete, absorb, and are acted on by various stimulants. They consist of an outer layer of small polygonal cells, containing purple gramular matter or fluid, and with the walls thicker than those of the pedicels. 
Within this layer of cells there is an inner one of differently shaped ones, likewise filled with purple fluid, but of a slightly different tint, and differently affected by chloride of gold. These two layers are sometimes well seen when a gland has been crushed or boiled in caustic potash. According to Dr. Warming, there is still another layer of much more elongated cells, as shown in the accompanying section (fig. 3) copied from his work; but these cells were not seen by Nitschke, nor by me. In the centre there is a group of elongated, cylindrical cells of unequal lengths, bluntly pointed at their upper ends, truncated or rounded at their lower ends, closely pressed together, and remarkable from being surrounded by a spiral line, which can be separated as a distinct fibre.

These latter cells are filled with limpid fluid, which after long immersion in alcohol deposits much brown matter. I presume that they are actually connected with the spiral vessels which run up the tentacles, for on several occasions the latter were seen to divide into two or three excessively thin branches, which could be traced close up to the spiriferous cells. Their development has been described by Dr. Warming. Cells of the same kind have been observed in other plants, as I hear from Dr. Hooker, and were seen by me in the margins of the leaves of Pinguicula. Whaterer their function may be, they are not necessary for the secretion of the digestive fluid, or for absorption, or for the communication of a motor impulse to other parts of the leaf, as we may infer from the structure of the glands in some other genera of the Droseracer.

The extreme marginal tentacles differ slightly from the others. Their bases are broader, and besides their own vessels, they receive a fine branch from those which enter the tentacles on each side. Their glands are much elongated, and lie embedded on the upper surface of the pedicel, instead of standing at the apex. In other respects they do not differ essentially from the oval ones, and in one specimen I found every possible transition between the two states. In another specimen there were no long-headed glands. These marginal tentacles lose their irritability earlier than the others; and when a stimulus is applied to the centre of the leaf, they are excited into action after the others. When cut-off leaves are immersed in water, they alone often become inflected.

The purple fluid or granular matter which fills the cells of the glands differs to a certain extent from that within the cells of the pedicels. For when a leaf is placed in hot water or in certain acids, the glands become quite white and opaque, whereas 
the cells of the pedicels are rendered of a bright red, with the exception of those close beneath the glands. These latter cells lose their pale red tint; and the green matter which they, as well as the basal cells, contain, becomes of a brighter green. The petioles bear many multicellular hairs, some of which near the blade are surmounted, according to Nitschke, by a fow rounded cells, which appear to be rudimentary glands. Ioth surfaces of the leaf, the pedicels of the tentacles, especially the lower sides of the onter ones, and the petioles, are studded with minute papillæ (hairs or trichomes), having a conical basis, and bearing on their summits two, and occasionally three or eren four, rounded cells, containing much protoplasm. These papillie are generally colourless, but sometimes include a little purple fluid. They vary in development, and graduate, as Nitschke* states, and as I repeatedly observed into the long multicellular hairs. The latter, as well as the papillæ, are probably rudiments of formerly existing tentacles.

I may here add, in order not to recur to the papillæ, that they do not secrete, but are easiiy permeated by rarious fluids: thus when living or dead leaves are immersed in a solution of one part of chloride of gold, or of nitrate of silver, to 437 of water, they are quickly blackened, and the discoloration soon spreads to the surrounding tissue. The long multicellular hairs are not so quickly affected. After a leaf had been left in a weak infusion of raw meat for 10 hours, the cells of the papillæ had evidently absorbed animal matter, for instead of limpid fluid they now contained small aggregated masses of protoplasm, which slowly and incessantly changed their forms. A similar result followed from an immersion of only 15 minutes in a solution of one part of carbonate of ammonia to 218 of water, and the adjoining cells of the tentacles, on which the papillæ were seated, now likewise contained aggregated masses of protoplasm. We may therefore conclude that when a leaf has closely clasped a captured insect in the manner immediately to be described, the papillæ, which project from the upper surface of the leaf and of the tentacles, probably absorb some of the animal matter dissolved in the secretion; but this cannot be the case with the papillæ on the backs of the leaves or on the petioles.

* Nitschko has claborately described and figured these papillo, 'But. 'Zeitung', 1sil1, Pp. '234, 25:3, 251. 
Preliminary Slietch of the Action of the several Parts, and of the Manner in which Insects are Captured.

If a small organic or inorganic object be placed on the glands in the centre of a leaf, these transmit a motor impulse to the marginal tentacles. The nearer ones are first affected and slowly bend towards the centre, and then those farther off, until at last all become closely inflected over the object. This takes place in from one hour to four or five or more hours. The difference in the time required depends on many circumstances; namely on the size of the object and on its nature, that is, whether it contains soluble matter of the proper kind; on the vigour and age of the leaf; whether it has lately been in action; and, according to Nitschke,* on the temperature of the day, as likewise seemed to me to be the case. A living insect is a more efficient object than a dead one, as in struggling it presses against the glands of many tentacles. An insect, such as a fly, with thin integuments, through which animal matter in solution can readily pass into the surrounding dense secretion, is more efficient in causing prolonged inflection than an insect with a thick coat, such as a beetle. The inflection of the tentacles takes place indifferently in the light and darkness; and the plant is not subject to any nocturnal movement of so-called sleep.

If the glands on the disc are repeatedly touched or brushed, although no object is left on them, the marginal tentacles curve inwards. So again, if drops of various fluids, for instance of saliva or of a solution of any salt of ammonia, are placed on the central glands, the same result quickly follows, sometimes in under half an hour.

* 'Bot. Zeitung,' 1860, p. 246. 
The tentacles in the act of inflection sweep through a wide space; thus a marginal tentacle, extended in the same plane with the blade, moves through an angle of $180^{\circ}$; and $\mathrm{I}$ have seen the much reflected tentacles of a leaf which stood upright move through an angle of not less than $270^{\circ}$. The bending part is almost confined to a short space near the base; but a rather larger portion of the elongated exterior tentacles

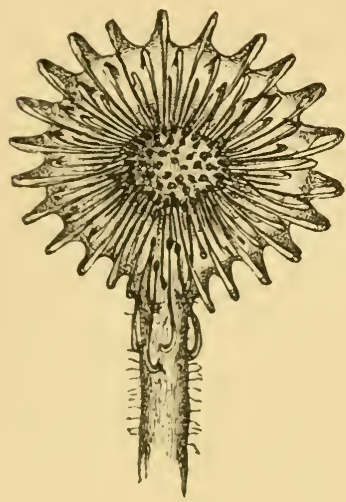

Fig. 4.

(Drosera rotundifolia.)

Leaf (enlarged) with all the tentacles clinely inflected, from immersion in a solution of phosphate of ammonla (one part to 87,500 of water).

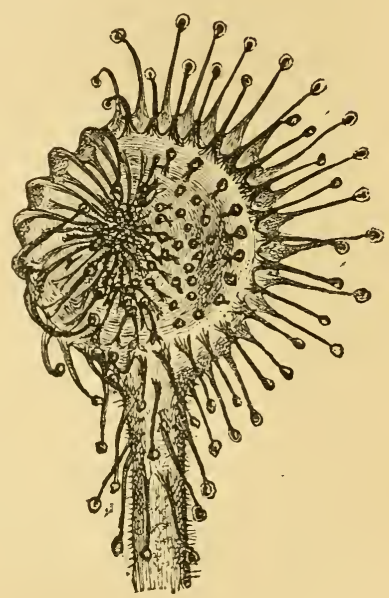

Fig. 5.

(Drosera rotundifolia.)

Leaf (enlarged) with the tentacles on one side inflected over a bit of meat placed on the disc.

becomes slightly incurved; the distal half in all cases remaining straight. The short tentacles in the centre of the dise when directly excited, do not become inflected; but they are capable of inflection if excited by a motor impulse received from other glands at a distance. Thus, if a leaf is immersed in an infusion of raw meat, or in a reak solution of ammonia (if the 
solution is at all strong, the leaf is paralysed), all the exterior tentacles bend inwards (see fig. 4), excepting those near the centre, which remain upright; but these bend towards any exciting object placed on one side of the disc, as shown in fig. 5. The glands in fig. 4 may be seen to form a dark ring round the centre; and this follows from the exterior tentacles increasing in length in due proportion, as they stand nearer to the circumference.

The kind of inflection which the tentacles undergo is best shown when the gland of one of the long exterior

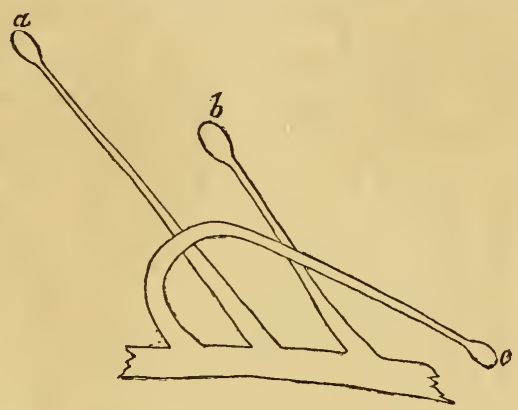

FIG. 6.

(Drosera rotundifolia.)

Diagram showing one of the exterior tentacles closely inflected; the two adjoining ones in their ordinary position.

tentacles is in any way excited; for the surrounding ones remain unaffected. In the accompanying outline (fig. 6) we see one tentacle, on which a particle of meat had been placed, thus bent towards the centre of the leaf, with two others retaining their original position. A gland may be excited by being simply touched three or four times, or by prolonged contact with organic or inorganic objects, and various fluids. I have distinctly seen, through a lens, a tentacle beginning to bend in ten seconds, after an object had been " 
placed on its gland; and I have often seen strongly pronounced inflection in under one minute. It is surprising how minute a particle of any substance, such as a bit of thread or hair or splinter of glass, if placed in actual contact with the surface of a gland, suffices to cause the tentacle to bend. If the object, which has been carried by this morement to the centre, be not very small, or if it contains soluble nitrogenous matter, it acts on the central glands; and these transmit a motor impulse to the exterior tentacles, causing them to bend inwards.

Not only the tentacles, but the blade of the leaf often, but by no means always, becomes much incurved, when any strongly exciting substance or fluid is placed on the disc. Drops of milk and of a solution of nitrate of ammonia or soda are particularly apt to produce this effect. The blade is thus converted into a little cup. The manner in which it bends varies greatly. Sometimes the apex alone, sometimes one side, and sometimes both sides, become incurved. For instance, I placed bits of hard-boiled egg on three leaves; one had the apex bent towards the base; the second had both distal margins much incurved, so that it became almost triangular in outline, and this perhaps is the commonest case ; whilst the third blade was not at all affected, though the tentacles were as clusely inflected as in the two previous cases. The whole blade also generally rises or bends upwards, and thus forms a smaller angle with the footstalk than it dicl before. This appears at first sight a distinct kind of movement, but it results from the incurvation of that part of the margin which is attached to the footstalk, causing the blade, as a whole, to curve or movo upwards.

" The length of time during which the tentacles as 
well as the blade remain inflected over an object placed on the disc, depends on various circumstances; namely on the vigour and age of the leaf, and, according to Dr. Nitschke, on the temperature, for during cold weather when the leaves are inactive, they re-expand at an earlier period than when the weather is warm. But the nature of the object is by far the most important circumstance; I have repeatedly found that the tentacles remain clasped for a much longer average time over objects which yield soluble nitrogenous matter than over those, whether organic or inorganic, which yield no such matter. After a period varying from one to seven days, the tentacles and blade reexpand, and are then ready to act again. I have seen the same leaf inflected three successive times over insects placed on the dise; and it would probably have acted a greater number of times.

The secretion from the glands is extremely viscid, so that it can be drawn out into long threads. It appears colourless, but stains little balls of paper pale pink. An object of any kind placed on a gland always causes it, as I believe, to secrete more freely; but the mere presence of the object renders this difficult to ascertain. In some cases, however, the effect was strongly marked, as when particles of sugar were added; but the result in this case is probably due merely to exosmose. Particles of carbonate and phosphate of ammonia and of some other salts, for instance sulphate of zinc, likewise increase the secretion. Immersion in a solution of one part of chloride of gold, or "of some other salts, to 437 of water, excites the glands to largely increased secretion; on the other hand, tartrate of antimony produces no such effect. Immersion in many acids (of the strength of one part to 437 of water) likewise causes a wonderful amount of 
secretion, so that when the leaves are lifted out, long ropes of extremely viscid fluid hang from them. Some acids, on the other hand, do not act in this manner. Increased secretion is not necessarily dependent on the inflection of the tentacle, for particles of sugar and of sulphate of zinc cause no movement.

It is a much more remarkable fact that when an object, such as a bit of meat or an insect, is placed on the dise of a leaf, as soon as the surrounding tentacles become considerably inflected, their glands pour forth an increased amount of secretion. I ascertained this by selecting leaves with equal-sized drops on the two sides, and by placing bits of meat on one side of the disc; and as soon as the tentacles on this side became much inflected, but before the glands touched the meat, the drops of secretion became larger. This was repeatedly observed, but a record was kept of only thirteen cases, in nine of which increased secretion was plainly observed; the four failures being due either to the leares being rather torpid, or to the bits of meat being too small to cause much inflection. We must therefore conclude that the central glands, when strongly excited, transmit some influence to the glands of the circumferential tentacles, causing them to secrete more copiously.

It is a still more important fact (as we shall sce more fully when we treat of the digestive power of the secretion) that when the tentacles become inflected, owing to the central glands having been stimulated mechanically, or by contact with animal matter, the secretion not only increases in quantity, but changes its nature and becomes acid; and this occurs before the grlands have touched the object on the centre of the leaf. This acid is of a different nature from that contained in the tissue of the leaves. As long as the 
tentacles remain closely inflected, the glands continue to secrete, and the secretion is acid; so that, if neutralised by carbonate of soda, it again becomes acid after a few hours. I have observed the same leaf with the tentacles closely inflected over rather indigestible substances, such as chemically prepared casein, pouring forth acid secretion for eight successive days, and over bits of bone for ten successive days.

The secretion seems to possess, like the gastric juice of the higher animals, some antiseptic power. During very warm weather I placed close together two equalsized bits of raw meat, one on a leaf of the Drosera, and the other surrounded by wet moss. They were thus left for $48 \mathrm{hrs}$, and then examined. The bit on the moss swarmed with infusoria, and was so much decayed that the transverse striæ on the muscular fibres could no longer be clearly distinguished; whilst the bit on the leaf, which was bathed by the secretion, was free from infusoria, and its striæ were perfectly distinct in the central and undissolved portion. In like manner small cubes of albumen and cheese placed on wet moss became threaded with filaments of mould, and had their surfaces slightly discoloured and disintegrated; whilst those on the leaves of Drosera remained clean, the albumen being changed into transparent fluid.

As soon as tentacles, which have remained closely inflected during several days over an object, begin to re-expand, their glands secrete less freely, or cease to secrete, and are left dry. In this state they are covered with a film of whitish, semi-fibrous matter, which was held in solution by the secretion. The drying of the glands during the act of re-expansion is of some little service to the plant; for I have often observed that objects adhering to the lcaves 
could then be blown away by a breath of air; the leares being thus left unencumbered and free for future action. Nevertheless, it often happens that all the glands do not become completely dry; and in this case delicate objects, such as fragile insects, are sometimes torn by the re-expansion of the tentacles into fragments, which remain scattered all over the leaf. After the re-expansion is complete, the glands quickly begin to re-secrete, and as soon as full-sized drops are formed, the tentacles are ready to clasp a new object.

When an insect alights on the central disc, it is instantly entangled by the viscid secretion, and the surrounding tentacles after a time begin to bend, and ultimately clasp it on all sides. Insects are generally killed, according to Dr. Nitschke, in about a quarter of an hour, owing to their tracheæ being closed by the secretion. If an insect adheres to only a few of the glands of the exterior tentacles, these soon become inflected and carry their prey to the tentacles next succeeding them inwards; these then bend inwards, and so onwards, until the insect is ultimately carried by a curious sort of rolling movement to the centre of the leaf. Then, after an interval, the tentacles on all sides become inflected and bathe their prey with their secretion, in the same manner as if the insect had first alighted on the central disc. It is surprising how minute an insect suffices to cause this action: for instance, I have seen one of the sinallest species of gnats (Culex), which had just settled with its excessively delicate feet on the glimrls of the outermost tentacles, and these were already beginning to curve inwards, thongh not a single gland had as yet touched the body of the insect. Had I not interfered, this minute gnat would 
assuredly have been carried to the centre of the leaf and been securely clasped on all sides. We shall hereafter see what excessively small doses of certain organic fluids and saline solutions cause strongly marked inflection.

Whether insects alight on the leaves by mere chance, as a resting-place, or are attracted by the odour of the secretion, I know not. I suspect from the number of insects caught by the English species of Drosera, and from what I have observed with some exotic species kept in my greenhouse, that the odour is attractive. In this latter case the leaves may be compared with a baited trap; in the former case with a trap laid in a run frequented by game, but without any bait.

That the glands possess the power of absorption, is shown by their almost instantaneously becoming darkcoloured when given a minute quantity of carbonate of ammonia ; the change of colour being chiefly or exclusively due to the rapid aggregation of their contents. When certain other fluids are added, they become palecoloured. Their power of absorption is, however, best shown by the widely different results which follow, from placing drops of various nitrogenous and nonnitrogenous fluids of the same density on the glands of the disc, or on a single marginal gland; and likewise by the very different lengths of time during which the tentacles remain inflected over objects, which yield or do not yield soluble nitrogenous matter. This same conclusion might indeed have been inferred from the structure and movements of the leaves, which are so admirably adapted for capturing insects.

The absorption of animal matter from captured insects explains how Drosera can flourish in extremely poor peaty soil,-in some cases where nothing but 
sphagnum moss grows, and mosses depend altogether on the atmosphere for their nourishment. Although the leaves at a basty glance do not appear green, owing to the purple colour of the tentacles, yet the upper and lower surfaces of the blade, the pedicels of the central tentacles, and the petioles contain chlorophyll, so that, no doubt, the plant obtains and assimilates carbonic acid from the air: Nevertheless, considering the nature of the soil where it grows, the supply of nitrogen would be extremely limited, or quite deficient, unless the plant had the power of obtaining this important element from captured insects. We can thus understand how it is that the roots are so poorly dereloped. These usually consist of only two or three slightly divided branches, from half to one inch in length, furnished with absorbent hairs. It appears, therefore, that the roots serve only to imbibe water; though, no doubt, they would absorb nutritious matter if present in the soil; for as we shall hereafter see, they absorb a weak solution of carbonate of ammonia. A plant of Drosera, with the edges of its leares curled inwards, so as to form a temporary stomach, with the glands of the closely inflected tentacles pouring forth their acid secretion, which dissolves animal matter, afterwards to be absorbed, may be said to feed like an animal. But, differently from an animal, it drinks by means of its roots; and it must drink largely, so as to retain many drops of viscid fluid round the glands, sometimes as many as 260 , exposed during the whole dlay to a glaring sun. 


\section{CHAPTER II.}

The Movements of the Tentacles from the Contact of Solin

BODIES.

Inflection of the exterior tentacles owing to the glands of the disc being excited by repeated touches, or by objects left in contact with them-Difference in the action of bodies yielding and not yielding soluble nitrogenous matter-Inflection of the exterior tentacles dircetly caused by objects left in contact with their glands-Periods of commencing inflection and of subsequent reexpansion - Extreme minuteness of the particles causing inflection - Action under water - Inflection of the exterior tentacles when their glands are excited by repeated touches-Falling drops of water do not cause inflection.

I wILL give in this and the following chapters some of the many experiments made, which best illustrate the manner and rate of movement of the tentacles, when excited in various ways. The glands alone in all ordinary cases are susceptible to excitement. When excited, they do not themselves move or change form, but transmit a motor impulse to the bending part of their own and adjoining tentacles, and are thus carried towards the centre of the leaf. Strictly speaking, the glands ought to be called irritable, as the term sensitive generally implies consciousness; but no one supposes that the Sensitive-plant is conscious, and as I have found the term convenient, I shall use it without scruple. I will commence with the movements of the exterior tentacles, when indirectly excited by stimulants applied to the glands of the short tentacles on the disc. The exterior tentacles may be said in this case to be indirectly excited, because their own glands are not directly acted on. The stimulus proceeding from the glands of the disc acts on the bending part of the 
exterior tentacles, near their bases, and does not (as will hereafter be proved) first travel up the pedicels to the glands, to be then reflected back to the bending place. Nevertheless, some influence does travel up to the glands, causing them to secrete more copiously, and the secretion to become acid. This latter fact is, I believe, quite new in the physiology of plants; it has indeed only recently been established that in the animal kingdom an influence can be transmitted along the nerres to glands, modifying their power of secretion, independently of the state of the bloodvessels.

The Inflection of the Exterior Tentacles from the Glands of the Disc being excited by Repeated Touches, or by Objects left in Contact with them.

The central glands of a leaf were irritated with a small stiff camel-hair brush, and in $70 \mathrm{~m}$. (minutes) several of the outer tentacles were inflected; in 5 hrs. (hours) all the sub-marginal tentacles were inflected; next morning after an interval of about $22 \mathrm{hrs}$. they were fully re-expanded. In all the following cases the period is reckoned from the time of first irritation. Another leaf treated in the same manner had a few tentacles inflected in $20 \mathrm{~m}$.; in $4 \mathrm{hrs}$. all the submarginal and some of the extreme marginal tentacles, as well as the. erlge of the leaf itself, were inflected; in $17 \mathrm{hrs}$. they had recovered their proper, expanded position. I then put a dead fly in the centre of the last-mentioned leaf, and next morning it was closely clasped; five days afterwards the leaf re-expanded, and the tentacles, with their glands surromnded by secretion, were ready to act again.

Particles of meat, dead flies, bits of paper, wood, dried moss, sponge, cinders, glass, \&c., were repeatedly 
placed on leaves, and these objects were well embraced in various periods from $1 \mathrm{hr}$. to as long as $24 \mathrm{hrs.}$, and set free again, with the leaf fully re-expanded, in from one or two, to seven or even ten days, according to the nature of the object. On a leaf which had naturally caught two flies, and therefore had already closed and reopened either once or more probably twice, I put a fresh fly: in 7 hrs. it was moderately, and in 21 hrs. thoroughly well, clasped, with the edges of the leaf inflected. In two days and a half the leaf had nearly re-expanded; as the exciting object was an insect, this unusually short period of inflection was, no doubt, due to the leaf having. recently been in action. Allowing this same leaf to rest for only"a single day, I put on another fly, and it again closed, but now very slowly; nevertheless, in less than two days it succeeded in thoroughly clasping the fly.

When a small object is placed on the glands of the disc, on one side of a leaf, as near as possible to its circumference, the tentacles on this side are first affected, those on the opposite side much later, or, as often occurred, not at all. This was repeatedly proved by trials with bits of meat; but I will here give only the case of a minute fly, naturally caught and still alive, which I found adhering by its delicate feet to the glands on the extreme left side of the central disc. The marginal tentacles on this side closed inwards and killed the fly, and after a time the edge of the leaf on this side also became inflected, and thus remained for several days, whilst neither the tentacles nor the edge on the opposite side were in the least affected.

If young and active leaves are selected, inorganic particles not larger than the head of a small pin, placed on the central glands, sometimes cause the 
outer tentacles to bend inwards. But this follows much more surely and quickly, if the object contains nitrogenous matter which can be dissolved by the secretion. On one occasion I observed the following unusual circumstance. Small bits of raw meat (which acts more energetically than any other substance), of paper, dried moss, and of the quill of a pen were placed on several leares, and they were all embraced equally well in about $2 \mathrm{hrs}$. On other occasions the above-named substances, or more commonly particles of glass, coal-cinder (taken from the fire), stone, gold-leaf, dried grass, cork, blotting-paper, cotton-wool, and hair rolled up into little balls, were used, and these substances, though they were sometimes well embraced, often caused no morement whatever in the outer tentacles, or an extremely slight and slow movement. Yet these same leaves were proved to be in an active condlition, as they were excited to more by substances yielding soluble nitrogenous matter, such as bits of raw or roast meat, the yolk or white of boiled $\mathrm{eggs}$, fragments of insects of all orders, spiders, ic. I will give only two instances. Minute flies were placed on the dises of several leares, and on others balls of paper, bits of moss and quill of about the same size as the flies, and the latter were well embraced in a few hours; whereas after $25 \mathrm{hrs}$. only a very fow tentacles were inflected over the other objects. The bits of paper, moss, and quill were then removed from these leaves, and bits of raw meat placed on them; and now all the tentacles were soon energetically inflected.

A gain, particles of coal-cinder (weighing rather more than the flies used in the last experiment) were placed on the centres of three leaves: after an interval of 19 hrs. one of the particles was tolerably well embraced; 
a second by a very few tentacles; and a third by none. I then removed the particles from the two latter leaves, and put on them recently killed flies. These were fairly well embraced in $7 \frac{1}{2} \mathrm{hrs}$. and thoroughly after $20 \frac{1}{2}$ hrs.; the tentacles remaining inflected for many subsequent days. On the other hand, the one leaf which had in the course of 19 hrs. embraced the bit of cinder moderately well, and to which no fly was given, after an additional 33 hrs. (i. e. in 52 hrs. from the time when the cinder was put on) was completely re-expanded and ready to act again.

From these and numerous other experiments not worth giving, it is certain that inorganic substances, or such organic substances as are not attacked by the secretion, act much less quickly and efficiently than organic substances yielding soluble matter which is absorbed. Moreover, I have met with very few exceptions to the rule, and these exceptions apparently depended on the leaf having been too recently in action, that the tentacles remain clasped for a much longer time over organic bodies of the nature just specified than over those which are not acted on by the secretion, or over inorganic objects.*

* Owing to the extraordinary belief held by M. Ziegler ('Comptes rendus,' May 1872 , p. 122), that albuminous substances, if held for a moment between the fingers, acquire the property of making the tentacles of Drosera contract, whereas, if not thus held, they have no such power, I tried some experiments with great care, but the results did not confirm this belief. Red-hot cinders were taken out of the fire, and bits of glass, cotton-thread, blotting paper and thin slices of cork were immersed in boiling water; and particles were then placed (every instrument with which they were touched having been previonsly immersed in boiling water) on the glands of several leaves, and they acted in exactly the same manner as other particles, which had been purposely haudled for some time. Bits of a boiled egg, cut with a knifo which had been washed in boiling water, also acted like any other animal substance. I breathed on some leaves for above a minute, and repeated the act two or three times, with my mouth close to 


\section{The Inflection of the Eaterior Tentacles as directly caused by Objects left in Contact with their Glands.}

I made a rast number of trials by placing, by means of a fine needle moistened with distilled water, and with the aid of a lens, particles of various substances on the viscid secretion surrounding the glands of the outer tentacles. I experimented on both the oval and long-headed glands. When a particle is thus placed on a single gland, the movement of the tentacle is particularly well seen in contrast with the stationary condition of the surrounding tentacles. (See previous fig. 6.) In four cases small particles of raw meat calused the tentacles to be greatly inflected in between 5 and $6 \mathrm{~m}$. Another tentacle similarly treated, and observed with special care, distinctly, though slightly, changed its position in $10 \mathrm{~s}$. (seconds); and this is the quickest morement seen by me. In $2 \mathrm{~m}$. $30 \mathrm{~s}$. it had moved through an angle of about $45^{\circ}$. 'The morement as seen through a lens resembled that of the hand of a large clock. In $5 \mathrm{~m}$. it had mored through $90^{\circ}$, and when I looked again after $10 \mathrm{~m}$., the particle had reached the centre of the leaf; so that the whole movement was completed in less

them, but this proluced no effect. I maty liere aekl, as showing that the leaves are not acted on liy the orlour of nitrogenous substinees, that picees of raw meat stuck on menlle's were fixed as elose as jossible, without actual enutiet, 1) several leaves, but prolneed un efficet whaterer. On the other lami, as wo shall hereafter see, tlı. vapours of rertitin volatile sulbstances and fluids, such as of rirbonate of ammonia, chloroform, ecrtain essential oils, fe., cause inflection. M. Ziegler makes still more extraordinary statements with respect to the power of animal substauces, which have been left close to, but not in contact with, sulphate of quinine. 'The action of salts of quinine will be described in a future chapter. Since the appearance of the paper above referred to, MI. Ziegler has published a book on the same sulyject, entitled, 'Atonicité et 'Luicité,' 187t. 
than $17 \mathrm{~m} .30 \mathrm{~s}$. In the course of some hours this minute bit of meat, from having been brought into contact with some of the glands of the central dise, aoted centrifugally on the outer tentacles, which all became closely inflected. Fragments of flies were placed on the glands of four of the outer tentacles, extended in the same plane with that of the blade, and three of these fragments were carried in $35 \mathrm{~m}$. through an angle of $180^{\circ}$ to the centre. The fragment on the fourth tentacle was very minute, and it was not carried to the centre until 3 hrs. had elapsed. In three other cases minute flies or portions of larger ones were carried to the centre in $1 \mathrm{hr}$. $30 \mathrm{~s}$. In these seven cases, the fragiments or small flies, which had been carried by a single tentacle to the central glands, were well embraced by the other tentacles after an interval of from 4 to 10 hrs.

I also placed in the manner just described six small balls of writing-paper (rolled up by the aid of pincers, so that they were not touched by my fingers) on the glands of six exterior tentacles on distinct leaves; three of these were carried to the centre in about $1 \mathrm{hr}$., and the other three in rather more than 4 hrs.; but after 24 hrs. only two of the six balls were well embraced by the other tentacles. It is possible that the secretion may have dissolved a trace of glue or animalised matter from the balls of paper. Four particles of coal-cinder were then placed on the glands of four exterior tentacles; one of these reached the centre in 3 hrs. $40 \mathrm{~m}$.; the second in 9 hrs.; the third within 24 hrs., but had moved only part of the way in 9 hrs.; whilst the fourth moved only a very short distance in 24 hrs., and never moved any farther. Of the above three bits of cinder which were ultimately carried to the centre, one alone was well embraced by 
many of the other tentacles. We here see clearly that such bodies as particles of cinder or little balls of paper, after being carried by the tentacles to the central glands, act rery differently from fragments of flies, in causing the movement of the surrounding tentacles.

I made, without carefully recording the times of morement, many similar trials with other substances, such as splinters of white and blue glass, particles of cork, minute bits of gold-leaf, \&c.; and the proportional number of cases raried much in which the tentacles reached the centre, or mored only slightly, or not at all. One evening, particles of glass and eork, rather larger than those usually employed, were placed on about a dozen glands, and next morning, after 13 hrs., every single tentacle had carried its little load to the centre; but the unusually large size of the particles will account for this result. In another case $\frac{6}{7}$ of the partieles of cinder, glass, and thread, placed on separate glands, were carried towards, or actually to, the centre; in another case $\frac{7}{9}$, in another $\frac{7}{12}$, and in the last case only $\frac{7}{20}$ were thus carried inwards, the small proportion being here due, at least in part, to the leaves being rather old and inactive. Occasionally a glind, with its light loarl, could be seen through a strong lens to move an extremely short distance and then stop; this was especially apt to occur when excessively minute particles, much less than those of which the measurements will be immediately giren. were placed on glands; so that we here have nearly the limit of any action.

I was so much surprised at the smallness of the particles which caused the tentacles to become greatly inflected that it secmed worth while carefully to ascertain how minute a particle would plainly act. 
Accordingly measured lengths of a narrow strip of blotting paper, of fine cotton-thread, and of a woman's hair, were carefully weighed for me by Mr. Trenham Reeks, in an excellent balance, in the laboratory in Jermyn Street. Short bits of the paper, thread, and hair were then cut off and measured by a micrometer, so that their weights could be easily calculated. The bits were placed on the viscid secretion surrounding the glands of the exterior tentacles, with the precautions already stated, and I am certain that the gland itself was never touched; nor indeed would a single touch have produced any effect. A bit of the blotting-paper, weighing $\frac{1}{465}$ of a grain, was placed so as to rest on three glands together, and all three tentacles slowly curved inwards; each gland, therefore, supposing the weight to be distributed equally, could have been pressed on by only $\frac{1}{1395}$ of a grain, or 0464 of a milligramme. Five nearly equal bits of cotton-thread were tried, and all acted. The shortest of these was $\frac{1}{30}$ of an inch in length, and weighed $\frac{1}{8197}$ of a grain. The tentacle in this case was considerably inflected in $1 \mathrm{hr} .30 \mathrm{~m}$., and the bit of thread was carried to the centre of the leaf in $1 \mathrm{hr} .40 \mathrm{~m}$. Again, two particles of the thinner end of a woman's hair, one of these being $\frac{18}{1000}$ of an inch in length, and weighing $\frac{1}{35 \frac{1}{1} \mathrm{~T}}$ of a grain, the other $\frac{19}{1000}$ of an inch in length, and weighing of course a little more, were placed on two glands on opposite sides of the same leaf, and these two tentacles were inflected halfway towards the centre in $1 \mathrm{hr} .10 \mathrm{~m}$. ; all the many other tentacles round the same leaf remaining motionless. The appearance of this one leaf showed in an unequivocal manner that these minute particles sufficed to cause the tentacles to bend. Altogether, ten such particles of hair were placed on ten glands on several leaves, and seven of them caused 
the tentacles to move in a conspicuous manner. The smallest particle which was tried, and which acted plainly, was only $\frac{8}{1000}$ of an inch ( 203 millimetre) in length, and weighed the $\overline{\overline{8}+\overline{7}}$ of a grain, or $\cdot 000822$ milligramme. In these several cases, not only was the inflection of the tentacles conspicuous, but the purple fluid within their cells became aggregated into little masses of protoplasm, in the manner to be described in the next chapter; and the aggregation was so plain . that I could, by this clue alone, have readily picked out under the microscope all the tentacles which had carried their light loads towards the centre, from the hundreds of other tentacles on the same leares which had not thus acted.

My surprise was greatly excited, not only by the minuteness of the particles which caused movement, but how they could possibly act on the glands; for it must be remembered that they were laid with the greatest care on the convex surface of the secretion. It first I thought-but, as I now know, erroneouslythat particles of such low specific gravity as those of cork, thread, and paper, would never come into contact with the surfaces of the glands. The particles cannot act simply by their weight being added to that of the secretion, for small drops of water, many times heavier than the particles, were repeatedly added, and never produced any effect. Nor does the disturbance of the secretion produce any effect, for long threads were drawn out by a needle, and affixed to some adjoining olject, and thus left for hours; but the tentacles remained motionless.

I also carefully remored the secretion from four glands with a sharply pointed piece of blotting-paper, so that they were exposed for a time naked to the air, but this caused no movement; yet these glands were 
in an efficient state, for after $24 \mathrm{hrs}$. had elapsed, they were tried with bits of meat, and all became quickly inflected. It then occurred to me that particles floating on the secretion would cast shadows on the glands, which might be sensitive to the interception of the light. Although this seemed highly improbable, as minute and thin splinters of colourless glass acted powerfully, nevertheless, after it was dark, I put on, by the aid of a single tallow candle, as quickly as possible, particles of cork and glass on the glands of a dozen tentacles, as well as some of meat on other glands, and covered them up so that not a ray of light could enter; but by the next morning, after an interval of $13 \mathrm{hrs.}$, all the particles were carried to the centres of the l'eaves.

These negative results led me to try many more experiments, by placing particles on the surface of the drops of secretion, observing, as carefully as I could, whether they penetrated it and touched the surface of the glands. The secretion, from its weight, generally forms a thicker layer on the under than on the upper sides of the glands, whatever may be the position of. the tentacles. Minute bits of dry cork, thread, blotting paper, and coal cinders were tried, such as those previously employed; and I now observed that they absorbed much more of the secretion, in the course of a few minutes, than I should have thought possible; and as they had been laid on the upper surface of the secretion, where it is thinnest, they were often drawn down, after a time, into contact with at least some one point of the gland. With respect to the minute splinters of glass and particles of hair, I observed that the secretion slowly spread itself a little over their surfaces, by which means they were likewise drawn downwards or sideways, and thus one end, or some minute 
prominence, often came to touch, sooner or later, the gland.

In the foregoing and following cases, it is probable that the vibrations, to which the furniture in every room is continually liable, aids in bringing the particles into contact with the glands. But as it was sometimes difficult, owing to the refraction of the secretion, to feel sure whether the particles were in contact, I tried the following experiment. Unusually minute particles of glass, hair, and cork, were gently placed on the drops round several glands, and very few of the tentacles moved. Those which were not affected were left for about half an hour, and the particles were then disturbed or tilted up several times with a fine needle under the microscope, the glands not being touched. And now in the course of a few minutes almost all the hitherto motionless tentacles began to move; and this, no doubt, was caused by one end or some prominence of the particles having come into contact with the surface of the glands. But as the particles were unusually minute, the movement was small.

Lastly, some dark blue glass pounded into fine splinters was used, in order that the points of the particles might be better distinguished when immersed in the secretion; and thirteen such particles were placed in contact with the depending and therefore thicker part of the drops round so many glands. Five of the tentacles began moving after an interval of a few minutes, and in these cases I clearly saw that the partieles tonched the lower surface of the gland. A sixth tentacle mored after $1 \mathrm{hr} .45 \mathrm{~m}$., and the particle was now in contact with the gland, which was not the case at first. So it was with the seventh tentacle, but its morement did not begin until 3 hrs. $45 \mathrm{~m}$. had 
clapsed. The remaining six tentacles never moved as long as they were observed; and the particles apparently never came into contact with the surfaces of the glands.

From these experiments we learn that particles not containing soluble matter, when placed on glands, often cause the tentacles to begin bending in the course of from one to five minutes; and that in such cases the particles have been from the first in contact with the surfaces of the glands. When the tentacles do not begin moving for a much longer time, namely, from half an hour to three or four hours, the particles have been slowly brought into contact with the glands, either by the secretion being absorbed by the particles or by its gradual spreading over them, together with its consequent quicker evaporation. When the tentacles do not move at all, the particles have never come into contact with the glands, or in some cases the tentacles may not have been in an active condition. In order to excite movement, it is indispensable that the particles should actually rest on the glands; for a touch once, twice, or even thrice repeated by any hard body is not sufficient to excite movement.

Another experiment, showing that extremely minute particles act on the glands when immersed in water, may here be given. A grain of sulphate of quinine was added to an ounce of water, which was not afterwards filtered; and on placing three leaves in ninety minims of this fluid, I was much surprised to find that all three leaves were greatly inflected in $15 \mathrm{~m}$.; for I knew from previous trials that the solution does not act so quickly as this. It immediately occurred to me that the particles of the undissolved salt, which were so light as to float about, might have come 
into contact with the glands, and caused this rapid movement. Accordingly I added to some distilled water a pinch of a quite innocent substance, namely, precipitated carbonate of lime, which consists of an impalpable powder; I shook the mixture, and thus got a fluid like thin milk. Two leaves were immersed in it, and in $6 \mathrm{~m}$. almost every tentacle was much inflected. I placed one of these leaves under the microscope, and saw innumerable atoms of lime adhering to the external surface of the secretion. Some, however, had penetrated it, and were lying on the surfaces of the glands; and no doubt it was these particles which caused the tentacles to bend. When a leaf is immersed in water, the secretion instantly swells much; and I presume that it is ruptured here and there, so that little addies of water rush in. If so, we can understand how the atoms of chalk, which rested on the surfaces of the glands, had penetrated the sccretion. Anyone who has rubbed precipitated chalk between his fingers will have perceived how excessively fino the powder is. No doubt there must be a limit, beyond which a particle would be too small to act on a gland; but what this limit is, I know not. I have often seen fibres and dust, which had fallen from the air, on the crlands of plants kept in my room, and these never induced any morgment; but then such particles lay on the surface of the secretion and never reached the gland itself.

Finally, it is an extraordinary fact that a littlo bit of soft threarl, $\frac{1}{3}$ of an inch in length and weighing $\frac{1}{81}$ of a grain, or of a human hair, $\frac{8}{100}$ of an inch in length and weighing only $=\frac{1}{7} \div \overline{70}$ of a grain (.000822 milligramme), or particles of precipitated chalk, after resting for a short time on a gland, should induce some change in its cells, exciting them 
to transmit a motor impulse throughout the whole length of the pedicel, consisting of about twenty cells, to near its base, causing this part to bend, and the tentacle to sweep through an angle of above $180^{\circ}$. That the contents of the cells of the glands, and afterwards those of the pedicels, are affected in a plainly visible manner by the pressure of minute particles, we shall have abundant evidence when we treat of the aggregation of protoplasm. But the case is much more remarkable than as yet stated; for the particles are supported by the viscid and dense secretion; nevertheless, even smaller ones than those of which the measurements have been given, when brought by an insensibly slow movement, through the means above specified, into contact with the surface of a gland, act. on it, and the tentacle bends. The pressure exerted by the particle of hair, weighing only $\frac{1}{78,40}$ of a grain and supported by a dense fluid, must have been inconceivably slight. We may conjecture that it could hardly have equalled the millionth of a grain; and we shall hereafter see that far less than the millionth of a grain of phosphate of ammonia in solution, when absorbed by a gland, acts on it and induces movement. A bit of hair, $\frac{1}{50}$ of an inch in length, and therefore much larger than those used in the above experiments, was not perceived when placed on my tongue; and it is extremely doubtful whether any nerve in the human body, even if in an inflamed condition, would be in any way affected by such a particle supported in a dense fluid, and slowly brought into contact with the nerve. Yet the cells of the glands of Drosera are thus excited to transmit a motor impulse to a distant point, inducing movement. It appears to me that hardly any more remarkable fact than this has been observed in the vegetable kingdom. 
The Inflection of the Exterior Tentacles, when their Glands are excited by Repeated Touches.

We have already seen that, if the central glands are excited by being gently brushed, they transmit a motor impulse to the exterior tentacles, causing them to bend; and we have now to consider the effects which follow from the glands of the exterior tentacles being themselves touched. On several occasions, a large number of glands were touched only once with a needle or fine brush, hard enough to bend the whole flexible tentacle; and though this must have caused a thousandfold greater pressure than the weight of the above clescribed particles, not a tentacle moved. On another occasion forty-five glands on eleven leaves were touched once, twice, or even thrice, with a needle or stiff bristle. This was done as quickly as possible, but with force sufficient to bend the tentacles; yet only six of them became inflected,-three plainly, and three in a slight degree. In order to ascertain whether these tentacles which were not affected were in an efficient state, bits of meat were placed on ten of them, and they all soon became greatly incurred. On the other hand, when a large number of glands were struck four, five, or six times with the same force as before, a needle or sharp splinter of glass being used, a much larger proportion of tentacles became inflected; but the result was so uncertain as to seem capricions. For instance, I struck in the above manner three glands, which happened to be extremely sensitive, and all three were inflected almost as quickly as if bits of meat had been placed on them. On another oceasion I gave a single for- 
cible touch to a considerable number of glands, and not one moved ; but these same glands, after an interval of some hours, being touched four or five times with a needle, several of the tentacles soon became inflected.

The fact of a single touch or even of two or three touches not causing inflection must be of some service to the plant; as during stormy weather, the glands cannot fail to be occasionally touched by the tall blades of grass, or by other plants growing near; and it would be a great evil if the tentacles were thus brought into action, for the act of re-expansion takes a considerable time, and until the tentacles are reexpanded they cannot catch prey. On the other hand, extreme sensitiveness to slight pressure is of the highest service to the plant; for, as we have seen, if the delicate feet of a minute struggling insect press ever so lightly on the surfaces of two or three glands, the tentacles bearing these glands soon curl inwards and carry the insect with them to the centre, causing, after a time, all the circumferential tentacles to embrace it. Nevertheless, the movements of the plant are not perfectly adapted to its requirements; for if a bit of dry moss, peat, or other rubbish, is blown on to the disc, as often happens, the tentacles clasp it in a useless manner. They soon, however, discover their mistake and release such innutritious objects.

It is also a remarkable fact, that drops of water falling from a height, whether under the form of natural or artificial rain, do not cause the tentacles to move; yet the drops must strike the glands with considerable force, more especially after the secretion has been all washed away by heavy rain; and this often occurs, 
though the secretion is so viscid that it can be removed with difficulty merely by waving the leaves in water. If the falling drops of water are small, they adhere to the secretion, the weight of which must be increased in a much greater degree, as before remarked, than by the addition of minute particles of solid matter; yet the drops never cause the tentacles to become inflected. It would obviously have been a great evil to the plant (as in the case of occasional touches) if the tentacles were excited to bend by every shower of rain; but this evil has been avoided by the glands either having become through habit insensible to the blows and prolonged pressure of drops of water, or to their having been originally rendered sensitive solely to the contact of solid bodies. We shall hereafter see that the filaments on the leaves of Dionæa are likewise insensible to the impact of fluids, though exquisitely sensitive to momentary turches from any solid body.

When the pedicel of a tentacle is cut off by a sharp pair of scissors quite close beneath the gland, the tentacle generally becomes infleeted. ' I tried this experiment repeatedly, as I was much surprised at the fict, for all other parts of the pedicels are insensible to any stimulus. These headless tentacles after a time re-expand; but I shall return to this subject. On the other hand, I occasionally succeeded in crushing a gland between a pair of pincers, but this caused no inflection. In this latter case the tentacles seem paralysed, as likewise follows from the action of too strong solutions of eertain salts, and by too great heat, whilst weaker solutions of the same salts and a more gentle heat cause morement. We shall also see in future chapters that various other fluids, some 
vapours, and oxygen (after the plant has been for some time excluded from its action), all induce inflection, and this likewise results from an induced galvanic current.*

* My son Francis, guided by the observations of Dr. Burdon Sanderson on Dionæa, finds that if two needles are inserted into the blade of a leaf of Drosera, the tentacles do not move; but that if similar needles in connection with the secondary coil of a Du Bois inductive apparatus are inserted, the tentacles curve inwards in the course of a few minutes. My son hopes soon to publish an account of his observations. 


\section{CHAPTER III.}

\section{Aggregation of the Protoplasm mithin the Cells of the Tentacles.}

Nature of the contents of the cells before aggregation - Various causes which excite aggregation-The process commences within the glands and travels down the tentacles - Description of the aggregated masses and of their spontaneous movements-Currents of protoplasm along the walls of the cells-Action of carbonate of ammonia-The granules in the protoplasm which flows along the walls coalesce with the central masses-Minuteness of the quantity of carbonate of ammonia causing aggregation-Action of other salts of ammonia - Of other substances, organic fluids, \&c.-Of water-Of heat-Redissolution of the aggregated masses -Proximate causes of the aggregation of the protoplasmSummary and concluding remarks-Supplementary observations on aggregation in the roots of plants.

I wiLL here interrupt my account of the movements of the leares, and describe the phenomenon of aggregation, to which subject I have already alluded. If the tentacles of a young, yet fully matured leaf, that has never been excited or become inflected, be examined, the cells forming the pedicels are seen to be filled with homogeneous, purple fluid. The walls are lined by a layer of colourless, circulating protoplasm; but this can be seen with much greater distinctness after the process of aggregation has been partly effected than before. 'The purple fluid which exudes from a crushed tentacle is somewhat coherent, and does not mingle with the surrounding water; it contains much floceulent or granular matter. But this matter may have been generated by the cells having been crushed; some degree of aggregation having been thus almost instantly caused. 
If a tentacle is examined some hours after the gland has been excited by repeated touches, or by an inorganic or organic particle placed on it, or by the absorption of certain fluids, it presents a wholly changed appearance. The cells, instead of being filled with homogeneous purple fluid, now contain variously shaped masses of purple matter, suspended in a colourless or almost colourless fluid. The change is so conspicuous that it is visible through a weak lens, and even sometimes by the naked eye; the tentacles now have a mottled appearance, so that one thus affected can be picked out with ease from all the others. The same result follows if the glands on the dise are irritated in any manner, so that the exterior tentacles become inflected; for their contents will then be found in an aggregated condition, although their glands have not as yet touched any object. But aggregation may occur independently of inflection, as we shall presently see. By whatever cause the process may have been excited, it commences within the glands, and then travels down the tentacles. It can be observed much more distinctly in the upper cells of the pedicels than within the glands, as these are somewhat opaque. Shortly after the tentacles have re-expanded, the little masses of protoplasm are all redissolved, and the purple fluid within the cells becomes as homogeneous and transparent as it was at first. The process of redissolution travels upwards from the bases of the tentacles to the glands, and therefore in a reversed direction to that of aggregation. Tentacles in an aggregated condition were shown to Prof. Huxley, Dr. Hooker, and Dr. Burdon Sanderson, who observed the changes under the microscope, and were much struck with the whole phenomenon. 
The little masses of aggregated matter are of the most diversified shapes, often spherical or oval, sometimes much elongated, or quite irregular with threador necklace-like or club-formed projections. They consist of thick, apparently viscid matter, which in the exterior tentacles is of a purplish, and in the short discal tentacles of a greenish, colour. These little masses incessantly change their forms and positions, being never at rest. A single mass will often separate into two, which afterwards reunite. Their movements are rather slow, and resemble those of Amoebre or of the white corpuseles of the blood. We

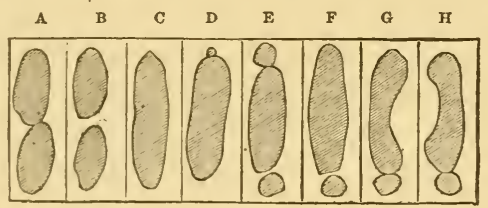

FIG. 7.

(Drosera rotundifolia.)

1)iagram of the same cell of a tentacle, showing the various forms successively assumed by the aggregated masses of protoplasm.

may, therefore, conclude that they consist of protoplasm. If their shapes are sketched at intervals of a few minutes, they are invariably seen to have undergone great changes of form; and the same cell has been obserred for several hours. Eight rude, though accurate sketches of the same cell, made at intervals of between $2 \mathrm{~m}$. or $3 \mathrm{~m}$., are here given (fig. 7), and illustrate some of the simpler and commonest changes. The cell A, when first sketched, included two oval masses of purple protoplasm touching each other. These became separate, as shown at $\mathrm{B}$, and then reunited, as at C. After the next interval a very common appearance was presented- 
$D$, namely, the formation of an extremely minute sphere at one end of an elongated mass. This rapidly increased in size, as shown in $\mathrm{E}$, and was then reabsorbed, as at F, by which time another sphere had been formed at the opposite end.

The cell above figured was from a tentacle of a dark red leaf, which had caught a small moth, and was examined under water. As I at first thought that the morements of the masses might be due to the absorption of water, I placed a fly on a leaf, and when after $18 \mathrm{hrs}$. all the tentacles were well inflected, these were examined without being immersed in water. The cell

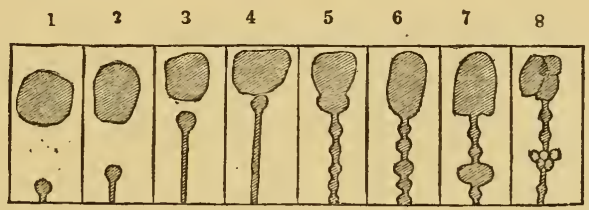

FIG. 8.

(Drosera rotundifolia.)

Diagram of the same cell of a tentacle, showing the various forms successively assumed by the aggregated masses of protoplasm.

here represented (fig. 8) was from this leaf, being sketched eight times in the course of $15 \mathrm{~m}$. These sketches exhibit some of the more remarkable changes which the protoplasm undergoes. At first, there was at the base of the cell 1 , a little mass on a short footstalk, and a larger mass near the upper end, and these seemed quite separate. Nevertheless, they may have been connected by a fine and invisible thread of protoplasm, for on two other occasions, whilst one mass was rapidly increasing, and another in the same cell rapidly decreasing, I was able by varying the light and using a high power, to detect a connecting thread of extreme tenuity, which evidently served as 
the channel of communication between the two. On the other hand, such connecting threads are sometimes seen to break, and their extremities then quickly become club-headed. The other sketches in fig. 8 show the forms successively assumed.

Shortly after the purple fluid within the cells has become aggregated, the little masses float about in a colourless or almost colourless fluid; and the layer of white granular protoplasm which flows along the walls can now be seen much more distinctly. The stream flows at an irregular rate, up one wall and down the opposite one, generally at a slower rate across the narrow ends of the elongated cells, and so round and round. But the current sometimes ceases. The morement is often in wares, and their crests sometimes stretch almost across the whole width of the cell, and then sink down again. Small spheres of protoplasm, apparently quite free, are often driven by the current round the cells; and filaments attached to the central masses are swayed to and fro, as if struggling to escape. Altogether, one of these cells with the erer changing central masses, and with the layer of protoplasm flowing round the walls, presents a wonderful scene of rital activity.

Many observations were made on the contents of the cells whilst undergoing the process of aggregation, but I shall detail only a few cases under different heads. A small portion of a leaf was cut off, placed under a high porrer, and the glands very gently pressed under a compressor. In $15 \mathrm{~m}$. I distinctly saw extremely minute spheres of protoplasm aggregating themsclves in the purple fluid; these rapidly increased in size, both within the cells of the glands and of the upper ends of the pedicels. Particles of glass, cork, and cinder's were also placed on the glands of many tentacles; in $1 \mathrm{hr}$. several of them were inflected, but after $1 \mathrm{hr}$. $35 \mathrm{~m}$. there was no aggregation. Other tentacles with these particles were examined after $8 \mathrm{hrs.}$, and 
now all their cells had undergone aggregation; so had the cells of the exterior tentacles which had become inflected through the irritation transmitted from the glands of the disc, on which the transported particles rested. This was likewise the case with the short tentacles round the margins of the disc, which had not as yet become inflected. This latter fact shows that the process of aggregation is independent of the inflection of the tentacles, of which indeed we have other and abundant evidence. Again, the exterior tentacles on three leaves were carefully examined, and found to contain only homogeneous purple fluid; little bits of thread were then placed on the glands of three of them, and after $22 \mathrm{hrs}$. the purple fluid in their cells almost down to their bases was aggregated into innumerable, spherical, elongated, or filamentous masses of protoplasm. The bits of thread had been carried some time previously to the central disc, and this had caused all the other tentacles to become somewhat inflected; and their cells had likewise undergone aggregation, which however, it should be observed, had not as yet extended down to their bases, but was confined to the cells close beneath the glands.

Not only do repeated touches on the glands* and the contact of minute particles cause aggregation, but if glands, without being themselves injured, are cut off from the summits of the pedicels, this induces a moderate amount of aggregation in the headless tentacles, after they have become inflected. On the other hand, if glands are suddenly crushed between pincers, as was tried in six cases, the tentacles seem paralysed by so great a shock, for they neither become inflected nor exhibit any signs of aggregation.

Carbonate of Ammonia.-Of all the causes inducing aggregation, that which, as far as I have seen, acts the quickest, and is the most powerful, is a solution of carbonate of ammonia. Whatever its strength may be, the glands are always affected first, and soon become quite opaque, so as to appear black. For instance, I placed a leaf in a few drops of a strong solution, namely, of one part to 146 of water (or $3 \mathrm{grs}$. to $1 \mathrm{oz}$.), and observed it under a high power. All the glands began to

* Judging from an account of MI. Heckel's observations, which I have only just seen quoted in the 'Gardener's Chronicle' (Oct. 10, 1874), he appears to have observed a similar phenomenon in the stamens of Berberis, after they have been excited by a touch and have moved; for he says, "the contents of each individual cell are collected together in the centre of the cavity." 
darken in $10 \mathrm{~s}$. (seconds); and in $13 \mathrm{~s}$. were conspicuously darker. In $1 \mathrm{~m}$. extremely small spherical masses of protoplasm could be seen arising in the cells of the pedicels close beneath the glands, as well as in the cushions on which the longheaded marginal glands rest. In several cases the process travelled down the pedicels for a length twice or thrice as great as that of the glands, in about $10 \mathrm{~m}$. It was interesting to observe the process momentarily arrested at each transverse partition between two cells, and then to see the transparent contents of the cell next below almost flashing into a cloudy mass. In the lower part of the pedicels, the action proceeded slower, so that it took about $20 \mathrm{~m}$. before the cells halfway down the long marginal and submarginal tentacles became aggregated.

We may infer that the carbonate of ammonia is absorbed by the glands, not only from its action being so rapid, but from its effect being somewhat different from that of other salts. As the glands, when excited, secrete an acid belonging to the acetic series, the carbonate is probably at once converted into a salt of this series; and we shall presently see that the acetate of ammonia causes aggregation almost or quite as energetically as does the carbonate. If a few drops of a solution of one part of the carbonate to 437 of water (or 1 gr. to $1 \mathrm{oz}$.) be added to the purple fluid which exudes from crushed tentacles, or to paper stained by being rubbed with them, the fluid and the paper are changed into a pale dirty green. Nevertheless, some purple colour could still be detected after $1 \mathrm{hr} .30 \mathrm{~m}$. within the glands of a leaf left in a solution of twice the above strength (viz. $2 \mathrm{grs}$. to $1 \mathrm{oz}$.) ; and after $21 \mathrm{hrs}$. the cells of the pedicels close beneath the glands still contained spheres of protoplasm of a fine purple tint. These facts show that the ammonia had not cntered as a carbonate, for otherwise the colour would have been discharged. I have, however, sometimes observed, especially with the long-headed tentacles on the margins of very pale leares immersed in a solution, that the glands as well as the upper cells of the pedicels were discoloured; and in these cases I presume that the unchanged carbonate had been absorbed. The appearance above described, of the aggregating process being arrested for a short time at each transverse partition, impresses the mind with the idea of matter passing downwards from cell to cell. But as the cells one beneath the other undergo aggregation when inorganic and insoluble particles are placed on the glands, the process must be, at least in these cases, one of molecular change, transmitted from the glands, 
independently of the absorption of any matter. So it may possibly be in the case of the carbonate of ammonia. As, however, the aggregation caused by this salt travels down the tentacles at a quicker rate than when insoluble particles are placed on the glands, it is probable that ammonia in some form is absorbed not only by the glands, but passes down the tentacles.

Having examined a leaf in water, and found the contents of the cells homogeneous, I placed it in a few drops of a solution of one part of the carbonate to 437 of water, and attended to the cells immediately beneath the glands, but did not use a very high power. No aggregation was visible in $3 \mathrm{~m}$; ; but after $15 \mathrm{~m}$. small spheres of protoplasm were formed, more especially beneath the long-headed marginal glands; the process, however, in this case took place with unusual slowness. In $25 \mathrm{~m}$. conspicuous spherical masses were present in the cells of the pedicels for a length about equal to that of the glands; and in $3 \mathrm{hrs}$. to that of a third or half of the whole tentacle.

If tentacles with cells containing only very pale pink fluid, and apparently but little protoplasm, are placed in a ferw drops of a weak solution of one part of the carbonate to 4375 of water (1 gr. to $10 \mathrm{oz}$.$) , and the highly transparent cells beneath$ the glands are carefully observed under a high power, these may be seen first to become slightly cloudy from the formation of numberless, only just perceptible, granules, which rapidly grow larger either from coalescence or from attracting more protoplasm from the surrounding fluid. On one occasion I chose a singularly pale leaf, and gave it, whilst under the microscope, a single drop of a stronger solution of one part to 437 of water; in this case the contents of the cells did not become cloudy, but after $10 \mathrm{~m}$. minute irregular granules of protoplasm could be detected, which soon increased into irregular masses and globules of a greenish or very pale purple tint; but these never formed perfect spheres, though incessantly changing their shapes and positions.

With moderately red leaves the first effect of a solution of the carbonate generally is the formation of two or three, or of several, extremely minute purple spheres which rapidly increase in size. To give an idea of the rate at which such spheres increase in size, I may mention that a rather pale purple leaf placed under a slip of glass was given a drop of a solution of one part to 292 of water, and in $13 \mathrm{~m}$. a few minute spheres of protoplasm were formed; one of these, after 2 hrs. $30 \mathrm{~m}$., was about two-thirds of the diameter of the cell. After $4 \mathrm{hrs} .25 \mathrm{~m}$. 
it nearly equalled the cell in diameter; and a second sphere about half as large as the first, together with a fow other minute ones, were formed. After 6 hrs. the fluid in which these spheres floated was almost colourless. After 8 hrs. $35 \mathrm{~m}$. (always reckoning from the time when the solution was first added) four now minute spheres had appeared. Next morning, after $22 \mathrm{hrs.}$ there were, besides the two large spheres, seven smaller ones, floating in absolutely colourless fluid, in which some flocculent greenish matter was suspended.

At the commencement of the process of aggregation, more especially in dark red leaves, the contents of the cells often present a different appearance, as if the layer of protoplasm (primordial utricle) which lines the cells had separated itself and shrunk from the walls; an irregularly shaped purple bag being thus formed. Other fluids, besides a solution of the carbonate, for instance an infusion of raw meat, produce this same effect. But the appearance of the primordial utricle shrinking from the walls is certainly false ${ }^{*}$ for before giving the solution, I saw on several occasions that the walls were lined with colourless flowing protoplasm, and after the bag-like masses wero formed, the protoplasm was still flowing along the walls in a conspicuous manner, even more so than before. It appeared jndeed as if the stream of protoplasm was strengthened by the action of the carbonate, but it was impossible to ascertain whether this was really the case. The bag-like masses, when once formed, soon begin to glide slowly round the cells, sometimes sending out projections which separate into little spheres; other spheres appear in the fluid surrounding the bags, and these travel much more quickly. That the small spheres are separate is often shown by sometimes one and then another travelling in advance, and sometimes they revolve round each other. I have occasionally seen spheres of this kind proceeding up and down the same side of a cell, instead of round it. The hag-like masses after a time generally divide into two rounded or oval masses, and these undergo the changes shown in figs. 7 and 8. At other times spheres appear within the bags; and these coalesce and separate in an endless cycle of change.

After leaves have been left for several hours in a solution of the carbonate, and complete aggregation has been effected, the

* With other plants I have often seen what appears to be a true shrinking of the primordial utriclo from tho walls of tho cells, caused by a solution of carbonate of ammonia, as likewise follows from mechanical injuries. 
stream of protoplasm on the walls of the cells eeases to be visible; I observed this fact repeatedly, but will give only one instance. A pale purple leaf was placed in a few drops of a solution of one part to 292 of water, and in $2 \mathrm{hrs}$. some fine purple spheres were formed in the upper cells of the pedicels, the stream of protoplasm round their walls being still quite distinct; but after an additional 4 hrs., during which time many more spheres were formed, the stream was no longer distinguishable on the most careful examination; and this no doubt was due to the contained granules having become united with the spheres, so that nothing was left by which the movement of the limpid protoplasm conld be perceived. But minute free spheres still travelled up and down the cells, showing that there was still a current. So it was next morning, after 22 hrs., by which time some new minute spheres had been formed; these oscillated from side to side and changed their positions, proving that the current had not ceased, though no stream of protoplasm was visible. On another occasion, however, a stream was seen flowing round the cell-walls of a vigorous, dark-coloured leaf, after it had been left for 24 hrs. in a rather stronger solution, namely, of one part of the carbonate to 218 of water. This leaf, therefore, was not much or at all injured by an immersion for this length of time in the above solution of two grains to the ounce; and on being afterwards left for $24 \mathrm{hrs}$. in water, the aggregated masses in many of the cells were redissolved, in the same manner as occurs with leaves in a state of nature when they re-expand after having caught insects.

In a leaf which had been left for 22 hrs. in a solution of one part of the carbonate to 292 of water, some spheres of protoplasm (formed by the self-division of a bag-like mass) were gently pressed beneath a covering glass, and then examined under a high power. They were now distinctly divided by well-defined radiating fissures, or were broken up into separate fragments with sharp edges; and they were solid to the centre. In the larger broken spheres the central part was more opaque, darker-coloured, and less brittle than the exterior; the latter alone being in some cases penetrated by the fissures. In many of the spheres the line of separation between the outer and inner parts was tolerably well defined. The outer parts were of exactly the same very pale purple tint, as that of the last formed smaller spheres; and these latter did not include any darker central core.

From these several facts we may conclude that when vigorous dark-coloured leaves are subjected to the action of carbonate of 
ammonia, the fluid within the cells of the tentacles often aggregates exteriorly into coherent viscid matter, forming a kind of bag. Small spheres sometimes appear within this bag, and the whole generally soon divides into two or more spheres, which repeatedly coalesce and redivide. After a longer or shorter time the granules in the colourless layer of protoplasm, which flows round the walls, are drawn to and unite with the larger spheres, or form small independent spheres; these latter being of a much paler colour, and more brittle than the first aggregated masses. After the granules of protoplasm have been thus attracted, the layer of flowing protoplasm can no longer be distinguished, though a current of limpid fluid still flows round the walls.

If a leaf is immersed in a very strong, almost concentrated, solution of carbonate of ammonia, the glands are instantly blackened, and they secrete copiously; but no movement of the tentacles ensues. Two leaves thus treated became after $1 \mathrm{hr}$. flaccid, and seemed killed; all the cells in their tentacles contained spheres of protoplasm, but these were small and discoloured. Two other leaves were placed in a solution not quite so strong, and there was well-marked aggregation in $30 \mathrm{~m}$. After 24 hrs. the spherical or more commonly oblong masses of protoplasm became opaque and granular, instead of being as usual translucent; and in the lower cells there were only innumerable minute spherical granules. It was evident that the strength of the solution had interfered with the completion of the process, as we shall see likewise follows from too great heat.

All the foregoing observations relate to the exterior tentacles, which are of a purple colour; but the green pedicels of the short central tentacles are acted on by the carbonate, and by an infusion of raw meat, in exactly the same manner, with the sole difference that the aggregated masses are of a greenish colour; so that the process is in no way dependent on the colour of the fluid within the cells.

Finally, the most remarkable fact with respect to this salt is the extraordinary small amount which suffices to cause aggregation. Full details will be given in the seventh chapter, and here it. will be cnough to say that with a sensitive leaf the alssorption by a gland of $\frac{1}{13+400}$ of a grain (·000482 mgr.) is enough to cause in the course of one hour well-marked aggregation in the cells immediately beneath the gland.

The Fiffects of certain other Salts and Fluids.-Two leaves were placed in a solution of one part of acctate of ammonia to about 
146 of water, and were acted on quite as energetically, but perhaps not quite so quickly, as by the carbonate. After $10 \mathrm{~m}$. the glands were black, and in the cells beneath them there were traces of aggregation, which after $15 \mathrm{~m}$. was well marked, extending down the tentacles for a length equal to that of the glands. After 2 hrs. the contents of almost all the cells in all the tentacles were broken up into masses of protoplasm. A leaf was immersed in a solution of one part of oxalate of ammonia to 146 of water; and after $21 \mathrm{~m}$. some, but not a conspicuous, change could be seen within the cells beneath the glands. After $47 \mathrm{~m}$. plenty of spherical masses of protoplasm were formed, and these extended down the tentacles for about the length of the glands. This salt, therefore, does not act so quickly as the carbonate. With respect to the citrate of ammonia, a leaf was placed in a little solution of the above strength, and there was not even a trace of aggregation in the cells beneath the glands, until $56 \mathrm{~m}$. had elapsed; but it was well marked after $2 \mathrm{hrs} .20 \mathrm{~m}$. On another occasion a leaf was placed in a stronger solution, of one part of the citrate to 109 of water ( 4 grs. to $1 \mathrm{oz}$.), and at the same time another leaf in a solution of the carbonate of the same strength. The glands of the latter were blackened in less than $2 \mathrm{~m}$., and after $1 \mathrm{hr} .45 \mathrm{~m}$. the aggregated masses, which were spherical and very dark-coloured, extended down all the tentacles, for between half and two-thirds of their lengths; whereas in the leaf immersed in the citrate the glands, after $30 \mathrm{~m}$., were of a dark red, and the aggregated masses in the cells beneath them pink and elongated. After $1 \mathrm{hr} .45 \mathrm{~m}$. these masses extended down for only about one-fifth or one-fourth of the length of the tentacles.

Two leaves were placed, each in ten minims of a solution of one part of nitrate of ammonia to 5250 of water ( $1 \mathrm{gr}$. to $12 \mathrm{oz}$.), so that each leaf received $\frac{1}{576}$ of a grain ( $\cdot 1124 \mathrm{mgr}$.). This quantity caused all the tentacles to be inflected, but after $24 \mathrm{hrs}$. there was only a trace of aggregation. One of these same leaves was then placed in a weak solution of the carbonate, and after $1 \mathrm{hr} .45 \mathrm{~m}$. the tentacles for half their lengths showed an astonishing degree of aggregation. Two other leaves were then placed in a much stronger solution of one part of the nitrate to 146 of water ( $3 \mathrm{grs}$. to $1 \mathrm{oz}$.) ; in one of these there was no marked change after $3 \mathrm{hrs}$; ; but in the other there was a trace of aggregation after $52 \mathrm{~m}$., and this was plainly marked after $1 \mathrm{hr}$. $22 \mathrm{~m}$., but evẹn after $2 \mathrm{hrs} .12 \mathrm{~m}$. there was certainly not more aggregation than would have fol- 
lowed from an immersion of from $5 \mathrm{~m}$. to $10 \mathrm{~m}$. in an equally strong solution of the carbonate.

Lastly, a leaf was placed in thirty minims of a solution of one part of phosphate of ammonia to 43,750 of water ( 1 gr. to $100 \mathrm{oz}$.), so that it received $\frac{1}{1600}$ of a grain ( $\left.\cdot 04079 \mathrm{mgr}.\right)$; this soon caused the tentacles to be strongly inflected; and after 21 hrs. the contents of the cells were aggregated into oval and irregularly globular masses, with a conspicuous current of protoplasm flowing round the walls. But after so long an interval aggregation would have ensued, whaterer had caused inflection.

Only a few other salts, besides those of ammonia, were tried in relation to the process of aggregation. A leaf was placed in a solution of one part of chloride of sodium to 218 of water, and after $1 \mathrm{hr}$. the contents of the cells were aggregated into small, irregularly globular, brownish masses; these after $2 \mathrm{hrs}$. were almost disintegrated and pulpy. It was evident that the protoplasm had been injuriously affected; and soon afterwards some of the cells appeared quite empty. These effects differ altogether from those produced by the several salts of ammonia, as well as by rarious organic fluids, and by inorganic particles placed on the glands. A solution of the same strength of carbonate of soda and carbonate of potash acted in nearly the same manner as the chloride; and here again, after 2 hrs. $30 \mathrm{~m}$., the outer cells of some of the glands had emptied themselves of their brown pulpy contents. We shall see in the eighth chapter that solutions of sereral salts of soda of half the abore strength cause inflection, but do not injure the leares. Weak solutions of sulphate of quinine, of nicotine, camphor, poison of the cobra, \&c., soon induce well-marked aggregation; whereas certain other substances (for instance, a solution of curare) have no such tendency.

Nany acids, though much diluted, are poisonous; and though, as will be shown in the eighth chapter, they cause the tentacles to bend, they do not excite true aggregation. Thus leares were placed in a solution of one part of benzoic acid to 437 of water; and in $15 \mathrm{~m}$. the purple fluid within the cells had shrunk a little from the walls, yet when carefully examined after $1 \mathrm{hr}$. $20 \mathrm{~m}$., there was no true aggregation; and after $24 \mathrm{hrs}$. the leaf was evidently dead. Other leaves in iodic acid, diluted to the same degree, showed after 2 hrs. $15 \mathrm{~m}$. the same surunken appearance of the purple fluid within the cells; and these, after 6 hrs. $15 \mathrm{~m}$., were seen under a high power to be filled with excessively minute spheres of dull reddish protoplasm, 
which by the next morning, after $24 \mathrm{hrs}$, had almost disappeared, the leaf being evidently dead. Nor was there any true aggregation in leaves immersed in propionie acid of the same strength; but in this case the protoplasm was collected in irregular masses towards the bases of the lower cells of the tentacles.

A filtered infusion of raw meat induces strong aggregation, but not very quiekly. In one leaf thus immersed there was a little aggregation after $1 \mathrm{hr} .20 \mathrm{~m}$., and in another after $1 \mathrm{hr}$. $50 \mathrm{~m}$. With other leaves a considerably longer time was required : for instance, one immersed for $5 \mathrm{hrs}$. showed no aggregation, but was plainly acted on in $5 \mathrm{~m}$., when placed in a few drops of a solution of one part of carbonate of ammonia to 146 of water. Some leaves were left in the infusion for $24 \mathrm{hrs}$., and these beeame aggregated to a wonderful degree, so that the inflected tentacles presented to the naked eye a plainly mottled appearanee. The little masses of purple protoplasm were generally oval or beaded, and not nearly so often spherieal as in the case of leaves subjected to carbonate of ammonia. They underwent incessant ehanges of form; and the current of colourless protoplasm round the walls was conspicuously plain after an immersion of $25 \mathrm{hrs}$. Raw meat is too powerful a stimulant, and even small bits generally injure, and sometimes kill, the leaves to which they are given: the aggregated masses of protoplasm become dingy or almost colourless, and present an unusual granular appearance, as is likewise the ease with leaves which have been immersed in a very strong solution of carbonate of ammonia. A leaf placed in milk had the contents of its cells somewhat aggregated in $1 \mathrm{hr}$. Two other leaves, one immersed in human saliva for $2 \mathrm{hrs}$. $30 \mathrm{~m}$., and another in unboiled white of egg for $1 \mathrm{hr}$. $30 \mathrm{~m}$., were not acted on in this manner; though they undoubtedly would have been so, had more time been allowed. These same two leaves, on being afterwards placed in a solution of carbonate of ammonia (3 grs. to $1 \mathrm{oz}$.), had their cells aggregated, the one in $10 \mathrm{~m}$. and the other in $5 \mathrm{~m}$.

Several leaves were left for $4 \mathrm{hrs}$. $30 \mathrm{~m}$. in a solution of one part of white sugar to 146 of water, and no aggregation ensued. on being placed in a solution of this same strength of carbonate of ammonia, they were acted on in $5 \mathrm{~m}$.; as was likewise a leaf which had been left for $1 \mathrm{hr} .45 \mathrm{~m}$. in a moderately thick solution of gum arabic. Several other leaves were immersed for some hours in denser solutions of sugar, gum, and starch, and they had the contents of their cells greatly aggregated. This 
effect may be attributed to exosmose; for the leares in the syrup became quite flaccid, and those in the gum and starch somewhat flaccid, with their tentacles twisted about in the most irregular manner, the longer ones like corkscrews. We shall hereafter sce that solutions of these substances, when placed on the discs of leaves, do not incite inflection. Particles of soft sugar were added to the secretion round several glands and were soon dissolved, causing a great increase of the secretion, no doubt by exosmose; and after $24 \mathrm{hrs}$. the cells showed a certain amount of aggregation, though the tentacles were not inflected. Glycerine causes in a few minutes well-pronounced aggregation, commencing as usual within the glands and then travelling down the tentacles; and this I presume may be attributed to the strong attraction of this substance for water. Immersion for several hours in water canses some degree of aggregation. Twenty leaves were first carefully examined, and re-examined after having been left immersed in distilled water for various periods, with the following results. It is rare to find even a trace of aggregation until 4 or 5 and generally not until several more hours have elapsed. When however a leaf becomes quickly inflected in water, as sometimes happens, especially during rery warm weather, aggregation may occur in little orer $1 \mathrm{hr}$. In all cases leaves left in water for more than $24 \mathrm{hrs}$. have their glands blackened, which shows that their contents are aggregated; and in the specimens which were carefully examined, there was fairly woll-marked aggregation in the upper cells of tho pedicels. These trials were made with cut-off leares, and it occurred to me that this circumstance might influence the result, as the footstalks would not perhaps absorb water quickly cnough to supply the glands as they continued to secrete. But this view was proved erroneous, for a plant with uninjured roots, bearing four leaves, was submerged in distilled water for 47 hrs., and the glands were blackened, though the tentacles were very little inflected. In one of these leaves there was only a slight degree of aggregation in the tentacles; in the second rather more, the purple contents of the cells being a littlo scparated from the walls; in the third and fourth, which were palo leaves, tho aggregation in tho upper parts of the pedicels was well marked. In these leares the little masses of protoplasm, many of which were oval, slowly changed their forms and positions; so that a submergence for 47 hr's. had not killed the protoplasm. In a previous trial with a submerged plant, the tentacles were not in the least inflected. 
Heat induces aggregation. A leaf, with the cells of the tentacles containing only homogeneous fluid, was waved about for $1 \mathrm{~m}$. in water at $130^{\circ} \mathrm{Fahr}$. (54.4 Cent.), and was then examined under the microscope as quickly as possible, that is in $2 \mathrm{~m}$. or $3 \mathrm{~m}$; ; and by this time the contents of the cells had undergone some degree of aggregation. A second leaf was waved for $2 \mathrm{~m}$. in water at $125^{\circ}\left(51^{\circ} .6\right.$ Cent.) and quickly examined as before; the tentacles were well inflected; the purple fluid in all the cells had shrunk a little from the walls, and contained many oval and. elongated masses of protoplasm, with a few minute spheres. A third leaf was left in water at $125^{\circ}$, until it cooled, and when examined after $1 \mathrm{hr} .45 \mathrm{~m}$., the inflected tentacles showed some aggregation, which became after 3 hrs. more strongly marked, but did not subsequently increase. Lastly, a leaf was waved for $1 \mathrm{~m}$. in water at $120^{\circ}$ ( $48^{\circ} .8$ Cent.) and then left for $1 \mathrm{hr} .26 \mathrm{~m}$. in cold water; the tentacles were but little inflected, and there was only here and there a trace of aggregation. In all these and other trials with warm water the protoplasm showed much less tendency to aggregate into spherical masses than when excited by carbonate of ammonia.

Redissolution of the Aggregated Masses of Protoplasm.-As soon as tentacles which have clasped an insect or any inorganic object, or have been in any way excited, have fully re-expanded, the aggregated masses of protoplasm are redissolved and disappear; the cells being now refilled with homogeneous purple fluid as they were before the tentacles were inflected. The process of redissolution in all cases commences at the bases of the tentacles, and proceeds up them towards the glands. In old leaves, however, especially in those which have been several times in action, the protoplasm in the uppermost cells of the pedicels remaius in a permanently more or less aggregated condition. In order to observe the process of redissolution, the following observations were made : a leaf was left for 24 hrs. in a little solution of one part of carbonate of ammonia to 218 of water, and the protoplasm was as usual aggregated into numberless purple spheres, which were incessantly changing their forms. The leaf was then washed and placed in distilled water, and after 3 hrs. $15 \mathrm{~m}$. some few of the spheres began to show by their less clearly defined edges signs of redissolution. After 9 hrs. many of them had become elongated, and the surrounding fluid in the cells was slightly more coloured, showing plainly that redissolution had commenced. After $24 \mathrm{hrs}$, thongh many cells still contained spheres, here and there one 
could be seen filled with purple fluid, without a vestige of aggregated protoplasm; the whole having been redissolved. A leaf with aggregated masses, caused by its having been waved for $2 \mathrm{~m}$. in water at the temperature of $125^{\circ}$ Fahr., was left in cold water, and after 11 hrs. the protoplasm showed traces of incipient redissolution. When again examined three days after its immersion in the warm water, there was a conspicuous difference, though the protoplasm was still somewhat aggregated. Another leaf, with the contents of all the cells strongly aggregated from the action of a weak solution of phosphate of ammonia, was left for between three and four days in a mixture (known to be innocuous) of one drachm of alcohol to eight drachms of water, and when re-examined every trace of aggregation had disappeared, the cells being now filled with homogeneous fluid.

We have seen that leaves immersed for some hours in dense solutions of sugar, gum, and starch, have the contents of their cells greatly aggregated, and are rendered more or less flaccirl, with the tentacles irregularly contorted. These leaves, after being left for four days in distilled water, became less flaccid, with their tentacles partially re-expanded, and the aggregated masses of protoplasm were partially redissolred. A leaf with its tentacles closely clasped over a fly, and with the contents of the cells strongly aggregated, was placed in a little sherry wine; after 2 hrs. several of the tentacles had reexpanded, and the others could by a mere touch be pushed back into their properly expanded positions, and now all traces of aggregation had disappeared, the cells being filled with perfectly homogeneous pink fluid. The redissolution in these cases may, I presume, be attributed to endosmose.

\section{On the Proximate Causes of the Process of Aggregation.}

As most of the stimulants which cause the inflection of the tentacles likewise induce aggregation in the contents of their cells, this latter process might be thought to be the direct result of inflection; but this is not the case. If leaves are placed in rather strong solutions of carbonate of ammonia, for instance of three or four, and even sometimes of only two grains to the ounce of water (i.e. one part to 109 , or 146 , or 
218 , of water), the tentacles are paralysed, and do not become inflected, yet they soon exhibit strongly marked aggregation. Moreover, the short central tentacles of a leaf which has been immersed in a weak solution of any salt of ammonia, or in any nitrogenous organic fluid, do not become in the least inflected; nevertheless they exhibit all the phenomena of aggregation. On the other hand, several acids cause strongly pronounced inflection, but no aggregation.

It is an important fact that when an organic or inorganic object is placed on the glands of the disc, and the exterior tentacles are thus cansed to bend inwards, not only is the secretion from the glands of the latter increased in quantity and rendered acid, but the contents of the cells of their pedicels become aggregated. The process always commences in the glands, although these have not as yet touched any object. Some force or influence must, therefore, be transmitted from the central glands to the exterior tentacles, first to near their bases causing this part to bend, and next to the glands causing them to secrete more copiously. After a short time the glands, thus indirectly excited, transmit or reflect some influence down their own pedicels, inducing aggregation in cell beneath cell to their bases.

It seems at first sight a probable view that aggregation is due to the glands being excited to secrete more copiously, so that sufficient fluid is not left in their cells, and in the cells of the pedicels, to hold the protoplasm in solution. In favour of this view is the fact that aggregation follows the inflection of the tentacles, and during the movement the glands generally, or, as I believe, always, secrete more copiously than they did before. Again, during the re-expansion 
of the tentacles, the glands secrete less freely, or quite cease to secrete, and the aggregated masses of protoplasm are then redissolved. MIoreover, when leaves are immersed in dense vegetable solutions, or in glycerine, the fluid within the gland-cells passes outwards, and there is aggregation; and when the leares are afterwards immersed in water, or in an innocuous fluid of less specific gravity than water, the protoplasm is redissolved, and this, no doubt, is due to endosmose.

Opposed to this view, that aggregation is caused by the outward passage of fluid from the cells, are the following facts. There seems no close relation between the degree of increased secretion and that of aggregation. Thus a particle of sugar added to the secretion round a gland causes a much greater increase of secretion, and much less aggregation, than does a particle of carbonate of ammonia given in the same manner. It does not appear probable that pure water would cause much exosmose, and yet aggregation often follows from an immersion in water of between $16 \mathrm{hrs}$. and $24 \mathrm{hrs}$., and always after from $24 \mathrm{hrs}$. to 48 hrs. Still less probable is it that water at a temperature of from $125^{\circ}$ to $130^{\circ} \mathrm{Fahr}$. $\left(51^{\circ} \cdot 6\right.$ to $54^{\circ} \cdot 4$ Cent.) should cause fluid to pass, not only from the glands, but from all the cells of the tentacles down to their bases, so quickly that aggregation is induced within $2 \mathrm{~m}$. or $3 \mathrm{~m}$. Another strong argument against this view is, that, after complete aggregation, the spheres and oval masses of protoplasm float about in an abunclant supply of thin colourless fluid; so that at least the latter stages of the process cannot be lue to the want of fluid to hold the protoplasm in solution. There. is still stronger evidence that agrgregation is independent of secretion; for the papillæ, described in the first chapter, with which the 
leaves are studded are not glandular, and do not secrete, yet they rapidly absorb carbonate of ammonia or an infusion of raw meat, and their contents then quickly undergo aggregation, which afterwards spreads into the cells of the surrounding tissues. We shall hereafter see that the purple fluid within the sensitive filaments of Dionæa, which do not secrete, likewise undergoes aggregation from the action of a weak solution of carbonate of ammonia.

The process of aggregation is a vital one; by which I mean that the contents of the cells must be alive and uninjured to be thus affected, and they must be in an oxygenated condition for the transmission of the process at the proper rate. Some tentacles in a drop of water were strongly pressed beneath a slip of glass; many of the cells were ruptured, and pulpy matter of a purple colour, with granules of all sizes and shapes, exuded, but hardly any of the cells were completely emptied. I then added a minute drop of a solution of one part of carbonate of ammonia to 109 of water, and after $1 \mathrm{hr}$. examined the specimens. Here and there a few cells, both in the glands and in the pedicels, had escaped being ruptured, and their contents were well aggregated into spheres which were constantly changing their forms and positions, and a current could still be seen flowing along the walls; so that the protoplasm was alive. On the other hand, the exuded matter, which was now almost colourless instead of being purple, did not exhibit a trace of aggregation. Nor was there a trace in the many cells which were ruptured, but which had not been completely emptied of their contents. Though I looked carefully, no signs of a current could be seen within these ruptured cells. They had evidently been killed by the pressure; and the matter which they 
still contained did not undergo aggregation any more than that which had exuded. In these specimens, as I may add, the individuality of the life of each cell was well illustrated.

$\Lambda$ full account will be given in the next chapter of the effects of heat on the leares, and I need here only state that leares immersed for a short time in water at a temperature of $120^{\circ} \mathrm{Fahr}$. ( $48^{\circ} .8 \mathrm{Cent}$.), which, as we have seen, does not immediately induce aggregation, were then placed in a few drops of a strong solution of one part of carbonate of ammonia to 109 of water, and became finely aggregated. On the other hand, leaves, after an immersion in water at $150^{\circ}\left(65^{\circ} .5\right.$ Cent.), on being placed in the same strong solution, did not undergo aggregation, the cells becoming filled with brownish, pulpy, or muddy matter. With leaves subjected to temperatures between these two extremes of $120^{\circ}$ and $150^{\circ}$ Fahr. $\left(48^{\circ} .8\right.$ and $65^{\circ} .5$ Cent.), there were gradations in the completeness of the process; the former temperature not preventing aggregation from the subsequent action of carbonate of ammonia, the latter quite stopping it. Thus, leaves immersed in water, heated to $130^{\circ}\left(54^{\circ} 4\right.$ Cent.), and then in the solution, formed perfectly defined spheres, but these were decidedly smaller than in ordinary cases. With other leaves heated to $140^{\circ}\left(60^{\circ}\right.$ Cent.), the spheres were extremely small, yet well defined, but many of the cells contained, in addition, some brownish pulpy matter. In two cases of leaves heated to $145^{\circ}\left(62^{\circ} \cdot 7\right.$ Cent.), a few tentacles could be found with some of their cells containing a few minute spheres; whilst the other cells and other whole tentacles included only the brownish, disintegrated or pulpy matter.

The fluid within the cells of the tentacles must be in an oxygenated condition, in order that the force or 
influence which induces aggregation should be transmitted at the proper rate from cell to cell. A plant, with its roots in water, was left for $45 \mathrm{~m}$. in a vessel containing 122 oz. of carbonic acid. A leaf from this plant, and, for comparison, one from a fresh plant, were both immersed for $1 \mathrm{hr}$. in a rather strong solution . of carbonate of ammonia. They were then compared, and certainly there was much .less aggregation in the leaf which had been subjected to the carbonic acid than in the other. Another plant was exposed in the same vessel for 2 hrs. to carbonic acid, and one of its leaves was then placed in a solution of one part of the carbonate to 437 of water; the glands were instantly blackened, showing that they had absorbed, and that their contents were aggregated; but in the cells close beneath the glands there was no aggregation even after an interval of $3 \mathrm{hrs}$. After $4 \mathrm{hrs}$. $15 \mathrm{~m}$. a few minute spheres of protoplasm were formed in these cells, but even after $5 \mathrm{hrs} .30 \mathrm{~m}$. the aggregation did not extend down the pedicels for a length equal to that of the glands. After numberless trials with fresh leaves immersed in a solution of this strength, I have never seen the aggregating action transmitted at nearly so slow a rate. Another plant was left for $2 \mathrm{hrs}$. in carbonic acid, but was then exposed for $20 \mathrm{~m}$. to the open air, during which time the leaves, being of a red colour, would have absorbed some oxygen. One of them, as well as a fresh leaf for comparison, were now immersed in the same solution as before. The former were looked at repeatedly, and after an interval of $65 \mathrm{~m}$. a few spheres of protoplasm were first observed in the cells close beneath the glands, but only in two or three of the longer tentacles. After 3 hrs. the aggregation had travelled down the pedicels of a few of the tentacles 
for a length equal to that of the glands. On the other hand, in the fresh leaf similarly treated, aggregation was plain in many of the tentacles after $15 \mathrm{~m}$; ; after $65 \mathrm{~m}$. it had extended down the pedicels for four, five, or more times the lengths of the glands; and after $3 \mathrm{hrs}$. the cells of all the tentacles were affected for one-third or one-half of their entire lengths. Hence there can be no doubt that the exposure of leaves to carbonic acid either stops for a time the process of aggregation, or checks the transmission of the proper influence when the glands are subsequently excited by carbonate of ammonia; and this substance acts more promptly and energetically than any other. It is known that the protoplasm of plants exhibits its spontaneous morements only as long as it is in an oxygenated condition; and so it is with the white corpuscles of the blood, only as long as they receive oxygen from the red corpuscles; ; but the cases above given are somewhat different, as they relate to the delay in the generation or aggregation of the masses of protoplasm by the exclusion of oxygen.

\section{Summary and Concluding Remarlis.-The process of} aggregation is independent of the inflection of the tentacles and of increased secretion from the glands. It commences within the glands, whether these have been directly excited, or indirectly by a stimulus received from other glands. In both cases the process is transmitted from cell to cell down the whole length of the tentacles, being arrested for a short time at each transverse partition. With pale-coloured leaves the first change which is perceptible, but only

* With respect to plants, Sachs, 'Traité de Bot.,' 3rd edit., 1874, p. 86t. On blood corpuscles, see
'Quarterly Journal of Microscopical Science,' April 187t, p. 
under a high power, is the appearance of the finest granules in the fluid within the cells, making it slightly cloudy. These granules soon aggregate into small globular masses. I have seen a cloud of this kind appear in $10 \mathrm{~s}$. after a drop of a solution of carbonate of ammonia had been given to a gland. With dark red leaves the first visible change often is the conversion of the outer layer of the fluid within the cells into bag-like masses. The aggregated masses, however they may have been dereloped, incessantly change their forms and positions. They are not filled with fluid, but are solid to their centres. Ultimately the colourless granules in the protoplasm which flows round the walls coalesce with the central spheres or masses; but there is still a current of limpid fluid flowing within the cells. As soon as the tentacles fully re-expand, the aggregated masses are redissolved, and the cells become filled with homogeneous purple fluid, as they were at first. The process of redissolution commences at the bases of the tentacles, thence proceeding upwards to the glands; and, therefore, in a reversed direction to that of aggregation.

Aggregation is excited by the most diversified causes,- by the glands being several times touched,by the pressure of particles of any kind, and as these are supported by the dense secretion, they can hardly press on the glands with the weight of a millionth of a grain, ${ }^{*}$-by the tentacles being cut off close beneath

* According to Hofmeister (as quoted by Sachs, 'Traité de Bot.' 1874 , p. 958), very slight pressure on the cell-membrane arrests immediately the movements of the protoplasm, and even determines its separation from the walls. But the process of aggre- gation is a different phenomenon, as it relates to the contents of the cells, and only secondarily to the layer of protoplasm which flows along the walls; though no doubt the effects of pressure or of a touch on the outside must bo transmitted through this layer. 
the glands,- by the glands absorbing various fluids or matter dissolved out of certain bodies,- - by exosmose,and by a certain degree of heat. On the other hand, a temperature of about $150^{\circ} \mathrm{Fahr}$. ( $65^{\circ} .5$ Cent.) does not excite aggregation; nor does the sudden crushing of a gland. If a cell is ruptured, neither the exuded matter nor that which still remains within the cell undergoes aggregation when carbonate of ammonia is added. A very strong solution of this salt and rather large bits of raw meat prevent the aggregated masses being well developed. From these facts we may conclude that the protoplasmic fluid within a cell does n.t. become aggregated unless it be in a living state, ani only imperfectly if the cell has been injured. We have also seen that the fluid must be in an oxygenated state, in order that the process of aggregation should travel from cell to cell at the proper rate.

Various nitrogenous organic fluids and salts of ammonia induce aggregation, but in different degrees and at very different rates. Carbonate of ammonia is the most powerful of all known substances; the absorption of $\frac{1}{13+10 \overline{0}}$ of a grain (·000482 mg.) by a gland suffices to cause all the cells of the same tentacle to become aggregated. The first effect of the carbonate and of certain other salts of ammonia, as well as of some other fluids, is the darkening or blackening of the glands. This follows even from long immersion in cold distilled water. It apparently depends in chief part on the strong aggregation of their cellcontents, which thus become opaque, and do not reflect light. Some other fluids render the glands of a brighter red; whilst certain acids, though much diluted, the poison of the cobra-snake, frc, make the glands perfectly white and opaque; and this seems to depend on the coagulation of their contents without 
any aggregation. Nevertheless, before being thus affected, they are able, at least in some cases, to excite aggregation in their own tentacles.

That the central glands, if irritated, send centrifugally some influence to the exterior glands, causing them to send back a centripetal influence inducing aggregation, is perhaps the most interesting fact given in this chapter. But the whole process of aggregation is. in itself a striking phenomenon. Whenever the peripheral extremity of a nerve is touched or pressed, and a sensation is felt, it is believed that an invisible molecular change is sent from one end of the nerve to the other; but when a gland of Drosera is repeatedly touched or gently pressed, we can actually see a molecular change proceeding from the gland down the tentacle; though this change is probably of a very different nature from that in a nerve. Finally, as so many and such widely different causes excite aggregation, it would appear that the living matter within the gland-cells is in so unstable a condition that almost any disturbance suffices to change its molecular nature, as in the case of certain chemical compounds. And this change in the glands, whether excited directly, or indirectly by a stimulus received from other glands, is transmitted from cell to cell, causing granules of protoplasm either to be actually generated in the previously limpid fluid or to coalesce and thus to become visible.

\section{Supplementary Observations on the Process of Aggre- gation in the Roots of Plants.}

It will hereafter be seen that a weak solution of the carbonate of ammonia induces aggregation in the cells of the roots of Drosera; and this led me to make a few trials on the roots of other plants. I dug up in the latter part of October the first weed which I met with, viz. Euphorbia peplus, being care- 
ful not to injure the roots; these were washed and placed in a little solution of one part of carbonate of ammonia to 146 of water. In less than one minute I saw a cloud travelling from cell to cell up the roots, with wonderful rapidity. After from $8 \mathrm{~m}$. to $9 \mathrm{~m}$. the fine granules, which caused this cloudy appearance, became aggregated towards the extremities of the roots into quadrangular masses of brown matter; and some of these soon changed their forms and became spherical. Some of the cells, however, remained unaffected. I repeated the experiment with another plant of the same species, but before I could get the specimen into focus under the microscope, clouds of granules and quadrangular masses of reddish and brown matter were formed, and had run far up all the roots. A fresh root tras now left for $18 \mathrm{hrs}$. in a drachm of a solution of one part of the carbonate to 437 of water, so that it received $\frac{1}{8}$ of a grain, or $2.024 \mathrm{mg}$. When examined, the cells of all the roots throughout their whole length contained aggregated masses of reddish and brown matter. Before making these experiments, several roots were closely examined, and not a trace of the cloudy appearance or of the granular masses could be seen in any of them. Roots were also immersed for $35 \mathrm{~m}$. in a solution of one part of carbonate of potash to 218 of water; but this salt produced no effect.

I may here add that thin slices of the stem of the Euphorbia were placed in the same solution, and the cells which were green instantly became cloudy, whilst others which were before colourless were clouded with brown, owing to the formation of numerous granules of this tint. I have also seen with various kinds of leaves, left for some time in a solution of carbonate of ammonia, that the grains of chlorophyll ran together and partially coalesced; and this seems to be a form of aggregation.

Plants of duck-weed (Lemna) were left for between $30 \mathrm{~m}$. and $45 \mathrm{~m}$. in a solution of one part of this same salt to 146 of water, and three of their roots were then examined. In two of them, all the cells which had previously contained only limpid fluid now included little green spheres. After from $1_{2}^{1} \mathrm{hr}$. to $2 \mathrm{hrs}$. similar spheres appeared in the cells on the borders of the leaves; but whether the ammonia had travelled up the roots or had been directly absorbed by the leaves, I cannot say. As one species, Lemna arrhiza, produces no roots, the latter alternative is perhaps the most probable. After about $2 \frac{1}{2}$ hrs. some of the little green spheres in the roots were broken up into small granules which exhibited Brownian movements. Some duckweed was also left for $1 \mathrm{hr} .30 \mathrm{~m}$. in a solution of one part of 
carbonate of potash to 218 of water, and no decided change could be perceived in the cells of the roots; but when these same roots were placed for $25 \mathrm{~m}$. in a solution of carbonate of ammonia of the same strength, little green spheres were formed.

A green marine alga was left for some time in this same solution, but was very doubtfully affected. On the other hand, a red marine alga, with finely pinnated fronds, was strongly affected. The contents of the cells aggregated themselves into broken rings, still of a red colour, which very slowly and slightly changed their shapes, and the central spaces within these rings became cloudy with red granular matter. The facts here given (whether they are new, I know not) indicate that interesting results would perhaps be gained by observing the action of various saline solutions and other fluids on the roots of plants. 


\section{CHAPTER IV.}

\section{The Effects of Heat on the Leaves.}

Naturo of the experiments - Effects of boiling water - Warm water causes rapid inflection - Water at a higher temperature does not cause immediate inflection, but does not kill the leaves, as shown by their subsequent re-expansion and by the aggregation of the protoplasm-A still higher temperature kills the leaves and coagulates the albuminous eontents of the glands.

Is my observations on Drosera rotundifolia, the leaves seemed to be more quickly inflected over animal substances, and to remain inflected for a longer period during very warm than during cold weather. I wished, therefore, to ascertain whether heat alone would induce inflection, and what temperature was the most efficient. Another interesting point presented itself, namely; at what degree life was extinguished; for Drosera offers unusual facilities in this respect, not in the loss of the power of inflection, but in that of subsequent re-expansion, and more especially in the failure of the protoplasm to become aggregated, when the leares after being heated are immersed in a solution of carbonate of ammonia.*

* When my experiments on the effects of heat were made, I was not aware that the subject had been carefully investigated by several obscrvers. For instance, Sicchs is eonvinced ("Traité do Botanique,' 187t, pp. 772, 85t) that the most different kinds of plunts all perish if kept for $10 \mathrm{~m}$. in water at $45^{\circ}$ to $46^{\circ}$ Cent., or $113^{\circ}$ to $115^{\circ}$ Falır.; and he eon- cludes that the protoplasm within their cells always coagulates, if in a damp condition, at a temperature of between $50^{\circ}$ and $60^{\circ}$ Cent., or $122^{\circ}$ to $140^{\circ}$ Fahr. MIax Schultze and Kühne (as quoted by Dr. Bastian in 'Contemp. lieview, 187t, p. 528) "found that the protoplasm of plantcells, with which they experimented, was always killed and 
My experiments were tried in the following manner. Leaves were cut off, and this does not in the least interfere with their powers; for instance, three cut-off leaves, with bits of meat placed on them, were kept in a damp atmosphere, and after 23 hrs. closely embraced the meat both with their tentacles and blades; and the protoplasm within their cells was well aggregated. Three ounces of doubly distilled water was heated in a porcelain vessel, with a delicate thermometer having a long bulb obliquely suspended in it. The water was gradually raised to the required temperature by a spirit-lamp moved about under the vessel; and in all cases the leaves were continuaily waved for some minutes close to the bulb. They were then placed in cold water, or in a solution of carbonate of ammonia. In other cases they were left in the water, which had been raised to a certain temperature, until it cooled. Again in other cases the leaves were suddenly plunged into water of a certain temperature, and kept there for a specified time. Considering that the tentacles are extremely delicate, and that their coats are very thin, it seems scarcely possible that the fluid contents of their cells should not have been heated to within a degree or two of the temperature of the surrounding water. Any further precautions would, I think, have been superfluous, as the leaves from age or constitutional causes differ slightly in their sensitiveness to heat.

It will be convenient first briefly to describe the effects of immersion for thirty seconds in boiling water. The leaves are rendered flaccid, with their tentacles bowed backwards, which, as we shall see in a future chapter, is probably due to their outer surfaces retaining their elasticity for a longer period than their inner surfaces retain the power of contraction. The purple fluid within the cells of the pedicels is rendered finely granular, but there is no true aggregation; nor does this follow

altered by a very brief exposure to a temperature of $118 \frac{1}{2}^{\circ}$ Fahr. as a maximum." As my results are deduced from special phenomena, namely, the subsequent aggregation of the protoplasm and the re-expansion of the tentacles, they seem to me worth giving. We shall find that Drosera resists heat somewhat better than most other plants. That there should be consider- able differences in this respect is not surprising, considering that some low vegetable organisms grow in hot springs - cases of which have been collected by Prof. Wyman ('American Journal of Science,' vol. xliv. 1867). 'Thus, Dr. Hooker found Confervæ in water at $168^{\circ}$ Fahr.; Humboldt, at $185^{\circ}$ Fahr.; and Descloizeaux, at $208^{\circ} \mathrm{Fahr}$. 
when the leares are subsequently placed in a solution of carbonate of ammonia. But the most remarkable change is that the glands become opaque and uniformly white; and this may be attributed to the coagulation of their albuminous contents.

My first and preliminary experiment consisted in putting scren leaves in the same ressel of water, and warming it slowly up to the temperature of $110^{\circ}$ Fahr. ( $43^{\circ} \cdot 3$ Cent.); a leaf being taken out as soon as the temperature rose to $80^{\circ}$ ( $26^{\circ} .6$ Cent.), another at $85^{\circ}$, another at $90^{\circ}$, and so on. Each leaf, when taken out, was placed in water at the temperature of my room, and the tentacles of all soon became slightly, though irregularly, inflected. They were now removed from the cold water and kept in damp air, with bits of meat placed on their discs. The leaf which had been exposed to the temperature of $110^{\circ}$ became in $15 \mathrm{~m}$. greatly inflected; and in 2 hrs. every single tentacle closely embraced the meat. So it was, but affer rather longer intervals, with the six other leaves. It appears, therefore, that the warm bath had increased their sensitiveness when excited by meat.

I next observed the degree of inflection which leaves underwent within stated periods, whilst still immersed in warm water, kept as nearly as possible at the same temperature; but I will here and elsewhere give only a few of the many trials made. A leaf was left for $10 \mathrm{~m}$. in water at $100^{\circ}$ (37.7 Cent.), but no inflection occurred. A second leaf, howerer, treated in the same manner, had a few of its exterior tentacles very slightly inflected in $6 \mathrm{~m}$., and sereral irregularly but not closely inflected in $10 \mathrm{~m}$. A third leaf, kept in water at $105^{\circ}$ to $106^{\circ}$ ( $40^{\circ} .5$ to $41^{\circ} .1$ Cent.), was very moderately inflected in $6 \mathrm{~m}$. A fourth leaf, in water at $110^{\circ}\left(43^{\circ} \cdot 3\right.$ Cent.), was somewhat inflected in $4 \mathrm{~m}$., and considerably so in from $6 \mathrm{~m}$. to $7 \mathrm{~m}$.

Three leaves were placed in water which was heated rather quickly, and by the time the temperature rose to $115^{\circ}-116^{\circ}$ ( $46^{\circ} .1$ to $46^{\circ} .06$ Cent.), all three were inflected. I then removed the lamp, and in a few minutes every single tentacle was closely inflected. The protoplasm within the cells was not killed, for it was seen to be in distinct morement; and the lcaves, having been left in cold water for $20 \mathrm{hrs}$., re-expanded. Another leaf was immersed in water at $100^{\circ}$ ( $37^{\circ} .7 \mathrm{Cent}$.), which was raised to $120^{\circ}\left(48^{\circ} .8\right.$ Cent.); and all the tentacles, except tho extreme marginal ones, soon became closely inflected. The leaf was now placed in cold water, and in $7 \mathrm{hrs}$. $30 \mathrm{~m}$. it had partly, and in $10 \mathrm{hrs}$. fully, re-expanded. On the followiug morning it was immersed in a weak solution of carbonate of 
ammonia, and the glands quickly became black, with strongly marked aggregation in the tentacles, showing that the protoplasm was alive, and that the glands had not lost their power of absorption. Another leaf was placed in water at $110^{\circ}\left(43^{\circ} \cdot 3\right.$ Cent.) which was raised to $120^{\circ}$ ( $48^{\circ} .8$ Cent.); and every tentacle, excepting one, was quickly and closely inflected. This leaf was now immersed in a few drops of a strong solution of carbonate of ammonia (one part to 109 of water); in $10 \mathrm{~m}$. all the glands became intensely black, and in $2 \mathrm{hrs.}$ the protoplasm in the cells of the pedicels was well aggregated. Another leaf was suddenly plunged, and as usual waved about, in water at $120^{\circ}$, and the tentacles became inflected in from $2 \mathrm{~m}$. to $3 \mathrm{~m}$., but only so as to stand at right angles to the disc. The leaf was now placed in the same solution (viz. one part of carbonate of ammonia to 109 of water, or 4 grs. to 1 oz., which I will for the future designate as the strong solution), and when I looked at it again after the interval of an hour, the glands were blackened, and there was well-marked aggregation. After an additional interval of $4 \mathrm{hrs}$. the tentacles had become much more inflected. It deserves notice that a solution as strong as this never causes inflection in ordinary cases. Lastly a leaf was suddenly placed in water at $125^{\circ}$ ( $51^{\circ} \cdot 6$ Cent.), and was left in it until the water cooled; the tentacles were rendered of a bright red and soon became inflected. The contents of the cells underwent some degree of aggregation, which in the course of three hours increased; but the masses of protoplasm did not become spherical, as almost always occurs with leaves immersed in a solution of carbonate of ammonia.

We learn from these cases that a temperature of from $120^{\circ}$ to $125^{\circ}\left(48^{\circ} \cdot 8\right.$ to $51^{\circ} .6$ Cent.) excites the tentacles into quick movement, but does not kill the leaves, as shown either by their subsequent re-expansion or by the aggregation of the protoplasm. We shall now see that a temperature of $130^{\circ}\left(54^{\circ} .4\right.$ Cent.) is too high to cause immediate inflection, yet does not kill the leaves.

Experiment 1.-A leaf was plunged, and as in all cases waved about for a few minutes, in water at $130^{\circ}\left(54^{\circ} \cdot 4\right.$ Cent.), but there was no trace of inflection; it was then placed in cold water, and after an interval of $15 \mathrm{~m}$. very slow movement was 
distinctly seen in a small mass of protoplasm in one of the cells of a tentacle.* After a few hours all the tentacles and the blade became inflected.

Lirperiment 2.-Another leaf was plunged into water at $130^{\circ}$ to $131^{\circ}$, and as befure there was no inflection. After being kept in cold water for an hour, it was placed in the strong solution of ammonia, and in the course of $55 \mathrm{~m}$. the tentacles were considerably inflected. The glands, which before had been rendered of a brighter red, were now blackened. The protoplasm in the cells of the tentacles was distinctly aggregated; but the spheres were much smaller than those usually generated in unheated leaves when suljected to carbonate of ammonia. After an additional 2 hrs. all the tentacles, excepting six or seven, were closely'inflected.

Experiment 3.-A similar experiment to the last, with exactly the same results.

Lixperiment 4.-A fine leaf was placed in water at $100^{\circ}\left(37^{\circ} \cdot 7\right.$ Cent.), which was then raised to $145^{\circ}\left(62^{\circ} \cdot 7\right.$ Cent.). Soon after immersion, there was, as might have been cxpected, strong inflection. The leaf was now removed and left in cold water; but from having been exposed to so high a temperature, it never re-cxpanded.

Eisperiment 5.-Leaf immersed at $130^{\circ}$ (54.4 Cent.), and the water raiscd to $145^{\circ}\left(62^{\circ} \cdot 7\right.$ Cent.), there was no immediate inflection; it was then placed in cold water, and after $1 \mathrm{hr} .20 \mathrm{~m}$. some of the tentacles on one side became inflected. This leaf was now placed in the strong solution, and in $40 \mathrm{~m}$. all the submarginal tentacles were well inflected, and the glands blacksned. After an additional interval of $2 \mathrm{hrs} .45 \mathrm{~m}$. all the tentacles, except eight or ten, were closely inflected, with their cells exhibiting a slight degree of aggregation; but the spheres of protoplasm were very small, and the cells of the exterior tentacles contained some pulpy or disintegrated brownish matter.

Experiments 6 and 7.-Two leaves were plunged in water at $135^{\circ}\left(57^{\circ} \cdot 2\right.$ Cent.) which was raised to $145^{\circ}\left(62^{\circ} \cdot 7\right.$ Cent.); neither became inflected. One of these, however, after having been left for $31 \mathrm{~m}$. in cold water, exhibited some slight inflection, which increased after an alditional interval of $1 \mathrm{hr}$. $45 \mathrm{~m}$., until

* Sachs states ("Traité de Botanique,' 1874 , p. 85.5) that tho movements of the protoplasm in the Lairs of a cucurbita ceased after they were exposed for $1 \mathrm{~m}$. in water to a temperature of $47^{\circ}$ to $48^{\circ}$ Cent., or $117^{\circ}$ to $119^{\circ}$ Fahr. 
all the tentacles, except sixteen or seventeen, were more or less inflected; but the leaf was so much injured that it never reexpanded. The other leaf, after having been left for half an hour in cold water, was put into the strong solution, but no inflection ensued; the glands, howerer, were blackened, and in some cells there was a little aggregation, the spheres of protoplasm being extremely small; in other cells, especially in the exterior tentacles, there was much greenish-brown pulpy matter.

Experiment 8.-A leaf was plunged and waved about for a few minutes in water at $140^{\circ}\left(60^{\circ}\right.$ Cent.), and was then left for half an hour in cold water, but there was no inflection. It was now placed in the strong solution, and after $2 \mathrm{hrs} .30 \mathrm{~m}$. the inner submarginal tentacles were well inflected, with their glands blackened, and some imperfect aggregation in the cells of the pedicels. Three or four of the glands were spotted with the white porcelain-like structure, like that produced by boiling water. I have seen this result in no other instance after an immersion of only a few minutes in water at so low a temperature as $140^{\circ}$, and in only one leaf out of four, after a similar immersion at a temperature of $145^{\circ}$ Fahr. On the other hand, with two leaves, one placed in water at $145^{\circ}\left(62^{\circ} \cdot 7 \mathrm{Cent}\right.$.), and the other in water at $140^{\circ}\left(60^{\circ}\right.$ Cent.), both being left therein until the water cooled, the glands of both became white and porcelain-like. So that the duration of the immersion is an important element in the result.

Experiment 9.-A leaf was placed in water at $140^{\circ}\left(60^{\circ}\right.$ Cent.), which was raised to $150^{\circ}\left(65^{\circ} .5\right.$ Cent. $)$; there was no inflection; on the contrary, the outer tentacles were somewhat bowed backwards. The glands became like porcelain, but some of them were a little mottled with purple. The bases of the glands were often more affected than their summits. This leaf having been left in the strong solution did not undergo any inflection or aggregation.

Experiment 10.-A leaf was plunged in water at $150^{\circ}$ to $1502^{\circ}$ $\left(65^{\circ} .5\right.$ Cent.); it became somewhat flaccid, with the outer tentacles slightly reflexed, and the inner ones a little bent inwards, but only towards their tips; and this latter fact shows that the movement was not one of true inflection, as the basal part alone normally bends. The tentacles were as usual rendered of a very bright red, with the glands almost white like porcelain, yet tinged with pink. The leaf having been placed in the strong solution, the cell-contents of the tentacles became of a muddy brown, with no trace of aggregation. 
Experiment 11.-A leaf was immersed in water at $145^{\circ}\left(62^{\circ} \cdot 7\right.$ Cent.), which was raised to $156^{\circ}\left(68^{\circ} .8\right.$ Cent.). The tentacles became bright red and somewhat reflexed, with almost all the glands like porcelain; those on the dise being still pinkish, those near the margin quite white. The leaf being placed as usual first in cold water and then in the strong solution, the cells in the tentacles became of a muddy greenish brown, with the protoplasm not aggregated. Nevertheless, four of the glands escaped being rendered like porcelain, and the pedicels of these glands were spirally curled, like a French horn, towards their upper ends; but this can by no means be considered as a case of true inflection. The protoplasm within the cells of the twisted portions was aggregated into distinct though excessively minute purple spheres. This case shows clearly that the protoplasm, after having been exposed to a high temperature for a fer minutes, is capable of aggregation when afterwards subjected to the action of carbonate of ammonia, unless the heat has been sufficient to cause coagulation.

Concluding Remarks.-As the hair-like tentacles are extremely thin and have delicate walls, and as the leares were waved about for some minutes close to the bulb of the thermometer, it seems scarcely possible that they should not have been raised very nearly to the temperature which the instrument indicated. From the eleven last observations we see that a temperature of $130^{\circ}\left(54^{\circ} \pm\right.$ Cent.) never causes the immediate inflection of the tentacles, though a temperature from $120^{\circ}$ to $125^{\circ}\left(48^{\circ} .8\right.$ to $51^{\circ} \cdot 6$ Cent.) quickly produces this effect. But the leaves are paralysed only for a time by a temperature of $130^{\circ}$, as afterwards, whether left in simple water or in a solution of carbonate of ammonia, they become inflected and their protoplasm undergoes aggregation. This great difference in the effects of a higher and lower temperature may be compared with that from immersion in strong and weak solutions of the salts of ammonia; for the former do not excite movement, whereas the latter act energetically. A temporary suspension of the 
power of movement due to heat is called by Sachs* heat-rigidity; and this in the case of the sensitiveplant (Mimosa) is induced by its exposure for a few minutes to humid air, raised to $120^{\circ}-122^{\circ}$ Fahr., or $49^{\circ}$ to $50^{\circ}$ Cent. It deserves notice that the leaves of Drosera, after being immersed in water at $130^{\circ} \mathrm{Fahr}$., are excited into movement by a solution of the carbonate so strong that it would paralyse ordinary leaves and cause no inflection.

The exposure of the leaves for a few minutes even to a temperature of $145^{\circ} \mathrm{Fahr}$. ( $62^{\circ} .7 \mathrm{Cent}$.) does not always kill them; as when afterwards left in cold water, or in a strong solution of carbonate of ammonia, they generally, though not always, become inflected; and the protoplasm within their cells undergoes aggregation, though the spheres thus formed are extremely small, with many of the cells partly filled with browuish muddy matter. In two instances, when leaves were immersed in water, at a lower temperature than $130^{\circ}\left(54^{\circ} \cdot 4\right.$ Cent.), which was then raised to $145^{\circ}$ $\left(62^{\circ} \cdot 7\right.$ Cent.), they became during the earlier period of immersion inflected, but on being afterwards left in cold water were incapable of re-expansion. Exposure for a few minutes to a temperature of $145^{\circ}$ sometimes causes some few of the more sensitive glands to be speckled with the porcelain-like appearance; and on one occasion this occurred at a temperature of $140^{\circ}\left(60^{\circ}\right.$ Cent.). On another occasion, when a leaf was placed in water at this temperature of only $140^{\circ}$, and left therein till the water cooled, every gland became like porcelain. Exposure for a few minutes to a temperature of $150^{\circ}\left(65^{\circ} .5\right.$ Cent.) generally produces this effect, yet many glands retain a

* 'Traité de Bot.' 1874, p. 1034. 
pinkish colour, and many present a speckled appearance. This high temperature never causes true inflection; on the contrary, the tentacles commonly become reflexed, though to a less degree than when immersed in boiling water; and this apparently is due to their passive power of elasticity. After exposure to a temperature of $150^{\circ} \mathrm{Fahr}$., the protoplasm, if subsequently subjected to carbonate of ammonia, instead of undergoing aggregation, is converted into disintegrated or pulpy discoloured matter. In short, the leaves are generally killed by this degree of heat; but owing to differences of age or constitution, they vary somewhat in this respect. In one anomalous case, four out of the many glands on a leaf, which had been immersed in water raised to $156^{\circ}$ ( $68^{\circ} .8$ Cent.), escaped being rendered porcellanous; ${ }^{*}$ and the protoplasm in the cells close beneath these glands underwent some slight, though imperfect, degree of aggregation.

Finally, it is a remarkable fact that the leaves of Drosera rotundifolia, which flourishes on bleak upland moors throughout Great Britain, and exists (Hooker) within the Arctic Circle, should be able to withstand for even a short time immersion in water heated to a temperature of $145^{\circ} . \dagger$

It may be worth adding that immersion in cold

* As the opacity and porcelainlike appearance of the glands is probably due to the coagulation of the albumen, I may add, on the authority of Dr. Burdon Sanderson, that albumen coagulates at about $155^{\circ}$, but, in presence of acils, the temperature of eoagulation is lower. The leaves of Drosera crintain an acid, and perhaps a difference in the amount contained may account for the slight differences in the results abovo recorded.

† It appears that cold-blooded auimals are, as might have been expected, far more sensitive to an increase of temperature than is Drosera. Thus, as I hear from Dr. Burdon Sanderson, a frog begins to be distressed in water at a temperature of only $85^{\circ} \mathrm{Fahr}$. At $95^{\circ}$ the muscles become rigid, and the animal dies in a stiffened condition. 
water does not cause any inflection: I suddenly placed four leaves, taken from plants which had been kept for several days at a high temperature, generally about $75^{\circ}$ Fahr. ( $23^{\circ} .8$ Cent.), in water at $45^{\circ}$ ( $7^{\circ} \cdot 2$ Cent.), but they were hardly at all affected; not so much as some other leaves from the same plants, which were at the same time immersed in water at $75^{\circ}$; for these became in a slight degree inflected. 


\section{CHAPTER V.}

The Effects of Non-nitrogenots and Nitrogenots Organic Fluids ON THE LEAvEs.

Non-nitrogenous fluids - Solutions of gum arabic - Sugar - Starch - Diluted alcohol - Olive oil - Infusion and decoction of teaNitrogenous fluids - Milk - Urine - Liquid albumen - Infusion of raw meat - Impure mucius - Saliva-Solution of isinglass Difference in the action of these two sets of fluids-Decoction of green peas-Decoction and infusion of cabbage-Decoction of grass leaves.

Whes, in 1860, I first observed Drosera, and was led to believe that the leaves absorbed nutritious matter from the insects which they captured, it seemed to me a good plan to make some preliminary trials with a few common fluids, containing and not containing nitrogenous matter; and the results are worth giving.

In all the following cases a drop was allowed to fall from the same pointed instrument on the centre of the leaf; and by repeated trials one of these drops was ascertained to be on an average rery nearly half a minim, or $\frac{1}{960}$ of a fluid ounce, or $\cdot 0295 \mathrm{ml}$. But these measurements obviously do not pretend to any strict accuracy; moreover, the drops of the viscid fluids were plainly larger than those of water. Only one leaf on the same plant was tried, and the plants were collected from two distant localities. The experiments were made during August and September. In judging of the effects, one caution is necessary: if a drop of any adhesive fluid is placed on an old or feeble leaf, the glands of which have ceased to secrete copiously, the drop sometimes dries up, especially if the plant 
is kept in a room, and some of the central and submarginal tentacles are thus drawn together, giving to them the false appearance of having become inflected. This sometimes occurs with water, as it is rendered adhesive by mingling with the viscid secretion. Hence the only safe criterion, and to this alone I have trusted, is the bending inwards of the exterior tentacles, which have not been touched by the fluid, or at most only at their bases. In this case the movement is wholly due to the central glands having been stimulated by the fluid, and transmitting a motor impulse to the exterior tentacles. The blade of the leaf likewise often curves inwards, in the same manner as when an insect or bit of meat is placed on the disc. This latter movement is never caused, as far as I have seen, by the mere drying up of an adhesive fluid and the consequent drawing together of the tentacles.

First for the non-nitrogenous fluids. As a preliminary trial, drops of distilled water were placed on between thirty and forty leaves, and no effect whatever was produced; nevertheless, in some other and rare cases, a few tentacles became for a short time inflected; but this may have been caused by the glands having been accidentally touched in getting the leaves into a proper position. That water should produce no effect might have been anticipated, as otherwise the leaves would have been excited into movement by every shower of rain.

Gum arabic.-Solutions of four degrees of strength were made; one of six grains to the ounce of water (one part to 73); a second rather stronger, yet very thin; a third moderately thick, and a fourth so thick that it would only just drop from a pointed instrument. These were tried on fourteen leaves; the drops being left on the discs from 24 hrs. to $44 \mathrm{hrs}$; ; generally about 
$30 \mathrm{hrs}$. Inflection was never thus caused. It is necessary to try pure gum arabic, for a friend tried a solution bought ready prepared, and this caused the tentacles to bend; but he afterwards ascertained that it contained much animal matter, probably glue.

Sugar.-Drops of a solution of white sugar of three strengths (the weakest containing one part of sugar to 73 of water) were left on fourteen leaves from $32 \mathrm{hrs}$. to $48 \mathrm{hrs}$; ; but no effect was produced.

Starch.-A mixture about as thick as cream was dropped on six leaves and left on them for 30 hrs., no effect being produced. I am surprised at this fact, as I believe that the starch of commerce generally contains a trace of gluten, and this nitrogenous substance causes inflection, as we shall see in the next chapter.

Alcohol, Diluted.-One part of alcohol was added to seven of water, and the usual drops were placed on the dises of three leaves. No inflection ensued in the course of $48 \mathrm{hrs}$. To ascertain whether these leaves had been at all injured, bits of meat were placed on them, and after 24 hrs. they were closely inflected. I also put drops of sherry-wine on three other leaves; no inflection was caused, though two of them seemed somewhat injured. We shall hereafter see that eut-off leaves immersed in diluted alcohol of the above strength do not become inflected.

Olive Oil.-Drops were placed on the discs of eleven leares, and no effect was produced in from $24 \mathrm{hrs}$. to $48 \mathrm{hrs}$. Four of these leares were then tested by bits of meat on their dises, and three of them were found after $21 \mathrm{hrs}$. with all their tentacles and blades closely inflected, whilst the fourth had only a few tentacles inflected. It will, however, be shown in a future place, that cut-off leares immersed in olive oil are powerfully affected.

Infusion and Decoction of Tea.-Drops of a strong infusion and decoction, as well as of a rather weak decoction, of tea were placed on ten leaves, none of which became inflected. I afterwards tested three of them by adding bits of meat to the drops which still remained on their discs, and when I examined them after 21 hrs. they were closely inflected. The chemical principle of tea, namely theine, was subsequently tried and produced no effect. The albuminous matter which the leaves must originally have contained, no doubt, had been rendered insoluble by their having been completely dried.

We thus see that, excluding the experiments with water, sixty-one leaves were tried with drops of the 
above-named non-nitrogenous fluids; and the tentacles were not in a single case inflected.

With respect to nitrogenous fluids, the first which came to hand were tried. The experiments were made at the samo time and in exactly the same manner as the foregoing. As it was immediately evident that these fluids produced a great effect, I neglected in most cases to record how soon the tentacles became inflected. But this always occurred in less than 24 hrs.; whilst the drops of non-nitrogenous fluids which produced no effect were observed in every case during a considerably longer period.

Milk.-Drops were placed on sixteen leaves, and the tentacles of all, as well as the blades of several, soon became greatly inflected. The periods were recorded in only three cases, namely, with leaves on which unusually small drops had been placed. Their tentacles were somewhat inflected in $45 \mathrm{~m}$.; and after 7 hrs. $45 \mathrm{~m}$. the blades of two were so much curved inwards that they formed little cups enclosing the drops. These leaves re-expanded on the third day. On another occasion the blade of a leaf was much inflected in $5 \mathrm{hrs}$. after a drop of milk had been placed on it.

Human Urine.-Drops were placed on twelve leaves, and the tentacles of all, with a single exception, became greatly inflected. Owing, I presume, to differences in the chemical nature of the urine on different occasions, the time required for the movements of the tentacles varied much, but was always effected in under $24 \mathrm{hrs}$. In two instances I recorded that all the exterior tentacles were completely inflected in $17 \mathrm{hrs}$., but not the blade of the leaf. In another case the edges of a leaf, after $2 \mathrm{~s} \mathrm{hrs}$. $30 \mathrm{~m}$., became so strongly inflected that it was converted into a cup. The power of urine does not lie in the urea, which, as we shall hereafter see, is inoperative.

Albumen (fresh from a hen's egg), placed on seven leaves, caused the tentacles of six of them to be well inflected. In one case the edge of the leaf itself became much curled in after 20 hrs. The one leaf which was unaffected remained so for $26 \mathrm{hrs}$, and was then treated with a drop of milk, and this caused the tentacles to bend inwards in $12 \mathrm{hrs}$.

Cold Filtered Infusion of Raw Meat.-This was tried only on a single leaf, which had most of its outer tentacles and the blade inflected in 19 hrs. During subsequent years, I repeatedly used this infusion to test leaves which had been experimented 
on with other sulustances, and it was found to act most energetically, but as no exact account of these trials was kept, they are not here introduced.

Mucus.-Thick and thin mucus from the bronchial tubes, placed on three leares, caused inflection. A leaf with thin mucus had its marginal tentacles and blade somewhat curved inward in $5 \mathrm{hrs} .80 \mathrm{~m}$., and greatly so in $20 \mathrm{hrs}$. The action of this fluid no doubt is due either to the saliva or to some albuminous matter* mingled with it, and not, as we shall see in the next chapter, to mucin or the chemical principle of mucus.

Saliva.-Human saliva, when evaporated, yieldst from $1 \cdot 14$ to

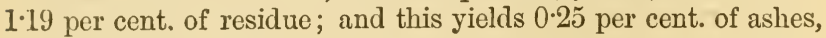
so that the proportion of nitrogenous matter which saliva eontains must be small. Nevertheless, drops placed on the dises of eight leaves acted on them all. In one case all the exterior tentacles, excepting nine, were inflected in $19 \mathrm{hrs} .30 \mathrm{~m}$. ; in another case a few became so in $2 \mathrm{hrs}$, and after $7 \mathrm{hrs} .80 \mathrm{~m}$. all those situated near where the drop lay, as well as the blade, were acted on. Since making these trials, I have many scores of times just touched glands with the handle of my scalpel wetted with saliva, to ascertain whether a leaf was in an active condition; for this was shown in the course of a few minutes by the bending inwards of the tentacles. The edible nest of the Chinese swallow is formed of matter secreted by the salivary glands; two grains were added to one ounce of distilled water (one part to 218), which was boiled for sereral minutes, but did not dissolve the whole. The usual-sized drops were placed on three leaves, and these in $1 \mathrm{hr}$. $30 \mathrm{~m}$. were well, and in $2 \mathrm{hrs}$. $15 \mathrm{~m}$. closely, inflected.

Isinglass.-Drops of a solution about as thick as milk, and of a still thicker solution, were placed on eight leaves, and the tentacles of all became inflected. In one case the exterior tentacles were well curved in after 6 lirs. $30 \mathrm{~m}$., and the blade of the leaf to a partial extent after $24 \mathrm{hrs}$. As saliva acted so efficiently, and yet contains so small a proportion of nitrogenous matter, I tried how small a quantity of isinglass would act. One part was dissolved in 218 parts of distilled water, and drops were placed on four leaves. After $5 \mathrm{hrs}$. two of these were considerably and two moderately inflected; after $22 \mathrm{hrs}$. the former were greatly and the latter much more inflected. In the course of $48 \mathrm{hrs}$.

* Mucus from the air-passages is said in Marshall, 'Ontlines of Physiology,' vol. ii. 1867, p. 36t, to contain some albumen.

$\dagger$ Müller's 'Elements of Physio-

logy, 'Lng. Trans. vol. i. p. 514. 
from the time when the drops were placed on the leaves, all four had almost re-expanded. They were then given little bits of meat, and these acted more powerfully than the solution. One part of isinglass was next dissolved in 437 of water; tho fluid thus formed was so thin that it could not be distinguished from pure water. The usual-sized drops were placed on seven leaves, each of which thus received $\frac{1}{960}$ of a grain (.0295 mg.). Three of them were observed for 41 hrs., but were in no way affected; the fourth and fifth had two or three of their exterior tentacles inflected after $18 \mathrm{hrs}$; the sixth had a few more; and the serenth had in addition the edge of the leaf just perceptibly curved inwards. The tentacles of the four latter leaves began to re-expand after an additional interval of only 8 hrs. Hence the $\frac{1}{960}$ of a grain of isinglass is sufficient to affect very slightly the more sensitive or active leaves. On one of the leaves, which had not been acted on by the weak solution, and on another, which had only two of its tentacles inflected, drops of the solution as thick as milk were placed; and next morning, after an interval of 16 hrs., both were found with all their tentacles strongly inflected.

Altogether I experimented on sixty-four leaves with the above nitrogenous fluids, the five leaves tried only with the extremely weak solution of isinglass not being included, nor the numerous trials subsequently made, of which no exact account was kept. Of these sixty-four leaves, sixty-three had their tentacles and often their blades well inflected. The one which failed was probably too old and torpid. But to obtain so large a proportion of successful cases, care must be taken to select young and active leaves. Leaves in this condition were chosen with equal care for the sixty-one trials with non-nitrogenous fluids (water not included); and we have seen that not one of these was in the least affected. We may therefore safely conclude that in the sixty-four experiments with nitrogenous fluids the inflection of the exterior tentacles was due to the absorption of 
nitrogenous matter by the glands of the tentacles on the disc.

Some of the leaves which were not affected by the non-nitrogenous fluids were, as above stated, immediately afterwards tested with bits of meat, and were thus proved to be in an active condition. But in addition to these trials, twenty-three of the leaves, with drops of gum, syrup, or starch, still lying on their discs, which had produced no effect in the course of between $24 \mathrm{hrs}$. and $48 \mathrm{hrs}$., were then tested with drops of milk, urine, or albumen. Of the twenty-three leares thus treated, seventeen had their tentacles, and in some cases their blades, well inflected; but their powers were somewhat impaired, for the rate of movement was decidedly slower than when fresh leaves were treated with these same nitrogenous fluids. This impairment, as well as the insensibility of six of the leaves, may be attributed to injury from exosmose, caused by the density of the fluids placed on their dises.

The results of a few other experiments with nitrogenous fluids may be here conveniently given. Decoctions of some vegetables, known to be rich in nitrogen, were made, and these acted like animal fluids. Thus, a few green peas were boiled for some time in distilled water, and the moderately thick decoction thus made was allowed to settle. Drops of the superincumbent fluid were placed on four leaves, and when these were looked at after 16 hrs., the tentacles and blades of all were found strongly inflected. I infer from a remark by Gerhardt* that legumin is present in peas "in combination with an alkali, forming an incoagulable solution," and this would mingle with boiling water. I may mention, in relation to the above and following expcriments, that according to Schiff $\nmid$ certain forms of albumen

* Watts' 'Dict. of Chemistry,' vol. iii. p. 568 .

t'Leçons sur la Phys. do la
Digestion,' tom. i. p. 379 ; tom. ii. pp. $15 t, 166$, on legumin. 
exist which are not coagulated by boiling water, but are converted into soluble peptones.

On three occasions chopped cabbage-leaves* were boiled in distilled water for $1 \mathrm{hr}$. or for $1_{4}^{1} \mathrm{hr}$.; and by decanting the decoction after it had been allowed to rest, a pale dirty green fluid was obtained. The usual-sized drops were placed on thirteen leaves. Their tentacles and blades were inflected after $4 \mathrm{hrs}$. to a quite extraordinary degree. Next day the protoplasm within the cells of the tentacles was found aggregated in the most strongly marked manner. I also touched the viscid secretion round the glands of several tentacles with minute drops of the decoction on the head of a small pin, and they became well inflected in a few minutes. The fluid proving so powerful, one part was diluted with three of water, and drops were placed on the discs of five leaves; and these next morning were so much acted on that their blades were completely doubled over. We thus see that a decoction of cabbage-leaves is nearly or quite as potent as an infusion of raw meat.

About the same quantity of chopped cabbage-leaves and of distilled water, as in the last experiment, were kept in a vessel for $20 \mathrm{hrs}$. in a hot closet, but not heated to near the boilingpoint. Drops of this infusion were placed on four leaves. One of these, after 23 hrs., was much inflected; a second slightly; a third had only the submarginal tentacles inflected; and the fourth was not at all affected. The power of this infusion is therefore very much less than that of the decoction; and it is clear that the immersion of cabbage-leaves for an hour in water at the boiling temperature is much more efficient in extracting matter which excites Drosera than immersion during many hours in warm water. Perhaps the contents of the cells are protected (as Schiff remarks with respect to legumin) by the walls being formed of cellulose, and that until these are ruptured by boiling-water, but little of the contained albuminous matter is dissolved. We know from the strong odour of cooked cabbage-leaves that boiling water produces some chemical change in them, and that they are thus rendered far more digestible and nutritious to man. It is therefore an interesting

* The leaves of young plants, before the heart is formed, such as were used by me, contain $2 \cdot 1$ per cent. of albuminous matter, and the outer leaves of mature plants 1.6 per' cent. Watts' 'Diet. of Chemistry,' vol. i. p. 653. 
fact that water at this temperature extracts matter from them which excites Drosera to an extraordinary degree.

Grasses contain far less nitrogenous matter than do peas or cabbages. The leaves and stalks of three common kinds were chopped and boiled for some time in distilled water. Drops of this decoction (after having stood for $24 \mathrm{hrs}$.) were placed on șix leaves, and acted in a rather peculiar manner, of which other instances will be given in the seventh chapter on the salts of ammonia. After $2 \mathrm{hrs} .30 \mathrm{~m}$. four of the leaves had their blades greatly inflected, but not their exterior tentacles; and so it was with all six leaves after $24 \mathrm{hrs}$. Two days afterwards the blades, as well as the few submarginal tentacles which had been inflected, all re-expanded; and much of the fluid on their discs was by this time absorbed. It appears that the decoction strongly excites the glands on the disc, causing the blade to be quickly and greatly inflected; but that the stimulus, differently from what occur's in ordinary cases, does not spread, or only in a feeble degree, to the exterior tentacles.

I may here add that one part of the extract of belladonna (procured from a druggist) was dissolved in 437 of water, and drops were placed on six leaves. Next day all six were somewhat inflected, and after $48 \mathrm{hrs}$. were completely re-expanded. It was not the included atropine which produced this effect, for I subsequently ascertained that it is quite porrerless. I also procured some extract of hyoscyamus from three shops, and made infusions of the same strength as before. Of these three infusions, only one acted on some of the leaves, which were tried. Though druggists believe that all the albumen is precipitated in the preparation of these drugs, I cannot doubt that some is occasionally retained; and a trace would be sufficient to excito the more sensitive leaves of Drosera. 


\section{CHAPTER VI.}

The Digestive Power of the Secretion of Drosera.

The secretion rendered acid by the direct and indirect excitement of the glands - Nature of the acid - Digestible substances - Albumen, its digestion arrested by alkalies, recommences by the addition of an acid-Meat-Fibrin - Syntonin - Areolar tissue Cartilage - Fibro-cartilage - Bone-Enamel and dentine-Phosphate of lime - Fibrous basis of bone-Gelatine - Chondrin Milk, casein and cheese - Gluten - Legumin - Pollen - Globulin - Hrmatin - Indigestible substances - Epidermic productions Fibro-elastic tissue - Mucin - Pepsin - Urea - Chitine - Cellulose - Gur-cotton - Chlorophyll - Fat and oil - Starch - Action of the secretion on living seeds - Summary and concluding remarks.

As we have seen that nitrogenous fluids act very differently on the leaves of Drosera from non-nitrogenous fluids, and as the leaves remain clasped for a much longer time over various organic bodies than over inorganic bodies, such as bits of glass, cinder, wood, \&c., it becomes an interesting inquiry, whether they can only absorb matter already in solution, or render it soluble,- - that is, have the power of digestion. We shall immediately see that they. certainly have this power, and that they act on albuminous compounds in exactly the same manner as does the gastric juice of mammals; the digested matter being afterward's absorbed. This fact, which will be clearly proved, is a wonderful one in the physiology of plants. I must here state that I have been aided throughout all my later experiments by many valuable suggestions and assistance given me with the greatest kindness by Dr. Burdon Sanderson. 
It may be well to premise for the sake of any reader who knows nothing about the digestion of albuminous compounds by animals that this is effected by means of a ferment, pepsin, together with weak hydrochloric acid, though almost any acid will serve. Yet neither pepsin nor an acid by itself has any such power.* We have seen that when the glands of the dise are excited by the contact of any object, especially of one containing nitrogenous matter, the outer tentacles and often the blade become inflected ; the leaf being thus converted into a temporary cup or stomach. At the same time the discal glands secrete more copiously, and the secretion becomes acid. Moreover, they transmit some influence to the glands of the exterior tentacles, causing them to pour forth a more copious secretion, which also becomes acid or more acid than it was before.

As this result is an important one, I will gire the evidence. The secretion of many glands on thirty leaves, which had not been in any way excited, was tested with litmus paper; and the secretion of twentytwo of these leaves did not in the least affect the colour, whereas that of eight caused an exceedingly feeble and sometimes doubtful tinge of red. 'Two other old leaves, however, which appeared to have been inflected several times, acted much more decidedly on the paper. Particles of clean glass were then placed on five of the leares, cubes of albumen on six, and bits of raw meat on three, on none of which was the secretion at this time in the least acid. After an interval of 24 hrs., when almost all the tentacles on

* It appears, however, according to Schiff, aud contrary to tho npinion of some physiolngists, that weak hydrochloric dissolres, though slowly, a very minute quantity of coagulated albumen.. Schiff, 'Phys. de la Digestion,' tom. ii: 1867 , p. 25. 
these fourteen leaves had become more or less inflected, I again tested the secretion, selecting glands which had not as yet reached the centre or touched any object, and it was now plainly acid. The degree of acidity of the secretion varied somewhat on the glands of the same leaf. On some leaves, a few tentacles did not, from some unknown cause, become inflected, as often happens; and in five instances their secretion was found not to be in the least acid; whilst the secretion of the adjoining and inflected tentacles on the same leaf was decidedly acid. With leaves excited by particles of glass placed on the central glands, the secretion which collects on the disc beneath them was much more strongly acid than that poured forth from the exterior tentacles, which were as yet only moderately inflected. When bits of albumen (and this is naturally alkaline), or bits of meat were placed on the disc, the secretion collected beneath them was likewise strongly acid. As raw meat moistened with water is slightly acid, I compared its action on litmus paper before it was placed on the leaves, and afterwards when bathed in the secretion; and there could not be the least doubt that the latter was very much more acid. I have indeed tried hundreds of times the state of the secretion on the discs of leaves which were inflected over various objects, and never failed to find it acid. We may, therefore, conclude that the secretion from unexcited leaves, though extremely viscid, is not acid or only slightly so, but that it becomes acid, or much more strongly so, after the tentacles have begun to bend over any inorganic or organic object; and still more strongly acid after the tentacles have remained for some time closely clasped over any object.

I may here remind the reader that the secretion 
appears to be to a certain extent antiseptic, as. it checks the appearance of mould and infusoria, thus preventing for a time the discoloration and decay of such substances as the. white of an egg, cheese, \&c. It therefore acts like the gastric juice of the higher animals, which is known to arrest putrefaction by destroying the microzymes.

As I was anxious to learn what acid the secretion contained, 445 leaves were washed in distilled water, given me by Prof. Frankland; but the secretion is so viscid that it is searcely possible to scrape or wash off the whole. The conditions were also unfavourable, as it was late in the year and the leaves were small. Prof. Frankland with great kindness undertook to test the fluid thus collected. The leaves were excited by clean particles of glass placed on them 24 hrs. previonsly. No doubt much more acid would have been secreted had the leaves been excited by animal matter, but this would have rendered the analysis more difficult. Prof. Frankland informs me that the fluid contained no trace of hydrochloric, sulphuric, tartaric, oxalic, or formic acids. This having been aseertained, the remainder of the fluid was evaporated nearly to dryness, and acidified with sulphuric acid; it then evolved volatile acid rapour, which was condensed and digested with carbonate of silver. " The weight of the silver salt thus produced was only -37 gr., much too small a quantity for the aceurate determination of the molceular weight of the acid. The number obtained, howerer, corresponded nearly with that of propionie acid; and I believe that this, or a mixture of acetic and butyric acids, were present in the liquid. The acid doubtless belongs to the acetic or fatty serics."

Prof. Frankland, as well as his assistant, observed (and this is an important fact) that the fluid, "when acidified with sulphuric acid, emitted a powerful odour like that of pepsin." The leares from which the secretion had been washed were also sent to Prof. Frankland; they wero macerated for some hours, then acidified with sulphurie acid and distilled, but no acid passed over. Therefore the acid which fresh leaves contain, as shown by their discolouring litmus paper when crushed, must bo of a different naturo from that present in the secretion. Nor was any odour of pepsin emitted by them. 
Although it has long been known that pepsin with acetic acid has the power of digesting albuminous compounds, it appeared advisable to ascertain whether acetic acid could be replaced, without the loss of digestive power, by the allied acids which are believed to occur in the secretion of Drosera, namely, propionic, butyric, or valerianic. Dr. Burdon Sanderson was so kind as to make for me the following experiments, the results of which are valuable, independently of the present inquiry. Prof. Frankland supplied the acids.

"1. The purpose of the following experiments was to determine the digestive activity of liquids containing pepsin, when acidulated with certain volatile acids belonging to the acctic series, in comparison with liquids acidulated with hydrochloric acid, in proportion similar to that in which it exists in gastric juice.

" 2 . It has been determined empirically that tho best results are obtained in artificial digestion when a liquid containing two per thousand of hydrochloric acid gas by weight is used. This corresponds to about 6.25 cubic centimetres per litre of ordinary strong hydrochloric acid. The quantities of propionic, butyric, and valerianic acids respectively which are required to neutralise as much base as 6.25 cubic centimetres of $\mathrm{HCl}$, are in grammes 4.04 of propionic acid, 4.82 of butyric acid, and 5.68 of valerianic acid. It was therefore judged expedient, in comparing the digestive powers of these acids with that of hydrochloric acid, to use them in these proportions.

"3. Five hundred cub. cent. of a liquid containing about $8 \mathrm{cub}$. cent. of a glycerine extract of the mucous membrane of the stomach of a dog killed during digestion having been prepared, $10 \mathrm{cub}$. cent. of it were evaporated and dried at $110^{\circ}$. This quantity yielded 0.0031 of residue.

"4. Of this liquid four quantities were taken which wore severally acidulated with hydrochloric, propionic, butyric, and valerianic acids, in the proportions above indicated. Each liquid was then placed in a tube, which was allowed to float in a water bath, containing a thermometer which indicated a temperature of $38^{\circ}$ to $40^{\circ}$ Cent. Into each, a quantity of unboiled fibrin was introduced, and the whole allowed to stand for four hours, the tomperature being maintained during the whole time, and care being taken that each contained throughout an excess of fibrin. At the end of the period each liquid was filtered. Of the filtrate, which of course contained as much of the fibrin as had been digested during the four hours, 
10 cub. cent. were measured out and eraporated, and dried at $110^{\circ}$ as before. The residues $\pi \in$ ere respectirely-

"In the liquid containing hydrochloric acid 0.1079

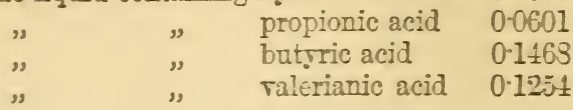

"Hence, deducting from each of these the abore-mentioned residue, left when the digestire liquid itself was eraporated, riz. 00031 , we have,

$\begin{array}{cccccc}\text { "For propionic acid .. } & . & \ldots & \ldots & 00570 \\ \text { " butrric acid } & . & . & \ldots & \ldots & 0.1137 \\ \text { " ralerianic acid.. } & . . & . . & \ldots & 0.1223\end{array}$

as compared with 0.1013 for hrdrochloric acid; these sereral numbers expressing the quantities of fibrin by meight digested in presence of equiralent quantities of the respectire acids under identical conditions.

"The results of the experiment mar be stated thus:-If 100 represent the digestive porrer of a liquid containing pepsin with the usual proportion of hrdrochloric acid, $11 \cdot 0,3.51$, and $30-2$, will represent respectirely the digestire powers of the three acids under inrestigation.

" 5 . In a second experiment in which the procedure was in erery respect the same, excepting that all the tubes were plunged into the same water-bath, and the residues dried at $115^{\circ} \mathrm{C}$., the results mere as follows :-

"Quantity of fibrin dissolreal in four hours by 10 cub. cent. of the liquid-

$\begin{array}{lllll}\text { "Propionic acid } & . . & . . & . . & 0.0563 \\ \text { Butrric acid } & \text {.. } & . & . . & 0.053 .5 \\ \text { Talerianic acid } & . . & \text {.. } & \text {.. } & 0.0615\end{array}$

"The quantity digested by a similar liquid containing hrdrochloric acid mas 0.3376 . Hence, taking this as 100 , the following numbers represent the relatire quantities digested by the other acids:

$\begin{array}{lllll}\text { "Propionic acid } & . . & . . & . . & 16.5 \\ \text { Butyric acid } & . . & . & . . & 24.7 \\ \text { Talerianic acid } & . . & . . & . . & 16 \cdot 1\end{array}$

"6. A third experiment of the same kind gare: 
"Quantity of fibrin digested in four hours by $10 \mathrm{cub}$ cont. of the liquid:

$\begin{array}{lllll}\text { " Hydrochloric acid } & . . & \text {.. } & 0.2915 \\ \text { Propionic acid } & . . & . . & . . & 0.1490 \\ \text { Butyric acid } & . . & . & . . & 0.1044 \\ \text { Valerianic acid } & \text {.. } & \text {.. } & \text {.. } & 0.0520\end{array}$

"Comparing, as before, the three last numbers with the first taken as 100, the digestive potver of propionic acid is represented by 16.8 ; that of butyric acid by 35.8 ; and that of valerianic by $17 \cdot 8$.

"The mean of these three sets of observations (hydrochloric acid being taken as 100) gives for

$\begin{array}{lllll}\text { " Propionic acid } & . . & \text {.. } & \text {.. } & 15 \cdot 8 \\ \text { Butyric acid } & \text {.. } & \text {. } & \text {.. } & 32 \cdot 0 \\ \text { Valerianic acid } & \text {.. } & \text {.. } & \text {.. } & 21 \cdot 4\end{array}$

"7. A further experiment was made to ascertain whether the digestive activity of butyric acid (which was selected as being apparently the most efficacious) was relatively greater at ordinary temperatures than at the temperature of the body. It was found that whereas $10 \mathrm{cub}$. cent. of a liquid containing the ordinary proportion of hydrochloric acid digested 0.1311 gramme, a similar liquid prepared with butyric acid digested 0.0455 gramme of fibrin.

"Hence, taking the quantities digested with hydrochloric acid at the temperature of the body as 100, we have the digestive power of hydrochloric acid at the temperature of $16^{\circ}$ to $18^{\circ}$ Cent. represented by 44.9 ; that of butyric acid at the same temperature being $15 \cdot 6 . "$

We here see that at the lower of these two temperatures, hydrochloric acid with pepsin digests, within the same time, rather less than half the quantity of fibrin compared with what it digests at the higher temperature; and the power of butyric acid is reduced in the same proportion under similar conditions and temperatures. We have also seen that butyric acid, which is much more efficacious than propionic or valerianic acids, digests with pepsin at the higher temperature less than a third of the fibrin which is digested at the same temperature by hydrochloric acid. 
I will now give in detail my experiments on the digestive power of the secretion of Drosera, dividing the substances tried into two series, namely those which are digested more or less completely, and those which are not digested. We shall presently see that all these substances are acted on by the gastric juice of the higher animals in the same manner. I beg leave to call attention to the experiments under the head albumen, showing that the secretion loses its power when neutralised by an alkali, and recovers it when an acid is added.

\section{Substances which are completely or partially digested by} the Secretion of Drosera.

Aloumen.-After having tried various substances, Dr. Burdon Sanderson suggested to me the use of cubes of coagulated albumen or hard-boiled egg. I may pre.mise that five cubes of the same size as those used in the following experiments were placed for the sake of comparison at the same time on wet moss close to the plants of Drosera. The weather was hot, and after four days some of the cubes were discoloured and mouldy, with their angles a little rounded; but they were not surrounded by a zone of transparent fluid as in the case of those undergoing digestion. Other cubes retained their angles and white colour. After eight days all were somewhat reduced in size, discoloured, with their angles much rounded. Nevertheless in four out of the five specimens, the central parts were still white and opaque. So that their state differed widely, as we shall see, from that of the cubes subjected to the action of the secretion.

Experiment 1. - Rather largo cubes of albumen wero first tried; the tentacles wero well inflected in $24 \mathrm{hrs}$; after an 
additional day the angles of the cubes were dissolved and rounded;* but the cubes were too large, so that the leaves were injured, and after seven days ono died and the others wero dying. Albumen which has been kept for four or five days, and which, it may be presumed, has begun to decay slightly, seems to act more quickly than freshly boiled eggs. As the latter were generally used, I often moistened them with a little saliva, to make the tentacles close more quickly.

Experiment 2.-A cube of $\frac{\lambda}{10}$ of an inch (i.e. with each side $\frac{1}{10}$ of an inch, or $2.54 \mathrm{~mm}$., in length) was placed on a leaf, and after 50 hrs. it was converted into a sphere about $\frac{3}{40}$ of an inch (1.905 mm.) in diameter, surrounded by perfectly transparent fluid. After ten days the leaf re-expanded, but there was still left on the disc a minute bit of albumen now rendered transparent. More albumen had been given to this leaf than could be dissolved or digested.

Experiment 3.-Two cubes of albumen of $\frac{1}{20}$ of an inch $(1.27 \mathrm{~mm}$.) were placed on two leaves. After $46 \mathrm{hrs}$. every atom of one was dissolved, and most of the liquefied matter was absorbed, the fluid which remained being in this, as in all other cases, very acid and viseid. The other cube was acted on at a rather slower rate.

Experiment 4.-Two cubes of albumen of the same size as the last were placed on two leaves, and were converted in 50 hrs. into two large drops of transparent fluid; but when these wero removed from beneath the inflected tentacles, and viewed by reflected light under the microseope, fine streaks of white opaque matter could be seen in the one, and traces of similar streaks in the other. The drops were replaced on the leaves, which re-expanded after I0 days; and now nothing was left except a very little transparent acid fluid.

Experiment 5.-This experiment was slightly varied, so that the albumen might be more quickly exposed to the action of the secretion. Two cubes, each of about $\frac{1}{40}$ of an inch (.635 mm.), were placed on the same leaf, and two similar cubes on another

* In all my numerous experiments on the digestion of cubes of albumen, the angles and edges were invariably first rounded. Now, Schiff' states ('Leçons phys. de la Digestion,' vol. ii. 1867, p. 149) that this is charac- teristic of the digestion of albumen by the gastric juice of animals. On the other hand, he remarks, "les dissolutions, en chimie, ont licu sur toute la sur. faco des corps en contact avec l'agent dissolvant." 
leaf. These were examined after $21 \mathrm{hrs} .30 \mathrm{~m}$., and all four were found rounded. After $46 \mathrm{hrs}$. the two cubes on the one leaf were completely liquefied, the fluid being perfectly transparent; on the other leaf some opaque white streaks could still be seen in the midst of the fluid. After $72 \mathrm{hrs}$. these streaks disappeared, but there was still a little viscid fluid left on the dise; whereas it was almost all absorbed on the first leaf. Both leaves were now beginning to re-expand.

The best and almost sole test of the presence of some fẹrment analogous to pepsin in the secretion appeared to be to neutralise the acid of the secretion with an alkali, and to observe whether the process of digestion ceased; and then to add a little acid and observe whether the process recommenced. This was done, and, as we shall see, with success, but it was necessary first to try two control experiments; namely, whether the addition of minute drops of water of the same size as those of the dissolved alkalies to be used would stop the process of digestion; and, secondly, whether minute drops of weak hydrochloric acid, of the some strength and size as those to be used, would injure the leaves. The two following experiments were therefore tried :-

Experiment 6.-Small cubes of albumen were put on three leaves, and minute drops of distilled water on the head of a pin were added two or three times daily. These did not in the least delay the process; for, after $48 \mathrm{hrs}$., the cubes were completely dissolved on all three leaves. On the third day the leaves began to re-expand, and on the fourth day all the fluid was absorbed.

Experiment 7.-Small cubes of albumen. were put on two leaves, and minute drops of hydrochloric acid, of the strength of one part to 437 of water, were added two or three times. This did not in the least delay, but seemed rather to hasten, the process of digestion; for every trace of the albumen disappeared in $21 \mathrm{hrs} .30 \mathrm{~m}$. After three days the leaves partially reexpanded, and by this time almost all the viseid fluid on their dises was absorbed. It is almost superfluous to state that 
cubes of albumen of the same size as those above used, left for seven days in a little hydrochloric acid of the above strength, retained all their angles as perfect as ever.

Experiment 8.-Cubes of albumen (of $\frac{x}{20}$ of an inch, or 2.54 $\mathrm{mm}$.) were placed on five leaves, and minute drops of a solution of one part of carbonate of soda to 437 of water were added at intervals to three of them, and drops of carbonate of potash of the same strength to the other two. The drops were given on the head of a rather large pin, and I ascertained that each was equal to about $\frac{1}{10}$ of a minim (.0059 ml.), so that each contained only $\frac{1}{4800}$ of a grain (.0135 mg.) of the alkali. This was not sufficient, for after $46 \mathrm{hrs}$. all five cubes were dissolved.

Experiment 9.-The last experiment was repeated on four leaves, with this difference, that drops of the same solution of carbonate of soda were added rather oftener, as often as the secretion became acid, so that it was much more effectually neutralised. And now after $24 \mathrm{hrs}$. the angles of three of the cubes were not in the least rounded, those of the fourth being so in a very slight degree. Drops of extremely weak hydrochloric acid (viz. one part to 847 of water) were then added, just enough to neutralise the alkali which was still present; and now digestion immediately recommenced, so that after $23 \mathrm{hrs}$. $30 \mathrm{~m}$. three of the cubes were completely dissolved, whilst the fourth was converted into a minute sphere, surrounded by transparent fluid; and this sphere next day disappeared.

Experiment 10.-Stronger solutions of carbonate of soda and of potash were next used, viz. one part to 109 of water; and as the same-sized drops were given as before, each drop contained $\frac{1}{1200}$ of a grain ( $0539 \mathrm{mg}$.) of either salt. Two cubes of albumen (each about $\frac{1}{40}$ of an inch, or $635 \mathrm{~mm}$.) were placed on the same leaf, and two on another. Each leaf received, as soon as the secretion became slightly acid (and this occurred four times within $24 \mathrm{hrs}$ ), drops either of the soda or potash, and the acid was thus effectually neutralised. The experiment now succeeded perfectly, for after $22 \mathrm{hrs}$. the angles of the cubes were as sharp as they were at first, and we know from experiment 5 that such small cubes would have been completely rounded within this time by the secretion in its natural state. Some of the fluid was now removed with blotting-paper from the discs of the leaves, and minute drops of hydrochloric acid of the strength of one part to 200 of water was added. Acid of this greater strength was used as the solutions of the alkalies wero stronger. The 
process of digestion now commenced, so that within $48 \mathrm{hrs}$. from the time when the acid was given the four cubes were not only completely dissolved, but much of the liquefied albumen was absorbed.

Experiment 11.-Two cubes of albumen ( $\frac{1}{40}$ of an inch, or . $635 \mathrm{~mm}$.) wero placed on two leaves, and were treated with alkalies as in the last experiment, and with the same result; for after $22 \mathrm{hrs}$. they had their angles perfectly sharp, showing that the digestive process had been completely arrested. I then wished to ascertain what would be the effect of using stronger hydrochloric acid; so I added minute drops of the strength of 1 per cent. This proved rather too strong, for after $48 \mathrm{hrs}$. from the time when the acid was added one cube was still almost perfect, and the other only very slightly rounded, and both were stained slightly pink. This latter fact shows that tho leaves were injured,* for during the normal process of digestion the albumen is not thus coloured, and wo can thus understand why tho cubes wero not dissolved.

From these experiments we clearly see that the secretion has the power of dissolving albumen, and we further see that if an alkali is added, the process of digestion is stopped, but immediately recommences as soon as the alkali is neutralised by weak hydrochloric acid. Even if I had tried no other experiments than these, they would have almost sufficed to prove that the glands of Drosera secrete some ferment analogous to pepsin, which in presence of an acid gives to the secretion its power of dissolving albuminous compounds.

Splinters of clean glass were scattered on a large number of leaves, and these became moderately inflected. They were cut off and divided into three lots; two of them, after being left for some time in a little distilled water, were strained, and some dis-

* Sachs remarks ('Traité do Brit.' 1s7t, p. 774), that cells which are killed hy freezing, by too great heit, or by chemical agents, allow all their colouring natter to escape into the surrounding water. 
coloured, viscid, slightly acid fluid was thus obtained. The third lot was well soaked in a few drops of glycerine, which is well known to dissolve pepsin. Cubes of albumen ( $\frac{1}{20}$ of an inch) were now placed in the three fluids in watch-glasses, some of which were kept for several days at about $90^{\circ}$ Fahr. $\left(32^{\circ} \cdot 2\right.$ Cent.), and others at the temperature of my room; but none of the cubes were dissolved, the angles remaining as sharp as ever. This fact probably indicates that the ferment is not secreted until the glands are excited by the absorption of a minute quantity of already soluble animal matter,- - a conclusion which is supported by what wo shall hereafter see with respect to Dionæa. Dr. Hooker likewise found that, although the fluid within the pitchers of Nepenthes possesses extraordinary power of digestion, yet when removed from the pitchers before they have been excited and placed in a ressel, it has no such power, although it is already acid; and we can account for this fact only on the supposition that the proper ferment is not secreted until some exciting matter is absorbed.

On three other occasions eight leaves were strongly excited with albumen moistened with saliva; they were then cut off, and allowed to soak for several hours or for a whole day in a few drops of glycerine. Some of this extract was added to a little hydrochloric acid of various strengths (generally one to 400 of water), and minute cubes of albumen were placed in the mixture.* In two of these trials the eubes were not in the least acted on; but in the third

* As a control experiment bits of albunien were placed in the samo glycerine with hydrochloric acid of the same strength; and the albumen, as might have been expected, was not in the least affected after two days. 
the experiment was successful. For in a vessel containing two cubes, both were reduced in size in 3 hrs.; and after $24 \mathrm{hrs}$. mere streaks of undissolved albumen were left. In a second vessel, containing two minute ragged bits of albumen, both were likewise reduced in size in 3 hrs., and after 24 hrs. completely disappeared. I then added a little weak hydrochloric acid to both vessels, and placed fresh cubes of albumen in them; but these were not acted on. This latter fact is intelligible according to the high authority of Schiff,* who has demonstrated, as he believes, in opposition to the view held by some physiologists, that a certain small amount of pepsin is destroyed during the act of digestion. So that if my solution contained, as is probable, an extremely small amount of the ferment, this would have been consumed by the dissolution of the cubes of albumen first given; none being left when the hydrochloric acid was added. The destruction of the ferment during the process of digestion, or its absorption after the albumen had been converted into a peptone, will also account for only one out of the three latter sets of experiments having been successful.

Digestion of Roast Meat.-Cubes of about $\frac{1}{20}$ of an inch $(1.27 \mathrm{~mm}$.) of moderately roasted meat wero placed on five leaves which became in 12 hrs. closely inflected. After 48 hrs. I gently opened one leaf, and the meat now consisted of a minute central sphere, partially digesterl and surrounded by a thick envelope of transparent viscid fluid. The whole, without being much disturbed, was removed and placed under the microscope. In the central part the transverse strix on the muscular fibres were quite distinct; and it was

* 'Leçons phyв. do la Digestion,' 1867, tom. ii. pp. 114-126. 
interesting to observe how gradually they disappeared, when the same fibre was traced into the surrounding fluid. They disappeared by the striæ being replaced by transverse lines formed of excessively minute dark points, which towards the exterior could be seen only under a very high power; and ultimately these points were lost. When I made these observations, I had not read Schiff's account* of the digestion of meat by gastric juice, and I did not understand the meaning of the dark points. But this is explained in the following statement, and we further see how closely similar is the process of digestion by gastric juice and by the secretion of Drosera.

"On a dit que le suc gastrique faisait perdre à la fibre musculaire ses stries transversales. Ainsi énoncée, cette proposition pourrait donner lieu à une équivoque, car ce qui se perd, ce n'est que l'aspect extérieur de la striature et non les éléments anatomiques qui la composent. On sait que les stries qui donnent un. aspect si caractéristique à la fibre musculaire, sont le résultat do la juxtaposition et du parallélisme des corpuscules élémentaires, placés, à distances égales, dans l'intérieur des fibrilles contiguës. Or, dès que le tissu connectif qui relie entre elles les fibrilles élémentaires vient à se gonfler et à se dissoudre, et que les fibrilles elles-mêmes se dissocient, ce parallélisme est détruit et avec lui l'aspect, le phénomène optique des stries. Si, après la désagrégation des fibres, on examine au microscope les fibrilles élémentaires, on distingue encore très-nettement à leur intérieur les corpuscules, et on continue à les voir, de plus en plus pâles, jusqu'au moment où les fibrilles elles-mêmes se liquéfient et disparaissent dans le suc gastrique. Ce qui constitue la striature, à proprement parler, n'est donc pas détruit, avant Ja liquéfaction de la fibre charnue elle-même."

In the viscid fluid surrounding the central sphere of undigested meat there were globules of fat and little bits of fibro-elastic tissue; neither of which were in

* 'Leçons phys. do la Digestion,' tom. ir. p. 145. 
the least digested. There were also little free parallelograms of yellowish, highly translucent matter. Schiff, in speaking of the digestion of meat by gastric juice, alludes to such parallelograms, and says :-

"Lo gonflement par lequel commence la digestion de la viande, résulte de l'action du suc gastrique acide sur le tissu connectif qui se dissout d'abord, et qui, par sa liquéfaction, désagrége les fibrilles. Celles-ci se dissolvent ensuite en grande partie, mais, avant de passer à l'état liquide, elles tendent à se briser en petits fragments transversaux. Les 'sarcous clements' de Bowman, qui ne sont autre chose que les produits de cette division transversale des fibrilles élémentaires, peuvent êtro préparés et isolés à l'aide du suc gastrique, pourvu qu'on n’attcnd pas jusqu’à la liquéfaction complète du muscle."

After an interval of $72 \mathrm{hrs}$., from the time when the five cubes were placed on the leaves, I opened the four remaining ones. On two nothing could be seen but littlo masses of transparent viscid fluid; but when theso were examined under a high power, fat-globules, bits of fibro-elastic tissue, and some few parallelograms of sarcous matter, could be distinguished, but not a vestige of transverse striæ. On the other two leaves there were minute spheres of only partially digested meat in the centre of much transparent fluid.

Filvin.-Bits of fibrin were left in water during four days, whilst the following experiments were tried, but they were not in the least acted on. The fibrin which I first used was not pure, and included dark particles: it had either not been well prepared or had subsequently undergone some change. Thin portions, about $\frac{1}{10}$ of an inch square, were placed ou several leaves, and though the fibrin was soon liquefied, the whole was never dissolved. Smaller particles were then placed on four leaves, and minute 
drops of hydrochloric acid (one part to 437 of water) were added; this seemed to hasten the process of digestion, for on one leaf all was liquefied and absorbed after $20 \mathrm{hrs.}$; but on the three other leaves some undissolved residue was left after $48 \mathrm{hrs.} \mathrm{It}$ is remarkable that in all the above and following experiments, as well as when much larger bits of fibrin were used, the leaves were very little excited; and it was sometimes necessary to add a little saliva to induce complete inflection. The leaves, moreover, began to re-expand after only $48 \mathrm{hrs}$., whereas they would have remained inflected for a much longer time had insects, meat, cartilage, albumen, \&c., been placed on them.

I then tried some pure white fibrin, sent mo by Dr. Burdon Sanderson.

Experiment 1.-Two particles, barely $\frac{1}{20}$ of an inch $(1.27 \mathrm{~mm}$.) square, were placed on opposite sides of the same leaf. One of these did not excite the surrounding tentacles, and the gland on which it rested soon dried. The other particle caused a few of the short adjoining tentacles to be inflected, the more distant ones not being affected. After 24 hrs. both were almost, and after $72 \mathrm{hrs.}$ completely, dissolved.

Experiment 2. -The same experiment with the same result, only one of the two bits of fibrin exciting the short surrounding tentacles. This bit was so slowly acted on that after a day I pushed it on to some fresh glands. In three days from the time when it was first placed on the leaf it was completely dissolved.

Experiment 3.-Bits of fibrin of about the same size as before were placed on the dises of two leaves; these caused very little inflection in $23 \mathrm{hrs.}$, but after $48 \mathrm{hrs}$. both were well clasped by the surrounding short tentacles, and after an additional $24 \mathrm{hrs}$. were completely dissolved. On the dise of one of these leares much clear acid fluid was left.

Experiment 4.-Similar bits of fibrin were placed on the dises of two leaves; as after $2 \mathrm{hrs}$. the glands seemed rather dry, they were freely moistened with saliva; this soon caused strong inflection both of the tentacles and blades, with copious 
secretion from the glands. In 18 hrs. the fibrin was com. pletely liquefied, but undigested atoms still floated in the liquid; these, however, disappeared in under two additional days.

From these experiments it is clear that the secretion completely dissolves pure fibrin. The rate of dissolution is rather slow; but this depends merely on this substance not exciting the leaves sufficiently, so that only the immediately adjoining tentacles are inflected, and the supply of secretion is small.

Syntonin.-This substance, extracted from muscle, was kindly prepared for me by Dr. Moore. Very differently from fibrin, it acts quickly and energetically. Small portions placed on the discs of three leaves caused their tentacles and blades to be strongly inflected within 8 hrs.; but no further observations were made. It is probably due to the presence of this substance that raw meat is too powerful a stimulant, often injuring or even killing the leaves.

Areolar Tissue.-Small portions of this tissue from a sheep were placed on the discs of three leaves; these became moderately well inflected in $24 \mathrm{hrs}$, but began to re-expand after $48 \mathrm{hrs}$, and were fully re-expanded in 72 hrs., always reckoning from the time when the bits were first given. This substance, therefore, liko fibrin, cxcites the leaves for only a short time. The residue left on the leaves, after they were fully reexpanded, was examined under a high power and found much altered, but, owing to the presence of a quantity of elastic tissue, which is never acted on, could hardly be said to be in a liquefied condition.

Some arcolar tissue free from elastic tissue was next procured from the visceral cavity of a toad, and moderately sized, as well as very small, bits were placed on five leaves. After 24 hrs. two of the bits 
were completely liquefied; two others were rendered transparent, but not quite liquefied; whilst the fifth was but little affected. Several glands on the three latter leaves were now moistened with a little saliva, which soon caused much inflection and secretion, with the result that in the course of 12 additional hrs. one leaf alone showed a remnant of undigested tissue. On the dises of the four other leaves (to one of which a rather large bit had been given) nothing was left except some transparent viscid fluid. I may add that some of this tissue included points of black pigment, and these were not at all affected. As a control experiment, small portions of this tissue were left in water and on wet moss for the same length of time, and remained white and opaque. From these facts it is clear that areolar tissue is easily and quickly digested by the secretion; but that it does not greatly excite the leaves.

Cartilage.-Three cubes ( $\frac{1}{20}$ of an inch or $1.27 \mathrm{~mm}$.) of white, translucent, extremely tough cartilage were cut from the end of a slightly roasted leg-bone of a sheep. These were placed on three leaves, borne by poor, small plants in my greenhouse during November; and it seemed in the highest degree improbable that so hard a substance would be digested under such unfavourable circumstances. Nevertheless, after 48 hrs., the cubes were largely dissolved and converted into minute spheres, surrounded by transparent, very acid fluid. Two of these spheres were completely softened to their centres; whilst the third still contained a very small irregularly shaped core of solid cartilage. Their surfaces were seen under the microscope to be curiously marked by prominent ridges, showing that the cartilage had been unequally corroded by the secretion. I need hardly 
say that cubes of the same cartilage, kept in water for the same length of time, were not in the least affected.

During a more favourable season, moderately sized bits of the skinned ear of a cat, which includes cartilage, areolar and elastic tissue, were placed on three leaves. Some of the glands were touched with saliva, which caused prompt inflection. Two of the leaves began to re-expand after three days, and the third on the fifth day. The fluid residue left on their dises was now examined, and consisted in one case of perfectly transparent, viscid matter; in the other two cases, it contained some elastic tissue and apparently remnants of half digested areolar tissue.

Fibro-cartilage (from between the vertebræ of the tail of a sheep). Moderately sized and small bits (the latter about $\frac{1}{20}$ of an inch) were placed on nine leaves. Some of these were well and some very little inflected. In the latter case the bits were dragged over the discs, so that they were well bedaubed with the secretion, and many glands thus irritated. All the leaves re-expanded after only two days; so that they were but little excited by this substance. The bits were not liquefied, but were certainly in an altered condition, being swollen, much more transparent, and so tender as to disintegrate very easily. IIy son Francis prepared some artificial gastric juice, which was proved efficient by quickly dissolving fibrin, and suspended portions of the fibro-cartilage in it. These swelled and became hyaline, exactly like those cxposed to the secretion of Drosera, but were not dissolved. This result surprised me much, as two physiologists were of opinion that fibro-cartilage would be easily digested by gastric juice. I therefore asked Dr. Klein to examino the specimens; and 
he reports that the two which had been subjected to artificial gastric juice were "in that state of digestion in which we find connective tissue when treated with an acid, viz. swollen, more or less hyaline, the fibrillar bundles having become homogeneous and lost their fibrillar strueture." In the specimens which had been left on the leaves of Drosera, until they reexpanded, "parts were altered, though only slightly so, in the same manner as those subjected to the gastric juice, as they had become more transparent, almost hyaline, with the fibrillation of the bundles indistinct." Fibro-cartilage is therefore acted on in nearly the same manner by gastric juice and by the secretion of Drosera.

Bone. - Small smooth bits of the dried hyoidal bone of a fowl moistened with saliva were placed on two leaves, and a similarly moistened splinter of an extremely hard, broiled mutton-chop bone on a third leaf. These leaves soon became strongly inflected, and remained so for an unusual length of time; namely, one leaf for ten and the other two for nino days. The bits of bone were surrounded all the time by acid secretion. When examined under a weak power, they were found quite softened, so that they were readily penetrated by a blunt needle, torn into fibres, or compressed. Dr. Klein was so kind as to make sections of both bones and examine them. He informs me that both presented the normal appearance of decalcified bone, with traces of the earthy salts occasionally left. The corpuscles with their processes were very distinct in most parts; but in some parts. especially near the periphery of the hyoidal bone, none could be seen. Other parts again appeared amorphous, with even the longitudinal striation of bone not distinguishable. This amorphous structure, 
as Dr. Klein thinks, may be the result either of the incipient digestion of the fibrous basis or of all the animal matter having been removed, the corpuscles being thus rendered invisible. A hard, brittle, yellowish substance occupied the position of the medulla in the fragments of the hyoidal bone.

As the angles and little projections of the fibrous basis were not in the least rounded or corroded, two of the bits were placed on fresh leaves. These by the next morning were closely inflected, and remained so,- - the one for six and the other for seven days,therefore for not so long a time as on the first occasion, but for a much longer time than ever occurs with leaves inflected over inorganic or even over many organic bodies. The secretion during the whole time coloured litmus paper of a bright red; but this may have been due to the presence of the acid superphosphate of lime. When the leaves re-expanded, the angles and projections of the fibrous basis were as sharp as ever. I therefore concluded, falsely as we shall presently see, that the secretion cannot touch the fibrous basis of bone. The more probable explanation is that the acid was all consumed in decomposing the phosphate of lime which still remained; so that none was left in a free state to act in conjunction with the ferment on the fibrous basis.

Enamel and Dentine.-As the secretion decalcified ordinary bone, I determined to try whether it would act on enamel and dentine, but did not expect that it would succeed with so hard a substance as enamel. Dr. Klein gave me some thin transverse slices of the canine tooth of a dog; small angular fragments of which were placed on four leaves; and these were examined each succeeding day at the same hour. The results are, I think, worth giving in detail. 
Experiment 1.-May 1st, fragment placed on leaf; 3rd, tentacles but little inflected, so a little saliva was added; 6 th, as the tentacles were not strongly inflected, the fragment was transferred to another leaf, which acted at first slowly, but by the 9th closely embraced it. On the 11th this second leaf began to re-expand; the fragment was manifestly, softened, and Dr. Klein reports, "a great deal of enamel and the greater part of the dentine decalcified."

Experiment 2.-May 1st, fragment placed on leaf; 2nd, tentacles fairly well inflected, with much secretion on the disc, and remained so until the 7 th, when the leaf re-expanded. The fragment was now transferred to a fresh leaf, which next day (8th) was inflected in the strongest manner, and thus remained until the 11th, when it re-expanded. Dr. Klein reports, "a great deal of enamel and the greater part of the dentine decalcified."

Experiment 3.-May 1st, fragment moistened with saliva and placed on a leaf, which remained well inflected until 5th, when it re-expanded. The enamel was not at all, and the dentine only slightly, softened. The fragment was now transferred to a fresh leaf, which next morning (6th) was strongly inflected, and remained so until the 11th. The enamel and dentine both now somewhat softened; and Dr. Klein reports, "less than half the enamel, but the greater part of the dentine, decalcified."

Experiment 4.-May 1st, a minute and thin bit of dentine, moistened with saliva, was placed on a leaf, which was soon inflected, and re-expanded on the 5th. The dentine had become as flexible as thin paper. It was then transferred to a fresh leaf, which next morning (6th) was strongly inflected, and reopened on the 10th. The decalcified dentine was now so tender that it was torn into shreds merely by the force of the re-expanding tentacles.

From these experiments it appears that enamel is attacked by the secretion with more difficulty than dentine, as might have been expected from its extreme hardness; and both with more difficulty than ordinary bone. After the process of dissolution has once commenced, it is carried on with greater ease; this may be inferred from the leaves, to which the fragments were transferred, becoming in all four cases strongly inflected in the course of a single day; whereas the first set of leaves acted much less quickly and 
energetically. The angles or projections of the fibrous basis of the enamel and dentine (except, perhaps, in No. 4, which could not be well observed) were not in the least rounded; and Dr. Klein remarks that their microscopical structure was not altered. But this could not have been expected, as the decalcification was not complete in the three specimens which were carefully examined.

Fibrous Basis of Bone.-I at first concluded, as already stated, that the secretion could not digest this substance. I therefore asked Dr. Burdon Sanderson to try bone, enamel, and dentine, in artificial gastric juice, and he found that they were after a considerable time completely dissolved. Dr. Klein examined some of the small lamellæ, into which part of the skull of a cat became broken up after about a week's immersion in the fluid, and he found that towards the edges the " matrix appeared rarified, thus producing the appearance as if the canaliculi of the bone-corpuscles had become larger. 'Otherwise the corpuscles and their canaliculi were very distinct." So that with bone subjected to artificial gastric juico complete decalcification precedes the dissolution of the fibrous basis. Dr. Burdon Sanderson suggested to me that the failure of Drosera to digest the fibrous basis of bone, enamel, and dentine, might be due to the acid being consumed in the decomposition of the earthy salts, so that there was none left for the work of digestion. Accordingly, my son thoroughly decalcified the bone of a sheep with weak hydrochloric acid; and seven minute fragments of the fibrous basis were placed on so many leaves, four of the fragments being first damped with saliva to aid prompt inflection. All seven leares became inflected, but only rery moderately, in the course of a day. 
They quickly began to re-expand; fire of them on the second day, and the other two on the third day. On all seven leaves the fibrous tissue was converted into perfectly transparent, viscid, more or less liquefied little masses. In the middle, however, of one, my son saw under a high power a few corpuscles, with traces of fibrillation in the surrounding transparent matter. From these facts it is clear that the leaves are very little excited by the fibrous basis of bone, but that the secretion easily and quickly liquefies it, if thoroughly decalcified. The glands which had remained in contact for two or three days with the viscid masses were not discoloured, and apparently had absorbed little of the liquefied tissue, or had been little affected by it.

Phosphate of Lime.-As we have seen that the tentacles of the first set of leaves remained clasped for nine or ten days over minute fragments of bone, and the tentacles of the second set for six or seven days over the same fragments, I was led to suppose that it was the phosphate of lime, and not any included animal matter, which caused such long continued inflection. It is at least certain from what has just been shown that this cannot have been due to the presence of the fibrous basis. With enamel and dentine (the former of which contains only 4 per cent. of organic matter) the tentacles of two successive sets of leaves remained inflected altogether for eleven days. In order to test my belief in the potency of phosphate of lime, I procured some from Prof. Frankland absolutely free of animal matter and of any acid. A small quantity moistened with water was placed on the discs of two leares. One of these was only slightly affected; the other remained closely inflected for ten days, when a few of the tentacles began to 
re-expand, the rest being much injured or killed. I repeated the experiment, but moistened the phosphate with saliva to insure prompt inflection; one leaf remained inflected for six days (the little saliva used would not have acted for nearly so long a time) and then died; the other leaf tried to re-expand on the sixth day, but after nine days failed to do so, and likewise died. Although the quantity of phosphate given to the above four leaves was extremely small, much was left in every case undissolved. A larger quantity wetted with water was next placed on the discs of three leaves; and these became most strongly inflected in the course of $24 \mathrm{hrs}$. They never reexpanded; on the fourth day they looked sickly, and on the sixth were almost dead. Large drops of not very viscid fluid hung from their edges during the six days. This fluid was tested each day with litmus paper, but never coloured it; and this circumstance I do not understand, as the superphosphate of lime is acid. I suppose that some superphosphate must have been formed by the acid of the secretion acting on the phosphate, but that it was all absorbed and injured the leaves; the large drops which hung from their edges being an abnormal and dropsical secretion. Anyhow, it is manifest that the phosphate of lime is a most powerful stimulant. Even small doses are more or less poisonous, probably on the same principle that raw meat and other nutritious substances, given in excess, kill the leaves. Hence the conclusion, that the long continued inflection of the tentacles over fragments of bone, enamel, and dentine, is caused by the presence of phosphate of lime, and not of any included animal matter, is no doubt correct.

Gelatine.-I used pure gelatine in thin sheets given 
me by Prof. Hoffmann. For comparison, squares of the same size as those placed on the leaves were left close by on wet moss. These soon swelled, but retained their angles for three days; after five days they formed rounded, softened masses, but even on the eighth day a trace of gelatine could still be detected. Other squares were immersed in water, and these, though much swollen, retained their angles for six days. Squares of $\frac{1}{10}$ of an inch ( $2.54 \mathrm{~mm}$.), just moistened with water, were placed on two leaves; and after two or three days nothing was left on them but some acid viscid fluid, which in this and other cases never showed any tendency to regelatinise; so that the secretion must act on the gelatine differently to what water does, and apparently in the same manner as gastric juice.* Four squares of the same size as before were then soaked for three days in water, and placed on large leaves; the gelatine was liquefied and rendered acid in two days, but did not excite much inflection. The leaves began to re-expand after four or five days, much viscid fluid being left on their discs, as if but little had been absorbed. One of these leaves, as soon as it re-expanded, caught a small fly, and after 24 hrs. was closely inflected, showing how much more potent than gelatine is the animal matter absorbed from an insect. Some larger pieces of gelatine, soaked for five days in water, were next placed on three leaves, but these did not become much inflected until the third day; nor was the gelatine completely liquefied until the fourth day. On this day one leaf began to re-expand; the second on the fifth; and third on the sixth. These several facts

* Dr. Lauder Brunton, 'Handbook for the Phys. Laboratory,' 1873 , pp. 477, 487 ; Schiff, 'Leçons phys. de la Digestion,' 1867, p. 249 . 
prove that gelatine is far from acting energetically. on Drosera.

In the last chapter it was shown that a solution of isinglass of commerce, as thick as milk or cream, induces strong inflection. I therefore wished to compare its action with that of pure gelatine. Solutions of one part of both substances to 218 of water were made; and half-minim drops (.0296 ml.) were placed on the discs of eight leares, so that each received $\frac{1}{480}$ of a grain, or $135 \mathrm{mg}$. The four with the isinglass were much more strongly inflected than the other four. I conclude therefore that isinglass contains some, though perhaps very little, soluble albuminous matter. As soon as these eight leaves reexpanded, they were given bits of roast meat, and in some hours all became greatly inflected; again showing how much more meat excites Drosera than does gelatine or isinglass. This is an interesting fact, as it is well known that gelatine by itself has little power of nourishing animals.*

Chondrin.--This was sent me by Dr. Moore in a gelatinous state. Some was slowly dried, and a small chip was placed on a leaf, and a much larger chip on a second leaf. The first was liquefied in a day; the larger piece was much swollen and softened, but was not completely liquefied until the third day. The undried jelly was next tried, and as a control experiment small cubes were left in water for four days and retained their angles. Cubes of the same size were placed on two leaves, and larger cubes on two other leares. The tentacles and laminæ of the latter were closely inflected after 22 hrs., but those of the

* Dr. Lauder Brunton gives in the 'Medieal Record,' January 1873 , p. 36 , an account of Voit's view of the indirect part which gelatine plays in nutrition. 
two leaves with the smaller cubes only to a moderate degree. The jelly on all four was by this time liquefied, and rendered very acid. The glands were blackened from the aggregation of their protoplasmic contents. In $46 \mathrm{hrs}$. from the time when the jelly was given, the leaves had almost re-expanded, and completely so after $70 \mathrm{hrs}$; and now only a little slightly adhesive fluid was left unabsorbed on their dises.

One part of chondrin jelly was dissolved in 218 parts of boiling water, and half-minim drops were given to four leaves; so that each received about $\frac{1}{4-\frac{1}{80}}$ of a grain ( $135 \mathrm{mg}$.) of the jelly; and, of course, much less of dry chondrin. This acted most powerfully, for after only $3 \mathrm{hrs} .30 \mathrm{~m}$. all four leaves were strongly inflected. Three of them began to reexpand after $24 \mathrm{hrs}$, and in $48 \mathrm{hrs}$. were completely open; but the fourth had only partially re-expanded. All the liquefied chondrin was by this time absorberl. Hence a solution of chondrin seems to act far more quickly and energetically than pure gelatine or isinglass; but I am assured by good authorities that it is most difficult, or impossible, to know whether chondrin is pure, and if it contained any albuminous compound, this would have produced the above effects. Nevertheless, I have thought these facts worth giving, as there is so much doubt on the nutritious value of gelatine; and Dr. Lauder Brunton does not know of any experiments with respect to animals on the relative value of gelatine and chondrin.

Milk.-We have seen in the last chapter that milk acts most powerfully on the leaves; but whether this is due to the contained casein or albumen, I know not. Rather large drops of milk excite so much secretion (which is very acid) that it sometimes trickles down 
from the leaves, and this is likewise characteristic of chemically prepared casein. Minute drops of milk, placed on leares, were coagulated in about ten minutes. Schiff denies* that the coagulation of milk by gastric juice is exclusively due to the acid which is present, but attributes it in part to the pepsin; and it seems doubtful whether with Drosera the coagulation can be wholly due to the acid, as the secretion does not commonly colour litmus paper until the tentacles have become well inflected; whereas the coagulation commences, as we have seen, in about ten minutes. Minute drops of skimmed milk were placed on the discs of five leaves; and a large proportion of the coagulated matter or curd was dissolved in $6 \mathrm{hrs}$. and still more completely in 8 hrs. These leaves re-expanded after two days, and the viscid fluid left on their dises was then carefully scraped off and examined. It seemed at first sight as if all the casein had not been dissolved, for a little matter was left which appeared of a whitish colour by reflected light. But this matter, when examined under a high power, and when compared with a minute drop of skimmed milk coagulated by acetic acid, was seen to consist exclusively of oilglobules, more or less aggregated together, with no trace of casein. As I was not familiar with the microscopical appearance of milk, I asked Dr. Lauder Brunton to examine the slides, and he tested the globules with ether, and found that they were dissolved. We may, therefore, conclude that the secretion quickly dissolves casein, in the state in which it exists in milk.

Chemically Prepared Casein.-This substance, which

* 'Leçons,' \&c. tom. ii. p. 151. 
is insoluble in water, is supposed by many chemists to differ from the casein of fresh milk. I procured some, consisting of hard globules, from Messrs. Hopkins and Williams, and tried many experiments with it. Small particles and the powder, both in a dry state and moistened with water, caused the leaves on which they were placed to be inflected very slowly, generally not until two days had elapsed. Other particles, wetted with weak hydrochloric acid (one part to 437 of water) acted in a single day, as did some casein freshly prepared for me by Dr. Moore. The tentacles commonly remained inflected for from seven to nine days; and during the whole of this time the secretion was strongly acid. Even on the eleventh day some secretion left on the disc of a fully reexpanded leaf was strongly acid. The acid seems to be secreted quickly, for in one case the secretion from the discal glands, on which a little powdered casein had been strewed, coloured litmus paper, before any of the exterior tentacles were inflected.

Small cubes of hard casein, moistened with water, were placed on two leaves; after three days one cube had its angles a little rounded, and after seven days both consisted of rounded softened masses, in the midst of much viscid and acid secretion; but it must not be inferred from this fact that the angles were dissolved, for cubes immersed in water were similarly acted on. After nine days these leaves began to reexpand, but in this and other cases the casein did not appear, as far as could be judged by the eye, much, if at all, reduced in bulk. According to Hoppe-Seyler and Lubavin* casein consists of an albuminous, with

* Dr. Lauder Brunton, 'IIandbook for Phys. Lab.' p. 529. 
a non-albuminous, substance; and the absorption of a very small quantity of the former would excite the leaves, and yet not decrease the casein to a perceptible degree. Schiff asserts*-and this is an important fact for us-that "la caséine purifiée des chimistes est un corps presque complètement inattaquable par le suc gastrique." So that here we have another point of accordance between the secretion of Drosera and gastric juice, as both act so differently on the fresh casein of milk, and on that prepared by chemists.

A few trials were made with cheese; cubes of $\frac{1}{20}$ of an inch (1.27 mm.) were placed on four leaves, and these after one or two days became well inflected, their glands pouring forth much acid secretion. After five days they began to re-expand, but one died, and some of the glands on the other leaves were injured. Judging by the eye, the softened and subsided masses of cheese, left on the discs, were very little or not at all reduced in bulk. We may, however, infer from the time during which the tentacles remained inflected,-from the changed colour of some of the glands, - and from the injury done to others, that matter had been absorbed from the cheese.

Legumin.-I did not procure this substance in a separate state; but there can hardly be a doubt that it would be easily digested, judging from the powerful effect produced by drops of a decoction of green peas, as described in the last chapter. Thin slices of a dried pea, after being soaked in water, were placed on two leares; these became somewhat inflected in the course of a single hour, and most strongly so in 21 hrs. They re-expanded after three or four days.

* 'Leŗons,' \&c. torn. ii. p. 153. 
The slices were not liquefied, for the walls of the cells, composed of cellulose, are not in the least acted on by the secretion.

Pollen.-A little fresh pollen from the common pea was placed on the dises of five leaves, which soon became closely inflected, and remained so for two or three days.

The grains being then removed, and examined under the microscope, were found discoloured, with the oilglobules remarkably aggregated. Many had their contents much shrunk, and some were almost empty. In only a few cases were the pollen-tubes emitted. There could be no doubt that the secretion had penetrated the outer coats of the grains, and had partially digested their contents. So it must be with the gastric juice of the insects which feed on pollen, without masticating it.* Drosera in a state of nature cannot fail to profit to a certain extent by this power of digesting pollen, as innumerable grains from the carices, grasses, rumices, fir-trees, and other windfertilised plants, which commonly grow in the same neighbourhood, will be inevitably caught by the viscid secretion surrounding the many glands.

Gluten.-This substance is composed of two albuminoids, one soluble, the other insoluble in alcohol. $\dagger^{\dagger}$ Some was prepared by merely washing wheaten flour in water. A provisional trial was made with rather large pieces placed on two leaves; these, after $21 \mathrm{hrs.}$ were closely inflected, and remained so for four days, when one was killed and the other had its glands extremely blackened, but was not afterwards observed.

* Mr. A. W. Bennett found the undigested coats of the grains in the intestinal canal of polleneating Diptera; see 'Journal of
Hort. Soc. of London,' vol. iv. 1874, p. 158.

† Watts' 'Dict. of Chemistry,' vol. ii. 1872 , p. 873 . 
Smaller bits were placed on two leaves; these were only slightly inflected in two days, but afterwards became much more so. Their secretion was not so strongly acid as that of leaves excited by casein. The bits of gluten, after lying for three days on the leares, were more transparent than other bits left for the same time in water. After seven days both leaves re-expanded, but the gluten seemed hardly at all reduced in bulk. The glands which had been in contact with it were extremely black. Still smaller bits of half putrid gluten were now tried on two leaves; these were well inflected in $24 \mathrm{hrs}$., and thoroughly in four days, the glands in contact being much blackened. After five days one leaf began to re-expand, and after eight days both were fully reexpanded, some gluten being still left on their discs. Four little chips of dried gluten, just dipped in water, were next tried, and these acted rather differently from fresh gluten. One leaf was almost fully re-expanded in three days, and the other three leaves in four days. The chips were greatly softened, almost liquefied, but not nearly all dissolved. The glands which had been in contact with them, instead of being much blackened, were of a very pale colour, and many of them were evidently killed.

In not one of these ten cases was the whole of the gluten dissolved, even when very small bits were given. I therefore asked Dr. Burdon Sanderson to try gluten in artificial digestive fluid of pepsin with liydrochloric acid; and this dissolved the whole. The gluten, however, was acted on much more slowly than fibrin; the proportion dissolved within four hours being as 40.8 of gluten to 100 of fibrin. Gluten was also tried in two other digestive fluids, in which hydrochloric acid was replaced by propionic 
and butyric acids, and it was completely dissolved by these fluids at the ordinary temperature of a room. Here, then, at last, we have a case in which it appears that there exists an essential difference in digestive power between the secretion of Drosera and gastric juice; the difference being confined to the ferment, for, as we have just seen, pepsin in combination with acids of the acetic series acts perfectly on gluten. I believe that the explanation lies simply in the fact that gluten is too powerful a stimulant (like raw meat, or phosphate of lime, or even too large a piece of albumen), and that it injures or kills the glands before they have had time to pour forth a sufficient supply of the proper secretion. That some matter is absorbed from the gluten, we have clear evidence in the length of time during which the tentacles remain inflected, and in the greatly changed colour of the glands.

At the suggestion of Dr. Sanderson, some gluten was left for $15 \mathrm{hrs}$. in weak hydrochloric acid ( 02 per cent.), in order to remove the starch. It became colourless, more transparent, and swollen. Small portions were washed and placed on five leaves, which were soon closely inflected, but to my surprise reexpanded completely in $48 \mathrm{hrs}$. A mere vestige of gluten was left on two of the leaves, and not a vestige on the other three. The viscid and acid secretion, which remained on the dises of the three latter leaves, was scraped off and examined by my son under a high power; but nothing could be seen except a little dirt, and a good many starch grains which had not been dissolved by the hydrochloric acid. Some of the glands were rather pale. We thus learn that gluten, treated with weak hydrochloric acid, is not so powerful or so enduring a 
stimulant as fresh gluten, and does not much injure the glands; and we further learn that it can be digested quickly and completely by the secretion.

Globulin or Crystallin.-This substance was kindly prepared for me from the lens of the eye by Dr. Moore, and consisted of hard, colourless, transparent fragments. It is said* that globulin ought to "swell up in water and dissolve, for the most part forming a gummy liquid;" but this did not occur with the above fragments, though kept in water for four days. Particles, some moistened with water, others with weak hydrochloric acid, others soaked in water for one or two days, were placed on nineteen leaves. Most of these leaves, especially those with the long soaked particles, became strongly inflected in a few hours. 'The greater number re-expanded after three or four days; but three of the leaves remained inflected during one, two, or three additional days. Hence some exciting matter must have been absorbed; but the fragments, though perhaps softened in a greater degree than those kept for the same time in water, retained all their angles as sharp as ever. As globulin is an albuminous substance, I was astonished at this result; and my object being to compare the action of the secretion with that of gastric juice, I asked Dr. Burdon Sanderson to try some of the globulin used by me. He reports that "it was subjected to a liquid containing $0^{\circ} \cdot 2$ per cent. of hydrochloric acid, and about 1 per cent. of glycerine extract of the stomach of a dog. It was then ascertained that this liquid was capable of digesting 1.31 of its weight of unboiled fibrin in $1 \mathrm{hr}$.; whereas, during the hour, only 0.141 of the above globulin was dissolved. In both cases an excess of the substance to be digested was subjected to the liquid." $\dagger$ We thus see that within the same time less than one-ninth by weight of globulin than of fibrin was dissolved; and bearing in mind that pepsin with acids of the acetic series lats only about one-third of the digestive power of pepsin with hydrochloric acid, it is not surprising that the fragments of

* Watts' 'Dict. of Chemistry,' vol. ii. p. $87 t$.

+ I may add that Dr. Sanderson prepared some fresh globulin hy Schmidt's method, and of this 0.865 was dissolved within the sime time, namely, one hour; so that it was far more soluble than that which I used, though less soluble than fibrin, of which, as we have seen, $1 \cdot 31$ was dissolved. I wish that I had tried on 'DroEcra globulin prepared by this method. 
globulin were not corroded or rounded by the secretion of Drosera, though some soluble matter was certainly extracted from them and absorbed by the glands.

Homatin.-Some dark red granules, prepared from bullock's blood, were given me; these were found by Dr. Sanderson to be insoluble in water, acids, and alcohol, so that they were probably hæmatin, together with other bodies derived from the blood. Particles with little drops of water were placed on four leaves, three of which were pretty closely inflected in two days; the fourth only moderately so. On the third day the glands in contact with the hæmatin were blackened, and some of the tentacles seemed injured. After five days two leaves died, and the third was dying; the fourth was beginning to reexpand, but many of its glands were blackened and injured. It is therefore clear that matter had been absorbed which was either actually poisonous or of too stimulating a nature. The particles were much more softened than those kept for the same time in water, but, judging by the eye, very little reduced in bulk. Dr. Sanderson tried this substance with artificial digestive fluid, in the manner described under globulin, and found that whilst 1.31 of fibrin, only 0.456 of the hæmatin was dissolved in an hour; but the dissolution by the secretion of even a less amount would account for its action' on Drosera. The residue left by the artificial digestive fluid at first yielded nothing more to it during several succeeding days.

\section{Substances which are not Digested by the Secretion.}

All the substances hitherto mentioned cause prolonged inflection of the tentacles, and are either completely or at least partially dissolved by the secretion. But there are many other substances, some of them containing nitrogen, which are not in the least acted on by the secretion, and do not induce inflection for a longer time than do inorganic and insoluble objects. These unexciting and indigestible substances are, as far as I have observed, epidermic productions (such as bits of human nails, balls of hair, the quills of feathers), fibro-elastic tissue, mucin, pepsin, urea, chitine, chlorophyll, cellulose, gun-cotton, fat, oil, and starch. 
To these may be added dissolved sugar and gum, diluted alcohol, and regetable infusions not containing albumen, for none of these, as shown in the last chapter, excite inflection. Now, it is a remarkable fact, which affords additional and important evidence, that the ferment of Drosera is closely similar to or identical with pepsin, that none of these same substances are, as far as it is known, digested by the gastric juice of animals, though some of them are acted on by the other secretions of the alimentary canal. Nothing more need be said about some of the above enumerated substances, excepting that they were repeatedly tried on the leaves of Drosera, and were not in the least affected by the secretion. About the others it will be advisable to give my experiments.

Fibro-elastic Tissue.-We have already seen that when little cubes of meat, \&c.; were placed on leaves, the muscles, areolar tissue, and cartilage were completely dissolved, but the fibroelastic tissue, even the most delicate threads, were left without the least signs of having been attacked. And it is well known that this tissue cannot be digested by the gastric juice of animals.*

Mucin.-As this substance contains about 7 per cent. of nitrogen, I expected that it would have excited the leares greatly and been digested by the seeretion, but in this I was mistaken. From what is stated in chemical works, it appears extremely doubtful whether mucin can be prepared as a pure principle. That which I used (prepared by Dr. Moore) was dry and hard. Particles moistened with water were placed on four leaves, but after two days there was only a trace of inflection in the immediately adjoining tentacles. These leaves were then tried with bits of meat, and all four soon became strongly inflected. Some of the dried mucin was then soaked in water for two days, and little cubes of the proper size wore placed on three leaves. After four days the tentacles

* See, for instance, Schiff, 'Phys. de la Digestion'’ 1Ṣ67, tom. ii p. 38 . 
round the margins of the dises were a little inflected, and the secretion collected on the disc was acid, but the exterior tentacles were not affected. One leaf began to re-expand on the fourth day, and all were fully re-expanded on the sixth. The glands which had been in contact with the mucin were a little darkened. We may therefore conclude that a small amount of some impurity of a moderately exciting nature had been absorbed. That the mucin employed by me did contain some soluble matter was proved by Dr. Sanderson, who on subjecting' it to artificial gastric juice found that in $1 \mathrm{hr}$. some was dissolved, but only in the proportion of 23 to 100 of fibrin during the same time. The cubes, though perhaps rather softer than. those left in water for the same time, retained their angles as sharp as ever. We may therefore infer that the mucin itself was not dissolved or digested. Nor is it digested by the gastric juice of living animals, and according to Schiff* it is a layer of this substance which protects the coats of the stomach from being corroded during digestion.

Pepsin.-My experiments are hardly worth giving, as it is scarcely possible to prepare pepsin free from other albuminoids; but I was curious to ascertain, as far as that was possible, whether the ferment of the secretion of Drosera would act on the ferment of the gastric juice of animals. I first used the common pepsin sold for medicinal purposes, and afterwards some which was much purer, prepared for me by Dr. Moore. Five leaves to which a considerable quantity of the former was given remained inflected for five days; four of them then died, apparently from too great stimulation. I then tried Dr. Moore's pepsin, making it into a paste with water, and placing such small particles on the dises of five leaves that all would have been quickly dissolved had it been meat or albumen. The leaves were soon inflected; two of them began to re-expand after only $20 \mathrm{hrs}$, and the other three were almost completely re-expanded after $44 \mathrm{hrs}$. Some of the glands which had been in contact with the particles of pepsin, or with the acid secretion surrounding them, were singularly pale, whereas others were singularly dark-coloured. Some of the secretion was s craped off and examined under a high power; and it abounded with granules undistinguishable from those of pepsin left in water for the same length of time. We may therefore infer, as highly probable (remembering what small quantities were given), that the ferment of Drosera does not act on or digest

* 'Leçons phys. de la Digestion'’ 1867, tom. ii. p. 304. 
pepsin, but absorbs from it some albuminous impurity which induces inflection, and which in large quantity is highly injurious. Dr. Lauder Brunton at my request endeavoured to ascertain whether pepsin with hydrochloric acid would digest pepsin, and as far as he could judge, it had no such power. Gastric juice, therefore, apparently agrees in this respect with the secretion of Drosera.

Urea.-It seemed to me an interesting inquiry whether this refuse of the living body, which contains much nitrogen, would, like so many other animal fluids and substances, be absorbed by the glands of Drosera and cause inflection. Halfminim drops of a solution of one part to 437 of water wero placed on the dises of four leaves, each drop containing the quantity usually employed by me, namely $\frac{1}{960}$ of a grain, or $.007 t \mathrm{mg}$; ; but the leaves were hardly at all affected. They were then tested with bits of meat, and soon became closely inflected. I repeated the same experiment on four leaves with some fresh urea prepared by Dr. Moore; after two days there was no inflection; I then gave them another dose, but still there was no inflection. These leares were afterwards tested with similarly sized drops of an infusion of raw meat, and in 6 hrs. there was considerable inflection, which becamo cxcessive in 21 hrs. But the urea apparently was not quito pure, for when four leares were immersed in $2 \mathrm{dr}$. $(7 \cdot 1 \mathrm{ml}$.) of the solution, so that all the glands, instead of merely those on the disc, were enabled to absorb any small amount of impurity in solution, there was considerable inflection after $2 \pm$ hrs., ccrtainly more than would have followed from a similar immersion in pure water. That the urea, which was not perfectly white, should have contained a sufficient quantity of albuminous matter, or of some salt of ammonia, to have caused the above effect, is far from surprising, for, as we shall see in the next chapter, astonishingly small doses of ammonia are highly efficient. We may therefore conclude that urea itself is not exciting or nutritious to Drosera; nor is it modified by the sceretion, so as to be rendered nutritious, for, had this been the case, all the leares with drops on their dises assuredly would have been well inflected. Dr. Lauder Brunton informs me that from experiments made at my request at St. Bartholomew's IIospital it appears that urea is not acted on by artificial gastric juice, that is by pepsin with hydrochloric acid.

Chitine.-I'Te chitinous coats of insects naturally captured by the leares do not appear in the least corroded. Small square pieces of the delicate wing and of the elytron of a Staphylinus 
were placed on some leaves, and after these had re-expanded, the pieces were carefully examined. Their angles were as sharp as ever, and they did not differ in appearance from the other wing and elytron of the same insect which had been left in water. The elytron, however, had evidently yielded some nutritious matter, for the leaf remained clasped over it for four days; whereas the leaves with bits of the true wing re-expanded on the second day. Any one who will examine the excrement of insect-eating animals will see how powerless their gastric juice is on chitine.

Cellulose.-I did not obtain this substance in a separate state, but tried angular bits of dry wood, cork, sphagnum moss, linen, and cotton thread. None of these bodies were in the least attacked by the secretion, and thcy caused only that moderate amount of inflection which is common to all inorganic objects. Gun-cotton, which consists of cellulose, with the hydrogen replaced by nitrogen, was tried with the same result. We have seen that a decoction of cabbage-leares excites the most powerful inflection. I therefore placed two little square bits of the blade of a cabbage-leaf, and four little cubes cut from the midrib, on six leaves of Drosera. These became well inflected in 12 hrs., and remained so for between two and four days; the bits of cabbage being bathed all the time by acid secretion. This shows that some exciting matter, to which I shall presently refer, had been absorbed; but the angles of the squares and cubes remained as sharp as ever, proving that the framework of cellulose had not been attacked. Small square bits of spinach-leaves were tried with the same result; the glands pouring forth a moderate supply of acid secretion, and the tentacles remaining inflected for three days. We have also seen that the delicate coats of pollen grains are not dissolved by the secretion. It is well known that the gastric juice of animals does not attack cellulose.

Chlorophyll.-This substance was tried, as it contains nitrogen. Dr. Moore sent me some preserved in alcohol; it was dried, but soon deliquesced. Particles were placed on four leaves; after $3 \mathrm{hr}$. the secretion was acid; after 8 hrs. there was a good deal of inflection, which in $24 \mathrm{hrs}$. became fairly well marked. After four days two of the leaves began to open, and the other two were then almost fully re-expanded. It is therefore clear that this chlorophyll contained matter which excited the leaves to a moderate degree; but judging by the eye, little or none was dissolved; so that in a pure state it would not probably have been attacked by the secretion. Dr. Sanderson tried that which I 
used, as well as some freshly prepared, with artificial digestive liquid, and found that it was not digested. Dr. Lauder Brunton likewise tried some prepared by the process given in the British Pharmacopoia, and exposed it for five days at the temperature of $37^{\circ}$ Cent. to digestive liquid, but it was not diminished in bulk, though the fluid acquired a slightly brown colour. It was also tried with the glycerine extract of pancreas with a negative result. Nor does chlorophyll seem affected by the intestinal secretions of various animals, judging by the colour of their excrement.

It must not be supposed from these facts that the grains of chlorophyll, as they exist in living plants, cannot be attacked by the secretion; for these grains consist of protoplasm merely coloured by chlorophyll. My son Francis placed a thin slice of spinach leaf, moistened with saliva, on a leaf of Drosera, and other slices on damp cotton-wool, all exposed to the same temperature. After $19 \mathrm{hrs}$. the slice on the leaf of Drosera was bathed in much secretion from the inflected tentacles, and was now examined under the microscope. No perfect grains of chlorophyll could be distinguished; some were shrunken, of a jellowish-green colour, and collected in the middle of the cells; others were disintegrated and formed a yellowish mass, likewise in the middle of the cells. On the other hand, in the slices surrounded by damp cotton-wool, the grains of chlorophyll were green and as perfect as ever. My son also placed some slices in artificial gastric juice, and these were acted on in nearly the same-manner as by the secretion. We have seen that bits of fresh cabbage and spinach leares cause the tentacles to be inflected and the glands to pour forth much acid asecretion; and there can be little doubt that it is the protoplasm forming the grains of chlorophyll, as well as that lining the walls of the cells, which excites the leares.

Fut and Oil.-Cubes of almost pure uncooked fat, placed on several leaves, did not have their angles in the least rounded. We have also seen that the oil-globules in milk are not digested. Nor does olive oil dropped on the dises of leares cause any inflection; but when they are immersed in olive oil, they become strongly inflected; but to this subject I shall have to recur. Oily substances are not digested by the gastric juice of animals.

Starch.-Rather large bits of dry starch caused well-marked inflection, and the leaves did not re-expand until the fourth day; but I have no doubt that this was due to the prolonged irritation of the glands, as the starch continued to absorb the secretion. The particles were not in the least reduced in size; 
and we know that leaves immersed in an emulsion of starch are not at all affected. I need hardly say that starch is not digested by the gastric juice of animals.

\section{Action of the Secretion on Living Seeds.}

The results of some experiments on living seeds, selected by hazard, may here be given, though they bear only indirectly on our present subject of digestion.

Seven cabbage seeds of the previous year were placed on the same number of leaves. Some of these leaves were moderately, but the greater number only slightly inflected, and most of them re-expanded on the third day. One, however, remained clasped till the fourth, and another till the fifth day. These leaves therefore were excited somewhat more by the seeds than by inorganic objects of the same size. After they re-expanded, the seeds were placed under favourable conditions on damp sand; other seeds of the same lot being tried at the same time in the same manner, and found to germinate well. Of the seven seeds which had been exposed to the secretion, only three germinated; and one of the three seedlings soon perished, the tip of its radicle being from the first decayed, and the edges of its cotyledons of a dark brown colour; so that altogether five out of the seven seeds ultimately perished.

Radish seeds (Raphanus sativus) of the previous year were placed on three leaves, which became moderately inflected, and re-expanded on the third or fourth day. Two of these seeds were transferred to damp sand; only one germinated, and that very slowly. This seedling had an extremely short, crooked, diseased, radicle, with no absorbent hairs; and the cotyledons were oddly mottled with purple, with the edges blackened and partly withered.

Cress seeds (Lepidum sativum) of the previous year were placed on four leaves; two of these next morning were moderately and two strongly inflected, and remained so for four, five, and even six days. Soon after these seeds were placed on the leaves and had become damp, they secreted in the usual manner a layer of tenacious mucus; and to ascertain whether it was the absorption of this substance by the glands which caused so much inflection, two seeds were put into water, and as much of the mucus as possible scraped off. They were then placed on leaves, which became very strongly inflected in the course of $3 \mathrm{hrs}$., and were still closely inflected on the third day; so that it evidently was not the mucus which excited so 
much inflection; on the contrary, this served to a certain extent as a protection to the seeds. T'wo of the six seeds germinated whilst still lying on the leares, but the seedlings, when transforred to damp sand, soon died; of the other four seeds, only one germinated.

Two seeds of mustard (Sinapis nigra), two of celery (Apium graveolens)-both of the previous year, two seeds well soaked of caraway (Carum carui), and two of wheat, did not excite the leares more than inorganic objects often do. Five seeds, hardly ripe, of a buttercup (Ranunculus), and two fresh seeds of Aneinone nemoros , induced only a little more effect. On the other hand, four seeds, perhaps not quite ripe, of Carex sylvatica caused the leaves on which they were placed to be very strongly inflected; and these only began to re-expand on the third day, one remaining inflected for seven days.

It follows from these few facts that different kinds of seeds excite the leaves in very different degrees; whether this is solely due to the nature of their coats is not clear. In the caso of the cress seeds, the partial removal of the layer of mucus hastened the inflection of the tentacles. Whenever the leares remain inflected during several days over seeds, it is clear that they absorb some matter from them. That the secretion penetrates their coats is also evident from the large proportion of cabbage, raddish, and cress seeds which were killed, and from several of the seedlings being greatly injured. This injury to the seeds and seedlings may, however, be due solely to the acid of the secretion, and not to any process of digestion; for Mr. T'raherne Moggridge has shown that very weak acids of the acetic series are highly injurious to seeds. It never occurred to me to observe whether seeds are often blown on to the viscid leaves of plants growing in a state of nature; but this can hardly fail sometimes to occur, as we shall hereafter see in the case of Pingnicula. If so, Drosera will profit to a slight degree by absorbing matter from such seeds.

\section{Summary and Concluding Remarks on the Digestive} Power of Drosera.

When the glands on the dise are excited either by the absorption of nitrogenous matter or by mechanical irritation, thcir secretion increases in quantity and becomes acid. They likewise transmit 
some influence to the glands of the exterior tentacles, causing them to secrete more copiously; and their secretion likewise becomes acid. With animals, according to Schiff,* mechanical irritation excites the glands of the stomach to secrete an acid, but not pepsin. Now, I have every reason to believe (though the fact is not fully established), that although the glands of Drosera are continually secreting viscid fluid to replace that lost by evaporation, yet they do not secrete the ferment proper for digestion when mechanically irritated, but only after absorbing certain matter, probably of a nitrogenous nature. I infer that this is the case, as the secretion from a large number of leaves which had been irritated by particles of glass placed on their discs did not digest albumen; and more especially from the analogy of Dionæa and Nepenthes. In like manner, the glands of the stomach of animals secrete pepsin, as Schiff asserts, only after they have absorbed certain soluble substances, which he designates as peptogenes. There is, therefore, a remarkable parallelism between the glands of Drosera and those of the stomach in the secretion of their proper acid and ferment.

The secretion, as we have seen, completely dissolves albumen, muscle, fibrin, areolar tissue, cartilage, the fibrous basis of bone, gelatin, chondrin, casein in the state. in which it exists in milk, and gluten which has been subjected to weak hydrochloric acid. Syntonin and legumin excite the leaves so powerfully and quickly that there can hardly be a doubt that both would be dissolved by the secretion. The secretion

* 'Phys. de la Digestion,' 1867, tom. ii. pp. 188, 245. 
failed to digest fresh gluten, apparently from its injuring the glands, though some was absorbed. Raw meat, unless in very small bits, and large pieces of albumen, \&c., likewise injure the leaves, which seem to suffer, like animals, from a surfeit. I know not whether the analogy is a real one, but it is worth notice that a decoction of cabbage leaves is far more exciting and probably nutritious to Drosera than an infusion made with tepid water; and boiled cabbages are far more nutritious, at least to man, than the uncooked leaves. The most striking of all the cases, though not really more remarkable than many others, is the digestion of so hard and tough a substance as cartilage. The dissolution of pure phosphate of lime, of bone, dentine, and especially enamel, seems wonderful; but it depends merely on the long-continued secretion of an acid; and this is secreted for a longer time under these circumstances than under any others. It was interesting to observe that as long as the acid was consumed in dissolving the "phosphate of lime, no true digestion occurred; but that as soon as the bone was completely decalcified, the fibrous basis was attacked and liquefied with the greatest ease. The twelve substances above enumerated, which are completely dissolved by the secretion, are likewise dissolved by the gastric juice of the higher animals; and they are acted on in the same manner, as shown by the rounding of the angles of albumen, and more especially by the manner in which the transverse strix of the fibres of muscle disappear.

The secretion of Drosera and gastric juice were both able to dissolve some element or impurity out of the globulin and hæmatin employed by me. The secretion also dissolved something out of chemically 
prepared casein, which is said to consist of two substances; and although Schiff asserts that casein in this state is not attacked by gastric juice, he might' easily have overlooked a minute quantity of some albuminous matter, which Drosera would detect and absorb. Again, fibro-cartilage, though not properly dissolved, is acted on in the same manner, both by the secretion of Drosera and gastric juice. But this substance, as well as the so-called hrmatin used by me, ought perhaps to have been classed with indigestible substances.

That gastric juice acts by means of its ferment, pepsin, solely in the presence of an acid, is well established; and we have excellent evidence that a ferment is present in the-secretion of Drosera, which likewise acts only in the presence of an acid; for we have seen that when the secretion is neutralised by minute drops of the solution of an alkali, the digestion of albumen is completely stopped, and that on the addition of a minute dose of hydrochloric acid it immediately recommences.

The nine following substances, or classes of substances, namely, epidermic productions, fibro-elastic tissue, mucin, pepsin, urea, chitine, cellulose, guncotton, chlorophyll, starch, fat and oil, are not acted on by the secretion of Drosera; nor are they, as far as is known, by the gastric juice of animals. Some soluble matter, however, was extracted from the mucin, pepsin, and chlorophyll, used by me, both by the secretion and by artificial gastric juice.

The several substances, which are completely dissolved by the secretion, and which are afterwards absorbed by the glands, affect the leaves rather differently. They induce infiection at very different 
rates and in very different degrees; and the tentacles remain inflected for very different periods of time. Quick inflection depends partly on the quantity of the substance given, so that many glands are simultaneously affected, partly on the facility with which it is penetrated and liquefied by the secretion, partly on its nature, but chiefly on the presence of exciting matter already in solution. Thus saliva, or a weak solution of raw meat, acts much more quickly than even a strong solution of gelatine. So again leares which have re-expanded, after absorbing drops of a solution of pure gelatine or isinglass (the latter being the more powerful of the two), if given bits of meat, are inflected much more energetically and quickly than they were before, notwithstanding that some rest is generally requisite between two acts of inflection. We probably see the influence of texture in gelatine and globulin when softened by having been soaked in water acting more quickly than when merely wetted. It may be partly due to changed texture, and partly to changed chemical nature, that albumen, which has been kept for some time, and gluten which has been subjected to weak hydrochloric acid, act more quickly than these substances in their fresh state.

The length of time during which the tentacles remain inflected largely depends on the quantity of the substance given, partly on the facility with which it is penetrated or acted on by the secretion, and partly on its essential nature. The tentacles always remain inflected much longer over large bits or larģe drops than over small bits or drops. Texture probably plays a part in determining the extraordinary length of time during which the tentacles remain inflected 
over the hard grains of chemically prepared casein. But the tentacles remain inflected for an equally long time over finely powdered, precipitated phosphate of lime; phosphorus in this latter case evidently being the attraction, and animal matter in the case of casein. The leaves remain long inflected over insects, but it is doubtful how far this is due to the protection afforded by their chitinous integuments; for animal matter is soon extracted from insects (probably by exosmose from their bodies into the dense surrounding secretion), as shown by the prompt inflection of the leaves. We see the influence of the nature of different substances in bits of meat, albumen, and fresh gluten acting very differently from equal-sized bits of gelatine, areolar tissue, and the fibrous basis of bone. The former cause not only far more prompt and energetic, but more prolonged, inflection than do the latter. Hence we are, I think, justified in believing that gelatine, areolar tissue, and the fibrous basis of bone, would be far less nutritious to Drosera than such substances as insects, meat, albumen, \&c. This is an interesting conclusion, as it is known that gelatine affords but little nutriment to animals; and so, probably, would areolar tissue and the fibrous basis of bone. The chondrin which I used acted more powerfully than gelatine, but then I do not know that it was pure. It is a more remarkable fact that fibrin, which belongs to the great class of Proteids,* including albumen in one of its sub-groups, does not excite the tentacles in a greater degree, or keep them inflected for a longer time, than does gelatine, or

* See the classification adopted by Dr. Michael Foster in Watts' 'Dict. of Chemistry', Supplement 1872, p. 963. 
areolar tissue, or the fibrous basis of bone. It is not known how long an animal would survive if fed on fibrin alone, but Dr. Sanderson has no doubt longer than on gelatine, and it would be hardly rash to predict, judging from the effects on Drosera, that albumen would be found more nutritious than fibrin. Globulin likewise belongs to the Proteids, forming another sub-group, and this substance, though containing some matter which excited Drosera rather strongly, was hardly attacked by the secretion, and was very little or very slowly attacked by gastric juice. How far globulin would be nutritious to animals is not known. We thus see how differently the above specified several digestible substances act on Drosera; and we may infer, as highly probable, that they would in like manner be nutritious in very different degrees both to Drosera and to animals. .

The glands of Drosera absorb matter from living seeds, which are injured or killed by the secretion. They likewise absorb matter from pollen, and from fresh leaves; and this is notoriously the case with the stomachs of vegetable-feeding animals. Drosera is properly an insectivorous plant; but as pollen cannot fail to be often blown on to the glands, as will occasionally the seeds and leares of surrounding "plants, Drosera is, to a certain extent, a regetablefeeder.

Finally, the experiments recorded in this chapter show us that there is a remarkable accordance in the power of digestion between the gastric juice of animals with its pepsin and hydrochloric acid and the secretion of Drosera with its ferment and acid belonging to the acetic series. We can, therefore, hardly doubt that the ferment in both cases is closely similar, 
if not identically the same. That a plant and an animal should pour forth the same, or nearly the same, complex secretion, adapted for the same purpose of digestion, is a new and wonderful fact in physiology. But I shall have to recur to this subject in the fifteenth chapter, in my concluding remarks on the Droseraceæ. 


\section{CHAPTER VII.}

\section{The Effects of Salts of Amronia.}

Manner of performing the experiments - Action of distilled water in comparison with the solutions - Carbonate of ammonia, absorbed by the roots - The vapour absorbed by the glands - Drops on the disc-Minute drops applied to separate glands-Leaves immersed in weak solutions - Minuteness of the doses which induce aggregation of the protoplasm - Nitrate of ammonia, analogous experiments with - Phosphate of ammonia, analogous experiments with - Other salts of ammonia - Summary and concluding remarks on the action of the salts of ammonia.

THE chief object in this chapter is to show how powerfully the salts of ammonia act on the leaves of Drosera, and more especially to show what an extraordinarily small quantity suffices to excite inflection. I shall, therefore, be compelled to enter into full details. Doubly distilled water was always used; and for the more delicate experiments, water which had been prepared with the utmost possible care was given me by Professor Frankland. The graduated measures were tested, and found as accurate as such measures can be. The salts were carefully weighed, and in all the more delicate experiments, by Borda's double method. But extreme accuracy would have been superfluous, as the leaves differ greatly in irritability, according to age, condition, and constitution. Even the tentacles on the same leaf differ in irritability to a marked degree. My experiments were tried in the following several ways.

Firstly.-Drops which were ascertained by repeated trials to be on an average about half a minim, or the $\frac{1}{960}$ of a fluid ounce (.0296 ml.), were placed by the same pointed instrument on the 
discs of the leaves, and the inflection of the exterior rows of tentacles observed at successive intervals of time. It was first ascertained, from between thirty and forty trials, that distilled water dropped in this manner produces no effect, except that sometimes, though rarely, two or three tentacles become inflected. In fact all the many trials with solutions which were so weak as to produce no effect lead to the same result that water is inefficient.

Secondly. - The head of a small pin, fixed into a handle, was dipped into the solution under trial. The small drop which adhered to it, and which was much too small to fall off, was cautiously placed, by the aid of a lens, in contact with the secretion surrounding the glands of one, two, three, or four of the. exterior tentacles of the same leaf. Great care was taken that the glands themselves should not be touched. I had supposed that the drops were of nearly the same size; but on trial this proved a great mistake. I first measured some water, and removed 300 drops, touching the pin's head each time on blottingpaper; and on again measuring the water, a drop was found to equal on an average about the $\frac{1}{60}$ of a minim. Some water in a small vessel was weighed (and this is a more accurate method), and 300 drops removed as before; and on again weighing the water, a drop was found to equal on an average only the $\frac{1}{89}$ of a minim. I repeated the operation, but endeavoured this time, by taking the pin's head out of the water obliquely and rather quickly, to remove as large drops as possible; and the result showed that I had succeeded, for each drop on an average equalled $\frac{1}{19^{\cdot 4}}$ of a minim. I repeated the operation in exactly the same manner, and now the drops averaged $\frac{1}{23.5}$ of a minim. Bearing in mind that on these two latter occasions special pains were taken to remove as large drops as possible, we may safely conclude that the drops used in my experiments were at least equal to the $\frac{1}{20}$ of a minim, or $0029 \mathrm{ml}$. One of these drops could be applied to three or even four glands, and if the tentacles became inflected, some of the solution must have been absorbed by all; for drops of pure water, applied in the same manner, never produced any effect. I was able to hold the drop in steady contact with the secretion only for ten to fifteen seconds; and this was not time enough for the diffusion of all the salt in solution, as was evident, from three or four tentacles treated successively with the same drop, often becoming inflected. All the matter in solution was even then probably not exhausted.

Thirdly.-Leaves were cut off and immersed in a measured 
quantity of the solution under trial; the same number of leaves being immersed at the same time, in the same quantity of the distilled water which had been used in making the solution. The leaves in the two lots were compared at short intervals, of time, up to $24 \mathrm{hrs}$., and sometimes to $48 \mathrm{hrs}$. They were immersed by being laid as gently as possible in numbered watch-glasses, and thirty minims $(1.775 \mathrm{ml}$.) of the solution or of water was poured over each.

Some solutions, for instance that of carbonate of ammonia, quickly discolour the glands; and as all on the same leaf were discoloured simultaneously, they must all have absorbed some of the salt within the same short period of time. This was likewise shown by the simultaneous inflection of the several exterior rows of tentacles. If we had no such evidence as this, it might have been supposed that only the glands of the exterior and inflected tentacles had absorbed the salt; or that only those on the disc had absorbed it, and had then transmitted a motor impulse to the exterior tentacles; but in this latter case the exterior tentacles would not have become inflected until some time had elapsed, instead of within half an hour, or even within a few minutes, as usually occurred. All the glands on the same leaf are of nearly the same size, as may best be seen by cutting off a narrow transverse strip, and laying it on its side; hence their absorbing surfaces are nearly equal. The long-headed glands on the extreme margin must be excepted, as they are much longer than the others; but only the upper surface is capable of absorption. Besides the glands, both surfaces of the leaves and the pedicels of the tentacles bear numerous minute papillæ, which absorb carbonate of ammonia, an infusion of raw meat, metallic salts, and probably many other substances, but the absorption of matter by these papille never induces inflection. We must remember that the movement of each separate tentacle depends on its gland being excited, except when a motor impulse is transmitted from the glands of the disc, and then the movement, as just stated, does not take place until some little time has elapsed. I have made these remarks because they show us that when a leaf is immersed in a solution, and the tentacles are inflected, we can judge with some accuracy how much of the salt each gland has absorbed. For instance, if a leaf bearing 212 glands be immersed in a measured quantity of a solution, containing $\frac{2}{10}$ of a grain of a salt, and all the exterior tentacles, except twelve, are inflected, we may feel sure that each of the 200 glands can on an average have absorbed at most $\frac{1}{2000}$ of a grain of the salt. I say at 
most, for the papillæ will have absorbed some small amount, and so will perhaps the glands of the twelve excluded tentacles which did not become inflected. The application of this principle leads to remarkable conclusions with respect to the minuteness of the doses causing inflection.

\section{On the Action of Distilled Water in causing Inflection.}

Although in all the more important experiments the difference between the leaves simultaneously immersed in water and in the several solutions will be described, nevertheless it may be well here to give a summary of the effects of water. The fact, moreover, of pure water acting on the glands deserves in itself some notice. Leaves to the number of 141 were immersed in water at the same time with those in the solutions, and their state recorded at short intervals of time. Thirty-two other leaves were separately observed in water, making altogether 173 experiments. Many scores of leaves were also immersed in water at other times, but no exact record of the effects produced was kept; yet these cursory observations support the conclusions arrived at in this chapter. A few of the long-headed tentacles, namely from one to about six, were commonly inflected within half an hour after immersion; as were occasionally a few, and rarely a considerable number of the exterior round-headed tentacles. After an immersion of from 5 to $8 \mathrm{hrs}$. the short tentacles surrounding the outer parts of the disc generally become inflected, so that their glands form a small dark ring on the disc; the exterior tentacles not partaking of this morement. Hence, excepting in a few cases hereafter to be specified, we can judge whether a solution produces any effect only by observing the exterior tentacles within the first 3 or 4 hrs. after immersion.

Now for a summary of the state of the 173 leaves after an immersion of 3 or $4 \mathrm{hrs}$. in pure water. One leaf had almost all its tentacles inflected; three leaves had most of them subinflected; and thirteen had on an average 36.5 tentacles inflected. Thus seventeen leaves out of the 173 were acted on in a marked manner. Eighteen leaves had from seven to nineteen tentacles inflected, the average being $9 \cdot 3$ tentacles for each leaf. Forty-four leaves had from one to six tentacles inflected, generally the long-headed ones. So that altogether of the 173 leaves carefully observed, seventy-nine were affected by the water in some degree, though commonly to a very slight degree; and ninety-four were not affected in the least degree. This 
amount of inflection is utterly insignificant, as we shall hereafter see, compared with that caused by very weak solutions of several salts of ammonia.

Plants which have lived for some time in a rather high temperature are far more sensitive to the action of water than those grown out of doors, or recently brought into a warm greenhouse. Thus in the above seventeen cases, in which the immersed leares had a considerable number of tentacles inflected, the plants had been kept during the winter in a very warm greenhouse; and they bore in the early spring remarkably fine leaves, of a light red colour. Had I then known that the sensitiveness of plants was thus increased, perhaps I should not have used the leaves for my experiments with the very weak solutions of phosphate of ammonia; but my experiments are not thus vitiated, as I invariably used leaves from the same plants for simultaneous immersion in water. It often happened that some leaves on the same plant, and some tentacles on the same leaf, were more sensitive than others; but why this should be so, I do not know.

Besides the differences just indicated between the leaves im-

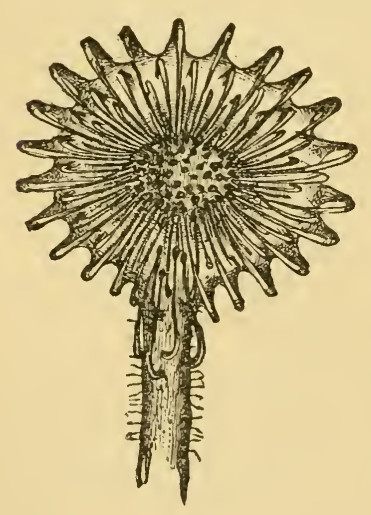

FIG. 9.

(Drosera rotundifolia.)

Leaf (enlarged) with all the tentacles closely inflected, from immersion in a solution of phosphate of ammonia (one part to 87,500 of water). mersed in water and in weak solutions of ammonia, the tentacles of the latter are in most cases much more closely inflected. The appearance of a leaf after immersion in a few drops of a solution of one grain of phosphate of ammonia to 200 oz. of water (i.e. one part to 87,500 ) is here reproduced : such energetic inflection is never caused by water alone. With leares in the weak solutions, the blade or lamina often becomes inflected; and this is so rare a circumstance with leaves in water that $I$ have seen only two instances; and in both of these the inflection was very feeble. Again, with leaves in the weak solutions, the inflection of the tentacles and blade often goes on steadily, thongh slowly, increasing during many hours; and 
this again is so rare a circumstance with leaves in water that I have seen only three instances of any such increase after the first 8 to $12 \mathrm{hrs}$; and in these three instances the two outer rows of tentacles were not at all affected. Hence there is sometimes a much greater difference between the leaves in water and in the weak solutions, after from $8 \mathrm{hrs}$. to $24 \mathrm{hrs}$., than there was within the first $3 \mathrm{hrs}$; though as a general rule it is best to trust to the difference observed within the shorter time.

With respect to the period of the re-expansion of the leaves, when left immersed either in water or in the weak solutions, nothing could be more variable. In both cases the exterior tentacles not rarely begin to re-expand, after an interval of only from 6 to 8 hrs.; that is just about the time when the short tentacles round the borders of the disc become inflected. On the other hand, the tentacles sometimes remain inflected for a whole day, or even two days; but as a general rule they remain inflected for a longer period in very weak solutions than in water. In solutions which are not extremely weak, they never re-expand within nearly so short a period as six or eight hours. From these statements it might be thought difficult to distinguish between the effects of water and the weaker solutions; but in truth there is not the slightest difficulty until excessively weak solutions are tried; and then the distinction, as might be expected, becomes very doubtful, and at last disappears. But as in all, except the simplest, cases the state of the leaves simultaneously immersed for an equal length of time in water and in the solutions will be described, the reader can judge for himself.

\section{Carbonate of Ammonia.}

This salt, when absorbed by the roots, does not cause the tentacles to be inflected. A plant was so placed in a solution of one part of the carbonate to 146 of water that the young uninjured roots could be observed. The terminal cells, which were of a pink colour, instantly became colourless, and their limpid contents cloudy, like a mezzo-tinto engraving, so that some degree of aggregation was almost instantly caused; but no further change ensued, and the absorbent hairs were not visibly affected. The tentacles 
did not bend. Two other plants were placed with their roots surrounded by damp moss, in half an ounce $(14.19 \mathrm{~s} \mathrm{ml.})$ of a solution of one part of the carbonate to 218 of water, and were observed for $24 \mathrm{hrs}$; but not a single tentacle was inflected. In order to produce this effect, the carbonate must be absorbed by the glands.

The vapour produces a powerful effect on the glands, and induces inflection. Three plants with their roots in bottles, so that the surrounding air could not have become very humid, were placed under a bell-glass (holding 122 fluid ounces), together with 4 grains of carbonate of ammonia in a watch-glass. After an interval of $6 \mathrm{hrs.} 15 \mathrm{~m}$. the leaves appeared nnaffected; but next morning, after 20 hrs., the blackened glands were secreting copiously, and most of the tentacles were strongly inflected. These plants soon died. Two other plants were placed under the same bellglass, together with half a grain of the carbonate, the air being rendered as damp as possible; and in 2 hrs. most of the leares were affected, many of the glands being blackened and the tentacles inflected. But it is a curious fact that some of the closely adjoining tentacles on the same leaf, both on the disc and round the margins, were much, and some, apparently, not in the least affected. The plants were kept under the bell-glass for $24 \mathrm{hrs.}$, but no further change ensued. One healthy leaf was hardly at all affected, though other leares on the same plant were much affected. On some leaves all the tentacles on one side, but not those on the opposite side, were inflected. I doubt whether this extremely unequal action can be explained by supposing that the more active glands absorb all the vapour as quickly as it is generated, so that none is left for the others for we shall meet with 
analogous cases with air thoroughly permeated with the vapours of chloroform and ether.

Minute particles of the carbonate were added to the secretion surrounding several glands. These instantly became black and secreted copiously; but, except in two instances, when extremely minute particles were given, there was no inflection. This result is analogous to that which follows from the immersion of leaves in a strong solution of one part of the carbonate to 109 , or 146 , or even 218 of water, for the leaves are then paralysed and no inflection ensues, though the glands are blackened, and the protoplasm in the cells of the tentacles undergoes strong aggregation.

We will now turn to the effects of solutions of the carbonate. Half-minims of a solution of one part to 437 of water were placed on the discs of twelve leaves; so that each received $\frac{1}{960}$ of a grain or $\cdot 0675 \mathrm{mg}$. Ten of these had their exterior tentacles well inflected; the blades of some being also much curved inwards. In two cases several of the exterior tentacles were inflected in $35 \mathrm{~m}$; ; but the movement was generally slower. These ten leaves re-expanded in periods varying between $21 \mathrm{hrs}$. and 45 hrs., but in one case not until 67 hrs. had elapsed; so that they re-expanded much more quickly than leares which have caught insects.

The same-sized drops of a solution of one part to $87 \check{\text { of water }}$ were placed on the dises of eleven leaves; six remained quite unaffected, whilst five had from three to six or eight of their exterior tentacles inflected; but this degree of movement can hardly be considered as trustworthy. Each of these leaves received $\frac{1}{T-29}$ of a grain ( $.0337 \mathrm{mg}$.), distributed between the glands of the disc, but this was too small an amount to produce any decided effect on the exterior tentacles, the glands of which had not themselves received any of the salt.

Minute drops on the head of a small pin, of a solution of one part of the carbonate to 218 of water, were next tried in the manner above described. A drop of this kind equals on an a verage $\frac{1}{20}$ of a minim, and therefore contains $\frac{7}{4500}$ of a grain ( $.013 .5 \mathrm{mg}$.) of the carbonate. I touched with it the viscid secretion round three glands, so that each gland received only 
$\frac{1}{14400}$ of a grain ( $\cdot 00445 \mathrm{mg}$.). Nevertheless, in two trials all the glands were plainly blackened; in one case all three tontacles were well inflected after an interval of $2 \mathrm{hrs} .40 \mathrm{~m}$.; and in another case two of the three tentacles were inflected. I then tried drops of a weaker solution of one part to 292 of water on twenty-four glands, always touching the viscid secretion round three glands with the same little drop. Each gland thus received only the $\frac{1}{19200}$ of a grain $(\cdot 00337 \mathrm{mg}$.), yet some of them were a little darkened; but in no one instance were any of the tentacles inflected, though they were watched for 12 hrs. When a still weaker solution (viz. one part to 437 of water) was tried on six glands, no effect whatever was perceptible. We thus learn that the $\frac{1}{1+400}$ of a grain ( $\cdot 00145 \mathrm{mg}$.) of carbonate of ammonia, if absorbed by a gland, suffices to induce inflection in the basal part of the same tentacle; but as already stated, I was able to hold with a steady hand the minute drops in contact with the secretion only for a few seconds; and if more time had been allowed for diffusion and absorption, a much weaker solution would certainly have acted.

Some experiments were made by immersing cut-off leaves in solutions of different strengths. Thus four leaves were left for about 3 hrs. each in a drachm $(3.549 \mathrm{ml}$.) of a solution of one part of the carbonate to 5250 of water; two of these had almost every tentacle inflected, the third had about half the tentacles and the fourth about one-third inflected; and all the glands were blackened. Another leaf was placed in the same quantity of a solution of one part to 7000 of water, and in $1 \mathrm{hr}$. $16 \mathrm{~m}$. every single tentacle was well inflected, and all the glands blackened. Six leaves were immersed, each in thirty minims (1.774 ml.) of a solution of one part to 4375 of water, and the glands were all blackened in $31 \mathrm{~m}$. All six leaves exhibited some slight inflection, and one was strongly inflected. Four leaves were then immersed in thirty minims of a solution of one part to 8750 of water, so that each leaf received the $\frac{1}{320}$ of a grain ( $2025 \mathrm{mg}$.). Only one became strongly inflected; but all the glands on all the leaves were of so dark a red after one hour as almost to deserve to be called black, whereas this did not occur with the leaves which were at the same time immersed in water; nor did water produce this effect on any other occasion in nearly so short a time as an hour. These cases of the simultaneous darkening or blackening of the glands from the action of weak solutions are important, as they show that all the glands absorbed tho carbonate within the same time, which fact indeed there was not the least reason to doubt. So again, whonever all the 
tentacles become inflected within the same time, we have evidence, as before remarked, of simultaneous absorption. I did not count the number of glands on these four leaves; but as they were fine ones, and as we know that the average number of glands on thirty-one leaves was 192, we may safely assume that each bore on an average at least 170; and if so, each blackened gland could have absorbed only $\frac{1}{5+400}$ of a grain ( $\cdot 00119 \mathrm{mg}$.$) of the carbonate.$

A large number of trials had been previously made with solutions of one part of the nitrate and phosphate of ammonia to 43750 of water (i.e. one grain to 100 ounces), and these were found highly efficient. Fourteen leaves were therefore placed, each in thirty minims of a solution of one part of the carbonate to the above quantity of water; so that each leaf received $\frac{1}{1600}$ of a grain (.0405 mg.). The glands were not much darkened. Ten of the leaves were not affected, or only very slightly so. Four, however, were strongly affected; the first having all the tentacles, except forty, inflected in $47 \mathrm{~m}$.; in $6 \mathrm{hrs}$. $30 \mathrm{~m}$. all except eight; and after $4 \mathrm{hrs}$. the blade itself. The second leaf after $9 \mathrm{~m}$. had all its tentacles except nine inflected; after $6 \mathrm{hrs}$. $30 \mathrm{~m}$. these nine were sub-inflected; the blade having become much inflected in $4 \mathrm{hrs}$. The third leaf after $1 \mathrm{hr} .6 \mathrm{~m}$. had all but forty tentacles inflected. The fourth, after $2 \mathrm{hrs} .5 \mathrm{~m}$., had about half its tentacles and after 4 hrs. all but forty-five inflected. Leaves which were immersed in water at the same time were not at all affected, with the exception of one; and this not until 8 hrs. had elapsed. Hence there can be no doubt that a highly sensitive leaf, if immersed in a solution, so that all the glands are enabled to absorb, is acted on by $\frac{1}{1600}$ of a grain of the carbonate. Assuming that the leaf, which was a large one, and which had all its tentacles excepting eight inflected, bore 170 glands, each gland could have absorbed only $\frac{1}{268500}$ of a grain ( $\cdot 00024 \mathrm{mg}$.$) ; yet this sufficed to act on each of the 162$ tentacles which were inflected. But as only four out of the above fourteen leaves were plainly affected, this is nearly the minimum dose which is efficient.

Aggregation of the Protoplasm from the Action of Carbonate of Ammonia.-I have fully described in the third chapter the remarkable effects of moderately strong doses of this salt in causing the aggregation of the protoplasm within the cells of the glands and tentacles; and here my object is merely to show what small doses suffice. A leaf was immersed in twenty minims $(1.183 \mathrm{ml}$.) of a solution of one part to 1750 of water, 
and another leaf in the same quantity of a solution of one part to 3062 ; in the former case aggregation occurred in $4 \mathrm{~m}$., in the latter in $11 \mathrm{~m}$. A leaf was then immersed in twenty minims of a solution of one part to 4375 of water, so that it received $\frac{1}{2+0}$ of a grain ( $27 \mathrm{mg}$.) ; in $5 \mathrm{~m}$. there was a slight change of colour in the glands, and in $15 \mathrm{~m}$. small spheres of protoplasm were formed in the cells beneath the glands of all the tentacles. In these cases there could not be a shadow of a doubt about the action of the solution.

A solution was then made of one part to 5250 of water, and I experimented on fourteen leaves, but will give only a few of the cases. Eight young leaves were selected and examined with care, and they showed no trace of aggregation. Four of these were placed in a drachm $(3.549 \mathrm{ml}$.) of distilled water; and four in a similar vessel, with a drachm of the solution. After a time the leaves were examined under a high power, being taken alternately from the solution and the water. The first leaf was taken out of the solution after an immersion of $2 \mathrm{hrs} .40 \mathrm{~m}$., and the last leaf out of the water after $3 \mathrm{hrs} .50 \mathrm{~m}$; the examination lasting for $1 \mathrm{hr} .40 \mathrm{~m}$. In the four leaves out of the water there was no trace of aggregation except in one specimen, in which a very few, extremely minute spheres of protoplasm were present beneath some of the round glands. All the glands were translucent and red. The four leaves which had been immersed in the solution, besides being inflected, presented a widely different appearance; for the contents of the cells of every single tentacle on all four leaves were conspicuously aggregatid; the spheres and elongated masses of protoplasm in many cases extending halfway down the tentacles. All the glands, both those of the central and exterior tentacles, were opaque and blackened; and this shows that all had absorbed some of the carbonate. These four leaves were of very nearly the same size, and the glands were counted on one and found to be 167 . This being the case, and the four leaves having been immersed in a drachm of the solution, each gland could have received on an average only $\frac{1}{6+1} \overline{2} 8$ of a grain ( $.001009 \mathrm{mg}$.) of the salt; and this quantity sufficed to induce within a short time conspicuous aggregation in the cells beneath all the glands.

A vigorous but rather small red leaf was placed in six minims of the same solution (viz. one part to 5250 of water), so that it received $\frac{1}{960}$ of a grain ( $0675 \mathrm{mg}$.). In $40 \mathrm{~m}$. the glands appeared rather darker; and in $1 \mathrm{hr}$. from four to six spheres of protoplasm were formed in the cells beneath the glands of all the tentacles. I did not count the tentacles, but we may 
safely assume that there were at least 140 ; and if so, each gland could have received only the $\frac{x}{134+0 \overline{0}}$ of a grain, or -0 $0048 \mathrm{mg}$.

A weaker solution was then made of one part to 7000 of water, and four leaves were immersed in it; but I will give only one case. A leaf was placed in ten minims of this solution; after $1 \mathrm{hr} .37 \mathrm{~m}$. the glands became somewhat darker, and the cells beneath all of them now contained many spheres of aggregated protoplasm. This leaf received $\frac{1}{768}$ of a grain, and bore 166 glands. Each gland could, therefore, have received only $\frac{1}{12748 \delta}$ of a grain ( $\cdot 000507 \mathrm{mg}$.) of the carbonate.

Two other experiments are worth giving. A leaf was immersed for 4 hrs. $15 \mathrm{~m}$. in distilled water, and there was no aggregation; it was then placed for $1 \mathrm{hr} .15 \mathrm{~m}$. in a little solution of one part to 5250 of water; and this excited well-marked aggregation and inflection. Another leaf, after having been immersed for 21 hrs. $15 \mathrm{~m}$. in distilled water, had its glands blackened, but there was no aggregation in the cells beneath them; it was then left in six minims of the same solution, and in $1 \mathrm{hr}$. there was much aggregation in many of the tentacles; in 2 hrs. all the tentacles (146 in number) were affected-the aggregation extending down for a length equal to half or the whole of the glands. It is extremely improbable that these two leaves would have undergone aggregation if they had been left for a little longer in the water, namely for $1 \mathrm{hr}$. and $1 \mathrm{hr} .15 \mathrm{~m}$., curing which time they were immersed in the solution; for the process of aggregation seems invariably to supervene slowly and very gradually in water.

Summary of the Results with Carbonate of Ammonia.The roots absorb the solution, as shown by their changed colour, and by the aggregation of the contents of their cells. The vapour is absorbed by the glands; these are blackened, and the tentacles are inflected. The glands of the disc, when excited by a half-minim drop $(\cdot 0296 \mathrm{ml}$.$) , containing \frac{1}{960}$ of a grain $(.0675 \mathrm{mg}$.), transmit a motor impulse to the exterior tentacles, causing them to bend inwards. A minute drop, containing $\frac{1}{14+00}$ of a grain (.00445 mg.), if held for a few seconds in contact with a gland, soon causes the tentacle bearing it to be inflected. If a leaf is left 
immersed for a few hours in a solution, and a gland absorbs the $\frac{1}{134+00}$ of a grain (.00048 mg.), its colour becomes darker, though not actually black; and the contents of the cells beneath the gland are plainly aggregated. Lastly, under the same circumstances, the absorption by a gland of the $\frac{1}{26800}$ of a grain ( $\cdot 00024 \mathrm{mg}$.) suffices to excite the tentacle bearing this gland into movement.

\section{Nitrate of Amionia.}

With the salt I attended only to the inflection of the leares, for it is far less efficient than the carbonate in causing aggregation, although considerably more potent in causing inflection. I experimented with half-minims $(-0296 \mathrm{ml}$.) on the discs of fiftytwo leaves, but will give only a few cases. A solution of one part to 109 of water was too strong, causing little inflection, and after 24 hrs. killing, or nearly killing, four out of six leaves which were thus tried; each of which received the $\frac{1}{240}$ of a grain (or $27 \mathrm{mg}$.). A solution of one part to 218 of water acted most energetically, causing not only the tentacles of all the leares, but the blades of some, to be strongly inflected. Fourteen leaves were tried with drops of a solution of one part to 875 of water, so that the disc of each received the $\frac{1}{1920}$ of a grain (.0337 mg.). Of these leaves, seven were very strongly acted on, the edges being generally inflected; two were moderately acted on ; and five not at all. I subsequently tried three of these latter five leares with urine, saliva, and mucus, but they were only slightly affected; and this proves that they were not in an active condition. I mention this fact to show how necessary it is to experiment on several leaves. Two of the leaves, which were well inflected, re-expanded after 51 hrs.

In the following experiment I happened to select very sensitive leaves. Half-minims of a solution of one part to 1094 of water (i.e. $1 \mathrm{gr}$. to $2 \frac{1}{2}$ oz.) were placed on the dises of nine leaves, so that each received the $\frac{1}{2400}$ of a grain $(\cdot 027 \mathrm{mg}$.). Three of them had their tentacles strongly inflected and their blades curled inwards; five were slightly and somewhat doubtfully affected, having from three to eight of their exterior tentacles inflected: one leaf was not at all affected, yet was afterwards acted on by saliva. In six of these cases, a trace of action was perceptible in 
7 hrs., but the full effect was not produced until from 24 hrs. to 30 hrs. had elapsed. Two of the leaves, which were only slightly inflected, re-expanded after an additional interval of $19 \mathrm{hrs}$.

Half-minims of a rather weaker solution, viz. of one part to 1312 of water ( 1 gr. to 3 oz.) were tried on fourteen leaves; so that each received $\frac{1}{2 \mathrm{~s}^{\mathrm{s} 0}}$ of a grain ( $0225 \mathrm{mg}$.), instead of, as in the last experiment, $\frac{1}{2400}$ of a grain. The blade of one was plainly inflected, as were six of the exterior tentacles; the blade of a second was slightly, and two of the exterior tentacles well, inflected, all the other tentacles being curled in at right angles to the disc; three other leaves had from five to eight tentacles inflected; five others only two or three, and occasionally, though very rarely, drops of pure water cause this much action; the four remaining leaves were in no way affected, yet three of them, when subsequently tried with urine, became greatly inflected. In most of these cases a slight effect was perceptible in from $6 \mathrm{hrs}$. to $7 \mathrm{hrs}$, but the full effect was not produced until from $24 \mathrm{hrs}$. to $30 \mathrm{hrs}$. had elapsed. It is obvious that we have bere reached very nearly the minimum amount, which, distributed between the glands of the disc, acts on the exterior tentacles; these having themselves not receired any of the solution.

In the next place, the viscid secretion round three of the exterior glands was touched with the same little drop ( $\frac{1}{20}$ of a minim) of a solution of one part to 437 of water; and after an interval of $2 \mathrm{hrs} .50 \mathrm{~m}$. all three tentacles were well inflected. Each of these glands could have received only the $\frac{1}{2 \mathrm{~s} 800}$ of a grain, or $00225 \mathrm{mg}$. A little drop of the same size and strength was also applied to four other glands, and in $1 \mathrm{hr}$. two became inflected, whilst the other two never moved. We here see, as in the case of the half-minims placed on the dises, that the nitrate of ammonia is more potent in causing inflection than the carbonate; for minute drops of the latter salt of this strength produced no effect. I tried minute drops of a still weaker solution of the nitrate, viz. one part to 875 of water, on twenty-one glands, but no effect whatever was produced, except perhaps in one instance.

Sixty-thrce leaves were immersed in solutions of various strengths; other leaves being immersed at the same time in the same pure water used in making the solutions. The results are so remarkable, though less so than with phosphate of ammonia, that I must describe the experiments in detail, but I will give only a few. In speaking of the successive periods when inflection occurred, I always reckon from the time of first immersion. 
Having made some preliminary trials as a guide, five leaves were placed in the same little ressel in thirty minims of a solution of one part of the nitrate to $787 j$ of water ( $1 \mathrm{gr}$. to $18 \mathrm{oz}$.$) ;$ and this amount of fluid just sufficed to cover them. After $2 \mathrm{hrs} .10 \mathrm{~m}$. three of the leaves were considerably inflected, and the other two moderately. The glands of all became of so dark a red as almost to deserve to be called black. After $8 \mathrm{hrs}$. four of the leares had all their tentacles more or less inflected; whilst the fifth, which I then perceived to be an old leaf, had only thirty tentacles inflected. Next morning, after 23 hrs. 40 m., all the leaves were in the same state, excepting that the old leaf had a few more tentacles inflected. Five leaves which had been placed at the same time in water were observed at the same intervals of time; after 2 hrs. $10 \mathrm{~m}$. two of them had four, one had seven, one had ten, of the long-headed marginal tentacles, and the fifth had four round-headed tentacles, inflected. After 8 hrs. there was no change in these leaves, and after 24 hrs. all the marginal tentacles had re-expanded; but in one leaf, a dozen, and in a second leaf, half a dozen, submarginal tentacles had become inflected. As the glands of the five leaves in the solution were simultaneously darkened, no doubt they had all absorbed a nearly equal amount of the salt: and as $\frac{1}{288}$ of a grain was given to the five leaves together, each got $\frac{1}{1440}$ of a grain $(\cdot 045 \mathrm{mg}$.). I did not count the tentacles on these leaves, which were moderately fine ones, but as the average number on thirty-one leaves was 192 , it would be safe to assume that each bore on an arerage at least 160 . If so, each of the darkened glands could hare received only $\frac{1}{230+00}$ of a grain of the nitrate; and this caused the inflection of a great majority of the tentacles.

This plan of immersing several leaves in the same vessel is a bad one, as it is impossible to feel sure that the more vigorous leaves do not rob the weaker ones of their share of the salt. The glands, moreover, must often touch one another or the sides of the vessel, and movement may have been thus excited; but the corresponding leaves in water, which were little inflected, though rather more so than commonly occurs, were exposed in an almost equal degree to these same sources of error. I will, therefore, give only one other experiment made in this manner, though many were tried and all confirmed the foregoing and following results. Four leares rere placed in forty minims of a solution of one part to 10,500 of water; and assuming that they absorber equally, each leaf received $\frac{1}{1152}$ of a grain $(\cdot 0562 \mathrm{mg}$.). After $1 \mathrm{hr} .20 \mathrm{~m}$. many of the tentacles on all four leares were somewhat inflected. After 
5 hrs. $30 \mathrm{~m}$. two leaves had all their tentacles inflected; a third leaf all except the extreme marginals, which seemed old and torpid; and the fourth a large number. After 21 hrs. every single tentacle, on all four leaves, was closely inflected. Of the four leaves placed at the same time in water, one had, after 5 hrs. $45 \mathrm{~m}$., five marginal tentacles inflected; a second, ten; a third, nine marginals and submarginals; and the fourth, twelve, chiefly submarginals, inflected. After $21 \mathrm{hrs}$. all these marginal tentacles re-expanded, but a few of the submarginals on two of the leaves remained slightly curved inwards. The contrast was wonderfully great between these four leaves in water and those in the solution, the latter having every one of their tentacles closely inflected. Making the moderate assumption that each of these leaves bore 160 tentacles, each gland could have absorbed only $\frac{1}{184320}$ of a grain (.000351 mg.). This experiment was repeated on three leaves with the same relative amount of the solution; and after 6 hrs. $15 \mathrm{~m}$. all the tentacles except nine, on all three leaves taken together, were closely inflected. In this case the tentacles on each leaf were counted, and gave an average of 162 per leaf.

The following experiments were tried during the summer of 1873 , by placing the leaves, each in a separate watch-glass and pouring over it thirty minims $(1.775 \mathrm{ml}$.) of the solution; other leaves being treated in exactly the same manner with the doubly distilled water used in making the solutions. The trials above given were made several years before, and when I read over my notes, I could not believe in the results; so I resolved to begin again with moderately strong solutions. Six leaves were first immersed, each in thirty minims of a solution of one part of the nitrate to 8750 of water ( $1 \mathrm{gr}$. to $20 \mathrm{oz}$.), so that each received $\frac{1}{320}$ of a grain ( $2025 \mathrm{mg}$.). Before $30 \mathrm{~m}$. had elapsed, four of these leaves were immensely, and two of them noderately, inflected. The glands were rendered of a dark red. The four corresponding leaves in water were not at all affected until $6 \mathrm{hrs}$. had elapsed, and then only the short tentacles on the borders of the disc; and their inflection, as previously explained, is never of any significance.

Four leaves were immersed, each in thirty minims of a solution of one part to 17,500 of water ( $1 \mathrm{gr}$. to $40 \mathrm{oz}$.), so that each received $\frac{1}{640}$ of a grain ( $101 \mathrm{mg}$.); and in less than $45 \mathrm{~m}$. three of them had all their tentacles, except from four to ten, inflected; the blade of one being inflected after $6 \mathrm{hrs}$., and the blade of a second after $21 \mathrm{hrs}$. The fourth leaf was not at all affected. The glands of none were darkened. Of the corresponding leaves 
in water, only one had any of its exterior tentacles, namely five, inflected; after $6 \mathrm{hrs}$. in one case, and after $21 \mathrm{hrs}$. in two other cases, the short tentacles on the borders of the disc formed a ring, in the usual manner.

Four leaves were immersed, each in thirty minims of a solution of one part to 43,750 of water ( 1 gr. to $100 \mathrm{oz}$.), so that each leaf got $\frac{1}{1600}$ of a grain (.0105 mg.). Of these, one was much inflected in $8 \mathrm{~m}$., and after 2 hrs. $7 \mathrm{~m}$. had all the tentacles, except thirteen, inflected. The second leaf, after $10 \mathrm{~m}$., had all except three inflected. The third and fourth were hardly at all affected, scarcely more than the corresponding leaves in water. Of the latter, only one was affected, this having two tentacles inflected, with those on the outer parts of the disc forming a ring in the usual manner. In the leaf which had all its tentacles except three inflected in $10 \mathrm{~m}$., each gland (assuming that the leaf bore 160 tentacles) could have absorbed only $\frac{1}{251200}$ of a grain, or $\cdot 0002: 58 \mathrm{mg}$.

Four leaves were separately immersed as before in a solution of one part to 131,250 of water ( $1 \mathrm{gr}$. to $300 \mathrm{oz}$.), so that each receired $\frac{1}{4800}$ of a grain, or $0135 \mathrm{mg}$. After $50 \mathrm{~m}$. one leaf had all its tentacles excopt sixteen, and after $8 \mathrm{hrs} .20 \mathrm{~m}$. all but fourteen, inflected. The second leaf, after $40 \mathrm{~m}$., had all but twenty inflected; and after $8 \mathrm{hrs} .10 \mathrm{~m}$. began to re-expand. The third, in 3 hrs. had about half its tentacles inflected, which legan to re-expand after 8 hrs. $15 \mathrm{~m}$. The fourth leaf, after 3 hrs. 7 m., had only twenty-nine tentacles more or less inflected. Thus three out of the four leaves were strongly acted on. It is clear that very sensitive leaves had been accidentally selected. The day moreover was hot. The four corresponding leares in water were likewise acted on rather more than is usual; for after $3 \mathrm{hrs}$. one had nine tentacles, another four, and another two, and the fourth none, inflected. With respect to the leaf of which all the tentacles, except sixteen, were inflected after $50 \mathrm{~m}$., each gland (assuming that the leaf bore 160 tentacles) could have absorbed only $\frac{1}{691^{2}} \overline{00}$ of a grain (.0000937 mg.), and this appears to be about the least quantity of the nitrate which suffices to induce the inflection of a single tentacle.

As negative results are important in confirming the foregoing positive ones, eight leaves were immersed as before, each in thirty minims of a solution of one part to 175,000 of water ( 1 gr. to $400 \mathrm{oz}$.), so that each received only $\frac{1}{6400}$ of a grain (.0101 mg.). This minute quantity produced a slight effect on only four of the eight leaves. One had fifty-six tentacles inflected after $2 \mathrm{hrs}$. $13 \mathrm{~m}$; ; a second, twenty-six inflected, or sub-inflected, after 
$38 \mathrm{~m}$.; a third, eighteen inflected, after $1 \mathrm{hr}$.; and a fourth, ten inflected, after $35 \mathrm{~m}$. The four other leaves were not in the least affected. Of the eight corresponding leaves in water, one had, after $2 \mathrm{hrs} .10 \mathrm{~m}$., nine tentacles, and four others from one to four long-headed tentacles, inflected; the remaining three being unaffected. Hence, the $\frac{1}{6400}$ of a grain given to a sensitive leaf during warm weather perhaps produces a slight effect; but we must bear in mind that occasionally water causes as great an amount of inflection as occurred in this last experiment.

Summary of the Results with Nitrate of Ammonia.The glands of the disc, when excited by a half-minim drop (.0296 ml.), containing $\frac{1}{2+00}$ of a grain of the nitrate $(.027 \mathrm{mg}$.), transmit a motor impulse to the exterior tentacles, causing them to bend inwards. A minute drop, containing $\frac{1}{28 \frac{1}{800}}$ of a grain (.00225 mg.), if held for a few - seconds in contact with a gland, causes the tentacle bearing this gland to be inflected If a leaf is left immersed for a few hours, and sometimes for only a few minutes, in a solution of such strength that each gland can absorb only the $\frac{1}{691200}$ of a grain (.0000937 mg.), this small amount is enough to excite each tentacle into movement, and it becomes closely inflected.

\section{Phosphate of Ammonia.}

This salt is more powerful than the nitrate, even in a greater degree than the nitrate is more powerful than the carbonate. This is shown by weaker solutions of the phosphate acting when dropped on the discs, or applied to the glands of the exterior tentacles, or when leaves are immersed. The difference in the power of these three salts, as tried in three different ways, supports the results presently to be 
given, which are so surprising that their credibility requires every kind of support. In 1872 I experimented on twelve immersed leaves, giving each only ten minims of a solution; but this was a bad method, for so small a quantity hardly covered them. None of these experiments will, therefore, be given, though they indicate that excessively minute doses are efficient. When I read over my notes, in 1873, I entirely disbelieved them, and determined to mako another set of experiments with scrupulous care, on the same plan as those made with the nitrate; namely by placing leaves in watch-glasses, and pouring over each thirty minims of the solution under trial, treating at the same time and in the same manner other leaves with the distilled water used in making the solutions. During 1873 , seventy-one leaves were thus tried in solutions of various strengths, and the same - number in water. Notwithstanding the care taken and the number of the trials made, when in the following year I looked merely at the results, without reading over my observations, I again thought that there must have been some error, and thirty-five fresh trials were made with the weakest solution; but the results were as plainly marked as before. Altogether, 106 carefully selected leaves were tried, both in water and in solutions of the phosphate. Hence, after the most anxious consideration, I can entertain no doubt of the substantial accuracy of my results.

Before giving my experiments, it may be well to premise that crystallised phosphate of ammonia, such as I used, contains 35.33 per cent. of water of erystallisation; so that in all the following trials the efficient elements formed only 64.67 per cent. of the salt used.

Extremely minute particles of the dry phosphate were placed 
with the point of a needle on the secretion surrounding several glands. These poured forth much secretion, were blackened, and ultimately died; but the tentacles moved only slightly. The dose, small as it was, evidently was too great, and the result was the same as with particles of the carbonate of ammonia.

Half-minims of a solution of one part to 437 of water were placed on the discs of three leaves and acted most energetically, causing the tentacles of one to be inflected in $15 \mathrm{~m}$., and the blades of all three to be much curved inwards in 2 hrs. $15 \mathrm{~m}$. Similar drops of a solution of one part to 1312 of water, ( $1 \mathrm{gr}$. to $3 \mathrm{oz}$.) were then placed on the discs of five leaves, so that each received the $\frac{1}{2880}$ of a grain ( $0225 \mathrm{mg}$.). After 8 hrs. the tentacles of four of them were considerably inflected, and after 24 hrs. the blades of three. After 48 hrs. all five were almost fully re-expanded. I may mention with respect to one of these leaves, that a drop of water had been left during the previous $24 \mathrm{hrs}$. on its disc, but produced no effect; and that this was hardly dry when the solution was added.

Similar drops of a solution of one part to 1750 of water ( $1 \mathrm{gr}$. to $4 \mathrm{oz}$.) were next placed on the discs of six leaves; so that each received $\frac{1}{38.0}$ of a grain (.0169 mg.); after $8 \mathrm{hrs}$. three of them had many tentacles and their blades inflected; two others had only a few tentacles slightly inflected, and the sixth was not at all affected. After $24 \mathrm{hrs}$. most of the leaves had a few more tentacles inflected, but one had begun to re-expand. We thus see that with the more sensitive leaves the $\frac{1}{3 \frac{1}{80}}$ of a grain, absorbed by the central glands, is enough to make many of the exterior tentacles and the blades bend, whereas the $\frac{1}{192} \overline{0}$ of a grain of the carbonate similarly given produced no effect; and $\frac{1}{2850}$ of a grain of the nitrate was only just sufficient to produce a well-marked effect.

A minute drop, about equal to $\frac{1}{20}$ of a minim, of a solution of one part of the phosphate to 875 of water, was applied to the secretion on three glands, each of which thus received only $\frac{1}{57600}$ of a grain ( $.00112 \mathrm{mg}$.), and all three tentacles became inflected. Similar drops of a solution of one part to 1312 of water ( $1 \mathrm{gr}$. to $3 \mathrm{oz}$.) were now tried on three leaves; a drop being applied to four glands on the same leaf. On the first leaf, three of the tentacles became slightly inflected in $6 \mathrm{~m}$., and re-expanded after 8 hrs. $45 \mathrm{~m}$. On the second, two tentacles became sub-inflected in $12 \mathrm{~m}$. And on the third all four tentacles were decidedly inflected in $12 \mathrm{~m}$.; they remained so for 8 hrs. $30 \mathrm{~m}$., but by the next morning were fully re-expanded. 
In this latter case each gland could have received only the $\frac{1}{115200}$ (or $000563 \mathrm{mg}$.) of a grain. Lastly, similar drops of a solution of one part to 1750 of water ( $1 \mathrm{gr}$. to $4 \mathrm{oz}$.) were tried on five leaves; a drop being applied to four glands on the same leaf. The tentacles on three of these leaves were not in the least affected; on the fourth leaf, two became inflected; whilst on the fifth, which happened to be a very sensitive one, all four tentacles were plainly inflected in $6 \mathrm{hrs}$. $15 \mathrm{~m}$.; but only one remained inflected after $24 \mathrm{hrs}$. I should, however, state that in this case an unusually large drop adhered to the head of the pin. Each of these glands could have received very little more than $\frac{x}{153600}$ of a grain (or 000423 ); but this small quantity sufficed to cause inflection. We must bear in mind that these drops were applied to the viscid secretion for only from 10 to 15 seconds, and we have good reason to believe that all the phosphate in the solution would not be diffused and absorbed in this time. We have seen under the same circumstances that the absorption by a gland of $\frac{1}{19^{2}} \overline{00}$ of a grain of the carbonate, and of $\frac{1}{57600}$ of a grain of the nitrate, did not cause the tentacle bearing the gland in question to be inflected; so that here again the phosphate is much more powerful than the other two salts.

We will now turn to the 106 experiments with immersed leaves. Having ascertained by repeated trials that moderately strong solutions were highly efficient, I commenced with sixteen leaves, each placed in thirty minims of a solution of one part to 43,750 of water ( $1 \mathrm{gr}$. to $100 \mathrm{oz}$.); so that each received $\frac{1}{1600}$ of a grain, or $01058 \mathrm{mg}$. Of these leaves, eleven had nearly all or a great number of their tentacles inflected in $1 \mathrm{hr}$., and the twelfth leaf in $3 \mathrm{hrs}$. One of the eleven had every single tentacle closely inflected in $50 \mathrm{~m}$. Two leaves out of the sixteen were only moderately affected, yet more so than any of those simultaneously immersed in water; and the remaining two, which were pale leaves, were hardly at all affected. Of the sixteen corresponding leaves in water, one liad nine tentacles, another six, and two others two tentacles inflected, in the course of 5 hrs. So that the contrast in appearance between the two lots was extremely great.

Eighteen leaves were immersed, each in thirty minims of a solution of one part to 87,500 of water ( $1 \mathrm{gr}$. to $200 \mathrm{oz}$.), so that each received $\frac{2}{3200}$ of a grain (.0202 mg.). Fourteen of these were strongly inflected within $2 \mathrm{hrs}$, and some of them within $15 \mathrm{~m}$; ; three out of the eighteen were only slightly affected, having twenty-one, nineteen, and twelve tentacles in- 
flected; and one was not at all acted on. By an accident only fifteen, instead of eighteen, leaves were immersed at the same time in water; these were observed for $24 \mathrm{hrs}$; one had six, another four, and a third two, of their outer tentacles inflected; the remainder being quite unaffected.

The next experiment was tried under very favourable circumstances, fort he day (July 8) was very warm, and I happened to have unusually fine leaves. Five were immersed as before in a solution of one part to 131,250 of water ( 1 gr. to $300 \mathrm{oz}$.), so that each received $\frac{1}{4800}$ of a grain, or $0135 \mathrm{mg}$. After are immersion of $25 \mathrm{~m}$. all five leaves were much inflected. After $1 \mathrm{hr} .25 \mathrm{~m}$. one leaf had all but eight tentacles inflected; the second, all but three; the third, all but five; the fourth, all but twenty-three; the fifth, on the other hand, never had more than twenty-four inflected. Of the corresponding five leaves in water, one had seven, a second two, a third ten, a fourth one, and a fifth none inflected. Let it be observed what a contrast is presented between these latter leaves and those in the solution. I counted the glands on the second leaf in the solution, and the number was 217; assuming that the three tentacles which did not become inflected absorbed nothing, we find that each of the 214 remaining glands could have absorbed only $\frac{1}{1027200}$ of a grain, or $0000631 \mathrm{mg}$. The third leaf bore 236 glands, and subtracting the five which did not become inflected, each of the remaining 231 glands could have absorbed only $\frac{1}{1108800}$ of a grain (or $0000584 \mathrm{mg}$.), and this amount sufficed to cause the tentacles to bend.

Twelve leaves were tried as before in a solution of one part to 175,000 of water ( 1 gr. to $400 \mathrm{oz}$.), so that èach leaf received $\frac{x}{6400}$ of a grain (.0101 mg.). My plants were not at the time in a good state, and many of the leaves were young and pale. Nevertheless, two of them had all their tentacles, except three or four, closely inflected in under $1 \mathrm{hr}$. Seven were considerably affected, some within $1 \mathrm{hr}$., and others not until $3 \mathrm{hrs}$, $4 \mathrm{hrs} .30 \mathrm{~m}$., and $8 \mathrm{hrs}$. had elapsed; and this slow action may be attributed to the leaves being young and pale. Of these nine leaves, four had their blades well inflected, and a fifth slightly so. The three remaining leaves were not affected. With respect to the twelve corresponding leaves in water, not one had its blade inflected; after from 1 to $2 \mathrm{hrs}$. one had thirteen of its outer tentacles inflected; a second six, and four others either one or two inflected. After $8 \mathrm{hrs}$. the outer tentacles did not become more inflected; whereas this occurred with the leaves in the solution. I record in my notes that 
after the $8 \mathrm{hrs}$. it was impossible to compare the two lots, and doubt for an instant the power of the solution.

Two of the above leaves in the solution had all their tentacles, except three and four, inflected within an hour. I counted their glands, and, on the same principle as before, each gland on one leaf could have absorbed only $\frac{1}{1164800}$, and on the other leaf only $\frac{1}{1+72000}$, of a grain of the phosphate.

Twenty leaves were immersed in the usual manner, each in thirty minims of a solution of one part to 218,750 of water ( $1 \mathrm{gr}$. to $500 \mathrm{oz}$.). So many leares were tried becanse I was then under the false impression that it was incredible that any weaker solution could produce an effect. Each leaf received $\frac{3}{\mathrm{soo0}}$ of a grain, or $0081 \mathrm{mg}$. The first eight leaves which I tried both in the solution and in water were either young and pale or too old; and the weather was not hot. They were hardly at all affected; nevertheless, it would be unfair to exclude them. I then waited until I got eight pairs of fine leares, and the weather was favourable; the temperature of the room where the leaves were immersed varying from $75^{\circ}$ to $81^{\circ}\left(23^{\circ} .8\right.$ to $27^{\circ} .2$ Cent.). In another trial with four pairs (included in the above twenty pairs), the temperature in my room was rather low, about $60^{\circ}\left(15^{\circ} .5\right.$ Cent.); but the plants had been kept for several days in a very warm greenhouse and thus rendered extremely sensitive. Special precautions were taken for this set of experiments; a chemist weighed for me a grain in an excellent balance; and fresh water, given me by Professor Frankland, was carefully measured. The leaves were selected from a large number of plants in the following manner: the four finest were immersed in water, and the next four finest in the solution, and so on till the twenty pairs were complete. The water specimens were thus a little favoured, but they did not undergo more inflection than in the previous cases, comparatively with those in the solution.

Of the twenty leares in the solution, eleven became inflected within $40 \mathrm{~m}$; ; eight of them plainly and three rather doubtfully; but the latter had at least twenty of their outer tentacles inflected. Owing to the weakness of the solution, inflection occurred, except in No. 1, much more slowly than in the previous trials. The condition of the eleven leaves which were considerably inflected will now be given at stated intervals, always reckoning from the time of immersion :-

(1) After only $8 \mathrm{~m}$. a large number of tentacles inflected, and after $17 \mathrm{~m}$. all but fifteen; after 2 hrs. all but eight in- 
flected, or plainly sub-inflected. After $4 \mathrm{hrs}$. the tentacles began to re-expand, and such prompt re-expansion is unusual; after $7 \mathrm{hrs} .30 \mathrm{~m}$. they were almost fully re-expanded.

(2) After $39 \mathrm{~m}$. a large number of tentacles inflected; after 2 hrs. $18 \mathrm{~m}$. all but twenty-five inflected; after $4 \mathrm{hrs} .17 \mathrm{~m}$. all but sixteen inflected. The leaf remained in this state for many hours.

(3) After $12 \mathrm{~m}$. a considerable amount of inflection; after 4 hrs. all the tentacles inflecter except those of the two outer rows, and the leaf remained in this state for some time; after $23 \mathrm{hrs}$. began to re-expand.

(4) After $40 \mathrm{~m}$. much inflection; after $4 \mathrm{hrs} .13 \mathrm{~m}$. fully half the tentacles inflected; after 23 hrs. still slightly inflected.

(5) After $40 \mathrm{~m}$. much inflection; after 4 hrs. $22 \mathrm{~m}$. fully half the tentacles inflected; after 23 hrs. still slightly inflected.

(6). After $40 \mathrm{~m}$. some inflection; after 2 hrs. $18 \mathrm{~m}$. about twenty-eight outer tentacles inflected; after $5 \mathrm{hrs} .20 \mathrm{~m}$. about a third of the tentacles inflected; after 8 hrs. much re-expanded.

(7) After $20 \mathrm{~m}$. some inflection; after 2 hrs. a considerable number of tentacles inflected; after $7 \mathrm{hrs} .45 \mathrm{~m}$. luegan to re-expand.

(8) After $38 \mathrm{~m}$. twenty-eight tentacles inflected; after $3 \mathrm{hrs.}$ $45 \mathrm{~m}$. thirty-three inflected, with most of the submarginal tentacles sub-inflected; continued so for two days, and then partially re-expanded.

(9) After $38 \mathrm{~m}$. forty-two tentacles inflected; after $3 \mathrm{hrs}$. $12 \mathrm{~m}$. sixty-six inflected or sub-inflected; after $6 \mathrm{hrs} .40 \mathrm{~m}$. all but twenty-four inflected or sub-inflected; after 9 hrs. $40 \mathrm{~m}$. all but seventeen inflected; after 24 hrs. all but four inflected or sub-inflected, only a few being closely inflected; after 27 hrs. $40 \mathrm{~m}$. the blado inflected. The leaf remained in this state for two days, and then began to re-expand.

(10) After $38 \mathrm{~m}$. twenty-one tentacles inflected; after $3 \mathrm{hrs}$. $12 \mathrm{~m}$. forty-sis tentacles inflected or sub-inflected; after $6 \mathrm{hrs}$. $40 \mathrm{~m}$. all but seventeen inflected, though none closely; after 21 hrs. every tentacle slightly curved inwards ; after 27 hrs. $40 \mathrm{~m}$. blade strongly inflected, and so continued for two days, and then the tentacles and blado very slowly re-expanded.

(11) This fine dark red and rather old leaf, though not very large, bore an extraordinary number of tentacles (viz. 252), and behaved in an anomalous manner. After $6 \mathrm{hrs} .40 \mathrm{~m}$. only the short tentacles round the outer part of the disc were inflected, forming a ring, as so often occurs in from 8 to $24 \mathrm{hrs}$. with leaves both in water and the weaker solutions. But after $9 \mathrm{hrs}$. 
$40 \mathrm{~m}$. all the outer tentacles except twenty-five were inflected, as was the blade in a strongly marked manner. After $24 \mathrm{hrs}$. every tentacle except one was closely inflected, and the blade was completely doubled over. Thus the leaf remained for two days, when it began to re-expand. I may add that the three latter leaves (Nos. 9, 10, and 11) were still somerwat inflected after three days. The tentacles in but few of these eleven leaves became closely inflected within so short a time as in the previous experiments with stronger solutions.

We will now turn to the twenty corresponding leaves in water. Nine had none of their outer tentacles inflected; nine others had from one to three inflected; and these re-expanded after 8 hrs. The remaining two leaves were moderately affected; ono having six tentacles inflected in $34 \mathrm{~m}$.; the other twenty-threo inflected in $2 \mathrm{hrs} .12 \mathrm{~m}$.; and both thus remained for $24 \mathrm{hrs}$. None of these leaves had their blades inflected. So that the contrast between the twenty leaves in water and the twenty in the solution was very great, both within the first hour and after from 8 to $12 \mathrm{hrs}$. had elapsed.

Of the leaves in the solution, the glands on leaf No. 1, which in 2 hrs. had all its tentacles except eight inflected, were counted and found to be 202. Subtracting the eight, each gland could have received only the $\frac{1}{1552000}$ of a grain (·0000411 mg.) of the phosphate. Leaf No. 9 had 213 tentacles, all of which, with the exception of four, were inflected after 24 hrs., but none of them closely; the blade was also inflected; each gland could have received only the $\frac{7}{1672000}$ of a grain, or 0000387 mg. Lastly, leaf No. 11, which had after 24 hrs. all its tentacles, except one, closely inflected, as well as the blade, bere the unusually large number of 252 tentacles; and on the same principle as before, each gland could have absorbed only the $\overline{200} \div \overline{1} \frac{1}{000}$ of a grain, or $0000322 \mathrm{mg}$.

With respect to the following experiments, I must premise that the leaves, both those placed in the solutions and in water, were taken from plants which had been kept in a very warm greenhouse during the winter. They were thus rendered extremely sensitive, as was shown by water exciting them much more than in the previous experiments. Before giving my observations, it may be well to remind the reader that, judging from thirty-one fine leaves, the average number of tentacles is 192 , and that the outer or exterior ones, the movements of which are alone significant, are to the short ones on the disc in the proportion of about sixteen to nine. 
Four leaves were immersed as before, each in thirty minims of a solution of one part to 328,125 of water $(1 \mathrm{gr}$. to $750 \mathrm{oz}$.). Each leaf thus received $\frac{1}{12000}$ of a grain (.0054 mg.) of the salt; and all four were greatly inflected.

(1) After $1 \mathrm{hr}$. all the outer tentacles but one inflected, and the blade greatly so ; after $7 \mathrm{hrs}$. began to re-expand.

(2) After $1 \mathrm{hr}$. all the outer tentacles but eight inflected; after $12 \mathrm{hrs}$. all re-expanded.

(3) After $1 \mathrm{hr}$. much inflection; after $2 \mathrm{hrs} .30 \mathrm{~m}$. all the tentacles but thirty-six inflected; after $6 \mathrm{hrs}$. all but twenty-two inflected; after $12 \mathrm{hrs}$. partly re-expanded.

(4) After $1 \mathrm{hr}$. all the tentacles but thirty-two inflected; after 2 hrs. $30 \mathrm{~m}$. all but twenty-one inflected; after 6 hrs. almost re-expanded.

Of the four corresponding leares in water:-

(1) After $1 \mathrm{hr}$. forty-five tentacles inflected; but after $7 \mathrm{hrs}$. so many had re-expanded that only ten remained much inflected.

(2) After $1 \mathrm{hr}$. seven tentacles inflected; these wero almost re-expanded in 6 hrs.

(3) and (4) Not affected, except that, as usual, after 11 hr's. the short tentacles on the borders of the dise formed a ring.

There can, therefore, be no doubt about the efficiency of the above solution; and it follows as before that each gland of No. 1 could have absorbed only $\frac{1}{2412000}$ of a grain (0000268 mg.) and of No. 2 only $\frac{1}{2460000}$ of a grain (.0000263 mg.) of the phosphate.

Seven leares were immersed, each in thirty minims of a solution of one part to 437,500 of water ( 1 gr. to 1000 oz.). Each leaf thus received $\frac{1}{16000}$ of a grain (.00405 mg.). The day was warm, and the leaves wero very fine, so that all circumstances were favourable.

(1) After $30 \mathrm{~m}$. all the outer tentacles except fivo inflected, and most of them closely; after $1 \mathrm{hr}$. blade slightly inflected; after 9 hrs. $30 \mathrm{~m}$. began to re-expand.

(2) After $33 \mathrm{~m}$. all the outer tentacles but twenty-five inflected, and blade slightly so; after $1 \mathrm{hr} .30 \mathrm{~m}$. blade strongly inflected and remained so for $21 \mathrm{hrs}$; ; but some of the tentacles had then re-expanded.

(3) After $1 \mathrm{hr}$. all but twelve tentacles inflected; after 2 hrs. $30 \mathrm{~m}$. all but nine inflected; and of the inflected tentacles all excepting four closely; blade slightly inflected. After $8 \mathrm{hrs.}$ blade quite doubled up, and now all the tentacles excepting 
eight closely inflected. The leaf remained in this state for two days.

(4) After 2 hrs. $20 \mathrm{~m}$. only fifty-nine tentacles inflected ; but after $5 \mathrm{hrs}$. all the tentacles closely inflected excepting two which were not affected, and eleven which were only sub-inflected; after $7 \mathrm{hrs}$. blado considerably inflected; after $12 \mathrm{hr}$. much re-expansion.

(5) After 4 hrs. all the tentacles but fourteen inflected; after 9 hrs. $30 \mathrm{~m}$. beginning to re-expand.

(6) After $1 \mathrm{hr}$. thirty-six tentacles inflected; after $5 \mathrm{hrs}$. all but fifty-four inflected; after $12 \mathrm{hrs}$. considerable re-expansion.

(7) After 4 hrs. $30 \mathrm{~m}$. only thirty-five tentacles inflected or sub-inflected, and this small amount of inflection never increased.

Now for the seven corresponding leaves in water:-

(1) After 4 hrs. thirty-eight tentacles inflected; but after 7 hirs. these, with the exception of six, re-expanded.

(2) After 4 hrs. $20 \mathrm{~m}$. twenty inflected; these after 9 hrs. partially re-expanded.

(3) After 4 hrs. five inflected, which began to re-expand after 7 lirs.

(4) After 24 hrs. one inflected.

(5), (6) and (7) Not at all affected, though observed for 21 hrs., excepting the short tentacles on the borders of the disc, which as usual formed a ring.

A comparison of the leaves in the solution, especially of the first five or even six on the list, with those in the water, after $1 \mathrm{hr}$. or after $4 \mathrm{hrs}$, and in a still more marked degrec after 7 hrs. or 8 hrs., could not leave the least doubt that the solution had produced a great effect. This was shown not only by the rastly greater number of inflected tentacles, but by the degree or closeness of their inflection, and by that of their blades. Yet each gland on leaf No. 1 (which bore 2555 glands, all of which, excepting five, were inflected in $30 \mathrm{~m}$.) could not have received more than one-four-millionth of a grain ( $\cdot 0000162$ mg.) of the salt. Again, each gland on leaf No. 3 (which bore 233 glands, all of which, except nine, were inflected in $2 \mathrm{hrs.} 30 \mathrm{~m}$.) conld have received at most only the $\frac{1}{358 \pm 000}$ of a grain, or $\cdot 0000181 \mathrm{mg}$.

Four leaves were immersed as before in a solution of one part to 656,250 of water ( $1 \mathrm{gr}$. to $1500 \mathrm{oz}$.) ; but on this occasion I happened to select leaves which were very little sensitive, as on other occasions I chanced to select unusually sensitive leaves. The leaves were not more affected after 12 hrs. than 
the four corresponding ones in water; but after 24 hr's. they were slightly more inflected. Such evidence, however, is not at all trustworthy.

Twelve leaves were immersed, each in thirty minims of a solution of one part to $1,312,500$ of water ( $1 \mathrm{gr}$. to $3000 \mathrm{oz}$.); so that each leaf received $\frac{1}{48000}$ of a grain (.00135 mg.). The leaves were not in very good condition; four of them were too old and of a dark red colour; four were too pale, yet one of these latter acted well; the four others, as far as could be told by the eye, seemed in excellent condition. The result was as follows:-

(1) This was a pale leaf; after $40 \mathrm{~m}$. about thirty-eight tentacles inflected; after 3 hrs. $30 \mathrm{~m}$. the blade and many of the outer tentacles inflected; after $10 \mathrm{hrs} .15 \mathrm{~m}$. all the tentacles but seventeen inflected, and the blade quite doubled up; after 24 hrs. all the tentacles but ten more or less inflected. Most of them were closely inflected, but twenty-five were only subinflected.

(2) After $1 \mathrm{hr} .40 \mathrm{~m}$. twenty-five tentacles inflected; after $6 \mathrm{hrs}$. all but twenty-one inflected; after $10 \mathrm{hrs}$. all but sixteen more or less inflected; after 24 hrs. re-expanded.

(3) After $1 \mathrm{hr} .40 \mathrm{~m}$. thirty-five inflected; after 6. hrs. " $几$ large number" (to quote my own memorandum) inflected, but from want of time they were not counted; after 24 hrs. re: expanded.

(4) After $1 \mathrm{hr} .40 \mathrm{~m}$. about thirty inflected; after $6 \mathrm{hr}$. "a large number all round the leaf" inflected, but they were not counted; after 10 hrs. began to re-expand.

(5) to (12) These were not more inflected than leaves often -are in water, having respectively $16,8,10,8,4,9,14$, and 0 tentacles inflected. Two of these leaves, however, were remarkable from having their blades slightly inflected after $6 \mathrm{hrs}$.

With respect to the twelve corresponding leaves in water, (1) had, after $1 \mathrm{hr} .35 \mathrm{~m}$., fifty tentacles inflected, but after $11 \mathrm{hrs}$. only twenty-two remained so, and these formed a group, with the blade at this point slightly inflected. It appeared as if this leaf had been in some manner accidentally excited, for instance by a particle of animal matter which was dissolved by the water. (2) After $1 \mathrm{hr} .45 \mathrm{~m}$. thirty-two tentacles inflected, but after $5 \mathrm{hrs} .30 \mathrm{~m}$. only twenty-five inflected, and these after $10 \mathrm{hrs}$. all re-expanded; (3) after $1 \mathrm{hr}$. twenty-five inflected, which after 10 hrs. $20 \mathrm{~m}$. were all re-expanded; (4) and (5) after 1 hr. $35 \mathrm{~m}$. six and seven tentacles inflected, which re-expanded after 11 hrs.; (6), (7) and (8) from one to three inflected, which 
soon re-expanded; (9), (10), (11) and (12) none inflected, though observed for twenty-four liours.

Comparing the states of the twelve leaves in water with those in the solution, there could be no doubt that in the latter a largernumber of tentacles were inflected, and these to a greater degree ; but the evidence was by no means so clear as in the former experiments with stronger solutions. It deserves attention that the inflection of four of the leaves in the solution went on increasing during the first 6 hrs., and with some of them for a longer time; whereas in the water the inflection of the three leaves which were the most affected, as well as of all the others, began to decrease during this same interval. It is also remarkable that the blacles of three of the leaves in the solution were slightly inflected, and this is a most rare event with leaves in water, though it occurred to a slight extent in one (No. 1), which seemed to have been in some manner accidentally excited. All this shows that the solution produced some effeet, though less and at a much slower rate than in the previous cases. The small effect produced may, howerer, be accounted for in large part by the majority of the leaves having been in a poor condition.

Of the leares in the solution, No. 1 bore 200 glands and received $\frac{1}{45000}$ of a grain of the salt. Subtracting the seventeen tentacles which were not inflected, each gland could have absorbed only the $\frac{1}{878 \div 000}$ of a grain (-00000738 mg.). This amount caused the tentacle bearing each gland to bo greatly inflected. The blade was also inflected.

Lastly, eight leaves were immersed, each in thirty minims of a solution of one part of the phosphate to $21,875,000$ of water ( $1 \mathrm{gr}$. to $5000 \mathrm{oz}$.). Each leaf thus received $\frac{1}{\mathrm{~s} 00 \overline{0}}$ of a grain of the salt, or $00081 \mathrm{mg}$. I took especial pains in selecting the finest leaves from the hot-house for immersion, both in the solution and the water, and almost all proved extremely sensitive. Beginning as before with those in the solution:-

(1) After 2 hrs. $30 \mathrm{~m}$. all the tentacles but twenty-two inflected, but some only sub-inflected; the blade much inflected; after 6 hrs. $30 \mathrm{~m}$. all but thirteen inflected, with the blade immensely inflected; and remained so for 48 hrs.

(2) No change for the first 12 hrs., but after 24 hrs. all the tentacles inflected, excepting those of the outermost row, of which only eleven were inflected. The inflection continued to increase, and after $48 \mathrm{hrs}$. all the tentacles except three were inflected, 
and most of them rather elosely, four or five being only subinflected.

(3) No change for the first $12 \mathrm{hrs}$; but after $24 \mathrm{hrs}$. all the tentacles excepting those of the outermost row were sub-inflected, with the blade inflected. After 36 hrs. blade strongly inflected, with all the tentacles, except three, inflected or sub-inflected. After $48 \mathrm{hrs}$. in the same state.

(4) to (8) These leaves, after $2 \mathrm{hrs} .30 \mathrm{~m}$., had respectively $32,17,7,4$, and 0 tentacles inflected, most of which, after a few hours, re-expanded, with the exception of No. 4, which retained its thirty-two tentacles inflected for $48 \mathrm{hrs}$.

Now for the eight corresponding leaves in water :-

(1) After $2 \mathrm{hrs} .40 \mathrm{~m}$. this had twenty of its outer tentacles inflected, five of which re-expanded after 6 hrs. $30 \mathrm{~m}$. After 10 hrs. $15 \mathrm{~m}$. a most unusual circumstance occurred, namely, the whole blade became slightly bowed towards the footstalk, and so remained for $48 \mathrm{hrs}$. The exterior tentacles, excepting those of the three or four outermost rows, were now also inflected to an unusual degree.

(2) to (8) These leaves, after $2 \mathrm{hrs} .40 \mathrm{~m}$., had respectively 42 , $12,9,8,2,1$, and 0 tentacles inflected, which all re-expanded within 24 hrs., and most of them within a much shorter time.

When the two lots of eight leaves in the solution and in the water were compared after the lapse of $24 \mathrm{hrs}$., they undoubtedly differed much in appearance. The few tentacles on the leaves in water which were inflected had after this interval reexpanded, with the exception of one leaf; and this presented the very unusual case of the blade being somewhat inflected, though in a degree hardly approaching that of the two leaves in the solution. Of these latter leaves, No. 1 had almost all its tentacles, together with its blade, inflected after an immersion of 2 hrs. $30 \mathrm{~m}$. Leaves No. 2 and 3 were affected at a much slower rate; but after from $24 \mathrm{hrs}$. to $48 \mathrm{hrs}$. almost all their tentacles were closely inflected, and the blade of one quite doubled up. We must therefore admit, incredible as the fact may at first appear, that this extremely weak solution acted on the more sensitive leaves; each of which received only the $\frac{1}{80000}$ of a grain (.00081 mg.) of the phosphate. Now, leaf No. 3 bore 178 tentacles, and subtracting the three which wero not inflected, each gland could have absorbed only the $\frac{1}{1400000}$ of a grain, or $00000463 \mathrm{mg}$. Leaf No. 1, which was strongly acted on within 2 hrs. $30 \mathrm{~m}$., and had all its outer tentacles, except thirteen, inflected within $6 \mathrm{hrs}$. $30 \mathrm{~m}$., bore 260 tentacles; and on the same principle as before, each gland could have 
absorbed only $\frac{1}{1976000}$ of a grain, or $00000328 \mathrm{mg}$; and this excessively minuto amount sufficed to cause all the tentacles bearing these glands to be greatly inflected. The blade was also inflected.

Summary of the Results with Phosphate of Ammonia.The glands of the disc, when excited by a half-minim drop (·0296 ml.), containing $\frac{1}{38 \div \overline{0}}$ of a grain ( 0169 $\mathrm{mg}$.) of this salt, transmit a motor impulse to the exterior tentacles, causing them to bend inwards. A minute drop, containing $\frac{1}{153600}$ of a grain (.000423 $\mathrm{mg}$.), if held for a fow seconds in contact with a gland, causes the tentacle bearing this gland to be inflected. If a leaf is left immersed for a few hours, and sometimes for a shorter time, in a solution so weak that each gland can absorb only the $\frac{1}{19760000}$ of a grain $(\cdot 00000328 \mathrm{mg}$.), this is enough to excite the tentacle into movement, so that it becomes closely inflected, as does sometimes the blade. In the general summary to this chapter a few remarks will be added, showing that the efficiency of such extremely minute doses is not so incredible as it must at first appear.

Sulphate of Ammonia.-The few trials made with this and the following five salts of ammonia were undertaken merely to ascertain whether they induced inflection. Half-minims of a solution of ono part of the sulphate of ammonia to 437 of water were placed on the discs of seven leares, so that each received $\frac{1}{960}$ of a grain, or $0675 \mathrm{mg}$. After $1 \mathrm{hr}$. the tentacles of five of them, as well as the blade of one, were strongly inflected. 'The leaves were not afterwards observed.

Citrate of Anmonia.-Half-minims of a solution of one part to 437 of water were placed on the dises of six leaves. In $1 \mathrm{hr}$. the short outer tentacles round the dises were a little inflected, with the glands on the dises blackened. After 3 hrs. $25 \mathrm{~m}$. one leaf had its blade inflected, but none of the exterior tentacles. All six leares remained in nearly the same state during the day, the submarginal tentacles, however, 
becoming more inflected. After $23 \mathrm{hrs.}$ three of the leaves had their blades somewhat inflected; and the submarginal tentacles of all considerably inflected, but in none were the two, three, or four outer rows affected. I have rarely seen cases like this, except from the action of a decoction of grass. The glands on the dises of the above leaves, instead of being almost black, as after the first hour, were now after 23 hrs. very pale. I next tried on four leaves half-minims of a weaker solution, of one part to 1312 of water $\left(1 \mathrm{gr}\right.$. to $3 \mathrm{oz}$.); so that each received $\frac{1}{2850}$ of a grain ( $0225 \mathrm{mg}$.). After 2 hrs. $18 \mathrm{~m}$. the glands on the disc were very dark-coloured; after 24 hrs. two of the leaves wcre slightly affected; the other two not at all.

Acetate of Ammonia.-Half-minims of a solution of cubout one part to 109 of water were placed on the dises of two leaves, both of which were acted on in 5 hrs. $30 \mathrm{~m}$., and after $23 \mathrm{hrs}$. had every single tentacle closely inflected.

Oxalate of Ammonia.-Half-minims of a solution of one part to 218 of water were placed on two leaves, which, after $7 \mathrm{hrs}$., became moderately, and after $23 \mathrm{hrs}$. strongly, inflected. Two other leaves were tried with a weaker solution of one part to 437 of water; one was strongly inflected in $7 \mathrm{hrs}$; the other not until $30 \mathrm{hrs}$. had elapsed.

Tartrate of Ammonia.-Half-minims of a solution of one part to 437 of water were placed on the discs of five leaves. In $31 \mathrm{~m}$. there was a trace of inflection in the exterior tentacles of some of the leaves, and this became more decided after $1 \mathrm{hr}$. with all the leaves; but the tentacles were never closely inflected. After 8 hrs. $30 \mathrm{~m}$. they began to re-expand. Next morning, after $23 \mathrm{hrs}$., all were fully re-expanded, excepting one which was still slightly inflected. The shortness of the period of inflection in this and the following case is remarkable.

Chloride of Ammonium. - Half-minims" of a solution of one part to 437 of water were placed on the dises of six leaves. A decided degree of inflection in the outer and submarginal tentacles was perceptible in $25 \mathrm{~m}$.; and this increased during the next three or four hours, but never became strongly marked. After only $8 \mathrm{hrs} .30 \mathrm{~m}$. the tentacles began to re-expand, and by the next morning, after $24 \mathrm{hrs}$., were fully re-expanded on four of the leaves, but still slightly inflected on two.

General Summary and Concluding Remarks on the Salts of Ammonia.-We have now seen that the nine 
salts of ammonia which were tried, all cause the inflection of the tentacles, and often of the blade of the leaf. As far as can be ascertained from the superficial trials with the last six salts, the citrate is the least powerful, and the phosphate certainly by far the most. The tartrate and chloride are remarkable from the short duration of their action. The relative efficiency of the carbonate, nitrate, and phosphate, is shown in the following table by the smallest amount which suffices to cause the inflection of the tentacles.

\begin{tabular}{|c|c|c|c|}
\hline Solutions, how applied. & $\begin{array}{l}\text { Carbonate of } \\
\text { Ammonia. }\end{array}$ & $\begin{array}{l}\text { Nitrate of } \\
\text { Ammonia. }\end{array}$ & $\begin{array}{c}\text { Phosphate of } \\
\text { Ammonia. }\end{array}$ \\
\hline $\begin{array}{l}\text { Placed on the glands of } \\
\text { the disc, so as to act } \\
\text { indirectly on the outer } \\
\text { tentacles. }\end{array}$ & $\begin{array}{c}\frac{1}{900} \text { of a } \\
\text { glain, or } \\
0675 \mathrm{mg} \text {. }\end{array}$ & $\begin{array}{l}\frac{1}{2100} \text { of a } \\
\text { grain, or } \\
.027 \mathrm{mg} .\end{array}$ & $\begin{array}{l}\frac{1}{3810} \text { of a } \\
\text { grain, or } \\
.0169 \mathrm{mg} \text {. }\end{array}$ \\
\hline $\begin{array}{l}\text { Applied for a few se- } \\
\text { conds directly to the } \\
\text { gland of an outer } \\
\text { tentacle }\end{array}$ & $\left\{\begin{array}{c}\frac{1}{\text { Hion }} \text { of a } \\
\text { grain, or } \\
.00 \pm \pm 5 \mathrm{mg} .\end{array}\right.$ & $\begin{array}{l}\frac{1}{28800} \text { of a } \\
\text { grain, or } \\
.0025 \mathrm{mg} \text {. }\end{array}$ & $\begin{array}{l}\frac{1}{153600} \text { of a } \\
\text { grain, or } \\
.000+23 \mathrm{mg} .\end{array}$ \\
\hline $\left.\begin{array}{l}\text { Leaf immersed, with } \\
\text { time allowed for each } \\
\text { gland to absorb all } \\
\text { that it can . . . . }\end{array}\right\}$ & $\begin{array}{l}\frac{1}{268 \times 00} \text { of a } \\
\text { grain, or } \\
00024 \mathrm{mg}\end{array}$ & $\begin{array}{c}\frac{1}{691200} \text { of a } \\
\text { grain, or } \\
.0000937 \mathrm{mg} .\end{array}$ & $\begin{array}{c}\frac{1}{19760000} \text { of a } \\
\text { grain, or } \\
.00000328 \mathrm{mg} .\end{array}$ \\
\hline $\begin{array}{l}\text { Amount absorbed by a } \\
\text { gland which suffices } \\
\text { to cause the aggre- } \\
\text { gation of the proto- } \\
\text { plasm in the adjoin- } \\
\text { ing cells of tho ten- } \\
\text { tacles. . . . }\end{array}$ & $\begin{array}{l}\frac{1}{13+100} \text { of a } \\
\text { grain, or } \\
00048 \mathrm{mg} .\end{array}$ & - & \\
\hline
\end{tabular}

From the experiments tried in these three different ways, we see that the carbonate, which contains 23.7 per cent. of nitrogen, is less efficient than the nitrate, which contains 35 per eent. The phosphate contains less nitrogen than either of these salts, namely, only 21.2 per cent., and yet is far more 
efficient; its power no doubt depending quite as much on the phosphorus as on the nitrogen which it contains. We may infer that this is the case, from the energetic manner in which bits of bone and phosphate of lime affect the leaves. The inflection excited by the other salts of ammonia is probably due solely to their nitrogen,-on the same principle that nitrogenous organic fluids act powerfully, whilst non-nitrogenous organic fluids are powerless. As such minute doses of the salts of ammonia affect the leaves, we may feel almost sure that Drosera absorbs and profits by the amount, though small, which is present in rain-water, in the same manner as other plants absorb these same salts by their roots.

The smallness of the doses of the nitrate, and more especially of the phosphate of ammonia, which cause the tentacles of immersed leaves to be infleeted, is perhaps the most remarkable fact recorded in this volume. When we see that much less than the millionth* of a grain of the phosphate, absorbed by a gland of one of the exterior tentacles, causes it to bend, it may be thought that the effects of the solution on the glands of the disc have been overlooked; namely, the transmission of a motor impulse from them to the exterior tentacles. No doubt the movements of the latter are thus aided; but the aid thus rendered must be insignificant; for we know that a drop containing as much as the $\frac{1}{3840}$ of a grain placed on the dise is only just able to cause the outer tentacles of a highly sensitive leaf to bend. It is cer-

* It is scarcely possible to realise what a million means. The best illustration which I have met with is that given by Mr. Croll, who says,-Take a narrow strip of paper $83 \mathrm{ft} .4$ in. in length, and stretch it along the wall of a large hall; then mark off at one end the tenth of an inch. This tenth will represent a hundred, and the entire strip a million. 
tainly a most surprising fact that the $\frac{1}{197600 n}$ of a grain, or in round numbers the one-twenty-millionth of a grain (.0000033 mg.), of the phosphate should affect any plant, or indeed any animal; and as this salt contains 35.33 per cent. of water of crystallisation, the efficient elements are reduced to $\frac{1}{30535126}$ of a grain, or in round numbers to one-thirty-millionth of a grain ( $.00000216 \mathrm{mg}$.). The solution, moreover, in these experiments was diluted in the proportion of one part of the salt to $2,187,500$ of water, or one grain to $5000 \mathrm{oz}$. The reader will perhaps best realiso this degree of dilution by remembering that $5000 \mathrm{oz}$. would more than fill a 31-gallon cask; and that to this large body of water one grain of the salt was adderl; only half a drachm, or thirty minims, of the solution being poured over a leaf. Yet this amount sufficed to cause the inflection of almost every tentacle, and often of the blade of the leaf.

I am well aware that this statement will at first appear incredible to almost every one. Drosera is far from rivalling the power of the spectroscope, but it can detect, as shown by the morements of its leares, a very much smaller quantity of the phosphate of ammonia than the most skilful chemist can of any substance.* My results were for a long time incredible

* When my first observations were made on the nitrate of ammonia, fourteen years ago, tho powers of the spectroseope had not been discovered; and I felt all the greater interest in the then unrivalled powers of Drosera. Now the spectroscope has altogether beaten Drosera; for accorrling to Bunsen and Kirchhoff probably less than one $\frac{1}{20000000}$ of a grain of sodium can be thus detceter (see Balfour Stewart,
'Treatise on Heat,' 2nd edit. 1871 , p. 228). With respect to ordinary chemical tests, I gather from Dr. Alfred Taylor's work on 'Poisons' that about $\frac{1}{4000}$ of a grain of arsenic, $\frac{1}{400}$ of a grain of prussic acid, $\frac{1}{100}$ of iodine, and $\frac{1}{2000}$ of tartarised antimony, ean be detected; but the power of detection depends much on the solutions under trial not being extremely weak. 
even to myself, and I anxiously sought for every source of error. The salt was in some cases weighed for me by a chemist in an excellent balance; and fresh water was measured many times with care. The observations were repeated during several years. Two of my sons, who were as incredulous as myself, compared several lots of leaves simultaneously immersed in the weaker solutions and in water, and declared that there could be no doubt about the difference in their appearance. I hope that some one may hereafter be induced to repeat my experiments; in this case he should select young and vigorous leaves, with the glands surrounded by abundant secretion. The leaves should be carefully cut off and Jaid gently in watch-glasses, and a measured quantity of the solution and of water poured over each. The water used must be as absolutely pure as it can be made. It is to be especially observed that the experiments with the weaker solutions ought to be tried after several days of very warm weather. Those with the weakest solutions should be made on plants which have been kept for a considerable time in a warm greenhouse, or cool hothouse; but this is by no means necessary for trials with solutions of moderate strength.

I beg the reader to observe that the sensitiveness or irritability of the tentacles was ascertained by three different methods-indirectly by drops placed on the disc, directly by drops applied to the glands of the outer tentacles, and by the immersion of whole leaves; and it was found by these three methods that the nitrate was more powerful than the carbonate, and the phosphate much more powerful than the nitrate; this result being intelligible from the difference in the amount of nitrogen in the first two salts, and from the presence of phosphorus in the third. It may aid the 
reader's faith to turn to the experiments with a solution of one grain of the phosphate to $1000 \mathrm{oz}$. of water, and he will there find decisive evidence that the one-four-millionth of a grain is sufficient to cause the inflection of a single tentacle. There is, therefore, nothing very improbable in the fifth of this weight, or the one-twenty-millionth of a grain, acting on the tentacle of a highly sensitive leaf. Again, two of the leaves in the solution of one grain to 3000 oz., and three of the leaves in the solution of one grain to 5000 oz., were affected, not only far more than the leaves tried at the same time in water, but incomparably more than any five leaves which can be picked out of the 173 observed by me at different times in water.

There is nothing remarkable in the mere fact of the one-twenty-millionth of a grain of the phosphate, dissolved in above two-million times.its weight of water, being absorbed by a gland. All physiologists admit that the roots of plants absorb the salts of ammonia brought to them by the rain; and fourteen gallons of rain-water contain* a grain of ammonia, therefore only a little more than twice as much as in the weakest solution employed by me. The fact which appears truly wonderful is, that the one-twentymillionth of a grain of the phosphate of ammonia (including less than the one-thirty-millionth of efficient matter), when absorbed by a gland, should induco some change in it, which leads to a motor impulse being transmitted down the whole length of the tentacle, causing the basal part to bend, often through an angle of above 180 degrees.

Astonishing as is this result, there is no sound reason

* Miller's 'Elements of Chemistry,' part ii. p. 107, 3rd edit. 1864. 
why we should reject it as incredible. Prof. Donders, of Utrecht, informs me that from experiments formerly made by him and Dr. De Ruyter, he inferred that less than the one-millionth of a grain of sulphate of atropine, in an extremely diluted state, if applied directly to the iris of a dog, paralyses the muscles of this organ. But, in fact, every time that we perceive an odour, we have evidence that infinitely smaller particles act on our nerves. When a dog stands a quarter of a mile to leeward of a deer or other animal, and perceives its presence, the odorous particles produce some change in the olfactory nerves; yet these particles must be infinitely smaller* than those of the phosphate of ammonia weighing the one-twenty-millionth of a grain. These nerves then transmit some influence to the brain of the dog, which leads to action on its part. With Drosera, the really marvellous fact is, that a plant without any specialised nervous system should be affected by such minute particles; but we have no grounds for assuming that other tissues could not be rendered as exquisitely susceptible to impressions from without if this were beneficial to the organism, as is the nervous system of the higher animals.

* My son, George Darwin, has calculated for me the diameter of a sphere of phosphate of ammonia (specific gravity $1 \cdot 678$ ), weighing the one-twenty-millionth of a grain, and finds it to be $\frac{1}{16 \pi}$ of an inch. Now, Dr. Klein informs me that the smallest Nicrococei, which are distinctly discernible under a power of 800 diameters, are estimated to be from $\cdot 0002$ to .0005 of a millimetre - that is, from $\frac{1}{50800}$ to $\frac{1}{127000}$ of an inch -in diameter. Therefore, an object between $\frac{1}{31}$ and $\frac{1}{77}$ of the size of a sphere of the phosphate of ammonia of the above weight ean be seen under a high power; and no one supposes that odorous particles, such as those emitted from the deer in the above illustration, could be seen under any power of the mieroscope. 


\section{CHAPTER VIII.}

The Effects of various Salts and Acids on the Leaves.

Salts of sodium, potassium, and other alkaline, earthy, and metallic salts - Summary on the action of these salts - Various acids Summary on their action.

Having found that the salts of ammonia were so powerful, I was led to investigate the action of some other salts.' It will be convenient, first, to give a list of the substances tried (including forty-nine salts and two metallic acids), divided into two columns, showing: those which cause inflection, and those which do not do so, or only doubtfully. My experiments were made by placing half-minim drops on the dises of leaves, or, more commonly, by immersing them in the solutions; and sometimes by both methods. A summary of the results, with some concluding remarks, will then be given. The action of various acids will afterwards be described.

\section{Salts causing Inflection.}

Salts not catsing Imflection.

(Arranged in Groups according to the Chemical Classification in Watts' 'Dictionary of Chemistry.')

Sodium earbonate, rapid inflection.

Sodium nitrate, rapid inflection.

Sodium sulphate, moderately rapid inflection.

Solium phosphate, rery rapid inflection.

Sudium citrate, rapid inflection.

Sodium oxalate, rapirl inflection.

Sodium chloride, moderately rapid inflection.
Potassium earbonate: slowly poisonous.

Potassium nitrate: sornewhat poisonous.

Potassium sulphate.

Potassium phosphate.

Potassium citrate.

Potassium chlorido. 


\section{Salts causing Inflection. Salts not causing Inflection.}

(Arranged in Groups according to the Chemical Classification in Watts' 'Dietionary of Chemistry.'

Sodium iodide, rather slow inflection.

Sodium bromide, moderately rapid inflection.

Potassium oxalate, slow and doubtful inflection.

Lithium nitrate, moderately rapid inflection.

Crsium chloride, rather slow inflection.

Silver nitrate, rapid inflection: quick poison.

Cadmium chloride, slow inflection. Mcreury perchloride, rapid inflection: quick poison.

Aluminium chloride, slow and doubtful inflection.

Gold chloride, rapid inflection : quick poison.

Tin chloride, slow inflection : poisonous.

Antimony tartrate, slow inflection: probably poisonous.

Arsenious acid, quick inflection : poisonous.

Iron chloride, slow inflection: probably poisonous.

Chromic acid, quick inflection : highly poisonous.

Copper chloride, rather slow inHlection: poísonous.

Nickel chloride, rapid inflection : probably poisonous.

Platinum chloride, rapid inflection: poisonous.
Potassium iodide, a slight and doubtful amount of inflection.

Potassium bromide.

Lithium acetate.

Rubidium chloride.

Calcium acetate.

Calcium nitrate.

Magnesium acetate.

Magnesium nitratė.

Magnesium chloride.

Magnesium sulphate.

Barium acetate.

Barium nitrate.

Strontium acetate.

Strontium nitrate.

Zinc chloride.

Aluminium nitrate, a trace of inflection.

Aluminium and potassium sul. phate.

Lead chlorido.

Manganese chloride.

Cobalt chloride. 
Sodium, Carbonate of (pure, given me by Prof. Hoffmann).Half-minims (.0296 ml.) of a solution of one part to 218 of water $(2 \mathrm{grs}$. to $1 \mathrm{oz}$.) were placed on the discs of twelve leares. Seven of these became well inflected; three had only two or three of their outer tentacles inflected, and the remaining two were quite unaffected. But the dose, though only the $\frac{1}{480}$ of a grain $(\cdot 135 \mathrm{mg}$.$) , was evidently too strong, for three of the$ seren well-infleeted leaves were killed. On the other hand, one of the seren, which had only. a few tentacles inflected, recxpanded and seemed quite healthy after 48 hrs. By employing a weaker solution (viz. one part to 437 of water, or $1 \mathrm{gr}$. to 1 oz.), doses of $\frac{1}{960}$ of a grain $(.0675 \mathrm{mg}$.) $\pi$ ere given to six leares. Some of these were affected in $37 \mathrm{~m}$.; and in $8 \mathrm{hrs}$. the outer tentacles of all, as well as the blades of two, were considerably inflected. After $23 \mathrm{hrs} .15 \mathrm{~m}$. the tentacles had almost re-expanded, but the blades of the two were still just perceptibly eurved inwards. After 48 hrs. all six leares wero fully re-expanded, and appeared perfectly healthy.

Three leaves were immersed, each in thirty minims of a solution of one part to 875 of water ( 1 gr. to $2 \mathrm{oz}$.), so that each received $\frac{1}{32}$ of a grain $(2.02 \mathrm{mg}$.); after $40 \mathrm{~m}$. the three $\pi$ ere much affected, and after $6 \mathrm{hrs} .45 \mathrm{~m}$. the tentacles of all and the blade of one closely inflected.

Sodium, Nitrate of (pure).-Half-minims of a solution of one part to 437 of water, containing $\frac{1}{960}$ of a grain (.0675 mg.), were placed on the dises of five leares. After $1 \mathrm{hr} .25 \mathrm{~m}$. tho tentacles of nearly all, and the blade of one, were somewhat inflected. The inflection continued to increase, and in $21 \mathrm{hrs}$. $15 \mathrm{~m}$. the tentacles and the blades of four of them were greatly affected, and the blade of the fifth to a slight extent. After an additional $24 \mathrm{hrs}$. the four leares still remained closely infleeted, whilst the fifth was beginning to expand. Four days after tho solution had been applied, two of the leares had quite, and ono had partially, re-cxpanded; whilst the remaining two remained closely inflected and appeared injured.

Three leaves wcre immersed, each in thirty minims of a solution of one part to 875 of water; in $1 \mathrm{hr}$. there was great inflection, and after $\mathrm{S}$ hrs. $15 \mathrm{~m}$. every tentacle and the blades of all three were most strongly inflected.

Solium, sulphate of.-Half-minims of a solution of one part to 437 of water were placed on the dises of six leares. After 5 hrs. $30 \mathrm{~m}$. the tentacles of three of them (with the blade of one) wero considerably, and those of the other three slightly, inflected. After 21 hrs. the inflection had a little decreased, 
and in $45 \mathrm{hrs}$. the leaves wero fully expanded, appearing quito healthy.

Three leaves were immersed, each in thirty minims of a solution of one part of the sulphate to 875 of water; after $1 \mathrm{hr}$. $30 \mathrm{~m}$. there was some inflection, which increased so much that in $8 \mathrm{hrs} .10 \mathrm{~m}$. all the tentacles and the blades of all three leaves were closely inflected.

Sodium, Phosphate of.-Half-minims of a solution of one part to 437 of water were placed on the dises of six leaves. The solution acted with extraordinary rapidity, for in $8 \mathrm{~m}$. the outer tentacles on several of the leaves were much incurved. After $6 \mathrm{hrs}$. the tentacles of all six leaves, and the blades of two, wero closely inflected. This state of things continued for $24 \mathrm{hrs}$., excepting that the blade of a third leaf became incurved. After 48 hrs. all the leaves re-expanded. It is clear that $\frac{1}{960}$ of a grain of phosphate of soda has great power in causing inflection.

Sodium, Citrate of.-Half-minims of a solution of one part to 437 of water were placed on the dises of six leares, but these were not observed until $22 \mathrm{hr}$. had elapsed. The submarginal tentacles of five of them, and the blades of four, were then found inflected; but the outer rows of tentacles were not affected. One leaf, which appeared older than the others, was very little affected in any way. After $46 \mathrm{hrs}$. four of the leaves were almost re-expanded, including their blades. Three leaves were also immersed, each in thirty minims of a solution of one part of the citrate to 875 of water; they were much acted on in $25 \mathrm{~m}$.; and after $6 \mathrm{hrs} .35 \mathrm{~m}$. almost all the tentacles, including those of the outer rows, were inflected, but not the blades.

Sodium, Oxalate of.-Half-minims of a solution of one part to 437 of water were placed on the dises of seven leaves; after 5 hrs. $30 \mathrm{~m}$. the tentacles of all, and the blades of most of them, were much affected. In $22 \mathrm{hrs}$, besides the inflection of the tentacles, the blades of all seven leaves were so much doubled over that their tips and bases almost touched. On no other occasion have I seen the blades so strongly affected. Three leaves were also immersed, each in thirty minims of a solution of one part to 875 of water; after $30 \mathrm{~m}$. there was much inflection, and after $6 \mathrm{hrs}$. $35 \mathrm{~m}$. the blades of two and the tentacles of all were closely inflected.

Sodium, Chloride of (best culinary salt).-Half-minims of a solution of one part to 218 of water were placed on tho dises 
of four leares. Two, apparently, were not at all affected in $48 \mathrm{hrs}$; the third had its tentacles slightly inflected; whilst the fourth had almost all its tentacles inflected in 24 hrs., and these did not begin to re-expand until the fourth day, and were not perfectly expanded on the seventh day. I presume that this leaf was injured by the salt. Half-minims of a weaker solution, of one part to 437 of water, were then dropped on the discs of six leaves, so that each received $\frac{1}{960}$ of a grain. In $1 \mathrm{hr}$. $33 \mathrm{~m}$. there was slight inflection; and after $5 \mathrm{hrs.} 30 \mathrm{~m}$. the tentacles of all six leaves were considerably, but not closely, inflected. After $23 \mathrm{hrs} .15 \mathrm{~m}$. all had completely re-expanded, and did not appear in the least injured.

Three leaves were immersed, each in thirty minims of a solution of one part to 875 of water, so that each received $\frac{1}{32}$ of a grain, or $2.02 \mathrm{mg}$. After $1 \mathrm{hr}$. there was much inflection; after 8 hrs. $30 \mathrm{~m}$. all the tentacles and the blades of all three were closely inflected. Four other leaves were also immersed in the solution, each receiving the same amount of salt as before, viz. $\frac{1}{32}$ of a grain. They all soon became inflected; after 48 hrs. they began to re-expand, and appeared quite uninjured, though the solution was sufficiently strong to taste saline.

Sodium, Iodide of.-Half-minims of a solution of one part to 437 of water were placed on the discs of six leaves. After $24 \mathrm{hrs}$. four of them had their blades and many tentacles inflected. The other two had only their submarginal tentacles inflected; the outer ones in most of the leares being but little affected. After $46 \mathrm{hrs}$. the leaves had nearly re-expanded. Three leaves were also immersed, each in thirty minims of a solution of one part to 875 of water. After $6 \mathrm{hrs} .30 \mathrm{~m}$. almost all the tentacles, and the blade of one leaf, were closely inflected.

Sodium, Bromide of.-Half-minims of a solution of one part to 437 of water were placed on six leaves. After $7 \mathrm{hrs}$. there was somo inflection; after $22 \mathrm{hrs}$. three of the leaves had their blades and most of their tentacles inflected; the fourth leaf was very slightly, and the fifth and sixth hardly at all, affected. Three leaves were also immersed, each in thirty minims of a solution of one part to 875 of water; after $40 \mathrm{~m}$. there was some inflection; after $4 \mathrm{hrs}$. the tentacles of all three leares and the blades of two wore inflected. Theso leaves were then placed in water, and after 17 hrs. $30 \mathrm{~m}$. two of them were almost completely, and the third partially, re-cxpanded; so that apparently they were not injured. 
Potassium, Carbonate of (pure)--Half-minims of a solution of one part to 437 of water were placed on six leaves. No effect was produced in $24 \mathrm{hrs}$; but after $48 \mathrm{hrs}$. some of the leaves had their tentacles, and one the blade, considerably inflected. This, however, seemed the result of their being injured; for on the third day after the solution was given, three of the leaves were dead, and one was very unhealthy; the other two were recovering, but with several of their tentacles apparently injured, and these remained permanently inflected. It is evident that the $\frac{1}{960}$ of a grain of this salt acts as a poison. Three leaves were also immersed, each in thirty minims of a solution of one part to 875 of water, though only for $9 \mathrm{hrs}$; and, very differently from what occurs with the salts of soda, no inflection ensued.

Potassium, Nitrate of.-Half-minims of a strong solution, of one part to 109 of water ( 4 grs. to $1 \mathrm{oz}$.), were placed on the dises of four leaves; two were much injured, but no inflection ensued. Eight leaves were treated in the same manner, with drops of a weaker solution, of one part to 218 of water. After $50 \mathrm{hrs}$. there was no inflection, but two of the leaves seemed injured. Five of these leaves were subsequently tested with drops of milk and a solution of gelatine on their discs, and only one became inflected; so that the solution of the nitrate of the above strength, acting for $50 \mathrm{hrs}$., apparently had injured or paralysed the leaves. Six leaves were then treated in the same manner with a still weaker solution, of one part to 437 of water, and these, after 48 hrs., were in no way affected, with the exception of perhaps a single leaf. Three leaves were next immersed for $2.5 \mathrm{hrs}$., each in thirty minims of a solution of one part to 875 of water, and this produced no apparent effect. They were then put into a solution of one part of carbonate of ammionia to 218 of water; the glands were immediately blackened, and after $1 \mathrm{hr}$. there was some inflection, and the protoplasmic contents of the cells became plainly aggregated. This shows that tho leaves had not been much injured by their immersion for 25 hrs. in the nitrate.

Potassium, Sulphate of.-Half-minims of a solution of one part to 437 of water were placed on the discs of six leaves. After $20 \mathrm{hrs} .30 \mathrm{~m}$. no effect was produced; after an additional 24 hrs. three remained quite unaffected; two seemed injured, and the sixth seemed almost dead with its tentacles inflected. Nevertheless, after two additional days, all six leaves recovered. The immersion of three leaves for 24 hrs., each in thirty minims of 
a solution of one part to 875 of water, produced no apparent effect. They were then treated with the same solution of carbonate of ammonia, with the same result as in the case of the nitrate of potash.

Potassium, Phosphate of.-Half-minims of a solution of one part to 437 of water were placed on the dises of six leaves, which were observed during three days ; but no effect was produced. The partial drying up of the fluid on the disc slightly drew together the tentacles on it, as often occurs in experiments of this kind. The leaves on the third day appeared quite healthy.

Potassium, Citrate of.-Half-minims of a solution of one part to 437 of water, left on the discs of six leaves for three days, and the immersion of three leaves for 9 hrs., each in 30 minims of a solution of one part to 875 of water, did not produce the least effect.

Potassium, Oxalate of.-Half-minims were placed on different occasions on the discs of seventeen leaves; and the results perplexed mo much, as they still do. Inflection supervened very slowly. After 24 hrs. four leares out of the serenteen were well inflected, together with the blades of two; six were slightly affected, and seren not at all. Three leaves of one lot were observed for five days, and all died; but in another lot of six, all excepting ono looked healthy after four days. Three leaves were immersed during 9 hrs., each in 30 minims of a solution of one part to 875 of water, and were not in the least affected; but they ought to have been observed for a longer time.

l'otassium, Chloride of. Neither half-minims of a solution of one part to 437 of water, left on the discs of six leaves for three days, nor the immersion of three leaves during $25 \mathrm{hrs}$., in 30 minims of a solution of one part to 875 of water, produced the least effect. The immersed leaves were then treated with carbonate of ammonia, as described under nitrate of potash, and with the same result.

Potassium, Iodide of.-Half-minims of a solution of one part to 437 of water were placed on the dises of seren leaves. In $30 \mathrm{~m}$. one leaf had the blade inflected; after some hours three leaves had most of their submarginal tentacles moderately inflected; the remaining threo being very slightly affected. Hardly any of these learcs had their outer tentacles inflected. After 21 hrs. all re-expanded, excepting two which still had a few submarginal tentacles inflected. Threo leaves wero next 
immersed for $8 \mathrm{hrs} .40 \mathrm{~m}$., each in 30 minims of a solution of one part to 875 of water, and were not in the least affected. I do not know what to conclude from this conflicting evidence; but it is clear that the iodide of potassium does not generally produce any marked effect.

Potassium, Bromide of.-Half-minims of a solution of one part to 437 of water were placed on the discs of six leaves; after $22 \mathrm{hrs}$. one had its blade and many tentacles inflected, but I suspect that an insect might have alighted on it and then escaped; the five other leaves were in no way affected. I tested three of these leaves with bits of meat, and after 24 hrs. they became splendidly inflected. Three leaves were also immersed for 21 hrs. in 30 minims of a solution of one part to 875 of water; but they were not at all affected, excepting that the glands looked rather pale.

Lithium, Acetate of.-Four leaves were immersed together in a vessel containing 120 minims of a solution of one part to 437 of water; so that each received, if the leaves absorbed equally, $\frac{1}{16}$ of a grain. After 24 hrs. there was no inflection. I then added, for the sake of testing the leaves, some strong solution (viz. $1 \mathrm{gr}$. to $20 \mathrm{oz}$., or one part to 8750 of water) of phosphato of ammonia, and all four became in $30 \mathrm{~m}$. closely inflected.

Lithium, Nitrate of.-Four leaves were immersed, as in the last case, in 120 minims of a solution of one part to 437 of water; after $1 \mathrm{~h} .30 \mathrm{~m}$. all four were a little, and after 24 hrs. greatly, inflected. I then diluted the solution with some water, but they still remained somewhat inflected on the third day.

Cosium, Chloride of.-Four leaves were immersed, as above, in 120 minims of a solution of one part to 437 of water. After $1 \mathrm{hr} .5 \mathrm{~m}$. the glands were darkened; after $4 \mathrm{hrs} .20 \mathrm{~m}$. there was a trace of inflection; after $6 \mathrm{hrs} .40 \mathrm{~m}$. two leaves were greatly, but not closely, and the other two considerably inflected. After $22 \mathrm{hrs}$. the inflection was extremely great, and two had their blades inflected. I then transferred the leaves into water, and in 46 hrs. from their first immersion they were almost reexpanded.

Rubidium, Chloride of.-Four leaves which were immersed, as above, in 120 minims of a solution of one part to 437 of water, were not acted on in $22 \mathrm{hrs}$. I then added some of the strong solution ( $1 \mathrm{gr}$. to $20 \mathrm{oz}$.) of phosphate of ammonia, and in $30 \mathrm{~m}$. all were immensely inflected.

Silver, Nitrate of. - Three leaves wore immersed in ninety 
minims of a solution of one part to 437 of water; so that each received, as before, $\frac{1}{16}$ of a grain. After $5 \mathrm{~m}$. slight inflection, and after $11 \mathrm{~m}$. very strong inflection, the glands becoming excessively black; after $40 \mathrm{~m}$. all the tentacles were closely inflected. After $6 \mathrm{hrs}$. the leaves were taken out of the solution, washed, and placed in water; but next morning they were evidently dead.

Calcium, Acetate of.-Four leaves were immersed in 120 minims of a solution of one part to 437 of water; after 24 hrs. none of the tentacles were inflected, excepting a few where the blade joined the petiole; and this may have been caused by the absorption of the salt by the cut-off end of the petiole. I then added some of the solution ( $1 \mathrm{gr}$. to $20 \mathrm{oz}$.) of phospate of ammonia, but this to my surprise excited only slight inflection, even after 21 hrs. Hence it would appear that the acetate had rendered the leaves torpid.

Calcium, Nitrate of.-Four leaves were immersed in 120 minims of a solution of one part to 437 of water, but were not affected in $24 \mathrm{hrs}$. I then added some of the solution of phosphate of ammonia ( $1 \mathrm{gr}$. to $20 \mathrm{oz}$.), but this caused only rery slight inflection after 24 hrs. $A$ fresh leaf was next put into a mixed solution of the above strengths of the nitrate of calcium and phosphate of ammonia, and it became closely inflected in between $5 \mathrm{~m}$. and $10 \mathrm{~m}$. Half-minims of a solution of one part of the nitrate of calcium to 218 of water were dropped on the dises of three leares, but produced no effect.

Magnesium, Acetute, Nitrate, and Chloride of.-Four leaves were immersed in 120 minims of solutions, of one part to 437 of water, of each of these three salts ; after 6 hrs. there was no inflection; but after 22 hrs. one of the leares in the acetate was rather more inflected than generally occurs from an immersion for this length of time in water. Some of the solution (1 gr. to $20 \mathrm{oz}$.) of phosphate of ammonia was then added to the three solutions. The leaves in the acetate mixed with the phosphate underwent some inflection; and this was well pronounced after $24 \mathrm{hrs}$. Those in the mixed nitrate were decidedly inflected in $4 \mathrm{hrs}$. $30 \mathrm{~m}$., but the degree of inflection did not afterwards much increase; whereas the four leaves in the mixed chloride were greatly inflected in a few minutes, and after $4 \mathrm{hrs}$. had almost every tentacle closely inflected. We thus see that the acetate and nitrate of magnesium injure the leares, or at least prevent the subsequent action of phosphate of ammonia; whereas the chloride has no such tendency. 
Magnesium, Sulphate of.-Half-minims of a solution of one part to 218 of water were placed on the discs of ten leaves, and produced no effect.

Barium, Acetate of.-Four leaves were immersed in 120 minims of a solution of one part to 437 of water, and after $22 \mathrm{hrs}$. there was no inflection, but the glands were blackened. The leaves were then placed in a solution (1 gr. to $20 \mathrm{oz}$.) of phosphate of ammonia, which caused after 26 hrs. only a little inflection in two of the leaves.

Barium, Nitrule of.-Four leaves were immersed in 120 minims of a solution of one part to 437 of water; and after $22 \mathrm{hrs}$. there was no more than that slight degree of inflection, which often follows from an immersion of this length in pure water. I then added some of the same solution of phosphate of ammonia, and after $30 \mathrm{~m}$. one leaf was greatly inflected, two others moderately, and the fourth not at all. The leaves remained in this state for 24 hrs.

Strontium, Acetate of.-Four leaves, immersed in 120 minims of a solution of one part to 437 of water, were not affected in 22 hrs. They were then placed in some of the same solution of phosphate of ammonia, and in $25 \mathrm{~m}$. two of them were greatly inflected; after 8 hrs. the third leaf was considerably inflected, and the fourth exhibited a trace of inflection. They. were in the same state next morning.

Strontium, Nitrate of.-Five leaves were immersed in 120 minims of a solution of one part to 437 of water; after $22 \mathrm{hrs}$. there was some slight inflection, but not more than sometimes occurs with leaves in water. They were then placed in the same solution of phosphate of ammonia; after $8 \mathrm{hrs}$. three of them were moderately inflected, as were all five after $21 \mathrm{hrs}$; but not one was closely inflected. It appears that the nitrate of strontium renders the leares half torpid.

Cudmium, Chloride of:-Three leaves were immersed in ninety minims of a solution of one part to 437 of water; after 5 hrs. $20 \mathrm{~m}$. slight inflection occurred, which increased during the next three hours. After 24 hrs. all three leaves had their tentacles well inflected, and remained so for an additional 24 hrs.; glands. not discoloured.

Mercury; Perchloride of.-Three leaves were immersed in ninety minims of a solution of one part to 437 of water; after $22 \mathrm{~m}$. there was some slight inflection, which in $48 \mathrm{~m}$. became well pronounced; the glands were now blackened. After 5 hrs. $35 \mathrm{~m}$. all the tentacles closely inflected; after 24 hrs. still 
inflected and. discoloured. The leares were then remored and left for two days in water; but they never re-expanded, being evidently dead.

Zinc, Chloride of.-Three leaves immersed in ninety minims of a solution of one part to 437 of water were not affected in $2.5 \mathrm{hrs} .30 \mathrm{~m}$.

Aluminium, Chloride of.-Four leaves were immersed in 120 minims of a solution of one part to 437 of water; after $7 \mathrm{hrs}$. $45 \mathrm{~m}$. no inflection; after 24 hrs. one leaf rather closely, the second moderately, the third and fourth hardly at all, inflected. The evidence is doubtful, but I think some power in slowly causing inflection must be attributed to this salt. These leaves were then placed in the solution ( 1 gr. to $20 \mathrm{oz}$.) of phosphate of ammonia, and after $7 \mathrm{hrs}$. $30 \mathrm{~m}$. the three, which had been but little affected by the chloride, became rather closely inflected.

Aluminium, Nitrate of.-Four leaves were immersed in 120 minims of a solution of one part to 437 of water; after $7 \mathrm{hrs}$. $45 \mathrm{~m}$. there was only a trace of inflection; after $24 \mathrm{hrs}$. one leaf was moderately inflected. The evidence is here again doubtful, as in the case of the chloride of aluminium. The leaves were then transferred to the same solution, as before, of phosphate of ammonia; this produced hardly any effect in $7 \mathrm{hrs} .30 \mathrm{~m}$.; but after $25 \mathrm{hrs}$. one leaf was pretty closely inflected, the three others very slightly, perhaps not more so than from water.

Aluminium and Potassium, Sulphate of (common alum).-Halfminims of a solution of the usual strength were placed on the discs of nine leares, but produced no effect.

Gold, Chloride of.--Seven leaves were immersed in so much of a solution of one part to 437 of water that each receired 30 minims, containing $\frac{1}{16}$ of a grain, or $4.018 \mathrm{mg}$., of the chloride. There was some inflection in $8 \mathrm{~m}$., which became extreme in $45 \mathrm{~m}$. In $3 \mathrm{hrs}$. the surrounding fluid was coloured purple, and the glands were blackened. After $6 \mathrm{hrs}$. the leaves were transferred to water; next morning they were found discoloured and evidently killed. The secretion decomposes the chloride very readily; the glands themselves becoming coated with the thinnest layer of metallic gold, and particles float about on the surface of the surrounding fluid.

Lead, Chloride of. - Three leaves were immersed in ninety minims of a solution of one part to 437 of water. After $23 \mathrm{hrs}$. there was not a trace of inflection; the glands were not blackened, and the leares did not appear injured. They were then trans- 
ferred to the solition ( $1 \mathrm{gr}$. to $20 \mathrm{oz}$.) of phosphate of ammonia, and after $24 \mathrm{hrs}$. two of them were somewhat, the third very little, inflected; and they thus remained for another $24 \mathrm{hrs}$.

Tiin, Chloride of.-Four leaves were immersed in 120 minims of a solution of about one part (all not being dissolved) to 437 of water. After 4 hrs. no effect; after 6 hrs. $30 \mathrm{~m}$. all four leaves had their submarginal tentacles inflected; after $22 \mathrm{hrs}$. every single tentacle and the blades were closely inflected. The surrounding fluid was now coloured pink. The leaves were washed and transferred to water, but next morning were evidently dead. This chloride is a deadly poison, but acts slowly.

Antimony, Tartrute of.-Three leaves were immersed in ninety minims of a solution of one part to 437 of water. After $8 \mathrm{hrs}$. $30 \mathrm{~m}$. there was slight inflection; after $24 \mathrm{hrs}$. two of the leaves were closely, and the third moderately, inflected; glands not much darkened. The leaves were washed and placed in water, but they remained in the same state for 48 additional hours. This salt is probably poisonous, but acts slowly.

Arsenious Acil.-A solution of one part to 437 of water; three leaves were immersed in ninety minims; in $25 \mathrm{~m}$. considerable inflection; in $1 \mathrm{~h}$. great inflection; glands not discoloured. -After 6 hrs. the leaves were transferred to water; next morning they looked fresh, but after four days were pale-coloured, had not re-expanded, and were evidently dead.

Iron, Chloride of.-Three leaves were immersed in ninety minims of a solution of one part to 437 of water; in $8 \mathrm{hrs}$. no inflection; but after 21 hrs. considerable inflection; glands blackened; fluid coloured yellow, with floating flocculent particles of oxide of iron. The leaves were then placed in water; after $48 \mathrm{hrs}$. they had re-expanded a very little, but I think were killed; glands excessively black.

Chromic Acid.-One part to 437 of water; three leares were immersed in ninety minims; in $30 \mathrm{~m}$. some, and in $1 \mathrm{hr}$. considerable, inflection; after $2 \mathrm{hrs}$. all the tentacles closely inflected, with the glands discoloured. Placed in water, next day leaves quite discoloured and evidently killed.

Manganese, Chloride of.-Three leaves immersed in ninety minims of a solution of one part to 437 of water; after $22 \mathrm{hrs}$. no more inflection than often occurs in water; glands not blackened. The leaves were then placed in the usual solution of phosphate of ammonia, but no inflection was caused even after 48 hrs.

Copper, Chloride of.-Three leaves immersed in ninety minims 
of a solution of one part to 437 of water; after 2 hrs. some inflection; after 3 hrs. $45 \mathrm{~m}$. tentacles closely inflected, with the glands blackened. After 22 hrs. still closely inflected, and the leaves flaccid. Placed in pure water, next day evidently dead. A rapid poison.

Nickel, Chloride of.-Three leaves immersed in ninety minims of a solution of one part to 437 of water; in $25 \mathrm{~m}$. considerable inflection, and in $3 \mathrm{hrs}$. all the tentacles closely inflected. After 22 hrs. still closely inflected; most of the glands, but not all, blackened. The leaves were then placed in water; after $21 \mathrm{hrs}$. remained inflected; were somewhat discoloured, with the glands and tentacles dingy red. Probably killed.

Cobalt, Chloride of.-Three leaves immersed in ninety minims of a solution of one part to 437 of water; after 23 hrs. there was not a trace of inflection, and the glands were not more blackened than often occurs after an equally long immersion in water.

Platinum, Chloride of.-Three leaves immersed in ninety minims of a solution of one part to 437 of water; in $6 \mathrm{~m}$. some inflection, which became immense after $48 \mathrm{~m}$. After 3 hrs. the glands were rather pale. After 24 hrs. all the tentacles still closely inflected; glands colourless; remained in same state for four days; leares evidently killed.

Conchuding Remarks on the Action of the foregoing Salts.-Of the fifty-one salts and metallic acids which were tried, twenty-five caused the tentacles to be inflected, and twenty-six had no such effect, two rather doubtful cases occurring in each series. In the table at the head of this discussion, the salts are arranged according to their chemical affinities; but their action on Drosera does not seem to be thus governed. The nature of the base is far more important, as far as can be judgerl from the few experiments here giren, than that of the acid; and this is the conclusion at which physiologists have arrived with respect to animals. We see this fact illustrated in all the nine salts of soda causing inflection, and in not being poisonous except when given in large doses; whereas seren of 
the corresponding salts of potash do not cause inflection, and some of them are poisonous. Two of them, however, viz. the oxalate and iodide of potash, slowly induced a slight and rather doubtful amount of inflection. This difference between the two series is interesting, as Dr. Burdon Sanderson informs me that sodium salts may be introduced in large doses into the circulation of mammals without any injurious effects; whilst small doses of potassium salts cause death by suddenly arresting the movements of the heart. An excellent instance of the different action of the two series is presented by the phosphate of soda quickly causing vigorous inflection, whilst phosphate of potash is quite inefficient. The great power of the former is probably due to the presence of phosphorus, as in the cases of phosphate of lime and of ammonia. Hence we may infer that Drosera cannot obtain phosphorus from the phosphate of potash. This is remarkable, as I hear from Dr. Burdon Sanderson that phosphate of potash is certainly decomposed within the bodies of animals. Most of the salts of soda act rery rapidly; the iodide acting slowest. The oxalate, nitrate, and citrate seem to have a special tendency to cause the blade of the leaf to be inflected. The glands of the disc, after absorbing the citrate, transmit hardly any motor impulse to the outer tentacles; and in this character the citrate of soda resembles the citrate of ammonia, or a decoction of grass-leaves; these three fluids all acting chiefly on the blade.

It seems opposed to the rule of the preponderant influence of the base that the nitrate of lithium causes moderately rapid inflection, whereas the acetate causes none; but this metal is closely allied to sodium 
and potassium,* which act so differently; therefore we might expect that its action would be intermediate. We see, also, that cæsium causes inflection, and rubidium does not; and these two metals are allied to sodium and potassium. Most of the earthy salts are inoperative. Two salts of calcium, four of magnesium, two of barium, and two of strontium, did not cause any inflection, and thus follow the rule of the preponderant power of the base. Of three salts of aluminium, one did not act, a second showed a trace of action, and the third acted slowly and doubtfully, so that their effects are nearly alike.

Of the salts and acids of ordinary metals, seventeen were tried, and only four, namely those of zinc, lead, manganese, and cobalt, failed to cause inflection. The salts of cadmium, tin, antimony, and iron, act slowly; and the three latter seem more or less poisonous. The salts of silver, mercury, gold, copper, nickel, and platinum, chromic and arsenious acids, cause great inflection with extreme quickness, and are deadly poisons. It is surprising, judging from animals, that lead and barium should not be poisonous. Most of the poisonous salts make the glands black, but chloride of platinum made them very pale. I shall have occasion, in the next chapter, to add a few remarks on the different effects of phosphate of ammonia on leaves previously immersed in various solutions.

\section{Acios.}

I will first give, as in the case of the salts, a list of the twenty-four acids which were tried, divided into two series, according as they cause or do not cause

* Miller's 'Elements of Chemistry', 3rd edit. pp. 337, 418. 
inflection. After describing the experiments, a few concluding remarks will be added.

ACIDS, MCCH DILCTED, WHICH CAUSE INFLECTION.

1. Nitric, strong inflection; poisonous.

2. Hydrochloric, moderate and slow inflection; not poisonous.

3. Hydriodic, strong inflection; poisonous.

4. Iodic, strong inflection; poisonous.

5. Sulphuric, strong inflection; somewhat poisonous.

6. Phosphoric, strong inflection ; poisonous.

7. Boracic, moderate and rather slow inflection; not poisonous.

8. Formic, very slight inflection; not poisonous.

9. Acetic, strong and rapid inflection; poisonous.

10. Propionic, strong but not very rapid inflection ; poisonous.

11. Oleic, quick inflection; very poisonous.

12. Carbolic, very slow inflection; poisonous.

13. Iactic, slow and moderate inflection; poisonous.

14. Oxalic, moderately quick inflection; very poisonous.

15. Malic, very slow but considerable inflection; not poisonous.

16. Benzoic, rapid inflection; very poisonous.

17. Succinic, moderately quick inflection; moderately poisonous.

18. Hippuric, rather slow inflection; poisonous.

19. Hydrocyanic, rather rapid inflection; very poisonous.
Acids, Diluted to THE SAME

DEGREE, WHICH DO NOT CALSE INFLECTION.

1. Gallic; not poisonous.

2. Tannic; not poisonous.

3. Tartaric; not poisonous.

4. Citric; not poisonous.

5. Uric; (?) not poisonous.

Nitric Acid.-Four leaves were placed, each in thirty minims of one part by weight of the acid to 437 of water, so that each received $\frac{1}{16}$ of a grain, or $4.048 \mathrm{mg}$. This strength was chosen for this and most of the following experiments, as it is the same 
as that of most of the foregoing saline solutions. In $2 \mathrm{hrs.} 30 \mathrm{~m}$. some of the leaves were considerably, and in $6 \mathrm{hrs} .30 \mathrm{~m}$. all were immensely, inflected, as were their blades. The surrounding fluid was slightly coloured pink, which always shows that the leaves have been injured. They were then left in water for three days; but they remained inflected and were evidently killed. MIost of the glands had become colourless. Two leaves were then immersed, each in thirty minims of one part to 1000 of water; in a few hours there was some inflection; and after $21 \mathrm{hrs}$. both leaves had almost all their tentacles and blades inflected; they were left in water for three days, and one partially re-expanded and recovered. Two leaves were next immersed, each in thirty minims of one part to 2000 of water; this produced very little effect, except that most of the tentacles close to the summit of the petiole were inflected, as if the acid had been absorbed by the cut-off end.

Hydroclloric Acid.-One part to 437 of water ; four leaves were immersed as before, each in thirty minims. After 6 hrs. only one leaf was considerably inflected. After 8 hrs. $15 \mathrm{~m}$. one had its tentacles and blade well inflected; the other three were moderately inflected, and the blade of one slightly. The surrounding fluid was not coloured at all pink. After 25 hrs. three of these four leaves began to re-expand, but their glands were of a pink instead of a red colour; after two more days they fully re-expanded; but the fourth leaf remained inflected, and seemed much injured or killed, with its glands white. Four leaves were then treated, each with thirty minims of one part to 875 of water; after $21 \mathrm{hrs}$. they were moderately inflected; and on being transferred to water, fully re-expanded in two days, and seemed quite healthy.

IIydriodic Acid.-One to 437 of water; three leaves were immersed as before, each in thirty minims. After $45 \mathrm{~m}$. the glands were discoloured, and the surrounding fluid became pinkish, but there was no inflection. After $5 \mathrm{hrs}$. all the tentacles were closely inflected; and an immense amount of mucus was secreted, so that the fluid could be drawn out into long ropes. The leares were then placed in water, but never re-expanded, and were evidently killed. Four leares were next immersed in one part to $87 \check{\jmath}$ of water; the action was row slower, but after $22 \mathrm{hrs}$. all four leaves were closely inflected, and were affected in other respects as abore deseribed. These leaves did not re-expand, though left for four days in water. This acid acts far more powerfully than hydrochloric, and is poisonous.

Iodic Acid.-One to 437 of water; three leaves were immersed, 
each in thirty minims; after $3 \mathrm{hrs}$. strong inflection; after 4 hrs. glands dark brown; after 8 hrs. 30 m. close inflection, and the leaves had become flaccid; surrounding fluid not coloured pink. These leaves were then placed in water, and next day wero evidently dead.

Sulphuric Acid.-One to 437 of water; four leaves were immersed; each in thirty minims; after 4 hrs. great inflection; after 6 hrs. surrounding fluid just tinged pink; they were then placed in water, and after 46 hrs. two of them were still closely inflected, two beginning to re-expand; many of the glands colourless. This acid is not so poisonous as hydriodic or iodic acids.

Phosplioric Acid.-One to 437 of water; three leaves were immersed together in ninety minims; after 5 hrs. $30 \mathrm{~m}$. some inflection, and some glands colourless; after $8 \mathrm{hrs}$. all the tentacles closely inflected, and many glands colourless ; surrounding fluid pink. Left in water for two days and a half, remained in the same state and appeared dead.

Boracic Acid.-One to 437 of water; four leaves were immersed together in 120 minims; after 6 hrs. very slight inflection; after 8 hrs. $15 \mathrm{~m}$. two were considerably inflected, the other two slightly. After $21 \mathrm{hrs}$. one leaf was rather closely inflected, the second less closely, the third and fourth moderately. The leaves were washed and put into water; after $24 \mathrm{hrs}$. they were almost fully re-expanded and looked healthy. This acid agrees closely with hydrochloric acid of the same strength in its power of causing inflection, and in not being poisonous.

Formic Acid.-Four leaves were immersed together in 120 minims of one part to 437 of water; after $40 \mathrm{~m}$. slight, and after $6 \mathrm{hrs} .30 \mathrm{~m}$. very moderate inflection; after $22 \mathrm{hrs}$. only a little more inflection than often occurs in water. Two of the leaves were then washed and placed in a solution ( 1 gr. to $20 \mathrm{oz}$.) of phosphate of ammonia; after 24 hrs. they were considerably inflected, with the contents of their cells aggregated, showing that the phosphate had acted, though not to the full and ordinary degree.

Acetic Acid.-Four leaves were immersed together in 120 minims of one part to 437 of water. In $1 \mathrm{hr}$. $20 \mathrm{~m}$. the tentacles of all four and the blades of two were greatly inflected. After $8 \mathrm{hrs}$. the leaves had become flaccid, but still remained closely inflected, the surrounding fluid being coloured pink. They were then washed and placed in water; next morning they were still inflected and of a very dark red colour, but with their glands colourless. After another day they were dingy-coloured, and 
evidently dead. This acid is far more powerful than formic, and is highly poisonous. Half-minim drops of a stronger mixture (viz. one part by measure to 320 of water) were placed on the discs of five leaves; none of the exterior tentacles, only those on the borders of the dise which actually absorbed the acid, became inflected. Probably the dose was too strong and paralysed the leares, for drops of a weaker mixture caused much inflection; nevertheless the leaves all died after two days.

Propionic Acid.-Three leaves were immersed in ninety minims of a mixture of one part to 437 of water; in $1 \mathrm{hr} .50 \mathrm{~m}$. there was no inflection; but after $3 \mathrm{hrs} .40 \mathrm{~m}$. one leaf was greatly inflected, and the other two slightly. The inflection continued to increase, so that in $8 \mathrm{hrs}$. all three leaves were closely inflected. Next morning, after $20 \mathrm{hrs}$., most of the glands were very paie, but some few were almost black. No mucus had been secreted, and the surrounding fluid was only just perceptibly tinted of a pale pink. After $46 \mathrm{hrs}$. the leaves became slightly flaccid and were evidently killed, as was afterwards proved to be the case by keeping them in water. The protoplasm in the

- closely inflected tentacles was not in the least aggregated, but towards their bases it was collected in little brownish masses at the bottoms of the cells. This protoplasm was dead, for on leaving the leaf in a solution of carbonate of ammonia, no aggregation ensued. Propionic acid is highly poisonous to Drosera, like its ally acetic acid, but induces inflection at a much slower rate.

Oleic Acid (given me by Prof. Frankland).-Three leaves were immersed in this acid; some inflection was almost immediately caused, which increased slightly, but then ceased, and the leaves seemed killed. Next morning they were rather shrivelled, and many of the glands had fallen off the tentacles. Drops of this acid were placed on the dises of four leaves; in $40 \mathrm{~m}$. all the tentacles were greatly inflected, excepting the extreme marginal ones; and many of these after $3 \mathrm{hrs}$. became inflected. I was led to try this acid from supposing that it was present (which does not seem to be the case)* in olire oil, the action of which is anomalous. Thus drops of this oil placed on the disc do not cause the outer tentacles to be inflected; yet when minute drops were added to the secretion surrounding the glands of the outer tentacles, these were occasionally, but by means always, inflected. Two leaves were also immersed in this oil, and there

* See articles on Glycerine and Oleic Acid in Watts' 'Dict. of Chemistry.' 
was no inflection for about 12 hrs.; but after 23 hrs. almost all the tentacles were inflected. Three leaves were likewise immersed in unboiled linseed oil, and soon became somewhat, and in $3 \mathrm{hrs}$. greatly, inflected. After $1 \mathrm{hr}$. the secretion round the glands was coloured pink. I infer from this latter fact that the power of linseed oil to cause inflection cannot be attributed to the albumin which it is said to contain.

Carbolic Acid.-Two leaves were immersed in sixty minims of a solution of 1 gr. to 437 of water; in $7 \mathrm{hrs}$. one was slightly, and in 24 hrs. both were closely, inflected, with a surprising amount of mucus secreted. These leaves were washed and left for two days in water; they remained inflected; most of their glands became pale, and they seemed dead. This acid is poisonous, but does not act nearly so rapidly or powerfully as might have been expected from its known destructive power on the lowest organisms. Half-minims of the same solution were placed on the discs of three leaves; after $24 \mathrm{hrs}$. no inflection of the outer tentacles ensued, and when bits of meat were given them, they became fairly well inflected. Again half-minims of a stronger solution, of one part to 218 of water, were placed on the dises of three leaves; no inflection of the outer tentacles ensued; bits of meat were then given as before; one leaf alone became well inflected, the discal glands of the other two appearing much injured and dry. We thus see that the glands of the discs, after absorbing this acid, rarely transmit any motor impulse to the outer tentacles; though these, when their own glands absorb the acid, are strongly acted on.

Lactic Acid.-Three leaves were immersed in ninety minims of one part to 437 of water. After $48 \mathrm{~m}$. there was no inflection, but the surrounding fluid was coloured pink; after $8 \mathrm{hrs}$. $30 \mathrm{~m}$. one leaf alone was a little inflected, and almost all the glands on all three leaves were of a very pale colour. The leaves were then washed and placed in a solution ( $1 \mathrm{gr}$. to $20 \mathrm{oz}$.) of phosphate of ammonia; after about $16 \mathrm{hrs}$. there was only a trace of inflection. They were left in the phosphate for $48 \mathrm{hrs}$., and remained in the same state, with almost all their glands discoloured. The protoplasm within the cells was not aggregated, except in a very few tentacles, the glands of which were not much discoloured. I believe, therefore, that almost all the glands and tentacles had been killed by the acid so suddenly that hardly any inflection was caused. Four leaves were next immersed in 120 minims of a weaker solution, of one part to 875 of water; after $2 \mathrm{hrs} .30 \mathrm{~m}$. the surrounding fluid was quite pink; the glands were pale, but 
there was no inflection; after $7 \mathrm{hrs} .30 \mathrm{~m}$. two of the leares showed some inflection, and the glands were almost white; after 21 hrs. two of the leaves were considerably inflected, and a third slightly; most of the glands were white, the others dark red. After $45 \mathrm{hrs}$. one leaf had almost every tentacle inflected; a second a large number; the third and fourth very few ; almost all the glands were white, excepting those on the discs of two of the leaves, and many of these were very dark red. The leaves appeared dead. Hence lactic acid acts in a very peculiar manner, causing inflection at an extraordinarily slow rate, and being highly poisonous. Immersion in even weaker solutions, viz. of one part to 1312 and 1750 of water, apparently killed the leares (the tentacles after a time being bowed backwards), and rendered the glands white, but caused no inflection.

Gallic, Tunnic, Tartaric, and Citric Acids.-One part to 437 of water. Three or four leaves were immersed, each in thirty minims of these four solutions, so that each leaf received $\frac{1}{16}$ of a grain, or $4.018 \mathrm{mg}$. No inflection was caused in $24 \mathrm{hrs}$. , and the leaves did not appear at all injured. Those which had been in the tannic and tartaric acids were placed in a solution ( $1 \mathrm{gr}$. to $20 \mathrm{oz}$.) of phosphate of ammonia, but no inflection ensued in 24 hrs. On the other hand, the four leaves which had been in the citrie acid, when treated with the phosphate, became decidedly inflected in $50 \mathrm{~m}$. and strongly inflected after $5 \mathrm{lr}$.s., and so remained for the next $24 \mathrm{hrs}$.

Malic Acid.-Three leaves were immersed in ninety minims of a solution of one part to 437 of water; no inflection was caused in $8 \mathrm{hrs} .20 \mathrm{~m}$., but after $24 \mathrm{hrs}$. two of them were considerably, and the third slightly, inflected-more so than could be accounted for by the action of water. No great amount of mucus was secreted. They were then placed in water, and after two days partially re-expanded. Hence this acid is not poisonous.

Oxalic Acid.- Three leaves were immersed in ninety minims of a solution of $1 \mathrm{gr}$. to 437 of water; after $2 \mathrm{hrs.} 10 \mathrm{~m}$. there was much inflection; glands pale; the surrounding fluid of a dark pink colour; after 8 hrs. excessive inflection. The leaves were then placed in water; after about 16 hrs. the tentacles were of a very dark red colour, like those of the leares in acetic acid. After 24 additional hours, the three leaves were dead and their glands colourless.

Benzoic Acid.-Five leaves were immersed, each in thirty minims of a solution of $1 \mathrm{gr}$. to 437 of water. 'This solution was so weak that it only just tasted acid, yet, as we shall see, was highly poisonous to Drosera. After $52 \mathrm{~m}$. the submarginal 
tentacles were somewhat inflected, and all the glands very palecoloured; the surrounding fluid was coloured pink. On one occasion the-fluid became pink in the course of only $12 \mathrm{~m}$, and the glands as white as if the leaf had been dipped in boiling water. After $4 \mathrm{hrs}$. much inflection; but none of the tentacles were closely inflected, owing, as I believe, to their having been paralysed before they had time to complete their movement. An extraordinary quantity of mucus was secreted. Some of the leaves were left in the solution; others, after an immersion of $6 \mathrm{hrs} .30 \mathrm{~m}$., were placed in water. Next morning both lots were quite dead; the leaves in the solution being flaccid, those in the water (now coloured yellow) of a pale brown tint, and their glands white.

Succinic Acid.-Three leaves were immersed in ninety minims of a solution of $1 \mathrm{gr}$. to 437 of water; after $4 \mathrm{hrs} .15 \mathrm{~m}$. considerable and after 23 hrs. great inflection; many of the glands pale; fluid coloured pink. The leaves were then washed and placed in water; after two days there was some re-expansion, but many of the glands were still white. This acid is not nearly so poisonous as oxalic or benzoic.

Uric Acid.-Three leaves were immersed in 180 minims of a solution of 1 gr. to 875 of warm water, but all the acid was not dissolved; so that each received nearly $\frac{1}{16}$ of a grain. After $25 \mathrm{~m}$. there was some slight inflection, but this never increased; after $9 \mathrm{hrs}$. the glands were not discoloured, nor was the solution coloured pink; nevertheless much mucus was secreted. The leaves were then placed in water, and by next morning fully re-expanded. I doubt whether this acid really causes inflection, for the slight movement which at first occurred may lave been due to the presence of a trace of albuminous matter. But it produces some effect, as shown by the secretion of so much mucus.

Hippuric Acid.-Four leaves were immersed in 120 minims of a solution of $1 \mathrm{gr}$. to 437 of water. After $2 \mathrm{hrs}$. the fluid was coloured pink; glands pale, but no inflection. After 6 hrs. some inflection; after 9 hrs. all four leaves greatly inflected; much mucus secreted; all the glands rery pale. The leaves were then left in water for two days; they remained closely inflected, with their glands colourless, and. I do not doubt were killed.

Hydrocyanic Acid.-Four leaves were immersed, each in thirty minims of one part to 437 of water; in $2 \mathrm{hrs} .45 \mathrm{~m}$. all the tentacles were considerably inflected, with many of the glands pale; after $3 \mathrm{hrs.} 45 \mathrm{~m}$. all strongly inflected, and the surrounding fluid coloured pink; after 6 hrs. all closely inflected. After 
an immersion of 8 hrs. $20 \mathrm{~m}$. the leaves were washed and placed in water; next morning, after about $16 \mathrm{hrs}$., they were still inflected and discoloured; on the succeeding day they were evidently dead. Two leares were immersed in a stronger mixture, of one part to fifty of water; in $1 \mathrm{hr} .15 \mathrm{~m}$. the glands became as white as porcelain, as if they had been dipped in boiling water; very few of the tentacles were inflected; but after 4 hrs. almost all were inflected. These leaves were then placed in water, and next morning were evidently deads Half-minim drops of the same strength (viz. one part to fifty of water) were next placed on the dises of five leaves; after $21 \mathrm{hrs}$. all the outer tentacles were inflected, and the leaves appeared much injured. I likewise touched the secretion round a large number of glands with minute drops (about $\frac{1}{20}$ of a minim, or $00296 \mathrm{ml}$.) of Scheele's mixture ( 6 per cent.); the glands first became bright red, and after $3 \mathrm{hrs}$. $15 \mathrm{~m}$. about two-thirds of the tentacles bearing these glands were inflected, and remained so for the two succeeding days, when they appeared dead.

Concluding Remarks on the Action of Acids.-It is evident that acids have a strong tendency to cause the inflection of the tentacles; ${ }^{*}$ for out of the twenty-four acids tried, nineteen thus acted, either rapidly and energetically, or slowly and slightly. This fact is remarkable, as the juices of many plants contain more acid, judging by the taste, than the solutions employed in my experiments. From the powerful effects of so many acids on Drosera, we are led to infer that those naturally contained in the tissues of this plant, as well as of others, must play some important part in their economy. Of the five cases in which acids did not cause the tentacles to be inflected, one is doubtful; for uric acid did act slightly, and caused a copions secretion of mucus. Mere sourness to the taste is no

* According to MI. Fournier ('De la Fécondation dans les Phanérogames.' 1863, p. 61) drops of acetic, hydrocyanic, and sulphuric acid cause the stamens of
Berberis instantly to close; though drops of water have no such power, which latter statement I can confirm. 
criterion of the power of an acid on Drosera, as citric and tartaric acids are very sour, yet do not excite inflection. It is remarkable how acids differ in their power. Thus, hydrochloric acid acts far less powerfully than hydriodic and many other acids of the same strength, and is not poisonous. This is an interesting fact, as hydrochloric acid plays so important a part in the digestive process of animals. Formic acid induces very slight inflection, and is not poisonous; whereas its ally, acetic acid, acts rapidly and powerfully, and is poisonous. Malic acid acts slightly, whereas citric and tartaric acids produce no effect. Lactic acid is poisonous, and is remarkable from inducing inflection only after a considerable interval of time. Nothing surprised me more than that a solution of benzoic acid, so weak as to be hardly acidulous to the taste, should act with great rapidity and be highly poisonous; for I am informed that it produces no marked effect on the animal economy. It may be seen, by looking down the list at the head of this discussion, that most of the acids are poisonous, often highly so. Diluted acids are known to induce negative osmose, ${ }^{*}$ and the poisonous action of so many acids on Drosera is, perhaps, connected with this power, for we have seen that the fluids in which they were immersed often became pink, and the glands pale-coloured or white. Many of the poisonous acids, such as hydriodic, benzoic, hippuric, and carbolic (but I neglected to record all the cases), caused the secretion of an extraordinary amount of mucus, so that long ropes of this matter hung from the leaves when they were lifted out of the solutions. Other acids, such as hydrochloric and malic, have no such ten-

* Miller's 'Elements of Chemistry' part i. 1867, p. 87. 
dency; in these two latter cases the surrounding fluid was not coloured pink, and the leaves were not poisoned. On the other hand, propionic acid, which is poisonous, does not cause much mucus to be secreted, yet the surrounding fluid became slightly pink. Lastly, as in the case of saline solutions, leaves, after being immersed in certain acids, were soon acted on by phosphate of ammonia; on the other hand, they were not thus affected after immersion in certain other acids. To this subject, however, I shall have to recur. 


\section{CHAPTER IX.}

The Effects of certain Alkaloid Poisons, other Substances and VAPOURS.

Strychnine, salts of - Quinine, sulphate of, does not soon arrest the movement of the protoplasm - Other salts of quinine-Digitaline - Nicotine - Atropine-Veratrine-Colchicine-Theine-Curare - Morphia - Hyoscyamus - Poison of the cobra, apparently accelerates the movements of the protoplasm - Camphor, a powerful stimulant, its vapour narcotic - Certain essential oils excite movement - Glycerine - Water and certain solutions retard or prevent the subsequent action of phosphate of ammonia-Alcohol innocuous, its vapour narcotic and poisonous - Chloroform, sulphuric and nitric ether, their stimulant, poisonous, and narcotic power Carbonic acid narcotic, not quickly poisonous - Concluding remarks.

As in the last chapter, I will first give my experiments, and then a brief summary of the results with some concluding remarks.

Acetate of Strychnine.-Half-minims of a solution of one part to 437 of water were placed on the dises of six leaves; so that each received $\frac{1}{960}$ of a grain, or $.0675 \mathrm{mg}$. In $2 \mathrm{hr} . \mathrm{s} .30 \mathrm{~m}$. the outer tentacles on some of them were inflected, but in an irregular manner, sometimes only on one side of the leaf. The next morning, after $22 \mathrm{hrs} .30 \mathrm{~m}$., the inflection had not increased. The glands on the central disc were blackened, and had ceased secreting. After an additional $24 \mathrm{hrs}$. all the central glands seemed dead, but the inflected tentacles had re-expanded and appeared quite healthy. Hence the poisonous action of strychnine seems confined to the glands which have absorbed it; nevertheless, these glands transmit a motor impulse to the exterior tentacles. Ninute drops (about $\frac{1}{20}$ of a minim) of the same solution applied to the glands of the outer tentacles occasionally caused them to bend. The poison does not seem to act quickly, for having applied to several glands similar drops of a rather stronger solution, of one part to 292 of water, this did not prevent the tentacles bending, when their glands 
were excited, after an interval of a quarter to three quarters of an hour, by being rubbed or given bits of meat. Similar drops of a solution of one part to 218 of water ( $2 \mathrm{grs}$. to $1 \mathrm{oz}$.) quickly blackened the glands; some few tentacles thus treated moved, whilst others did not. The latter, however, on being subsequently moistened with saliva or given bits of meat, became incurved, though with extreme slowness; and this shows that they had been injured. Stronger solutions (but the strength was not ascertained) sometimes arrested all power of movement very quickly; thus bits of meat were placed on the glands of several exterior tentacles, and as soon as they began to move, minute drops of the strong solution were added. They continued for a short time to go on bending, and then suddenly stood still; other tentacles on the same leaves, with meat on their glands, but not wetted with the strychnine, continued to bend and soon reached the centre of the leaf.

Citrate of Strychnine.-Half-minims of a solution of one part to 437 of water were placed on the dises of six leaves; after $24 \mathrm{hrs}$. the outer tentacles showed only a trace of inflection. Bits of meat were then placed on three of these leaves, but in 24 hrs. only slight and irregular inflection occurred, proving that the leaves had been greatly injured. Two of the leaves to which meat had not been given had their discal glands dry and much injured. Minute drops of a strong solution of one part to 109 of water ( 4 grs. to 1 oz.) were added to the secretion round several glands, but did not produce nearly so plain an effect as the drops of a much weaker solution of the acetate. Particles of the dry citrate were placed on six glands; two of these moved some way towards the centre, and then stood still, being no doubt killed; three others curved much farther inwards, and were then fixed; one alone reached the centre. Five leaves were immersed, each in thirty minims of a solution of one part to 437 of water; so that each received $\frac{1}{16}$ of a grain; after about $1 \mathrm{hr}$. some of the outer tentacles became inflected, and the glands were oddly mottled with black and white. These glands, in from $4 \mathrm{hrs}$. to $5 \mathrm{hrs}$., became whitish and opaque, and the protoplasm in the cells of the tentacles was well aggregated. By this time two of the leaves were greatly inflected, but the three others not much more inflected than they were before. Nevertheless two fresh leares, after an immersion respectively for $2 \mathrm{hrs}$. and $4 \mathrm{hrs}$. in the solution, were not killed; for on being left for $1 \mathrm{hr}$. $30 \mathrm{~m}$. in a solution of one part of carbonate of ammonia to 218 of water, their tentacles became more inflected, and there was much aggregation. The glands 
of two other leaves, after an immersion for $2 \mathrm{hrs}$. in a stronger solution, of one part of the citrate to 218 of water, became of an opaque, pale pink colour, which before long disappeared, leaving them white. One of these two leaves had its blade and tentacles greatly inflected; the other hardly at all; but the protoplasm in the cells of both was aggregated down to the bases of the tentacles, with the spherical masses in the cells close beneath the glands blackened. After $24 \mathrm{hrs}$. one of these leaves was colourless, and evidently dead.

Sulphate of Quinine.-Some of this salt was added to water, which is said to dissolve $\frac{1}{1000}$ part of its weight. Five leaves were immersed, each in thirty minims of this solution, which tasted bitter. In less than $1 \mathrm{hr}$. some of them had a few tentacles inflected. In $3 \mathrm{hrs}$. most of the glands became whitish, others dark-coloured, and many oddly mottled. After 6 hrs. two of the leaves had a good many tentacles inflected, but this very moderate degree of inflection never increased. One of the leaves was taken out of the solution after $4 \mathrm{hrs}$., and placed in water; by the next morning some few of the inflected tentacles had re-expanded, showing that they were not dead; but the glands were still much discoloured. Another leaf not included in the above lot, after an immersion of $3 \mathrm{hrs} .15 \mathrm{~m}$., was carefully examined; the protoplasm in the cells of the outer tentacles, and of the short green ones on the disc, had become strongly aggregated down to their bases; and I distinctly saw that the little masses changed their positions and shapes rather rapidly; some coalescing and again separating. I was surprised at this fact, because quinine is said to arrest all movement in the white corpuscles of the blood; but as, according to Binz, ${ }^{*}$ this is due to their being no longer supplied with oxygen by the red corpuscles, any such arrestment of movement could not be expected in Drosera. That the glands had absorbed some of the salt was evident from their change of colour; but I at first thought that the solution might not have travelled down the cells of the tentacles, where the protoplasm was seen in active movement. This view, however, I have no doubt, is erroneous, for a leaf which had been immersed for $3 \mathrm{hrs}$, in the quinine solution was then placed in a little solution of one part of carbonate of ammonia to 218 of water; and in $30 \mathrm{~m}$. the glands and the upper cells of the tentacles became intensely black, with the protoplasm presenting a very unusual appearance; for it

* 'Quarterly Journal of Microscopical Science,' April 1874, p. 185. 
had become aggregated into reticulated dingy-coloured masses, having rounded and angular interspaces. As I have never seen this effect produced by the carbonate of ammonia alone, it must be attributed to the previous action of the quinine. These reticulated masses were watched for some time, but did not change their forms; so that the protoplasm no doubt had been killed by the combined action of the two salts, though exposed to them for only a short time.

Another leaf, after an immersion for $24 \mathrm{hrs}$. in the quinine solution, became somewhat flaccid, and the protoplasm in all the cells was aggregated. Many of the aggregated masses were discoloured, and presented a granular appearance; they were spherical, or elongated, or still more commonly consisted of little curved chains of small globules. None of these masses exhibited the least movement, and no doubt were all dead.

Half-minims of the solution were placed on the dises of six leaves; after $23 \mathrm{hrs}$. one had all its tentacles, two had a few, and the others none inflected; so that the discal glands, when irritated by this salt, do not transmit any strong motor impulse to the outer tentacles. After 48 hrs. the glands on the discs of all six leaves were evidently much injured or quite killed. It is clear that this salt is highly poisonous.*

Acetate of Quinine.-Four leares were immersed, each in thirty minims of a solution of one part to 437 of water. The solution was tested with litmus paper, and was not acid. After only $10 \mathrm{~m}$. all four leares were greatly, and after 6 hrs. immensely, inflected. They were then left in water for $60 \mathrm{hrs}$., but never re-expanded; the glands were white, and the leaves evidently dead. This salt is far more efficient than the sulphate in causing inflection, and, like that salt, is highly poisonous.

Nitrate of Quinine.-Four leaves were immersed, each in thirty minims of a solution of one part to 437 of water. After 6 lirs. there was hardly a trace of inflection; after $22 \mathrm{hrs}$. three of the leaves were moderately, and the fourth slightly inflected; so that this salt induces, though rather slowly, well-marked inflection. These leaves, on boing left in water for $48 \mathrm{hrs}$, almost

* Binz found several years ago (as stated in 'The Jnurnal of Anatomy and Phys.' November 1572 , p. 195) that quinia is an encrgetic pnison to low regetrble and animal organisms. Even one part added to 4000 parts of hiood arrests the movements of the white corpuscles, which become "rounded and granular." In the tentacles of Drosera the aggregated masses of protoplasm, which appeared killed by the quinine, likewise presented a granular appearance. A similar appearance is caused by very hot water. 
completely re-expanded, but the glands were much discoloured. Hence this salt is not poisonous in any high degree. The different action of the three foregoing salts of quinine is singular.

Digitaline.-Hali-minims of a solution of one part to 437 of water were placed on the dises of five leaves. In $3 \mathrm{hrs} .45 \mathrm{~m}$. some of them had their tentacles, and one had its blade, moderately inflected. After $8 \mathrm{hrs}$. three of them were well inflected; the fourth had only a few tentacles inflected, and the fifth (an old leaf) was not at all affected. They remained in nearly the same state for two days, but the glands on their discs became pale. On the third day the leaves appeared much injured. Nevertheless, when bits of meat were placed on two of them, the outer tentacles became inflected. A minute drop (about $\frac{1}{20}$ of a minim) of the solution was applied to three glands, and after $6 \mathrm{hrs}$. all three tentacles were inflected, but next day had nearly re-expanded; so that this very small dose of $\frac{1}{28800}$ of a grain ( $.0022 .5 \mathrm{mg}$.) acts on a tentacle, but is not poisonous. It appears from these several facts that digitaline causes inflection, and poisons the glands which absorb a moderately large amount.

Nicotine.-The secretion round several glands was touched with a minute drop of the pure fluid, and the glands were instantly blackened; the tentacles becoming inflected in a few minutes. Two leaves were immersed in a weak solution of two drops to $1 \mathrm{oz}$. , or 437 grains, of water. When examined after $3 \mathrm{hrs} .20 \mathrm{~m}$., only twenty-one tentacles on one leaf were closely inflected, and six on the other slightly so; but all the glands were blackened, or very dark-coloured, with the protoplasm in all the cells of all the tentacles much aggregated and dark-coloured. The leaves were not quite killed, for on being placed in a little solution of carbonate of ammonia ( 2 grs. to 1 oz.) a few more tentacles became inflected, the remainder not being acted on during the next 24 hrs.

Half-minims of a stronger solution (two drops to $\frac{1}{2} \mathrm{oz}$. of water) were placed on the discs of six leaves, and in $30 \mathrm{~m}$. all those tentacles became inflected; the glands of which had actually touched the sulution, as shown by their blackness; but hardly any motor influence was transmitted to the outer tentacles. After $22 \mathrm{hrs}$. most of the glands on the discs appeared dead; but this could not have been the case, as when bits of meat were placed on three of them, some few of the onter tentacles were inflected in 21 hrs. Hence nicotine has a great tendency to blacken the glands and to induce aggregation 
of the protoplasm, but, except when pure, has very moderate powrer of inducing inflection, and still less power of causing a motor influence to be transmitted from the discal glands to the outer tentacles. It is moderately poisonous.

Atropine.-A grain was added to 437 grains of water, but was not all dissolved; another grain was added to 437 grains of a mixture of one part of alcohol to seven parts of water; and a third solution was made by adding one part of valerianate of atropine to 437 of water. Half-minims of these three solutions were placed, in each case, on the discs of six leaves; but no effect whatever was produced, excepting that the glands on the discs to which the valerianate was given were slightly discoloured. The six leaves on which drops of the solution of atropine in diluted alcohol had been left for $21 \mathrm{hrs}$. were given bits of meat, and all became in $24 \mathrm{hrs}$. fairly well inflected; so that atropine does not excite morement, and is not poisonous. I also tried in the same manner the alkaloid sold as daturine, which is believed not to differ from atropine, and it produced no effect. Three of the leaves on which drops of this latter solution had been left for $24 \mathrm{hrs}$. were likewise given bits of meat, and they had in the course of $24 \mathrm{hrs}$. a good many of their submarginal tentacles inflected.

Veratrine, Colchicine, Theine.-Solutions were made of these three alkaloids by adding one part to 437 of water. Half-minims were placed, in each ease, on the dises of at least six leaves, but no inflection was caused, except perhaps a very slight amount by the theine. Half-minims of a strong infusion of tea likewise produced, as formerly stated, no effect. I also tried similar drops of an infusion of one part of the extract of colchicum, sold by druggists, to 218 of water; and the leaves were observed for 48 hrs., without any effect being produced. The seven leaves on which drops of veratrine had been left for $26 \mathrm{hrs}$. were given bits of meat, and after $21 \mathrm{hrs}$. were well inflected. These three alkaloids are therefore quite innocuous.

Curare.-One part of this famous poison was added to 218 of water, and three leares were immersed in ninety minims of the filtered solution. In $3 \mathrm{hrs} .30 \mathrm{~m}$. some of the tentacles were a little inflected; as was the blade of one, after $4 \mathrm{hrs}$. After $7 \mathrm{hrs}$. the glands were wonderfully blackened, showing that matter of some kind had beeu absorbed. In $9 \mathrm{hrs}$. two of the leaves had most of their tentacles sub-inflected, but the inflection did not increase in the course of $24 \mathrm{hrs}$. One of theso leaves, after being immersed for 9 hrs. in the solution, was placed in water, and by next morning had largely re-expanded; 
the other two, after their immersion for $24 \mathrm{hrs}$., were likewise placed in water, and in $24 \mathrm{hrs}$. were considerably re-expanded, though their glands were as black as ever. Half-minims wero placed on the dises of six leaves, and no inflection ensued; but after three days the glands on the dises appeared rather dry, yet to my surprise were not blackened. On another occasion drops were placed on the dises of six leaves, and a considerable amount of inflection was soon caused; but as I had not filtered the solution, floating particles may have acted on the glands. After $24 \mathrm{hrs}$. bits of meat were placed on the discs of three of these leaves, and next day they became strongly inflected. As I at first thought that the poison might not have been dissolved in pure water, one grain was added to 437 grains of a mixture of one part of alcohol to seven of water, and half-minims were placed on the discs of six leaves. These were not at all affected, and when after a day bits of meat were given them, they were slightly inflected in $5 \mathrm{hrs}$., and closely after $24 \mathrm{hrs}$. It follows from these several facts that a solution of curare induces a very moderate degree of inflection, and this may perhaps be due to the presence of a minute quantity of albumen. It certainly is not poisonous. The protoplasm in one of the leaves, which had been immersed for 24 hrs., and which had become slightly inflected, had undergone a very slight amount of aggregationnot more than often ensues from an immersion of this length of time in water.

Acetate of Morphia.-I tried a great number of experiments with this substance, but with no certain result. A considerable number of leaves were immersed from between $2 \mathrm{hrs}$. and $6 \mathrm{hrs}$. in a solution of one part to 218 of water, and did not become inflected. Nor were they poisoned; for when they were washed and placed in weak solutions of phosphate and carbonate of ammonia, they soon became strongly inflected, with the protoplasm in the cells well aggregated. If, however, whilst the leaves were immersed in the morphia, phosphate of ammonia was added, inflection did not rapidly ensue. Minute drops of the solution were applied in the usual manner to the secretion round between thirty and forty glands; and when, after an interval of $6 \mathrm{~m}$., bits of meat, a little saliva, or particles of glass, were placed on them, the movement of the tentacles was greatly retarded. But on other occasions no such retardation occurred. Drops of water similarly applied never have any retarding power. Minute drops of a solution of sugar of the same strength (one part to 218 of water) sometimes retarded the subsequent action of meat and of particles of glass, and 
sometimes did not do so. At one time I felt convinced that morphia acted as a narcotic on Drosera, but after having found in what a singular manner immersion in certain non-poisonous salts and acids prevents the subsequent action of phosphate of ammonia, whereas other solutions have no such power, my first eonviction seems rery doubtful.

Extract of Hyoscyamus.-Several leaves were placed, each in thirty minims of an infusion of 3 grs. of the extract sold by druggists to $1 \mathrm{oz}$. of water. One of them, after being immersed for $5 \mathrm{hrs} .15 \mathrm{~m}$., was not inflected, and was then put into a solution ( $1 \mathrm{gr}$. to $1 \mathrm{oz}$.) of carbonate of ammonia; after $2 \mathrm{hrs}$. $40 \mathrm{~m}$. it was found considerably inflected, and the glands much blackened. Four of the leaves, after being immersed for 2 hrs. 14 m., were placed in 120 minims of a solution (1 gr. to $20 \mathrm{oz}$.) of phosphate of ammonia; they had already become slightly inflected from the hyoscyamus, probably owing to the presenee of some albuminous matter, as formerly explained, but the inflection immediately increased, and after $1 \mathrm{hr}$. was strongly pronounced; so that hyoseyamus does not act as a narcotic or poison.

Poison from the Fang of a Living Adder.-Minute drops were placed on the glands of many tentacles; these were quickly infleeted, just as if saliva had been given them. Next morning, after 17 hrs, $30 \mathrm{~m}$., all were beginning to re-expand, and they appeared uninjured.

Poison fiom the Cobra.-Dr. Fayrer, well known from his investigations on the poison of this deadly snake, was so kind as to give me some in a dried state. It is an albuminous substance, and is believed to replace the ptyaline of saliva. ${ }^{*} A$ minute drop (about $\frac{1}{20}$ of a minim) of a solution of one part to 437 of water was applied to the seeretion round four glands; so that each receired only about $\frac{1}{38 \pm 00}$ of a grain (·0016 mg.). Tho operation was repeated on four other glands; and in $15 \mathrm{~m}$. several of the eight tentacles became rell inflected, and all of them in 2 hrs. Next morning, after $24 \mathrm{hrs}$, they were still inflected, and the glands of a very pale pink colour. After an additional 21 lurs. they were nearly re-expanded, and completely so on the sueceeding day; but most of the glands remained almost white.

Half-minims of the same solution were placed on the dises of three leaves, so that each receired $\frac{1}{960}$ of a grain (.0675 mg.); in

Dr. Fayrer, 'The Thanatophidia of India,' 1872, p. 150. 
4 lirs. $15 \mathrm{~m}$. the outer tentacles were much inflected; and after $6 \mathrm{hrs.} 30 \mathrm{~m}$. those on two of the leaves were closely inflected and the blade of one; the third leaf was only moderately affected. The leaves remained in the same state during the next day, but after 48 hrs. re-expanded.

Three leaves were now immersed, each in thirty minims of the solution, so that each received $\frac{1}{16}$ of a grain, or $4.048 \mathrm{mg}$. In $6 \mathrm{~m}$. there was some inflection, which steadily increased, so that after 2 hrs. $30 \mathrm{~m}$. all three leaves were closcly inflected; the glands were at first somewhat darkened, then rendered pale; and the protoplasm within the cells of the tentacles was partially aggregated. The little masses of protoplasm were examined after $3 \mathrm{hrs}$, and again after $7 \mathrm{hrs.}$, and on no other occasion have I seen them undergoing such rapid changes of form. After 8 hrs. $30 \mathrm{~m}$. the glands had become quite white; they had not secreted any great quantity of mucus. The leaves were now placed in water, and after $40 \mathrm{hr}$. re-expanded, showing that they were not much or at all injured. During their immersion in water the protoplasm within the cclls of the tentacles was occasionally examined, and always found in strong movement.

Two leaves were next immersed, each in thirty minims of a much stronger solution, of one part to 109 of water; so that each received $\frac{1}{4}$ of a grain, or $16.2 \mathrm{mg}$. After $1 \mathrm{hr}$. $45 \mathrm{~m}$. the submarginal tentacles were strongly inflected, with the glands somewhat pale; after 3 hrs. $30 \mathrm{~m}$. both leaves had all their tentacles closely inflected and the glands white. Hence the weaker solution, as in so many other cases, induced more rapid inflection than the stronger one; but the glands were sooner rendered white by the latter. After an immersion of $24 \mathrm{hrs}$. some of the tentacles were examined, and the protoplasm, still of a fine purple colour, was found aggregated into chains of small globular masses. These changed their shapes with remarkable quickness. After an immersion of $48 \mathrm{hrs}$. they were again examined, and their movements were so plain that they could easily be seen under a weak power. The leaves were now placed in water, and after 24 hrs. (i.e. $72 \mathrm{hrs}$. from their first immersion) the little masses of protoplasm, which had become of a dingy purple, were still in strong movement, changing their shapes, coaleseing, and again separating.

In 8 hrs. after these two leaves had been placed in water (i.e. in 56 hrs. after their immersion in the solution) they began to re-expand, and by the next morning were more expanded. After an additional day (i.e. on the fourth day after their immersion in the solution) they were largely, but not quite fully 
expanded. The tentacles were now examined, and the aggregated masses were almost wholly redissolved; the cells being filled with homogeneous purple fluid, with the exception here and there of a single globular mass. TTe thus see how completely the protoplasm had escaped all injury from the poison. As the glands were soon rendered quite white, it occurred to me that their texture might have been rnodified in such a mauner as to prevent the poison passing into the cells beneath, and consequently that the protoplasm within these cells had not been at all affected. Accordingly I placed another leaf, which had been immersed for $48 \mathrm{hrs}$. in the poison and afterwards for $24 \mathrm{hrs}$. in water, in a little solution of one part of carbonate of ammonia to 218 of water; in $30 \mathrm{~m}$. the protoplasm in the cells beneath the glands became darker, and in the course of 24 hrs. the tentacles were filled down to their bases with dark-coloured spherical masses. Hence the glands had not lost their power of absorption, as far as the carbonate of ammonia is concerned.

From these facts it is manifest that the poison of the cobra, though so deadly to animals, is not at all poisonous to Drosera; yet it causes strong and rapid inflection of the tentacles, and soon discharges all colour from the glands. It seems even to act as a stimulant to the protoplasm, for after considerable experience in observing the morements of this substance in Drosera, I have never seen it on any other occasion in so active a state. I was therefore anxious to learn how this poison affected animal protoplasm; and Dr. Fayrer was so kind as to make some observations for me, which he has since published.* Ciliated epithelium from the mouth of a frog was placed in a solution of . 03 gramme to $4 \cdot 6$ cubic $\mathrm{cm}$. of water; others being placed at the same time in pure water for comparison. The movements of the cilia in the solution seemed at first increased, but soon languished, and after between 15 and 20 ninutes ceased; whilst those in the water were still acting vigorously. The white corpuscles of the blood of a frog, and the cilia on two infusorial animals, a Paramæcium and Volvox, were similarly affected by the poison. Dr. Fayrer also found that the muscle of a frog lost its irritability after an immersion of $20 \mathrm{~m}$. in the solution, not then responding to a strong electrical current. On the other hand, the morements of the cilia on the mantle of an Unio were not always arlested, even when left for a consider-

* 'Proceedings of Royal Society' Feb. 18, 1875. 
able time in a very strong solution. On the whole, it seems that the poison of the cobra acts far more injuriously on the protoplasm of the higher animals than on that of Drosera.

There is one other point which may be noticed. I have occasionally observed that the drops of secretion round the glands were rendered somewhat turbid by certain solutions, and more especially by some acids, a film being formed on the surfaces of the drops; but I never saw this effect produced in so conspicuous a manner as by the cobra poison. When the stronger solution was employed, the drops appeared in $10 \mathrm{~m}$. like little white rounded clouds. After $48 \mathrm{hrs}$. the secretion was changed into threads and sheets of a membranous substance, including minute granules of various sizes.

Camphor.-Some scraped camphor was left for a day in a bottle with distilled water, and then filtered. A solution thus made is said to contain $\frac{1}{1000}$ of its weight of camphor; it smelt and tasted of this substance. Ten leaves were immersed in this solution; after $15 \mathrm{~m}$. five of them were well inflected, two showing a first trace of movement in $11 \mathrm{~m}$. and $12 \mathrm{~m}$.; the sixth leaf did not begin to move until $15 \mathrm{~m}$. had elapsed, but was fairly well inflected in $17 \mathrm{~m}$. and quite closed in $24 \mathrm{~m}$.; the seventh began to move in $17 \mathrm{~m}$., and was completely shut in $26 \mathrm{~m}$. The eighth, ninth, and tenth leaves were old and of a very dark red colour, and these were not inflected after an immersion of $24 \mathrm{hrs}$; so that in making experiments with camphor it is necessary to aroid such leaves. Some of these leaves, on being left in the solution for $4 \mathrm{hrs}$., became of a rather dingy pink colour, and secreted much mucus; although their tentacles were closely inflected, the protoplasm within the cells was not at all aggregated. On another occasion, however, after a longer immersion of $24 \mathrm{hrs}$, there was well marked aggregation. A solution made by adding two drops of camphorated spirits to an ounce of water did not act on one leaf; whereas thirty minims added to an ounce of water acted on two leaves immersed together.

M. Vogel has shown* that the flowers of various plants do not wither so soon when their stems are placed in a solution of camphor as when in water; and that if already slightly withered, they recover more quickly. The germination of certain seeds is also accelerated by the solution. So that camphor acts as a stimulant, and it is the only known stimulant for plants. I

* 'Gardener's Chronicle,' 1874, p. 671. Nearly similar observations were made in 1798 by B. S. Barton. 
wished, therefore, to ascertain whether camphor would render the leaves of Drosera more sensitive to mechanical irritation than they naturally are. Six leaves were left in distilled water for $5 \mathrm{~m}$. or $6 \mathrm{~m}$., and then gently brushed twice or thrice, whilst still under water, with a soft camel-hair brush; but no morement ensued. Nine leaves, which had been immersed in the abore solution of camphor for the times stated in the following table, were next brushed only once with the same brush and in the same manner as before; the results are given in the table. My first trials were made by brushing the leaves whilst still immersed in the solution; but it occurred to me that the viscid secretion round the glands would thus be removed, and the camphor might act more effectually on them. In all the following trials, therefore, each leaf was taken out of the solution, waved for about $15 \mathrm{~s}$. in water, then placed in fresh water and brushed, so that the brushing would not allow the freer access of the camphor; but this treatment made no difference in the results.

\begin{tabular}{|c|c|c|c|}
\hline 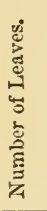 & $\begin{array}{c}\text { Length of } \\
\text { Immersion in } \\
\text { the Solution } \\
\text { of Camphor. }\end{array}$ & $\begin{array}{l}\text { Length of Time between the Act of Brushing } \\
\text { and the Inflection of the Tentacles. }\end{array}$ & $\begin{array}{l}\text { Length of } \\
\text { Time between } \\
\text { the Immersion } \\
\text { of the Leaves in } \\
\text { the Solution } \\
\text { and the First } \\
\text { Sign of the } \\
\text { Inflection of the } \\
\text { Tentacles. } \\
\end{array}$ \\
\hline 1 & $5 \mathrm{~m}$. & $\left\{\begin{array}{r}3 \mathrm{~m} \text {. considerable inflection ; } 4 \mathrm{~m} \text {. all } \\
\text { the tentacles except } 3 \text { or } 4 \text { inflected. }\end{array}\right\}$ & $8 \mathrm{~m}$. \\
\hline 2 & $5 \mathrm{~m}$. & $6 \mathrm{~m}$. first sign of inflection. & $11 \mathrm{~m}$. \\
\hline 3 & $5 \mathrm{~m}$. & $\left\{\begin{array}{l}6 \mathrm{~m} .30 \mathrm{~s} . \text { slight inflection; } 7 \mathrm{~m} .30 \mathrm{~s} . \\
\text { plain inflection. }\end{array}\right.$ & $11 \mathrm{~m} .30 \mathrm{~s}$ \\
\hline 4 & $4 \mathrm{~m} .30 \mathrm{~s}$. & $\left\{\begin{array}{c}2 \mathrm{~m} .30 \mathrm{~s} . \text { a trace of inflection ; } 3 \mathrm{~m} . \\
\text { plain } ; 4 \mathrm{~m} \text {. strongly marked. }\end{array}\right\}$ & $7 \mathrm{~m}$. \\
\hline 5 & $4 \mathrm{~m}$. & $\left\{\begin{array}{l}2 \mathrm{~m} .30 \text { s. a trace of inflection; } 3 \mathrm{~m} . \\
\text { plain inflection. }\end{array}\right.$ & $6 \mathrm{~m} .30 \mathrm{~s}$ \\
\hline 6 & $4 \mathrm{~m}$. & $\left\{\begin{array}{c}2 \mathrm{~m} .30 \mathrm{~s} . \text { decided inflection; } 3 \mathrm{~m} .30 \mathrm{~s} . \\
\text { strongly marked. }\end{array}\right\}$ & $6 \mathrm{~m} .30 \mathrm{~s}$. \\
\hline 7 & $4 \mathrm{~m}$. & $\left\{\begin{array}{l}2 \mathrm{~m} .30 \mathrm{~s} . \text { slight inflection; } 3 \mathrm{~m} . \\
\text { plain } ; 4 \mathrm{~m} \text {. well marked. }\end{array}\right\}$ & $6 \mathrm{~m} .30 \mathrm{~s}$ \\
\hline S & $3 \mathrm{~m}$. & $\left\{\begin{array}{c}2 \mathrm{~m} \text {. trace of inflection; } 3 \mathrm{~m} \text {. con- } \\
\text { siderable, } 6 \mathrm{~m} \text {. strong inflection. }\end{array}\right\}$ & $5 \mathrm{~m}$. \\
\hline 9 & $3 \mathrm{~m}$. & $\left\{\begin{array}{c}2 \mathrm{~m} \text {. trace of inflection; } 3 \mathrm{~m} . \text { con- } \\
\text { siderable, } 6 \mathrm{~m} \text {. strong inflection. }\end{array}\right\}$ & $5 \mathrm{~m}$. \\
\hline
\end{tabular}

Other leaves were left in the solution without being brushed; one of these first showed a trace of inflection after $11 \mathrm{~m}$; a second after $12 \mathrm{~m}$; fire were not inflected until $15 \mathrm{~m}$. had 
elapsed, and two not until a few minutes later. On the other hand, it will be seen in the right-hand column of the table that most of the leaves subjected to the solution, and which were brushed, became inflected in a much shorter time. The movement of the tentacles of some of these leaves was so rapid that it could be plainly seen through a very weak lens.

Two or three other experiments are worth giving. A large old leaf, after being immersed for $10 \mathrm{~m}$. in the solution, did not appear likely to be soon inflected; so I brushed it, and in $2 \mathrm{~m}$. it began to move, and in $3 \mathrm{~m}$. was completely shut. Another leaf, after an immersion of $15 \mathrm{~m}$., showed no signs of inflection, so was brushed, and in $4 \mathrm{~m}$. was grandly inflected. A third leaf, after an immersion of $17 \mathrm{~m}$., likcwise showed no signs of inflection; it was then brushed, but did not move for $1 \mathrm{hr}$.; so that here was a failure. It was again brushed, and now in $9 \mathrm{~m}$. a few tentacles became inflected; the failure therefore was not complete.

We may conclude that a small dose of camphor in solution is a powerful stimulant to Drosera. It not only soon excites the tentacles to bend, but apparently renders the glands sensitive to a touch, which by itself does not cause any movement. Or it may be that a slight mechanical irritation not enough to canse any inflection yet gives some tendency to movement, and thus reinforces the action of the camphor. This latter view would have appeared to me the more probable one, had it not been shown by M. Vogel that camphor is a stimulant in other ways to various plants and seeds.

Two plants bearing four or five leaves, and with their roots in a little cup of water, were exposed to the vapour of some bits of camphor (about as large as a filbert-nut), under a vessel holding ten fluid ounces. After $10 \mathrm{hrs}$. no inflection ensued; but the glands appeared to be secreting more copiously. The leaves were in a narcotised condition, for on bits of meat being placed on two of them, there was no inflection in $3 \mathrm{hrs}$. $15 \mathrm{~m}$., and even after 13 hrs. $15 \mathrm{~m}$. only a few of the outer tentacles were slightly inflected; but this degree of movement shows that the leaves had not been killed by an exposure during $10 \mathrm{hrs}$. to the vapour of camphor.

Oil of Caraway. - Water is said to dissolve about a thousandth part of its weight of this oil. A drop was added to an ounce of water and the bottle occasionally shaken during a day; but many minute globules remained undissolved. Five leaves were immersed in this mixture; in from $4 \mathrm{~m}$. to $5 \mathrm{~m}$. there was corne inflection, which became moderately pronounced in two or 
three additional minutes. After $14 \mathrm{~m}$. al'. five leaves were well, and some of them elosely, inflected. After 6 hrs. the glands were white, and much mucus had been secreted. The leaves were now flaccid, of a peculiar dull-red colour, and evidently dead. One of the leaves, after an immersion of $4 \mathrm{~m}$., was brushed, like the leaves in the camphor, but this produced no effect. A plant with its roots in water was exposed under a $10-\mathrm{oz}$. vessel to the vapour of this oil, and in $1 \mathrm{hr} .20 \mathrm{~m}$. one leaf showed a trace of inflection. After 5 hrs. $20 \mathrm{~m}$. the cover was taken off and the leaves examined; one had all its tentacles closely inflected, the second about half in the same state; and the third all subinflected. The plant was left in the open air for $42 \mathrm{hrs}$., but not a single tentacle expanded; all the glands appeared dead, except here and there one, which was still secreting. It is evident that this oil is highly exciting and poisonous to Drosera.

Oil of Cloves. - A mixture was made in the same manner as in the last case, and three leaves were immersed in it. After $30 \mathrm{~m}$. there was only a trace of inflection which never increased. After $1 \mathrm{hr} .30 \mathrm{~m}$. the glands were pale, and after $6 \mathrm{hrs}$. white. No doubt the' leares were much injured or killed.

Turpentine.-Small drops placed on the dises of some leaves killed them, as did likewise drops of creosote. A plant was left for $15 \mathrm{~m}$. under a 12-oz. vessel, with its inner surface wetted with twelve drops of turpentine; but no movement of the tentacles ensued. After 24 hrs. the plant was dead.

Glycerine.-Half-minims were placed on the dises of three leares: in $2 \mathrm{hrs}$. some of the outer tentacles were irregularly inflected; and in $19 \mathrm{hrs}$. the leares were flaccid and apparently dead; the glands which had touched the glycerine were colourless. Minute drops (about $\frac{1}{20}$ of a minim) were applied to the glands of several tentacles, and in a few minutes these mored and soon reached the centre. Similar drops of a mixture of four dropped drops to $1 \mathrm{oz}$. of water were likewise ápplied to several glands; but only a fer of the tentacles moved, and these very slowly and slightly. Half-minims of this same mix. ture placed on the discs of some leaves caused, to my surprise, no inflection in the course of $48 \mathrm{hrs}$. Bits of meat were then giren them, and next day they were well inflected; notwithstanding that some of the discal glands had been rendered almost colourless. Two leaves were immersed in the same mixture, but only for $4 \mathrm{hrs}$; they were not inflectel, and on being afterwards left for 2 hrs. $30 \mathrm{~m}$. in a solution ( $1 \mathrm{gr}$. to $1 \mathrm{oz}$.) of carbonate of ammonia, their glands were blackened, their tentacles inflected, and the protoplasm within their cells aggregater. It appears 
from these facts that a mixture of four drops of glyeerine to an ounce of water is not poisonous, and excites very little inflection; but that pure glycerine is poisonous, and if applied in very minute quantities to the glands of the outer tentacles causes their inflection.

The Effects of Immersion in Water and in various Solutions on the subsequent Action of Phosphate and Carbonate of Ammonia.We have seen in the third and seventh chapters that immersion in distilled water causes after a time some degree of aggregation of the protoplasm, and a moderate amount of inflection, especially in the case of plants which have been kept at a rather high temperature. Water does not excite a copious secretion of mucus. We have here to consider the effects of immersion in various fluids on the subsequent action of salts of ammonia and other stimulants. Four leaves which had been left for $24 \mathrm{hrs}$. in water were given bits of meat, but did not clasp them. Ten leaves, after a similar immersion, were left for $24 \mathrm{hrs}$. in a powerful solution ( $1 \mathrm{gr}$. to $20 \mathrm{oz}$.) of phosphate of ammonia, and only one showed even a trace of inflection. Three of these leaves, on being left for an additional day in the solution, still remained quite unaffected. When, however, some of these leaves, which had been first immersed in water for 24 hrs., and then in the phosphate for 24 hrs. were placed in a solution of carbonate of ammonia (one part to 218 of water), the protoplasm in the cells of the tentacles became in a few hours strongly aggregated, showing that this salt had been absorbed and taken effect.

A short immersion in water for $20 \mathrm{~m}$. did not retard the subsequent action of the phosphate, or of splinters of glass placed on the glands; but in two instances an immersion for $50 \mathrm{~m}$. prevented any effect from a solution of eamphor. Several leaves which had been left for $20 \mathrm{~m}$. in a solution of one part of white sngar to 218 of water were placed in the phosphate solution, the action of which was delayed; whereas a mixed solution of sugar and the phosphate did not in the least interfere with the effects of the latter. 'Three leaves, after being immersed for $20 \mathrm{~m}$. in the sugar solution, were placed in a solution of carbonate of ammonia (one part to 218 of water); in $2 \mathrm{~m}$. or $3 \mathrm{~m}$. the glands were blackened, and after $7 \mathrm{~m}$. the tentacles were considerably inflected, so that the solution of sugar, though it delayed the action of the phosphate, did not delay that of the carbonate. Immersion in a similar solution of gum arabic for $20 \mathrm{~m}$. had no retarding action on the phosphate. Three leaves were left for $20 \mathrm{~m}$. in a mixture of one part of alcohol to seven parts of water, 
and then placed in the phosphate solution : in 2 hrs. $15 \mathrm{~m}$. there was a trace of inflection in one leaf, and in 5 hrs. $30 \mathrm{~m}$. a second was slightly affected; the inflection subsequently increased, though slowly. Hence diluted alcohol, which, as we shall see, is hardly at all poisonous, plainly retards the subsequent action of the phosphate.

It was shown in the last chapter that leaves which did not become inflected by nearly a day's immersion in solutions of various salts and acids behaved very differently from one another when subsequently placed in the phosphate solution. I here give a table summing up the results.

\begin{tabular}{|c|c|c|}
\hline $\begin{array}{l}\text { Name of the S } \\
\text { Acids in Sulu }\end{array}$ & $\begin{array}{l}\text { Period of } \\
\text { Immersion } \\
\text { of the } \\
\text { Leaves in } \\
\text { Solutions } \\
\text { of one part } \\
\text { to } 437 \text { of } \\
\text { water. }\end{array}$ & $\begin{array}{l}\text { Effects produced on the Leaves by their subse- } \\
\text { quent Inmersion for stated periods in a } \\
\text { Sulution of one part of phosphate of } \\
\text { ammonia to } 8750 \text { of water, or } 1 \mathrm{gr} \text {. to } \\
20 \mathrm{oz} \text {. }\end{array}$ \\
\hline Tubidium chloride. & $22 \mathrm{hrs}$. & $\begin{array}{l}\text { After } 30 \mathrm{~m} \text {. strong inflection of the } \\
\text { tentacles. }\end{array}$ \\
\hline Potassium carbonate & $20 \mathrm{~m}$. & $\begin{array}{l}\text { Scarcely any inflection until } 5 \text { hrs. } \\
\text { had elapsed. }\end{array}$ \\
\hline Calcium acetate & $2 \pm$ hrs. & After 24 lirs. very slight inflection. \\
\hline Calcium & $2+\mathrm{hrs}$. & Do. do. \\
\hline Magnesium acetate. & $22 \mathrm{hrs}$. & $\begin{array}{l}\text { Some slight inflection, which became } \\
\text { well pronounced in } 24 \text { hrs. }\end{array}$ \\
\hline Magnesium nitrate. & 22 hrs. & $\begin{array}{l}\text { After } 4 \text { hrs. } 30 \mathrm{~m} \text {. a fair amount of } \\
\text { inflection, which never increased. }\end{array}$ \\
\hline Magnesium chloride & 22 hrs. & $\begin{array}{l}\text { After a few minutes great inflection; } \\
\text { after } 4 \text { hrs. all four leaves with almost } \\
\text { every tentacle closely inflected. }\end{array}$ \\
\hline Barium acetate. & 22 hrs. & $\begin{array}{l}\text { After } 24 \text { hrs. two leaves out of four } \\
\text { slightly inflected. }\end{array}$ \\
\hline Barium nitrate. & $22 \mathrm{hrs}$. & $\begin{array}{l}\text { After } 30 \mathrm{~m} \text {. one leaf greatly, and two } \\
\text { others moderately, inflected; they } \\
\text { remained thus for } 24 \text { hrs. }\end{array}$ \\
\hline Strontium acetate & 22 hrs. & $\begin{array}{l}\text { After } 25 \mathrm{~m} \text {. two leaves greatly in- } \\
\text { flected; after } 8 \text { hrs. a third leaf } \\
\text { - moderately, and the fourth very } \\
\text { slightly, inflected. All four thus } \\
\text { remained for } 24 \text { hrs. }\end{array}$ \\
\hline Strontium nitrate & 22 hrs. & $\begin{array}{l}\text { After } 8 \text { hrs. three leaves out of five } \\
\text { moderately inflceted; after } 2 t \text { lirs. } \\
\text { all five in this state; but not one } \\
\text { closely inflected. }\end{array}$ \\
\hline Altuminium chloricle & $21 \mathrm{hrs}$. & $\begin{array}{l}\text { Three leaves which had either been } \\
\text { slightly or not at all afferted by tho } \\
\text { chloride became after } 7 \text { hrs. } 30 \mathrm{~m} \text {. } \\
\text { rather closely intlected. }\end{array}$ \\
\hline
\end{tabular}




\begin{tabular}{|c|c|c|}
\hline $\begin{array}{l}\text { Name of the Salts and } \\
\text { Acids in Solution. }\end{array}$ & $\begin{array}{c}\text { Period of } \\
\text { Immersion } \\
\text { of the } \\
\text { Leaves in } \\
\text { Solutions } \\
\text { of one part } \\
\text { to } 437 \text { of } \\
\text { water. }\end{array}$ & $\begin{array}{l}\text { Effects produced on the Leaves by their sub- } \\
\text { sequent Immersion for stated periods in a } \\
\text { Solution of one part of phosphate of } \\
\text { ammonia to } 8750 \text { of water, or } 1 \text { gr. to } \\
20 \mathrm{oz} \text {. }\end{array}$ \\
\hline Aluminium nitrate. & $2+$ hrs. & Aftèr 25 hrs. slight and doubtful effect. \\
\hline Lead chloride . & $23 \mathrm{hrs}$. & $\begin{array}{l}\text { After } 24 \text { hrs. two leaves somewhat } \\
\text { inflected, the third very little; and } \\
\text { thus remained. }\end{array}$ \\
\hline Manganese chloride & 22 hrs. & After 48 hrs. not the least inflection. \\
\hline Lactie acid . . & 48 hrs. & $\begin{array}{l}\text { After } 24 \text { hrs. a trace of inflection in } \\
\text { a few tentacles, the glands of } \\
\text { which had not been killed by the } \\
\text { aeid. }\end{array}$ \\
\hline Tannic acid . & 24 hrs. & After 24 hrs. no inflection. " \\
\hline Tartaric acid . & $2 \pm$ hrs. & Do. do. \\
\hline Citrie acid . . & 24 lirs. & $\begin{array}{l}\text { After } 50 \mathrm{~m} \text {. tentacles decidedly in- } \\
\text { flected, and after } 5 \text { hrs. strongly } \\
\text { infleeted; so remained for the next } \\
2 t \text { hrs. }\end{array}$ \\
\hline Formic acid . & $22 \mathrm{hrs}$. & $\begin{array}{l}\text { Not observed until } 24 \text { hrs. had elapsed; } \\
\text { tentacles considerably inflected, and } \\
\text { protoplasm aggregated. }\end{array}$ \\
\hline
\end{tabular}

In a large majority of these twenty cases, a varying degree of inflection was slowly caused by the phosphate. In four cases, however, the inflection was rapid, occurring in less than half an hour or at most in $50 \mathrm{~m}$. In three cases the phosphate did not produce the least effect. Now what are we to infer from these facts? We know from ten trials that immersion in distilled water for 24 hrs. prevents the subsequent action of the phosphate solution. It would, therefore, appear as if the solutions of chloride of manganese, tannic and tartaric acids, which are not poisonons, acted exactly like water, for the phosphate produced no effect on the leaves which had been previously immersed in these three solutions. The majority of the other solutions behaved to a certain extent like water, for the phosphate produced, after a considerable interval of time, only a slight effect. On the other hand, the leaves which had been immersed in the solutions of the chloride of rubidium and magnesium, of acetate of strontium, nitrate of barium, and citric acid, were quickly acted on by the phosphate. Now was water absorbed from these five weak solutions, and yet, owing to the presence of the saits, did not prevent the subsequent action of the phosphate? Or 
may we not suppose * that the interstices of the walls of the glands were blocked up with the molecules of these five substances, so that they were rendered impermeable to water; for had water entered, we know from the ten trials that the phosphate would not afterwards have produced any effect? It further appears that the molecules of the carbonate of ammonia ean quickly pass into glands which, from having been immersed for $20 \mathrm{~m}$. in a weak solution of sugar, either absorb the phosphate very slowly or are acted on by it very slowly. On the other hand, glands, however they may have been treated, seem easily to permit the subsequent entrance of the molecules of carbonate of ammonia. Thus leaves which had been immersed in a solution (of one part to 437 of water) of nitrate of potassium for 48 hrs.-of sulphate of potassium for 24 hrs. - and of the chloride of potassium for $25 \mathrm{hrs}$. - on being placed in a solution of one part of carbonate of ammonia to 218 of water, had their glands immediately blackened, and after $1 \mathrm{hr}$. their tentacles somewhat inflected, and the protoplasm aggregated. But it wonld be an endless task to endeavour to ascertain the wonderfully diversified effects of various solutions on Drosera.

Alcohol (one part to seren of water). - It has already been shown that half-minims of this strength placed on the dises of leares do not cause any inflection; and that when two days afterwards the leaves were given bits of meat, they became strongly inflected. Four leaves were immersed in this mixture, and two of them after $30 \mathrm{~m}$. were brushed with a camel-hair brush, like the leaves in the solution of camphor, but this produced no effect.

* See Dr. M. Traube's eurious experiments on the production of artificial cells, and on their permeability to various salts, described in his papers: "Experimente zur 'Theorie der 'Zellenbildung und Endosmose," Breslau, 1866 ; and "Experimente zur physicalischen Erklärung der Bildung der Zellhaut, ihres Wachsthums durch Intussusception," Breslau, 187t. These researches perhaps explain my results. Dr. 'Traube commonly employed as a membrane the precipitate formed when tamnic acid comes into contact with a solution of grelatine.
By allowing a precipitation of sulphate of barium to take place at the same time, the membrane becomes "infiltrated" with this salt; and in consequence of the intercalation of molecules of sulphate of barium among those of the gelatine precipitate, the molecular interstices in the membrane are made smaller. In this altered condition, the membrane no longer allows the passage through it of cither sulphate of ammonia or nitrate of barium, though it retains its permeability for water and chloride of ammonia. 
Nor did these four leaves, on being left for $24 \mathrm{hrs}$. in the diluted alcohol, undergo any inflection. They were then removed; one being placed in an infusion of raw meat, and bits of meat on the discs of the other three, with their stalks in water. Next day one seemed a little injured, whilst two others showed merely a trace of inflection. We must, however, bear in mind that immersion for $24 \mathrm{hrs}$. in water prevents leaves from clasping meat. Hence alcohol of the above strength is not poisonous, nor does it stimulate the leaves like camphor does.

The vapour of alcohol acts differently. A plant having three good leaves was left for $25 \mathrm{~m}$. under a receiver holding $19 \mathrm{oz}$. with sixty minims of alcohol in a watch-glass. No movement ensued, but some few of the glands were blackened and shrivelled, whilst many became quite pale. These were scattered over all the leaves in the most irregular manner, reminding me of the manner in which the glands were affected by the vapour of carbonate of ammonia. Immediately on the removal of the receiver particles of raw meat were placed on many of the glands, those which retained their proper colour being chiefly selected. But not a single tentacle was inflected during the next 4 hrs. After the first 2 hrs. the glands on all the tentacles began to dry; and next morning; after 22 hrs., all three leaves appeared almost dead, with their glands dry; the tentacles on one leaf alone being partially inflected.

A second plant was left for only $5 \mathrm{~m}$. with some alcohol in a watch-glass, under a 12-oz. receiver, and particles of meat were then placed on the glands of sereral tentacles. After $10 \mathrm{~m}$. some of them began to curve inwards, and after $55 \mathrm{~m}$. nearly all were considerably inflected; but a few did not move. Some anæsthethic effect is here probable, but by no means certain. A third plant was also left for $5 \mathrm{~m}$. under the same small vessel, with its whole inner surface wetted with about a dozen drops of alcohol. Particles of meat were now placed on the glands of several tentacles, some of which first began to move in $25 \mathrm{~m}$. ; after $40 \mathrm{~m}$. most of them were somewhat inflected, and after $1 \mathrm{hr} .10 \mathrm{~m}$. almost all were considerably inflected. From their slow rate of movement there can be no doubt that the glands of these tentacles had been rendered insensible for a time by - exposure during $5 \mathrm{~m}$. to the vapour of alcohol.

Vapour of Chloroform. - The action of this vapour on Drosera is very variable, depending, I suppose, on the constitution or age of the plant, or on some unknown condition. It sometimes causes the tentacles to move with extraordinary rapidity, and sometimes produces no such effect. The glands are sometimes 
rendered for a time insensible to the action of raw meat, but sometimes are not thus affected, or in a very slight degree. A plant recovers from a small dose, but is easily killed by a larger one.

A plant was left for $30 \mathrm{~m}$. under a bell-glass holding 19 fluid oz. (539.6 ml.) with eight drops of chloroform, and before the cover was removed, most of the tentacles became much inflected, though they did not reach the centre. After the cover was removed, bits of meat were placed on the glands of several of the somewhat incurved tentacles; these glands were found much blackened after 6 hrs. $30 \mathrm{~m}$., but no further movement ensued. After $24 \mathrm{hrs}$. the leaves appeared almost dead.

A smaller bell-glass, holding 12 fluid oz. ( $310 \cdot 8 \mathrm{ml}$.), was now employed, and a plant was left for $90 \mathrm{~s}$. under it, with only two drops of chloroform. Immediately on the removal of the glass all the tentacles curved inwards so as to stand perpendicularly up; and some of them conld actually be seen moving with extraordinary quickness by little starts, and therefore in an unnatural manner; but they never reached the centre. After 22 hrs. they fully re-expanded, and on meat being placed on their glands, or when roughly touched by a needle, they promptly became inflected; so that these leares had not been in the least injured.

Another plant was placed under the same small bell-glass with three drops of chloroform, and before two minutes had elapsed, the tentacles began to curl inwards with rapid little jerks. The glass was then removed, and in the course of two or three additional minutes almost every tentacle reached the centre. On- several other occasions the vapour did not excite any movement of this kind.

There seems also to be great variability in the degree and manner in which chloroform renders the glands insensible to the subsequent action of meat. In the plant last referred to, which had been exposed for $2 \mathrm{~m}$. to three drops of chloroform, some few tentacles curved up only to a perpendicular position, and particles of meat were placed on their glands; this caused them in $5 \mathrm{~m}$. to begin moring, but they mored so slowly that they did not reach the centre until $1 \mathrm{hr} .30 \mathrm{~m}$. had elapsed. Another plant was similarly exposed, that is, for $2 \mathrm{~m}$. to three drops of chloroform, and on particles of meat being placed on the glands of several tentacles, which had curved up into a perpendicular position, one of these began to bend in $8 \mathrm{~m}$., but alterwards moved very slowly; whilst none of the other tentacles 
moved for the next $40 \mathrm{~m}$. Nevertheless, in $1 \mathrm{hr} .45 \mathrm{~m}$. from the time when the bits of meat had been given, all the tentacles reached the centre. In this case some slight anæsthetic effect apparently had been produced. On the following day the plant had perfectly recovered.

Another plant bearing two leaves was exposed for $2 \mathrm{~m}$. under the 19-oz. vessel to two drops of chloroform; it was then taken out and examined; again exposed for $2 \mathrm{~m}$. to two drops; taken out, and re-exposed for $3 \mathrm{~m}$. to three drops; so that altogether it was exposed alternately to the air and during $7 \mathrm{~m}$. to the vapour of seven drops of chloroform. Bits of meat were now placed on thirteen glands on the two leaves. On one of these leaves, a single tentacle first began moving in $40 \mathrm{~m}$., and two others in $54 \mathrm{~m}$. On the second leaf some tentacles first moved in $1 \mathrm{hr} .11 \mathrm{~m}$. After $2 \mathrm{hrs}$. many tentacles on both leaves were inflected; but none had reached the centre within this time. In this case there could not be the least doubt that the chloroform had exerted an anæsthetic influence on the leaves.

On the other hand, another plant was exposed under the same vessel for a much longer time, viz. $20 \mathrm{~m}$., to twice as much chloroform. Bits of meat were then placed on the glands of many tentacles, and all of them, with a single exception, reached the centre in from $13 \mathrm{~m}$. to $14 \mathrm{~m}$. In this case, little or no anæsthetic effect had been produced; and how to reconcile. these discordant results, I know not.

Vupour of Sulphuric Ether.-A plant was exposed for $30 \mathrm{~m}$. to thirty minims of this ether in a vessel holding $19 \mathrm{oz}$; and bits of raw meat were afterwards placed on many glands which had become pale-coloured; but none of the tentacles moved. After 6 hrs. $30 \mathrm{~m}$. the leaves appeared sickly, and the diseal glands were almost dry. By the next morning many of the tentacles were dead, as were all those on which meat had been placed; showing that matter had been absorbed from the meat which had increased the evil effects of the vapour. After four days the plant itself died. Another plant was exposed in the same vessel for $15 \mathrm{~m}$. to forty minims. One young, small, and tender leaf had all its tentacles inflected, and seemed much injured. Bits of raw meat were placed on several glands on two other and older leares. These glands became dry after $6 \mathrm{hrs.}$, and seemed injured; the tentacles never moved, excepting one which was ultimately a little inflected. The glands of the other tentacles continued to secrete, and appeared uninjured, but the whole plant after three days became very sickly. 
In the two foregoing experiments the doses were evidently too large and poisonous. With weaker doses, the anæsthetic effect was variable, as in the case of chloroform. A plant was exposed for $5 \mathrm{~m}$. to ten drops under a 12-oz. vessel, and bits of meat were then placed on many glands. None of the tentacles thus treated began to move in a decided manner until $40 \mathrm{~m}$. had elapsed; but then some of them mored very quickly, so that two reached the centre after an additional interval of only $10 \mathrm{~m}$. In 2 hrs. $12 \mathrm{~m}$. from the time when the meat was given, all the tentacles reached the centre. Another plant, with two leares, was exposed in the same vessel for $5 \mathrm{~m}$. to a rather larger dose of ether, and bits of meat were placed on several glands. In this case one tentacle on each leaf began to bend in $5 \mathrm{~m}$.; and after $12 \mathrm{~m}$. two tentacles on one leaf, and one on the second leaf, reached the centre. In $30 \mathrm{~m}$. after the meat had been given, all the tentacles, both those with and without meat, were closely inflected; so that the ether apparently had stimulated these leares, causing all the tentacles to bend.

Vupour of Nitric Ether.-This vapour seems more injurious than that of sulphuric ether. A plant was exposed for $5 \mathrm{~m}$. in a 12oz. vessel to eight drops in a watch-glass, and I distinctly saw a few tentacles curling inwards before the glass was removed. Immediately afterwards bits of meat were placed on three glands, but no movement ensued in the course of $18 \mathrm{~m}$. The same plant was placed again under the same vessel for $16 \mathrm{~m}$. with ten drops of the ether. None of the tentacles moved, and next morning those with the meat were still in the same position. After $48 \mathrm{hrs}$. one leaf seemed healthy, but the others were much injured.

Another plant, having two good leaves, was exposed for $6 \mathrm{~m}$. under a 19-oz. vessel to the rapour from ten minims of the ether, and bits of meat were then placed on the glands of many tentacles on both leaves. After $36 \mathrm{~m}$. several of them on one leaf became inflected, and after $1 \mathrm{hr}$. almost all the tentacles, those with and without meat, nearly reached the centre. On the other leaf the glands began to dry in $1 \mathrm{hr} .40 \mathrm{~m}$., and after several hours not a single tentacle was inflected; but by the next morning, after 21 hrs., many were inflected, though they seemed much injured. In this and the previous experiment, it is doubtful, owing to the injury which the leares had suffered, whether any anæsthetic effect had been produced.

A third plant, having two good leaves, was exposed for only $4 \mathrm{~m}$. in the 19-oz. vessel to the vapour from six drops. Bits of meat were then placed on the glands of seven tentacles on the 
same leaf. A single tentacle moved after $1 \mathrm{hr} .23 \mathrm{~m}$; after 2 hrs. $3 \mathrm{~m}$. several were inflected; and after $3 \mathrm{hrs.} 3 \mathrm{~m}$. all the seven tentacles with meat were well inflected. From the slowness of these movements it is clear that this leaf had been rendered insensible for a time to the action of the meat. A second leaf was rather differently affected; bits of meat were placed on the glands of five tentacles, three of which were slightly inflected in $28 \mathrm{~m}$.; after $1 \mathrm{hr}$. $21 \mathrm{~m}$. one reached the centre, but the other two were still only slightly inflected; after 3 hrs. they were much more inflected; but even after 5 hrs. $16 \mathrm{~m}$. all five had not reached the centre. Although some of the tentacles began to move moderately soon, they afterwards moved with extreme slowness. By next morning, after $20 \mathrm{hrs.}$, most of the tentacles on both leaves were closely inflected, but not quite regularly. After 48 hrs. neither leaf appeared injured, though the tentacles were still inflected; after $72 \mathrm{hrs}$. une was almost dead, whilst the other was re-expanding and recovering.

Carbonic Acid.-A plant was placed under a 122-oz. bell-glass filled with this gas and standing over water; but I did not make sufficient allowance for the absorption of the gas by the water, so that towards the latter part of the experiment some air was drawn in. After an exposure of 2 hrs. the plant was removed, and bits of raw meat placed on the glands of three leares. One of these leaves hung a little down, and was at first partly and soon afterwards completely covered by the water, which rose within the vessel as the gas was absorbed. On this latter leaf the tentacles, to which meat had been given, became well inflected in $2 \mathrm{~m} .30 \mathrm{~s}$, that is, at about the normal rate; so that until I remembered that the leaf had been protected from the gas, and might perhaps have absorbed oxygen from the water which was continually drawn inwards, I falsely concluded that the carbonic acid had produced no effect. On the other two leaves, the tentacles with meat behaved very differently from those on the first leaf; two of them first began to move slightly in $1 \mathrm{hr} .50 \mathrm{~m}$., always reckoning from the time when the meat was placed on the glands-were plainly inflected in $2 \mathrm{hrs}$. $22 \mathrm{~m}$.- and in 3 hrs. $22 \mathrm{~m}$. reached the centre. Three other tentacles did not begin to move until $2 \mathrm{hrs.} 20 \mathrm{~m}$. had elapsed, but reached the centre at about the same time with the others, viz. in $3 \mathrm{hrs} .22 \mathrm{~m}$.

This experiment was repeated several times with nearly the same results, excepting that the interval before the tentacles began to move varied a little. I will give only one other case. 
A plant was exposed in the same ressel to the gas for $45 \mathrm{~m}$., and bits of meat were then placed on four glands. But the tentacles did not move for $1 \mathrm{hr} .40 \mathrm{~m}$.; after 2 hrs. $30 \mathrm{~m}$. all four were well inflected, and after $3 \mathrm{hrs}$. reached the centre.

The following singular phenomenon sometimes, but by no means always, occurred. A plant was immersed for 2 his., and bits of meat were then placed on several glands. In the course of $13 \mathrm{~m}$. all the submarginal tentacles on one leaf became considerably inflected; those with the meat not in the least degree more than the others. On a second leaf, which was rather old, the tentacles with meat, as well as a few others, were moderately inflected. On a third leaf all the tentacles were closely inflected, though meat had not been placed on any of the glands. This movement, I presume, may be attributed to excitement from the absorption of oxygen. The last-mentioned leaf, to which no meat had been given, was fully re-expanded after 24 hrs.; whereas the two other leaves had all their tentacles elosely inflected over the bits of meat which by this time had been carried to their centres. Thus these three leaves had perfectly recovered from the effects of the gas in the course of $24 \mathrm{hr}$.

On another occasion some fine plants, aiter having been left for 2 hrs. in the gas, were immediately given bits of meat in the usual manner, and on their exposure to the air most of their tentacles became in $12 \mathrm{~m}$. curved into a rertical or sub-rertical position, but in an extremely irregular manner; some only on one side of the leaf and some on the other. They remained in this position for some, time; the tentacles with the bits of meat not having at first moved more quickly or farther inwards than the others withont meat. But after 2 hrs. $20 \mathrm{~m}$. the former began to move, and steadily went on bending until they reached the centre. Next morning, after $22 \mathrm{hrs}$, all the tentacles on these leares were closely clasped over the meat which had been carried to their centres; whilst the vertical and sub-rertical tentacles on the other leaves to which no meat had been given had fully re-expanded. Judging, however, from the subsequent action of a weak solution of carbonate of ammonia on one of these latter leares, it had not perfectly recorered its excitability and power of movement in $22 \mathrm{hrs}$; but another leaf, after an additional 24 hrs., had completely recovered, judging from the manner in which it clasped a fly placed on its disc.

I will give only one other experiment. After the exposure of a plant for 2 hrs. to the gas, one of its leaves was immersed in a rather strong solution of carbonate of ammonia, together with 
a fresh leaf from another plant. The latter had most of its tentacles strongly inflected within $30 \mathrm{~m}$.; whereas the leaf which had been exposed to the carbonic acid remained for $24 \mathrm{hrs}$. in the solution without undergoing any inflection, with the exception of two tentacles. This leaf had been almost completely paralysed, and was not able to recover its sensibility whilst still in the solution, which from having been made with distilled water probably contained little oxygen.

\section{Concluding Remarlis on the Effects of the foregoing} Agents.-As the glands, when excited, transmit some influence to the surrounding tentacles, causing them to bend and their glands to pour forth an increased amount of modified secretion, I was anxious to ascertain whether the leaves included any element having the nature of nerve-tissue, which, though not continuous, served as the channel of transmission. This led me to try the several alkaloids and other substances which are known to exert a powerful influence on the nervous system of animals. I was at first encouraged in my trials by finding that strychnine, digitaline, and nicotine, which all act on the nervous system, were poisonous to Drosera, and caused a certain amount of inflection. Hydrocyanic acid, again, which is so deadly a poison to animals, caused rapid movement of the tentacles. But as several innocuous acids, though much diluted, such as benzoic, acetic, \&c., as well as some essential oils, are extremely poisonous to Drosera, and quickly cause strong inflection, it seems probable that strychnine, nicotine, digitaline, and hydrocyanic acid, excite inflection by acting on elements in no way analogous to the nerve-cells of animals. If elements of this latter nature had been present in the leaves, it miglit have been expected that morphia, hyoscyamus, atropine, veratrine, colchicine, curare, and diluted alcohol would have produced some marked effect; whereas 
these substances are not poisonous and have no power, or only a very slight one, of inducing inflection. It should, however, be observed that curare, colchicine, and veratrine are muscle-poisons-that is, act on nerves having some special relation with the muscles, and, therefore, could not be expected to act on Drosera. The poison of the cobra is most deadly to animals, by paralysing their nerve-centres, ${ }^{*}$ yet is not in the least so to Drosera, though quickly causing strong inflection.

Notwithstanding the foregoing facts, which show how widely different is the effect of certain substances on the health or life of animals and of Drosera, yet there exists a certain degree of parallelism in the action of certain other substances. We have seen that this holds good in a striking manner with the salts of sodium and potassium. Again, various metallic salts and acids, namely those of silver, mercury, gold, tin, arsenic, chromium, copper, and platina, most or all of which are highly poisonous to animals, are equally so to Drosera. But it is a singular fact that the chloride of lead and two salts of barium were not poisonous to this plant. It is an equally strange fact, that, though acetic and propionic acids are highly poisonous, their ally, formic acid, is not so; and that, whilst certain vegetable acids, namely oxalic, benzoic, \&c., are poisonous in a high degree, gallic, tannic, tartaric, and malic (all diluted to an equal degree) are not so. IIalic acid induces inflection, whilst the three other just named regetable acids have no such power. But a pharmacopœia would be requisite to describe the diversified effects of various substances on Drosera.†

* Dr. Fayrer, 'The Thanatophidia of India,' 1872 , p. 4.

+ Seeing that acetic, hydro- cyanic, and chromic acids, acetate of strychnine, and -vapour of ether, are poisonous to Drosera, 
Of the alkaloids and their salts which were tried, several had not the least power of inducing inflection; others, which were certainly absorbed, as shown by the changed colour of the glands, had but a very moderate power of this kind; others, again, such as the acetate of quinine and digitaline, caused strong inflection.

The several substances mentioned in this chapter affect the colour of the glands very differently. These often become dark at first, and then very pale or white, as was conspicuously the case with glands subjected to the poison of the cobra and citrate of strychnine. In other cases they are from the first rendered white, as with leaves placed in hot water and several acids; and this, I presume, is the result of the coagulation of the albumen. On the same leaf some glands become white and others dark-coloured, as occurred with leaves in a solution of the sulphate of quinine, and in the vapour of alcohol. Prolonged immersion in nicotine, curare, and even water, blackens the glands; and this, I believe, is due to the aggregation of the protoplasm within their cells. Yet curare caused very little aggregation in the cells of the tentacles, whereas nicotine and sulphate of quinine induced strongly maiked aggregation down their bases. The aggregated masses in leaves which had been immersed for 3 hrs. $15 \mathrm{~m}$. in a saturated solution of sulphate of quinine exhibited incessant

it is remarkable that Dr. Ransom ('Philosoph. 'Transact.' 1867, p. 480 ), who used much stronger solutions of these substances than I did, states "that the rhythmic contractility of the yolk (of the ova of the pike) is not materially influenced by any of the poisons used, which did not act chemi- cally, with the exception of chloroform and carbonic acil." I find it stated by several writers that curare has no influence on sarcole or protoplasm, and we have seen that, though curare excites some degree of inflection, it causes very little aggregation of the protoplasm. 
changes of form, but after 24 hrs. were motionless; the leaf being flaccid and apparently dead. On the other hand, with leaves subjected for 48 hrs. to a strong solution of the poison of the cobra, the protoplasmic masses were unusually active, whilst with the higher animals the vibratile cilia and white corpuscles of the blood seem to be quickly paralysed by this substance.

With the salts of alkalies and earths, the nature of the base, and not that of the acid, determines their physiological action on Drosera, as is likewise the case with animals; but this rule hardly applies to the salts of quinine and strychnine, for the acetate of quinine causes much more inflection than the-sulphate, and both are poisonous, whereas the nitrate of quinine is not poisonous, and induces inflection at a much slower rate than the acetate. The action of the citrate of strychnine is also somewhat different from that of the sulphate.

Leaves which have been immersed for 24 hrs. in water, and for only $20 \mathrm{~m}$. in diluted alcohol, or in a weak solution of sugar, are afterwards acted on very slowly, or not at all, by the phosphate of ammonia, though they are quickly acted on by the carbonate. Immersion for $20 \mathrm{~m}$. in a solution of gum arabic has no such inhibitory power. The solutions of certain salts and acids affect the leaves, with respect to the subsequent action of the phosphate, exactly like water, whilst others allow the phosphate afterwards to act quickly and energetically. In this latter case, the interstices of the cell-walls may have been blocked up by the molecules of the salts first given in solution, so that water could not afterwards enter, though the molecules of the phosphate could do so, and those of the carbonate still more easily. 
The action of camphor dissolved in water is remarkable, for it not only soon induces inflection, but apparently renders the glands extremely sensitive to mechanical irritation; for if they are brushed with a soft brush, after being immersed in the solution for a short time, the tentacles begin to bend in about $2 \mathrm{~m}$. It may, however, be that the brushing, though not a sufficient stimulus by itself, tends to excite movement merely by reinforcing the direct action of the camphor. The vapour of camphor, on the other hand, serves as a narcotic.

Some essential oils, both in solution and in vapour, cause rapid inflection, others have no such porrer; those which I tried were all poisonous.

Diluted alcohol (one part to seven of water) is not poisonous, does not induce inflection, nor increase the sensitiveness of the glands to mechanical irritation. The vapour acts as a narcotic or anæsthetic, and long. exposure to it kills the leares.

The vapours of chloroform, sulphuric and nitric ether, act in a singularly variable manner on different leaves, and on the several tentacles of the same leaf. This, I suppose, is owing to differences in the age or constitution of the leaves, and to whether certain tentacles have lately been in action. That these vapours are absorbed by the glands is shown by their changed colour; but as other plants not furnished with glands are affected by these vapours, it is probable that they are likewise absorbed by the stomata of Drosera. They sometimes excite extraordinarily rapid inflection, but this is not an invariable result. If allowed to act for even a moderately long time, they kill the leaves; whilst a small dose acting for only a short time serves as a narcotic or anæsthetic. In this case the tentacles, whether or not they have 
become inflected, are not excited to further movement by bits of meat placed on the glands, until some considerable time has elapsed. It is generally believed that with animals and plants these vapours act by arresting oxidation.

Exposure to carbonic acid for $2 \mathrm{hrs}$, and in one case for only $45 \mathrm{~m}$., likewise rendered the glands insensible for a time to the powerful stimulus of raw meat. The leaves, however, recovered their full powers, and did not seem in the least injured, on being left in the air for 24 or $48 \mathrm{hrs}$. We have seen in the third chapter that the process of aggregation in leares subjected for two hours to this gas and then immersed in a solution of the carbonate of ammonia is much retarded, so that a considerable time elapses before the protoplasm in the lower cells of the tentacles becomes aggregated. In some cases, soon after the leares were removed from the gas and brought into the air, the tentacles mored spontaneously; this being due, I presume, to the excitement from the access of oxygen. These inflected tentacles, however, could not be excited for some time afterwards to any further movement by their glands being stimulated. With other irritable plants it is known* that the exclusion of oxygen prevents their moving, and arrests the movements of the protoplasm within their cells, but this arrest is a different phenomenon from the retardation of the process of aggregation just alluded to. Whether this latter fact ought to be attributed to the direct action of the carbonic acid, or to the exclusion of oxygen, I know not.

* Sachs, 'Traité de Bot.' 1874, pp. \$46, 1037. 


\section{CHAPTER X.}

On the Sensitiveness of the Leaves, and on the Lines of Transmission of the Motor Impulse.

Glands and summits of the tentacles alone sensitive-Transmission of the motor impulse down the pedicels of the tentacles, and across the blade of the leaf - Aggregation of the protoplasm, a reflex action - First discharge of the motor impulse sudden Direction of the movements of the tentacles-Motor impulse transmitted through the cellular tissue-Mechanism of the movements - Nature of the motor impulse - Re-expansion of the tentaclés.

We have seen in the previous chapters that many widely different stimulants, mechanical and chemical, excite the movement of the tentacles, as well as of the blade of the leaf; and we must now consider, firstly, what are the points which are irritable or sensitive, and secondly how the motor impulse is transmitted from one point to another. The glands are almost exclusively the seat of irritability, yet this irritability must extend for a very short distance below them; for when they were cut off with a sharp pair of scissors without being themselves touched, the tentacles often became inflected. These headless tentacles frequently re-expanded; and when afterwards drops of the two most powerful known stimulants were placed on the cut-off ends, no effect was produced. Nevertheless these headless tentacles are capable of subsequent inflection if excited by an impulse sent from the disc. I succeeded on several occasions in crushing glands between fine pincers, but this did not excite any movement; nor did raw meat and salts of ammonia, when placed on such crushed glands. 
It is probable that they were killed so instantly that they were not able to transmit any motor impulse; for in six observed cases (in two of which however the gland was quite pinched off) the protoplasm within the cells of the tentacles did not become aggregated; whereas in some adjoining tentacles, which were inflected from having been roughly touched by the pincers, it was well aggregated. In like manner the protoplasm does not become aggregated when a leaf is instantly killed by being dipped into boiling water. On the other hand, in several cases in which tentacles became inflected after their glands had been cut off with sharp scissors, a distinct though moderate degree of aggregation supervened.

The pedicels of the tentacles were roughly and repeatedly rubbed; raw meat or other exciting substances were placed on them, both on the upper surface near the base and elsewhere, but no distinct morement ensued. Some bits of meat, after being left for a considerable time on the pedicels, were pushed upwards, so as just to touch the glands, and in a minute the tentacles began to bend. I believe that the blade of the leaf is not sensitive to any stimulant. I drove the point of a lancet through the blades of several leaves, and a needle three or four times through nineteen leares: in the former case no movement ensued; but about a dozen of the leaves which were repeatedly pricked had a few tentacles irregularly inflected. As, however, their backs had to be supported during the operation, some of the - outer glands, as well as those on the disc, may have been touched; and this perhaps sufficed to cause the slight degree of morement observed. Nitschke* says

* 'Bot. Zeitung;' 1860, p. 234. 
that cutting and pricking the leaf does not excite movement. The petiole of the leaf is quite insensible.

The backs of the leaves bear numerous minute papillæ, which do not secrete, but have the power of absorption. These papillæ are, I believe, rudiments of formerly existing tentacles together with their glands. Many experiments were made to ascertain whether the backs of the leaves could be irritated in any way, thirty-seven leaves being thus tried. Some were rubbed for a long time with a blunt needle, and drops of milk and other exciting fluids, raw meat, crúshed flies, and various substances, placed on others. These substances were apt soon to becomo dry, showing that no secretion had been excited. Hence I moistened them with saliva, solutions of ammonia, weak hydrochloric acid, and frequently with the secretion from the glands of other leaves. I also kept some leaves, on the backs of which exciting objects had been placed, under a damp bell-glass; but with all my care I never saw any true movement. I was led to make so many trials because, contrary to my previous experience, Nitschke states* that, after affixing objects to the backs of leaves by the aid of the viscid secretion, he repeatedly saw the tentacles (and in one instance the blade) become reflexed. This movement, if a true one, would be most anomalous; for it implies that the tentacles receive a motor impulse from an unnatural source, and have the power of bending in a direction exactly the reverse of that which is habitual to them; this power not being of the least use to the plant, as insects cannot adhere to the smooth backs of the leaves.

I have said that no effect was produced in the above

* 'Bot. Zeitung,' 1860, p. 437. 
cases; but this is not strictly true, for in three instances a little syrup was added to the bits of raw meat on the backs of leaves, in order to keep them damp for a time; and after 36 hrs. there was a trace of reflexion in the tentacles of one leaf, and certainly in the blade of another. After twelve additional hours, the glands began to dry, and all three leaves seemed much injured. Four leaves were then placed under a bell-glass, with their footstalks in water, with drops of syrup on their backs, but without any meat. Two of these leaves, after a day, had a few tentacles reflexed. The drops had now increased considerably in size, from having imbibed moisture, so as to trickle down the backs of the tentacles and footstalks. On the second day, one leaf had its blade much reflexed; on the third day the tentacles of two were much reflexed, as well as the blades of all four to a greater or less degree. The upper side of one leaf, instead of being, as at first, slightly concave, now presented a strong convexity upwards. Even on the fifth day the leaves did not appear deacl. Now, as sugar does not in the least excite Drosera, we may safely attribute the reflexion of the blades and tentacles of the above leares to exosmose from the cells which were in contact with the syrup, and their consequent contraction. When drops of syrup are placed on the leaves of plants with their roots still in damp earth, no inflection ensues, for the roots, no doubt, pump up water as quickly as it is lost by exosmose. But if cut-off leaves are immersed in syrup, or in any dense fluid, the tentacles are greatly, though irregularly, inflected, some of them assuming the shape of corkscrews; and the leaves soon become flaccid. If they are now immersed in a fluid of low specific gravity, the tentacles re-expand. From these 
facts we may conclude that drops of syrup placed on the backs of leaves do not act by exciting a motor impulse which is transmitted to the tentacles; but that they cause reflexion by inducing exosmose. Dr. Nitschke used the secretion for sticking insects to the backs of the leaves; and I suppose that he used a large quantity, which from being dense probably caused exosmose. Perhaps he experimented on cut-off leaves, or on plants with their roots not supplied with enough water.

As far, therefore, as our present knowledge serves, we may conclude that the glands, together with the immediately underlying cells of the tentacles, are the exclusive seats of that irritability or sensitiveness with which the leaves are endowed. The degree to which a gland is excited can be measured only by the number of the surrounding tentacles which are inflected, and by the amount and rate of their movement. Equally vigorous leaves, exposed to the same temperature (and this is an important condition), are excited in different degrees under the following circumstances. A minute quantity of a weak solution produces no effect; add more, or give a rather stronger solution, and the tentacles bend. Touch a gland once or twice, and no movement follows; touch it three or four times, and the tentacle becomes inflected. But the nature of the substance which is given is a very important element : if equal-sized particles of glass (which acts only mechanically), of gelatine, and raw meat, are placed on the discs of several leaves, the meat causes far more rapid, energetic, and widely extended movement than the two former substances. The number of glands which are excited also makes a great difference in the result: place a bit of meat on one or two of the discal 
glands, and only a few of the immediately surrounding short tentacles are inflected; place it on several glands, and many more are acted on; place it on thirty or forty, and all the tentacles, including the extreme marginal ones, become closely inflected. We thus see that the impulses proceeding from a number of glands strengthen one another, spread farther, and act on a larger number of tentacles, than the impulse from any single gland.

Transmission of the Motor Impulse.-In every case the impulse from a gland has to travel for at least a short distance to the basal part of the tentacle, the upper part and the gland itself being merely carried by the inflection of the lower part. The impulse is thus always transmitted down nearly the whole length of the pedicel. When the central glands are stimulated, and the extreme marginal tentacles become inflected, the impulse is transmitted across half the diameter of the disc; and when the glands on one side of the disc are stimulated, the impulse is transmitted across nearly the whole width of the disc. A gland transmits its motor impulse far more easily and quickly down its own tentacle to the bending place than across the disc to neighbouring tentacles. Thus a minute dose of a very weak solution of ammonia, if given to one of the glands of the exterior tentacles, causes it to bend and reach the centre; whereas a large drop of the same solution, given to a score of glands on the disc, will not cause through their combined influence the least inflection of the exterior tentacles. Again, when a bit of meat is placed on the gland of an exterior tentacle, I have seen movement in ten seconds, and repeatedly within a minute; but a much larger bit placed on several glands on the disc does not cause 
the exterior tentacles to bend until half an hour or even several hours have elapsed.

The motor impulse spreads gradually on all sides from one or more excited glands, so that the tentacles which stand nearest are always first affected. Hence, when the glands in the centre of the disc are excited, the extreme marginal tentacles are the last inflected. But the glands on different parts of the leaf transmit their motor power in a somewhat different manner. If a bit of meat be placed on the long-headed gland of a marginal tentacle, it quickly transmits an impulse to its own bending portion; but never, as far as I have observed, to the adjoining tentacles; for these are not affected until the meat has been carried to the central glands, which then radiate forth their conjoint impulse on all sides. On four occasions leaves were prepared by removing some days previously all the glands from the centre, so that these could not be excited by the bits of meat brought to them by the inflection of the marginal tentacles; and now these marginal tentacles re-expanded after a time without any other tentacle being affected. Other leaves were similarly prepared, and bits of meat were placed on the glands of two tentacles in the third row from the outside, and on the glands of two tentacles in the fifth row. In these four cases the impulse was sent in the first place laterally, that is, in the same concentric row of tentacles, and then towards the centre; but not centrifugally, or towards the exterior tentacles. In one of these cases only a single tentacle on each side of the one with meat was affected. In the three other cases, from half a dozcn to a dozen tentacles, both laterally and towards the centre, were well inflected or sub-inflected. Lastly, in 
ten other experiments, minute bits of meat were placed on a single gland or on two glands in the centre of the disc. In order that no other glands should touch the meat, through the inflection of the closely adjoining short tentacles, about half a dozen glands had been previously removed round the selected ones. On eight of these leaves from sixteen to twenty-five of the short surrounding tentacles were inflected in the course of one or two days ; so that the motor impulse radiating from one or two of the discal glands is able to produce this much effect. The tentacles which had been removed are included in the above numbers; for, from standing so close, they would certainly have been affected. On the two remaining leaves, almost all the short tentacles on the disc were inflected. With a more powerful stimulus than meat, namely a little phosphate of lime moistened with saliva, I have seen the inflection spread still farther from a single gland thus treated; but even in this case the three or four outer rows of tentacles were not affected. From these experiments it appears that the impulse from a single gland on the disc acts on a greater number of tentacles than that from a gland of one of the exterior elongated tentacles; and this probably follows, at least in part, from the impulse having to travel a very short distance down the pedicels of the central tentacles, so that it is able to spread to a considerable distance all round.

Whilst examining these leaves, I was struck with the fact that in six, perhaps seven, of them the tentacles were much more inflected at the distal and proximal ends of the leaf (i.e. towards the apex and base) than on either side; and yet the tentacles on the sides stood as near to the gland where the bit of meat lay as did those at the two ends. It thus appeared as 
if the motor impulse was transmitted from the centro across the disc more readily in a longitudinal than in a transverse direction; and as this appeared a new and interesting fact in the physiology of plants, thirty-five fresh experiments were made to test its truth. Minute bits of meat were placed on a single gland or on a few glands, on the right or left side of the discs of eighteen leaves; other bits of the same size being placed on the distal or proximal ends of seventeen other leaves. Now if the motor impulse were transmitted with equal force or at an equal rate through the blade in all directions, a bit of meat placed at one side or at one end of the disc ought to affect equally all the tentacles situated at an equal distance from it; but this certainly is not the case. Before giving the general results, it may be well to describe three or four rather unusual cases.

(1) A minute fragment of a fly was placed on one side of the disc, and after $32 \mathrm{~m}$. seven of the outer tentacles near the fragment were inflected; after $10 \mathrm{hrs}$. several more became so, and after 23 hrs. a still greater number; and now the blade of the leaf on this side was bent inwards so as to stand up at right angles to the other side. Neither the blade of the lcaf nor a single tentacle on the opposite side was affected; the line of separation between the two halves extending from the footstalk to the apex. The leaf remained in this state for three days, and on the fourth day began to re-expand; not a single tentacle having been inflected on the opposite side.

(2) I will here give a case not included in the above thirtyfive experiments. A small fly was found adhering by its feet to the left side of the disc. The tentacles on this side soon closed in and killed the fly; and owing probably to its struggle whilst alive, the leaf was so much excited that in about $24 \mathrm{hrs}$. all the tentacles on the opposite side became inflected; but as they found no prey, for their glands did not reach the fly, they reexpanded in the course of $15 \mathrm{hrs}$; the tentacles on the left side remaining clasped for several days.

(3) $\Lambda$ bit of meat, rather larger than those commonly used, 
was placed in a medial line at the basal end of the disc, near the footstalk; after 2 hrs. $30 \mathrm{~m}$. some neighbouring tentacles were inflected; after $6 \mathrm{hrs}$. the tentacles on both sides of the footstalk, and some way up both sides, were moderately inflected; after $8 \mathrm{hrs}$. the tentacles at the further or distal end were more inflected than those on either side; after $23 \mathrm{hrs}$. the meat was well clasped by all the tentacles, excepting by the exterior ones on the two sides.

( 1 ) Another bit of meat was placed at the opposite or distal end of another leaf, with exactly the same relative results.

(5) A minute bit of meat was placed on one side of the disc; next day the neighbouring short tentacles were inflected, as well as in a slight degree three or four on the opposite sido near the footstalk. On the second day these latter tentacles showed signs of re-expanding, so I added a fresh bit of meat at nearly the same spot, and after troo days some of the short tentacles on the opposite side of the disc were inflected. As soon as these began to re-expand, I added another bit of meat, and next day all the tentacles on the opposite side of the dise were inflected towards the meat; whereas we have seen that those on the same side were affected by the first bit of meat which was given.

Now for the general results. Of the eighteen leares on which bits of meat were placed on the right or left sides of the disc, eight had a rast number of tentacles inflected on the same side, and in four of them the blade itself on this side was likewise inflected; whereas not a single tentacle nor the blade was affected on the opposite side. These leares presented a very curious appearance, as if only the inflected side was active, and the other paralysed. In the remaining ten cases, a few tentacles became inflected beyond the medial line, on the side opposite to that where the meat lay; but, in some of these cases, only at the proximal or distal ends of the leares. The inflection on the opposite side always occurred considerably after that on the same side, and in one instance not until the fourth day. We have also seen 
with No. 5 that bits of meat had to be added thrice before all the short tentacles on the opposite side of the disc were inflected.

The result was widely different when bits of meat were placed in a medial line at the distal or proximal ends of the disc. In three of the seventeen experiments thus made, owing either to the state of the leaf or to the smallness of the bit of meat, only the immediately adjoining tentacles were affected; but in the other fourteen cases the tentacles at the opposite end of the leaf were inflected, though these were as distant from where the meat lay as were those on one side of the disc from the meat on the opposite side. In some of the present cases the tentacles on the sides were not at all affected, or in a less degree, or after a longer interval of time, than those at the opposite end. One set of experiments is worth giving in fuller detail. Cubes of meat, not quite so small as those usually employed, were placed on one side of the dises of four leaves, and cubes of the same size at the proximal or distal end of four other leares. Now, when these two sets of leaves were compared after an interval of 24 hrs., they presented a striking difference. Those having the cubes on one side were very slightly affected on the opposite side; whereas those with the cubes at either end had almost every tentacle at the opposite end, even the marginal ones, closely inflected. After $48 \mathrm{hrs}$. the contrast in the state of the two sets was still great; yet those with the meat on one side now had their discal and submarginal tentacles on the opposite side somewhat inflected, this being due to the large size of the cubes. Finally we may conclude from these thirty-five experiments, not to mention the six or seven previous ones, that the motor impulse is transmitted from any single gland 
or small group of glands through the blade to the other tentacles more readily and effectually in a longitudinal than in a transverse direction.

As long as the glands remain excited, and this may last for many days, even for eleren, as when in contact with phosphate of lime, they continue to transmit a motor impulse to the basal and bending parts of their own pedicels, for otherwise they would re-expand. The great difference in the length of time during which tentacles remain inflected over inorganic objects, and over objects of the same size containing soluble nitrogenous matter, proves the same fact. But the intensity of the impulse transmitted from an excited gland, which has begun to pour forth its acid secretion and is at the same time absorbing, seems to be very small compared with that which it transmits when first excited. Thus, when moderately large bits of meat were placed on one side of the disc, and the discal and submarginal tentacles on the opposite side became inflected, so that their glands at last touched the meat and absorbed matter from it, they did not transmit any motor influence to the exterior rows of tentacles on the same side, for these nerer became inflected. If, howerer, meat had been placed on the glands of these same tentacles before they had begun to secrete copiously and to absorb, they undoubtedly would have affected the exterior rows. Nerertheless, when I gare some phosphate of lime, which is a most powerful stimulant, to several submarginal tentacles already considerably inflected, but not yet in contact with some phosphate previously placed on two glands in the centre of the disc, the exterior tentacles on the same side rere acted on.

- When a gland is first excited, the motor impulse is discharged within a few seconds, as we know from the 
bending of the tentacle; and it appears to be discharged at first with much greater force than afterwards. Thus, in the case above given of a small fly naturally caught by a few glands on one side of a leaf, an impulse was slowly transmitted from them across the whole breadth of the leaf, causing the opposite tentacles to be temporarily inflected, but the glands which remained in contact with the insect, though they continued for several days to send an impulse down their own pedicels to the bending place, did not prevent the tentacles on the opposite side from quickly re-expanding; so that the motor discharge must at first have been more powerful than afterwards.

When an object of any kind is placed on the disc, and the surrounding tentacles are inflected, their glands secrete more copiously and the secretion becomes acid, so that some influence is sent to them from the discal glands. This change in the nature and amount of the secretion cannot depend on the bending of the tentacles, as the glands of the short central tentacles secrete acid when an object is placed on them, though they do not themselves bend. Therefore I inferred that the glands of the disc sent some influence up the surrounding tentacles to their glands, and that these reflected back a motor impulse to their basal parts; but this view was soon proved erroneous. It was found by many trials that tentacles with their glands closely cut off by sharp scissors often become inflected and again re-expand, still appearing healthy. Ono which was observed continued healthy for ten days after the operation. I therefore cut the glands off twenty-five tentacles, at different times and on different leaves, and seventeen of these soon became inflected, and afterwards re-expanded. The re-expansion commenced in about 
8 hrs. or 9 hrs., and was completed in from $22 \mathrm{hrs}$. to $30 \mathrm{hrs}$. from the time of inflection. After an interval of a day or two, raw meat with saliva was placed on the discs of these seventeen leares, and when observed next day, seven of the headless tentacles were inflected over the meat as closely as the uninjured ones on the same leaves; and an eighth headless tentacle became inflected after three additional days. The meat was removed from one of these leaves, and the surface washed with a little stream of water, and after three days the headless tentacle re-expanded for the second time. These tentacles without glands were, however, in a different state from those provided with glands and which had absorbed matter from the meat, for the protoplasm within the cells of the former had undergone far less aggregation. From these experiments with headless tentacles it is certain that the glands do not, as far as the motor impulse is concerned, act in a reflex manner like the nerve-ganglia of animals.

But there is another action, namely that of aggregation, which in certain cases may be called reflex, and it is the only known instance in the vegetable kingdom. We should bear in mind that the process does not depend on the previous bending of the tentacles, as we clearly see when leaves are immersed in certain strong solutions. Nor does it depend on increased secretion from the glands, and this is shown by several facts, more especially by the papillæ, which do not secrete, yet undergoing aggregation, if given carbonate of ammonia or an infusion of raw meat. When a gland is directly stimulated in any way, as by the pressure of a minute particle of glass, the protoplasm within the cells of the gland first becomes aggregated, then that in the cells immediately beneath the gland, and so lower and lower down the tentacles to their bases;- 
that is, if the stimulus has been sufficient and not injurious. Now, when the glands of the disc are excited, the exterior tentacles are affected in exactly the same manner: the aggregation always commęnces in their glands, though these have not been directly excited, but have only received some influence from the disc, as shown by their increased acid secretion. The protoplasm within the cells immediately beneath the glands are next affected, and so downwards from cell to cell to the bases of the tentacles. This process apparently deserves to be called a reflex action, in the same manner as when a sensory nerve is irritated, and carries an impression to a ganglion which sends back some influence to a muscle or gland, causing movement or increased secretion; but the action in the two cases is probably of a widely different nature. After the protoplasm in a tentacle has been aggregated, its redissolution always begins in the lower part, and slowly travels up the pedicel to the gland, so that the protoplaism last aggregated is first redissolved. This probably depends merely on the protoplasm being less and less aggregated, lower and lower down in the tentacles, as can be seen plainly when the excitement has been slight. As soon, therefore, as the aggregating action altogether ceases, redissolution naturally commences in the less strongly aggregated matter in the lowest part of the tentacle, and is there first completed.

Direction of the Inflected Tentacles. - When a particle of any kind is placed on the gland of one of the outer tentacles, this invariably moves towards the centre of the leaf; and so it is with all.the tentacles of a leaf immersed in any exciting fluid. The glands of the exterior tentacles then form a ring round the middle part of the disc, as shown in a previous figure (fig. 4. 
p. 10). The short tentacles within this ring still retain their vertical position, as they likewise do when a large object is placed on their glands, or when an insect is caught by them. In this latter case we can see that the inflection of the short central tentacles would be useless, as their glands are already in contact with their prey.

The result is very different when a single gland on one side of the disc is excited, or a few in a group, These send an impulse to

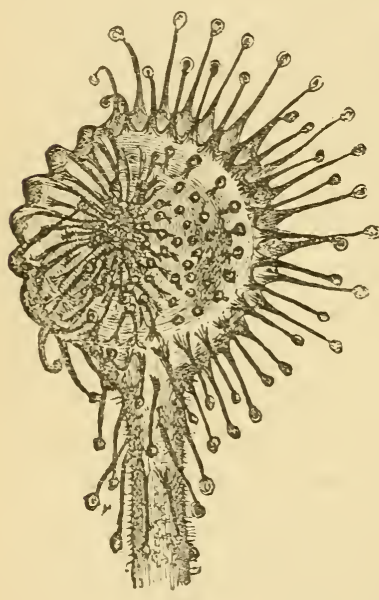

FIG. 10.

(Drosera rotundifolia.)

the surrounding tentacles, which do not now bend towards the centre of the leaf, but to the point of excitement. We owe this capital observation to Nitschke, ${ }^{*}$ and since reading his paper a few years ago, I hare repeatedly verified it. If a minute bit of meat be placed by the aid of a needle on a single gland, or on three or four together, halfway between the centre and the circumference of the disc, the directed morement of the surrounding tentacles is well exhibited. An accuLeaf (enlarged) with the tentacles inflected over a bit of meat placed on one side of the disc. rate drawing of a leaf with meat in this position is here reproduced (fig. 10), and we see the tentacles, including some of the exterior ones, accurately directed to the point where the meat lay. But a much better

* 'Bot. Zeitung,' 1860, p. 210. 
plan is to place a particle of the phosphate of lime moistened with saliva on a single gland on one side of the disc of a large leaf, and another particle on a single gland on the opposite side. In four such trials the excitement was not sufficient to affect the outer tentacles, but all those near the two points were directed to them, so that two wheels were formed on the disc of the same leaf; the pedicels of the tentacles forming the spokes, and the glands united in a mass over the phosphate representing the axles. The precision with which each tentacle pointed to the particle was wonderful; so that in some cases I could detect no deviation from perfect accuracy. Thus, although the short tentacles in the middle of the disc do not bend when their glands are excited in a direct manner, yet if they receive a motor impulse from a point on one side, they direct themselves to the point equally well with the tentacles on the borders of the disc.

In these experiments, some of the short tentacles on the disc, which would have been directed to the centre, had the leaf been immersed in an exciting fluid, were now inflected in an exactly opposite direction, viz. towards the circumference. These tentacles, therefore, had deviated as much as $180^{\circ}$ from the direction which they would have assumed if their own glands had been stimulated, and which may be considered as the normal one. Between this, the greatest possible and no deviation from the normal direction, every degree could be observed in the tentacles on these several leaves. Notwithstanding the precision with which the tentacles generally were directed, those near the circumference of one leaf were not accurately directed towards some phosphate of lime at a rather distant point on the opposite side of the disc. It appeared as if the motor 
impulse in passing transversely across nearly the whole width of the disc had departed somewhat from a true course. This accords with what we have already seen of the impulse travelling less readily in a transverse than in a longitudinal direction. In some other cases, the exterior tentacles did not seem capable of such accurate movement as the shorter and more central ones.

Nothing could be more striking than the appearance of the above four leaves, each with their tentacles pointing truly to the two little masses of the phosphate on their discs. We might imagine that we were looking at a lowly organised animal seizing prey with its arms. In the ease of Drosera the explanation of this accurate power of movement, no doubt, lies in the motor impulse radiating in all directions, and whicherer side of a tentacle it first strikes, that side contracts, and the tentacle consequently bends towards the point of excitement. The pedicels of the tentacles are flattened, or elliptic in section. Near the bases of the short central tentacles, the flattened or broad face is formed of about five longitudinal rows of cells; in the outer tentacles of the disc it consists of about six or seven rows; and in the extreme marginal tentacles of above a dozen rows. As the flattened bases are thus formed of only a few rows of cells, the precision of the movements of the tentacles is the more remarkable; for when the motor impulse strikes the base of a tentacle in a very oblique direction relatively to its broad face, scarcely more than one or two cells towards one end can be affected at first, and the contraction of these cells must draw the whole tentacle into the proper direction. It is, perhaps, owing to the exterior pedicels being much flattened that they do not bend quite so accurately to the point of excitement as the 
more central ones. The properly directed movement of the tentacles is not an unique case in the vegetable kingdom, for the tendrils of many plants curve towards the side which is touched; but the case of Drosera is far more interesting, as here the tentacles are not directly excited, but receive an impulse from a distant point; nevertheless, they bend accurately towards this point.

On the Nature of the Tissues through which the Motor Inpulse is Transmitted.-It will be necessary first to describe briefly the course of the main fibrovascular bundles. These are shown in the accompanying sketch (fig. 11) of a small leaf. Littlo vessels from the neighbouring bundles enter all the many tentacles with which the surface is studded; but these are not here represented. The central trunk, which runs up the footstalk, bifurcates near the centre of the leaf, each branch bifurcating again and again according to the

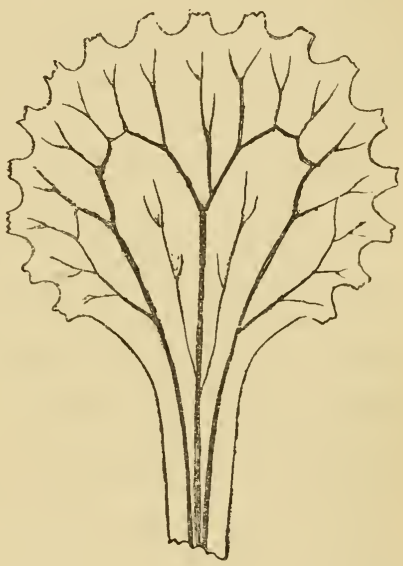

Fig. 11.

(Drosera rotundifolia.)

Diagram showing the distribution of the vascular tissue in a small leaf. size of the leaf. This

central trunk sends off, low down on each side, a delicate branch, which may be called the sublateral branch. There is also, on each side, a main lateral branch or bundle, which bifurcates in the same manner as the others. Bifurcation does not imply that any single vessel divides, but that a bundle 
divides into two. By looking to either side of the leaf, it will be seen that a branch from the great central bifurcation inosculates with a branch from the lateral bundle, and that there is a smaller inosculation between the two chief branches of the lateral bundle. The course of the ressels is very complex at the larger inosculation; and here vessels, retaining the same diameter, are often formed by the union of the bluntly pointed ends of two vessels, but whether these points open into each other by their attached surfaces, I do not know. By means of the two inosculations all the vessels on the same side of the leaf are brought into some sort of connection. Near the circumference of the larger leaves the bifurcating branches also come into close union, and then separate again, forming a continuous zigzag line of vessels round the whole circumference. But the union of the vessels in this zigzag line seems to be much less intimate than at the main inosculation. It should be added that the course of the vessels differs somewhat in different leaves, and even on opposite sides of the same leaf, but the main inosculation is always present.

Now in my first experiments with bits of meat placed on one side of the disc, it so happened that not a single tentacle was inflected on the opposite side; and when I saw that the vessels on the same side were all connected together by the two inosculations, whilst not a vessel passed over to the opposite side, it seemed probable that the motor impulse was conducted exclusively along them.

In order to test this view, I divided transversely with the point of a lancet the central trunks of four leaves, just beneath the main bifurcation; and two days afterwards placed rather large bits of raw meat 
(a most powerful stimulant) near the centre of the disc above the incision-that is, a little towards the apex - with the following results :-

(1) This leaf proved rather torpid: after $4 \mathrm{hrs} .40 \mathrm{~m}$. (in all cases reckoning from the time when the meat was given) the tentacles at the distal end were a little inflected, but nowhere else; they remained so for three days, and re-expanded on the fourth day. The leaf was then dissected, and the trunk, as well as the two sublateral branches, were found divided.

(2) After $4 \mathrm{hrs}$. $30 \mathrm{~m}$. many of the tentacles at the distal end were well inflected. Next day the blade and all the tentacles at this end were strongly inflected, and were separated by a distinct transverse line from the basal half of the leaf, which was not in the least affected. On the third day, however, some of the short tentacles on the disc near the base were very slightly inflected. The incision was found on dissection to extend across the leaf as in the last case.

(3) After $4 \mathrm{hrs} .30 \mathrm{~m}$. strong inflection of the tentacles at the distal end, which during the next two days never extended in the least to the basal end. The incision as before.

(4) This leaf was not observed until $15 \mathrm{hrs}$. had elapsed, and then all the tentacles, except the extreme marginal ones, were found equally well inflected all round the leaf. On careful examination the spiral vessels of the central trunk were certainly divided; but the incision on one side had not passed through the fibrous tissue surrounding these vessels, though it had passed through the tissue on the other side.*

The appearance presented by the leaves (2) and (3) was very curious, and might be aptly compared with that of a man with his backbone broken and lower extremities paralysed. Excepting that the line between the two halves was here transverse instead of longitudinal, these leaves were in the same state as some of those in the former experiments, with bits of meat placed on one side of the disc. The case of leaf (4)

* Ir. Ziegler mado similar experiments by cutting the spiral vessels of Drosera intermedia
('Comptes rendus,' 1874, p. 1417), but arrived at conclusions widely different from mine. 
proves that the spiral vessels of the central trunk may be divided, and yet the motor impulse be transmitted from the distal to the basal end; and this led me at first to suppose that the motor force was sent through the closely surrounding fibrous tissue; and that if one half of this tissue was left undivided, it sufficed for complete transmission. But opposed to this conclusion is the fact that no vessels pass directly from one side of the leaf to the other, and yet, as we have seen, if a rather large bit of meat is placed on one side, the motor impulse is sent, though slowly and imperfectly, in a transverse direction across the whole breadth of the leaf. Nor can this latter fact be accounted for by supposing that the transmission is effected through the two inosculations, or through the circumferential zigzag line of union, for had this been the case, the exterior tentacles on the opposite side of the disc would have been affected before the more central ones, which never occurred. We have also seen that the extreme marginal tentacles appear to have no power to transmit an impulse to the adjoining tentacles; yet the little bundle of vessels which enters each marginal tentacle sends off a minute branch to those on both sides, and this I have not observed in any other tentacles; so that the marginal ones are more closely connected together by spiral vessels than are the others, and yet have much less power of communicating a motor impulse to one another.

But besides these several facts and arguments we have conclusive evidence that the motor impulse is not sent, at least cxclusively, through the spiral ressels, or through the tissue immediately surrounding them. We know that if a bit of meat is placed on a gland (the immediately adjoining ones having been removed) on any part of the disc, all the short sur- 
rounding tentacles bend almost simultaneously with great precision towards it. Now there are tentacles on the disc, for instance near the extremities of the sublateral bundles (fig. 11), which are supplied with vessels that do not come into contact with the branches that enter the surrounding tentacles, except by a very long and extremely circuitous course. Nevertheless, if a bit of meat is placed on the gland of a tentacle of this kind, all the surrounding ones are inflected towards it with great precision. It is, of course, possible that an impulse might be sent through a long and circuitous course, but it is obviously impossible that the direction of the movement could be thus communicated, so that all the surrounding tentacles should bend precisely to the point of excitement. The impulse no doubt is transmitted in straight radiating lines from the excited gland to the surrounding tentacles; it cannot, therefore, be sent along the fibrovascular bundles. The effect of cutting the central vessels, in the above cases, in preventing the transmission of the motor impulse from the distal to the basal end of a leaf, may be attributed to a considerable space of the cellular tissue having been divided. We shall hereafter see, when we treat of Dionæa, that this same conclusion, namely that the motor impulse is not transmitted by the fibro-vascular bundles, is plainly confirmed; and Professor Cohn has come to the same conclusion with respect to Aldrovanda-both members of the Droseraceæ.

As the motor impulse is not transmitted along the vessels, there remains for its passage only the cellular tissue; and the structure of this tissue explains to a certain extent how it travels so quickly down the long exterior tentacles, and much more slowly across the blade of the leaf. We shall also see why it crosses 
the blade more quickly in a longitudinal than in a transverse direction; though with time it can pass in any direction. We know that the same stimulus causes movement of the tentacles and aggregation of the protoplasm, and that both influences originate in and proceed from the glands within the same brief space of time. It seems therefore probable that the motor impulse consists of the first commencement of a molecular change in the protoplasm, which, when well devoloped, is plainly visible, and has been designated aggregation; but to this subject I shall return. IVe further know that in the transmission of the aggregating process the chief delay is caused by the passage of the transverse cell-walls; for as the aggregation travels down the tentacles, the contents of each successive cell seem almost to flash into a eloudy mass. We may therefore infer that the motor impulse is in like manner delayed chiefly by passing through the cell-walls.

The greater celerity with which the impulse is transmitted down the long exterior tentacles than across the dise may be largely attributed to its being closely confined within the narrow pedicel, instead of radiating forth on all sides as on the disc. But besides this confinement, the exterior cells of the tentacles are fully twice as long as those of the disc; so that only half the number of transverse partitions have to be traversed in a given length of a tentacle, compared with an equal space on the disc; and there would be in the same proportion less retardation of the impulse. NLoreover, in sections of the exterior tentacles given by Dr. Warming,* the parenchymatous

* 'Videnskabelige Meddelelser de la Soc. d'Hist. nat. de Copen hague,' Nos. 10-12, 1872, woodcuts iv. and v. 
cells are shown to be still more elongated; and these would form the most direct line of communication from the gland to the bending place of the tentacle. If the impulse travels down the exterior cells, it would have to cross from between twenty to thirty transverse partitions; but rather ferwer if down the inner parenchymatous tissue. In either case it is remarkable that the impulse is able to pass through so many partitions down nearly the whole length of the pedicel, and to act on the bending place, in ten seconds. Why the impulse, after having passed so quickly down one of the extreme marginal tentacles (about $\frac{1}{20}$ of an inch in length), should never, as far as I have seen, affect the adjoining tentacles, I do not understand. It may be in part accounted for by much energy being expended in the rapidity of the transmission.

Most of the cells of the disc, both the superficial ones and the larger cells which form the five or six underlying layers, are about four times as long as broad. They are arranged almost longitudinally, radiating from the footstalk. The motor impulse, therefore, when transmitted across the disc, has to cross nearly four times as many cell-walls as when transmitted in a longitudinal direction, and would consequently be much delayed in the former case. The cells of the disc converge towards the bases of the tentacles, and are thus fitted to convey the motor impulse to them from all sides. On the whole, the arrangement and shape of the cells, both those of the dise and tentacles, throw much light on the rate and manner of diffusion of the motor impulse. But why the impulse proceeding from the glands of the exterior rows of tentacles tends to travel laterally and towards the centre of the leaf, but not centrifugally, is by no means clear. 
Mechanism of the Movements, and Nature of the Motor Impulse.-Whatever may be the means of movement, the exterior tentacles, considering their delicacy, are inflected with much force. A bristle, held so that a length of 1 inch projected from a handle, yielded when I tried to lift with it an inflected tentacle, which was somewhat thinner than the bristle. The amount or extent, also, of the movement is great. Fully expanded tentacles in becoming inflected sweep through an angle of $180^{\circ}$; and if they are beforehand reflexed, as often occurs, the angle is considerably greater. It is probably the superficial cells at the bending place which chiefly or exclusively contract; for the interior cells have very delicate walls, and are so few in number that they could hardly cause a tentacle to bend with precision to a definite point. Though I carefully looked, I could never detect any wrinkling of the surface at the bending place, even in the ease of a tentacle abnormally curved into a complete cirele, under circumstances hereafter to be mentioned.

All the cells are not acted on, though the motor impulse passes through them. When the gland of one of the long exterior tentacles is excited, the upper cells are not in the least affected; about halfway down there is a slight bending, but the chief movement is confined to a short space near the base; and no part of the inner tentacles bends except the basal portion. With respect to the blade of the leaf, the motor impulse may be transmitted through many cells, from the centre to the circumference, without their being in the least affected, or they may be strongly acted on and the blade greatly inflected. In the latter case the movement seems to depend partly on the strength of the stimulus, and partly on 
its nature, as when leaves are immersed in certain fluids.

The power of movement which various plants possess, when irritated, has been attributed by high authorities to the rapid passage of fluid out of certain cells, which, from their previous state of tension, immediately contract.* Whether or not this is the primary cause of such movements, fluid must pass out of closed cells when they contract or are pressed together in one direction, unless they at the same time expand in some other direction. For instance, fluid can be seen to ooze from the surface of any young and vigorous shoot if slowly bent into a semi-circle. $f$ In the case of Drosera there is certainly much movement of the fluid throughout the tentacles whilst they are undergoing inflection. Many leaves can be found in which the purple fluid within the cells is of an equally dark tint on the upper and lower sides of the tentacles, extending also downwards on both sides to equally near their bases. If the tentacles of such a leaf are excited into movement, it will generally be found after some hours that the cells on the concave side are much paler than they were before, or are quite colourless, those on the convex side having become much darker. In two instances, after particles of hair had been placed on glands, and when in the course of $1 \mathrm{hr} .10 \mathrm{~m}$. the tentacles were incurved halfway towards the centre of the leaf, this change of colour in the two sides was conspicuously plain. In another case, after a bit of . meat had been placed on a gland, the purple colour was observed at intervals to be slowly travelling from the upper to the lower part, down the convex side of

* Sachs, 'Traité de Bot.' 3rd edit. 1874, p. 1038 . 'This view was, I believe, first suggested by
Lamarck.

† Sachs, ibid. p. 919. 
the bending tentacle. But it does not follow from these observations that the cells on the convex side become filled with more fluid during the act of inflection than they contained before; for fluid may all the time be passing into the disc or into the glands which then secrete freely.

The bending of the tentacles, when leaves are immersed in a dense fluid, and their subsequent reexpansion in a less dense fluid, show that the passage of fluid from or into the cells can cause movements like the natural ones. But the inflection thus caused is often irregular; the exterior tentacles being sometimes spirally curved. Other unnatural movements are likewise caused by the application of dense fluids, as in the case of drops of syrup placed on the backs of leaves and tentacles. Such movements may be compared with the contortions which many vegetable tissues undergo when subjected to exosmose. It is therefore doubtful whether they throw any light on the natural movements.

If we admit that the outward passage of fluid is the cause of the bending of the tentacles, we must suppose that the cells, before the act of inflection, are in a high state of tension, and that they are elastic to an extraordinary degree; for otherwise their contraction could not cause the tentacles often to sweep through an angle of above $180^{\circ}$. Professor Cohn, in his interesting paper* on the movements of the stamens of certain Compositx, states that these organs, when dead, are as elastic as threads of indiarubber, and are then only half as long as they were when alive. He believes that the living protoplasm.

* 'Abhand. der Schles. Gesell. is given in the 'Annals and Mag. fuir vaterl. Cultur,' 1861, Heft i. of Nat. Hist.' 3rd series, 1863, An exeellent abstract of this paper vol. xi. pp. 188-197. 
within their cells is ordinarily in a state of expansion, but is paralysed by irritation, or may be said to suffer temporary death; the elasticity of the cell-walls then coming into play, and causing the contraction of the stamens. Now the cells on the upper or concave side of the bending part of the tentacles of Drosera do not appear to be in a state of tension, nor to be highly elastic; for when a leaf is suddenly killed, or dies slowly, it is not the upper but the lower sides of the tentacles which contract from elasticity. We may, therefore, conclude that their movements cannot be accounted for by the inherent elasticity of certain cells, opposed as long as they are alive and not irritated by the expanded state of their contents.

A somewhat different view has been advanced by other physiologists - namely that the protoplasm, when irritated, contracts like the soft sarcode of the muscles of animals. In Drosera the fluid within the cells of the tentacles at the bending place appears under the microscope thin and homogeneous, and after aggregation consists of small, soft masses of matter, undergoing incesssant changes of form and floating in almost colourless fluid. These masses are completely redissolved when the tentacles re-expand. Now it seems scarcely possible that such matter should have any direct mechanical power; but if through some molecular change it were to occupy less space than it did before, no doubt the cell-walls would close up and contract. But in this case it might be expected that the walls would exhibit wrinkles, and none could ever be seen. Moreover, the contents of all the cells seem to be of exactly the same nature, both before and after aggregation; and yet only a few of the basal cells contract, the rest of the tentacle remaining straight.

A third view maintained by some physiologists, 
though rejected by most others; is that the whole cell, including the walls, actively contracts. If the walls are composed solely of non-nitrogenous cellulose, this view is highly improbable; but it can hardly be doubted that they must be permeated by proteid matter, at least whilst they are growing. Nor does there seem any inherent improbability in the cell-walls of Drosera contracting, considering their high state of organisation; as shown in the case of the glands by their power of absorption and secretion, and by being exquisitely sensitive so as to be affected by the pressure of the most minute particles. The cell-walls of the pedicels also allow various impulses to pass through them, inducing movement, increased secretion and aggregation. On the whole the belief that the walls of certain cells contract, some of their contained fluid being at the same time forced outwards, perhaps accords best with the observed facts. If this view is rejected, the next most probable one is that the fluid contents of the cells shrink, owing to a change in their molecular state, with the consequent closing in of the walls. Anyhow, the movement can hardly be attributed to the elasticity of the walls, together with a previous state of tension.

With respect to the nature of the motor impulse which is transmitted from the glands down the pedicels and across the disc, it seems not improbable that it is closely allied to that influence which causes the protoplasm within the cells of the glands and tentacles to aggregate. We have seen that both forces originate in and proceed from the glands within a few seconds of the same time, and are excited by the same causes. The aggregation of the protoplasm lasts almost as long as the tentacles remain inflected, even though this be for more than a week; but the 
protoplasm is redissolved at the bending p place shortly before the tentacles re-expand, showing that the exciting cause of the aggregating process has then quite ceased. Exposure to carbonic acid causes both the latter process and the motor impulse to travel very slowly down the tentacles. We know that the aggregating process is delayed in passing through the cellwalls, and we have good reason to believe that this holds good with the motor impulse; for we can thus understand the different rates of its transmission in a longitudinal and transverse line across the disc. Under a high power the first sign of aggregation is the appearance of a cloud, and soon afterwards of extremely fine granules, in the homogeneous purple fluid within the cells; and this apparently is due to the union of molecules of protoplasm. Now it does not seem an improbable view that the same tendency-namely for the molecules to approach each other-should be communicated to the inner surfaces of the cell-walls which are in contact with the protoplasm; and if so, their molecules would approach each other, and the cell-wall would contract.

To this view it may with truth be objected that when leaves are immersed in various strong solutions, or are subjected to a heat of above $130^{\circ}$ Fahr. ( $54^{\circ} .4$ Cent.), aggregation ensues, but there is no morement. Again, various acids and some other fluids cause rapid movement, but no aggregation, or only of an abnormal nature, or only after a long interval of time; but as most of these fluids are more or less injurious, they may check or prevent the aggregating process by injuring or killing the protoplasm. There is another and more important difference in the two processes: when the glands on the disc are excited, they transmit some influence up the surrounding 
tentacles, which acts on the cells at the bending place, but does not induce aggregation until it has reached the glands; these then send back some other influence, causing the protoplasm to aggregate, first in the upper and then in the lower cells.

The Re-expansion of the Tentacles.-This morement is always slow and gradual. When the centre of the leaf is excited, or a leaf is immersed in a proper solution, all the tentacles bend directly towards the centre, and afterwards directly back from it. But when the point of excitement is on one side of the disc, tho surrounding tentacles bend towards it, and therefore obliquely with respect to their normal direction; when they afterwards re-expand, they bend obliquely back, so as to recover their original positions. The tentacles farthest from an excited point, wherever that may be, are the last and the least affected, and probably in consequence of this they are the first to re-expand. The bent portion of a closely inflected tentacle is in a. state of active contraction, as shown by the following experiment. Meat was placed on a leaf, and after tho tentacles were closely inflected and had quite ceased to move, narrow strips of the disc, with a few of the outer tentacles attached to it, were cut off and laid on one side under the microscope. After several failures, I succeeded in cutting off the convex surface of the bent portion of a tentacle. Movement immediately recommenced, and the already greatly bent portion went on bending until it formed a perfect circle; the straight distal portion of the tentacle passing on one side of the strip. The convex surface must therefore have previously been in a state of tension, sufficient to counterbalance that of the concave surface, which, when free, curled into a complete ring.

The tentacles of an expanded and unexcited leaf 
- are moderately rigid and elastic; if bent by a needle, the upper end yields more easily than the basal and thicker part, which alone is capable of becoming inflected. The rigidity of this basal part seems due to the tension of the outer surface balancing a state of active and persistent contraction of the cells of the inner surface. I believe that this is the case, because, when a leaf is dipped into boiling water, the tentacles suddenly become reflexed, and this apparently indieates that the tension of the outer surface is mechanical, whilst that of the inner surface is vital, and is instantly destroyed by the boiling water. We can thus also understand why the tentacles as they grow old and feeble slowly become much reflexed. If a leaf with its tentacles closely inflected is dipped into boiling water, these rise up a little, but by no means fully re-expand. This may be owing to the heat quickly destroying the tension and elasticity of the cells of the convex surface; but I can hardly believe that their tension, at any one time, would suffice to earry back the tentacles to their original position, often through an angle of above $180^{\circ}$. It is more probable that fluid, which we know travels along the tentacles during the act of inflection, is slowly reattracted into the cells of the convex surface, their tension being thus gradually and continually increased.

A recapitulation of the chief facts and discussions in this chapter will be given at the close of the next chapter. 


\section{CHAPTER XI.}

\section{Recaptrulation of the Chief Observations on}

Drosera rotexdifolia.

As summaries have been given to most of the chapters, it will be sufficient here to recapitulate, as briefly as I can, the chief points. In the first chapter a preliminary sketch was given of the structure of the leaves, and of the manner in which they capture insects. This is effected by drops of extremely viscid fluid surrounding the glands and by the inward movement of the tentacles. As the plants gain most of their nutriment by this means, their roots are very poorly developed; and they often grow in places where hardly any other plant except mosses can exist. The glands have the power of absorption, besides that of secretion. They are extremely sensitive to various stimulants, namely repeated touches, the pressure of minute particles, the absorption of animal matter and of various fluids, heat, and galvanic action. A tentacle with a bit of raw meat on the gland has been seen to begin bending in $10 \mathrm{~s}$., to be strongly incurved in $5 \mathrm{~m}$., and to reach the centre of the leaf in half an hour. The blade of the leaf often becomes so much inflected that it forms a cup, enclosing any object placed on it.

A gland, when excited, not only sends some influence down its own tentacle, causing it to bend, but likewise to the surrounding tentacles, which become incurved; so that the bending place can be acted on by an impulse received from opposite directions, 
namely from the gland on the summit of the same tentacle, and from one or more glands of the neighbouring tentacles. Tentacles, when inflected, re-expand after a time, and during this process the glands secrete less copiously, or become dry. As soon as they begin to secrete again, the tentacles are ready to re-act; and this may be repeated at least three, probably many more times.

It was shown in the second chapter that animal substances placed on the discs cause much more prompt and energetic inflection than do inorganic bodies of the same size, or mere mechanical irritation; but there is a still more marked difference in the greater length of time during which the tentacles remain inflected over bodies yielding soluble and nutritious matter, than over those which do not yield such matter. Extremely minute particles of glass, cinders, hair, thread, precipitated chalk, \&c., when placed on the glands of the outer tentacles, cause them to bend. A particle, unless it sinks through the secretion and actually touches the surface of the gland with some one point, does not produce any effect. A little bit of thin human hair $\frac{8}{1000}$ of an inch $(203 \mathrm{~mm}$.) in length, and weighing only $\frac{1}{78.74}$ of a grain (·000822 mg.), though largely supported by the dense secretion, suffices to induce movement. It is not probable that the pressure in this case could have amounted to that from the millionth of a grain. Even smaller particles cause a slight movement, as could be seen through a lens. Larger particles than those of which the measurements have been given cause no sensation when placed on the tongue, one of the most sensitive parts of the human body.

Movement ensues if a gland is momentarily touched three or four times; but if touched only once or twice, 
though with considerable force and with a hard object, the tentacle does not bend. The plant is thus saved from much useless movement, as during a high wind the glands can hardly escape being occasionally brushed by the leaves of surrounding plants. Thongh insensible to a single touch, they are exquisitely sensitive, as just stated, to the slightest pressure if prolonged for a few seconds; and this capacity is manifestly of service to the plant in capturing small insects. Even gnats, if they rest on the glands with their delicate feet, are quickly and securely embraced. The glands are insensible to the weight and repeated blows of drops of heavy rain, and the plants are thus likewise saved from much useless movement.

The description of the movements of the tentacles was interrupted in the third chapter for the sake of describing the process of aggregation. This process always commences in the cells of the glands, the contents of which first become cloudy; and this has been observed within $10 \mathrm{~s}$. after a gland has been excited. Granules just resolvable under a very high power soon appear, sometimes within a minute, in the cells beneath the glands; and these then aggregate into minute spheres. The process afterwards travels duwn the tentacles, being arrested for a short time at each transverse partition. The small spheres coalesce into larger spheres, or into oval, club-headed, threador necklace-like, or otherwise shaped masses of protoplasm, which, suspended in almost colourless fluirl, exhibit incessant spontaneous changes of form. These frequently coalesce and again separate. If a gland has been powerfully excited, all the cells down to the base of the tentacle are affected. In cells, especially if filled with dark red fluid, the first step in the 
process often is the formation of a dark red, baglike mass of protoplasm, which afterwards divides and undergoes the usual repeated changes of form. Before any aggregation has been excited, a sheet of colourless protoplasm, including granules (the primordial utricle of Mohl), flows round the walls of the cells; and this becomes more distinct after the contents have. been partially aggregated into spheres or bag-like masses. But after a time the granules are drawn towards the central masses and unite with them; and then the circulating sheet can no longer be distinguished, but there is still a current of transparent fluid within the cells.

Aggregation is excited by almost all the stimulants which induce movement; such as the glands being touched two or three times, the pressure of minute inorganic particles, the absorption of various fluids, even long immersion in distilled water, exosmose, and heat. Of the many stimulants tried, carbonate of ammonia is the most energetic and acts the quickest: a dose of $\frac{1}{13+\overline{1}}$ of a grain (.00048 mg.) given to a single gland suffices to cause in one hour wellmarked aggregation in the upper cells of the tentacle. The process goes on only as long as the protoplasm is in a living, vigorous, and oxygenated condition.

The result is in all respects exactly the same, whether a gland has been excited directly, or has received an influence from other and distant glareds. But there is one important difference: when the central glands are irritated, they transmit centrifugally an influence up the pedicels of the exterior tentacles to their glands; but the actual process of aggregation travels centripetally, from the glands of the exterior tentacles down their pedicels. The exciting influence, therefore, which is transmitted from 
one part of the leaf to another must be different from that which actually induces aggregation. The process does not depend on the glands secreting more copiously than they did before; and is independent of the inflection of the tentacles. It continues as long as the tentacles remain inflected, and as soon as these are fully re-expanded, the little masses of protoplasm are all redissolved; the cells becoming filled with homogeneous purple fluid, as they were before the leaf was excited.

As the process of aggregation can be excited by a few touches, or by the pressure of insoluble particles, it is evidently independent of the absorption of any matter, and must be of a molecular nature. Even when caused by the absorption of the carbonate or other salt of ammonia, or an infusion of meat, the process seems to be of exactly the same nature. The protoplasmic fluid must, therefore, be in a singularly unstable condition, to be acted on by such slight and varied causes. Physiologists believe that when a nerve is touched, and it transmits an influence to other parts of the nervous system, a molecular change is induced in it, though not visible to us. Therefore it is a very interesting spectacle to watch the effects on the cells of a gland, of the pressure of a bit of hair, weighing only $\frac{1}{78 \div 00}$ of a grain and largely supported by the dense secretion, for this excessively slight pressure socn causes a visible change in the protoplasm, which change is transmitted down the whole length of the tentacle, giving it at last a mottled appearance, distinguishable even by the naked eye.

In the fourth chapter it was shown that leaves placed for a short time in water at a temperature of $110^{\circ}$ Fahr. ( $43^{\circ} \cdot 3$ Cent.) become somewhat inflected; they are thus also rendered more sensitive to the action 
of meat than they were beforc. If exposed to a temperature of between $115^{\circ}$ and $125^{\circ}\left(46^{\circ} \cdot 1-51^{\circ} \cdot 6\right.$ Cent.), they are quickly inflected, and their protoplasm undergoes aggregation; when afterwards placed in cold water, they re-expand. Exposed to $130^{\circ}\left(54^{\circ} \cdot 4\right.$ Cent.), no inflection immediately occurs, but the leaves are only temporarily paralysed, for on being left in cold water, they often become inflected and afterwards re-expand. In one leaf thus treated, I distinctly saw the protoplasm in movement. In other leaves, treated in the same manner, and then immersed in a solution of carbonate of ammonia, strong aggregation ensued. Leaves placed in cold water, after an exposure to so high a temperature as $145^{\circ}\left(62^{\circ} .7\right.$ Cent.), sometimes become slightly, though slowly, inflected; and afterwards have the contents of therr cells strongly aggregated by carbonate of ammonia. But the duration of the immersion is an important element, for if left in water at $145^{\circ}\left(62^{\circ} \cdot 7\right.$ Cent.), or only at $140^{\circ}\left(60^{\circ}\right.$ Cent.), until it becomes cool, they are killed, and the contents of the glands are rendered white and opaque. This latter result seems to be due to the coagulation of the albu-

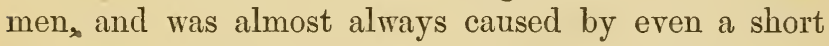
exposure to $150^{\circ}\left(65^{\circ} .5\right.$ Cent.) ; but different leaves, and even the separate cells in the same tentacle, differ considerably in their power of resisting heat. Unless the heat has been sufficient to coagulate the albumen, carbonate of ammonia subsequently induces aggregation.

In the fifth chapter, the results of placing drops of various nitrogenous and non-nitrogenous organic fluids on the discs of leaves were given, and it was shown that they detect with almost unerring certainty the presence of nitrogen. A decoction of green peas or of fresh cabbage-leaves acts almost as powerfully as an infusion of raw meat; whereas an infusion of cabbage- 
leaves made by keeping them for a long time in merely warm water is far less efficient. A decoction of grass-leaves is less powerful than one of green peas or cabbage-leaves.

These results led me to inquire whether Drosera possessed the power of dissolving solid animal matter. The experiments proving that the leaves are capable of true digestion, and that the glands absorb the digested matter, are given in detail in the sixth chapter. These are, perhaps, the most interesting of all my observations on Drosera, as no such power was before distinctly known to exist in the vegetable kingdom. It is likewise an interesting fact that the glands of the disc, when irritated, should transmit some influence to the glands of the exterior tentacles, causing them to secrete more copiously and the secretion to become acid, as if they had been directly excited by an object placed on them. The gastric juice of animals contains, as is well known, an acid and a ferment, both of which are indispensable for digestion, and so it is with the secretion of Drosera. When the stomach of an animal is mechanically irritated, it secretes an acid, and when particles of glass or other such objects were placed on the glands of Drosera, the secretion, and that of the surrounding and untouched glands, was increased in quantity and became acid. But, according to Schiff, the stomach of an animal does not secrete its proper ferment, pepsin, until certain substances, which he calls peptogenes, are absorbed; and it appears from my experiments that some matter must be absorbed by the glands of Drosera before they secrete their proper ferment. That the secretion does contain a ferment which acts only in the presence of an acid on solid animal matter, was clearly proved by adding minute doses of 
an alkali, which entirely arrested the process of digestion, this immediately recommencing as soon as the alkali was neutralised by a little weak hydrochloric acid. From trials made with a large number of substances, it was found that those which the secretion of Drosera dissolves completely, or partially, or not at all, are acted on in exactly the same manner by gastric juice. We may, therefore, conclude that the ferment of Drosera is closely analogous to, or identical with, the pepsin of animals.

The substances which are digested by Drosera act on the leaves very differently. Some cause much more energetic and rapid inflection of the tentacles, and keep them inflected for a much longer time, than do others. We are thus led to believe that the former are more nutritious than the latter, as is known to be the case with some of these same substances when given to animals; for instance, meat in comparison with gelatine. As cartilage is so tough a substance and is so little acted on by water, its prompt dissolution by the secretion of Drosera, and subsequent absorption, is, perhaps, one of the most striking cases. But it is not really more remarkable than the digestion of meat, which is dissolved by this secretion in the same manner and by the same stages as by gastric juice. The secretion dissolves bone, and even the enamel of teeth, but this is simply due to the large quantity of acid secreted, owing, apparently, to the desire of the plant for phosphorus. In the case of bone, the ferment does not come into play until all the phosphate of lime has been decomposed and free acid is present, and then the fibrous basis is quickly dissolved. Lastly, the secretion attacks and dissolves matter out of living seeds, which it sometimes kills, or injures, as shown by the diseased state 
of the seedlings. It also absorbs matter from pollen, and from fragments of leaves.

The serenth chapter was deroted to the action of the salts of ammonia. These all cause the tentacles, and often the blade of the leaf, to be inflected, and the protoplasm to be aggregated. They act with very different power; the citrate being the least powerful, and the phosphate, owing, no doubt, to the presence of phosphorus and nitrogen, by far the most porrerful. But the relative efficiency of only three salts of ammonia was carefully determined, namely the carbonate, nitrate, and phosphate. The experiments were made by placing half-minims (.0296 ml.) of solutions of different strengths on the discs of the leares,-by applying a minute drop (about the $\frac{1}{2} \overline{0}$ of a minim, or $.00296 \mathrm{ml}$.) for a few seconds to three or four glands,and by the immersion of whole leares in a measured quantity. In relation to these experiments it was necessary first to ascertain the effects of distilled water, and it was found, as described in detail, that the more sensitive leares are affected by it, but only in a slight degree.

A solution of the carbonate is absorbed by the roots and induces aggregation in their cells, but does not affect the leaves. The vapour is absorbed by the glands, and causes inflection as well as aggregation. A drop of a solution containing $\frac{1}{960}$ of a grain (.0675 mg.) is the least quantity which, when placed on the glands of the disc, excites the exterior tentacles to bend inwards. But a minute drop, containing $\frac{1}{14400}$ of a grain $(\cdot 00445 \mathrm{mg}$.), if applied for a few seconds to the secretion surrounding a gland, causes the inflection of the same tentacle. When a highly sensitive leaf is immersed in a solution, and there is ample time for absorption, the $\frac{1}{20800}$ of a grain 
(.00024 mg.) is sufficient to excite a single tentacle into movement.

The nitrate of ammonia induces aggregation of the protoplasm much less quickly than the carbonate, but is more potent in causing inflection. A drop containing $\frac{1}{2400}$ of a grain ( $.027 \mathrm{mg}$.) placed on the disc acts powerfully on all the exterior tentacles, which have not themselves received any of the solution; whereas a drop with $\frac{1}{2800}$ of a grain caused only a few of these tentacles to bend, but affected rather more plainly the blade. A minute drop applied as before, and containing $\frac{1}{28800}$ of a grain (.0025 mg.), caused the tentacle bearing this gland to bend. By the immersion of whole leaves, it was proved that the absorption by a single gland of $\frac{1}{691200}$ of a grain ( $0000937 \mathrm{mg}$.) was sufficient to set the same tentacle into movement.

The phosphate of ammonia is much more powerful than the nitrate. A drop containing $\frac{1}{384}$ of a grain (.0169 mg.) placed on the disc of a sensitive leaf causes most of the exterior tentacles to be inflected, as well as the blade of the leaf. A minute drop containing $\frac{1}{153600}$ of a grain ( $000423 \mathrm{mg}$.), applied for a few seconds to a gland, acts, as shown by the movement of the tentacle. When a leaf is immersed in thirty minims $(1.7748 \mathrm{ml}$.) of a solution of one part by weight of the salt to $21,875,000$ of water, the absorption by a gland of only the $\frac{1}{19700000}$ of a grain (.00000328 mg.), that is, about the one-twenty-millionth of a grain, is sufficient to cause the tentacle bearing this gland to bend to the centre of the leaf. In this experiment, owing to the presence of the water of crystallisation, less than the one-thirtymillionth of a grain of the efficient elements could have been absorbed. There is nothing remarkable in such minute quantities being absorbed by the glands, 
for all physiologists admit that the salts of ammonia, which must be brought in still smaller quantity by a single shower of rain to the roots, are absorbed by them. Nor is it surprising that Drosera should be enabled to profit by the absorption of these salts, for yeast and other low fungoid forms flourish in solutions of ammonia, if the other necessary elements are present. But it is an astonishing fact, on which I will not here again enlarge, that so inconceivably minute a quantity as the one-twenty-millionth of a grain of phosphate of ammonia should induce some change in a gland of Drosera, sufficient to cause a motor impulse to be sent down the whole length of the tentacle; this impulse exciting movement often through an angle of above $180^{\circ}$. I know not whether to be most astonished at this fact, or that the pressure of a minute bit of hair, supported by the dense secretion, should quickly cause conspicuons movement. Moreover, this extreme sensitiveness, exceeding that of the most delicate part of the human body, as well as the power of transmitting various impulses from one part of the leaf to another, have been acquired without the intervention of any nervous system.

As few plants are at present known to possess glands specially adapted for absorption, it seemed worth while to try the effects on Drosera of various other salts, besides those of ammonia, and of various acids. Their action, as described in the eighth chapter, does not correspond at all strictly with their chemical affinities, as inferred from the classification commonly followed. The nature of the base is far more influential than that of the acid; and this is known to hold good with animals. For instance, nine salts of sodinm all caused well-marked inflection, and none of them were poisonous in small doses; whereas seven of the nine corre- 
sponding salts of potassium produced no effect, two causing slight inflection. Small doses, moreover, of some of the latter salts were poisonous. The salts of sodium and potassium, when injected into the veins of animals, likewise differ widely in their action. The so-called earthy salts produce hardly any effect on Drosera. On the other hand, most of the metallic salts cause rapid and strong inflection, and are highly poisonous; but there are some odd exceptions to this rule; thus chloride of lead and zinc, as well as two salts of barium, did not cause inflection, and were not poisonous.

Most of the acids which were tried, though much diluted (one part to 437 of water), and given in small doses, acted powerfully on Drosera; nineteen, out of the twenty-four, causing the tentacles to be more or less inflected. Most of them, even the organic acids, are poisonous, often highly so ; and this is remarkable, as the juices of so many plants contain acids. Benzoic acid, which is innocuous to animals, seems to be as poisonous to Drosera as hydrocyanic. On the other hand, hydrochloric acid is not poisonous either to animals or to Drosera, and induces only a moderate amount of inflection. Many acids excite the glands to secrete an extraordinary quantity of mucus; and the protoplasm within their cells seems to be often killed, as may be inferred from the surrounding fluid soon becoming pink. It is strange that allied acids act very differently: formic acid induces very slight inflection, and is not poisonous; whereas acetic acid of the same strength acts most powerfully and is poisonous. Lactic acid is also poisonous, but causes inflection only after a considerable lapse of time. Malic acid acts slightly, whereas citric and tartaric acids produce no effect. 
In the ninth chapter the effects of the absorption of rarious alkaloids and certain other substances were described. Although some of these are poisonous, yet as several, which act powerfully on the nervous system of animals, produce no effect on Drosera, we may infer that the extreme sensibility of the glands, and their power of transmitting an influence to other parts of the leaf, causing movement, or modified secretion, or aggregation, does not depend on the presence of a diffused element, allied to nerve-tissue. One of the most remarkable facts is that long immersion in the poison of the cobra-snake does not in the least check, but rather stimulates, the spontaneous movements of the protoplasm in the cells of the tentacles. Solutions of various salts and acids behave very differently in delaying or in quite arresting the subsequent action of a solution of phosphate of ammonia. Camphor dissolved in water acts as a stimulant, as do small doses of certain essential oils, for they cause rapid and strong inflection. Alcohol is not a stimulant. The rapours of camphor, alcohol, chloroform, sulphuric and nitric ether, are poisonous in moderately large doses, but in small doses serve as narcotics or anæsthetics, greatly delaying the subsequent action of meat. But some of these vapours also act as stimulants, exciting rapid, almost spasmodic movements in the tentacles. Carbonic acid is likewise a narcotic, and retards the aggregation of the protoplasm when carbonate of ammonia is subsequently given. The first access of air to plants which have been immersed in this gas sometimes acts as a stimulant and induces movement. But, as before remarked, a special pharmacopœia would be necessary to describe the diversified effects of various substances on the leaves of Drosera.

In the tenth chapter it was shown that the sensitive- 
ness of the leaves appears to be wholly confined to the glands and to the immediately underlying cells. It was further shown that the motor impulse and other forces or influences, proceeding from the glands when excited, pass through the cellular tissue, and not along the fibro-vascular bundles. A gland sends its motor impulse with great rapidity down the pedicel of the same tentacle to the basal part which alone bends. The impulse, then passing onwards, spreads on all sides to the surrounding tentacles, first affecting those which stand nearest and then those farther off. But by being thus spread out, and from the cells of the disc not being so much elongated as those of the tentacles, it loses force, and here travels much more slowly than down the pedicels. Owing also to the direction and form of the cells, it passes with greater ease and celerity in a longitudinal than in a transverse line across the dise. The impulse proceeding from the glands of the extreme marginal tentacles does not seem to have force enough to affect the adjoining tentacles; and this may be in part due to their length. The impulse from the glands of the next ferw inner rows spreads chiefly to the tentacles on each side and towards the centre of the leaf; but that proceeding from the glands of the shorter tentacles on the disc radiates almost equally on all sides.

When a gland is strongly excited by the quantity or quality of the substance placed on it, the motor impulse travels farther than from one slightly excited; and if several glands are simultaneously excited, the impulses from all unite and spread still farther. As soon as a gland is excited, it discharges an impulse which extends to a considerable. distance; but afterwards, whilst the gland is secreting and absorbing, the impulse suffices only to keep the same tentacle 
inflected; though the inflection may last for many days.

If the bending place of a tentacle receives an impulse from its own gland, the movement is always towards the centre of the leaf; and so it is with all the tentacles, when their glands are excited by immersion in a proper fluid. The short ones in the middle part of the disc must be excepted, as these do not bend at all when thus excited. On the other hand, when the motor impulse comes from one side of the dise, the surrounding tentacles, including the short ones in the middle of the disc, all bend with precision towards the point of excitement, wherever this may be seated. This is in every way a remarkable phenomenon; for the leaf falsely appears as if endowed with the senses of an animal. It is all the more remarkable, as when the motor impulse strikes the base of a tentacle obliquely with respect to its flattened surface, the contraction of the cells must be confined to one, two, or a very few rows at one end. And different sides of the surrounding tentacles must be acted on, in order that all should bend with precision to the point of excitement.

The motor impulse, as it spreads from one or more glands across the disc, enters the bases of the surrounding tentacles, and immediately acts on the bending place. It does not in the first place proceed up the tentacles to the glands, exciting them to reflect back an impulse to their bases. Nevertheless, some influence is sent up to the glands, as their secretion is soon increased and rendered acid; and then the glands, being thus excited, send back some other influence (not dependent on increased secretion, nor on the inflection of the tentacles), causing the protoplasm to aggregate in cell beneath cell. This may 
be called a reflex action, though probably very different from that proceeding from the nerve-ganglion of an animal; and it is the only known case of reflex action in the vegetable kingdom.

About the mechanism of the movements and the nature of the motor impulse we know very little. During the act of inflection fluid certainly travels from one part to another of the tentacles. But the hypothesis which agrees best with the observed facts is that the motor impulse is allied in nature to the aggregating process; and that this causes the molecules of the cell-walls to approach each other, in the same manner as do the molecules of the protoplasm within the cells; so that the cell-walls contract. But some strong objections may be urged against this view. The re-expansion of the tentacles is largely due to the elasticity of their outer cells, which comes into play as soon as those on the inner side cease contracting with prepotent force; but we have reason to suspect that fluid is continually and slowly attracted into the outer cells during the act of re-expansion, thus increasing their tension.

I have now given a brief recapitulation of the chief points observed by me, with respect to the structure, movements, constitution, and habits of Drosera rotundifolia; and we see how little has been made out in comparison with what remains unexplained and unknown. 


\section{CHAPTER XII.}

Ox the Strcctrene axd Movemexts of some other Species of Drosera.

Drosera anglica-Drosera intermedia-Drosera capensis-Drosera spathulata-Drosera filiformis-Drosera linata-Concluding remarks.

I EXAMINED six other species of Drosera, some of them inhabitants of distant countries, chiefly for the sake of ascertaining whether they caught insects. This seemed the more necessary as the leaves of some of the species differ to an extraordinary degree in shape from the rounded ones of Drosera rotundifotia. In functional powers, however, they differ very little.

Drosera anglica (Hudson). ${ }^{*}$-The leares of this species, which was sent to me from Ireland, are much elongated, and gradually widen from the footstalk to the bluntly pointed apex. They stand almost erect, and their blades sometimes exceed 1 inch in length, whilst their breadth is only the $\frac{1}{5}$ of an inch. The glands of all the tentacles have the same structure, so that the extreme marginal ones do not differ from the others, as in the case of Drosera rotundifolia. When they are irritated by being roughly touched, or by the pressure of minute inorganic particles, or by contact with animal matter, or by the absorption of carbonate of ammonia, the tentacles become inflected; the basal portion being the chief seat of morement. Cutting or pricking the blade of the leaf did not excite any morement. They frequently capture insects, and the glands of the inflected tentacles pour forth much acid secretion. Bits of roast meat were placed on some glands, and the tentacles began to move in $1 \mathrm{~m}$. or

* Mrs. Treat has given an excellent account in 'The American Naturalist,' December 1873,p.705, of Drasera longifolia (which is a synonym in part of Drosera anglica), of Drosera rotundifolia and filiformis. 
$1 \mathrm{~m} .30 \mathrm{~s}$; ; and in $1 \mathrm{hr} .10 \mathrm{~m}$. reached the centro. Two bits of boiled cork, one of boiled thread, and two of coal-cinders taken from the fire, were placed, by the aid of an instrument which had been immersed in boiling water, on five glands; these superfluous precautions having been taken on account of M. Ziegler's statements. One of the particles of cinder caused some inflection in $8 \mathrm{hrs} .45 \mathrm{~m}$., as did after $23 \mathrm{hrs}$. the other particle of cinder, the bit of thread, and both bits of cork. Three glands were touched half a dozen times with a needle; one of the tentacles became well inflected in $17 \mathrm{~m}$., and re-expanded after $24 \mathrm{hrs}$; the two others never moved. The homogeneous fluid within the cells of the tentacles undergoes aggregation after these have become inflected; especially if given a solution of carbonate of ammonia ; and I observed the usual movements in the masses of protoplasm. In one case, aggregation ensued in $1 \mathrm{hr} .10 \mathrm{~m}$. after a tentacle had carried a bit of meat to the centre. From theso facts it is clear that the tentacles of Drosera anglica behave like those of Drosera rotundifolia.

If an insect is placed on the central glands, or has been naturally caught there, the apex of the leaf curls inwards. For instance, dead flies were placed on three leaves near their bases, and after 24 hrs. the previously straight apices were curled completely over, so as to embrace and conceal the flies; they had therefore moved through an angle of $180^{\circ}$. After three days the apex of one leaf, together with the tentacles, began to re-expand. But as far as I have seen-and I made many trials-the sides of the leaf are never inflected, and this is the one functional difference between this species and Drosera rotundifolia.

Drosera intermedia (Hayne).-This species is quite as common in some parts of England as Drosera rotundifolia. It differs from Drosera anglica, as far as the leaves are concerned, only in their smaller size, and in their tips being generally a little reflexed. They capture a large number of insects. The tentacles are excited into movement by all the causes above specified; and aggregation ensues, with movement of the protoplasmic masses. I have seen, throngh a lens, a tentacle beginning to bend in less than a minute after a particle of raw meat had been placed on the gland. The apex of the leaf curls over an exciting object as in the case of Drosera anylica. Acid secretion is copiously poured over captured insects. A leaf which had embraced a fly with all its tentacles re-expanded after nearly three days.

Drosera capensis.-This species, a native of the Cape of Good Hope, was sent to me by Dr. Hooker. The leaves are elongated, slightly concave along the middle and taper towards the apex, 
which is bluntly pointed and reflexed. They rise from an almost woody axis, and their greatest peculiarity consists in their foliaceous green footstalks, which are almos't as broad and eren longer than the gland-bearing blade. This species, therefore, probably draws more nourishment from the air, and less from captured insects, than the other species of the genus. Nevertheless, the tentacles are crowded together on the disc, and are extremely numerous; those on the margins being much longer than the central ones. All the glands have the same form; their secretion is extremely viscid and acid..

'The specimen which I examined had only just recovered from a weak state of health. This may account for the tentacles moving very slowly when particles of meat were placed on the glands, and perhaps for my never succeeding in causing any movement by repcatedly touching them with a needle. But with all the species of the genus this latter stimulus is the least effective of any. Particles of glass, cork, and coal-cinders, were placed on the glands of six tentacles; and one alone moved after an interval of 2 hrs. $30 \mathrm{~m}$. Nevertheless, two glands were extremely sensitive to very small doses of the nitrate of ammonia, namely to about $\frac{1}{20}$ of a minim of a solution (one part to 5250 of water), containing only $\frac{1}{115200}$ of a grain (.000562 mg.) of the salt. Fragments of flies were placed on two leaves near their tips, which became incurved in 15 hrs. A fly was also placed in the middle of the leaf; in a few hours the tentacles on each side embraced it, and in $8 \mathrm{hrs}$. the whole leaf directly beneath the fly was a little bent transversely. By the next morning, after $23 \mathrm{hrs}$, the leaf was curled so completely over that the apex rested on the upper end of the footstalk. In no case did the sides of the leaves become inflected. A crushed fly was placerl on the foliaceous footstalk, but produced no effect.

- Drosera spathulata (sent to me by Dr. Hooker).-I made only a few observations on this Australian species, which has long, narrow leaves, gradually widening towardis their tips. The glands of the extreme marginal tentacles are elongated and differ from the others, as in the case of Drosera rotundifolia. A fly was placed on a leaf, and in 18 hrs. it was embraced by the adjoining tentacles. Gum-water dropped on sereral leaves produced no effect. A fragment of a leaf was immersed in a few drops of a solution of one part of carbonate of ammonia to 146 of water ; all the glands were instantly blackened; the process of aggregation could be seen travelling rapidly down the cells of the tentacles; and the granules of protoplasm soon united into spheres and variously shaped masses, which displayed the usual move- 
ments. Half a minim of a solution of one part of nitrate of ammonia to 146 of water was next placed on the centre of a leaf ; after $6 \mathrm{hrs}$. some marginal tentacles on both sides were inflected, and after 9 hrs. they met in the centre. The lateral edges of the leaf also became incurved, so that it formed a half-cylinder ; dbut the apex of the leaf in none of my few trials was inflected. The above dose of the nitrate (viz. $\frac{1}{320}$ of a grain, or $\cdot 202 \mathrm{mg}$.) was too powerful, for in the course of $23 \mathrm{hrs}$. the leaf died.

Drosera filiformis.-This North American species grows in such abundance in partso of New Jersey as almost to cover the ground. It catches, according to Mrs. Treat, ${ }^{*}$ an extraordinary number of small and large insects,-even great flies of the genus Asilus, moths, and butterflies. The specimen which I examined, sent me by Dr. Hooker, had thread-like leaves, from 6 to 12 inches in length, with the upper surface convex and the lower flat and slightly channelled. The whole convex surface, down to the roots-for there is no distinct footstalk-is covered with short gland-bearing tentacles, those on the margins being the longest and reflexed. Bits of meat placed on the glands of some tentacles caused them to be slightly inflected in $20 \mathrm{~m}$. ; but the plant was not in a vigorous state. After 6 hrs. they moved through an angle of $90^{\circ}$, and in $24 \mathrm{hrs}$. reached the centre. The surrounding tentacles by this time began to curve inwards. Ultimately a large drop of extremely viscid, slightly acid secretion was poured over the meat from the united glands. Several other glands were touched with a little saliva, and the tentacles became incurved in under $1 \mathrm{hr}$., and re-expanded after $18 \mathrm{hrs.}$ Particles of glass, cork, cinders, thread, and gold-leaf, were placed on numerous glands on two leaves; in about $1 \mathrm{hr}$. four tentacles became curved, and four others after an additional interval of $2 \mathrm{hrs} .30 \mathrm{~m}$. I never once succeeded in causing any movement by repeatedly touching the glands with a needle; and Mrs. Treat made similar trials for me with no success. Small flies were placed on several leaves near their tips, but the thread-like blade became only on one occasion very slightly bent, directly beneath the insect. Perhaps this indicates that the blades of vigorous plants would bend over captured insects, and Dr. Canby informs me that this is the case; but the morement cannot be strongly pronounced, as it was not observed by Mrs. Treat.

Drosera binata (or dichotoma).-I am much indebted to Lady

* 'American Naturalist,' Dec. 1873, p. 705. 
Dorothy Nevill for a fine plant of this almost gigantic Australian species, which differs in some interesting points from those previously described. In this specimen the rush-like footstalks of the leaves were 20 inches in length. The blade bifurcates at its junction with the footstalk, and twice or thrice afterwards, curling about in an irregular manner. It is narrow, being only $\frac{3}{20}$ of an inch in breadth. One blade was $7 \frac{1}{2}$ inches long, so that the entire leaf, including the footstalk, was above 27 inches in length. Both surfaces are slightly hollowed out. The upper surface is covered with tentacles arranged in alternate rows; those in the middle being short and crowded together, those towards the margins longer, even twice or thrice as long as the blade is broad. The glands of the exterior tentacles are of a much darker red than those of the central ones. The pedicels of all are green. The apex of the blade is attenuated, and bears very long tentacles. MIr. Copland informs me that the leaves of a plant which he kept for some jears were generally covered with captured insects before they withered.

The leaves do not differ in essential points of structure or of function from those of the previously described species. Bits of meat or a little saliva placed on the glands of the exterior tentacles caused well-marked movement in $3 \mathrm{~m}$., and particles of glass acted in $4 \mathrm{~m}$. The tentacles with the latter particles re-expanded after 22 hrs. A piece of leaf immersed in a few drops of a solution of one part of carbonate of ammonia to 437 of -water had all the glands blackened and all the tentacles inflected in $5 \mathrm{~m}$. A bit of raw meat, placed on several glands in the medial furrow, was well clasped in 2 hrs. $10 \mathrm{~m}$. by the marginal tentacles on both sides. Bits of roast meat and small flies did not act quite so quickly; and albumen and fibrin still less quickly. One of the bits of meat excited so much secretion (which is always acid) that it flowed some way down the medial furrow, causing the inflection of the tentacles on both sides as far as it extended. Particles of glass placed on the glands in the medial furrow did not stimulate them sufficiently for any motor impulse to be sent to the outer tentacles. In no case was the blade of the leaf, even the attenuated apex, at all inflected.

On both the upper and lower surface of the blade there are numerous minute, almost sessile glands, consisting of four, eight, or twelve cells. On the lower surface they are pale purple, on the upper greenish. Nearly similar organs occur on the footstalks, but they are smaller and often in a shrivelled condition. The minute glands on the blade can absorb rapidly: thus, a piece of leaf was immersed in a solution of one part of carbonate 
of ammonia to 218 of water ( $1 \mathrm{gr}$. to $2 \mathrm{oz}$.), and in $5 \mathrm{~m}$. they were all so much darkened as to be almost black, with their contents aggregated. They do not, as far as I could observe, secrete spontaneously; but in between 2 and 3 hrs. after a leaf had been rubbed with a bit of raw meat moistened with saliva, they seemed to be secreting freely; and this conclusion was afterwards supported by other appearances. They are, therefore, homologous with the sessile glands hereafter to be described on the leaves of Dionæa and Drosophyllum. In this latter genus they are associated, as in the present ease, with glands which secrete spontaneously, that is, without being excited.

Drosera binata presents another and more remarkable pecnliarity, namely, the presence of a few tentacles on the backs of the leaves, near their margins. These are perfect in structure; spiral vessels run up their pedicels; their glands are surrounded by drops of viscid secretion, and they have the power of absorbing. This latter fact was shown by the glands immediately becoming black, and the protoplasm aggregated, when a leaf was placed in a little solution of one part of carbonate of ammonia to 437 of water. These dorsal tentacles are short, not being nearly so long as the marginal ones on the upper surface; some of them are so short as almost to graduate into the minute sessile glands. Their presence, number, "and size, vary on different leaves, and they are arranged rather irregularly. On the back of one leaf I counted as many as twentyone along one side.

These dorsal tentacles differ in one important respect from those on the upper surface, namely, in not possessing any power of movement, in whatever manner they may be stimulated. Thus, portions of four leaves were placed at different times in solutions of carbonate of ammonia (one part to 437 or 218 of water), and all the tentacles on the upper surface soon became closely inflected; but the dorsal ones did not move, though the leaves were left in the solution for many hours, and though their glands from their blackened colour had obviously absorbed some of the salt. Rather young leaves should be selected for such trials, for the dorsal tentacles, as they grow old and begin to wither, often spontaneously incline towards the middle of the leaf. If these tentacles had possessed the power of movement, they would not have been thus rendered more serviceable to the plant; for they are not long enough to bend round the margin of the leaf so as to reach an insect canght on the upper surface, Nor would it have been of any use if these tentacles could have 
moved towards the middle of the lower surface, for there are no viscid glands there by which insects can be caught. Although they have no power of movement, they are probably of some use by absorbing animal matter from any minute insect which may be caught by them, and by absorbing ammonia from the rain-water. But their varying presence and size, and their irregular position, indicate that they are not of much service, and that they are tending towards abortion. In a future chapter we shall see that Drosophyllum, with its elongated leaves, probably represents the condition of an early progenitor of the genus Drosera; and none of the tentacles of Drosophyllum, neither those on the upper nor lower surface of the leaves, are capable of movement when excited, though they capture numerous insects, which serve as nutriment. Therefore it seems that Drosera binata has retained remnants of certain ancestral charactersnamely a few motionless tentacles on the backs of the leaves, and fairly well developed sessile glands-which have been lost by most or all of the other species of the genus.

Concluding Remarlis.-From what we have now seen, there can be little doubt that most or probably all the species of Drosera are adapted for catching insects by nearly the same means. Besides the two Australian species above described, it is said* that two other species from this country, namely Drosera pallida and Drosera sulphurea, "close their leaves upon insects with "great rapidity: and the same phenomenon is mani"fested by an Indian species, $D$. lunata, and by several " of those of the Cape of Good Hope, especially by "D. trinervis." Another Australian species, Drosera heterophylla (made by Lindley into a distinct genus, Sondera) is remarkable from its peculiarly shaped leaves, but I know nothing of its power of catching insects, for I hare seen only dried specimens. The leaves form minute flattened cups, with the footstalks attached not to one margin, but to the bottom. The

* 'Gardener's Chronicle,' 1874, p. 209. 
inner surface and the edges of the cups are studded with tentacles, which include fibro-vascular bundles. rather different from those seen by me in any other species; for some of the vessels are barred and punctured, instead of being spiral. The glands secrete copiously, judging from the quantity of dried secretion adhering to them. 


\section{CHAPTER XIII.}

\section{Dionea mescipula.}

Structure of the leaves-Sensitiveness of the filaments-Rapid movement of the lobes caused by irritation of the filaments Glands, their power of secretion-Slow movement caused by the absorption of animal matter-Evidence of absorption from the aggregated condition of the glands - Digestive power of the secretion - Action of chloroform, ether, and hydrocyanic acid-The månner in which insects are captured-Use of the marginal spikes-Kinds of insects captured-The transmission of the motor impulse and mechanism of the movements - Re-expansion of the lobes.

'TuIs plant, commonly called Venus' fly-trap, from the rapidity and force of its movements, is one of the most wonderful in the world.* It is a member of the small family of the Droseracer, and is found only in the eastern part of North Carolina, growing in damp situations. The roots are small; those of a moderately fine plant which I examined consisted of two branches about 1 inch in length, springing from a bulbous enlargement. They probably serve, as in the case of Drosera, solely for the absorption of water; for a gardener, who has been very successful in the cultivation of this plant, grows it, like an epiphytic orchid, in well-drained damp moss without any soil. $\dagger$ The form of the bilobed leaf, with its foliaceous footstalk, is shown in the accompanying drawing (fig. 12).

* Dr. Hooker, in his address to the British Association at Belfast, $187 t$, has given so full an.historical account of the observations which have been published on the habits of this plant, that it would be superfluous on my part to repeat them.

p. 464 . 
The two lobes stand at rather less than a right angle to each other. Three minute pointed processes or filaments, placed triangularly, project from the upper surfaces of both; but I have seen two leaves with four filaments on each side, and another with only two. These filaments are remarkable from their extreme sensitiveness to a touch, as shown not by their own movement, but by that of the lobes. The margins of the leaf are prolonged into sharp rigid projections which I will call spikes, into each of which a bundle

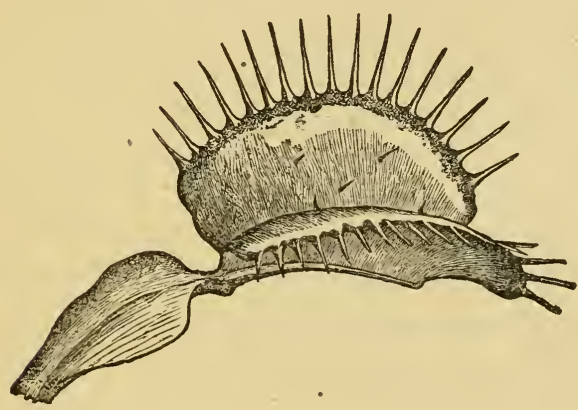

Fig. 12.

(Dionara muscipula.)

Leaf viewed laterally in its expanded state.

of spiral vessels enters. The spikes stand in such a position that, when the lobes close, they inter-lock like the teeth of a rat-trap. The midrib of the leaf, on the lower side, is strongly developed and prominent.

The upper surface of the leaf is thickly covered; excepting towards the margins, with minute glands of a reddish or purplish colour, the rest of the leaf being green. There are no glands on the spikes, or on the foliaceous footstalk. The glands are formed of from 
twenty to thirty polygonal cells, filled with purple fluid. Their upper surface is convex. They stand on very short pedicels, into which spiral vessels do not enter, in which respect they differ from the tentacles of Drosera. They secrete, but only when excited by the absorption of certain matters; and they have the power of absorption. Minute projections, formed of eight divergent arms of a reddish-brown or orange colour, and appearing under the microscope like elegant little flowers, are scattered in considerable numbers over the foot-stalk, the backs of the leaves, and the spikes, with a few on the upper surface of the lobes. These octofid projections are no doubt homologous with the papillæ on the leaves of Drosera rotundifolia. There are also a few very minute, simple, pointed hairs, about $\frac{7}{12000}(.0148 \mathrm{~mm}$.) of an inch in length on the backs of the leaves.

The sensitive filaments are formed of several rows of elongated cells, filled with purplish fluid. They are a little above the $\frac{1}{20}$ of an inch in length ; are thin and delicate, and taper to a point. I examined the bases of several, making sections of them, but no trace of the entrance of any vessel could be seen. The apex is sometimes bifid or even trifid, owing to a slight separation between the terminal pointed cells. Towards the base there is constriction, formed of broader cells, beneath which there is an articulation, supported on an enlarged base, consisting of differently shaped polygonal cells. As the filaments project at right angles to the-surface of the leaf, they would have been liable to be broken whenever the lobes closed together, had it not been for the articulation which allows them to bend flat down.

These filaments, from their tips to their bases, are exquisitely sensitive to a momentary touch. It is scarcely 
possible to touch them ever so lightly or quickly with any hard object without causing the lobes to close. A piece of very delicate human hair, $2 \frac{1}{2}$ inches in length, held dangling over a filament, and swayed to and fro so as to touch it, did not excite any movement. But when a rather thick cotton thread of the same length was similarly swayed, the lobes closed. Pinches of fine wheaten flour, dropped from a height, produced no effect. The above-mentioned hair was then fixed into a handle, and cut off so that 1 inch projected; this length being sufficiently rigid to support itself in a nearly horizontal line. The extremity was then brought by a slow movement laterally into contact with the tip of a filament, and the leaf instantly closed. On another occasion two or three touches of the same kind were necessary before any movement ensued. When we consider how flexible a fine hair is, we may form some idea how slight must be the touch given by the extremity of a piece, 1 inch in length, moved slowly.

Although these filaments are so sensitive to a momentary and delicate touch, they are far less sensitive than the glands of Drosera to prolonged pressure. Several times I succeeded in placing on the tip of a filament, by the aid of a needle moved with extreme slowness, bits of rather thick human hair, and these did not. excite movement, although they were more than ten times as long as those which caused the tentacles of Drosera to bend; and although in this latter case they were largely supported by the dense secretion. On the other hand, the glands of Drosera may be struck with a needle or any hard object, once, twice, or even thrice, with considerable force, and no movement ensues. This singular difference in the nature of the sensitiveness of the filaments of Dionæa and of 
the glands of Drosera evidently stands in relation to the habits of the two plants. If a minute insect alights with its delicate feet on the glands of Drosera, it is caught by the viscid secretion, and the slight, though prolonged pressure, gives notice of the presence of prey, which is secured by the slow bending of the tentacles. On the other hand, the sensitive filaments of Dionæa are not viscid, and the capture of insects can be assured only by their sensitiveness to a momentary touch, followed by the rapid closure of the lobes.

As just stated, the filaments are not glandular, and do not secrete. Nor have they the power of absorption, as may be inferred from drops of a solution of carbonate of ammonia (one part to 146 of water), placed on two filaments, not producing any effect on the contents of their cells, nor causing the lobes to close. When, however, a small portion of a leaf with an attached filament was cut off and immersed in the same solution, the fluid within the basal cells became almost instantly aggregated into purplish or colourless, irregularly shaped masses of matter. The process of aggregation gradually travelled up the filaments from cell to cell to their extremities, that is in a reverse course to what occurs in the tentacles of Drosera when their glands have been excited. Several other filaments were cut off close to their bases, and left for $1 \mathrm{hr}$. $30 \mathrm{~m}$. in a weaker solution of one part of the carbonate to 218 of water, and this caused aggregation in all the cells, commencing as before at the bases of the filaments.

Long immersion of the filaments in distilled water likewise causes aggregation. Nor is it rare to find the contents of a few of the terminal cells in a spontaneously aggregated condition. The aggregated 
masses undergo incessant slow changes of form, uniting and again separating; and some of them apparently revolve round their own axes. A current of colourless granular protoplasm could also be seen travelling round the walls of the cells. This current ceases to be visible as soon as the contents are well aggregated; but it probably still continues, though no longer visible, owing to all the granules in the flowing layer having become united with the central masses. In all these respects the filaments of Dionæa behave exactly like the tentacles of Drosera.

Notwithstanding this similarity there is one remarkable difference. The tentacles of Drosera, after their glands have been repeatedly touched, or a particle of any kind has been placed on them, become inflected and strongly aggregated. No such effect is produced by touching the filaments of Dionæa; I compared, after an hour or two, some which had been touched and some which had not, and others after twenty-five hours, and there was no difference.in the contents of the cells. The leaves were kept open all the time by clips; so that the filaments were not pressed against the opposite lobe.

Drops of water, or a thin broken stream, falling from a height on the filaments, did not cause the blades to close ; though these filaments were afterwards proved to be highly sensitive. No doubt, as in the case of Drosera, the plant is indifferent to the heaviest shower of rain. Drops of a solution of a half an ounce of sugar to a fluid ounce of water were repeatedly allowed to fall from a height on the filaments, but produced no effect, unless they adhered to them. Again, I blew many times through a fine pointed tube with my utmost force against the filaments without any effect; such blowing being received 
with as much indifference as no doubt is a heavy gale of wind. We thus see that the sensitiveness of the filaments is of a specialised nature, being related to a momentary touch rather than to prolonged pressure; and the touch must not be from fluids, such as air or water, but from some solid object.

Although drops of water and of a moderately strong solution of sugar, falling on the filaments, does not excite them, yet the immersion of a leaf in pure water sometimes caused the lobes to close. One leaf was left immersed for $1 \mathrm{hr} .10 \mathrm{~m}$., and three other leaves for some minutes, in water at temperatures varying between $59^{\circ}$ and $65^{\circ}\left(15^{\circ}\right.$ to $18^{\circ} \cdot 3$ Cent.) without any effect. One, however, of these four leaves, on being gently withdrawn from the water, closed rather quickly. The three other leaves were proved to be in good condition, as they closed when their filaments were touched. Nerertheless two fresh leaves on being dipped into water at $75^{\circ}$ and $62 \frac{1}{2}^{\circ}\left(23^{\circ} \cdot 8\right.$ and $16^{\circ} \cdot 9$ Cent.) instantly closed. These were then placed with their footstalks in water, and after 23 hrs. partially re-expanded; on touching their filaments one of them closed. This latter leaf after an additional 24 hrs. again re-expanded, and now, on the filaments of both leaves being touched, both closed. We thus see that a short immersion in water does not at all injure the leaves, but sometimes excites the lobes to close. The movement in the above cases was evidently not caused by the temperature of the water. It has been shown that long immersion causes the purple fluid within the cells of the sensitive filaments to become aggregated; and the tentacles of Drosera are acted on in the same manner by long immersion, often being somewhat inflected. In both cases the result is probably due to a slight degree of exosmose. 
I am confirmed in this belief by the effects of immersing a leaf of Dionæa in a moderately strong solution of sugar; the leaf having been previously left for $1 \mathrm{hr} .10 \mathrm{~m}$. in water without any effect; for now the lobes closed rather quickly, the tips of the marginal spikes crossing in $2 \mathrm{~m}$. $30 \mathrm{~s}$, and the leaf being com= pletely shut in $3 \mathrm{~m}$. Three leaves were then immersed in a solution of half an ounce of sugar to a fluid ounce of water, and all three leaves closed quickly. As I was doubtful whether this was due to the cells on the upper surface of the lobes, or to the sensitive filaments, being acted on by exosmose, one leaf was first tried by pouring a little of the same solution in the furrow between the lobes over the midrib, which is the chief seat of movement. It was left there for some time, but no movement ensued. The whole upper surface of leaf was then painted (except close round the bases of the sensitive filaments, which I could not do without risk of touching them) with the same solution, but no effect was produced. So that the cells on the upper surface are not thus affected. But when, after many trials, I succeeded in getting a drop of the solution to cling to one of the filaments, the leaf quickly closed. Hence we may, I think, conclude that the solution causes fluid to pass out of the delicate cells of the filaments by exosmose; and that this sets up some molecular change in their contents, analogous to that which must be produced by a touch.

The immersion of leaves in a solution of sugar affects them for a much longer time than does an immersion in water, or a touch on the filaments; for in these latter cases the lobes begin to re-expand in less than a day. On the other hand, of the three leaves which were immersed for a short time in the solution, and were then washed by means of a syringe inserted 
between the lobes, one re-expanded after two days; a second after seren days; and the third after nine days. The leaf which closed, owing to a drop of the solution having adhered to one of the filaments, opened after two days.

I was surprised to find on two occasions that the heat from the rays of the sun, concentrated by a lens on the bases of several filaments, so that they were scorched and discoloured, did not cause any movement; though the leaves were active, as they closed, though rather slowly, when a filament on the opposite side was touched. On a third trial, a fresh leaf closed after a time, though very slowly; the rate not being increased by one of the filaments, which had not been injured, being touched. After a day these three leaves opened, and were fairly sensitive when the uninjured filaments were touched. The sudden immersion of a leaf into boiling water does not cause it to close. Judging from the analogy of Drosera, the heat in these several cases was too great and too suddenly applied. The surface of the blade is very slightly sensitive; it may be freely and roughly handled, without any movement being caused. A leaf was scratched rather hard with a needle, but did not close; but when the triangular space between the three filaments on another leaf was similarly scratched, the lobes closed. They always closed when the blade or midrib was deeply pricked or cut. Inorganic bodies, even of large size, such as bits of stone, glass, \&c.- - or organic bodies not containing soluble nitrogenous matter, such as bits of wood, cork, moss, - or bodies containing soluble nitrogenous matter, if perfectly dry, such as bits of meat, albumen, gelatine, \&c., may be long left (and many were tried) on the lobes, and no movement is excited. The result, however, is widely different, as we 
shall presently see, if nitrogenous organic bodies which are at all damp, are left on the lobes; for these then close by a slow and gradual movement, very different from that caused by touching. one of the sensitive filaments. The footstalk is not in the least sensitive; a pin-may be driven through it, or it may be cut off, and no movement follows.

The upper surface of the lobes, as already stated, is thickly covered with small purplish, almost sessile glands. These have the power both of secretion and absorption; but unlike those of Drosera, they do not secrete until excited by the absorption of nitrogenous matter. No other excitement, as far as I have seen, produces this effect. Objects, such as bits of wood, cork, moss, paper, stone, or glass, may be left for a length of time on the surface of a leaf, and it remains quite dry. Nor does it make any difference if the lobes close over such objects. For instance, some little balls of blotting paper were placed on a leaf; and a filament was touched; and when after 24 hrs. the lobes began to re-open, the balls were removed by the aid of thin pincers, and were found perfectly dry. On the other hand, if a bit of damp meat or a crushed fly is placed on the surface of an expanded leaf, the glands after a time secrete freely: In one such case there was a little secretion directly beneath the meat in $4 \mathrm{hrs.}$; and after an additional 3 hrs. there was a considerable quantity both under and close round it. In another case, after 3 hrs. $40 \mathrm{~m}$., the bit of meat was quite wet. But none of the glands secreted, excepting those which actually touched the meat or the secretion containing dissolved animal matter.

If, however, the lobes are made to close over a bit of meat or an insect, the result is different, for the glands over the whole surface of the leaf now secrete copiously. 
As in this case the glands on both sides are pressed against the meat or insect, the secretion from the first is twice as great as when a bit of meat is laid on the surface of one lobe; and as the tro lobes come into almost close contact, the secretion, containing dissolved animal matter, spreads by capillary attraction, causing fresh glands on both sides to begin secreting in a continually widening circle. The secretion is almost colourless, slightly mucilaginous, and, judging by the manner in which it coloured litmus paper, more strongly acid than that of Drosera. It is so copious that on one occasion, when a leaf was cut open, on which a small cube of albumen had been placed 45 hrs. before, drops rolled off the leaf. On another occasion, in which a leaf with an enclosed bit of roast meat spontaneously opened after eight days, there was so much secretion in the furrow orer the midrib that it trickled down. A large crushed fly (Tipula) was placed on a leaf from which a small portion at the, base of one lobe had preriously been cut away, so that an opening was left; and through this, the secretion continued to run down the footstalk during nine days,--that is, for as long a time as it was observed. By forcing up one of the lobes, I was able to see some distance between them, and all the glands within sight were secreting freely.

We hare seen that inorganic and non-nitrogenous objects placed on the leaves do not excite any morement; but nitrogenous bodies, if in the least degree damp, cause after several hours the lobes to close slowly. Thus bits of quite dry meat and gelatine were placed at opposite ends of the same leaf, and in the course of $2 t$ hrs. excited neither secretion nor morement. They were then dipped in water, their surfaces dried on blotting paper, and replaced on the same 
leaf, the plant being now covered with a boll-glass. After 24 hrs. the damp meat had excited some acid secretion, and the lobes at this end of the leaf were almost shut. At the other end, where the damp gelatine lay, the leaf was still quite open, nor had any secretion been excited; so that, as with Drosera, gelatine is not nearly so exciting a substance as meat. The secretion beneath the meat was tested by pushing a strip of litmus paper under it (the filaments not being touched), and this slight stimulus caused the leaf to shut. On the eleventh day it reopened; but the end where the gelatine lay, expanded several hours before the opposite end with the meat.

A second bit of roast meat, which appeared dry, though it had not been purposely dried, was left for 24 hrs. on a leaf, caused neither morement nor secretion. The plant in its pot was now covered with a bell-glass, and the meat absorbed some moisture from the air; this sufficed to excite acid secretion, and by the next morning the leaf was closely shut. A third bit of meat, dried so as to be quite brittle, was placed on a leaf under a bell-glass, and this also became in 24 hrs. slightly damp, and excited some acid secretion, but no morement.

A rather large piece of perfectly dry albumen was left at one end of a leaf for 24 hrs. without any effect. It was then soaked for a few minutes in water, rolled about on blotting paper, and replaced on the leaf; in 9 hrs. some slightly acid secretion was excited, and in $24 \mathrm{hrs}$. this end of the leaf was partially closed. The bit of albumen, which was now surrounded by much secretion, was gently removed, and although no filament was touched, the lobes closed. In this and the previous case, it appears that the absorption of animal matter by the glands renders 
the surface of the leaf much more sensitive to a touch than it is in its ordinary state; and this is a curious fact. Two days afterwards the end of the leaf where nothing had been placed began to open, and on the third day was much more open than the opposite end where the albumen had lain.

Lastly, large drops of a solution of one part of carbonate of ammonia to 146 of water were placed on some leaves, but no immediate movement ensued. I did not then know of the slow movement caused by animal matter, otherwise I should have observed the leaves for a longer time, and they would probably have been found closed, though the solution (judging . from Drosera) was, perhaps, too strong.

From the foregoing cases it is certain that bits of meat and albumen, if at all damp, excite not only the glands to secrete, but the lobes to close. This movement is widely different from the rapid closure caused by one of the filaments being touched. We shall see its importance when we treat of the manner in which insects are captured. There is a great contrast between Drosera and Dionæa in the effects produced by mechanical irritation on the one hand, and the absorption of animal matter on the other. Particles of glass placed on the glands of the exterior tentacles of Drosera excite movement within nearly the same time, as do particles of meat, the latter being rather the most efficient; but when the glands of the disc have bits of meat given them, they transmit a motor impulse to the exterior tentacles much more quickly than do these glands when bearing inorganic particles, or when irritated by repeated touches. On the other hand, with Dionæa, touching the filaments excites incomparably quicker movement than the absorption of animal matter by the glands. Nevertheless, in 
certain cases, this latter stimulus is the more powerful of the two. On three occasions leaves were found which from some cause were torpid, so that their lobes closèd only slightly, however much their filaments were irritated; but on inserting crushed insects between the lobes, they became in a day closely shut.

The facts just given plainly show that the glands bave the power of absorption, for otherwise it is impossible that the leaves should be so differently affected by non-nitrogenous and nitrogenous bodies, and between these latter in a dry and damp condition. It is surprising how slightly damp a bit of meat or albumen need be in order to excite secretion and afterwards slow movement, and equally surprising how minute a quantity of animal matter, when absorbed, suffices to produce these two effects. It seems hardly credible, and yet it is certainly a fact, that a bit of hard-boiled white of egg, first thoroughly dried, then soaked for some minutes in water and rolled on blotting. paper, should yield in a few hours enough animal matter to the glands to cause them to secrete, and afterwards the lobes to close. That the glands have the power of absorption is likewise shown by the very different lengths of time (as we shall presently see) during which the lobes remain closed over insects and other bodies yielding soluble nitrogenous matter, and over such as do not yield any. But there is direct evidence of absorption in the condition of the glands which have remained for some time in contact with animal matter. Thus bits of meat and crushed insects were several times placed on glands, and these were compared after some hours with other glands from distant parts of the same leaf. The latter showed not a trace of aggregation, whereas those which had been in contact with the animal matter were 
well aggregated. Aggregation may be seen to occur very quickly if a piece of a leaf is immersed in a weak solution of carbonate of ammonia. Again, small cubes of albumen and gelatine were left for eight days on a leaf, which was then cut open. The whole surface was bathed with acid secretion, and every cell in the many glands which were examined had its contents aggregated in a beautiful manner into dark or pale purple, or colourless globular masses of protoplasm. These underwent incessant slow changes of forms; sometimes separating from one another and then reuniting, exactly as in the cells of Drosera. Boiling water makes the contents of the gland-cells white and opaque, but not so purely white and porcelain-like as in the case of Drosera. How living insects, when naturally caught, excite the glands to secrete so quickly as they do, I know not; but I suppose that the great pressure to which they are subjected forces a little excretion from either extremity of their bodies, and we have seen that an extremely small amount of nitrogenous matter is sufficient to excite the glands.

Before passing on to the subject of digestion, I may state that I endeavoured to discover, with no success, the functions of the minute octofid processes with which the leaves are studded. From facts hereafter to be given in the chapters on Aldrovanda and Utricularia, it seemed probable that they served to absorb decayed matter left by the captured insects; but their position on the backs of the leares and on the footstalks rendered this almost impossible. Nevertheless, leaves were immersed in a solution of one part of urea to 437 of water, and after 24 hrs. the orange layer of protoplasm within the arms of these processes did not appear more aggregated than in other speci- 
mens kept in water. I then tried suspending a leaf in a bottle over an excessively putrid infusion of raw meat, to see whether they absorbed the vapour, but their contents were not affected.

Digestive Power of the Secretion. *-When a leaf closes over any object, it may be said to form itself into a temporary stomach; and if the object yields ever so little animal matter, this serves, to use Schiff's expression, as a peptogene, and the glands on the surface pour forth their acid secretion, which acts like the gastric juice of animals. As so many experiments were tried on the digestive power of Drosera, only a few were made with Dionæa, but they were amply sufficient to prove that it digests. This plant, moreover, is not so well fitted as Drosera for observation, as the process goes on within the closed lobes. Insects, even beetles, after being subjected to the secretion for several days, are surprisingly softened, though their chitinous coats are not corroded.

Experiment 1.-A cube of albumen of $\frac{1}{10}$ of an inch $(2: 540$ $\mathrm{mm}$.) was placed at one end of a leaf, and at the other end an oblong piece of gelatine, $\frac{1}{5}$ of an inch $(5.08 \mathrm{~mm}$.) long, and

* Dr. W. M. Canby, of Wilmington, to whom I am much indebted for information regarding Dionæa in its ative home, has published in the 'Gardener's Monthly,' Philadelphia, August 1868 , some interesting observations. He ascertained that the secretion digests animal matter, such as the contents of insects, bits of meat, \&c.; and that the secretion is reabsorbed. He was also well aware that the lobes remain closed for a much longer time when in contact with animal matter than when made to shut by a mere touch, or over objects not yielding soluble nutriment; and that in these latter cases the glands do not secrete. The Rev. Dr. Curtis first observed ('Boston Journal Nat. Hist.' vol. i. p. 123) the secretion from the glands. I may here add that a gardener. Mr. Knight, is said (Kirby and Spencer's 'Introduction to Entomology,' 1818, vol. i. p. 295) to have found that a plant of the Dionæa, on the leaves of which "he laid fine filaments of raw beef, was much more luxuriant in its growth than others not so treated." 
$\frac{1}{10}$ broad; the leaf was then made to close. It was cut open after 45 hrs. The albumen was hard and compressed, with its angles only a little rounded; the gelatine was corroded into an oval form; and both were bathed in so much acid secretion that it dropped off the leaf. The digestive process apparently is rather slower than in Drosera, and this agrees with the length of time during which the leaves remain closed over digestible objects.

Experiment 2.-A bit of albumen $\frac{1}{10}$ of an inch square, but only $\frac{1}{20}$ in thickness, and a piece of gelatine of the same size as before, were placed on a leaf, which eight days afterwards was cut open. The surface was bathed with slightly adhesive, very acid secretion, and the glands were all in an aggregated condition. Not a vestige of the albumen or gelatine was left. Similarly sized pieces were placed at the same time on wet moss on the same pot, so that they were subjected to nearly similar conditions; after eight days these were brown, decayed, and matted with fibres of mould, but had not disappeared.

Experiment 3.-A piece of albumen $\frac{3}{20}$ of an inch $(3.81 \mathrm{~mm}$.) long, and $\frac{1}{20}$ broad and thick, and a piece of gelatine of the same size as before, were placed on another leaf, which was cut open after seven days; not a vestige of either substance was left, and only a moderate amount of secretion on the surface.

Experiment 4.-Pieces of albumen and gelatine, of the same size as in the last experiment, were placed on a leaf, which spontaneously opened after twelve days, and here again not a vestige of either was left, and only a little secretion at one end of the midrib.

Experiment 5.-Pieces of albumen and gelatine of the same size were placed on another leaf, which after twelve days was still firmly closed, but had begun to wither; it was cut open, and contained nothing except a vestige of brown matter where the albumen had lain.

Experiment 6.-A cube of albumen of $\frac{1}{10}$ of an inch and a piece of gelatine of the same size as before were placed on a leaf, which opened spontaneously after thirteen days. The albumen, which was twice as thick as in the latter experiments, was too large; for the glands in contact with it were injured and were dropping off; a film also of albumen of a brown colour, matted with mould, was left. All the gelatine was absorbed, and there was only a little acid secretion left on the midrib.

lixperiment 7.-A bit of half roasted meat (not measured) and a bit of gelatine were placed on the two ends of a leaf, which 
opened spontaneously after eleven days; a vestige of the meat was left, and the surface of the leaf was here blackened; the gelatine had all disappeared.

Experiment 8.-A bit of half roasted meat (not measured) was placed on a leaf which was forcibly kept open by a clip, so that it was moistened with the secretion (very acid) only on its lower surface. Nevertheless, after only $22 \frac{1}{2} \mathrm{hrs}$. it was surprisingly softened, when compared with another bit of the same meat which had been kept damp.

Experiment 9.-A cube of $\frac{1}{10}$ of an inch of very compact roasted beef was placed on a leaf, which opened spontaneously after twelve days; so much feebly acid secretion was left on the leaf that it trickled off. The meat was completely disintegrated, but not all dissolved; there was no mould. The little mass was placed under the microscope; some of the fibrillæ in the middle still exhibited transverse striæ; others showed not a vestige of strix; and every gradation could be traced between these two states. Globules, apparently of fat, and some undigested fibro-elastic tissue remained. The meat was thus in tho same state as that formerly described, which was half digested by Drosera. Here, again, as in the case of albumen, the digestive process secms slower than in Drosera. At tho opposite end of the same leaf, a firmly compressed pellet of bread had been placed; this was completely disintegrated, I suppose, owing to the digestion of the gluten, but seemed very little reduced in bulk.

Experiment 10. - A cube of $\frac{1}{20}$ of an inch of cheese and. another of albumen were placed at opposite ends of the same leaf. After nine days the lobes opened spontaneously a little at the end enclosing the cheese, but hardly any or none was dissolved, though it was softened and surrounded by secretion. Two days subsequently the end with the albumen also opened spontaneously (i.e. eleven days after it was put on), a mere trace in a blackened and dry condition being left.

Experiment 11.-The same experiment with cheese and albumen repeated on another and rather torpid leaf. The lobes at the cnd with the cheese, after an interval. of six days, opened spontaneously a little; the cube of cheeso was much softened, but not dissolved, and but little, if at all, reduced in size. Twelvo hours afterwards the end with the albumen opened, which now consisted of a large drop of transparent, not acid, viscid fluid.

Experiment 12.--Samo experiment as the two last, and horo again the leaf at the end enclosing the checse opened before the 
opposite end with the albumen; but no further observations were made.

Experiment 13.-A globule of chemically prepared casein, about $\frac{\lambda}{10}$ of an inch in diameter, was placed on a leaf, which spontaneously opened after eight days. The casein now consisted of a soft sticky mass, very little, if at all, reduced in size, but bathed in acid secretion.

These experiments are sufficient to show that the secretion from the glands of Dionæa dissolves albumen, gelatine, and meat, if too large pieces are not given." Globules of fat and fibro-elastic tissue are not digested. The secretion, with its dissolved matter, if not in excess, is subsequently absorbed. On the other hand, although chemically prepared casein and cheese (as in the case of Drosera) excite much acid secretion, owing, I presume, to the absorption of some included albuminous matter, these substances are not digested, and are not appreciably, if at all, reduced in bulk.

Effects of the Vapours of Chloroform, SuTphuric Ether, and Hydrocyanic Acid.-A plant bearing one leaf was introduced into a large bottle with a drachm (3.519 ml.) of chloroform, the mouth being imperfectly closed with cotton-wool. The vapour caused in $1 \mathrm{~m}$. the lobes to begin moving at an imperceptibly slow rate; but in $3 \mathrm{~m}$. the spikes crossed, and the leaf was soon completely shut. The dose, however, was much too large, for in between 2 and $3 \mathrm{hrs}$. the leaf appeared as if burnt, and soon died.

Two leaves were exposed for $30 \mathrm{~m}$. in a 2-oz. ressel to the vapour of 30 minims $(1.774 \mathrm{ml}$.) of sulphnric ether. One leaf closed after a time, as did the other whilst being removed from the vessel without being touched. Both leaves were greatly injured. Another leaf, exposed for $20 \mathrm{~m}$. to 15 minims of ether, closed its lobes to a certain extent, and the sensitive filaments were now quite insensible. After $24 \mathrm{hrs}$. this leaf recovered its sensibility, but was still rather torpid. A leaf exposed in a large bottle for only $3 \mathrm{~m}$. to ten drops was rendered insensible. After $52 \mathrm{~m}$. it recovered its sensibility, and when one of the filaments was touched, the lobes closed. It began 
to reopen after $20 \mathrm{hrs}$. Lastly another leaf was exposed for $4 \mathrm{~m}$. to only four drops of the ether; it was rendered insensible, and did not close when its filaments were repeatedly touched, but closed when the end of the open leaf was cut off. This shows either that the internal parts had not been rendered insensible, or that an incision is a more powerful stimulus than repeated tonches on the filaments. Whether the larger doses of chloroform and ether, which caused the leaves to close slowly, acted on the sensitive filaments or on the leaf itself, I do not know.

Cyanide of potassium, when left in a bottle, generates prussic or hydrocyanic acid. A leaf was exposed for $1 \mathrm{hr}$. $35 \mathrm{~m}$. to the vapour thus formed; and the glands became within this time so colourless and shrunken as to be searcely visible, and I at first thought that they had all dropped off. The leaf was not rendered insensible; for as soon as one of the filaments was touched it closed. It had, however, suffered, for it did not reopen until nearly two days had passed, and was not even then in the least sensitive. After an additional day it recovered its powers, and closed on being touched and subsequently reopened. Another leaf behaved in nearly the same manner after a shorter exposure to this vapour.

On the Manner in which Insects are caught.-We will now consider the action of the leares when insects happen to touch one of the sensitive filaments. This often occurred in my greenhouse, but I do not know whether insects are attracted in any special way by the leaves. They are caught in large numbers by the plant in its native country. As soon as a filament is touched, both lobes close with astonishing quickness; and as they stand at less than a right angle to each other, they have a good chance of catching any intruder. The angle between the blade and footstalk does not change when the lobes close. The chief seat of movement is near the midrib, but is not confined to this part; for, as the lobes come together, each curves inwards across its whole breadth; the marginal spikes however, not becoming curved. This move- 
ment of the whole lobe was well seen in a leaf to which a large fly had been given, and from which a large portion had been cut off the end of one lobe; so that the opposite lobe, meeting with no resistance in this part, went on curving inwards much beyond the medial line. The whole of the lobe, from which a portion had been cut, was afterwards removed, and the opposite lobe now curled completely over, passing through an angle of from $120^{\circ}$ to $130^{\circ}$, so as to occupy a position almost at right angles to that which it would have held had the opposite lobe been present.

From the curving inwards of the two lobes, as they move towards each other, the straight marginal spikes intercross by their tips at first, and ultimately by their bases. The leaf is then completely shut and encloses a shallow cavity. If it has been made to shut merely by one of the sensitive filaments having been touched, or if it includes an object not yielding soluble nitrogenous matter, the two lobes retain their inwardly concave form until they re-expand. The re-expansion under these circumstances-that is when no organic matter is enclosed-was observed in ten cases. In all of these, the leares re-expanded to about two-thirds of the full extent in 24 hrs. from the time of closure. Even the leaf from which a portion of one lobe had been cut off opened to a slight degree within this same time. In one case a leaf re-expanded to about twothirds of the full extent in 7 hrs., and completely in 32 hrs.; but one of its filaments had been touched merely with a hair just enough to cause the leaf to close. Of these ten leaves only a few re-expanded completely in less than two days, and two or three required even a little longer time. Before, however, they fully re-expand, they are ready to close 
instantly if their sensitive filaments are touched. How many times a leaf is capable of shutting and opening if no animal matter is left enclosed, I do not know; but one leaf was made to close four times, reopening afterwards, within six days. On the last occasion it caught a fly, and then remained closed for many days.

This power of reopening quickly after the filaments have been accidentally touched by blades of grass, or by objects blown on the leaf by the wind, as occasionally happens in its native place, ${ }^{*}$ must be of some importance to the plant; for as long as a leaf remains closed, it cannot of course capture an insect.

When the filaments are irritated and a leaf is made to shut over an insect, a bit of meat, albumen, gelatine, casein, and, no doubt, any other substance containing soluble nitrogenous matter, the lobes, instead of remaining concave, thus including a concavity, slowly press closely together throughout their whole breadth. As this takes place, the margins gradually become a little everted, so that the spikes, which at first intercrossed, at last project in two parallel rows. The lobes press against each other with such force that I have seen a cube of albumen much flattened, with distinct impressions of the little prominent glands; but this latter circumstance may have been partly caused by the corroding action of the secretion. So firmly do they become pressed together that, if any large insect or other object has been caught, a corresponding projection on the outside of the leaf is distinctly visible. When the two lobes are thus completely shut, they

* According to Dr. Curtis, in 'Doston Journal of Nat. Hist.' vol. i. 1837, p. 123. 
resist being opened, as by a thin wedge driven between them, with astonishing force, and are generally ruptured rather than yield. If not ruptured, they close again, as Dr. Canby informs me in a letter, "with quite a loud flap." But if the end of a leaf is held firmly between the thumb and finger, or by a clip, so that the lobes cannot begin to close, they exert, whilst in this position, very little force.

I thought at first that the gradual pressing together of the lobes was caused exclusively by captured insects crawling over and repeatedly irritating the sensitive filaments; and this view seemed the moro probable when I learnt from Dr. Burdon Sanderson that whenever the filaments of a closed leaf are irritated, the normal electric current is disturbed. Nerertheless, such irritation is by no means necessary, for a dead insect, or a bit of meat, or of albumen, all act equally well; proving that in these cases it is the absorption of animal matter which excites the lobes slowly to press close together. We have seen that the absorption of an extremely small quantity of such matter also causes a fully expanded leaf to close slowly; and this morement is clearly analogous to the slow pressing together of the concare lobes. This latter action is of high functional importance to tho plant, for the glands on both sides are thus brought into contact with a captured insect, and consequently secrete. The secretion with animal matter in solution is then drawn by capillary attraction over the whole surface of the leaf, causing all the glands to secrete and allowing them to absorb the diffused animal matter. The morement, excited by the absorption of such matter, though slow, suffices for its final purpose, whilst the morement excited by one of the sensitive filaments being touched is rapid, and this is indis- 
pensable for the capturing of insects. These two movements, excited by two such widely different means, are thus both well adapted, like all the other functions of the plant, for the purposes which they subserve.

There is another wide difference in the action of leaves which enclose objects, such as bits of wood, cork, balls of paper, or which have had their filaments merely touched, and those which enclose organic bodies yielding soluble nitrogenous matter. In the former case the leaves, as we have seen, open in under $24 \mathrm{hrs}$. and are then ready, even before being fully expanded, to shut again. But if they have closed over nitrogen-yielding bodies, they remain closely shut for many days; and after re-expanding aro torpid, and never act again, or only after a considerable interval of time. In four instances, leaves after catching insects never reopened, but began to wither, remaining closed-in one case for fifteen days over a fly; in a second, for twenty-four days, though the fly was small; in a third for twenty-four days over a woodlouse; and in a fourth, for thirty-five days over a large Tipula. In two other cases leaves remained closed for at least nine days over flies, and for how many more I do not know. It should, however, be added that in two instances in which very small insects had been naturally caught the leaf opened as quickly as if nothing had been caught; and I suppose that this was due to such small insects not having been crushed or not having excreted any animal matter, so that the glands were not excited. Small angular bits of albumen and gelatine were placed at both ends of three leaves, two of which remained closed for thirteen and the other for twelve days. Two other leaves remained closed over bits of 
meat for eleven days, a third leaf for eight days, and a fourth (but this had been cracked and injured) for only six days. Bits of cheese, or casein, were placed at one end and albumen at the other end of three leaves; and the ends with the former opened after six, eight, and nine days, whilst the opposite ends opened a little later. None of the above bits of meat, albumen, \&c., exceeded a cube of $\frac{1}{10}$ of an inch $(2.54 \mathrm{~mm}$. $)$ in size, and were sometimes smaller; yet these small portions sufficed to keep the leaves closed for many days. Dr. Canby informs me that leaves remain shut for a longer time over insects than over meat; and from what I have seen, I can well believe that this is the case, especially if the insects are large.

In all the above cases, and in many others in which leaves remained closed for a long but unknown period over insects naturally caught, they were more or less torpid when they reopened. Generally they were so torpid during many succeeding days that no excitement of the filaments caused the least movement. In one instance, however, on the day after a leaf opened which had clasped a fly, it closed with extreme slowness when one of its filaments was touched; and although no object was left enclosed, it was so torpid that it did not re-open for the second time until 44 hrs. had elapsed. In a second case, a leaf which had expanded after remaining closed for at least nine days orer a fly, when greatly irritated, moved one alone of its two lobes, and retained this unusual position for the next two days. A third case offers the strongest exception which I have observed ; a leaf, after remaining clasped for an unknown time over a fly, opened, and when one of its filaments was touched, closed, though rather slowly. Dr. Canby, 
who observed in the United States a large number of plants which, although not in their native site, were probably more vigorous than my plants, informs me that he has "several times known vigorous leaves to devour their prey several times; but ordinarily twice, or, quite often, once was enough to render them unserviceable." Mrs. Treat, who cultivated many plants in New Jersey, also informs me that "several leaves caught successively three insects each, but most of them were not able to digest the third fly, but died in the attempt. Five leaves, however, digested each three flies, and closed over the fourth, but died soon after the fourth capture. Many leaves did not digest even one large insect." It thus appears that the power of digestion is somewhat limited, and it is certain that leaves always remain clasped for many days over an insect, and do not recover their power of closing again for many subsequent days. In this respect Dionæa differs from Drosera, which eatches and digests many insects after shorter intervals of time.

We are now prepared to understand the use of the marginal spikes, which form so conspicuous a feature in the appearance of the plant (fig. 12, p. 287), and which at first seemed to me in my ignorance useless appendages. From the inward curvature of the lobes as they approach each other, the tips of the marginal spikes first intercross, and ultimately their bases. Until the edges of the lobes come into contact, elongated spaces between the spikes, varying from the $\frac{1}{15}$ to the $\frac{1}{10}$ of an inch (1.693 to $2.54 \mathrm{~mm}$.) in breadth, according to the size of the leaf, are left open. Thus an insect, if its body is not thicker than these measurements, can easily escape between the crossed spikes, when disturbed by the closing lobes and in 
creasing darkness; and one of my sons actually saw a small insect thus escaping. A moderately large insect, on the other hand, if it tries to escape between the bars will surely be pushed back again into its horrid prison with closing walls, for the spikes continue to cross more and more until the edges of the lobes come into contact. A rery strong insect, however, would be able to free itself, and Mrs. Treat saw this effected by a rose-chafer (Macrodactylus subspinosus) in the United States. Now it would manifestly be a great disadvantage to the plant to waste many days in remaining clasped over a minute insect, and several additional days or weeks in afterwards recovering its sensibility; inasmuch as a minute insect would afford but little nutriment. It would be far better for the plant to wait for a time until a moderately large insect was captured, and to allow all the little ones to escape; and this advantage is secured by the slowly intercrossing marginal spikes, which act like the large meshes of a fishing-net, allowing the small and useless fry to escape.

As I was anxious to know whether this view was correct-and as it seems a good illustration of how cautious we ought to be in assuming, as I had dono with respect to the marginal spikes, that any fully developed structure is useless-I applied to Dr. Canby. He visited the native site of the plant, early in the season, before the leaves had grown to their full size, and sent me fourteen leaves, containing naturally captured insects. Four of these had caught rather small insects, viz. three of them ants, and the fourth a rather small fly, but the other ten bad all caught large insects, namely, five elaters, two chrysomelas, a curculio, a thick and broad spider, and' a scolopendra. Out of these ten inscets, no less than eight 
were beetles,* and out of the whole fourteen there was only one, viz. a dipterous insect, - which could readily take flight. Drosera, on the other hand, lives chiefly on insects which are good flyers, especially Diptera, caught by the aid of its viscid secretion. But what most concerns us is the size of the ten larger insects. Their average length from head to tail was 256 of an inch, the lobes of the leaves being on an average .53 of an inch in length, so that the insects were very nearly half as long as the leaves within which they were enclosed. Only a few of these leaves: therefore, had wasted their powers by capturing small prey, though it is probable that many small insects had crawled over them and been caught, but had then escaped through the bars.

The Transmission of the Motor Impulse, and Means of Movement.-It is sufficient to touch any one of the six filaments to cause both lobes to close, these becoming at the same time incurved throughout their whole breadth. The stimulus must therefore radiate in all directions from any one filament. It must also be transmitted with much rapidity across the leaf, for in all ordinary cases both lobes close simultaneously, as far as the eye can judge. Most physiologists believe that in irritable plants the excitement is transmitted along, or in close connection with, the fibrovascular bundles. In Dionae, the course of these ressels (composed of spiral and ordinary vascular

* Dr. Canby remarks ('Gardener's Monthly,' Angust 1868), "as a general thing beetles and insects of that kind, though always killed, seem to be too hardshelled to serve as food, and after a short time are rejected." I am surprised at this statement, at least with respect to such bectles as elaters, for the five which I examined were in an extremely fragile and empty condition, as if all their internal parts had been partially digested. MIrs. Treat informs me that the plants which she cultivated in New Jersey chiefly caught Diptera. 
tissue) seems at first sight to favour this belief; for they run up the midrib in a great bundle, sending off small bundles almost at right angles on each side. These bifurcate occasionally as they extend towards the margin, and close to the margin small branches from adjoining vessels unite and enter the marginal spikes. At some of these points of union the vessels form curious loops, like those described under Drosera. A continuous zigzag line of vessels thus runs round the whole circumference of the leaf, and in the midrib all the vessels are in close contact; so that all parts of the leaf seem to be brought into some degree of communication. Nevertheless, the presence of ressels is not necessary for the transmission of the motor impulse, for it is transmitted from the tips of the sensitive filaments (these being about the $\frac{1}{20}$ of an inch in length), into which no vessels enter; and these could not have been overlooked, as I made thin vertical sections of the leaf at the bases of the filaments.

On several occasions, slits about the $\frac{1}{10}$ of an inch in length were made with a lancet, close to the bases of the filaments, parallel to the midrib, and, therefore, directly across the course of the vessels. These were made sometimes on the inner and sometimes on the outer sides of the filaments; and after several days, when the leares had reopened, these filaments were touched roughly (for they were always rendered in some degree torpid by the operation), and the lobes then closed in the ordinary manner, though slowly, and sometimes not until after a considerable interval of time. These cases show that the motor impulse is not transmitted along the vessels, and they further show that there is no necessity for a direct line of communication from the filament which is 
touched towards the midrib and opposite lobe, or towards the outer parts of the same lobe.

Two slits near each other, both parallel to the midrib, were next made in the same manner as before, one on each side of the base of a filament, on five distinct leaves, so that a little slip bearing a filament was connected with the rest of the leaf only at its two ends. These slips were nearly of the same size; one was carefully measured; it was $\cdot 12$ of an inch $(3.048 \mathrm{~mm}$.) in length, and 08 of an inch (2.032 mm.) in breadth; and in the middle stood the filament. Only one of these slips withered and perished. After the leaf had recovered from the operation, though the slits were still open, the filaments thus circumstanced were roughly touched, and both lobes, or one alone, slowly closed. In two instances touching the filament produced no effect; but when the point of a needle was driven into the slip at the base of the filament, the lobes slowly closed. Now in these cases the impulse must have proceeded along the slip in a line parallel to the.midrib, and then have radiated forth, either from both ends or from one end alone of the slip, over the whole surface of the two lobes.

Again, two parallel slits, like the former ones, were made, one on each side of the base of a filament, at right angles to the midrib. After the leaves (two in number) had recovered, the filaments were roughly touched, and the lobes slowly closed; and here the impulse must have travelled for a short distance in a line at right angles to the midrib, and then have radiated forth on all sides over both lobes. These several cases prove that the motor impulse travels in all directions through the cellular tisstre, independently of the course of the vessels.

With Drosera we have seen that the motor impulse 
is transmitted in like manner in all directions through the cellular tissue; but that its rate is largely governed by the length of the cells and the direction of their longer axes. Thin sections of a leaf of Dionæa were made by my son, and the cells, both those of the central and of the more superficial layers, were found much elongated, with their longer axes directed towards the midrib; and it is in this direction that the motor impulse must be sent with great rapidity from one lobe to the other, as both close simultaneously. The central parenchymatous cells are larger, more loosely attached together, and have more delicate walls than the more superficial cells. A thick mass of cellular tissue forms the upper surface of the midrib over the great central bundle of vessels.

When the filaments were roughly touched, at the bases of which slits had been made, either on both sides or on one side, parallel to the midrib or at right angles to it, the two lobes, or only one, mored. In one of these cases, the lobe on the side which bore the filament that was touched moved, but in three other cases the opposite lobe alone moved; so that an injury which was sufficient to prevent a lobe moving did not prevent the transmission from it of a stimulus which excited the opposite lobe to more. We thus also learn that, although normally both lokes move together, each has the power of independent movement. A case, indeed, has already been given of a torpid leaf that had lately re-opened after catching an insect, of which one lobe alone moved when irritated. MIoreorer, one end of the same lobe can close and reexpand, independently of the other end, as was seen in some of the foregoing experiments.

When the lobes, which are rather thick, close, no trace of wrinkling can be seen on any part of their upper 
surfaces. It appears therefore that the cells must contract. The chief seat of the morement is evidently in the thick mass of cells which overlies the central bundle of vessels in the midrib. To ascertain whether this part contracts, a leaf was fastened on the stage of the microscope in such a manner that the two lobes could not become quite shut, and having made two minute black dots on the midrib, in a transverse line and a little towards one side, they were found by the micrometer to be $\frac{17}{1000}$ of an inch apart. One of the filaments was then touched and the lobes closed; but as they were prevented from meeting, I could still see the two dots, which now were $\frac{15}{1000}$ of an inch apart, so that a small portion of the upper surface of the midrib had contracted in a transverse $\operatorname{lin} \theta \frac{2}{1000}$ of an inch (.0508 mm.).

We know that the lobes, whilst closing, become slightly incurved throughout their whole breadth. This movement appears to be due to the contraction of the superficial layers of cells over the whole upper surface. In order to observe their contraction, a narrow strip was cut out of one lobe at right angles to the midrib, so that the surface of the opposite lobe could be seen in this part when the leaf was shut. After the leaf had recovered from the operation and had re-expanded, three minute black dots were made on the surface opposite to the slit or window, in a line at right angles to the midrib. The distance between the dots was found to be $\frac{40}{1000}$ of an inch, so that the two extreme dots were $\frac{80}{1000}$ of an inch apart. One of the filaments was now touched and the leaf closed. On again measuring the distances between the dots, the two next to the midrib were nearer together by $\frac{1}{1002}$ of an inch, and the two further dots by $\frac{3 \text { to } 4}{1000}$ of an inch, than they were before; so that the two extreme 
dots now stood about $\frac{5}{1000}$ of an inch $(127 \mathrm{~mm}$.) nearer together than before. If we suppose the whole upper surface of the lobe, which was $\frac{4 n 0}{1000}$ of an inch in breadth, to have contracted in the same proportion, the total contraction will have amounted to about $\frac{25}{1000}$ or $\frac{1}{40}$ of an inch $(.635 \mathrm{~mm}$.) ; but whether this is sufficient to account for the slight inward curvature of the whole lobe, I am unable to say.

Finally, with respect to the movement of the leaves, the wonderful discovery made by Dr. Burdon Sanderson* is now universally known; namely that there exists a normal electrical current in the blade and footstalk; and that when the leaves are irritated, the current is disturbed in the same manner as takes place during the contraction of the muscle of an animal.

The Re-expansion of the Leaves. - This is effected at an insensibly slow rate, whether or not any object is enclosed. $\dagger$ One lobe can re-expand by itself, as occurred with the torpid leaf of which one lobe alone had closed. We have also seen in the experiments with cheese and albumen that the two ends of the same lobe can re-expand to a certain extent independently of each other. But in all ordinary cases both lobes open at the same time. The re-expansion is not determined by the sensitive filaments; all three filaments on one lobe were cut off close to their bases; and the three

* 'Proc. Royal Soc.' rol. xxi. p. 495 ; and lecture at the Royal Institution, June 5, 1874, given in 'Nature,' 1874, pp. 105 and 127.

$\dagger$ Nuttall, in his 'Gen. American Plants,' p. 277 (note), says that, whilst collecting this plant in its native home, "I had occasion to observe that a detached leaf would make repeated efforts towards disclosing itself to the influence of the sun; these attempts consisted in an undulatory motion of the marginal cilix, accompanied by a partial opening and succeeding collapse of the lamina, which at length terminated in a complete expansion and in the destruction of sensibility." I am indebted to Prof. Oliver for this reference; but I do not understand what took place. 
leaves thus treated re-expanded,-one to a partial extent in $24 \mathrm{hrs} .,-\mathrm{a}$ second to the same extent in 48 hrs.,-and the third, which had been previously injured, not until the sixth day. "These leaves after their re-expansion closed quickly when the filaments on the other lobe were irritated. These were then cut off one of the leaves, so that none were left. This mutilated leaf, notwithstanding the loss of all its filaments, re-expanded in two days in the usual manner. When the filaments have been excited by immersion in a solution of sugar, the lobes do not expand so soon as when the filaments have been merely touched; and this, I presume, is due to their having been strongly affected through exosmose, so that they continue for some time to transmit a motor impulse to the upper surface of the leaf.

The following facts make me believe that the several layers of cells forming the lower surface of the leaf are always in a state of tension; and that it is owing to this mechanical state, aided probably by fresh fluid being attracted into the cells, that the lobes begin to separate or expand as soon as the contraction of the upper surface diminishes. A leaf was cut off and suddenly plunged perpendicularly into boiling water: I expected that the lobes would have closed, but instead of doing so, they diverged a little. I then took another fine leaf, with the lobes standing at an angle of nearly $80^{\circ}$ to each other; and on immersing it as before, the angle suddenly increased to $90^{\circ}$. A third leaf was torpid from having recently re-expanded after having caught a fly, so that repeated touches of the filaments caused not the least movement; nevertheless, when similarly immersed, the lobes separated a little. As these leaves were inserted perpendicularly into the boiling water, both surfaces and the filaments 
must have been equally affected; and I can understand the divergence of the lobes only by supposing that the cells on the lower side, owing to their state of tension, acted mechanically and thus suddenly drew the lobes a little apart, as soon as the cells on the upper surface were killed and lost their contractile power. We have seen that boiling water in like manner causes the tentacles of Drosera to curve backwards; and this is an analogous movement to the divergence of the lobes of Dionæa.

- In some concluding remarks in the fifteenth chapter on the Droseracex, the different kinds of irritability possessed by the severial genera, and the different manner in which they capturo insects, will be compared. 


\section{CHAPTER XIV.}

\section{ALdROVANDA VESICULOSA.}

Captures crustaceans-Structure of the leaves in comparison with those of Dionæa - Absorption by the glands, by the quadrifid processes, and points on the infolded margins - Aldrovanda vesiculosa, var. australis - Captures prey - Absorption of animal matterAldrovanda vesiculosa, var. verticillata - Concluding remarks.

Tris plant may be called a miniature aquatic Dionæa. Stein discovered in 1873 that the bilobed leaves, which are generally found closed in Europe, open under a sufficiently high temperature, and, when touched, suddenly close.* They re-expand in from 24 to 36 hrs., but only, as it appears, when inorganic objects are enclosed. The leaves sometimes. contain bubbles of air, and were formerly supposed to be bladders; hence the specific name of vesiculosa. Stein observed that water-insects were sometimes caught, and Prof. Cohn has recently found within the leaves of naturally growing plants many kinds of crustaceans and larvæ. $\dagger$ Plants which had been kept in filtered water were placed by him in a vessel con-

* Since his original publication, Stein has found out that the irritability of the lcaves was observed by De Sassus, as recorded in 'Bull. Bot. Soc. de France,' in 1861. Delpino states in a paper published in 1871 ('Nuovo ( $i$ iornale Bot. Ital.' vol. iii. p. 174) that "una quantità di chioccioline e di altri auimalcoli acquatici" are caught and suffocated by the leaves. I presume that clicoccioline are fresh-water molluscs. It would be interesting to know whether their shells are at all corroded by the acid of the digestive secretion.

$\dagger$ I am greatly indebted to this distinguished naturalist for having sent me a copy of his memoir on Aldrovanda, before its publication in his 'Beiträge zur Biologie der Pflanzen,' drittes Heft, 1875, p. 71 . 
taining numerous crustaceans of the genus Cypris, and next morning many were found imprisoned and alive, still swimming about within the closed leares, but doomed to certain death.

Directly after reading Prof. Cohn's memoir, I receired through the kindness of Dr. Hooker living plants from Germany. As I can add nothing to Prof. Cohn's excellent description, I will give only two illustrations, one of a whorl of leaves copied from his work, and the other of a leaf pressed flat open, drawn by my son Francis. I will, however, append a few remarks on the differences between this plant and Dionæa.

Aldrovanda is destitute of roots and floats freely in the water. The leaves are arranged in whorls round the stem. Their broad petioles terminate in from four to six rigid projections,* each tipped with a stiff, short bristle. The bilobed leaf, with the midrib like-wise tipped with a bristle, stands in the midst of these projections, and is evidently defended by them. The lobes are formed of very delicate tissue, so as to be translucent; they open, according to Cohn, about as much as the two ralres of a living mussel-shell, therefore even less than the lobes of Dionæa; and this must make the capture of aquatic animals more easy. The outside of the leares and the petioles are covered with minute two-armed papillæ, evidently answering to the eight-rayed papillæ of Dionæa.

Each lobe rather exceeds a semi-circle in convexity, and consists of two very different concentric portions; the inner and lesser portion, or that next to the midrib,

* There has been much discussion by botanists on the homologieill nature of these projections. Dr. Nitschke ('Bot. 'Zeitung;'
1S61, p. 146) believes that they eorrespond with the fimbriated scale-like bodies found at the bases of the petioles of Drosera. 
Chap. XIV.

is slightly concave, and is formed, according to Cohn, of three layers of cells. Its upper surface is studded with colourless glands like, but more simple than, those of Dionæa; they are supported on distinct footstalks, consisting of two rows of cells. The outer
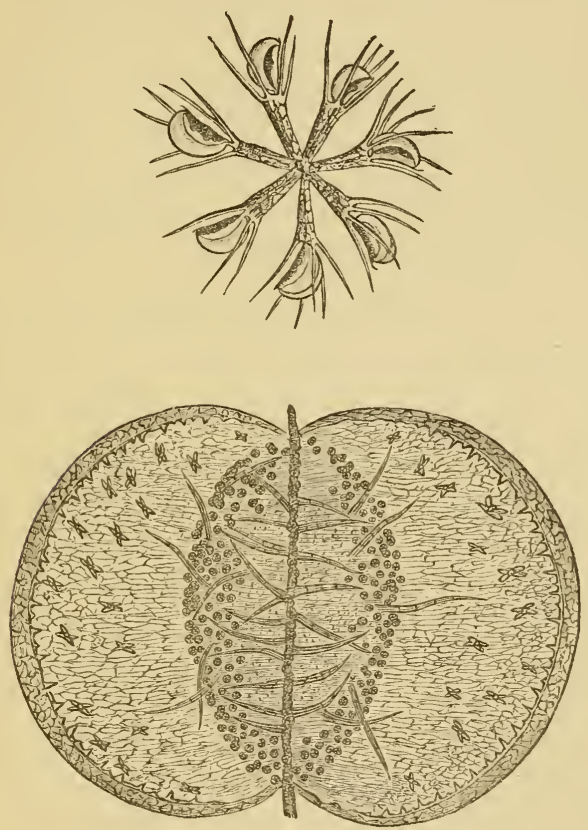

FIG. 13.

(Aldrovanda vesiculosa.)

Upper figure, whorl of leaves (from Prof. Cohn).

Lower figure, leaf pressed flat open and greatly enlarged.

and broader portion of the lobe is flat and very thin, being formed of only two layers of cells. Its upper surface does not bear any glands, but, in their place, small quadrifid processes, each consisting of four tapering projections, which rise from a common 
prominence. These processes are formed of very delicate membrane lined with a layer of protoplasm; and they sometimes contain aggregated globules of hyaline matter. Two of the slightly diverging arms are directed towards the circumference, and two towards the midrib, forming together a sort of Greek cross. Occasionally two of the arms are replaced by one, and then the projection is trifid. We shall see in a future chapter that these projections curiously resemble those found within the bladders of Utricularia, more especially of Utricularia montana, although this genus is not related to Aldrovanda.

A narrow rim of the broad flat exterior part of each lobe is turned inwards, so that, when the lobes are closed, the exterior surfaces of the in-folded portions come into contact. The edge itself bears a row of conical, flattened, transparent points with broad bases, like the prickles on the stem of a bramble or Rubus. As the rim is infolded, these points are directed towards the midrib, and they appear at first as if they were adapted to prevent the escape of prey; but this can hardly be their chief function, for they are composed of very delicate and highly flexible membrane, which can be easily bent or quite doubled back without being cracked. Nevertheless, the infolded rims, together with the points, must somewhat interfere with the retrograde movement of any small creature, as soon as the lobes begin to close. The circumferential part of the leaf of Aldrovanda thus differs greatly from that of Dionra; nor can the points on the rim be considered as homologous with the spikes round the leaves of Dionæa, as these latter are prolongations of the blade, and not mere epidermic productions. They appear also to serve for a widely different purpose. 
On the concave gland-bearing portion of the lobes, and especially on the midrib, there are numerous, long, finely pointed hairs, which, as Prof. Cohn remarks, there can be little doubt are sensitive to a touch, and, when touched, cause the leaf to close. They are formed of two rows of cells, or, according to Cohn, sometimes of four, and do not include any vascular tissue. They differ also from the six sensitive filaments of Dionæa in being colourless, and in having a medial as well as a basal articulation. No doubt it is owing to these two articulations that, notwithstanding their length, they escape being broken when the lobes close.

The plants which I received during the early part of October from Kew never opened their leaves, though subjected to a high temperature. After examining the structure of some of them, I experimented on only two, as I hoped that the plants would grow; and I now regret that I did not sacrifice a greater number.

A leaf was cut open along the midrib, and the glands examined under a high power. It was then placed in a few drops of an infusion of raw meat. After 3 hirs. $20 \mathrm{~m}$. there was no change, but when next examined after $23 \mathrm{hrs} .20 \mathrm{~m}$., the outer cells of the glands contained, instead of limpid fluid, spherical. masses of a granular substance, showing that matter had been absorbed from the infusion. That these glands secrete a fluid which dissolves or digests animal matter out of the bodies of the creatures which the leaves capture, is also highly probable from tho analogy of Dionæa. If we may trust to the same analogy, the concave. and inner portions of the two lobes probably close together by a slow movement, as soon as the glands have absorbed a slight amount of 
already soluble animal matter. The included water would thus be pressed out, and the secretion consequently not be too much diluted to act. With respect to the quadrifid processes on the outer parts of the lobes, I was not able to decide whether they had been acted on by the infusion; for the lining of protoplasm was somewhat shrunk before they were immersed. Many of the points on the infolded rims also had their lining of protoplasm similarly shrunk, and contained spherical granules of hyaline matter.

A solution of urea was next employed. This substance was chosen partly because it is absorbed by the quadrifid processes and more especially by the glands of Utricularia - a plant which, as we shall hereafter see, feeds on decayed animal matter. As urea is one of the last products of the chemical changes going on in the living body, it seems fitted to represent the early stages of the decay of the dead body. I was also led to try urea from a curious little fact mentioned by Prof. Cohn, namely that when rather large crustaceans are caught between the closing lobes, they are pressed so hard whilst making their escape that they often void their sausage-shaped masses of excrement, which were found within most of the leaves. These masses, no doubt, contain urea. They would be left either on the broad outer surfaces of the lobes where the quadrifids are situated, or within the closed concavity. In the latter case, water charged with excrementitious and decaying matter would be slowly forced outwards, and would bathe the quadrifids, if I am right in believing that the concave lobes contract after a time like those of Dionæa. Foul water would also be apt to ooze out at all times, especially when bubbles of air were generated within the concavity.

A leaf was cut open and examined, and the outer 
cells of the glands were found to contain only limpid fluid. Some of the quadrifids included a few spherical granules, but several were transparent and empty, and their positions were marked. This leaf was now immersed in a little solution of one part of urea to 146 of water, or three grains to the ounce. After $3 \mathrm{hrs}$. $40 \mathrm{~m}$. there was no change either in the glands or quadrifids; nor was there any certain change in the glands after 24 hrs.; so that, as far as one trial goes, urea does not act on them in the same manner as an infusion of raw meat. It was different with the quadrifids; for the lining of protoplasm, instead of presenting a uniform texture, was now slightly shrunk, and exhibited in many places minute, thickened, irregular, yellowish specks and ridges, exactly like thoso which appear within the quadrifids of Utricularia when treated with this same solution. Moreover, several of the quadrifids, which were before empty, now contained moderately sized or very small, more or less aggregated, globules of yellowish matter, as likewise occurs under the same circumstances with Utricularia. Some of the points on the infolded margins of the lobes were similarly affected ; for their lining of protoplasm was a little shrunk and included yellowish specks; and those which were before empty now contained small spheres and irregular masses of hyaline matter, more or less aggregated; so that both the points on the margins and the quadrifids had absorbed matter from the solution in the course of $24 \mathrm{hrs}$. ; but to this subject I shall recur. In another rather old leaf, to which nothing had been given, but which had been kept in foul water, some of the quadrifids contained aggregated translucent globules. These were not acted on by a solution of one part of carbonate of ammonia to 218 of water; and this negative result 
agrees with what $I$ have observed under similar cirstances with Utricularia.

Aldrovanda vesiculosa, var. australis.-Dried leaves of this plant from Queensland in Australia were sent me by Prof. Oliver from the herbarium at Kew. Whether it ought to be considered as a distinct species or a variety, cannot be told until the flowers are examined by a botanist. The projections at the upper end of the petiole (from four to six in number) aro considerably longer relatively to the blade, and much more attenuated than those of the European form. They are thickly covered for a considerable spaco near their extremities with the upcurved prickles, which are quite absent in the latter form; and they generally bear on their tips two or three straight prickles instead of one. The bilobed leaf appears also to be rather larger and somewhat broader, with the pedicel by which it is attached to the upper end of the petiole a little longer. The points on the infolded margins likewise differ; they have narrower bases, and are more pointed; long and short points also alternate with much more regularity than in the European form. The glands and sensitive hairs are similar in the two forms. No quadrifid processes could be seen on several of the leaves, but I do not doubt that they were present, though indistinguishable from their delicacy and from having shrivelled; for they were quite distinct on one leaf under circumstances presently to be mentioned.

Some of the closed leaves contained no prey, but in one there was a rather large beetle, which from its flattened tibix I suppose was an aquatic species, but was not allied to Colymbetes. All the softer tissues of this beetle were completely dissolved, and its chitinous integuments were as clean as if they had been 
boiled in caustic potash; so that it must have been enclosed for a considerable time. The glands were browner and more opaque than those on other leares which had caught nothing; and the quadrifid processes, from being partly filled with brown granular matter, could be plainly distinguished, which was not the case, as already stated, on the other leaves. Some of the points on the infolded margins likewise contained brownish granular matter. We thus gain additional evidence that the glands, the quadrifid processes, and the marginal points, all have the power of absorbing matter, though probably of a different nature.

Within another leaf disintegrated remnants of a rather small animal, not a crustacean, which had simple, strong, opaque mandibles, and a large unarticulated chitinous coat, were present. Lumps of black organic matter, possibly of a vegetable nature, were enclosed in two other leaves; but in one of these there was also a small worm much decayed. But the nature of partially digested and decayed bodies, which have been pressed flat, long dried, and then soaked in water, cannot be recognised easily. All the leaves contained unicellular and other Algæe, still of a greenish colour, which had evidently lived as intruders, in the same manner as occurs, according to Cohn, within the leaves of this plant in Germany.

Aldrovanda vesiculosa, var. verticillata.-Dr. King, Superintendent of the Botanic Gardens, kindly sent me dried specimens collected near Calcutta. This form was, I believe, considered by Wallich as a distinct species, under the name of verticillata. It resembles the Australian form much more nearly than the European; namely in the projections at the upper end of the petiole being much attenuated and covered with 
upcurved prickles; they terminate also in two straight little prickles. The bilobed leaves are, I believe, larger and certainly broader even than those of the Australian form; so that the greater convexity of their margins was conspicuous. The length of an open leaf being taken at 100, the breadth of the Bengal form is nearly 173, of the Australian form 147, and of the German 134. The points on the infolded margins are like those in the Australian form. Of the few leaves which were examined, three contained entomostracan crustaceans.

Concluding Remarks.-The leaves of the three foregoing closely allied species or varieties are manifestly adapted for catching living creatures. With respect to the functions of the several parts, there can be little doubt that the long jointed hairs are sensitive, like those of Dionæa, and that, when touched, they cause the lobes to close. That the glands secrete a true digestive fluid and afterwards absorb the digested matter, is highly probable from the analogy of Dionæa,-from the limpid fluid within their cells being aggregated into spherical masses, after they had absorbed an infusion of raw meat,-from their opaque and granular condition in the leaf, which had enclosed a beetle for a long time,- and from the clean condition of the integuments of this insect, as well as of crustaceans (as described by Cohn), which have been long captured. Again, from the effect produced on the quadrifid processes by an immersion for $24 \mathrm{hrs}$. in a solution of urea,-from the presence of brown granular matter within the quadrifids of the leaf in which the beetle had been caught,-and from the analogy of Utricularia,-it is probable that these processes absorb excrementitious and decaying animal matter. It is a more curious fact that the points on 
the infolded margins apparently serve to absorb decayed animal matter in the same manner as the quadrifids. We can thus understand the meaning of the infolded margins of the lobes furnished with delicate points directed inwards, and of the broad, flat, outer portions, bearing quadrifid processes; for these surfaces must be liable to be irrigated by foul water flowing from the concavity of the leaf when it contains dead animals. This would follow from various causes, - from the gradual contraction of the concavity, -from fluid in excess being secreted,-and from the generation of bubbles of air. More observations are requisite on this head; but if this view is correct, we have the remarkable case of different parts of the same leaf serving for very different purposes-one part for true digestion, and another for the absorption of decayed animal matter. We can thus also understand how, by the gradual loss of either power, a plant might be gradually adapted for the one function to the exclusion of the other; and it will hereafter be shown that two genera, namely Pinguicula and Utricularia, belonging to the same family, have been adapted for these two different functions. 


\section{CHAPTER XV.}

Drosopitllem - Roridela - Brblis - Glandelar Hairs of other Plants - Concluding Remarks on the Droseracee.

Drosophyllum - Structure of leaves - Nature of the secretion - Mlanner of catching insects - Power of absorption - Digestion of animal substances - Summary on Drosophyllum - Roridula - Byblis Glandular hairs of other plants, their power of absorption - Saxifraga - Primula - Pelargonium - Erica - Mirabilis - Nicotiana - Summary on glandular hairs - Concluding remarks on the Droseraceæ.

Drosophyllum Lusitaxicum.-This rare plant has been found only in Portugal, and, as I hear from Dr. Hooker, in Morocco. I obtained living specimens through the great kindness of MIr. W. C. 'Tait, and afterwards from Mr. G. Maw and Dr. Moore. Mr. Tait informs me that it grows plentifully on the sides of dry hills near Oporto, and that vast numbers of flies adhere to the leaves. This latter fact is well known to the villagers, who call the plant the "fly-catcher," and hang it up in their cottages for this purpose. A plant in my hot-house caught so many insects during the early part of April, although the weather was cold and insects scarce, that it must have been in some manner strongly attractive to them. On four leaves of a young and small plant, 8, 10, 14, and 16 minute insects, chiefly Diptera, were found in the autumn adhering to them. I neglected to examine the roots, but I hear from Dr. Hooker that they are very small, as in the case of the previously mentioned members of the same family of the Droseracer.

The leaves arise from an almost woody axis; they 
are linear, much attenuated towards their tips, and several inches in length. The upper surface is concave, the lower convex, with a narrow channel down the middle. Both surfaces, with the exception of the channel, are covered with glands, supported on pedicels and arranged in irregular longitudinal rows. These organs I shall call tentacles, from their close resemblance to those of Drosera, though they have no power of movement. Those on the same leaf differ much in length. The glands also differ in size, and are of a bright pink or of a purple colour; their upper surfaces are convex, and the lower flat or even concave, so that they resemble miniature mushrooms in appearance. They are formed of two (as I believe) layers of delicate angular cells, enclosing eight or ten larger cells with thicker, zigzag walls. Within these larger cells there are others marked by spiral lines, and apparently connected with the spiral vessels which run up the green multicellular pedicels. The glands secrete large drops of viscid secretion. Other glands, having the same general appearance, are found on the flowerpeduncles and calyx.

Besides the glands which are borne on longer or shorter pedicels, there are numerous ones, both on the upper and lower surfaces of the leaves, so small as to be scarcely visible to the naked eye. They are colourless and almost sessile, either circular or oval in outline; the latter occurring chiefly

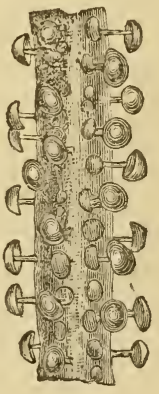

Fig. 14.

(Drosophyllum lusitanicum.)

Part of leaf, enlarged seven times, showing lower surface. on the backs of the leaves (fig. 14). Internally they have exactly the same structure as the larger glands which are supported on pedicels; 
and indeed the two sets almost graduate into one another. But the sessile glands differ in one important respect, for they never secrete spontaneously, as far as I have seen, though I have examined them under a high power on a hot day, whilst the glands on pedicels were secreting copiously. Nevertheless, if little bits of damp albumen or fibrin are placed on these sessile glands, they begin after a time to secrete, in the same manner as do the glands of Dionæa when similarly treated. When they were merely rubbed with a bit of raw meat, I believe that they likewise secreted. Both the sessile glands and the taller ones on pedicels have the power of rapidly absorbing nitrogenous matter.

The secretion from the taller glands differs in a remarkable manner from that of Drosera, in being acid before the glands have been in any way excited; and judging from the changed colour of litmus paper, more strongly acid than that of Drosera. This fact was observed repeatedly; on one occasion I chose a young leaf, which was not secreting freely, and had never caught an insect, yet the secretion on all the glands coloured litmus paper of a bright red. From the quickness with which the glands are able to obtain animal matter from such substances as well-washed fibrin and cartilage, I suspect that a small quantity of the proper ferment must be present in the secretion before the glands are excited, so that a little animal matter is quickly dissolved.

Owing to the nature of the secretion or to the shape of the glands, the drops are removed from them with singular facility. It is even somewhat difficult, by the aid of a finely pointed polished needle, slightly damped with water, to place a minute particle of any kind on one of the drops; for on withdrawing the 
needle, the drop is generally withdrawn; whereas with Drosera there is no such difficulty, though the drops are occasionally withdrawn. From this peculiarity, when a small insect alights on a leaf of Drosophyllum, the drops adhere to its wings, feet, or body, and are drawn from the gland; the insect then crawls onward and other drops adhere to it; so that at last, bathed by the viscid secretion, it sinks down and dies, resting on the small sessile glands with which the surface of the leaf is thickly covered. In the case of Drosera, an insect sticking to one or more of the exterior glands is carried by their movement to the centre of the leaf; with Drosophyllum, this is effected by the crawling of the insect, as from its wings being clogged by the secretion it cannot fly away.

There is another difference in function between the glands of these two plants : we know that the glands of Drosera secrete more copiously when properly excited. But when minute particles of carbonate of ammonia, drops of a solution of this salt or of the nitrate of ammonia, saliva, small insects, bits of raw or roast meat, albumen, fibrin or cartilage, as well as inorganic particles, were placed on the glands of Drosophyllum, the amount of secretion never appeared to be in the least increased. As insects do not commonly adhere to the taller glands, but withdraw the secretion, we can see that there would be little use in their having acquired the habit of secreting copiously when stimulated; whereas with Drosera this is of use, and the habit has been acquired. Nevertheless, the glands of Drosophyllum, without being stimulated, continually secrete, so as to replace the loss by evaporation. Thus when a plant was placed under a small bellglass with its inner surface and support thoroughly wetted, there was no loss by evaporation, and so much 
secretion was accumulated in the course of a day that it ran down the tentacles and covered large spaces of the leaves.

The glands to which the above named nitrogenous substances and liquids were given did not, as just stated, secrete more copiously; on the contrary, they absorbed their own drops of secretion with surprising quickness. Bits of damp fibrin were placed on fire glands, and when they were looked at after an interval of $1 \mathrm{hr} .12 \mathrm{~m}$., the fibrin was almost dry, the secretion having been all absorbed. So it was with three cubes of albumen after $1 \mathrm{hr} .19 \mathrm{~m}$., and with four other cubes, though these latter were not looked at until 2 hrs. $15 \mathrm{~m}$. had elapsed. The same result followed in between $1 \mathrm{hr} .15 \mathrm{~m}$. and $1 \mathrm{hr} .30 \mathrm{~m}$. when particles both of cartilage and meat were placed on several glands. Lastly, a minute drop (about $\frac{1}{20}$ of a minim) of a solution of one part of nitrate of ammonia to 146 of water was distributed between the secretion surrounding three glands, so that the amount of fluid surrounding each was slightly increased; yet when looked at after 2 hrs., all three were dry. On the other hand, seven particles of glass and three of coalcinders, of nearly the same size as those of the above named organic substances, were placed on ten glands; some of them being observed for 18 hrs., and others for two or three days; but there was not the least sign of the secretion being absorbed. Hence, in the former cases, the absorption of the secretion must have been due to the presence of some nitrogenous matter, which was either already soluble or was rendered so by the secretion. As the fibrin was pure, and had been well washed in distilled water after being kept in glycerine, and as the cartilage had been soaked in water, I suspect that these substances must 
have been slightly acted on and rendered soluble within the above stated short periods.

The glands have not only the power of rapid absorption, but likewise of secreting again quickly; and this latter habit has perhaps been gained, inasmuch as insects, if they touch the glands, generally withdraw the drops of secretion, which have to be restored. The exact period of re-secretion was recorded in only a few cases. The glands on which bits of meat were placed, and which were nearly dry after about $1 \mathrm{hr} .30 \mathrm{~m}$., when looked at after 22 additional hours, were found secreting; so it was after $24 \mathrm{hrs}$. with one gland on which a bit of albumen had been placed. The three glands to which a minute drop of a solution of nitrate of ammonia was distributed, and which became dry after 2 hrs., were beginning to re-secrete after only 12 additional hours.

Tentacles Incapable of Movement.-Many of the tall tentacles, with insects adhering to them, were carefully observed; and fragments of insects, bits of raw meat, albumen, \&c., drops of a solution of two salts of ammonia and of saliva, were placed on the glands of many tentacles; but not a trace of movement could ever be detected. I also repeatedly irritated the glands with a needle, and scratched and pricked the blades, but neither the blade nor the tentacles became at all inflected. We may therefore conclude that they are incapable of movement.

On.the Power of Absorption possessed by the Glands.It has already been indirectly shown that the glands on pedicels absorb animal matter; and this is further shown by their changed colour, and by the aggregation of their contents, after they have been left in contact with nitrogenous substances or liquids. The following observations apply both to the glands supported on 
pedicels and to the minute sessile ones. Before a gland has been in any way stimulated, the exterior cells commonly contain only limpid purple fluid; the more central ones including mulberry-like masses of purple granular matter. A leaf was placed in a little solution of one part of carbonate of ammonia to 146 of water (3 grs. to $1 \mathrm{oz}$.$) , and the glands were instantly darkened$ and very soon became black; this change being due to the strongly marked aggregation of their contents, more especially of the inner cells. Another leaf was placed in a solution of the same strength of nitrate of ammonia, and the glands were slightly darkened in $25 \mathrm{~m}$., more so in $50 \mathrm{~m}$., and after $1 \mathrm{hr} .30 \mathrm{~m}$. were of so dark a red as to appear almost black. Other leares were placed in a weak infusion of raw meat and in human saliva, and the glands were much darkened in $25 \mathrm{~m}$., and after $40 \mathrm{~m}$. were so dark as almost to deserve to be called black. Even immersion for a whole day in distilled water occasionally induces some aggregation within the glands, so that they become of a darker tint. In.all these cases the glands are affected in exactly the same manner as those of Drosera. Millk, however, which acts so energetically on Drosera, seems rather less effective on Drosophyllum, for the glands were only slightly darkened by an immersion of $1 \mathrm{hr}$. $20 \mathrm{~m}$., but became decidedly darker after 3 hrs. Leaves which had been left for $7 \mathrm{hrs}$. in an infusion of raw meat or in saliva were placed in the solution of carbonate of ammonia, and the glands now became greenish; whereas, if they had been first placed in the carbonate, they would have become black. In this latter case, the ammonia probably combines with the acid of the secretion, and therefore does not act on the colouring matter; but when the glands are first subjected to an organic 
fluid, either the acid is consumed in the work of digestion or the cell-walls are rendered more permeable, so that the undecomposed carbonate enters and acts on the colouring matter. If a particle of the dry carbonate is placed on a gland, the purple colour is quickly discharged, owing probably to an excess of the salt. The gland, moreover, is killed.

Turning now to the action of organic substances, the glands on which bits of raw meat were placed became dark-coloured; and in 18 hrs. their contents were conspicuously aggregated. Several glands with bits of albumen and fibrin were darkened in between $2 \mathrm{hrs}$. and $3 \mathrm{hrs.}$; but in one case the purple colour was completely discharged. Some glands which had caught flies were compared with others close by ; and though they did not differ much in colour, there was a marked difference in their state of aggregation. In some few instances, however, there was no such difference, and this appeared to be due to the insects having been caught long ago, so that the glands had recovered their pristine state. In one case, a group of the sessile colourless glands, to which a small fly adhered, presented a peculiar appearance; for they had become purple, owing to purple granular matter coating the cell-walls. I may here mention as a caution that, soon after some of my plants arrived in the spring from Portugal, the glands were not plainly acted on by bits of meat, or insects, or a solution of ammonia-a circumstance for which I cannot account.

Digestion of Solid Animal Matter. - Whilst I was trying to place on two of the taller glands little cubes of albumen, these slipped down, and, besmeared with secretion, were left resting on some of the small sessile glands. After $24 \mathrm{hrs}$. one of these cubes was found 
completely liquefied, but with a few white streaks still visible; the other was much rounded, but not quite dissolved. Two other cubes were left on tall glands for $2 \mathrm{hrs} .45 \mathrm{~m}$., by which time all the secretion was absorbed; but they were not perceptibly acted on, though no doubt some slight amount of animal matter had been absorbed from them. They were then placed on the small sessile glands, which being thus stimulated secreted copiously in the course of $7 \mathrm{hrs}$. One of these cubes was much liquefied within this short time; and both were completely liquefied after $21 \mathrm{hrs} .15 \mathrm{~m}$. ; the little liquid masses, however, still showing some white streaks. These streaks disappeared after an additional period of 6 hrs. $30 \mathrm{~m}$; and by next morning (i.e. 48 hrs. from the time when the cubes were first placed on the glands) the liquefied matter was wholly absorbed. A cube of albumen was left on another tall gland, which first absorbed the secretion and after 24 hrs. poured forth a fresh supply. This cube, now surrounded by secretion, was left on the gland for an additional 24 hrs., but was very little, if at all, acted on. We may, therefore, conclude, either that the secretion from the tall glands has little power of digestion, though strongly acid, or that the amount poured forth from a single gland is insufficient to dissolve a particle of albumen which within the same time would have been dissolved by the secretion from several of the small sessile glands. Owing to the death of my last plant, I was unable to ascertain which of these alternatives is the true one.

Four minute' shreds of pure fibrin were placed, each resting on one, two, or three of the taller glands. In the course of 2 hrs. $30 \mathrm{~m}$. the secretion was all absorber, and the shreds were left almost dry. They 
were then pushed on to the sessile glands. One shred, after 2 hrs. $30 \mathrm{~m}$., seemed quite dissolved, but this may have been a mistake. A second, when examined after 17 hrs. $25 \mathrm{~m}$., was liquefied, but the liquid as seen under the microscope still contained floating granules of fibrin. The other two shreds were completely liquefied after $21 \mathrm{hrs} .30 \mathrm{~m}$.; but in one of the drops a very few granules could still be detected. These, however, were dissolved after an additional interval of $6 \mathrm{hrs} .30 \mathrm{~m}$.; and the surface of the leaf for some distance all round was covered with limpid fluid. It thus appears that Drosophyllum digests albumen and fibrin rather more quickly than Drosera can; and this may perhaps be attributed to the acid, together probably with some small amount of the ferment, being present in the secretion, before the glands have been stimulated; so that digestion begins at once.

Concluding Remarts. - The linear leaves of Drosophyllum differ but slightly from those of certain species of Drosera; the chief differences being, firstly, the presence of minute, almost sessile, glands, which, like those of Dionæa, do not secrete until they are excited by the absorption of nitrogenous matter. But glands of this kind are present on the leaves of Drosera binata, and appear to be represented by the papilla on the leares of Drosera rotundifotia. Secondly, the presence of tentacles on the backs of the leaves; but we have seen that a few tentacles, irregularly placed and tending towards abortion, are retained on the backs of the leaves of Drosera binata. There are greater differences in function between the two genera. The most important one is that the tentacles of Drosophyllum have no power of movement; this loss being partially replaced by the drops of viscid 
secretion being readily withdrawn from the glands; so that, when an insect comes into contact with a drop, it is able to crawl away, but soon touches other drops, and then, smothered by the secretion, sinks down on the sessile glands and dies. Another difference is, that the secretion from the tall glands, before they have been in any way excited, is strongly acid, and perhaps contains a small quantity of the proper ferment. Again, these glands do not secrete more copiously from being excited by the absorption of nitrogenous matter; on the contrary, they then absorb their own secretion with extraordinary quickness. In a short time they begin to secrete again. All these circumstances are probably connected with the fact that insects do not commonly adhere to the glands with which they first come into contact, though this does sometimes occur; and that it is chiefly the secretion from the sessile glands which dissolves animal matter out of their bodies.

\section{Roridula.}

Roridula dentata.-This plant, a native of the western parts of the Cape of Good Hope, was sent to me in a dried state from Kew. It has an almost woody stem and branches, and apparently grows to a height of some feet. The leaves are linear, with their summits much attenuated. Their upper and lower surfaces are concave, with a ridge in the middle, and both are covered with tentacles, which differ greatly in length; some being very long, especially those on the tips of the leaves, and some very short. The glands also differ much in size and are somewhat elongated. They are supported on multicellular pedicels.

This plant, therefore, agrees in several respects with 
Drosophyllum, but differs in the following points. I could detect no sessile glands; nor would these have been of any use, as the upper surface of the leaves is thickly clothed with pointed, unicellular hairs directed upwards. The pedicels of the tentacles do not include spiral vessels; nor are there any spiral cells within the glands. The leaves often arise in tufts and are pinnatifid, the divisions projecting at right angles to the main linear blade. These lateral divisions are often very short and bear only a single terminal tentacle, with one or two short ones on the sides. No distinct line of demarcation can be drawn between the pedicels of the long terminal tentacles and the much attenuated summits of the leaves. We may, indeed, arbitrarily fix on the point to which the spiral vessels proceeding from the blade extend; but there is no other distinction.

. It was evident from the many particles of dirt sticking to the glands that they secrete much viscid matter. A large number of insects of many kinds also adhered to the leaves. I could nowhere discover any signs of the tentacles having been inflected over the captured insects; and this probably would have been seen even in the dried specimens, had they possessed the power of movement. Hence, in this negative character, Roridula resembles its northern representative, Drosophyllum.

\section{Byblis.}

Byblis gigantea (Western Australia). - A dried specimen, about 18 inches in height, with a strong stem, was sent me from Kew. The leaves are some inches in length, linear, slightly flattened, with a small projecting rib on the lower surface. They are covered on all sides by glands of two kinds 
-sessile ones arranged in rows, and others supported on moderately long pedicels. Towards the narrow summits of the leaves the pedicels are longer than elsewhere, and here equal the diameter of the leaf. The glands are purplish, much flattened, and formed of a single layer of radiating cells, which in the larger glands are from forty to fifty in number. The pedicels consist of single elongated cells, with colourless, extremely delicate walls, marked with the finest intersecting spiral lines. Whether these lines are the result of contraction from the drying of the walls, I do not know, but the whole pedicel was often spirally rolled up. These glandular hairs are far more simple in structure than the so-called tentacles of the preceding genera, and they do not differ essentially from those borne by innumerable other plants. The flower-peduncles bear similar glands. The most singular character about the leaves is that the apex is enlarged into a little knob, covered with glands, and about a third broader than the adjoining part of the attenuated leaf. In two places dead flies adhered to the glands. As no instance is known of unicellular structures having any power of movement,* Byblis, no doubt, eatches insects solely by the aid of its viscid secretion. These probably sink down besmeared with the secretion and rest on the small sessile glands, which, if we may judge by the analogy of Drosophyllum, then pour fourth their secretion and afterwards absorb the digested matter.

Supplementary Observations on the Power of Absorption by the Glandular Hairs of other Plants.-A few olservations on this subject may be here conveniently introduced. As the glands of many, probably of all,

* Sachs, 'Traité do Bot.' 3rd edit. 1874, p. 1026. 
the species of Droseraceæ absorb various fluids or at least allow them readily to enter,* it seemed desirable to ascertain how far the glands of other plants which are not specially adapted for capturing insects, had the same power. Plants were chosen for trial at hazard, with the exception of two species of saxifrage, which were selected from belonging to a family allied to the Droseracex. Most of the experiments were made by immersing the glands either in an infusion of raw meat or more commonly in a solution of carbonate of ammonia, as this latter substance acts so powerfully and rapidly on protoplasm. It seemed also particularly desirable to ascertain whether ammonia was absorbed, as a small amount is contained in rainwater. With the Droseracex the secretion of a viscid fluid by the glands does not prevent their absorbing; so that the glands of other plants might excrete superfluous matter, or secrete an odoriferous fluid as a protection against the attacks of insects, or for any other purpose, and yet have the power of absorbing. I regret that in the following cases I did not try whether the secretion could digest or render soluble animal substances, but such experiments would have been difficult on account of the small size of the glands and the small amount of secretion. We shall see in the next chapter that the secretion from the glandular hairs of Pinguicula certainly dissolves animal matter.

Sxaifraga umbrosa.-The flower-peduncles and petioles of the leâves are clothed with short hairs, bearing: pink-coloured glands, formed of several polygonal cells, with their pedicels divided by partitions into distinct cells, which are generally colourless, but sometimes pink. The glands secrete a yellowish viscid fluid, by

* The distinction between true ahsorption and mere permeation, or imbibition, is by no means clearly understood: see Müller's 'Physiology,' Eng. translat. 1838, vol. i. p. 280. 
which minute Diptera are sometimes, though not often, caught.* The cells of the glands contain bright pink fluid, charged with granules or with globular masses of pinkish pulpy matter. This matter must be protoplasm, for it is seen to undergo slow but incessant changes of form if a gland be placed in a drop of water and examined. Similar movements were observed after glands had been immersed in water for 1, 3, 5, 18, and 27 hrs. Even after this latter period the glands retained their bright pink colour; and the protoplasm within their cells did not appear to have become more aggregated. The continually changing forms of the little masses of protoplasm are not due to the absorption of water, as they were seen in glands kept dry.

A flower-stem, still attached to a plant, was bent (May 29) so as to remain immersed for $23 \mathrm{hrs} .30 \mathrm{~m}$. in a strong infusion of raw meat. The colour of the contents of the glands was slightly changed, being now of a duller and more purple tint than before. The contents also appeared more aggregated, for the spaces between the little masses of protoplasm were wider; but this latter result did not follow in some other and similar experiments. The masses seemed to change their forms more rapidly than did those in water; so that the cells had a different appearance every four or five minutes. Elongated masses became in the course of one or two minutes spherical; and spherical ones drew themselves out and united with others. Ninute masses rapidly increased in size, and three distinct ones were seen to unite. The movements were, in short, exactly like those described in the case of Drosera. The cells of the pedicels were not affected by the infusion; nor were they in the following experiment.

Another flower-stem was placed in the same manner and for the same length of time in a solution of one part of nitrate of ammonia to 146 of water (or 3 grs. to $1 \mathrm{oz}$.), and the glands were discoloured in exactly the same manner as by the infusion of raw meat.

Another flower-stem was immersed, as before, in a solution of one part of carbonate of ammonia to 109 of water. The glands, after $1 \mathrm{hr} .30 \mathrm{~m}$., were not discoloured, but after $3 \mathrm{hrs.} 45 \mathrm{~m}$. most of them had become dull purple, some of them blackish-

* In the case of Saxifraga tridactylites, Mr. Druce says ('Pharmaceutical Journal,' MIay 1s75) that he examined some dozens of plants, and in almost every in- stance remnants of insects adhered to the leaves. So it is, as I hear from a friend, with this plant in Ireland. 
green, a fow being still unaffected. The little masses of protoplasm within the cells were seen in movement. The cells of the pedicels were unaltered. The experiment was repeated, and a fresh flower-stem was left for $23 \mathrm{hrs}$. in the solution, and now a great effect was produced; all the glands were much blackened, and the previously transparent fluid in the cells of the pedicels, even down to their bases, contained spherical masses of granular matter. By comparing many different hairs, it was evident that the glands first absorb the carbonate, and that the effect thus produced travels down the hairs from cell to cell. The first change which could be observed is a cloudy appearance in the fluid, due to the formation of very fine granules, which afterwards aggregate into larger masses. Altogether, in the darkening of the glands, and in the process of aggregation travelling down the cells of the pedicels, there is the closest resemblance to what takes place when a tentacle of Drosera is immersed in a weak solution of the same salt. The glands, however, absorb very much more slowly than those of Drosera. Besides the glandular hairs, there are star-shaped organs which do not appear to secrete, and which were not in the least affected by the above solutions.

Although in the caso of uninjured flower-stems and leaves the carbonate seems to be absorbed only by the glands, yet it enters a cut surface much more quickly than a gland. Strips of the rind of a flower-stem were torn off, and the cells of the pedicels were seen to contain only colourless transparent fluid; those of the glands including as usual some granular matter. These strips were then immersed in the same solution as before (one part of the carbonate to 109 of water), and in a few minutes granular matter appeared in the lower cells of all the pedicels. The action invariably commenced (for I tried the experiment repeatedly) in the lowest cells, and therefore close to the torn surface, and then gradually travelled up the hairs until it reached the glands, in a reversed direction to what occurs in uninjured specimens. The glands then became discoloured, and the previously contained granular matter was aggregated into larger masses. Two short bits of a flower-stem were also left for $2 \mathrm{hrs} .40 \mathrm{~m}$. in a weaker solution of one part of the carbonate to 218 of water; and in both specimens the pedicels of the hairs near the cut ends now contained much granular matter; and the glands were completely discoloured.

Lastly, bits of meat were placed on some glands; these were examined after $23 \mathrm{hrs}$, as were others, which had apparently not long before caught minute flies; but they did not present any 
difference from the glands of other hairs. Perhaps there may not have been time enough for absorption. I think so as some glands, on which dead flies had evidently long lain, were of a pale dirty purple colour or even almost colourless, and the granular matter within them presented an unusual and somewhat peculiar appearance. That these glands had absorbed animal matter from the flies, probably by exosmose into the viscid secretion, we may infer, not only from their changed colour, but because, when placed in a solution of carbonate of ammonia, some of the cells in their pedicels become filled with granular matter; whereas the cells of other hairs, which had not caught flies, after being treated with the same solution for the same length of time, contained only a small quantity of granular matter. But more evidence is necessary before we fully admit that the glands of this saxifrage can absorb, even with ample time allowed, animal matter from the minute insects which they occasionally and accidentally capture.

Suxifraga rotundifolia (?).-The hairs on the flower-stems of this species are longer than those just described, and bear pale brown glands. Many were examined, and the cells of the pedicels were quite transparent. A bent stem was immersed for $30 \mathrm{~m}$. in a solution of one part of carbonate of ammonia to 109 of water, and two or three of the uppermost cells in the pedicels now contained granular or aggregated matter; the glands having become of a bright yellowish-green. The glands of this species therefore absorb the carbonate much more quickly than do those of Saxifraga umbrosa, and the upper cells of the pedicels are likewise affected much more quickly. Pieces of the stem were cut off and immersed in the same solution; and now the process of aggregation travelled up the hairs in a reversed direction; the cells close to the cut surfaces being first affected.

Primula sinensis.-The flower-stems, the upper and lower surfaces of the leaves and their footstalks, are all clothed with a multitude of longer and shorter hairs. The pedicels of tho longer hairs are divided by transverse partitions into eight or nine cells. The enlarged terminal cell is globular, forming a gland which secretes a variable amount of thick, slightly viscid, not acid, brownish-jellow matter.

A piece of a young flower-stem was first immersed in distilled water for 2 hrs. $30 \mathrm{~m}$., and the glandular hairs were not at all affecter. Another piece, bearing twenty-five short and nine long hairs, was carefully examined. The glands of the latter contained no solid or semi-solid matter; and those of only two 
of the twenty-five short hairs contained some globules. This piece was then immersed for $2 \mathrm{hrs}$. in a solution of one part of carbonate of ammonia to 109 of water, and now the glands of the twenty-five shorter hairs, with two or three exceptions, contained either one large or from two to five smaller spherical masses of semi-solid matter. Three of the glands of the nine long hairs likewise included similar masses. In a few hairs there were also globules in the cells immediately beneath the glands. Looking to all thirty-four hairs, there could be no doubt that the glands had absorbed some of the carbonate. Another pieco was left for only $1 \mathrm{hr}$. in the same solution, and aggregated matter appeared in all the glands. My son Francis examined some glands of the longer hairs, which contained little masses of matter, before they were immersed in any solution; and these masses slowly changed their forms, so that no doubt they consisted of protoplasm. He then irrigated these hairs for $1 \mathrm{hr}$. $15 \mathrm{~m}$., whilst under the microscope, with a solution of one part of the carbonate to 218 of water; the glands were not perceptibly affected, nor conld this have been expected, as their contents were already aggregated. But in the cells of the pedicels numerons, almost colourless, spheres of matter appeared, which changed their forms and slowly coalesced; the appearance of the cells being thus totally changed at successive intervals of time.

The glands on a young flower-stem, after having been left for 2 hrs. $45 \mathrm{~m}$. in a strong solution of one part of the carbonate to 109 of water, contained an abundance of aggregated masses, but whether generated by the action of the salt, I do not know. This piece was again placed in the solntion, so that it was immersed altogether for 6 hrs. $15 \mathrm{~m}$., and now there was a great change ; for almost all the spherical masses within the gland-cells had disappeared, being replaced by granular matter of a darker brown. The experiment was thrice repeated with nearly the same result. On one occasion the piece was left immersed for $8 \mathrm{hrs} .30 \mathrm{~m}$., and though almost all the spherical masses were changed into the brown granular matter, a few still remained. If the spherical masses of aggregated matter had been originally produced merely by some chemical or physical action, it seems strange that a somewhat longer immersion in the same solution should so completely alter their character. But as the masses which slowly and spontaneously changed their forms must have consisted of living protoplasm, there is nothing surprising in its being injured or killed, and its appearance wholly changed by long immersion in so strong a solution of the carbonate as that 
employed. A solution of this strength paralyses all movement in Drosera, but does not kill the protoplasm; a still stronger solution prevents the protoplasm from aggregating into the ordinary full-sized globular masses, and these, though they do not disintegrate, become granular and opaque. In nearly the same manner, too hot water and certain solutions (for instance, of the salts of soda and potash) cause at first an imperfect kind of aggregation in the cells of Drosera; the little masses afterwards breaking up into granular or pulpy brown matter. All the foregoing experiments were made on flowerstcms, but a piece of a leaf was immersed for $30 \mathrm{~m}$. in a strong solution of the carbonate (one part to 109 of water), and little globular masses of matter appeared in all the glands, which before contained only limpid fluid.

I made also several experiments on the action of the vapour of the carbonate on the glands; but will give only a few cases. The cut end of the footstalk of a young leaf was protected with sealing-wax, and was then placed under a small bell-glass, with a large pinch of the carbonate. After $10 \mathrm{~m}$. the glands showed a considerable degree of aggregation, and the protoplasm lining the cells of the pedicels was a little separated from the walls. Another leaf was left for $50 \mathrm{~m}$. with the same result, excepting that the hairs became throughout their whole length of a brownish colour. In a third leaf, which was exposed for $1 \mathrm{hr}$. $50 \mathrm{~m}$., there was much aggregated matter in the glands; and some of the masses showed signs of breaking up into brown granular matter. This leaf was again placed in the vapour, so that it was exposed altogether for $5 \mathrm{hrs} .30 \mathrm{~m}$.; and now, though I examined a large number of glands, aggregated masses were found in only two or three; in all the others, the masses, which before had been globular, were converted into brown, opaque, granular matter. We thus see that exposure to the vapour for a considerable time produces the same effects as long immersion in a strong solution. In both cases there could hardly be a doubt that the salt had been absorbed chiefly or exclusively by the glands.

On another occasion bits of damp fibrin, drops of a weak infusion of raw meat and of water, were left for $24 \mathrm{hrs}$. on some leaves; the hairs were then examined, but to my surprise differed in no respect from others which had not been touched by these fluids. Most of the cells, however, included hyaline, motionless little spheres, which did not scem to consist of protoplasm, but, I suppose, of some balsam or essential oil.

Pelargonium zonale (var. edged with white).-The leaves 
are clothed with numerous multicellular hairs; some simply pointed; others bearing glandular heads, and differing much in length. The glands on a piece of leaf were examined and found to contain only limpid fluid; most of the water was removed from beneath the covering glass, and a minute drop of one part of carbonate of ammonia to 146 of water was added; so that an extremely small dose was given. After an interval of only $3 \mathrm{~m}$. there were signs of aggregation within the glands of the shorter hairs; and after $5 \mathrm{~m}$. many small globules of a pale brown tint appeared in all of them; similar globules, but larger, being found in the large glands of the longer hairs. After the specimen had been left for $1 \mathrm{hr}$. in the solution, many of the smaller globules had changed their positions; and two or three vacuoles or small spheres (for I know not which they were) of a rather darker tint appeared within some of the larger globules. Little globules could now be seen in some of the uppermost cells of the pedicels, and the protoplasmic lining was slightly separated from the walls of the lower cells. After $2 \mathrm{hrs} .30 \mathrm{~m}$. from the time of first immersion, the large globules within the glands of the longer hairs were converted into masses of darker brown granular matter. Hence from what we have seen with Primula sinensis, there can be little doubt that theso masses originally consisted of living protoplasm.

A drop of a weak infusion of raw meat was placed on a leaf, and after 2 hrs. $30 \mathrm{~m}$. many spheres could be seen within the glands. These spheres, when looked at again after $30 \mathrm{~m}$., had slightly changed their positions and forms, and one had separated into two; but the changes were not quite like those which the protoplasm of Drosera undergoes. These hairs, moreover, had not been examined before immersion, and there were similar spheres in some glands which had not been touched by the infusion.

Erica tetralix.-A few long glandular hairs project from the margins of the upper surfaces of the leares. The pedicels are formed of several rows of cells, and support rather large globular heads, secreting viscid matter, by which minute insects are occasionally, though rarely, caught. Some leaves were left for 23 hrs. in a weak infusion of raw meat and in water, and the hairs were then compared, but they differed very little or not at all. In both cases the contents of the cells seemed rather more granular than they were before; but the granules did not exhibit any movement. Other leaves were left for $23 \mathrm{hrs}$. in a solution of one part of carbonate of ammonia to 218 of water, and here again the granular matter appeared to have increased 
in amount; but one such mass retained exactly the same form as before after an interval of $5 \mathrm{hrs}$., so that it could hardly have consisted of living protoplasm. These glands seem to have very little or no power of absorption, certainly much less than those of the foregoing plants.

Mirabilis longiflora.-The stems and both surfaces of the leaves bear viscid hairs. Young plants, from 12 to 18 inches in height in my greenhouse, caught so many minute Diptera, Coleoptera, and larvæ, that they were quite dusted with them. The hairs are short, of unequal lengths, formed of a single row of cells, surmounted by an enlarged cell which secretes viscid matter. These terminal cells or glands contain granules and often globules of granular matter. Within a gland which had caught a small insect, one such mass was observed to undergo incessant changes of form, with the occasional appearance of vacuoles. But I do not beliere that this protoplasm had been generated by matter absorbed from the dead insect; for, on comparing several glands which had and had not caught insects, not a shade of difference could be perceived between them, and they all contained fine granular matter. A piece of leaf was immersed for $24 \mathrm{hrs}$. in a solution of one part of carbonate of ammonia to 218 of water, but the hairs seemed very little affected by it, excepting that perhaps the glands wero rendered rather more opaque. In the leaf itself, however, the grains of chlorophyll near the cut surfaces had run together, or become aggregated. Nor were the glands on another leaf, after an immersion for $24 \mathrm{hrs}$. in an infusion of raw meat, in the least affected; but the protoplasm lining the cells of the pedicels had shrunk greatly from the walls. This latter effect may have been due to exosmose, as the infusion was strong. We may, therefore, conclude that the glands of this plant either have no power of absorption or that the protoplasm which they contain is not acted on by a solution of carbonate of ammonia (and this seems scarcely credible) or by an infusion of meat.

Nicotiana tabacum.-This plant is covered with innumerablo hairs of unequal lengths, which catch many minute insects. The pedicels of the hairs are divided by transverse partitions, and the secreting glands are formed of many cells, containing greenish matter with little globules of some substance. Leaves were left in an infusion of raw meat and in water for $26 \mathrm{hrs}$, but presented no difference. Some of these same leaves were then left for above $2 \mathrm{hrs}$. in a solution of carbonate of ammonia, but no effect was produced. I regret that other experiments were not tried with more care, as M. Schloesing 
has shown* that tobacco plants supplied with the vapour of carbonate of ammonia yield on analysis a greater amount of nitrogen than other plants not thus treated; and, from what we have seen, it is probable that some of the vapour may be absorbed by the glandular hairs.

Summary of the Observations on Glandular Hairs.From the foregoing observations, few as they are, wo see that the glands of two species of Saxifraga, of a Primula and Pelargonium, have the power of rapid absorption; whereas the glands of an Erica, Mirabilis, and Nicotiana, either have no such power, or the contents of the cells are not affected by the fluids employed, namely a solution of carbonate of ammonia and an infusion of raw meat. As the glands of the Mirabilis contain protoplasm, which did not become aggregated from exposure to the fluids just named, though the contents of the cells in the blade of the leaf were greatly affected by carbonate of ammonia, we may infer that they cannot absorb. We may further infer that the innumerable insects caught by this plant are of no more service to it than are those which adhere to the deciduous and sticky scales of the leaf-buds of the horse-chestnut.

The most interesting case for us is that of the two species of Saxifraga, as this genus is distantly allied to Drosera. Their glands absorb matter from an infusion of raw meat, from solutions of the nitrate and carbonate of ammonia, and apparently from decayed insects. This was shown by the changed dull purple colour of the protoplasm within the cells of the glands, by its state of aggregation, and apparently by its more rapid spontaneous moviements.

\footnotetext{
* 'Comptes rendus,' June 15, 1874. A good abstract of this paper is giren in the 'Gardener's Chronicle,' July 11, 1874.
} 
The aggregating process spreads from the glands down the pedicels of the hairs; and we may assume that any matter which is absorbed ultimately reaches the tissues of the plant. On the other hand, the process travels up the hairs whenever a surface is cut and exposed to a solution of the carbonate of ammonia.

The glands on the flower-stalks and leaves of Primula sinensis quickly absorb a solution of the carbonate of ammonia, and the protoplasm which they contain becomes aggregated. The process was seen in some cases to travel from the glands into the upper cells of the pedicels. Exposure for $10 \mathrm{~m}$. to tho vapour of this salt likewise induced aggregation. When leaves were left from $6 \mathrm{hrs}$. to $7 \mathrm{hrs}$. in a strong - solution, or were long exposed to the vapour, the little masses of protoplasm became disintegrated, brown, and granular, and were apparently killed. An infusion of raw meat produced no effect on the glands.

The limpid contents of the glands of Pelargonium zonate became cloudy and granular in from $3 \mathrm{~m}$. to $5 \mathrm{~m}$. when they were immersed in a weak solution of the carbonate of ammonia; and in the course of $1 \mathrm{hr}$. granules appeared in the upper cells of the pedicels. As tho aggregated masses slowly changed their forms, and as they suffered disintegration when left for a considerable time in a strong solution, there can be little doubt that they consisted of protoplasm. It is doubtful whether an infusion of raw meat produced any effect.

The glandular hairs of ordinary plants have generally been considered by physiologists to serve only as secreting or excreting organs, but we now know that they have the power, at least in some cases, of absorbing both a solution and the vapour of ammonia. As rainwater contains a small percentage of ammonia, and the atmosphere a minuto quantity of the carbonate, this 
power can hardly fail to be beneficial. Nor can the benefit be quite so insignificant as it might at first be thought, for a moderately fine plant of Primula sinensis bears the astonishing number of above two millions and a half of glandular hairs, ${ }^{*}$ all of which are able to absorb ammonia brought to them by the rain. It is moreover probable that the glands of some of the above named plants obtain animal matter from the insects which are occasionally entangled by the viscid secretion.

\section{Concluding Remariss on the Droseracem.}

The six known genera composing this family have now been described in relation to our present subject, as far as my means have permitted. They all capture insects. This is effected by Drosophyllum, Roridula, and Byblis, solely by the viscid fluid secreted from their glands; by Drosera, through the same means, together with the movements of the tentacles; by Dionæa and Aldrovanda, through the closing of the blades of the leaf. In these two last genera rapid

* My son Francis counted the hairs on a space measured by means of a micrometer, and found that there were 35,336 on a square inch of the upper surface of a leaf, and 30,035 on the lower surface; that is, in about the proportion of 100 on the upper to 85 on the lower surface. On a square inch of both surfaces there were 65,371 hairs. A moderately fine plant bearing twelve leares (the larger ones being a little more than 2 inches in diameter) was now selected, and tho area of all the leaves, together with their foot-stalks (the flower-stems not being included), was found by a planimeter to be 39.285 square inches; so that the area of both surfaces was 78.57 square inches. Thus the plant (excluding tho flower-stems) nust have borne the astonishing number of $2,568,099$ glandular hairs. The hairs were counted late in the autumn, and by the following spring (May) the leaves of some other plants of the same lot were found to be from one-third to onefourth broader and longer than they were before; so that no doubt the glandular hairs had increased in number, and probably now much exceeded thrce millious. 
movement makes up for the loss of viscid secretion. In every case it is some part of the leaf which moves. In Aldrovanda it appears to be the basal parts alone which contract and carry with them the broad, thin margins of the lobes. In Dionæa the whole lobe, with the exception of the marginal prolongations or spikes, curves inwards, though the chief seat of movement is near the midrib. In Drosera the chief seat is in the lower part of the tentacles, which, homologically, may be considered as prolongations of the leaf; but the whole blade often curls inwards, converting the leaf into a temporary stomach.

There can hardly be a doubt that all the plants belonging to these six genera have the power of dissolving animal matter by the aid of their secretion, which contains an acid, together with a ferment almost identical in nature with pepsin; and that they afterwards absorb the matter thus digested. This is certainly the case with Drosera, Drosophyllum, and Dionæa; almost certainly with Aldrovanda; and, from analogy, very probable with Roridula and Byblis. We can thus understand how it is that the three firstnamed genera are provided with such small roots, and that Aldrovanda is quite rootless; about the roots of the two other genera nothing is known. It is, no dloubt, a surprising fact that a whole group of plants (and, as we shall presently see, some other plants not allied to the Droseracex) should subsist partly by digesting animal matter, and partly by decomposing carbonic acid, instead of exclusively by this latter means, together with the absorption of matter from the soil by the aid of roots. We have, however, an equally anomalous case in the animal kingdom; the rhizocephalous crustaceans do not feed like other animals by their mouths, for they are destitute of an 
alimentary canal; but they live by absorbing through root-like processes the juices of the animals on which they are parasitic.*

Of the six genera, Drosera has been incomparably the most successful in the battle for life; and a large part of its success may be attributed to its manner of catching insects. It is a dominant form, for it is believed to include about 100 species, $\uparrow$ which range in the Old World from the Arctic regions to Southern India, to the Cape of Good Hope, Madagascar, and Australia; and in the New World from Canada to Tierra del Fuego. In this respect it presents a marked contrast with the five other genera, which appear to be failing groups. Dionæa includes only a single species, which is confined to one district in Carolina. The three varieties or closely allied species of Aldrovanda, like so many water-plants, have a wide range from Central Europe to Bengal and Australia. Drosophyllum includes only one species, limited to Portugal and Moroceo. Roridula and Byblis each have (as I

* Fritz Müller, ' Facts for Darwin,' Eng. trans. 1869, p. 139. The rhizocephalous crustaceans are allied to the cirripedes. It is hardly possible to imagine a greater difference than that between an animal with prehensile limbs, a wellconstructed mouth and alimeutary canal, and one destitute of all these organs and feeding by absorption through branching rootlike processes. If one rare cirripede, the Anelasma squalicola, had become extinct, it would have been very difficult to conjecture how so enormous a change could have been gradually effected. But, as Fritz Müller remarks, we have in Anelasma an animal in an almost exactly intermediate condition, for it has root-like processes embedded in the skin of the shark on which it is parasitic, and its prehensile cirri and mouth (as described in my monograph on the Lepadidx, 'Ray Soe.' 1851, p. 169) are in a most feeble and almost rudimentary condition. Dr. R. Kossmann has given a very interesting discussion on this subject in his 'Suctoria and Lepadidx,' 1873. See also, Dr. Dohrn, 'Der Ursprung der Wirbelthiere,' 1875 , p. 77.

† Bentham and Hooker, 'Genera Plautarum.' Australia is the metropolis of the genus, forty-ono species having been described from this country, as Prof. Oliver informs me. 
hear from Prof. Oliver) two species; the former confined to the western parts of the Cape of Good Hope, and the latter to Australia. It is a strange fact that Dionæa, which is one of the most beautifully adapted plants in the vegetable kingdom, should apparently be on the high-road to extinction. This is all the more strange as the organs of Dionæa are more highly differentiated than those of Drosera; its filaments serve exclusively as organs of touch, the lobes for capturing insects, and the glands, when excited, for secretion as well as for absorption; whereas with Drosera the glands serve all these purposes, and secrete without being excited.

By comparing the structure of the leaves, their degree of complication, and their rudimentary parts in the six genera, we are led to infer that their common parent form partook of the characters of Drosophyllum, Roridula, and Byblis. The leaves of this ancient form were almost certainly linear, perhaps divided, and bore on their upper and lower surfaces glands which had the power of secreting and absorbing. Some of these glands were mounted on pedicels, and others were almost sessile; the latter secreting only when stimulated by the absorption of nitrogenous matter. In Byblis the glands consist of a single layer of cells, supported on a unicellular pedicel; in Roridula they have a more complex structure, and are supported on pedicels formed of several rows of cells; in Drosophyllum they further include spiral cells, and the pedicels include a bundle of spiral vessels. But in these three genera these organs do not possess any power of movement, and there is no reason to doubt that they are of the nature of hairs or trichomes. Although in innumerable instances foliar organs move when excited, no case is known of a trichome having such 
power.* We are thus led to inquire how the so-called tentacles of Drosera, which are manifestly of the same general nature as the glandular hairs of the above three genera, could have acquired the power of moving. Many botanists maintain that these tentacles consist of prolongations of the leaf, because they include vascular tissue, but this can no longer be considered as a trustworthy distinction. $\uparrow$ The possession of the power of movement on excitement would have been safer evidence. But when we consider the vast number of the tentacles on both surfaces of the leaves of Drosophyllum, and on the upper surface of the leaves of Drosera, it seems scarcely possible that each tentacle could have aboriginally existed as a prolongation of the leaf. Roridula, perhaps, shows us how we may reconcile these difficulties with respect to the homological nature of the tentacles. The lateral divisions of the leaves of this plant terminate in long tentacles; and these include spiral vessels which extend for only a short distance up them, with no line of demarcation between what is plainly the prolongation of the leaf and the pedicel of a glandular hair. Therefore there would be nothing anomalous or unusual in the basal parts of these tentacles, which correspond with the marginal ones of Drosera, acquiring the power of movement; and we know that in Drosera it is only the lower part which becomes inflected. But in order to understand how in this latter genus not only the marginal but all the inner tentacles have become capable of movement, we must further assume, either that through the principle of correlated development this

* Sachs, 'Traité de Botanique,' 3rd edit. 1874, p. 1026.

† Dr. Warming. 'Sur la Différence entre les Trichomes,' Copen- hague, 1873, p. 6. 'Extrait des Videnskabelitre. Meddelelser de la Soc. d'Hist. nat. do Copenhague,' Nos. 10-12, 1872. 
power was transferred to the basal parts of the hairs, or that the surface of the leaf has been prolonged upwards at numerous points, so as to unite with the hairs, thus forming the bases of the inner tentacles.

The above named three genera, namely Drosophyllum, Roridula, and Byblis, which appear to have retained a primordial condition, still bear glandular hairs on both surfaces of their leaves; but those on the lower surface have since disappeared in the more highly developed genera, with the partial exception of one species, Drosera binata. The small sessile glands have also disappeared in some of the genera, being replaced in Roridula by hairs, and in most species of Drosera by absorbent papillæ. Drosera binata, with its linear and bifurcating leaves, is in an intermediate condition. It still bears some sessile glands on both surfaces of the leaves, and on the lower surface a few irregularly placed tentacles, which are incapable of movement. A further slight change would convert the linear leaves of this latter species into the oblong leaves of Drosera anglica, and these might easily pass into orbicular ones with footstalks, like those of Drosera rotundifolia. The footstalks of this latter species bear multicellular hairs, which we have good reason to believe represent aborted tentacles.

The parent form of Dionæa and Aldrovanda seems to have been closely allied to Drosera, and to have had rounded leaves, supported on distinct footstalks, and furnished with tentacles all round the circumference, with other tentacles and sessile glands on the upper surface. I think so because the marginal spikes of Dionæa apparently represent the extreme marginal tentacles of Drosera, the six (sometimes eight) sensitive filaments on the upper surface, as well as the more numerous ones in Aldrovanda, representing the central 
tentacles of Drosera, with their glands aborted, but their sensitiveness retained. Under this point of view we should bear in mind that the summits of the tentacles of Drosera, close beneath the glands, are sensitive.

The three most remarkable characters possessed by the several members of the Droseracere consist in the leaves of some having the power of movement when excited, in their glands secreting a fluid which digests animal matter, and in their absorption of the digested matter. Can any light be thrown on the steps by which these remarkable powers were gradually acquired?

As the walls of the cells are necessarily permeable to fluids, in order to allow the glands to secrete, it is not surprising that they should readily allow fluids to pass inwards ; and this inward passage would deserve to be called an act of absorption, if the fluids combined with the contents of the glands. Judging from the evidence above given, the secreting glands of many other plants can absorb salts of ammonia, of which they must receive small quantities from the rain. This is the case with two species of Saxifraga, and the glands of one of them apparently absorb matter from captured insects, and certainly from an infusion of raw meat. There is, therefore, nothing anomalous in the Droseraceæ having acquired the power of absorption in a much more highly developed degree.

It is a far more remarkable problem how the members of this family, and Pinguicula, and, as Dr. Hooker has recently shown, Nepenthes, could all have acquired the power of secreting a fluid which dissolves or digests animal matter. The six genera of the Droseraceæ have probably inherited this power from a common progenitor, but this cannot apply to 
Pinguicula or Nepenthes, for these plants are not at all closely related to the Droseraceæ. But the difficulty is not nearly so great as it at first appears. Firstly, the juices of many plants contain an acid, and, apparently, any acid serves for digestion. Secondly, as Dr. Hooker has remarked in relation to the present subject in his address at Belfast (1874), and as Sachs repeatedly insists,* the embryos of some plants secrete a fluid which dissolves albuminous substances out of the endosperm; although the endosperm is not actually united with, only in contact with, the embryo. All plants, moreover, have the power of dissolving albuminous or proteid substances, such as protoplasm, chlorophyll, gluten, aleurone, and of carrying them from one part to other parts of their tissues. This must be effected by a solvent, probably consisting of a ferment together with an acid. $\dagger$ Now, in the case of plants which are able to absorb already soluble matter from captured insects, though not capable of true digestion, the solvent just referred to, which must be occasionally present in the glands, would be apt to exude from the glands together with the viscid secretion, inasmuch as endosmose is accompanied by exosmose. If such exudation did ever occur, the solvent would act on the animal matter contained within the captured insects, and this would be an act of true digestion. As it cannot be doubted that this process would be of high service to plants

* 'Traité de Botanique,' 3rd edit. 1874, p. 844 . See also for following facts pp. $64,76,828$, $8: 31$.

$\dagger$ Since this sentence was written, I have reseived a paper by Gorup-Besanez ('Bcrichte der Deutschen Chem. Gesellschaft,'
Berlin, 1874, p. 1478), who, with the aid of Dr. H. Will, has actually made the discovery that the seeds of the vetch contain a ferment, which, when extracted by glycerine, dissolves albuminous substances, such as fibrin, and converts them into true peptones. 
growing in very poor soil, it would tend to be perfected through natural selection. Therefore, any ordinary plant having viscid glands, which occasionally caught insects, might thus be converted under favourable circumstances into a species capable of true digestion. It ceases, therefore, to be any great mystery how several genera of plants, in no way closely related together, have independently acquired this same power.

As there exist several plants the glands of which cannot, as far as is known, digest animal matter, yet can absorb salts of ammonia and animal fluids, it is probable that this latter power forms the first stage towards that of digestion. It might, however, happen, under certain conditions, that a plant, after having acquired the power of digestion, should degenerate into one capable only of absorbing animal matter in solution, or in a state of decay, or the final products of decay, namely the salts of ammonia. It would appear that this has actually occurred to a partial extent with the leaves of Aldrovanda; the outer parts of which possess absorbent organs, but no glands fitted for the secretion of any digestive fluid, these being confined to the inner parts.

Little light can be thrown on the gradual acquirement of the third remarkable character possessed by the more highly developed genera of the Droseracex, namely the power of movement when excited. It should, however, be borne in mind that leaves and their homologues, as well as flower-peduncles, have gained this power, in innumerable instances, independently of inheritance from any common parent form; for instance, in tendril-bearers and leaf-climbers (i. e. plants with their leaves, petioles and flower-peduncles, \&c., modified for prehension) belonging to a large 
number of the most widely distinct orders,-in the leaves of the many plants which go to sleep at night, or move when shaken, - and in the irritable stamens and pistils of not a few species. We may therefore infer that the power of movement can be by some means readily acquired. Such movements imply irritability or sensitiveness, but, as Cohn has remarked,* the tissues of the plants thus endowed do not differ in any uniform manner from those of ordinary plants; it is therefore probable that all leaves are to a slight degree irritable. Even if an insect alights on a leaf, a slight molecular change is probably transmitted to some distance across its tissue, with the sole difference that no perceptible effect is produced. We have some evidence in farour of this belief, for we know that a single touch on the glands of Drosera does not excite inflection; yet it must produce some effect, for if the glands have been immersed in a solution of camphor, inflection follows within a shorter time than would have followed from the effects of camphor alone. So again with Dionæa, the blades in their ordinary state may be roughly touched without their closing; yet some effect must be thus caused and transmitted across the whole leaf, for if the glands have recently absorbed animal matter, even a delicate touch causes them to close instantly. On the whole we may conclude that the acquirement of a high degree of sensitiveness and of the power of movement by certain genera of the Droseraceæ presents no greater difficulty than that presented by the similar but feebler powers of a multitude of other plants.

* See the abstract of his memoir on the contractile tissues of plants, in the 'Annals and
Mag. of Nat. Hist.' 3rd series, vol. xi. p. 188. 
The specialised nature of the sensitiveness possessed by Drosera and Dionæa, and by certain other plants, well deserves attention. A gland of Drosera may be forcibly hit once, twice, or even thrice, without any effect being produced, whilst the continued pressure of an extremely minute particle excites movement. On the other hand, a particle many times heavier may be gently laid on one of the filaments of Dionæa with no effect; but if touched only once by the slow movement of a delicate hair, the lobes close; and this difference in the nature of the sensitiveness of these two plants stands in manifest adaptation to their manner of capturing insects. So does the fact, that when the central glands of Drosera absorb nitrogenous matter, they transmit a motor impulse to the exterior tentacles much more quickly than when they are mechanically irritated; whilst with Dionæa the absorption of nitrogeneous matter causes the lobes to press together with extreme slowness, whilst a touch excites rapid movement. Somewhat analogous cases may be observed, as I have shown in another work, with the tendrils of various plants; some being most excited by contact with fine fibres, others by contact with bristles, others. with a flat or a creviced surface. The sensitive organs of Drosera and Dionæa are also specialised, so as not to be uselessly affected by the weight or impact of drops of rain, or by blasts of air. This may be accounted for by supposing that these plants and their progenitors have grown accustomed to the repeated action of rain and wind, so that no molecular change is thus induced; whilst they have been rendered more sensitive by means of natural selection to the rarer impact or pressure of solid bodies. Although the absorption by the glands of Drosera of various fluids excites move- 
ment, there is a great difference in the action of allied fluids; for instance, between certain vegetable acids, and between citrate and phosphate of ammonia. The specialised nature and perfection of the sensitiveness in these two plants is all the more astonishing as no one supposes that they possess nerves; and by testing Drosera with several substances which act powerfully on the nervous system of animals, it does not appear that they include any diffused matter analogous to nerve-tissue.

Although the cells of Drosera and Dionæa are quite as sensitive to certain stimulants as are the tissues which surround the terminations of the nerves in the higher animals, yet these plants are inferior even to animals low down in the scale, in not being affected except by stimulants in contact with their sensitive parts. They would, however, probably be affected by radiant heat; for warm water excites energetic movement. When a gland of Drosera, or one of the filaments of Dionæa, is excited, the motor impulse radiates in all directions, and is not, as in the case of animals, directed towards special points or organs. This holds good even in the case of Drosera when some exciting substance has been placed at two points on the disc, and when the tentacles all round are inflected with marvellous precision towards the two points. The rate at which the motor impulse is transmitted, though rapid in Dionæa, is much slower than in most or all animals. This fact, as well as that of the motor impulse not being specially directed to certain points, are both no doubt due to the absence of nerves. Nevertheless we perhaps see the prefigurement of the formation of nerves in animals in the transmission of the motor impulse being so much more rapid down the confined space within the tentacles of Drosera than 
elsewhere, and somewhat more rapid in a longitudinal than in a transverse direction across the disc. These plants exhibit still more plainly their inferiority to animals in the absence of any reflex action, except in so far as the glands of Drosera, when excited from a distance, send back some influence which causes the contents of the cells to become aggregated down to the bases of the tentacles. But the greatest inferiority of all is the absence of a central organ, able to receivo impressions from all points, to transmit their effects in any definite direction, to store them up and reproduce them. 


\section{CHAPTER XVI.}

\section{Pisgeictla.}

P'inguicula vulgaris - Structure of leares-Number of insects and other objects caught-Morement of the margins of the leares Uses of this morement-Secretion, digestion, and absorptionAction of the secretion on rarious animal and regetable substances - The effects of substances not containing soluble nitrogenous matter on the glands - Pinguicula grandiflora - Pinguicula lusitanica, catches insects-Morement of the leares, secretion and digestion.

Pinguiclia vulgaris.-This plant grows in moist places, generally on mountains. It bears on an average eight, rather thick, oblong, light green leaves, having scarcely any footstalk. A full-sized leaf is about $1 \frac{1}{2}$ inch in length and $\frac{3}{4}$ inch in breadth. The young central leares are deeply concare, and project upwards; the older anes torrards the outside are flat or convex, and lie close to the ground, forming a rosette from 3 to 4 inches in diameter. The margins of the leares are incurved. Their upper surfaces are thickly covered with two sets of glandular hairs, differing in the size of the glands and in the length of their pedicels. The larger glands hare a circular outline as seen from above, and are of moderate thickness; they are divided by radiating partitions into sixteen cells, containing light-green, homogeneous fluid. They are supported on elongated, unicellular pedicels (containing a nucleus with a nucleolus) which rest on slight prominences. The small glands differ only in being formed of about half the number of cells, containing much paler fluid, and supported on much shorter pedicels. Near the midrib, towards the base of the leaf, the 
pedicels are multicellular, are longer than elsewhere, and bear smaller glands. All the glands secrete a colourless fluid, which is so viscid that I have seen a fine thread drawn out to a length of 18 inches; but the fluid in this case was secreted by a gland which had been excited. The edge of the leaf is translucent, and does not bear any glands; and here the spiral vessels, proceeding from the midrib, terminate in cells marked by a spiral line, somewhat like those within the glands of Drosera.

The roots are short. Three plants were dug up in North Wales on June 20, and carefully washed; each bore five or six unbranched roots, the longest of which was only 1.2 of an inch. Two rather young plants were examined on September 28; these had a greater number of roots, namely eight and eighteen, all under 1 inch in length, and very little branched.

I was led to investigate the habits of this plant by being told by Mr. W. Marshall that on the mountains of Cumberland many insects adhere to the leaves.

A friend sent me on June 23 thirty-nine leaves from North Wales, which were selected owing to objects of some kind adhering to them. Of these leaves, thirty-two had caught 142 insects, or on an average 4.4 per leaf, minute fragments of insects not being included. Besides the insects, small leaves belonging to four different kinds of plants, those of Erica tetralix being much the commonest, and three minute seedling plants, blown by the wind, adhered to nineteen of the leaves. One had caught as many as ten leaves of the Erica: Seeds or fruits, commonly of Carex and one of Juncus, besides bits of 'moss and other rubbish, likewise adhered to six of the thirty-nino leaves. The same friend, on June 27, collected nine plants bearing seventy-four leaves, and all of these, with the exception of three young leaves, had caught insects; thirty insects were counted on one leaf, eighteen on a second, and sixteen on a third. Another friend examined on August 22 some plants in Donegal, Ireland, and found insects on 70 out of 157 leaves; fifteen of 
these leaves were sent me, each having caught on an average 2.4 insects. To nine of them, leaves (mostly of Erica tetralix) adhered; but they had been specially selected on this latter account. I may add that early in August my son found leaves of this same Erica and the fruits of a Carex on the leaves of a Pinguicula in Switzerland, probably Pinguicula alpina; some insects, but no great number, also adhered to the leaves of this plant, which had much better developed roots than those of Pinguicula vulgaris. In Cumberland, Mr. Marshall, on September 3, carefully examined for me ten plants bearing eighty leaves; and on sixtythree of these (i.e. on 79 per cent.) he found insects, 143 in number; so that each leaf had on an arerage $2 \cdot 27$ insects. A few days later he sent me some plants with sixteen seeds or fruits adhering to fourteen leaves. There was a seed on three leaves on the same plant. The sixteen seeds belonged to nino different kinds, which could not be recognised, excepting one of Ranunculus, and several belonging to three or four distinct species of Carex. It appears that fewer insects are caught lato in the year than earlier; thus in Cumberland from twenty to twenty-four insects were observed in the middle of July on several leares, whereas in the beginning of September the average number was only 2.27. Most of the insects, in all the foregoing cases, were Diptera, but with many minute Hymenoptera, including some ants, a ferv small Coleoptera, larræ, spiders, and even small moths.

We thus see that numerous insects and other objects are caught by the viscid leaves; but we have no right to infer from this fact that the habit is beneficial to the plant, any more than in the before given case of the Mirabilis, or of the horse-chestnut. But it will presently be seen that dead insects and other nitrogenous bodies excite the glands to increased secretion; and that the secretion then becomes acid and has the power of digesting animal substances, such as albumen, fibrin, \&c. Moreover, the dissolved nitrogenous matter is absorbed by the glands, as shown by their limpid contents being aggregated into slowly moving granular masses of protoplasm. The same results follow when insects are naturally captured, and as the plant lives in poor soil and has small roots, there can be no 
doubt that it profits by its power of digesting and absorbing matter from the prey which it habitually captures in such large numbers. It will, however, be convenient first to describe the movements of the leaves.

Movements of the Leaves. - That such thick, large leaves as those of Pinguicula vulgaris should have the power of curving inwards when excited has never even been suspected. It is necessary to select for experiment leaves with their glands secreting freely, and which have been prevented from capturing many insects; as old leaves, at least those growing in a state of nature, have their margins already curled so much inwards that they exhibit little power of movement, or move very slowly. I will first give in detail the more important experiments which wero tried, and then make some concluding remarks.

Experiment 1.-A young and almost upright leaf was selected, with its two lateral edges equally and very slightly incurved. A row of small flies was placed along one margin. When looked at next day, after 15 hrs., this margin, but not the other, was found folded inwards, like the helix of the human ear, to the breadth of $\frac{x}{10}$ of an inch, so as to lie partly over the row of flies (fig. 15). The glands on which the flies rested, as well as those on the overlapping margin which had been brought into contact with the flies, were all secreting copiously.

Experiment 2.-A row of flies was placed on one margin of a rather old leaf, which lay flat on the ground; and in this case the margin, after the same interval as before, namely $15 \mathrm{hrs}$., had only just begun to curl inwards; but so much secretion had been poured forth that the spoonshaped tip of the leaf was filled with it.

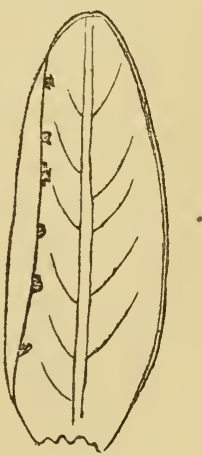

Frg. 15.

(Pinguicula vulgaris.)

Outline of leaf with left margin inflected over a row of small flies.

Experiment 3.-Fragments of a large fly were placed close to the apex of a vigorous leaf, as well as along half one margin. 
After 4 hrs. $20 \mathrm{~m}$. there was decided incurvation, which increased a little during the afternoon, but was in the same state on the following morning. Near the apex both margins were inwardly curved. I have never seen a case of the apex itself being in the least curved towards the base of the leaf. After 48 hrs. (always reckoning from the time when the flies were placed on the leaf) the margin had everywhere begun to unfold.

Experiment 4.-A large fragment of a fly was placed on a leaf, in a medial line, a little beneath the apex. Both lateral margins were perceptibly incurved in $3 \mathrm{hrs}$, and after $4 \mathrm{hrs} .20 \mathrm{~m}$. to such a degree that the fragment was clasped by both margins. After $24 \mathrm{hrs}$. the two infolded edges near the apex (for the lower part of the leaf was not at all affected) were measured and found to be $\cdot 11$ of an inch $(2.795 \mathrm{~mm}$.) apart. The fly was now removed, and a stream of water poured over the leaf so as to wash the surface; and after 24 hrs. the margins were $\cdot 25$ of an inch $(6.349 \mathrm{~mm}$.) apart, so that they were largely unfolded. After an additional $24 \mathrm{hrs}$. they were completely unfolded. Another fly was now put on the same spot to see whether this leaf, on which the first fly had been left 24 hrs., would move again; after $10 \mathrm{hrs}$. there was a trace of incurvation, but this did not increase during the next $24 \mathrm{hrs}$. A bit of meat was also placed on the margin of a leaf, which four days previously had become strongly incurved over a fragment of a fly and had aft:rwards re-expanded; but the meat did not cause even a trace of incurvation. On the contrary, the margin became somewhat reflexed, as if injured, and so remained for the three following days, as long as it was observed.

Experiment 5.-A large fragment of a fly was placed halfway between the apex and base of a leaf and halfway between the midrib and one margin. A short space of this margin, opposite the fly, showed a trace of incurvation after $3 \mathrm{hrs}$., and this became strongly pronounced in $7 \mathrm{hrs}$. After $24 \mathrm{hrs}$. the infolded edge was only 16 of an inch $(4.064 \mathrm{~mm}$.) from the midrib. The margin now began to unfold, though the fly was left on the leaf; so that by the next morning (i.e. 48 hrs. from the time when the fly was first put on) the infolded edge had almost completely recovered its original position, being now 3 of an inch $(7 \cdot 62 \mathrm{~mm}$.), instead of 16 of an inch, from the midrib. A trace of flexure was, however, still visible.

Experiment 6.-A young and concave leaf was selected with its margins slightly and naturally incurved. Two rather large, oblong, rectangular pieces of roast meat were placed with their ends touching the infolded edge, and 46 of an inch ( $11.68 \mathrm{~mm}$.) 
apart from one another. After $24 \mathrm{hrs}$. the margin was greatly and equally incurved (see fig. 16) throughout this space, and for a length of 12 or 13 of an inch (3.048 or $3.302 \mathrm{~mm}$.) above and below each bit; so that the margin had been affected over a greater length between the two bits, owing to their conjoint action, than beyond them. The bits of meat were too large to be clasped by the margin, but they were tilted up, one of them so as to stand almost vertically. After $48 \mathrm{hrs}$. the margin was almost unfolded, and the bits had sunk down. When again examined after two days, the margin was quite unfolded, with the exception of the naturally inflected edge; and one of the bits of meat, the end of which had at first touched the edge, was now 067 of an inch $(1.70 \mathrm{~mm}$.) distant from it; so that this bit had been pushed thus far across the blade of the leaf.

Experiment 7.-A bit of meat was placed close to the incurved edge of a rather young leaf, and after it had re-expanded, the bit was left lying 11 of an inch $(2.795 \mathrm{~mm}$.) from the edge. The distance from the edge to the midrib of the fully expanded leaf was 35 of an inch $(8.89 \mathrm{~mm}$.); so that the bit had been pushed inwards and across nearly one-third of its semi-diameter.

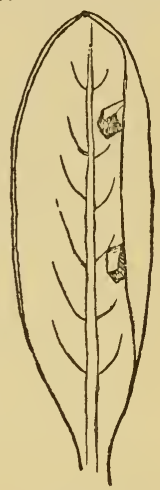

FIg 16.

(Pinguicula vulgaris.)

Outline of leaf, with right margin inflected against two square bits of meat.

Experiment 8.-Cubes of sponge, soaked in a strong infusion of raw meat, were placed in close contact with the incurved edges of two leaves,-an older and younger one. The distance from the edges to the midribs was carefully measured. After $1 \mathrm{hr} .17 \mathrm{~m}$. there appeared to be a trace of incurvation. After $2 \mathrm{hrs} .17 \mathrm{~m}$. both leaves were plainly inflected; the distance between the edges and midribs being now only half what it was at first. The incurvation increased slightly during the next $4 \frac{1}{2}$ hrs., but remained nearly the same for the next $17 \mathrm{hrs} .30 \mathrm{~m}$. In $35 \mathrm{hrs}$. from the time when the sponges were placed on the leares, the margins were a little unfolded-to a greater degreo in the younger than in the older leaf. The latter was not quite unfolded until the third day, and now both bits of sponge were left at the distance of 11 of an inch $(2.54 \mathrm{~mm}$.) from the edges; or about a quarter of the distance between the edge and midrib. A third bit of sponge adhered to the edge, and, as the margin unfolded, was dragged backwards, into its original position. 
Experiment 9.-A chain of fibres of roast meat, as thin as bristles and moistened with saliva, were placed down one whole side, close to the narrow, naturally incurved edge of a leaf. In $3 \mathrm{hrs}$, this side was greatly incurved along its whole length, and after $8 \mathrm{hrs}$. formed a cylinder, about $\frac{1}{20}$ of an inch (1.27 $\mathrm{mm}$.) in diameter, quite concealing the meat. This cylinder remained closed for $32 \mathrm{hrs}$., but after $48 \mathrm{hrs}$. was half unfolded, and in $72 \mathrm{hrs}$. was as open as the opposite margin where no meat had been placed. As the thin fibres of meat were completely overlapped by the margin, they were not pushed at all inwards, across the blade.

Experiment 10.-Six cabbage seeds, soaked for a night in water, were placed in a row close to the narrow incurved edge of a leaf. We shall hereafter see that these seeds yield soluble matter to the glands. In $2 \mathrm{hrs.} 25 \mathrm{~m}$. the margin was decidedly inflected; in 4 hrs. it extended orer the seeds for about half their breadth, and in $7 \mathrm{hrs}$. over three-fourths of their breadth, forming a cylinder not quite closed along the inner side, and about .7 of an inch $(1.778 \mathrm{~mm}$.) in diameter. After $24 \mathrm{hrs}$. the inflection had not increased, perhaps had decreased. The glands which had been brought into contact with the upper surfaces of the seeds were now secreting freely. In $36 \mathrm{hrs}$. from the time when the seeds were put on the leaf the margin had greatly, and after $48 \mathrm{hrs}$. had completely, re-expanded. As the seeds were no longer held by the inflected margin, and as the secretion was beginning to fail, they rolled some way down the marginal channel.

Experiment 11. - Fragments of glass were placed on the margins of two fine young leares. After $2 \mathrm{hrs} .30 \mathrm{~m}$. the margin of one certainly became slightly incurved; but the inflection never increased, and disappeared in 16 hrs. $30 \mathrm{~m}$. from the time when the fragments were first applied. With the second leaf there was a trace of incurration in $2 \mathrm{hrs} .15 \mathrm{~m}$., which became decided in $4 \mathrm{hrs} .30 \mathrm{~m}$., and still more strongly pronounced in $7 \mathrm{hrs}$, but after $19 \mathrm{hrs}$. $30 \mathrm{~m}$. had plainly decreased. The fragments excited at most a slight and doubtful increase of the secretion; and in two other trials, no increase could be perceived. Bits of coal-cinders, placed on a leaf, produced no effect, either owing to their lightness or to the leaf being torpid.

Experiment 12.-We will now turn to fluids. A row of drops of a strong infusion of raw meat were placed along the margins of two leaves; squares of sponge soaked in the same infusion being placed on the opposite margins. My object was to ascer- 
tain whether a fluid would act as energetically as a substance yielding the same soluble matter to the glands. No distinct difference was perceptible; certainly none in the degree of incurvation; but the incurvation round the bits of sponge lasted rather longer, as might perhaps have been expected from the sponge remaining damp and supplying nitrogenous matter for a longer time. The margins, with the drops, became plainly incurved in $2 \mathrm{hrs} .17 \mathrm{~m}$. The incurvation subsequently increased somewhat, but after $24 \mathrm{hrs}$. had greatly decreased.

Experiment 13.-Drops of the same strong infusion of raw meat were placed along the midrib of a young and rather deeply concave leaf. The distance across the broadest part of the leaf, between the naturally incurved edges, was 55 of an inch (13.97 $\mathrm{mm}$.). In $3 \mathrm{hrs} .27 \mathrm{~m}$. this distance was a trace less; in $6 \mathrm{hrs}$. $27 \mathrm{~m}$. it was exactly 45 of an inch $(11.43 \mathrm{~mm}$.), and had therefore decreased by 1 of an inch $(2.54 \mathrm{~mm}$.). After only $10 \mathrm{hrs} .37 \mathrm{~m}$. the margin began to re-expand, for the distance from edge to edge was now a trace wider, and after $24 \mathrm{hrs}$. $20 \mathrm{~m}$. was as great, within a hair's breadth, as when the drops were first placed on the leaf. From this experiment we learn that the motor impulse can be transmitted to a distance of 22 of an inch $(5.590 \mathrm{~mm}$.) in a transverse direction from the midrib to both margins; but it would be safer to say 2 of an inch $(5.08 \mathrm{~mm}$.), as the drops spread a little beyond the midrib. The incurvation thus caused lasted for an unusually short time.

Experiment 14.-Three drops of a solution of one part of carbonate of ammonia to 218 of water ( 2 grs. to $1 \mathrm{oz}$.) were placed on the margin of a leaf. These excited so much secretion that in $1 \mathrm{~h} .22 \mathrm{~m}$. all three drops ran together; but although the leaf was observed for $24 \mathrm{hrs}$, there was no trace of inflection. We know that a rather strong solution of this salt, though it does not injure the leaves of Drosera, paralyses their power of movement, and I have no doubt, from the following case, that this holds good with Pinguicula.

Experiment 15.-A row of drops of a solution of one part of carbonate of ammonia to 875 of water $(1 \mathrm{gr}$. to $2 \mathrm{oz}$.) was placed on the margin of a leaf. In $1 \mathrm{hr}$. there was apparently some slight incurvation, and this was well marked in $3 \mathrm{hrs} .30 \mathrm{~m}$. After $24 \mathrm{hrs}$. the margin was almost completely re-expanded.

Experiment 16.-A row of large drops of a solution of one part of phosphate of ammonia to 4375 of water ( $1 \mathrm{gr}$. to $10 \mathrm{oz}$.) was placed along the margin of a leaf. No effect was produced, and after 8 hrs. fresh drops were added along the same margin without the least effect. We know that a solution of this 
strength acts powerfully on Drosera, and it is just possible that the solution was too strong. I regret that I did not try a weaker solution.

Experiment 17.-As the prossure from bits of glass causes incurvation, I scratched the margins of two leaves for some minutes with a blunt needle, but no effect was produced. The surface of a leaf beneath a drop of a strong infusion of raw meat was also rubbed for $10 . \mathrm{m}$. with the end of a bristle, so as to imitate the struggles of a captured insect; but this part of the margin did not bend sooner than the other parts with undisturbed drops of the infusion.

We learn from the foregoing experiments that the margins of the leares curl inwards when excited by the mere pressure of objects not yielding any soluble matter, by objects yielding such matter, and by some fluids-namely an infusion of raw meat and a weak solution of carbonate of ammonia. A stronger solution of two grains of this salt to an ounce of water, though exciting copious secretion, paralyses the leaf. Drops of water and of a solution of sugar or gum did not cause any movement. Scratching the surface of the leaf for some minutes produced no effect. Therefore, as far as we at present know, only two causes-namely slight continued pressure and the absorption of nitrogenous matter-excite movement. It is only the margins of the leaf which bend, for the apex never curves towards the base. The pedicels of the glandular hairs have no porrer of movement. I observed on several occasions that the surface of the leaf became slightly. concave where bits of meat or large flies had long lain, but this may have been due to injury from over-stimulation.

The shortest time in which plainly marked movement was observed was 2 hrs. $17 \mathrm{~m}$., and this occurred when either nitrogenous substances or fluids were placed on the leaves; but I believe that in some cases 
there was a trace of movement in $1 \mathrm{hr}$. or $1 \mathrm{hr} .30 \mathrm{~m}$. The pressure from fragments of glass excites movement almost as quickly as the absorption of nitrogenous matter, but the degree of incurvation thus caused is much less. After a leaf has become well incurved and has again expanded, it will not soon answer to a fresh stimulus. The margin was affected longitudinally, upwards or downwards, for a distance of -13 of an inch $(3.302 \mathrm{~mm}$.) from an excited point, but for a distance of 46 of an inch between two excited points, and transversely for a distance of 2 of an inch $(5.08 \mathrm{~mm}$.). The motor impulse is not accompanied, as in the case of Drosera, by any influence causing increased secretion; for when a single gland was strongly stimulated and secreted copiously, the surrounding glands were not in the least affected. The incurvation of the margin is independent of increased secretion, for fragments of glass cause little or no secretion, and yet excite movement; whereas a strong solution of carbonate of ammonia quickly excites copious secretion, but no movement.

One of the most curious facts with respect to the movement of the leaves is the short time during which they remain incurved, although the exciting object is left on them. In the majority of cases there was wellmarked re-expansion within $24 \mathrm{hrs}$. from the time when even large pieces of meat, \&c., were placed on the leaves, and in all cases within 48 hrs. In one instance the margin of a leaf remained for $32 \mathrm{hrs}$. closely inflected round thin fibres of meat; in another instance, when a bit of sponge, soaked in a strong infusion of raw meat, had been applied to a leaf, the margin began to unfold in 35 hrs. Fragments of glass keep the margin incurved for a shorter time than do nitrogenous bodies; for in the former case there was 
complete re-expansion in $16 \mathrm{hrs} .30 \mathrm{~m}$. Nitrogenous fluids act for a shorter time than nitrogenous substances; thus, when drops of an infusion of raw meat were placed on the midrib of a leaf, the incurved margins began to unfold in only $10 \mathrm{hrs} .37 \mathrm{~m}$., and this was the quickest act of re-expansion observed by me; but it may have been partly due to the distance of the margins from the midrib where the drops lay.

We are naturally led to inquire what is the use of this movement which lasts for so short a time? If very small objects, such as fibres of meat, or moderately small objects, such as little flies or cabbage-seeds, are placed close to the margin, they are either completely or partially embraced by it. The glands of the overlapping margin are thus brought into contact with such objects and pour forth their secretion, afterwards absorbing the digested matter. But as the incurvation lasts for so short a time, any such benefit can be of only slight importance, yet perhaps greater than at first appears. The plant lives in humid districts, and the insects which adhere to all parts of the leaf aro washed by every heavy shower of rain into the narrow channel formed by the naturally incurved edges. For instance, my friend in North Wales placed several insects on some leaves, and two days afterwards (there having been heary rain in the interval) found some of them quite washed array, and many others safely tucked under the now closely inflected margins, the glands of which all round the insects were no doubt secreting. We can thus, also, understand how it is that so many insects, and fragments of insects, are generally found lying within the incurved margins of the leares.

The incurvation of the margin, due to the presence of an exciting object, must be serviceable in another 
and probably more important way. We have seen that when large bits of meat, or of sponge soaked in the juice of meat, were placed on a leaf, the margin was not able to embrace them, but, as it became incurved, pushed them very slowly towards the middle of the leaf, to a distance from the outside of fully $\cdot 1$ of an inch $(2.54 \mathrm{~mm}$.), that is, across between one-third and one-fourth of the space between the edge and midrib. Any object, such as a moderately sized insect, would thus be brought slowly into contact with a far larger number of glands, inducing much more secretion and absorption, than would otherwise have been the case. That this would be highly serviceable to the plant, we may infer from the fact that Drosera has acquired highly developed powers of movement, merely for the sake of bringing all its glands into contact with captured insects. So again, after a leaf of Dionæa has caught an insect, the slow pressing together of the two lobes serves merely to bring the glands on both sides into contact with it, causing also the secretion charged with animal matter to spread by capillary attraction over the whole surface. In the case of Pinguicula, as soon as an insect has been pushed for some little distance towards the midrib, immediate re-expansion would be beneficial, as the margins could not capture fresh prey until they were unfolded. The service rendered by this pushing action, as well as that from the marginal glands being brought into contact for a short time with the upper surfaces of minute captured insects, may perhaps account for the peculiar movements of the leaves; otherwise, we must look at these movements as a remnant of a more highly developed power formerly possessed by the progenitors of the genus.

In the four British species, and, as I hear from 
Prof. Dyer, in most or all the species of the genus, the edges of the leaves are in some degree naturally and permanently incurved. This incurvation serves, as already shown, to prevent insects from being washed away by the rain; but it likewise serves for another end. When a number of glands have been powerfully excited by bits of meat, insects, or any other stimulus, the secretion often trickles down the leaf, and is caught by the incurved edges, instead of rolling off and being lost. As it runs down the channel, fresh glands are able to absorb the animal matter held in solution. Moreover, the secretion often collects in little pools within the channel, or in the spoon-like tips of the leaves ; and I ascertained that bits of albumen, fibrin, and gluten, are here dissolved more quickly and completely than on the surface of the leaf, where the secretion cannot accumulate; and so it would be with naturally caught insects. The secretion was repeatedly seen thus to collect on the leares of plants protected from the rain; and with exposed plants there would be still greater need of some provision to prevent, as far as possible, the secretion, with its dissolved animal matter, being wholly lost.

It has already been remarked that plants growing in a state of nature have the margins of their leaves much more strongly incurved than those grown in pots and prevented from catching many insects. We have seen that insects washed down by the rain from all parts of the leaf often lodge within the margins, which are thus excited to curl farther inwards; and we may suspect that this action, many times repeated during the life of the plant, leads to their permanent and well-marked incurvation. I regret that this view did not occur to me in time to test its truth.

It may here be added, though not immediately 
Chap. XVI. SECRETION, ABSORption, Digestion. 381

bearing on our subject, that when a plant is pulled up, the leaves immediately curl downwards so as almost to conceal the roots,- - a fact which has been noticed by many persons. I suppose that this is due to the same tendency which causes the outer and older leaves to lie flat on the ground. It further appears that the flower-stalks are to a certain extent irritable, for Dr. Johnson states that they "bend backwards if rudely handled." *

Secretion, Absorption, and Digestion.-I will first give my observations and experiments, and then a summary of the results.

The Effects of Objects containing Soluble Nitrogenous Matter.

(1) Flies were placed on many leaves, and excited the glands to secrete copiously; the secretion always becoming acid, though not so before. After a time these insects were rendered so tender that their limbs and bodies could be separated by a mere touch, owing no doubt to the digestion and disintegration of their muscles. The glands in contact with a small fly continued to secrete for four days, and then became almost dry. A narrow strip of this leaf was cut off, and the glands of the longer and shorter hairs, which had lain in contact for the four days with the fly, and those which had not touched it, were compared under the microscope and presented a wonderful contrast. Those which had been in contact were filled with brownish granular matter, the others with homogeneous fluid. There could therefore be no doubt that the former had absorbed matter from the fly.

(2) Small bits of roast meat, placed on a leaf, always caused much acid secretion in the course of a few hours-in one case within $40 \mathrm{~m}$. When thin fibres of meat were laid along the margin of a leaf which stood almost upright, the secretion ran down to the ground. Angular bits of meat, placed in little pools of the secretion near the margin, were in the course of

* 'English Botany,' hy Sir J. E. Smith ; with coloured figures by J. Sowerby ; edit. of 1832 , tab. 24, 25, 26. 
two or three days much reduced in size, rounded, rendered more or less colourless and transparent, and so much softened that they fell to pieces on the slightest touch. In only one instance was a very minute particle completely dissolved, and this occurred within $48 \mathrm{hrs}$. When only a small amount of secretion was excited, this was gencrally absorbed in from $24 \mathrm{hrs}$. to 48 hrs. ; the glands being left dry. But when the supply of secretion was copious, round either a single rather large bit of meat, or round several small bits, the glands did not become dry until six or seven days had elapsed. The most rapid case of absorption observed by me was when a small drop of an infusion of raw meat was placed on a leaf, for the glands here became almost dry in 3 hrs. $20 \mathrm{~m}$. Glands excited by small particles of meat, and which have quickly absorbed their own secretion, begin to secrete again in the course of seven or eight days from the time when the meat was given them.

(3) Three minute cubes of tough cartilage from the leg-bone of a sheep were laid on a leaf. After 10 hrs. $30 \mathrm{~m}$. some acid secretion was excited, but the cartilage appeared little or not at all affected. After $24 \mathrm{hrs}$. the cubes were rounded and much reduced in size; after $32 \mathrm{hrs}$. they were softened to the centre, and one was quite liquefied; after $35 \mathrm{hrs}$. mere traces of solid cartilage were left; and after $48 \mathrm{hrs}$. a trace could still be seen through a lens in only one of the three. After $82 \mathrm{hrs}$. not only were all three cubes completely liquefied, but all the secretion was absorbed and the glands left dry.

(4) Small cubes of albumen were placed on a leaf; in $8 \mathrm{hrs}$. feebly acid secretion extended to a distance of nearly $\frac{1}{10}$ of an inch round them, and the angles of one cube were rounded. After $24 \mathrm{hrs}$. the angles of all the cubes were rounded, and they were rendered throughout very tender; after $30 \mathrm{hrs}$. the secretion began to decrease, and after $48 \mathrm{hrs}$. the glands were left dry; but very minute bits of albumen were still left undissolved.

(5) Smaller cubes of albumen (about $\frac{1}{50}$ or $\frac{1}{60}$ of an inch, - 508 or $\cdot 423 \mathrm{~mm}$.) were placed on four glands; after $18 \mathrm{hrs}$. one cube was completely dissolved, the others being much reduced in size, softened, and transparent. After $24 \mathrm{hrs}$. two of the cubes were completely dissolved, and already the secretion on these glands was almost wholly absorbed. After $42 \mathrm{hrs}$. the two other cubes were completely dissolved. These four glands began to secrete again after eight or nine days.

(6) Two large cubes of albumen (fully $\frac{1}{20}$ of an inch, $1 \cdot 27 \mathrm{~mm}$.) were placed, one near the midrib and the other near the margin 
of a leaf; in $6 \mathrm{hrs}$. there was much secretion, which after $48 \mathrm{hrs}$. accumulated in a little pool round the cube near the margin. This cube was much more dissolved than that on the blade of the leaf; so that after three days it was greatly reduced in size, with all the angles rounded, but it was too large to be wholly dissolved. The secretion was partially absorbed after four days. The cube on the blade was much less reduced, and the glands on which it rested began to dry after only two days.

(7) Fibrin excites less secretion than does meat or albumen. Several trials were made, but I will give only three of them. Two minute shreds were placed on some glands, and in $3 \mathrm{hrs}$. $45 \mathrm{~m}$. their secretion was plainly increased. The smaller shred of the two was completely liquefied in $6 \mathrm{hrs} .15 \mathrm{~m}$, and the other in 24 hrs. ; but even after 48 hrs. a few granules of fibrin could still be seen through a lens floating in both drops of secretion. After 56 hrs. $30 \mathrm{~m}$. these granules were completely dissolved. A third shred was placed in a little pool of secretion, within the margin of a leaf where a seed had been lying, and this was completely dissolved in the course of $15 \mathrm{hrs} .30 \mathrm{~m}$.

(8) Five very small bits of gluten were placed on a leaf, and they excited so much secretion that one of the bits glided down into the marginal furrow. After a day all five bits seemed much reduced in size, but none were wholly dissolved. On the third day I pushed two of them, which had begun to dry, on to fresh glands. On the fourth day undissolved traces of three out of the five bits could still be detected, the other two having quite disappeared; but I am doubtful whether they had really been completely dissolved. Two fresh bits were now placed, one near the middle and the other near the margin of another leaf; both excited an extraordinary amount of secretion; that near the margin had a little pool formed round it, and was much more reduced in size than that on the blade, but after four days was not completely dissolved. Gluten, therefore, excites the glands greatly, but is dissolved with much difficulty, exactly as in the case of Drosera. I regret that I did not try this substance after having been immersed in weak hydrochloric acid, as it would thon probably have been quickly dissolved.

(9) A small square thin piece of pure gelatine, moistened with water, was placed on a leaf, and excited very little secretion in 5 hrs. $30 \mathrm{~m}$., but later in the day a greater amount. After 24 hrs. the whole square was completely liquefied; and this would not have occurred had it been left in water. The liquid was acid.

(10) Small particles of chemically prepared casein excited 
acid secretion, but were not quite dissolved after two days; and the glands then began to dry. Nor could their complete dissolution have been expected from what we have seen with Drosera.

(11) Minute drops of skimmed milk were placed on a leaf, and these caused the glands to secrete freely. After $3 \mathrm{hrs}$. the milk was found curdled, and after $23 \mathrm{hrs}$. the curds were dissolved. On placing the now clear drops under the microscope, nothing could be detected except some oil-globules. The secretion, therefore, dissolves fresh casein.

(12) Two fragments of a leaf were immersed for $17 \mathrm{hrs.}$, each in a drachm of a solution of carbonate of ammonia, of two strengths, namely of one part to 437 and 218 of water. The glands of the longer and shorter hairs were then examined, and their contents found aggregated into granular matter of a brownish-green colour. These granular masses were seen by my son slowly to change their forms, and no doubt consisted of protoplasm. The aggregation was more strongly pronounced, and the movements of the protoplasm more rapid, within the glands subjected to the stronger solution than in the others. The experiment was repeated with the same result; and on this occasion I observed that the protoplasm had shrunk a little from the walls of the single elongated cells forming the pedicels. In order to observe the process of aggregation, a narrow strip of leaf was laid edgeways under the microscope, and the glands were seen to be quite transparent; a little of the stronger solution (viz. one part to 218 of water) was now added under the covering glass; after an hour or two the glands contained very fine granular matter, which slowly became coarsely granular and slightly opaque; but even after 5 hrs. not as yet of a brownish tint. By this time a few rather large, transparent, globular masses appeared within the upper ends of the pedicels, and the protoplasm lining their walls had shrunk a little. It is thus evident that the glands of Pinguicula absorb carbonate of ammonia; but they do not absorb it, or are not acted on by it, nearly so quickly as those of Drosera.

(13) Little masses of the orange-coloured pollen of the common pea, placed on several leaves, excited the glands to secrete freely. Even a very few grains which accidentally fell on a single gland caused the drop surrounding it to increase so much in size, in $23 \mathrm{hrs}$., as to be manifestly larger than the drops on the adjoining glands. Grains subjected to the secretion for 48 hrs. did not emit their tubes; they were quite discoloured, and seemed to contain less matter than before; that 
which was left being of a dirty colour, including globules of oil. They thus differed in appearance from other grains kept in water for the same length of time. The glands in contact with the pollen-grains had evidently absorbed matter from them; for they had lost their natural pale-green tint, and contained aggregated globular masses of protoplasm.

(14) Square bits of the leaves of spinach, cabbage, and a saxifrage, and the entire leaves of Erica tetralix, all excited the glands to increased secretion. The spinach was the most effective, for it caused the secretion evidently to increase in $1 \mathrm{hr}$. $40 \mathrm{~m}$., and ultimately to run some way down the leaf; but the glands soon began to dry, viz. after $35 \mathrm{hrs}$. The leaves of Erica tetralix began to act in $7 \mathrm{hrs}$. $30 \mathrm{~m}$., but never caused much secretion; nor did the bits of leaf of the saxifrage, though in this case the glands continued to secrete for seven days. Some leaves of Pinguicula were sent me from North Wales, to which leaves of Erica tetrulix and of an unknown plant adhered; and the glands in contact with them had their contents plainly aggregated, as if they had been in contact with insects; whilst the other glands on the same leaves contained only clear homogeneous fluid.

(15) Seeds.-A considerable number of seeds or fruits selected by hazard, some fresh and some a year old, some soaked for a short time in water and some not soaked, were tried. The ten following kinds, namely cabbage, radish, Anemone nemorosa, Rumex acetosa, Carex sylvatica, mustard, turnip, cress, lianunculus acris, and Avena pubescens, all excited much secretion, whic' 1 was in several cases tested and found always acid. The five first-named seeds excited the glands more than the others. The secretion was seldom copious until about $24 \mathrm{hrs}$. had elapsed, no doubt owing to the coats of the seeds not being easily permeable. Nevertheless, cabbage seeds excited some secretion in $4 \mathrm{hrs} .30 \mathrm{~m}$. ; and this increased so much in $18 \mathrm{hrs}$. as to run down the leaves. The seeds or properly the fruits of Carex are much oftener found adhering to leaves in a state of nature than those of any other genus; and the fruits of Carex sylvatica excited so much secretion that in $15 \mathrm{hrs}$. it ran into the incurved edges; but the glands ceased to secrete after $40 \mathrm{hrs}$. On the other hand, the glands on which the seeds of the Rumex and Arena rested continued to secrete for nine days.

The nine following kinds of seeds excited only a slight amount of secretion, namely celery, parsnip, caraway, Linum grandiflorum, Cassia, Trifolium pannonicum, Plantago, onion, 
and Bromus. Most of these seeds did not excite any secretion until 48 hrs. had elapsed, and in the case of the Trifolium only one seed acted, and this not until the third day. Although the seeds of the Plantago excited very little secretion, the glands continued to secrete for six days. Lastly, the five following kinds excited no secretion, though left on the leaves for two or three days, namely lettuce, Erica tetralix, Atriplex hortensis, Phaluris canariensis, and wheat. Nevertheless, when the seeds of the lettuce, wheat, and Atriplex were split open and applied to leares, secretion was excited in considerable quantity in 10 hrs., and I believe that some was excited in six hours. In the case of the Atriplex the secretion ran down to the margin, and after 24 hrs. I speak of it in my notes "as immense in quantity and acid." The split seeds also of the Trifolium and celery acted porrerfully and quickly, though the whole seeds caused, as we have seen, very little secretion, and only after a long interval of time. A slice of the common pea, which however was not tried whole, caused secretion in 2 hrs. From these facts we may conclude that the great difference in the degree and rate at which various kinds of seeds excite secretion, is chiefly or wholly due to the different permeability of their coats.

Some thin slices of the common pea, which had been previously soaked for $1 \mathrm{hr}$. in water, were placed on a leaf, and quickly excited much acid secretion. After $24 \mathrm{hrs}$. these slices were compared uncler a high power with others left in water for the same time; the latter contained so many fine granules of legumin that the slide was rendered muddy; whereas the slices which had been subjected to the secretion were much cleaner and more transparent, the granules of legumin apparently having been dissolved. A cabbage seed which had lain for two days on a leaf and had excited much acid secretion, was cut into slices, and these were compared with those of a seed which had been left for the same time in water. Those subjected to the secretion were of a paler colour; their coats presenting the greatest differences, for they were of a pale dirty tint instead of chestnut-brown. The glands on which the cabbage seeds had rested, as well as those bathed by the surrounding secretion, differed greatly in appearance from the other glands on the same leaf, for they all contained brownish granular matter, proving that they had absorbed matter from the seeds.

That the secretion acts on the seeds was also shown by some of them being killed, or by the seedlings being injured. Fourteen cabbage seeds were left for three days on leaves and excited 
much secretion; they were then placed on damp sand under conditions known to be favourable for germination. Three never germinated, and this was a far larger proportion of deaths than occurred with seeds of the same lot, which had not been subjected to the secretion, but were otherwise treated in the same manner. Of the eleven seedlings raised, three had the edges of their cotyledons slightly browned, as if scorched; and the cotyledons of one grew into a curious indented shape. Two mustard seeds germinated; but their cotyledons were marked with brown patches and their radicles deformed. Of two radish seeds, neither germinated; whereas of many seeds of the same lot not subjected to the secretion, all, excepting one, germinated. Of the two Rumex seeds, one died and the other germinated; but its radicle was brown and soon withered. Both seeds of the Avena germinated, one grew well, the other had its radicle brown and withered. Of six seeds of the Erica none germinated, and when cut open after having been left for five months on damp sand, one alone seemed alive. Twenty-two seeds of various kinds were found adhering to the leares of plants growing in a state of nature; and of these, though kept for five months on damp sand, none germinated, some being then evidently dead.

\section{The Effects of Objects not containing Soluble Nitrogenous Matter.}

(16) It has already been shown that bits of glass, placed on leaves, excite little or no secretion. The small amount which lay beneath the fragments was tested and found not acid. A bit of wood excited no secretion; nor did the several kinds of seeds of which the coats are not permeable to the secretion, and which, therefore, acted like inorganic bodies. Cubes of fat, left for two days on a leaf, produced no effect.

(17) A particle of white sugar, placed on a leaf, formed in $1 \mathrm{hr} .10 \mathrm{~m}$. a large drop of fluid, which in the course of 2 additional hours ran down into the naturally inflected margin. This fluid was not in the least acid, and began to dry up, or more probably was absorbed, in 5 hrs. $30 \mathrm{~m}$. The experiment was repeated; particles being placed on a leaf, and others of the same size on a slip of glass in a moistened state; both being covered by a bell-glass. This was done to see whether the increased amount of fluid on the leaves could be due to mere leliquescence; but this was proved not to be the case. The particle on the leaf caused so much secretion that in the course of $4 \mathrm{hrs}$. it ran down across two-thirds of the leaf. After $8 \mathrm{hr}$. the leaf, which was concave, was actually filled with very viscid 
fluid ; and it particularly deserres notice that this, as on the former occasion, was not in the least acid. This great amount of secretion may be attributed to exosmose. The glands which had been covered for $24 \mathrm{hrs}$. by this fluid did not differ, when examined under the microscope, from others on the same leaf, which had not come into contact with it. This is an interesting fact in contrast with the invariably aggregated condition of glands which have been bathed by the secretion, when holding animal matter in solution.

(18) Two particles of gum arabic were placed on a leaf, and they certainly caused in $1 \mathrm{hr} .20 \mathrm{~m}$. a slight increase of secretion. This continued to increase for the next $5 \mathrm{hrs}$., that is for as long a time as the leaf was obserred.

(19) Six small particles of dry sturch of commerce were placed on a leaf, and one of these caused some secretion in $1 \mathrm{hr} .15 \mathrm{~m}$., and the others in from $8 \mathrm{hrs}$. to $9 \mathrm{hrs}$. The glands which had thus been excited to secrete soon became dry, and did not begin to secrete again until the sixth day. A larger bit of starch was then placed on a leaf, and no secretion was excited in 5 hrs. $30 \mathrm{~m}$.; but after 8 hrs. there was a considerable supply, which increased so much in $24 \mathrm{hrs}$. as to run down the leaf to the distance of $\frac{3}{4}$ of an inch. This secretion, though so abundant, was not in the least acid. As it was so copiously excited, and as seeds not rarely adhere to the leaves of naturally growing plants, it occurred to me that the glands might perhaps have the power of secreting a ferment, like ptyaline, capable of dissolving starch; so I carefully observed the above six small particles during several days, but they did not seem in the least reduced in bulk. A particle was also left for two days in a little pool of secretion, which had run down from a piece of spinach leaf; but although the particle was so minute no diminution was perceptible. We may therefore conclude that the secretion cannot dissolve starch. The increase caused by this substance may, I presume, be attributed to exosmose. But I am surprised that starch acted so quickly and powerfully as it did, though in a less degree than sugar. Colloids are known to possess some slight power of dialysis; and on placing the leaves of a Primula in water, and others in syrup and diffused starch, those in the starch became flaccid, but to a less degree and at a much slower rate than the leaves in the syrup; those in water remaining all the time crisp.

\section{From the foregoing experiments and observations we}


see that objects not containing soluble matter have little or no power of exciting the glands to secrete. Non-nitrogenous fluids, if dense, cause the glands to pour forth a large supply of viscid fluid, but this is not in the least acid. On the other hand, the secretion from glands excited by contact with nitrogenous solids or liquids is invariably acid, and is so copious that it often runs down the leaves and collects within the naturally incurved margins. The secretion in this state has the power of quickly dissolving, that is of digesting, the muscles of insects, meat, cartilage, albumen, fibrin, gelatine, and casein as it exists in the curds of milk. The glands are strongly excited by chemically prepared casein and gluten; but these substances (the latter not having been soaked in weak hydrochloric acid) are only partially dissolved, as was likewise the case with Drosera. The secretion, when containing animal matter in solution, whether derived from solids or from liquids, such as an infusion of raw meat, milk, or a weak solution of carbonate of ammonia, is quickly absorbed; and the glands, which were before limpid and of a greenish colour, become brownish and contain masses of aggregated granular matter. This matter, from its spontaneous movements, no doubt consists of protoplasm. No such effect is produced by the action of non-nitrogenous fluids. After the glands have been excited to secrete freely, they cease for a time to secrete, but begin again in the course of a few days.

Glands in contact with pollen, the leaves of other plants, and various kinds of seeds, pour forth much acid secretion, and afterwards absorb matter probably of an albuminous nature from them. Nor can the benefit thus derived be insignificant, for a considerable 
amount of pollen must be blown from the many wind-fertilised carices, grasses, \&c., growing where Pinguicula lives, on to the leaves thickly covered with viscid glands and forming large rosettes. Even a few grains of pollen on a single gland causes it to secrete copiously. We have also seen how frequently the small leaves of Erica tetratix and of other plants, as well as various kinds of seeds and fruits, especially of Carex, adhere to the leares. One leaf of the Pinguicula had caught ten of the little leaves of the Erica; and three leaves on the same plant had each caught a seed. Seeds subjected to the action of the secretion are sometimes killed, or the seedlings injured. We may, therefore, conclude that Pinguicula vulgaris, with its small roots, is not only supported to a large extent by the extraordinary number of insects which it habitually captures, but likewise draws some nourishment from the pollen, leaves, and seeds of other plants which often adhere to its leaves. It is therefore partly a vegetable as well as an animal feeder.

\section{Pinguicula grandiflora.}

This species is so closely allied to the last that it is ranked by Dr. Hooker as a sub-species. It differs chiefly in the larger size of its leaves, and in the glandular hairs near the basal part of the midrib being longer. But it likewise differs in constitution; I hear from MIr. Ralfs, who was so kind as to send me plants from Cornwall, that it grows in rather different sites; and Dr. Moore, of the Glasnevin Botanic Gardens, informs me that it is much more manageable under culture, growing freely and flowering annually; whilst Pinguicula vulgaris has to be renewed every year. Mr. Ralfs found numerous 
insects and fragments of insects adhering to almost all the leaves. These consisted chiefly of Diptera, with some Hymenoptera, Homoptera, Coleoptera, and a moth. On one leaf there were nine dead insects, besides a few still alive. He also observed a few fruits of Carex pulicaris, as well as the seeds of this same Pinguicula, adhering to the leaves. I tried only two experiments with this species; firstly, a fly was placed near the margin of a leaf, and after 16 hrs. this was found well inflected. Secondly, several small flies were placed in a row along one margin of another leaf, and by the next morning this whole margin was curled inwards, exactly as in the case of Pinguicala vulgaris.

\section{Pinguicula lusitanica.}

This species, of which living specimens were sent me by Mr. Ralfs from Cornwall, is very distinct from the two foregoing ones. The leaves are rather smaller, much more transparent, and are marked with purple branching veins. The margins of the leaves are much more involuted; those of the older ones extending over a third of the space between the midrib and the outside. As in the two other species, the glandular hairs consist of longer and shorter ones, and have the same structure; but the glands differ in being purple, and in often containing granular matter before they have been excited. In the lower part of the leaf, almost half the space on each side between the midrib and margin is destitute of glands ; these being replaced by long, rather stiff, multicellular hairs, which intercross over the midrib. These hairs perhaps serve to prevent insects from settling on this part of the leaf, where there are no viscid glands by which they could be caught; but it is hardly probable that they were developed for this purpose. The spiral vessels pro- 
ceeding from the midrib terminate at the extreme margin of the leaf in spiral cells; but these are not so well developed as in the two preceding species. The flower-peduncles, sepals, and petals, are studded with glandular hairs, like those on the leaves.

The leaves catch many small insects, which are found chiefly beneath the involuted margins, probably washed there by the rain. The colour of the glands on which insects have long lain is changed, being either brownish or pale purple, with their contents coarsely granular; so that they evidently absorb matter from their prey. Leaves of the Erica tetralix, flowers of a Galium, scales of grasses, \&c. likewise adhered to some of the leaves. Several of the experiments which were tried on Pinguicula vulgaris were repeated on Pinguicula lusitanica, and these will now be given.

(1) A moderately sized and angular bit of ulbumen was placed on one side of a leaf, halfway between the midrib and the naturally involuted margin. In 2 hrs. $15 \mathrm{~m}$. the glands poured forth much secretion, and this side became more infolded than the opposite one. The inflection increased, and in 3 hrs. $30 \mathrm{~m}$. extended up almost to the apex. After 24 hrs. the margin was rolled into a cylinder, the outer surface of which touched the blade of the leaf and reached to within the $\frac{1}{20}$ of an inch of the midrib. After $48 \mathrm{hrs}$. it began to unfold, and in 72 hrs. was completely unfolded. The cube was rounded and greatly reduced in size; the remainder being in a semi-liquefied state.

(2) A moderately sized bit of albumen was placed near the apex of a leaf, under the naturally incurred margin. In 2 hrs. $30 \mathrm{~m}$. much secretion was excited, and next morning the margin on this side was more incurved than the opposite one, but not to so great a degree as in the last case. The margin unfolded at the same rate as before. A large proportion of the albumen was dissolved, a remnant being still left.

(3) Large bits of albumen were laid in a row on the midribs of two leaves, but produced in the course of $24 \mathrm{hrs}$. no effect; 
nor could this have been expected, for even had glands existed here, the long bristles would have prevented the albumen from coming in contact with them. On both leaves the bits were now pushed close to one margin, and in $3 \mathrm{hrs}$. $30 \mathrm{~m}$. this becarne so greatly inflected that the outer surface touched the blade; the opposite margin not being in the least affected. After three days the margins of both leaves with the albumen were still as much inflected as ever, and the glands were still secreting copiously. With Pinguicula vulgaris I have never seen inflection lasting so long.

(4) Two cubbage seeds, after being soaked for an hour in water, were placed near the margin of a leaf, and caused in $3 \mathrm{hrs}$. $20 \mathrm{~m}$. increased secretion and incurvation. After $24 \mathrm{hrs}$. the leaf was partially unfolded, but the glands were still secreting freely. These began to dry in $48 \mathrm{hrs}$., and after $72 \mathrm{hrs}$. were almost dry. The two seeds were then placed on damp sand under favourable conditions for growth; but they never germinated, and after a time were found rotten. They had no doubt been killed by the secretion.

(5) Small bits of a spinach leaf caused in $1 \mathrm{hr} .20 \mathrm{~m}$. increased secretion; and after $3 \mathrm{hrs} .20 \mathrm{~m}$. plain incurvation of the margin. The margin was well inflected after $9 \mathrm{hrs} .15 \mathrm{~m}$., but after $24 \mathrm{hrs}$. was almost fully re-expanded. The glands in contact with the spinach became dry in $72 \mathrm{hrs}$. Bits of albumen had been placed the day before on the opposite margin of this same leaf, as well as on that of a leaf with cabbage seeds, and these margins remained closely inflected for $72 \mathrm{hrs}$, showing how much more enduring is the effect of albumen than of spinach leaves or cabbage seeds.

(6) A row of small fragments of glass was laid along ono margin of a leaf; no effect was produced in $2 \mathrm{hrs} .10 \mathrm{~m}$., but after $3 \mathrm{hrs} .25 \mathrm{~m}$. there seemed to be a trace of inflection, and this was distinct, though not strongly marked, after $6 \mathrm{hrs}$. The glands in contact with the fragments now secreted more freely than before; so that they appear to be more easily excited by the pressure of inorganic objects than are the glands of Pinguicula vulgaris. The above slight inflection of the margin had not increased after $24 \mathrm{hrs}$, and the glands were now beginning to dry. The surface of a leaf, near the midrib and towards the base, was rubbed and scratched for some time, but no movement ensued. The long hairs which are situated here were treated in the same manner, with no effect. This latter trial was made because I thought that the hairs might perhaps be sensitive to a touch, like the filaments of Dionæa. 
(7) The flower-peduncles, sepals and petals, bear glands in general appearance like those on the leaves. A piece of a flower-peduncle was therefore left for $1 \mathrm{hr}$. in a solution of one part of carbonate of ammonia to 437 of water, and this caused the glands to change from bright pink to a dull purple colour; but their contents exhibited no distinct aggregation. After $8 \mathrm{hrs} .30 \mathrm{~m}$. they became colourless. Two minuto cubes of albumen were placed on the glands of a flowerpeduncle, and another cube on the glands of a sepal; but they were not excited to increased secretion, and the albumen after two days was not in the least softened. Hence these glands apparently differ greatly in function from those on the leaves.

From the foregoing observations on Pinguicula lusitanica we see that the naturally much incurved margins of the leaves are excited to curve still farther inwards by contact with organic and inorganic bodies; that albumen, cabbage seeds, bits of spinach leaves, and fragments of glass, cause the glands to secrete more freely;- - that albumen is dissolved by the secretion, and cabbage seeds killed by it;-and lastly that matter is absorbed by the glands from the insects which are caught in large numbers by the viscid secretion. The glands on the flower-peduncles seem to have no such power. This species differs from Pinguicala vulgaris and grandiflora in the margins of the leaves, when excited by organic bodies, being inflected to a greater degree, and in the inflection lasting for a longer time. The glands, also, seem to be more easily excited to increased secretion by bodies not yielding soluble nitrogenous matter. In other respects, as far as my observations serve, all three species agree in their functional powers. 


\section{CHAPTER XVII.}

\section{UTRICLLARIA.}

Utricularia neglecta-Structure of the bladder-The uses of the several parts - Number of imprisoned animals - Manner of capture The bladders cannot digest animal matter, but absorb the products of its decay - Experiments on the absorption of certain fluids by the quadrifid processes - Absorption by the glands-Summary of the observation on absorption - Development of the bladders Utricularia vulgaris - Utricularia minor - Utricularia clandestina.

I was led to investigate the habits and structure of the species of this genus partly from their belonging to the same natural family as Pinguicula, but more especially by MIr. Holland's statement, that "water insects are often found imprisoned in the bladders," which he suspects "are destined for the plant to feed on." * The plants which I first received as Utricularia vulgaris from the New Forest in Hampshire and from Cornwall, and which I have chiefly worked on, have been determined by Dr. Hooker to be a very rare British species, the Utricularia neglecta of Lehm. $\dagger$ I subsequently received the true Utricularia vulgaris from Yorkshire. Since drawing up the following description from my own observations and those of my son, Francis Darwin, an important memoir by Prof. Cohn

* The 'Quart. Mag. of the High Wycombe Nat. Hist. Soc.' July 1868, p. 5. Delpino ('Ult. Osservaz. sulla Dicogamia,' \&c. 1868-1869, p. 16) also quotes Crouan as having found (1858) crustaceans within the bladders of Utricularia vulgaris. $\dagger$ I am much indebted to the Rev. H. M. Wilkinson, of Bistern, for having sent me several fine lots of this species from the New Forest. Mr. Ralfs was also so kind as to send me living plants of the same species from near Penzance in Cornwall. 
on Utricularia vulgaris has appeared ; * and it has been no small satisfaction to me to find that my account agrees almost completely with that of this distinguished observer. I will publish my description as it stood before reading that by Prof. Cohn, adding occasionally some statements on his authority.

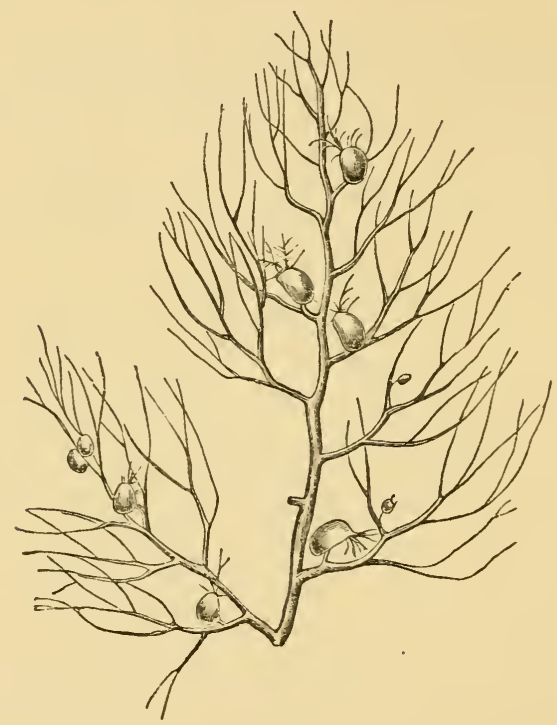

FIG. 17.

(Utricularia neglecta.)

Branch with the divided leaves bearing bladders; about twice enlarged.

Utricularia neglecta.-The general appearance of a branch (about twice enlarged), with the pinnatifid leares bearing bladders, is represented in the above sketch (fig. 17). The leaves continually bifurcate, so that a full-grown one terminates in from twenty to thirty

* 'Beiträge zur Biologie der Pflanzen,' drittes Heft, 1875. 
points. Each point is tipped by a short, straight bristle; and slight notches on the sides of the leaves bear similar bristles. On both surfaces there are many small papillæ, crowned with two hemispherical cells in close contact. The plants float near the surface of the water, and are quite destitute of roots, even during the earliest period of growth.* They commonly inhabit, as more than one observer has remarked to me, remarkably foul ditches.

The bladders offer the chief point of interest. There are often two or three on the same divided leaf, generally near the base; though I have seen a single one growing from the stem. They are supported on short footstalks. When fully grown, they are nearly $\frac{1}{10}$ of an inch $(2.54 \mathrm{~mm}$.) in length. They are translucent, of a green colour, and the walls are formed of two layers of cells. The exterior cells are polygonal and rather large; but at many of the points where the angles meet, there are smaller rounded cells. These latter support short conical projections, surmounted by two hemispherical cells in such close apposition that they appear united; but they often separate a little when immersed in certain fluids. The papillæ thus formed are exactly like those on the surfaces of the leaves. Those on the same bladder vary much in size; and there are a few, especially on very young bladders, which have an elliptical instead of a circular outline. The two terminal cells are transparent, but must hold much matter in solution, judging from the quantity coagulated by prolonged immersion in alcohol or ether.

* I infer that this is the case from a drawing of a seedling given by Dr. Warming in his paper, "Bidrag til Kundskaben om Lentibulariacer," from the 'Videnskabelige Meddelelser,' Copenhagen, 1874, Nos. 3-7, pp. 33-58. 
The bladders are filled with water. They generally, but by no means always, contain bubbles of air. According to the quantity of the contained water and air, they vary much in thickness, but are always somewhat compressed. At an early stage of growth, the flat or ventral surface faces the axis or stem; but the footstalks must have some power of movement; for in plants kept in my greenhouse the ventral surface was generally turned either straight or obliquely downwards. The Rev. H. M. Wilkinson examined

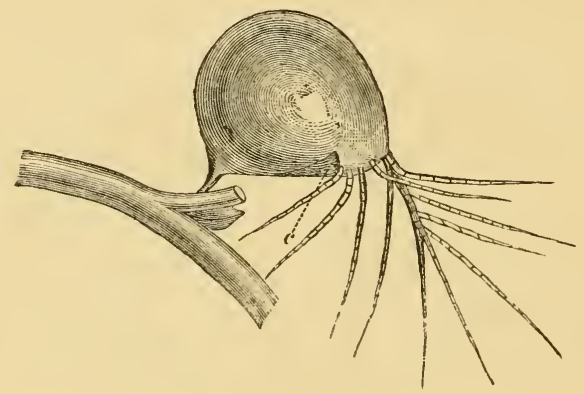

Fig. 18.

(Vtricularia neglecta.)

Bladder; much enlarged. $c$, collar indistinctly seen through the walls.

plants for me in a state of nature, and found this commonly to be the case, but the younger bladders often bad their valves turned upwards.

The general appearance of a bladder viewed laterally, with the appendages on the near side alone represented, is shown in the accompanying figure (fig. 18). The lower side, where the footstalk arises, is nearly straight, and I have called it the ventral surface. The other or dorsal surface is convex, and terminates in two long prolongations, formed of several rows of cells, containing chlorophyll, and bearing, chiefly on 
the outside, six or seven long, pointed, multicellular bristles. These prolongations of the bladder may be conveniently called the antennx, for the whole bladder (see fig. 17) curiously resembles an entomostracan crustacean, the short footstalk representing, the tail. In fig. 18, the near antenna alone is shown. Beneath the two antennæ the end of the bladder is slightly truncated, and here is situated the most important part of the whole structure, namely the entrance and valve. On each side of the entrance from three to rarely seven long, multicellular bristles project out-

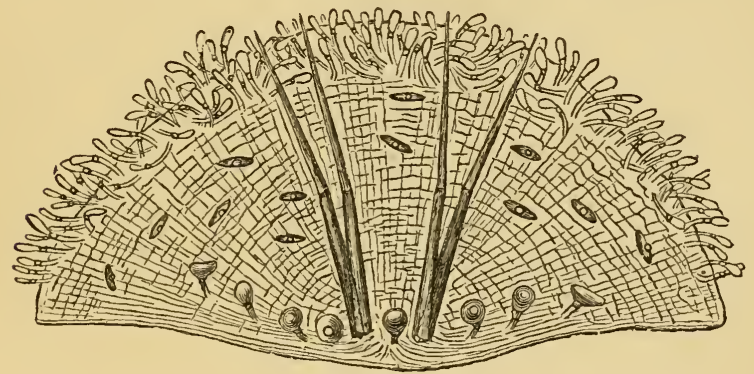

FIG. 19.

(Utricularia neglecta.)

Valve of bladder; greatly enlarged.

wards; but only those (four in number) on the near side are shown in the drawing. These bristles, together with those borne by the antennæ, form a sort of hollow cone surrounding the entrance.

The valve slopes into the cavity of the bladder, or upwards in fig. 18. It is attached on all sides to the bladder, excepting by its posterior margin, or the lower one in fig. 19, which is free, and forms one side of the slit-like orifice leading into the bladder. This margin is sharp, thin, and smooth, and rests on the edge of a rim or collar, which dips deeply into the 
bladder, as shown in the longitudinal section (fig. 20) of the collar and valve; it is also shown at $c$, in fig. 18. The edge of the valve can thus open only inwards. As both the valve and collar dip into the bladder, a hollow or depression is here formed, at the base of which lies the slit-like orifice.

The valve is colourless, highly transparent, flexible and elastic. It is convex in a transverse direction, but has been drawn (fig. 19) in a flattened state, by which its apparent breadth is increased. It is formed,

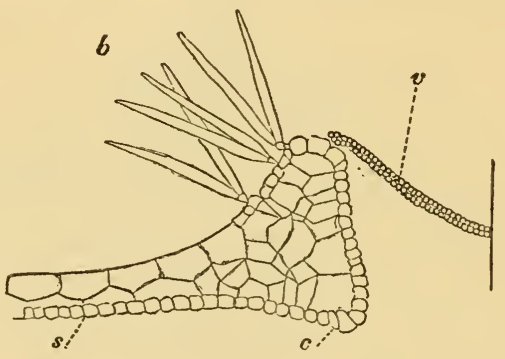

FIG. 20.

(ctricularia neglecta.)

Longitudinal vertical section through the rentral portion of a bladder; showing valve and collar. $v$, valve; the whole projection above $c$ forms the collar; $b$, bifid processes; $s$, ventral surface of bladder.

according to Cohn, of two layers of small cells, which are continuous with the two layers of larger cells forming the walls of the bladder, of which it is evidently a prolongation. Two pairs of transparent pointed bristles, about as long as the valve itself, arise from near the free posterior margin (fig. 18), and point obliquely outwards in the direction of the antennæ. There are also on the surface of the valve numerous glands, as I will call them; for they have the power of absorption, though I doubt whether they ever secrete. They consist of three kinds, which 
to a certain extent graduate into one another. Those situated round the anterior margin of the valve (upper margin in fig. 19) are very numerous and crowded together; they consist of an oblong head on a long pedicel. The pedicel itself is formed of an elongated cell, surmounted by a short one. The glands towards the free posterior margin are much larger, few in number, and almost spherical, having short footstalks; the head is formed by the confluence of two cells, the lower one answering to the short upper cell of the pedicel of the oblong glands. The glands of the third kind have transversely elongated heads, and are seated on very short footstalks; so that they stand parallel and close to the surface of the valve; they may be called the two-armed glands. The cells forming all these glands contain a nucleus, and are lined by a thin layer of more or less granular protoplasm, the primordial utricle of Mohl. They are filled with fluid, which must hold much matter in solution, judging from the quantity coagulated after they have been long immersed in alcohol or ether. The depression in which the valve lies is also lined with innumerable glands; those at the sides having oblong heads and elongated pedicels, exactly like the glands on the adjoining parts of the valve.

The collar (calied the peristome by Cohn) is evidently formed, like the valve, by an inward projection of the walls of the bladder. The cells composing the outer surface, or that facing the valve, have rather thick walls, are of a brownish colour, minute, very numerous, and elongated; the lower ones being divided into two by vertical partitions. The whole presents a complex and elegant appearance. The cells forming the inner surface are continuous with those over the whole inner surface of the bladder. The space be- 
tween the imner and outer surface consists of coarse cellular tissue (fig. 20). The inner side is thickly corered with delicate bifid processes, hereafter to be described. The collar is thus made thick; and it is rigid, so that it retains the same outline whether the bladder contains little or much air and water. This is of great importance, as otherwise the thin and flexible valve would be liable to be distorted, and in this case would not act properly.

Altogether the entrance into the bladder, formed by the transparent valve, with its four obliquely projecting bristles, its numerous diversely shaped glands, surrounded by the collar, bearing glands on the inside and bristles on the outside, together with the bristles borne by the antennæ, presents an extraordinarily complex appearance when viewed under the microscope.

We will now consider the internal structure of the bladder. The whole inner surface, with the exception of the valve, is seen under a moderately high power to be covered with a serried mass of processes (fig. 21). Each of these consists of four divergent arms ; whence their name of quadrifid processes. They arise from small angular cells, at the junctions of the angles of the larger cells which form the interior of the bladder. The middle part of the upper surface of these small cells projects a little, and then contracts into a very short and narrow footstalk which bears the four arms (fig. 22). Of these, two are long, but often of not quite equal length, and project obliquely inwards and towards the posterior end of the bladder. The two others are much shorter, and project at a smaller angle, that is, are more nearly horizontal, and are directed towards the anterior end of the bladder. These arms are only moderately sharp; they are composed of ex- 
tremely thin transparent membrane, so that they can be bent or doubled in any direction without being broken. They are lined with a delicate layer of protoplasm, as is likewise the short conical projection from which they arise. Each arm generally (but not invariably) contains a minute, faintly brown particle, either rounded or more commonly elongated, which exhibits incessant Brownian movements. These par-

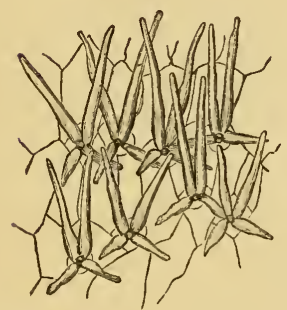

Fig. 21. (Utricularia neglecta.)

Snall portion of inside of bladder, much enlarged, showing quadrifid processes.

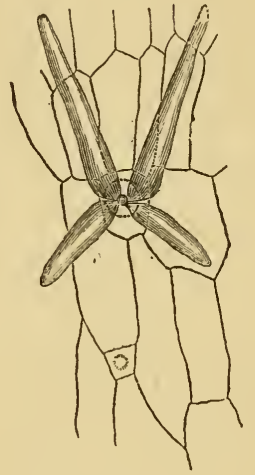

FIg. 22 .

(Ctricularia neylecta.)

One of the quadrifid processes greatly enlarged.

ticles slowly change their positions, and travel from one end to the other of the arms, but are commonly found near their bases. They are present in the quadrifids of young bladders, when only about a third of their full size. They do not resemble ordinary nuclei, but I believe that they are nuclei in a modified condition, for when absent, I could occasionally just distinguish in their places a delicate halo of matter, including a darker spot. Moreover, the quadrifids of Utricularia montana contain rather larger and much 
more regularly spherical, but otherwise similar, particles, which closely resemble the nuclei in the cells forming the walls of the bladders. In the present case there were sometimes two, three, or even more, nearly similar particles within a single arm; but, as we shall hereafter see, the presence of more than one seemed always to be connected with the absorption of decayed matter.

The inner side of the collar (see the previous fig. 20) is covered with several crowded rows of processes, differing in no important respect from the quadrifids, except in bearing only two arms instead of four; they are, however, rather narrower and more delicate. I shall call them the bifids. They project into the bladder, and are directed towards its posterior end. The quadrifid and bifid processes no doubt are homologous with the papillæe on the outside of the bladder and of the leaves; and we shall see that they are dereloped from closely similar papillæ.

The Uses of the several Parts.-After the above long but necessary description of the parts, we will turn to their uses. The bladders have been supposed by some authors to serve as floats; but branches which bore no bladders, and others from which they had been removed, floated perfectly, owing to the air in the intercellular spaces. Bladders containing dead and eaptured animals usually include bubbles of air, but these cannot have been generated solely by the process of decay, as I have often seen air in young, clean, and empty bladders; and some old bladders with much decaying matter had no bubbles.

The real use of the bladders is to capture small aquatic animals, and this they do on a large scale. In the first lot of plants, which I received from the New Forest early in July, a large proportion of the fully 
grown bladders contained prey; in a second lot, received in the beginning of August, most of the bladders were empty, but plants had been selected which had grown in unusually pure water. In the first lot, my son examined seventeen bladders, including prey of some kind, and eight of these contained entomostracan crustaceans, three larvæ of insects, one being still alive, and six remnants of animals so much decayed that their nature could not be distinguished. I picked out five bladders which seemed very full, and found in them four, five, eight, and ten crustaceans, and in the fifth a single much elongated larva. In five other bladders, selected from containing remains, but not appearing very full, there were one, two, four, two, and five crustaceans. A plant of Utricularia vulgaris, which had been kept in almost pure water, was placed by Cohn one evening into water swarming with crustaceans, and by the next morning most of the bladders contained these animals entrapped and swimming round and round their prisons. They remained alive for several days; but at last perished, asphyxiated, as I suppose, by the oxygen in the water having been all consumed. Freshwater worms were also found by Cohn in some bladders. In all cases the bladders with decayed remains swarmed with living Algæ of many kinds, Infusoria, and other low organisms, which evidently lived as intruders.

Animals enter the bladders by bending inwards the posterior free edge of the valve, which from being highly elastic shuts again instantly. As the edge is extremely thin, and fits closely against the edge of the collar, both projecting into the bladder (see section, fig. 20), it would evidently be very difficult for any animal to get out when once imprisoned, and apparently they never do escape. To show how closely the edge 
fits, I may mention that my son found a Daphnia which had inserted one of its antennæ into the slit, and it was thus held fast during a whole day. On three or four occasions I have seen long narrow larvæ, both dead and alive, wedged between the corner of the valve and collar, with half their bodies within the bladder and half out.

As I felt much difficulty in understanding how such minute and weak animals, as are often captured, could force their way into the bladders, I tried many experiments to ascertain how this was effected. The free margin of the valve bends so easily that no resistance is felt when a needle or thin bristle is inserted. A thin human hair, fixed to a handle, and cut off so as to project barely $\frac{1}{4}$ of an inch, entered with some difficulty; a longer piece yielded instead of entering. On three occasions minute particles of blue glass (so as to be easily distinguished) were placed on ralves whilst under water; and on trying gently to move them with a needle, they disappeared so suddenly that, not seeing what had happened, I thought that I had flirted them off; but on examining the bladders, they were found safely enclosed. The same thing occurred to my son, who placed little cubes of green box-wood (about $\frac{1}{60}$ of an inch, 423 $\mathrm{mm}$.) on some valves; and thrice in the act of placing them on, or whilst gently moring them to another spot, the valre suddenly opened and they were engulfed. He then placed similar bits of wood on other valves, and mored them about for some time, but they did not enter. Again, particles of blue glass were placed by me on three valves, and extremely minute shavings of lead on two other valves; after 1 or $2 \mathrm{hrs}$. none har entered, but in from 2 to 5 hrs. all five were enclosed. One of the particles of glass was a 
long splinter, of which one end rested obliquely on the valve, and after a few hours it was found fixed, half within the bladder and half projecting out, with the edge of the valve fitting closely all round, except at one angle, where a small open space was left. It was so firmly fixed, like the above mentioned larvæ, that the bladder was torn from the branch and shaken, and yet the splinter did not fall out. My son also placed little cubes (about $\frac{1}{65}$ of an inch, $\cdot 391 \mathrm{~mm}$.) of green box-wood, which were just heavy enough to sink in water, on three valves. These were examined after 19 hrs. $30 \mathrm{~m}$., and were still lying on the valves; but after 22 hrs. $30 \mathrm{~m}$. one was found enclosed. I may - here mention that I found in a bladder on a naturally growing plant a grain of sand, and in another bladder three grains; these must have fallen by some accident on the valves, and then entered like the particles of glass.

The slow bending of the valve from the weight of particles of glass and even of box-wood, though largely supported by the water, is, I suppose, analogous to the slow bending of colloid substances. For instance, particles of glass were placed on various points of narrow strips of moistened gelatine, and these yielded and became bent with extreme slowness. It is much more difficult to understand how gently moving a particle from one part of a valve to another causes it suddenly to open. To ascertain whether the valves were endowed with irritability, the surfaces of several were scratched with a needle or brushed with a fine camel-hair brush, so as to imitate the crawling movement of small crustaceans, but the valve did not open. Some bladders, before being brushed, were left for a time in water at temperatures between $80^{\circ}$ and $130^{\circ} \mathrm{F}$. $\left(26^{\circ} \cdot 6-54^{\circ} \cdot 4\right.$ Cent.), as, judging from a wide- 
spread analogy, this would have rendered them more sensitive to irritation, or would by itself have excited movement; but no effect was produced. We may, therefore, conclude that animals enter merely by forcing their way through the slit-like orifice; their heads serving as a wedge. But I am surprised that such small and weak creatures as are often captured (for instance, the nauplius of a crustacean, and a tardigrade) should be strong enough to act in this manner, seeing that it was difficult to push in one end of a bit of a hair $\frac{1}{4}$ of an inch in length. Nevertheless, it is certain that weak and small creatures do enter, and Mrs. Treat, of New Jersey, has been more successful than any other observer, and has often witnessed in the case of Utricularia clandestina the whole process.* She saw a tardigrade slowly walking round a bladder, as if reconnoitring; at last it crawled into the depression where the valve lies, and then easily entered. She also witnessed the entrapment of various minute crustaceans. Cypris "was "quite wary, but nevertheless was often caught. "Coming to the entrance of a bladder, it would some" times pause a moment, and then dash away; at " other times it would come close up, and even ven" ture part of the way into the entrance and back out " as if afraid. Another, more heedless, would open " the door and walk in; but it was no sooner in than " it manifested alarm, drew in its feet and antennæ, and closed its shell." Larvæ, apparently of gnats, when "feeding near the entrance, are pretty certain " to run their heads into the net, whence there is no "retreat. A large larva is sometimes three or four " hours in being swallowed, the process bringing to

* 'Ner York Tribume,' reprinted in the 'Gard. Chron.' 1875, p. 303. 
" mind what I have witnessed when a small snake "makes a large frog its victim." But as the valve does not appear to be in the least irritable, the slow swallowing process must be the effect of the onward movement of the larva.

It is difficult to conjecture what can attract so many creatures, animal- and regetable-feeding crustaceans, worms, tardigrades, and various larvæ, to enter the bladders. Mrs. Treat says that the larvæ just referred to are vegetable-feeders, and seem to have a special liking for the long bristles round the valve, but this taste will not account for the entrance of animalfeeding crustaceans. Perhaps small aquatic animals habitually try to enter every small crevice, like that between the valve and collar, in search of food or protection. It is not probable that the remarkable transparency of the valve is an accidental circumstance, and the spot of light thus formed may serve as a guide. The long bristles round the entrance apparently serve for the same purpose. I believe that this is the case, because the bladders of some epiphytic and marsh species of Utricularia which live embedded either in entangled vegetation or in mud, have no bristles round the entrance, and these under such conditions would be of no service as a guide. Nevertheless, with these epiphytic and marsh species, two pairs of bristles project from the surface of the valve, as in the aquatic species; and their use probably is to prevent too large animals from trying to force an entrance into the bladder, thus rupturing the orifice.

As under favourable circumstances most of the bladders succeed in securing prey, in one case as many as ten crustaceans; - as the valve is so well fitted to 
allow animals to enter and to prevent their escape;and as the inside of the bladder presents so singular a structure, clothed with innumerable quadrifid and bifid processes, it is impossible to doubt that the plant has been specially adapted for securing prey. From the analogy of Pinguicula, belonging to the same family, I naturally expected that the bladders would have digested their prey; but this is not the case, and there are no glands fitted for secreting the proper fluid. Nevertheless, in order to test their power of digestion, minute fragments of roast meat, three small culbes of albumen, and three of cartilage, were pushed through the orifice into the bladders of vigorous plants. They were left from one day to three days and a half within, and the bladders were then cut open; but none of the abore substances exhibited the least signs of digestion or dissolution; the angles of the cubes being as sharp as ever. These observations were made subsequently to those on Drosera, Dionæa, Drosophyllum, and Pinguicula; so that I was familiar with the appearance of these substances when undergoing the early and final stages of digestion. We may therefore conclude that Utricularia cannot digest the animals which it habitually captures.

In most of the bladders the captured animals are so much decayed that they form a pale brown, pulpy mass, with their chitinous coats so tender that they fall to pieces with the greatest ease. The black pigment of the eye-spots is preserved better than anything else. Limbs, jaws, \&c. are often found quite detached; and this I suppose is the result of the vain struggles of the later captured animals. I have sometimes felt surprised at the small proportion of imprisoned animals in a fresh state compared with those utterly decayed. MIrs. Treat states with respect 
to the larvæ above referred to, that " usually in less " than two days after a large one was captured the fluid " contents of the bladders began to assume a cloudy " or muddy appearance, and often became so dense " that the outline of the animal was lost to view." This statement raises the suspicion that the bladders secrete some ferment hastening the process of decay. There is no inherent improbability in this supposition, considering that meat soaked for ten minutes in water mingled with the milky juice of the papaw becomes quite tender and soon passes, as Browne remarks in his 'Natural History of Jamaica,' into a state of putridity.

Whether or not the decay of the imprisoned animals is in any way hastened, it is certain that matter is absorbed from them by the quadrifid and bifid processes. The extremely delicate nature of the membrane of which these processes are formed, and the large surface which they expose, owing to their number crowded over the whole interior of the bladder, are circumstances all favouring the process of absorption. Many perfectly clean bladders which had never caught any prey were opened, and nothing could be distinguished with a No. 8 object-glass of Hartnack within the delicate, structureless protoplasmic lining of the arms, excepting in each a single yellowish particle or modified nucleus. Sometimes two or even three such particles were present; but in this case traces of decaying matter could generally be detected. On the other hand, in bladders containing either one large or several small decayed animals, the processes presented a widely different appearance. Six such bladders were carefully examined; one contained an elongated, coiledup larva; another a single large entomostracan crustacean, and the others from two to five smaller ones, all 
in a decayed state. In these six bladders, a large number of the quadrifid processes contained transparent, often yellowish, more or less confluent, spherical or irregularly shaped, masses of matter. Some of the processes, however, contained only fine granular matter, the particles of which were so small that they could not be defined clearly with No. 8 of Hartnack. The delicate layer of protoplasm lining their walls was in some cases a little shrunk. On three occasions the above small masses of matter were observed and sketched at short intervals of time; and they certainly changed their positions relatively to each other and to the walls of the arms. Separate masses sometimes became confluent, and then again divided. A single little mass would send out a projection, which after a time separated itself. Hence there could be no doubt that these masses consisted of protoplasm. Bearing in mind that many clean bladders were examined with equal care, and that these presented no such appearance, we may confidently believe that the protoplasm in the above cases had been generated by the absorption of nitrogenous matter from the decaying animals. In two or three other bladders, which at first appeared quite clean, on careful search a few processes were found, with their outsides clogged with a little brown matter, showing that some minute animal had been captured and had decayed, and the arms here included a very few more or less spherical and aggregated masses; the processes in other parts of the bladders being empty and transparent. On the other hand, it must be stated that in three bladders containing dead crustaceans, the processes were likewise empty. This fact may be accounted for by the animals not having been sufficiently decayed, or by time enough not having been allowed for the generation of proto- 
plasm, or by its subsequent absorption and transference to other parts of the plant. It will hereafter be seen that in three or four other species of Utricularia the quadrifid processes in contact with decaying animals likewise contained aggregated masses of protoplasm.

On the Absorption of certain Fluids by the Quadrifid and Bifid Processes.-These experiments were tried to ascertain whether certain fluids, which seemed adapted for the purpose, would produce the same effects on the processes as the absorption of decayed animal matter. Such experiments are, however, troublesome; for it is not sufficient merely to place a branch in the fluid, as the valve shuts so closely that the fluid apparently does not enter soon, if at all. Even when bristles were pushed into the orifices, they were in several cases wrapped so closely round by the thin flexible edge of the valve that the fluid was apparently excluded; so that the experiments tried in this manner are doubtful and not worth giving. The best plan would have been to puncture the bladders, but I did not think of this till too late, excepting in a few cases. In all such trials, however, it cannot be ascertained positively that the bladder, though translucent, does not contain some minute animal in the last stage of decay. Therefore most of my experiments were made by cutting bladders longitudinally into two ; the quadrifids were examined with No. 8 of Hartnack, then irrigated, whilst under the covering glass, with a few drops of the fluid under trial, kept in a damp chamber, and re-examined after stated intervals of time with the same power as before.

Four bladders were first tried as a control experiment, in the manner just described, in a solution of one part of gum arabic to 218 of water, and two bladders in a solution of one part of sugar to 437 of water; and in neither case was any 
change perceptible in the quadrifids or bifids after $21 \mathrm{hrs}$. Four bladders were then treated in the same manner with a solution of one part of nitrate of ammonia to 437 of water, and re-examined after $21 \mathrm{hrs}$. In two of these the quadrifids now appeared full of very finely granular matter, and their protoplasmic lining or primordial utricle was a little shrunk. In the third bladder, the quadrifids included distinctly visible granules, and the primordial utricle was a little shrunk after only $8 \mathrm{hrs}$. In the fourth bladder the primordial utricle in most of the processes was here and there thickened into little, irregular, yellowish specks; and from the gradations which could be traced in this and other cases, these specks appear to give rise to the larger free granules contained within some of the processes. Other bladders, which, as far as could be judged, had never caught any prey, were punctured and left in the same solution for 17 hrs.; and their quadrifids now contained rery fine granular matter.

A bladder was bisected, examined, and irrigated with a solution of one part of carbonate of ammonia to 437 of water. After 8 hrs. $30 \mathrm{~m}$. the quadrifids contained a good many granules, and the primordial utricle was somewhat shrunk; after $23 \mathrm{hrs}$. the quadrifids and bifids contained many spheres of hyaline matter, and in one arm twenty-four such spheres of moderate size were counted. Two bisected bladders, which had been previously left for $21 \mathrm{hrs}$. in the solution of gum (one part to 218 of water) without being affected, were irrigated with the solution of carbonate of ammonia ; and both had their quadrifids modified in nearly the same manner as just described,-one after only $9 \mathrm{hrs}$., and the other after $24 \mathrm{hrs}$. Two bladders which appeared never to have caught any prey were punctured and placed in the solution; the quadrifids of one were examined after $17 \mathrm{hrs}$., and found slightly opaque; the quadrifids of the other, examined after $45 \mathrm{hrs}$., had their primordial utricles more or less shrunk with thickened yellowish specks, like those due to the action of nitrate of ammonia. Sever.al uninjured bladder's were left in the same solution, as well as a weaker solution of one part to 1750 of water, or $1 \mathrm{gr}$. to $4 \mathrm{oz}$; and after two days the quadrifids were more or less opaque, with their contents finely granular; but whether the solution had entered by the orifice, or had been absorbed from the outside, I know not.

Two bisected bladders were irrigated with a solution of one part of urea to 218 of water; but when this solution was employed, I forgot that it had been kept for some days in a warm room, and had therefore probably generated ammonia; anyhow 
the quadrifids were affected after 21 hrs. as if a solution of carbonate of ammonia had been used; for the primordial utricle was thickened in specks, which seemed to graduate into separate granules. Three bisected bladders were also irrigated with a fresh solution of urea of the same strength; their quadrifids after $21 \mathrm{hrs}$. were much less affected than in the former case; nevertheless, the primordial utricle in some of the arms was a little shrunk, and in others was divided into two almost symmetrical sacks.

Three bisected bladders, after being examined, were irrigated with a putrid and very offensive infusion of raw meat. After $23 \mathrm{hrs}$. the quadrifids and bifids in all three specimens abounded with minute, hyaline, spherical masses; and some of their primordial utricles were a little shrunk. Three bisected bladders were also irrigated with a fresh infusion of raw meat; and to my surprise the quadrifids in one of them appeared, after 23 hrs., finely granular, with their primordial utricles somewhat shrunk and marked with thickened yellowish specks; so that they had been acted on in the same manner as by the putrid infusion or by the salts of ammonia. In the second bladder some of the quadrifids were similarly acted on, though to a very slight degree; whilst the third bladder was not at all affected.

From these experiments it is clear that the quadrifid and bifid processes have the power of absorbing carbonate and nitrate of ammonia, and matter of some kind from a putrid infusion of meat. Salts of ammonia were selected for trial; as they are known to be rapidly generated by the decay of animal matter in the presence of air and water, and would therefore be generated within the bladders containing captured prey. The effect produced on the processes by these salts and by a putrid infusion of raw meat differs from that produced by the decay of the naturally captured animals only in the aggregated masses of protoplasm being in the latter case of larger size; but it is probable that the fine granules and small hyaline spheres produced by the solutions would coalesce into larger masses, with time enough allowed. 
We have seen with Drosera that the first effect of a weak solution of carbonate of ammonia on the cellcontents is the production of the finest granules, which afterwards aggregate into larger, more or less rounded, masses ; and that the granules in the layer of protoplasm which flows round the walls ultimately coalesce with these masses. Changes of this nature are, however, far more rapid in Drosera than in Utricularia. Since the bladders have no power of digesting albumen, cartilage, or roast meat, I was surprised that matter was absorbed, at least in one case, from a fresh infusion of raw meat. I was also surprised, from what we shall presently see with respect to the glands round the orifice, that a fresh solution of urea produced only a moderate effect on the quadrifids.

As the quadrifids are developed from papillæ which at first closely resemble those on the outside of the bladders and on the surfaces of the leares, I may here state that the two hemispherical cells with which these latter papillæ are crowned, and which in their natural state are perfectly transparent, likewise absorb carbonate and nitrate of ammonia ; for, after an immersion of 23 hrs. in solutions of one part of both these salts to 437 of water, their primordial utricles were a little shrunk and of a pale brown tint, and sometimes finely granular. 'The same result followed from the immersion of a whole branch for nearly three days in a solution of one part of the carbonate to 1750 of water. The grains of chlorophyll, also, in the cells of the leares on this branch became in many places aggregated into little green masses, which were often connected together by the finest threads.

On the Absorption of certain Fluids by the Glands on the Valve and Collar.-The glands round the orifices of bladders which are still young, or which have been 
long kept in moderately pure water, are colourless; and their primordial utricles are only slightly or hardly at all granular. But in the greater number of plants in a state of nature-and we must remember that they generally grow in very foul water-and with plants kept in an aquarium in foul water, most of the glands were of a pale brownish tint; their primordial utricles were more or less shrunk, sometimes ruptured, with their contents often coarsely granular or aggregated into little masses. That this state of the glands is due to their having absorbed matter from the surrounding water, I cannot doubt; for, as we shall immediately see, nearly the same results follow from their immersion for a few hours in various solutions. Nor is it probable that this absorption is useless, seeing that it is almost universal with plants growing in a state of nature, excepting when the water is remarkably pure.

The pedicels of the glands which are situated close to the slit-like orifice, both those on the valve and on the collar, are short; whereas the pedicels of the more distant glands are much elongated and project inwards. The glands are thus well placed so to be washed by any fluid coming out of the bladder through the orifice. The valve fits so closely, judging from the result of immersing uninjured bladders in various solutions, that it is doubtful whether any putrid fluid habitually passes outwards. But we must remember that a bladder generally captures several animals; and that each time a fresh animal enters, a puff of foul water must pass out and bathe the glands. Moreover, I have repeatedly found that, by gently pressing bladders which contained air, minute bubbles were driven out through the orifice; and if a bladder is laid on blotting paper and gently pressed, water oozes out. 
In this latter case, as soon as the pressure is relaxed, air is drawn in, and the bladder recorers its proper form. If it is now placed under water and again gently pressed, minute bubbles issue from the orifice and nowhere else, showing that the walls of the bladder have not been ruptured. I mention this because Cohn quotes a statement by Treviranus, that air cannot be forced out of a bladder without rupturing it. We may therefore conclude that whenever air is secreted within a bladder already full of water, some water will be slowly driven out through the orifice. Hence I can hardly doubt that the numerous glands crowded round the orifice are adapted to absorb matter from the putrid water, which will occasionally escape from bladders including decayed animals.

In order to test this conclu-ion, I experimented with various solutions on the glands. As in the case of the quadrifids, salts of ammonia were tried, since these are generated by the final decay of animal matter under water. Unfortunately the glands camnot be carefully examined whilst attached to the bladders in their entire state. Their summits, therefore, including the valve, collar, and antennæ, were sliced off, and the condition of the glands observed; they were then irrigated, whilst beneath a covering glass, with the solutions, and after a time re-examined with the same power as before, namely No. 8 of Hartnack. The following experiments were thus made.

As a control experiment solutions of one part of white sugar and of one part of gum to 218 of water were first used, to see whether these produced any change in the glands. It was also necessary to observe whether the glands were affected by the summits of the bladders having been cut off. The summits of four were thus tried; one being examined after $2 \mathrm{hrs.} 30 \mathrm{~m}$., and the other three after 23 hrs.; but there was no marked change in the glands of any of them.

Two summits bearing quite colourless glands were irrigated with a solution of carbonate of ammonia of the same strength (viz. one part to 218 of water), and in $5 \mathrm{~m}$. the primordial utricles of most of the glands were somewhat contracted; they were also thickened in specks or patches, and had assumed a pale 
brown tint. When looked at again after $1 \mathrm{hr}$. $30 \mathrm{~m}$., most of them presented a somewhat different appearance. A third specimen was treated with a weaker solution of one part of the carbonate to 437 of water, and after $1 \mathrm{hr}$. the glands were pale brown and contained numerous granules.

Four summits were irrigated with a solution of one part of nitrate of ammonia to 437 of water. One was examined after $15 \mathrm{~m}$., and the glands seemed affected; after $1 \mathrm{hr} .10 \mathrm{~m}$. there was a greater change, and the primordial utricles in most of them were somewhat shrunk, and included many granules. In the second specimen, the primordial utricles were considerably shrunk and brownish after 2 hrs. Similar effects were observed in the two other specimens, but these were not examined until 21 hrs. had elapsed. The nuclei of many of the glands apparently had increased in size. Five bladders on a branch, which had been kept for a long time in moderately pure water, were cut off and examined, and their glands found very little modified. The remainder of this branch was placed in the solution of the nitrate, and after $21 \mathrm{hrs}$. two bladders were examined, and all their glands were brownish, with their primordial utricles somewhat shrunk and finely granular.

The summit of another bladder, the glands of which were in a beautifully clear condition, was irrigated with a few drops of a mixed solution of nitrate and phosphate of ammonia, each of one part to 437 of water. After $2 \mathrm{hrs}$. some few of the glands were brownish. After 8 hrs: almost all the oblong glands were brown and much more opaque than they were before; their primordial utricles were somewhat shrunk and contained a little aggregated granular matter. The spherical glands were still white, but their utricles were broken up into three or four small hyaline spheres, with an irregularly contracted mass in the middle of the basal part. These smaller spheres changed their forms in the course of a few hours, and some of them disappeared. By the next morning, after $23 \mathrm{hrs}$. $30 \mathrm{~m}$., they had all disappeared, and the glands were brown; their utricles now formed a globular shrunken mass in the middle. The utricles of the oblong glands had shrunk very little, but their contents were somewhat aggregated. Lastly, the summit of a bladder which had been previously irrigated for 21 hrs. with a solution of one part of sugar to 218 of water without being affected, was treated with the above mixed solution; and after 8 hrs. $30 \mathrm{~m}$. all the glands became brown, with their primordial utricles slightly shrunk.

Four summits were irrigated with a putrid infusion of raw 
meat. No change in the glands was observable for some hours, but after 24 hrs. most of them had become brownish, and more opaque and granular than they were before. In these specimens, as in those irrigated with the salts of ammonia, the nuclei seemed to have increased both in size and solidity, but they were not measured. Five summits were also irrigated with a fresh infusion of raw meat; three of these were not at all affected in 24 hrs., but the glands of the other two had perhaps become more granular. One of the specimens which was not affected was then irrigated with the mixed solution of the nitrate and phosphate of ammonia, and after only $25 \mathrm{~m}$. the glands contained from four or five to a dozen granules. After six additional hours their primordial utricles were greatly shrunk.

The summit of a bladder was examined, and all the glands found colourless, with their primordial utricles not at all shrunk; yet many of the oblong glands contained granules just resolvable with No. 8 of Hartnack. It was then irrigated with a few drops of a solution of one part of urea to 218 of water. After 2 hrs. $25 \mathrm{~m}$. the spherical glands were still colourless; whilst the oblong and two-armed ones were of a brownish tint, and their primordial utricles much shrunk, some containing distinctly visible granules. After $9 \mathrm{hrs}$. some of the spherical glands were brownish, and the oblong glands were still more changed, but they contained fewer separate granules; their nuclei, on the other hand, appeared larger, as if they had absorbed the granules. After $23 \mathrm{hrs}$. all the glands were brown, their primordial utricles greatly shrunk, and in many cases ruptured.

A bladder was now experimented on, which was already somewhat affected by the surrounding water; for the spherical glands, though colourless, had their primordial utricles slightly shrunk; and the oblong glands were brownish, with their utricles much, but irregularly, shrunk. The summit was treated with the solution of urea, but was little affected by it in $9 \mathrm{hrs}$; nevertheless, after $23 \mathrm{hrs}$. the spherical glands were brown, with their utricles more shrunk; several of the other glands were still browner, with their utricles contracted into irregular little masses.

Two other summits, with their glands colourless and their utricles not shrunk, were treated with the same solution of urea. After 5 hrs. many of the glands presented a shade of brown, with their utricles slightly shrunk. After $20 \mathrm{hrs}$. $40 \mathrm{~m}$. some few of them were quite brown, and contained 
irregularly aggregated masses; others were still colourless, though their utricles were shrunk; but the greater number were not much affected. This was a good instance of how unequally the glands on the same bladder are sometimes affected, as likewise often occurs with plants growing in foul water. Two other summits were treated with a solution which had been kept during several days in a warm room, and their glands were not at all affected when examined after $21 \mathrm{hrs}$.

A weaker solution of one part of urea to 437 of water was next tried on six summits, all carefully examined before being irrigated. The first was re-examined after $8 \mathrm{hrs} .30 \mathrm{~m}$., and the glands, including the spherical ones, were brown; many of the oblong glands having their primordial utricles much shrunk and including granules. The second summit, before being irrigated, had been somewhat affected by the surrounding water, for the spherical glands were not quite uniform in appearance; and a few of the oblong ones were brown, with their utricles shrunk. Of the oblong glands, those which were before colourless, became brown in 3 hrs. $12 \mathrm{~m}$. after irrigation, with their utricles slightly shrunk. The spherical glands did not become brown, but their contents seemed changed in appearance, and after $23 \mathrm{hrs}$. still more changed and granular. Most of the oblong glands were now dark brown, but their utricles were not greatly shrunk. The four other specimens were examined after 3 hrs. $30 \mathrm{~m}$., after $4 \mathrm{hrs}$, and 9 hrs. ; a brief account of their condition will be sufficient. The spherical glands were not brown, but some of them were finely granular. Many of the oblong glands were brown; and these, as well as others which still remained colourless, had their utricles more or less shrunk, some of them including small aggregated masses of matter.

Summary of the Observations on Absorption.-From the facts now given there can be no doubt that the variously shaped glands on the valve and round the collar have the power of absorbing matter from weak solutions of certain salts of ammonia and urea, and from a putrid infusion of raw meat. Prof. Cohn believes that they secrete slimy matter; but I was not able to perceive any trace of such action, excepting that, after immersion in alcohol, extremely fine lines could sometimes be seen radiating from their 
surfaces. The glands are variously affected by absorption; they often become of a brown colour; sometimes they contain very fine granules, or moderately sized grains, or irregularly aggregated little masses ; sometimes the nuclei appear to have increased in size; the primordial utricles are generally more or less shrunk and sometimes ruptured. Exactly the same changes may be observed in the glands of plants growing. and flourishing in foul water. The spherical glands are generally affected rather differently from the oblong and two-armed ones. The former do not so commonly become brown, and are acted on more slowly. We may therefore infer that they differ somewhat in their natural functions.

It is remarkable how unequally the glands on the bladders on the same branch, and even the glands of the same kind on the same bladder, are affected by the foul water in which the plants have grown, and by the solutions which were employed. In the former case I presume that this is due either to little currents bringing matter to some glands and not to others, or to unknown differences in their constitution. When the glands on the same bladder are differently affected by a solution, we may suspect that some of them had previously absorbed a small amount of matter from the water. However this may be, we have seen that the glands on the same leaf of Drosera are sometimes very unequally affected, more especially when exposed to certain vapours.

If glands which have already become brown, with their primordial utricles shrunk, are irrigated with one of the effective solutions, they are not acted on, or only slightly and slowly. If, howerer, a gland contains merely a few coarse granules, this does not prevent a solution from acting. I have never seen 
any appearance making it probable that glands which have been strongly affected by absorbing matter of any kind are capable of recovering their pristine, colourless, and homogeneous condition, and of regaining the power of absorbing.

From the nature of the solutions which were tried, I presume that nitrogen is absorbed by the glands; but the modified, brownish, more or less shrunk, and aggregated contents of the oblong glands were never seen by me or by my son to undergo those spontaneous changes of form characteristic of protoplasm. On the other hand, the contents of the larger spherical glands often separated into small hyaline globules or irregularly shaped masses, which changed their forms very slowly and ultimately coalesced, forming a central shrunken mass. Whatever may be the nature of the contents of the several kinds of glands, after they have been acted on by foul water or by one of the nitrogenous solutions, it is probable that the matter thus generated is of service to the plant, and is ultimately transferred to other parts.

The glands apparently absorb more quickly than do the quadrifid and bifid processes; and on the view above maintained, namely that they absorb matter from putrid water occasionally emitted from the bladders, they ought to act more quickly than the processes; as these latter remain in permanent contact with captured and decaying animals.

Finally, the conclusion to which we are ied by the foregoing experiments and observations is that the bladders have no power of digesting animal matter, though it appears that the quadrifids are somewhat affected by a fresh infusion of raw meat. It is certain that the processes within the bladders, and the glands outside, absorb matter from salts of 
ammonia, from a putrid infusion of raw meat, and from urea. The glands apparently are acted on more strongly by a solution of urea, and less strongly by an infusion of raw meat, than are the processes. The case of urea is particularly interesting, because we have seen that it produces no effect on Drosera, the leaves of which are adapted to digest fresh animal matter. But the most important fact of all is, that in the present and following species the quadrifid and bifid processes of bladders containing decayed animals generally include little masses of spontaneously moving protoplasm; whilst such masses are never seen in perfectly clean bladrlers.

Development of the Bladders.-My son and I spent much time over this subject with small success. Our observations apply to the present species and to Utricularia vulgaris, but were made chiefly on the latter, as the bladders are twice as large as those of Utricularia neglecta. In the early part of autumn the stems terminate in large buds, which fall off and lie dormant during the winter at the bottom. The young leaves forming these buds bear bladders in various stages of early development. When the bladders of Utricularia vulgaris are about $\frac{1}{100}$ inch $(.254 \mathrm{~mm}$.) in diameter (or $\frac{1}{200}$ in the case of Utricularia neglecta), they are circular in outline, with a narrow, almost closed, transverse orifice, leading into a hollow filled with water; but the bladders are hollow when much under $\frac{1}{100}$ of an inch in diameter. The orifices face inwards or towards the axis of the plant. At this early age the bladders are flattened in the plane in which the orifice lies, and therefore at right angles to that of the mature bladders. They are covered exteriorly with papillæe of different sizes, many of which have an elliptical outline. A bundle of vessels, formed of 
simple elongated cells, runs up the short footstalk, and divides at the base of the bladder. One branch extends up the middle of the dorsal surface, and the other up the middle of the ventral surface. In full-grown bladders the ventral bundle divides close beneath the collar, and the two branches run on each side to near where the corners of the valve unite with the collar; but these branches could not be seen in very young bladders.

The accompanying figure (fig. 23) shows a section, which happened to be strictly medial, through the footstalk and between the nascent antennæ of a bladder of Utricularia vulgaris, $\frac{1}{100}$ inch in diameter. The specimen was soft, and the young valve became separated from the collar to a greater degree than is natural, and is thus represented. We here clearly see that the valve and collar are infolded prolongations of the walls of the bladder. Even at this early age, glands could be detected on the valve. The state of the quadrifid processes will presently be described. The antennæ at this

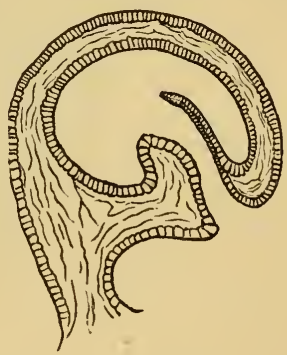

FIG. 23.

(Ctricularia vulgaris.)

Longitudinal section thruugh a young bladder, $\frac{1}{100}$ of an inch in length, with the orifice too widely open. period consist of minute cellular projections (not shown in the above figure, as they do not lie in the medial plane), which soon bear incipient bristles. In five instances the young antennæ were not of quite equal length; and this fact is intelligible if I am right in believing that they represent two divisions of the leaf, rising from the end of the bladder; for, with the true leaves, whilst very young, the divisions are never, as far as I have seen, strictly opposite; they 
must therefore be developed one after the other, and so it would be with the two antennæ.

At a much earlier age, when the half formed bladders are only $\frac{1}{300}$ inch $(.0846 \mathrm{~mm}$.) in diameter or a little more, they present a totally different appearance. One is represented on the left side of the accompanying drawing (fig. 24). The young leaves

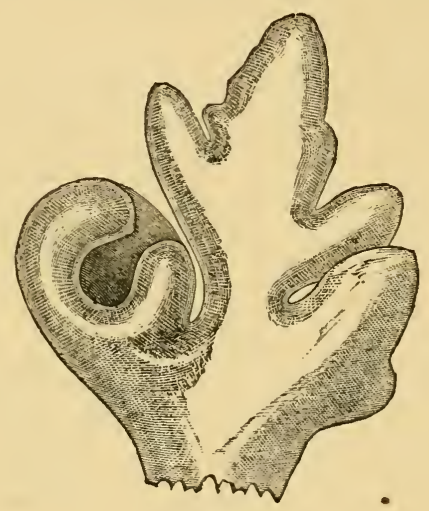

Fig. 24.

(Dtricularia vulgaris.)

Young leaf from a winter bud, showing on the left side a bladder in its earliest stage of development.

at this age have broad flattened segments, with their future divisions represented by prominences, one of which is shown on the right side. Now, in a large number of specimens examined by my son, the young bladders appeared as if formed by the oblique folding over of the apex and of one margin with a prominence, against the opposite margin. The circular hollow between the infolded apex and infolded prominence apparently contracts into the narrow orifice, wherein the valve and collar will be developed; the bladder itself being: formed by the confluence of the opposed 
margins of the rest of the leaf. But strong objections may be urged against this view, for we must in this case suppose that the valve and collar are developed asymmetrically from the sides of the apex and prominence. Moreover, the bundles of vascular tissue have to be formed in lines quite irrespective of the original form of the leaf. Until gradations can be shown to exist between this the earliest state and a young yet perfect bladder, the case must be left iloubtful.

As the quadrifid and bifid processes offer one of the greatest peculiarities in the genus, I carefully observed their development in Utricularia neglecta. In bladders about $\frac{1}{100}$ of an inch in diameter, the inner surface is studded with papillæ, rising from small cells at the junctions of the larger ones. These papillæ consist of a delicate conical protuberance, which narrows into a very short footstalk, surmounted by two minute cells. They thus occupy the same relative position, and closely resemble, except in being smaller and rather more prominent, the papilla on the outside of the bladders, and on the surfaces of the leaves. The two terminal cells of the papillæ first become much elongated in a line parallel to the inner surface of the bladder. Next, each is divided by a longitudinal partition. Soon the two half-cells thus formed separate from one another; and we now have four cells or an incipient quadrifid process. As there is not space for the two new cells to increase in breadth in their original plane, the one slides partly under the other. Their manner of growth now changes, and their outer sicles, instead of their apices, continue to grow. The two lower cells, which have slid partly beneath the two upper ones, form the longer and more upright pair of processes; whilst the two upper cells form the shorter 
and more horizontal pair; the four together forming a perfect quadrifid. A trace of the primary division between the two cells on the summits of the papillæ can still be seen between the bases of the longer processes. The development of the quadrifids is very liable to be arrested. I have seen a bladder $\frac{1}{50}$ of an inch in length including only primordial papillæ; and another bladder, about half its full size, with the quadrifids in an early stage of derelopment.

As far as I could make out, the bifid processes are developed in the same manner as the quadrifids, excepting that the two primary terminal cells never become divided, and only increase in length. The glands on the valve and collar appear at so early an age that I could not trace their development; but we may reasonably suspect that they are developed from papillæ like those on the outside of the bladder, but with their terminal cells not divided into two. The two segments forming the pedicels of the glands probably answer to the conical protuberance and short footstalk of the quadrifid and bifid processes. I am strengthened in the belief that the glands are developed from papillæ like those on the outside of the bladders, from the fact that in Utricularia amethystina the glands extend along the whole ventral surface of the bladder close to the footstalk.

\section{UtricUlaria VULGaRIS.}

Living plants from Yorkshire were sent me by Dr. Hooker. This species differs from the last in the stems and leaves being thicker or coarser; their divisions form a more acute angle with one another; the notches on the leaves hear three or four short bristles instead of one; and the bladders are twice as large, or about $\frac{1}{5}$ of an inch $(5.08 \mathrm{~mm}$.) in diameter. In all essential respects the bladders resemble those of Utricularic neglecia, but the sides of the peristome are perhaps a little more 
prominent, and always bear, as far as I have seen, seven or eight long multicellular bristles. There are eleven long bristles on each antenna, the terminal pair being included. Five bladders, containing prey of some kind, were examined. The first included five Cypris, a large copepod and a Diaptomus; the second, four Cypris; the third, a single rather large crustacean; the fourth, six crustaceans; and the fifth, ten. My son examined the quadrifid processes in a bladder containing the remains of two crustaceans, and found some of them full of spherical or irregularly shaped masses of matter, which were observed to move and to coalesce. These masses therefore con. sisted of protoplasm.

\section{UTRICULARIA MINOR.}

This rare species was sent me in a living state from Cheshire, through the kindness of Mr. John Price. The leaves and bladders are much smaller than those of Utricularia neglecta. The leaves bear fewer and shorter bristles, and the bladders are more globular. The antennæ, instead of projecting in front of the bladders, are curled under the valve, and are armed with twelve or fourteen extremely long multicellular bristles, generally arranged in pairs. These, with seven or eight long bristles on both sides of the peristome, form a sort of net over the valve, which would tend to prevent all animals, excepting very small ones, entering the bladder. The valve and collar have the same essential structure as in the two previous species; but the glands are not

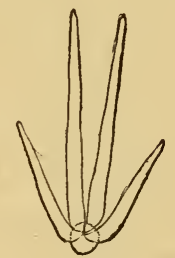

FIG. 25.

(Ctricularia minor.)

Quadrifid process; greatly enlarged. quite so numerous; the oblong ones are rather more elongated, whilst the two-armed ones are rather less elongated. The four bristles which project obliquely from the lower edge of the valve are short. Their shortness, compared with those on the valves of the foregoing species, is intelligible if my view is correct that they serve to prevent too large animals forcing an entrance through the valve, thus injuring it; for the valve is already protected to a certain extent by the incurved antennæ, together with the lateral bristles. The bifid processes are like those in the previous species; but the quadrifids differ in the four arms (fig. 25) 
being directed to the same side; the two longer ones being central, and the two shorter ones on the outside.

The plants were collected in the middle of July; and the contents of five bladders, which from their opacity seemed full of prey, were examined. The first contained no less than twenty-four minute fresh-water crustaceans, most of them consisting of empty shells, or including only a ferw drops of red oily matter; the second contained twenty; the third, fifteen; the fourth, ten, some of them being rather larger than usual; and the fifth, which seemed stuffed quite full, contained only seven, but five of these were of unusually large size. The prey, therefore, judging from these five bladders, consists exclusively of fresh-water crustaceans, most of which appeared to be distinct species from those found in the bladders of the two former species. In one bladder the quadrifids in contact with a decaying mass contained numerous spheres of granular matter, which slowly changed their forms and positions.

\section{UTRICULARIA CLANDESTINA.}

This North American species, which is aquatic like the three foregoing ones, has been described by Mrs. Treat, of New Jersey, whose excellent observations have already been largely quoted. I have not as yet seen any full description by her of the structure of the bladder, but it appears to be lined with quadrifid processes. A rast number of captured animals were found within the bladders; some being crustaceans, but the greater number delicate, elongated larvæ, I suppose of Culicidæ. On some stems, "fully nine out of every ten bladders contained these larvæ or their remains." The larra "showed signs of life from twenty-four to thirty-six hours after being imprisoned," and then perished. 


\section{CHAPTER XVIII.}

\section{Utricclaria (continued).}

Utricularic montana-Description of the bladders on the subterranean rhizomes - Prey captured by the bladders of plants under culture and in a state of nature - Absorption by the quadrifid processes and glands-Tubers serving as reservoirs for waterVarious other species of Utricularia - Polypompholyx - Genlisea, different nature of the trap for capturing prey-Diversified methods by which plants are nourished.

Utricularia Montana.-This species inhabits the tropical parts of South America, and is said to be epiphytic; but, judging from the state of the roots (rhizomes) of some dried specimens from the herbarium at Kew, it likewise lives in earth, probably in crevices of rocks. In English hothouses it is grown in peaty soil. Lady Dorothy Nevill was so kind as to give me a fine plant, and I received another from Dr. Hooker. The leaves are entire, instead of being much divided, as in the foregoing aquatic species. They are elongated, about $1 \frac{1}{2}$ inch in breadth, and furnished with a dis-

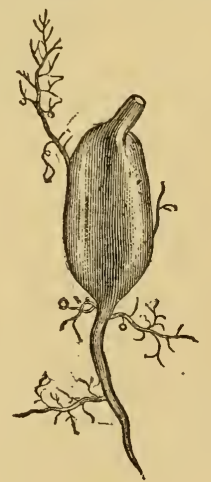

Frg. 26.

Rhizome swollen into a tuber; the branches bearing minute bladders; of natural size. tinct footstalk. The plant produces numerous colourless rhizomes, as thin as threads, which bear minute bladders, and occasionally swell into tubers, as will 
hereafter be described. These rhizomes appear exactly like roots, but occasionally throw up green shoots. They penetrate the earth sometimes to the depth of more than 2 inches; but when the plant grows as an epiphyte, they must creep amidst the mosses, roots, decayed bark, \&c., with which the trees of these countries are thickly covered.

As the bladders are attached to the rhizomes, they are necessarily subterranean. They are produced in extraordinary numbers. One of my plants, though young, must have borne several hundreds; for a single branch out of an entangled mass had thirty-two, and another branch, about 2 inches in length (but with its end and one side branch broken off), had seventy-three bladders.* The bladders are compressed and rounded, with the ventral surface, or that between the summit of the long delicate footstalk and valve, extremely short (fig. 27). They are colourless and almost as transparent as glass, so that they appear smaller than they really are, the largest being under the $\frac{1}{80}$ of an inch $(1.27 \mathrm{~mm}$.) in its longer diameter. They are formed of rather large angular cells, at the junctions of which oblong papillæ project, corresponding with those on the surfaces of the bladders of the previous species. Similar papillæ abound on the rhizomes, and even on the entire leares, but they are rather broader on the latter. Vessels, marked with parallel bars instead of by a spiral line, run up the footstalks, and

* Prof. Oliver has figured a plant of Utricularia Jamesoniana ('Proc. Linn. Soc.' vol. iv. p. 169) having entire leaves and rhizomes, like those of our present species; but the margins of the terminal halves of some of the leaves are converted into bladders. 'This fact clearly indicates that the bladders on the rhizomes of the present and following species are modified segments of the leaf; and they are thus brought into accordance with the blaclders attached to the divided and floating leaves of the aquatic species. 
just enter the bases of the bladders; but they do not bifurcate and extend up the dorsal and ventral surfaces, as in the previous species.

The antennæ are of moderate length, and taper to a fine point; they differ conspicuously from those before described, in not being armed with bristles. Their bases are so abruptly curved that their tips generally rest one on each side of the middle of the bladder, but

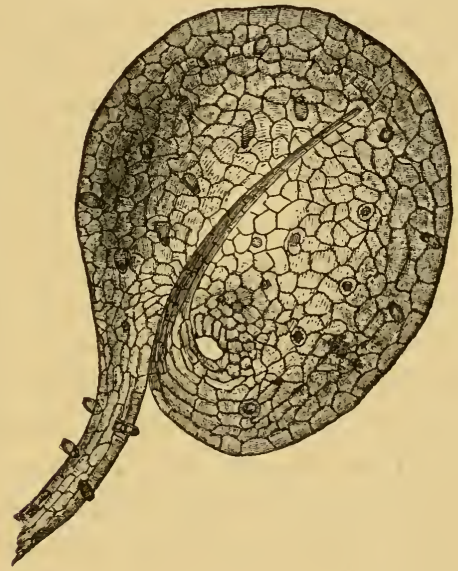

Fig. 27.

(Utricularia montana.)

Bladder; about 27 times enlarged.

sometimes near the margin. Their curved bases thus form a roof over the cavity in which the valve lies; but there is always left on each side a little circular passage into the cavity, as may be seen in the drawing, as well as a narrow passage between the bases of the two antennr. As the bladders are subterranean, had it not been for the roof, the cavity in which the valve lies would have been liable to be blocked up with earth 
and rubbish; so that the curvature of the antennx is a serviceable character. There are no bristles on the outside of the collar or peristome, as in the foregoing species.

The valve is small and steeply inclined, with its free posterior edge abutting against a semicircular, deeply depending collar. It is moderately transparent, and bears two pairs of short stiff bristles, in the same position as in the other species. The presence of these four bristles, in contrast with the absence of those on the antennæ and collar, indicates that they are of functional importance, namely, as I believe, to prevent too large animals forcing an entrance through the valve. The many glands of diverse shapes attached to the valve and round the collar in the previous species are here absent, with the exception of about a dozen of the two-armed or transversely elongated kind, which are seated near the borders of the valve, and are mounted on rery short footstalks. These glands are only the $\frac{3}{4000}$ of an inch $(.019 \mathrm{~mm}$.) in length; though so small, they act as absorbents. The collar is thick, stiff, and almost semi-circular; it is formed of the same peculiar brownish tissue as in the former species.

The bladders are filled with water, and sometimes. include bubbles of air. They bear internally rather short, thick, quadrifid processes arranged in approximately concentric rows. The two pairs of arms of which they are formed differ only a little in length, and stand in a peculiar position (fig. 28); the two longer ones forming one line, and the two shorter ones another parallel line. Each arm includes a small spherical mass of brownish matter, which, when crushed, breaks into angular pieces. I have no doubt that these spheres are nuclei, for closely similar ones 
are present in the cells forming the walls of the bladders. Bifid processes, having rather short oval arms, arise in the usual position on the inner side of the collar.

These bladders, therefore, resemble in all essential respects the larger ones of the foregoing species. They differ chiefly in the absence of the numerous glands on the valve and round the collar, a few minute ones of one kind alone being present on the valve. 'They differ more conspicuously in the absence of the long bristles on the antennæe and on the outside of the collar. The presence of these bristles in the previously mentioned species probably relates to the capture of aquatic animals.

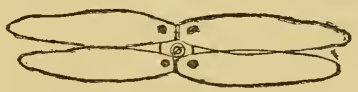

FIG. 28.

(Etricularia montana.)

One of the quadrifid processes; much enlarged.

It secmed to me an interesting question whether the minute bladders of Utricularia montana served, as in the previous species, to capture animals living in the earth, or in the dense regetation covering the trees on which this species is epiphytic; for in this case we should have a new sub-class of carnivorous plants, namely, subterranean feeders. Many bladders, therefore, were examined, with the following results :-

(1) A small bladder, less than $\frac{1}{30}$ of an inch $(847 \mathrm{~mm}$.) in diameter, contained a minute mass of brown, much decayed matter; and in this, a tarsus with four or five joints, terminating in a double hook, was clearly distinguished under the microscope. I suspect that it was a remnant of one of the Thysanoura. The quadrifids in contact with this decayed remnant contained either small masses of translucent, yellowish matter, generally more 
or less globular, or fine granules. In distant parts of the same bladder, the processes were transparent and quite empty, with the exception of their solid nuclei. My son made at short intervals of time sketches of one of the above aggregated masses, and found that they continually and completely changed their forms; sometimes separating from one another and again coalescing. Evidently protoplasm had been generated by the absorption of some element from the decaying animal matter.

(2) Another bladder included a still smaller speck of decayed brown matter, and the adjoining quadrifids contained aggregated matter, exactly as in the last case.

(3) A third bladder included a larger organism, which was so much decayed that I could only make out that it was spinose or hairy. The quadrifids in this case were not much affected, excepting that the nuclei in the several arms differed much in size; some of them containing two masses having a similar appearance.

(4) A fourth bladder contained an articulate organism, for I distinctly saw the remnant of a limb, terminating in a hook. The quadrifids were not examined.

(5) A fifth included much decayed matter apparently of some animal, but with no recognisable features. The quadrifids in contact contained numerous spheres of protoplasm.

(6) Some few bladders on the plant which I received from Kew were examined; and in one, there was a worm-shaped animal very little decayed, with a distinct remnant of a similar one greatly decayed. Several of the arms of the processes in contact -with these remains contained two spherical masses, like the single solid nucleus which is properly found in each arm. In another bladder there was a minute grain of quartz, reminding me of two similar cases with Utricularia neglecta.

As it appeared probable that this plant would capture a greater number of animals in its native country than under culture, I obtained permission to remove small portions of the rhizomes from dried specimens in the herbarium at Kew. I did not at first find out that it was advisable to soak the rhizomes for two or three days, and that it was necessary to open the bladders and spread out their contents on glass; as from their state of decay and from having been dried and pressed, their nature could not otherwise be well distinguished. Several bladders on a plant which had grown in black earth in New Granada were first examined; and four of these included remnants of animals. The first contained a hairy Acarus, so much decayed that nothing was left except its transparent coat; 
also a yellow chitinous head of some animal with an internal fork, to which the oesophagus was suspended, but I could see no mandibles; also the double hook of the tarsus of some animal; also an elongated greatly decayed animal; and lastly, a curious flask-shaped organism, having the walls formed of rounded cells. Professor Claus has looked at this latter organism, and thinks that it is the shell of a rhizopod, probably one of the Arcellidæ. In this bladder, as well as in several others, there were some unicellular Algæ, and one multicellular Alga, which no doubt had lived as intruders.

A second bladder contained an Acarus much less decayed than the former one, with its eight legs preserved; as well as remnants of several other articulate animals. A third bladder contained the end of the abdomen with the two hinder limbs of an Acarus, as I believe. A fourth contained remnants of a distinctly articulated bristly animal, and of several other organisms, as well as much dark brown organic matter, the nature of which could not be made out.

Some bladders from a plant, which had lived as an epiphyte in Trinidad, in the West Indies, were next examined, but not so carefully as the others; nor had they been soaked long enough. Four of them contained much brown, translucent, granular matter, apparently organic, but with no distinguishable parts. The quadrifids in two were brownish, with their contents granular; and it was evident that they had absorbed matter. In a fifth bladder there was a flask-shaped organism, like that above mentioned. A sixth contained a very long, much decayed, worm-shaped animal. Lastly, a seventh bladder contained all organism, but of what nature could not be distinguished.

Only one experiment was tried on the quadrifid processes and glands with reference to their power of absorption. A bladder was punctured and left for 24 hrs. in a solution of one part of urea to 437 of water, and the quadrifid and bifid processes were found much affected. In some arms there was only a single symmetrical globular mass, larger than the proper nucleus, and consisting of yellowish matter, generally translucent but sometimes granular; in others there were two masses of different sizes, one large and the 
other small; and in others there were irregularly shaped globules; so that it appeared as if the limpid contents of the processes, owing to the absorption of matter from the solution, had become aggregated sometimes round the nucleus, and sometimes into separate masses; and that these then tended to coalesce. The primordial utricle or protoplasm lining the processes was also thickened here and there into irregular and variously shaped specks of yellowish translucent matter, as occurred in the case of Utricularia neglecta under similar treatment. These specks apparently did not change their forms.

The minute two-armed glands on the valve were also affected by the solution; for they now contained several, sometimes as many as six or eight, almost spherical masses of translucent matter, tinged with yellow, which slowly changed their forms and positions. Such masses were never observed in these glands in their ordinary state. We may therefore infer that they serve for absorption. Whenever a little water is expelled from a bladder containing animal remains (by the means formerly specified, more especially by the generation of bubbles of air), it will fill the cavity in which the valve lies; and thus the glands will be able to utilise decayed matter which otherwise would have been wasted.

Finally, as numerous minute animals are captured by this plant in its native country and when cultivated, there can be no doubt that the bladders, though so small, are far from being in a rudimentary condition; on the contrary, they are highly efficient traps. Nor can there be any doubt that matter is absorbed from the decayed prey by the quadrifid and bifid processes, and that protoplasm is thus generated. What tempts animals of such diverse kinds to enter 
the cavity beneath the bowed antennx, and then force their way through the little slit-like orifice between the valve and collar into the bladders filled with water, I cannot conjecture.

Tubers.-These organs, one of which is represented in a previous figure (fig. 26) of the natural size, deserve a few remarks. T'wenty were found on the rhizomes of a single plant, but they cannot be strictly counted; for, besides the twenty, there were all possible gradations between a short length of a rhizome just perceptibly swollen and one so much swollen that it might be doubtfully called a tuber. When well developed, they are oval and symmetrical, more so than appears in the figure. The largest which I saw was 1 inch $(25.4 \mathrm{~mm}$.) in length and 45 inch $(11.43 \mathrm{~mm}$.$) in breadth. They commonly lie near$ the surface, but some are buried at the depth of 2 inches. The buried ones are dirty white, but those partly exposed to the light become greenish from the development, of chlorophyll in their superficial cells. They terminate in a rhizome, but this sometimes decays and drops off. They do not contain any air, and they sink in water; their surfaces are covered with the usual papillæ. The bundle of vessels which runs up each rhizome, as soon as it enters the tuber, separates into three distinct bundles, which reunite at the opposite end. A rather thick slice of a tuber is almost as transparent as glass, and is seen to consist of large angular cells, full of water and not containing starch or any other solid matter. Some slices were left in alcohol for several days, but only a few extremely minute granules of matter were precipitated on the walls of the cells; and these were much smaller and fewer than those precipitated on the cell-walls of the rhizomes and bladders. We may therefore con- 
clude that the tubers do not serve as reservoirs for food, but for water during the dry season to which the plant is probably exposed. The many little bladders filled with water would aid towards the same end.

To test the correctness of this view, a small plant, growing in light peaty earth in a pot (only $4 \frac{1}{2}$ by $4 \frac{1}{2}$ inches outside measure) was copiously watered, and then kept without a drop of water in the hothouse. Two of the upper tubers were beforehand uncovered and measured, and then loosely covered up again. In a fortnight's time the earth in the pot appeared extremely dry; but not until the thirty-fifth day were the leaves in the least affected; they then became slightly reflexed, though still soft and green. This plant, which bore only ten tubers, would no doubt have resisted the drought for even a longer time, had I not preriously removed three of the tubers and cut off several long rhizomes. When, on the thirty-fifth day, the earth in the pot was turned out, it appeared as dry as the dust on a road. All the tubers had their surfaces much wrinkled, instead of being smooth and tense. They had all shrunk, but I cannot say accurately how much; for as they were at first symmetrically oval, I measured only their length and thickness; but they contracted in a transrerse line much more in one direction than in another, so as to become greatly flattened. One of the two tubers which had been measured was now three-fourths of its original length, and two-thirds of its original thickness in the direction in which it had been measured, but in another direction only one-third of its former thickness. The other tuber was one-fourth shorter, oneeighth less thick in the direction in which it had been measured, and only half as thick in another direction.

A slice was cut from one of these shrivelled tubers 
and examined. The cells still contained much water and no air, but they were more rounded or less angular than before, and their walls not nearly so straight ; it was therefore clear that the cells had contracted. The tubers, as long as they remain alive, have a strong attraction for water; the shrivelled one, from which a slice had been cut, was left in water for $22 \mathrm{hrs} .30 \mathrm{~m}$., and its surface became as smooth and tense as it originally was. On the other hand, a shrivelled tuber, which by some accident had been separated from its rhizome, and which appeared dead, did not swell in the least, though left for several days in water.

With many kinds of plants, tubers, bulbs, \&c. no doubt serve in part as reservoirs for water, but I know of no case, besides the present one, of such organs having been developed solely for this purpose. Prof. Oliver informs me that two or three other species of Utricularia are provided with these appendages; and the group containing them has in consequence received the name of orchidioides. All the other species of Utricularia, as well as of certain closely related genera, are either aquatic or marsh plants; therefore, on the principle of nearly allied plants generally having a similar constitution, a never failing supply of water would probably be of great importance to our present species. We can thus understand the meaning of the development of its tubers, and of their number on the same plant, amounting in one instance to at least twenty.

UtricUlaria NELUMBIFOLIA, AMETHYSTINA, GRIFFItHi, CARULEA, orbiculata, mUlticaulis.

As I wished to ascertain whether the bladders on the rhizomes of other species of Utricularia, and of the 
species of certain closely allied genera, had the same essential structure as those of Utricularia montana, and whether they captured prey, I asked Prof. Oliver to send me fragments from the herbarium at Kew. He kindly selected some of the most distinct forms, having entire leaves, and believed to inhabit marshy ground or water. My son, Francis Darwin, examined them, and has given me the following observations; but it should be borne in mind that it is extremely difficult to make out the structure of such minute and delicate objects after they have been dried and pressed.*

Utricularia nelumbifolia (Organ Mountains, Brazil).The habitat of this species is remarkable. According to its discoverer, Mrr. Gardner, $\dagger$ it is aquatic, but " is only to be found growing in the water which collects in the bottom of the leaves of a large Tillandsia, that inhabits abundantly an arid rocky part of the mountain, at an elevation of about 5000 feet above the level of the sea. Besides the ordinary method by seed. it propagates itself by runners, which it throws out from the base of the flower-stem; this runner is always found directing itself towards the nearest Tillandsia, when it inserts its point into the water and gives origin to a new plant, which in its turn sends out another shoot. In this manner I have seen not less than six plants united." The bladders resemble those of Utricularia montana in all essential respects, even to the presence of a few minute two-armed glands on the valve. Within one bladder there was the remnant of the abdomen of some larva or crustacean of large size,

* Prof. Oliver has given ('Proc. Linn. Soc.' vol. iv. p. 169) figures of the bladders of two South American species, namely, Utricularia Jamesoniana and peltata; but he does not appear to have paid particular attention to these organs.

$\dagger$ 'Travels in the Interior of Brazil, 1836-t1,' p. 527. 
having a brush of long sharp bristles at the apex. Other bladders included fragments of articulate animals, and many of them contained broken pieces of a curious organism, the nature of which was not recognised by anyone to whom it was shown.

Utricularia amethystina (Guiana).-This species has small entire leaves, and is apparently a marsh plant; but it must grow in places where crustaceans exist, for there were two small species within one of the bladders. The bladders are nearly of the same shape as those of Utricularia montana, and are covered outside with the usual papillæ; but they differ remarkably in the antennæ being reduced to two short points, united by a membrane hollowed out in the middle. This membrane is covered with innumerable oblong glands supported on long footstalks; most of which are arranged in two rows converging towards the valve. Some, however, are seated on the margins of the membrane; and the short ventral surface of the bladder, between the petiole and valve, is thickly covered with glands. Most of the heads had fallen off, and the footstalks alone remained; so that the ventral surface and the orifice, when viewed under a weak power, appeared as if clothed with fine bristles. The valve is narrow, and bears a few almost sessile glands. The collar against which the edge shuts is yellowish, and presents the usual structure. From the large number of glands on the ventral surface and round the orifice, it is probable that this species lives in very foul water, from which it absorbs matter, as well as from its captured and decaying prey.

Utricularia griffithii (Malay and Borneo). - The bladders are transparent and minute; one which was measured being only $\frac{28}{1000}$ of an inch $(711 \mathrm{~mm}$.) in diameter. The antennæ are of moderate length, and 
project straight forward; they are united for a short space at their bases by a membrane; and they bear a moderate number of bristles or hairs, not simple as heretofore, but surmounted by glands. The bladders also differ remarkably from those of the previous species, as within there are no quadrifid, only bifid, processes. In one bladder there was a minute aquatic larva; in another the remains of some articulate animal; and in most of them grains of sand.

Utricularia cærulea (India). - The bladders resemble those of the last species, both in the general character of the antennæ and in the processes within being exclusively bifid. They contained remnants of entomostracan crustaceans.

Utricularia orbiculata (India).-The orbicular leaves and the stems bearing the bladders apparently float in water. The bladders do not differ much from those of the two last species. The antennæ, which are united for a short distance at their bases, bear on their outer surfaces and summits numerous, long, multicellular hairs, surmounted by glands. The processes within the bladders are quadrifid, with the four diverging arms of equal length. The prey which they had captured consisted of entomostracan crustaceans.

Utricularia multicaulis (Sikkim, India, 7000 to 11,000 feet). - The bladders, attached to rhizomes, are remarkable from the structure of the antennæ. These are broad, flattened, and of large size; they bear on their margins multicellular hairs, surmounted by glands. Their bases are united into a single, rather narrow pedicel, and they thus appear like a great digitate expansion at one end of the bladder. Internally the quadrifid processes have divergent arms of equal length. The bladders contained remnants of articulate animals. 


\section{Polypompholyx.}

This genus, which is confined to Western Australia, is characterised by having a "quadripartite calyx." In other respects, as Prof. Oliver remarks, " "it is quite a Utricularia."

Polypompholyx multifida.-The bladders are attached in whorls round the summits of stiff stalks. The two antennæe are represented by a minute membranous fork, the basal part of which forms a sort of hood over the orifice. This hood expands into two wings on each side of the bladder. A third wing or crest appears to be formed by the extension of the dorsal surface of the petiole; but the structure of these three wings could not be clearly made out, owing to the state of the specimens. The inner surface of the hood is lined with long simple hairs, containing aggregated matter, like that within the quadrifid processes of the previously described species when in contact with decayed animals. These hairs appear therefore to serve as absorbents. A valve was seen, but its structure could not be determined. On the collar round the valve there are in the place of glands numerous one-celled papillæ, having very short footstalks. The quadrifid processes have divergent arms of equal length. Remains of entomostracan crustaceans were found within the bladders.

Polypompholyx tenella.-The bladders are smaller than those of the last species, but have the same general structure. They were full of débris, apparently organic, but no remains of articulate animals could be distinguished.

* 'Proc. Linn. Soc.' vol. iv. p. 171. 


\section{Genlisea.}

This remarkable genus is technically distinguished from Utricularia, as I hear from Prof. Oliver, by having a five-partite calyx. Species are found in several parts of the world, and are said to be "herbæ annuæ paludosæ."

Gentisea ornata (Brazil). - This species has been described and figured by Dr. Warming,* who states that it bears two kinds of leaves, called by him spathulate and utriculiferous. The latter include cavities; and as these differ much from the bladders of the foregoing species, it will be convenient to speak of them as utricles. The accompanying figure (fig. 29) of one of the utriculiferous leaves, about thrice enlarged, will illustrate the following description by my son, which agrees in all essential points with that given by Dr. Warming. The utricle $(b)$ is formed by a slight enlargement of the narrow blade of the leaf. A hollow neck $(n)$, no less than fifteen times as long as the utricle itself, forms a passage from the transverse slit-like orifice $(o)$ into the cavity of the utricle. A utricle which measured $\frac{1}{36}$ of an inch $(705 \mathrm{~mm}$.$) in its longer diameter had a neck \frac{15}{36}$ $\left(10.583 \mathrm{~mm}\right.$.) in length, and $\frac{1}{100}$ of an inch $(.254 \mathrm{~mm}$.) in breadth. On each side of the orifice there is a long spiral arm or tube $(a)$; the structure of which will be best understood by the following illustration. Take a narrow ribbon and wind it spirally round a thin cylinder, so that the edges come into contact along its whole length; then pinch up the two edges so as to form a little crest, which will of course wind spirally

* "Bidrag til Kundskaben om Lentibulariacex," Copenhagen, 1874. 
round the cylinder like a thread round a screw. If the cylinder is now removed, we shall have a tube like one of the spiral arms. The two projecting edges are not actually united, and a needle can be pushed in easily between them. They are indeed in many places a little separated, forming narrow entrances into the tube; but this may be the result of the drying of the specimens. The lamina of which the tube is formed seems to be a lateral prolongation of the lip of the orifice; and the spiral line between the two projecting edges is continuous with the corner of the orifice. If a fine bristle is pushed down one of the arms, it passes into the top of the hollow neck. Whether the arms are open or closed at their extremities could not be determined, as all the specimens were broken; nor does it appear that Dr. Warming ascertained this point.

So much for the external structure. Internally the

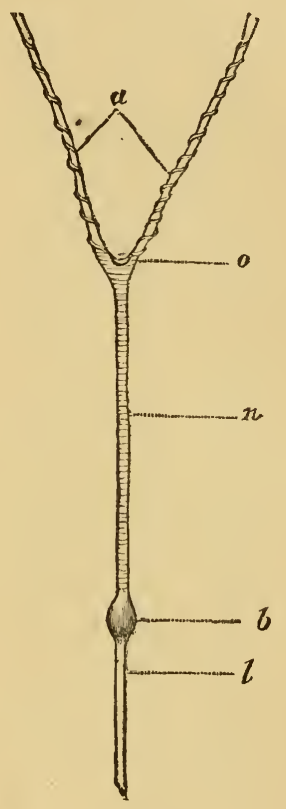

F1G. 29.

(Genlisea ornata.)

Utriculiferous leaf; enlarged about three times.

$l$ Upper part of lamina of leaf.

$b$ Utricle or bladder.

$n$ Neck of utricle.

o Orifice.

a Spirally wound arms, with their ends broken off. lower part of the utricle is covered with spherical papillæ, formed of four cells (sometimes eight according to Dr. Warming), which evidently answer to the quadrifid processes within the bladders of Utricularia. 
These papillæ extend a little way up the dorsal and ventral surfaces of the utricle; and a few, according to Warming, may be found in the upper part. This upper region is covered by many transverse rows, one above the other, of short, closely approximate hairs, pointing downwards. These hairs have broad bases,

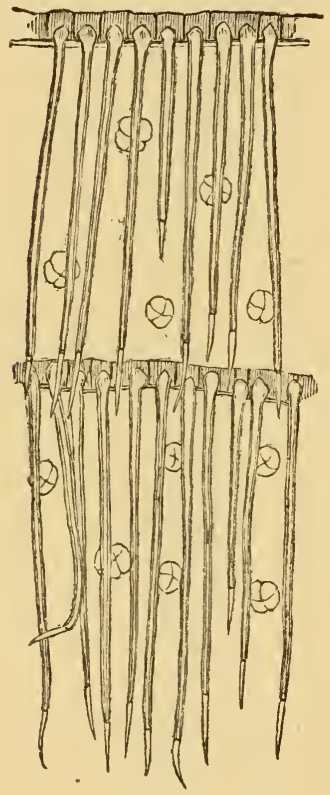

Fig. 30.

(Genlisea ornata.)

Portion of inside of neck leading into the utricle, greatly enlarged, showing the downward pointed bristles, and small quadrifid cells or processes. and their tips are formed by a separate cell. They are absent in the lower part of the utricle where the papillæ abound. The neck is likewise lined throughout its whole length with transverse rows of long, thin, transparent hairs, having broad bulbous (fig. 30 ) bases, with similarly constructed sharp points. They arise from little projecting ridges, formed of rectangular epidermic cells. The hairs vary a little in length, but their points generally extend down to the row next below; so that if the neck is split open and laid flat, the inner surface resembles a paper of pins,the hairs representing the pins, and the little transverse ridges representing the folds of paper through which the pins are thrust. These rows of hairs are indicated in the previous figure (29) by numerous transverse lines crossing the neck. The inside of the neck is 
also studded with papillæ; those in the lower part are spherical and formed of four cells, as in the lower part of the utricle; those in the upper part are formed of two cells, which are much elongated downwards beneath their points of attachment. These two-celled papillæ apparently correspond with the bifid process in the upper part of the bladders of Utricularia. The narrow transverse orifice (o, fig. 29) is situated between the bases of the two spiral arms. No valve could be detected here, nor was any such structure seen by Dr. Warming. The lips of the orifice are armed with many short, thick, sharply pointed, somewhat incurved hairs or teeth.

The two projecting edges of the spirally wound lamina, forming the arms, are provided with short incurved hairs or teeth, exactly like those on the lips. These project inwards at right angles to the spiral line of junction between the two edges. The inner surface of the lamina supports two-celled, elongated papillæ, resembling those in the upper part of the neck, but differing slightly from them, according to Warming, in their footstalks being formed by prolongations of large epidermic cells; whereas the papillæ within the neck rest on small cells sunk amidst the larger ones. These spiral arms form a conspicuous difference between the present genus and Utricularia.

Lastly, there is a bundle of spiral vessels which, running up the lower part of the linear leaf, divides close beneath the utricle. One branch extends up the dorsal and the other up the ventral side of both the utricle and neck. Of these two branches, one enters one spiral arm, and the other branch the other arm.

The utricles contained much débris or dirty matter, which seemed organic, though no distinct organisms 
could be recognised. It is, indeed, scarcely possible that any object could enter the small orifice and pass down the long narrow neck, except a living creature. Within the necks, however, of some specimens, a worm with retracted horny jaws, the abdomen of some articulate animal, and specks of dirt, probably the remnants of other minute creatures, were found. Many of the papillæ within both the utricles and necks were discoloured, as if they had absorbed matter.

From this description it is sufficiently obvious how Genlisea secures its prey. Small animals entering the narrow orifice-but what induces them to enter is not known any more than in the case of Utriculariawould find their egress rendered difficult by the sharp incurved hairs on the lips, and as soon as they passed some way down the neck, it would be scarcely possible for them to return, owing to the many transverse rows of long, straight, downward pointing hairs, together with the ridges from which these project. Such creatures would, therefore, perish either within the neck or utricle; and the quadrifid and bifid papillæ would absorb matter from their decayed remains. The transverse rows of hairs are so numerous that they seem superfluous merely for the sake of preventing the escape of prey, and as they are thin and delicate, they probably serve as additional absorbents, in the same manner as the flexible bristles on the infolded margins of the leaves of Aldrovanda. The spiral arms no doubt act as accessory traps. Until fresh leares are examined, it cannot be told whether the line of junction of the spirally wound lamina is a little open along its whole course, or only in parts, but a small creature which forced its way into the tube at any point, would be prevented from escaping by the incurved hairs, and would find an open path down 
the tube into the neck, and so into the utricle. If the creature perished within the spiral arms, its decaying remains would be absorbed and utilised by the bifid papillæ. We thus see that animals are captured by Genlisea, not by means of an elastic valve, as with the foregoing species, but by a contrivance resembling an eel-trap, though more complex.

Genlisea africana (South Africa).--Fragments of the utriculiferous leaves of this species exhibited the same structure as those of Genlisea ornata. A nearly perfect Acarus was found within the utricle or neck of one leaf, but in which of the two was not recorded.

Genlisea aurea (Brazil).-A fragment of the neck of a utricle was lined with transverse rows of hairs, and was furnished with elongated papillæ, exactly like those within the neck of Genlisea ornata. It is probable, therefore, that the whole utricle is similarly constructed.

Genlisea filiformis (Bahia, Brazil).-Many leaves were examined and none were found provided with utricles, whereas such leaves were found without difficulty in the three previous species. On the other hand, the rhizomes bear bladders resembling in essential character those on the rhizomes of Utricularia. These bladders are transparent, and very small, viz. only $\frac{1}{100}$ of an inch $(.254 \mathrm{~mm}$.) in length. The antennæ are not united at their bases, and apparently bear some long hairs. On the outside of the bladders there are only a few papillæ, and internally very few quadrifid processes. These latter, however, are of unusually large size, relatively to the bladder, with the four divergent arms of equal length. No prey could be seen within these minute bladders. As the rhizomes of this species were furnished with bladders, those of Genlisea africana, ornata, and aurea were carefully 
examined, but none could be found. What are we to infer from these facts? Did the three species just named, like their close allies, the several species of Utricularia, aboriginally possess bladders on their rhizomes, which they afterwards lost, acquiring in their place utriculiferous leaves? In support of this view it may be urged that the bladders of Genlisea filiformis appear from their small size and from the fewness of their quadrifid processes to be tending towards abortion; but why has not this species acquired utriculiferous leaves, like its congeners?

Conclusion.- It has now been shown that many species of Utricularia and of two closely allied genera, inhabiting the most distant parts of the worldEurope, Africa, India, the MIalay Archipelago, Australia, North and South America-are admirably adapted for capturing by two methods small aquatic or terrestrial animals, and that they absorb the products of their decay.

Ordinary plants of the higher classes procure the requisite inorganic elements from the soil by means of their roots, and absorb carbonic acid from the atmosphere by means of their leaves and stems. But we have seen in a previous part of this work that there is a class of plants which digest and afterwards absorb animal matter, namely, all the Droseracex, Pinguicula, and, as discovered by Dr. Hooker, Nepenthes, and to this class other species will almost certainly soon be added. These plants can dissolve matter out of certain regetable substances, such as pollen, seeds, and bits of leaves. No doubt their glands likewise absorb the salts of ammonia brought to them by the rain. It has also been shown that some other plants can absorb ammonia by 
their glandular hairs; and these will profit by that brought to them by the rain. There is a second class of plants which, as we have just seen, cannot digest, but absorb the products of the decay of the animals which they capture, namely, Utricularia and its close allies; and from the excellent observations of Dr. Mellichamp and Dr. Canby, there can scarcely be a doubt that Sarracenia and Darlingtonia may be added to this class, though the fact can hardly be considered as yet fully proved. There is a third class of plants which feed, as is now generally admitted, on the products of the decay of vegetable matter, such as the bird's-nest orchis (Neottia), \&c. Lastly, there is the well-known fourth class of parasites (such as the mistletoe), which are nourished by the juices of living plants. Most, however, of the plants belonging to these four classes obtain part of their carbon, like ordinary species, from the atmosphere. Such are the diversified means, as far as at present known, by which higher plants gain their subsistence. 



\section{IN DEX.}

ABSORPTION.

A.

Absonption by Dionæa, 295

— by Drosera, 17

by Drosophyllum, 337

- by Pinguicula, 381

— by glandular hairs, 344 421

by glands of Utricularia, 416 ,

- by quadrifids of Utricularia, 413,421

_ by Utricularia montana, 437

Acid, nature of, in digestive secretion of Drosera, 88

- present in digestive fluid of various species of Drosera, Dionæa, Drosophyllum, and Pinguicula, 278, 301, 339, 381

Acids, various, action of, on Diosera, 188

- of the acetic series replacing hydrochloric in digestion, 89

- arsenious and chromic, action on Drosera, 185

- diluted, inducing negative osmose, 197

Adder's poison, action on Drosera, 206

Aggregation of protoplasm in Drosera, 38

- in Drosera induced by salts of ammonia, 43

_ caused by small doses of carbonate of ammonia, 145 - of protoplasm in Drosera, a reflex action, 242

- in various species of Drosera, 278

- _ in Dionæa, 290, 300

\section{AMMONIA.}

Aggregation of protoplasm in Drosophyllum, 337, 339

—_ in Pinguicula, 370, 389 $429,430,436$

Albumen, digested by Drosera, 92

- , liquid, action on Drosera, 79

Alcohol, diluted, action of, on Drosera, 78,216

Aldrovanda vesiculosa, 321

- , absorption and digestion by, 325

$\longrightarrow$, varieties of, 329

Algæ, aggregation in fronds of, 65 Alkalies, arrest digestive process in Drosera, 94

Aluminium, salts of, action on Drosera, 184

Ammonia, amount of, in rain water, 172

- carbonate, action on heated leaves of Drosera, 69

,,-- smallness of doses causing aggregation in Drosera, 145

$-1,-$ its action on Drosera, 141

$\longrightarrow$, , vapour of, absorbed by glands of Drosera, 142

$\longrightarrow, \ldots$, smallness of doses causing inflection in Drosera, 145, 168

- , phosphate, smallness of doses causing inflection in Drosera, 153,168

,,-- , size of particles affecting Drosera, 173

- nitrate, smallness of doses causing inflection in Drosera, 148, 168

- , salts of, action on Drosera, 136 


\section{AMMONIA.}

Ammonia, salts of, their action affected by previous immersion in water and various solutions, 213

\section{Drosera, 43}

induce aggregation in

, various salts of, causing inflection in Drosera, 166

Antimony, tartrate, action on Drosera, 185

Areolar tissue, its digestion by Drosera, 102

Arsenious acid, action on Drosera, 185

Atropine, action on Drosera, 204

\section{B.}

Barium, salts of, action on Droscra, 183

Bases of salts, preponderant action of, on Drosera, 186

Basis, fibrous, of bone, its digestion by Drosera, 108

Belladonna, extract of, action on Drosera, 84

Bennett, Mr. A. W., on Drose a, 2 _- coats of pollen-grains not digested by insects, 117

Binz, on action of quinine on white blood-corpuscles, 201

- , on poisonous action of quinine on low organisms, 202

Bone, its digestion by Drosera, 105

Brunton, Lauder, on digestion of gelatine, 111

115

- , on the digestion of urea, 124

- - - of chlorophyll, 126

Byblis, 343 of pepsin, 124

\section{c.}

Cabbage, decoction of, action on Drosera, 83

Cadmium chloride, action on Drosera, 183

Cæsium, chloride of, action on Drosera, 181

\section{CURTIS.}

Calcium, salts of, action on Drosera, 182

Camphor, action on Drosera, 209

Canby, Dr., on Dionæa, 301, 310, 313

- on Drosera filiformis, 281

Caraway, oil of, action on Drosera, 211

Carbonic acid, action on Drosera, 221 - delays aggregation in Drosera, 59

Cartilage, its digestion by Drosera, 103

Casein, its digestion by Drosera, 114

Cellulose, not digested by Drosera, 125

Chalk, precipitated, causing inflection of Drosera, 32

Cheese, its digestion by Drosera, 116

Chitine, not digested by Drosera, 124

Chloroform, effects of, on Drosera, 217

,-- , on Dionæa, 304

Chlorophyll, grains of, in living plants, digested by Drosera, 126

- , pure, not digested by Drosera, 125

Chondrin, its digestion by Droscra, 112

Chromic acid, action on Drosera, 185

Cloves, oil of, action on Drosera, 212

Cobalt chloride, action on Drosera, 186

Cobra poison, action on Drosera, 206

Cohn, Prof., on Aldrovanda, 321

- on contractile tissues in plants, 364

- on movements of stamens of Compositæ, 256

- on Utricularia, 395

Colchicine, action on Drosern, 204

Copper chloride, action on Drosera, 1 s5

Crystallin, its digestion by Drosera, - 120

Curare, action on Drosera, 204

Curtis, Dr., on Dionæa, 301 


\section{DARWIN.}

D.

Darwin, Francis, on the effect of an induced galvanic current on Drosera, 37

- on the digestion of grains of chlorophyll, 126

-, on Utricularia, 442

Delpino, on Aldrovanda, 321

, on Utricularia, 395

Dentine, its digestion by Drosera, 106

Digestion of various substances by Dionæa, 301

- by Drosera, 85

_ _ by Drosophyllum, 339

—— by Pinguicula, 381

- origin of power of, 361

Digitaline, action on Drosera, 203

Dionæa muscipula, small size of roots, 286

_- structure of leaves, 287

289

, absorption by, 295

- , secretion by, 295

_- digestion by, 301

_- effects on, of chloroform, 304

- manner of capturing insects, 305

- , transmission of motor impulse, 313

_

Direction of inflected tentacles of Drosera, 243

Dohrn, Dr, on rhizocephalous crustaceans, 357

Dunders, Prof., small amount of atropine affecting the iris of the dog, 172

Dragonfly caught by Drosera, 2

Drosera anglica, 278

— binata, vel dichotoma, 281

— capensis, 279

- filiformis, 281

- heterophylla, 281

- intermedia, 279

Drosera rotundifolia, structure of leaves, 4

- effects on, of nitrogenous
FIBROUS.

Drosera rotundifolia, effects of heat on, 66

- its power of digestion, 85 231

- transmission of motor impulse, 234

—, general summary, 262

- spathulata, 280

Droseracex, concluding remarks on. 355

- their sensitiveness compared with that of animals, 366

Drosophyllum, structure of leaves, 333

- , secretion by, 334

—, absorption by, 337

—, digestion by, 339

\section{E.}

Enamel, its digestion by Drosera, 106

Erica tetralix, glandular hairs of, 351

Ether, effects of, on Drosera, 219

— , - on Dionæa, 301

Euphorbia, process of aggregation in roots of, 63

Exosmose from backs of leaves of Drosera, 231

F.

Fat not digested by Drosera, 126

Fayrer, Dr., on the nature of cobra poison, 206

$\longrightarrow$, on the action of cobra poison on animal protoplasm, 208

nerve centres, 224

Ferment, nature of, in secretion of Drosera, 94, 97

Fibrin, its digestion by Drosera, 100

Fibro-cartilage, its digestion by Drosera, 104

Fibro-elastic tissue, not digested by Drosera, 122

Fibrous basis of bone, its digestion by Drosera, 108 


\section{FLUIDS,}

Fluids, nitrogenous, effects of, on Drosera, 76

Fournier, on acids causing movements in stamens of Berberis, 196

Frankland, Prof., on nature of acid in secretion of Drosera, 88

G.

Galvanism, current of, causing inflection of Drosera, 37

- effects of, on Dionæa, 318

Gardner, Mr., on Utricularia nelumbifolia, 442

Gelatine, impure, action on Drosera, 80

- , pure, its digestion by Drosera, 110

Genlisea africana, 451

filiformis, 451

Genlisea ornata, structure of, 446

- manner of capturing prey, 450

Glandular hairs, absorption by, 344

$\longrightarrow$, summary on, 353

Globulin, its digestion by Drosera, $1 \div 0$

Gluten, its digestion by Drosera, 117

Glycerine, inducing aggregation in Drosera, 52

, action on Drosera, 212

Gold chloride, action on Drosera, 184

Gorup-Besanez on the presence of a solvent in seeds of the vetch, 362

Grass, decoction of, action on Drosera, 84

Gray, Asa, on the Droseraceæ, 2

Groenland, on Drosera, 1, 5

Gum, action of, on Drosera, 77

Gun-cotton, not digested by Drosera, 125

\section{H.}

Hxmatin, its digestion by Drosera, 121

Hairs, glandular, absorption by, 344

$\longrightarrow$, , summary on, 353

\section{LEAVES,}

Heat, inducing aggregation in Drosera, 53

- , effect of, on Drosera, 66

$\longrightarrow,-$, on Dionæa, 29t, 319

Heckel, on state of stamens of Berberis after excitement, 43

Hofmeister, on pressure arresting movements of protoplasm, 61

Holland, Mr., on Utricularia, 395

Hooker, Dr., on carnivorous plants, 2

$\longrightarrow$, on power of digestion by $\mathrm{Ne}$ penthes, 97

, history of observations on Dionæa, 286

Hydrocyanic acid, effects of, on Dionæa, 305

Hyoscyamus, action on Drosera, 84, 206

I.

Iron chloride, action on Drosera, 185

Isinglass, solution of, action on Drosera, 80

J.

Johnson, Dr., on movement of flowerstems of Pinguicula, 381

\section{K.}

Klein, Dr., on microscopic character of half digested bone, 106

$\longrightarrow$, on state of half digested fibrocartilage, $10 t$

$\longrightarrow$, on size of micrococci, 173

Knight, Mr., on feeding Dionæa, 301

Kossmann, Dr., on rhizocephalous crustaceans, 357

\section{I.}

Lead chloride, action on Drosera, 184

Leaves of Drosera, backs of, not sensitive, 231 


\section{LEGUMIN.}

Legumin, its digestion by Drosera, 116

Lemna, aggregation in leaves of, 64 Lime, carbonate of, precipitated, causing inflection of Drosera, 32

- phosphate of, its action on Drosera, 109

Lithium, salts of, action on Drosera, 181

\section{. M.}

Magnesium, salts of, action on Drosera, 182

Manganese chloride, action on Drosera, $15 \tilde{5}$

Marsball, Mr. W., on Pinguicula, 369

Means of movement in Dionæa, 313 in Drosera, 254

Meat, infusion of, causing aggregation in Drosera, 51

$\longrightarrow$ - action on Drosera, 79

_ its digestion by Drosera, 98

Mercury perchloride, action on Drosera, 183

Milk, inducing aggregation in Drosera, 51

- action on Drosera, 79

__ , its digestion by Drosera, 113

Mirabilis longiflora, glandular hairs of, 352

Moggridge, Traherne, or acids injuring seeds, 128

Moore, Dr., on Pinguicula, 390

Morphia acetate, action on Drosera, 205

Motor impulse in Drosera, 234, 258

- in Dionæa, 313

Movement, origin of power of, 363

Movements of leaves of Pinguicula, 371

- of tentacles of Drosera, means of, 254

- of Dionæa, means of, 313

Mucin, not digested by Drosera, 122

Mucus, action on Drosera, 80

Müller, Fritz, on rhizocephalous crustaceans. 357

\section{PINGUICCLA.}

N.

Nepenthes, its power of digestion, 97

Nickel chloride, action on Drosera, 186

Nicotiana tabacum, glandular hairs of, 352

Nicotine, action on Drosera, 203

Nitric ether, action on Drosera, 220

Nitschke, Dr., references to his papers on Drosera, 1

- , on sensitiveness of backs of leaves of Drosera, 231

- , on direction of inflected tentacles in Drosera, 244

- on Aldrovanda, 322

Nourishment, various means of, by plants, 452

Nuttall, Dr., on re-expansion of Dionæa, 318

\section{0.}

Odour of pepsin, emitted from leaves of Drosera, 88

Oil, olive, action of, on Drosera, 78, 126

Oliver, Prof., on Utricularia, 432, 441-446

P.

Papaw, juice of, hastening putrefaction, 411

Particles, minute size of, causing inflection in Drosera, 27, 32

Peas, decoction of, action on Drosera, 82

Pelargonium zonale, glandular hair's of, 350

Pepsin, odour of, emitted from Drosera leaves, 88

—, not digested by Drosera, 123

_ cited only after absorption, 129

Peptogenes, 129

Pinguicula grandiflora, 390

- lusitanica, 391 


\section{PINGUICLLA.}

Pinguicula vulgaris, structure of leaves and roots, 368

- , number of insects caught by, 369

-, power of movement, 371

$\longrightarrow$, secretion and absorption by, 381

—

seeds, 390

Platinum chloride, action on Drosera, 186

Poison of cobra and adder, their action on Drosera, 206

Pollen, its digestion by Drosera, 117

Polypompholyx, structure of, 445

Potassium, salts of, inducing aggregation in Drosera, 50

$\longrightarrow,-$, action on Drosera, 179

- phosphate, not decomposed by Drosera, 180, 187

Price, Mr. John, on Utricularia, 429

Primula sinensis, glandular hairs of, 348

- number of glandular hairs of, 355

Protoplasm, aggregation of, in Drosera, 38

$\longrightarrow, \frac{}{11}$, in Drosera, caused by small doses of carbonate of ammonia, 145

$-\frac{1}{2}$, in Drosera, a reflex action, 242

53

- aggregation of, in. various species of Drosera, 278

$\longrightarrow$, in Dionæa, 290, 300 $-339-$, in Drosophyllum, 337,

,-- , in Pinguicula, 370, 389

- - - , in Utricularia, 411, 415, $429,430,436$

Q.

Quinine, salts of, action on Drosera, 201

\section{SAXIFRAGA.}

R.

Rain-water, amount of ammonia in, 172

Ralfs, Mr., on Pinguicula, 390

Ransom, Dr., action of poisons on the yolk of eggs, 225

Re-expansion of headless tentacles of Drosera, 229

— of tentacles of Drosera, 260 - of Dionæa, 318

Roots of Drosera, 18

- of Drosera, process of aggregation in, 63

- of Drosera, absorb carbonate of ammonia, 141

- of Dionæa, 286

- of Drosophyllum, 332

- of Pinguicula, 369

Roridula, $3 \pm 2$

Rubidium chloride, action on Drosera, 181

\section{S.}

Sachs, Prof., effects of heat on protoplasm, 66, 70

$\longrightarrow$, on the dissolution of proteid compounds in the tissues of plants, 362

Saliva, action on Drosera, 80

Salts and acids, various, effects of, on subsequent action of ammonia, 214

Sanderson, Burdon, on coagulation of albumen from heat, 74

- on acids replacing hydrochloric in digestion, 89

$\longrightarrow$, on the digestion of fibrous basis of bone, 108

,-- of gluten, 118

- - of globulin, 120

$\longrightarrow,-$ of chlorophyll, 126

- , on different effect of solium and potassium on animals, 187 -318 , on electric currents in Dionæa,

Saxifraga umbrosa, glandular hairs of, 3 15 


\section{SCHUFF.}

Schiff, on hydrochloric acid dissolving cQ̣agulated albumen, 86

- on manner of digestion of albumen, 93

- on changes in meat during digestion, 99

114 116

on the digestion of casein,

- — of mucus, 123

$\longrightarrow$, on peptogenes, 129

Schloesing, on absurption of nitrogen by Nicotiana, 352

Scott, Mr., on Drosera, 1

Secretion of Drosera, general account of, 13

15

- its antiseptic power,

_- becomes acid from excitement, 86

94,97

by Dionæa, 295

by Drosophyllum, 335

by Pinguicula, 381

Seeds, living, acted on by Drosera, 127

$385, \overrightarrow{390}$

Sensitiveness, localisation of, in Drosera, 229

- of Dionæa, 289

of Pinguicula, 371

Silver nitrate, action on Drosera, 181

Sodium, salts of, action on Drosera, 176

\section{Drosera, 50}

Sondera heterophylla, 284

Sorby, Mr., on colouring matter of Drosera, 5

Spectroscope, its power compared with that of Drosera, 170

Starch, action of, on Drosera, 78, 126

Stein, on Aldrovanda, 321

Strontium, salts of, action on Drosera, 183

\section{TURPENTLNE.}

Strychnine, salts of, action on Drosera, 199

Sugar, solution of, action of, on Drosera, 78

,-- , inducing aggregation in Drosera, 51

Sulphuric ether, action on Drosera, 219

- - on Dionæa, 304

Syntonin, its action on Drosera, 102

\section{T.}

Tait, Mr., on Drosophyllum, 332

Taylor, Alfred, on the detection of minute doses of poisons, 170

Tea, infusion of, action on Drosera, 78

Tentacles of Drosera, move when glands cut of, 36,229

$\longrightarrow$, inflection, direction of, 243

- means of movement, 254

- , re-expansion of, 260

Theine, action on Drosera, 204

Tin chloride, action on Drosera, 185

Tissue, areolar, its digestion by Drosera, 102

- , fibro-elastic, not digested by Drosera, 122

Tissues through which impulso is transmitted in Drosera, 247

- in Dionæa, 313

Touches repeated, causing inflection in Drosera. 34

Transmission of motor impulse in Drosera, 234

—_ - in Dionæa, 313

Traube, Dr., on artificial cells, 216

Treat, Mrs., on Drosera filiformis, 281

- , on Dionæa, 311

- , on Utricularia, 408,430

Trécul, on Drosera, 1,5

Tubers of Utricularia montana, 439

Turpentine, action on Drosera, 212 


\section{CREA,}

ర.

Urea, not digested by Drosera, 124

Urine, action on Drosera, 79

Utricularia clandestina, 430 minor, 429

Utricularia montana, structure of bladders, 431

- animals caught by, 435

-

, tubers of, serving as reservoirs, 439

Utricularia neglecta, structure of bladders, 397

—_, animals caught by, 405

-

_- summary on absorption, 421

- development of bladders, 424

Utricularia, various species of, $4 t 1$

Utricularia vulgaris, 428

V.

Veratrine, action on Drosera, 204

Vessels in leaves of Drosera, 247 of Dionæa, 314

Vogel, on effects of camphor on plants, 209
ZLNC.

W.

Warming, Dr., on Drósera, 2, 6

- , on roots of Utricularia, 397

- on trichomes, 359

__, on Genlisea, 446

, on parenchymatous cells in tentacles of Drosera, 252

Water, drops of, not causing inflection in Drosera, 35

- its power in causing aggregation in Drosera, 52

- its power in causing inflection in Drosera, 139

and various solutions, effects of, on subsequent action of ammonia, 213

Wilkinson, Rev., on Utricularia, 398

\section{$\mathbf{Z}$}

Ziegler, his statements with respect to Drosera, 23

sels of Drosera, $2 \pm 9$

Zinc chloride, action on Drosera, 184 


\section{Works of Charles Darwin.}

JOURNAL OF RESEARCHES into the Natural History and Geology of the Countries visited during the Voyage of H. M. S. Beagle round the World, under the command of Captain Fitzroy, R. N. I vol., I2mo. 579 pages. Cloth. Price, $\$ 2.00$.

"Darwin was nearly five years on board the Beagle. A keen observer, and a genuine philosopher, he has brought back to us a precious freight of facts and truths. The work has been for some time before the public, and has won a high place among readers of every class. It is not so scientific as to be above the comprehension of intelligent readers who are not scientific. Some facts and species, new even to the scientific, are brought to light. Darwin's transparent, eloquent style richly illuminates his observations. The weightier matters to which he alludes are interspersed among more familiar observations, such as would naturally be made by a traveler passing through new and wonderful scenes. It is an instructive and interesting book."Northwestern Christian Advocate.

THE ORIGIN OF SPECIES by Means of Natural Selection, or the Preservation of Favored Races in the Struggle for Life. New and revised edition, with Additions. With copious Index. I vol., I2mo. Cloth. Price, \$2.00.

"Personally and practically exercised in zoölogy, in minute anatomy, in geology, a student of geographical distribution, not in maps and in museums, but by long voyages and laborious collection; having largely advanced each of these branches of science, and having spent many years in gathering and sifting materials for his present work, the store of accurately-registered facts upon which the author of the "Origin of Species' is able to draw at will, is prodigious. "-Prof. T. H. Huxley.

THE DESCENT OF MAN, and Selection in Relation to Sex. With Illustrations. New edition, revised and augmented. Complete in one volume. 688 pages. Price, \$3.00.

"This theory is now indorsed by many eminent scientists, who at first combated it, including Sir Charles Lyell, probably the most learned of geologists, and even by a class of Christian divines like Dr. McCosh, who think that certain theories of cosmogony, like the nebular hypothesis and the law of evolution, may be accepted without doing violence to faith." -Evening Builetin.

THE EXPRESSION OF THE EMOTIONS IN MAN AND the Lower Animals. With Photographic and other Illustrations. I vol., thick I2mo. Cloth. Price, $\$ 3.50$.

"Whatever one thinks of Mr. Darwin's theory, it must be admitted that his great powers of observation are as conspicuous as ever in this inquiry. During a space of more than thirty years, he has, with exemplary patience, been accumulating information from all available sources. The result of all this is undoubtedly the collection of a mass of minute and trustworthy information which must possess the highest value, whatever may be the conclusions ultimately deduced from it." -London Times.

INSECTIVOROUS PLANTS. With Illustrations. I vol., I2mo.

Cloth. Price, $\$ 2.00$.

"In conclusion, we lay this book down with increased admiration for Mr. Darwin as a discoverer and expositor of facts, and with great satisfaction at the increase to our knowledge of plant physiology given us, as well as the ample promise of further additions as the direct consequence of the present publication." - London Athenceum.

"In this work Mr. Darwin's patient and painstaking methods of investigation appear to the best possible advantage. It is impossible to read it without enthusiastic admiration for the ingenuity which he displays in devising tests to determine the characteristics of the plants, the peculiarities of which he is studying, and, as is always the case with him, he presents the conclusions arrived at in language so lucid that he who reads simply for information is sure to be attracted and charmed quite as much as the professional student." $-N . Y$. Times.

D. APPLETON \& CO., Publishers, $549 \& 55$ I Broadway, N. Y. 


\section{THE DESCENT OF MAN.}

The Descent of Man,

DARWIN.

AND SElection IN Relation TO SEX. By Charles Darwis, M. A., F. R. S., etc. With Illustrations. New, revised and enlarged edition. Complete in one vol. 12mo. Cloth. Price, $\$ 3$.

\section{Origin of Species by Means of Natural Selection;}

Or, the Preservation of Favored Races in the Struggle for Life. New and revised edition. By Charles Darwin, M. A., F. R. S., F. G. S, etc. With copious Index. 1 rol., $12 \mathrm{mo}$. Cloth. Price, $\$ 2.00$

$$
\text { ST. GEORGE MIVART. }
$$

\section{On the Genesis of Species.}

By St. George Mivart, F.R.S. 12mo, 316 pages. Illicstratod. Cloth. Price, $\$ 1.75$.

\section{SPENCER.}

\section{The Principles of Biology.}

\section{By Herbert Spencer. 2 vols. $\$ 5.00$.}

Man's Place in Nature.

\section{HUXIFY.}

By Thomas H. Huxlex, LL. D., F.R.S, 1 vol, 12mo. Cluth. Price, $\$ 1.25$.

On the Origin of Species.

By Thomas H. Huxlex, LL. D., F. R. S. 1 vol., 12mo. Cloth. Price, \$L.

\section{Hereditary Genius:}

\section{GALTON.}

An Inquiry into its Laws and Consequences. By FrANCLU GALTON

New revised edition. 12mo. Cloth. Price, $\$ 2.00$.

\section{Primitive Man.}

\section{FIGUIER.}

Illustrated with thirty Scenes of Primitive Life, and 233 Figures of Objects belonging to Prehistoric Ages. By Lovis FIGUIER, author of "The World before the Deluge," "The Ocean World," eto. 1 rol., 8vo. Cloth. Price, $\$ 4.00$.

\section{Origin of Civilization,}

\section{IUBBOCK.}

AND THE PRIMITIVE CONDITION OF MAN. By Sir JoHN Luвbоск, Bart., M. P. 1 vol., $12 \mathrm{mo}$. Cloth. Price $\$ 2.00$.

Either of the above mailed to any address within the United Stotes, on nareipt of price.

D. APPLETON \& CO., Publishers, Nos. $549 \& 551$ BROADWAY. N. Y. 


\title{
INTERNATIONAL SCIENTIFIC SERIES.
}

\author{
NOW READY.
}

No. 1. FORMS OF WATER, in Clouds, Rain, Rivers, Ice, and Glaciers. By Prof. John Tyndall, LL. D., F. R. S. I vol. Cloth. Price, \$r.5o.

No. 2. PHYSICS AND POLITICS; or, Thoughts on the Application of the Principles of "Natural Selection" and "Inheritance" to Political Society. By WALter BAgehot, Esq., author of "The English Constitution." I vol. Cloth. Price, \$r.5o.

No. 3. Foods. By Edward Smith, M. D., LL. B., F. R.S. I vol. Cloth Price, \$r.75.

No. 4. MIIND AND BODY. The Theories of their Relation. By Alex. Ba1n, LL. D., Professor of Logic in the University of Aberdeen. I vol., r2mo. Cloth. Price, \$1.5o.

No. 5. THE STUdY OF SOCIOLOGY. By Herbert Spencer. Price, $\$ 1.50$.

No. 6. THE NEW CHEMISTRY. By Prof. Josiah P. Cooke, Jr., of Harvard University. I vol., I2mo. Cloth. Price, $\$ 2.00$.

No. $\%$. THE CONSERVATION OF ENERGY. By Prof. Balfour Stewart, LL. D., F. R. S. I vol., I2mo. Cloth. Price, \$r.50.

No. 8. ANIMAL LOCOMOTION; or, Walking, Swimming, and Flying, with a Dissertation on Aëronautics. By J. Bell Petrigrew, M. D., F. R.S., F. R. S. E., F. R. C.P. E. I vol., ז2mo. Fully illustrated. Price, \$r. 75 .

No. 9. RESPONSIBILITY IN MENTAL DISEASE. By HENRY Maudsley, M. D. I vol., r2mo. Cloth. Price, \$r.50.

No. 10. THE SCIENCE OF LAW. By Prof. Sheldon Amos. I vol., I2mo. Cloth. Price, \$1.75.

No. 11. ANIMAL MECHANISM. A Treatise on Terrestrial and Aërial Locomotion. By E. J. MAREy. With II 7 Illustrations. Price, \$r.75.

NO. 12. THE HISTORY OF THE CONFLICT BETWEEN RELIGION AND SCIENCE. By JOHN WM. DRAPER, M.D., author of "The Intellectual Development of Europe." Price, \$r.75.

No. 13. THE DOCTRINE OF DESCENT AND DARWINISM. By Prof. Oscar Schmid, Strasburg University. Price, \$I.50.

No. 14. THE CHEMISTRY OF LIGHT AND PHOTOGRAPHY. In its Application to Art, Science, and Industry. By Dr. Hermann VoGEL. IOo Illustrations. Price, $\$ 2.00$.

No. 15. FUNGI; their Nature, Influence, and Uses. By M C. Cooke, M. A., LL. D. Edited by Rev. M. J. Berkeley, M. A., F. L. S. With rog Illustrations. Price, \$r.50.

No. 16. THE LIFE AND GROWTH OF LANGUAGE. By Prof. W. D. Whitney, of Yale College. Price, \$1.50.

No. 17. THE NATURE OF LIGHT, with a General Account of Physical Optics. By Dr. Eugene Lommel, Professor of Physics in the University of Erlangen. With I88 Illustrations and a Plate of Spectra in Chromolithography. (In press.)

D. APPLETON \& CO., Publishers, 549 \& 55 I Broadway, N. Y. 


\section{International Scientific Series.}

D. APPLETon \& Co. have the pleasure of announcing that they have made arrange. ments for publishing, and have recently commenced the issue of, a SiERIES OF POPULAR MIONOGRAPHS, or small works, under the above title, which will embody the results of recent inquiry in the most interesting departments of advancing science.

The character and scope of this series will be best indicated by a reference to the names and subjects included in the subjoined list, from which it will be seen that the coöperation of the most distinguished professors in England, Germany, France, and the United States, has been secured, and negotiations are pending for contributions from other eminent scientific writers.

The works will be issued in New York, London, Paris, Leipsic, Milan, and St. Petersburg.

The International Scientific Series is entirely an American project, and was originated and organized by Dr. E. L. Youmans, who spent the greater part of a year in Europe, arranging with authors and publishers. The forthcoming volumes are as follows:

Prof. Loumel (University of Erlangen), Optics. (In press.)

Rev. M. J. BERKELEY, M. A., F. L. S., and M. Cooke, M. A., LL. D., Fungi; their Nature, Influences, and Uses. (In press.)

Prof. W. Kingdon Clifford, M. A., The First Principles of the Exact Sciences explained to the non-mathematical.

Prof. T. H. Huxley, LL. D., F. R. S., Bodily Motion and Consciousness.

Dr. W. B. CARPENTER, LL. D., F. R. S., The Physical Geography of the Sea.

Prof. William Odlong, F. K. S., The Old Chemistry viewed from the New Standpoint.

W. LAUDER LiNDSAY, M. D., F. R. S. E., Mind in the Lower Animals.

Sir John LubBock, Bart., F. R. S., The Antiquity of Man.

Prof. W. T. Thiselton Dyer, B. A., B. Sc. Form and Habit in Flowering Plants.

Mr. J. N. Lockyer, F. R. S., Spectrum Analysis.

Prof. Michael Foster, M. D., Protoplasm and the Cell Theory.

Prof. W. Stanley Jevons, Money: and the Mechanism of Exchange.

H. Charlton Bastian, M. D., F. R. S., The Brain as an Organ of Mind.

Prof. A. C. Ramsay, LL. D., F. R. S., Earth Sculpture: Hills, Valleys, Mlourtains, Plains, Rivers, Lakes: how they were produced, and how they have been destroyed.

Prof. RuDOLPH VIRCHOw (Berlin University), Morbid Physiological Action.

Prof. Claude Bernard, Physical and Metaphysical Phenomena of Life.

Prof. H. Sainte-Claire Deville, $A n$ Introduction to General Chemistry.

Prof. Wurtz, Atoms and the Atomic Theory.

Prof. DE Quatrefages, The Negro Races.
Prof. Lacaze-Duthiers, Zoology since Cuvier.

Prof. Berthelot, Chemical Synthesis.

Prof. J. Rosenthal, General Physiology of Minscles and Nerves.

Prof. James D. Dana, M. A., LL. D., On Cephalization; or, Head-Characters in the Gradation and Progress of Life.

Prof. S. W. Johnson, M. A., On the Nutrition of Plants.

Prof. Austin Fint, Jr., M. D., The Nervous System and its Relation to the Bodily Functions.

Prof. W. D. Whitney, Modern Linguistic Science.

Prof. C. A. Young, Ph. D. (of Dartmouth College), The Sun.

Prof. Bernstein (University of Halle), Physiology of the Senses.

Prof. Ferdinand Cohn (Breslau University), Thallophytes (Algae, Lichens, Fitngi).

Prof. Hermann (University of Zurich), Respiration.

Prof. LeUCKaRT (University of Leipsic), Outlines of A nimal Organization.

Prof. LIEBREICH (University of Berlin), Outlines of Toxicology.

Prof. KUNDT (University of Strasburg), On Sound.

Prof. ReEs (University of Erlangen), On Parasitic Plants.

Prof. Steinthal (University of Berlin), Outlines of the Science of Language.

E. Alglave (Professor of Constitutional and Administrative Law at Douai, and of Political Economy at Lille), The Primitive Elements of Political Constitutions.

P. Lorain (Professor of Medicine, Paris), Modern Epidemics.

Prof. SCHÜTZENBERGER (Director of the Chemical Laboratory at the Sorbonne), On Fermentations.

Mons. Debray, Precious Metals 


\section{POPULAR SCIENCE LIBRARY.}

Under this title will be issued a series of neat and attractive books, at the uniform price of a dollar each, that shall bring the varied and important results of modern scientific inquiry within easy reach of all classes of readers. Much of the wonderful intellectual activity of the age is taking a scientific direction, and nearly every department of knowledge is powerfully affected by it; but the results are usually embodied in books so large that many people have neither money to buy them nor time to read them, while the reproduction of the ripest scientific literature, in form suitable for extensive diffusion, has by no means kept pace with the general advance of thought. The "POPULAR SCIENCE LIBRARY" will contribute to this desirable object by presenting a series of volumes-original, translations, reprints, and abridgments - with copious illustrations, in all the departments of science that are of practical and popular interest. It will take a free range in its choice of subjects, and treat them in a way that will be most interesting and profitable to general readers.

The following works have just been issued, to be followed by others of a similar character, from time to time.

$$
\text { Price, - - - - - \$I.00 each. }
$$

I. HEALTH. By Dr. Edward Smith, F. R. S.

II. THE NATURAL HISTORY OF MAN. By Prof. A. DE QuATRefages. Illustrated. Translated from the French by Eliza A. Youmans.

III. THE SCIENCE OF MUSIC. Illustrated. By SEdey TAYLOR.

IV. OUTLINE OF THE EVOLUTION PHI- LOSOPHY. By Dr. E. Cazelles. Translated from the French by Rev. O. B. Frothingham.

V. ENGLISH MEN OF SCIENCE: their Nature and Nurture. By Francis Galton, F. R. S.

D. APPLETON \& CO.,- Publishers, 549 \& 551 Broadway, N. Y. 


\section{THE GREAT ICE AGE,}

\section{AND ITS RELATIONS TO THE ANTIQUITY OF MAN.}

By JAMES GEIKIE, F. R. S. E.

With Maps, Charts, and numerous Illustrations.

I vol., thick 12mo. . . Price, $\$ 2.50$.

\section{OPINIONS OF THE PRESS.}

"Intelligent general readers, as well as students of geology, will find more information and reasonable speculation concerning the great glacial epoch of our globe in this volume than can be gathered from a score of other sources. The author writes not only for the benefit of his 'fellow-hammerers,' but also for non-specialists, and any one gifted with curiosity in respect to the natural history of the earth will be delighted with the clear statements and ample illustrations of Mr. Geikie's 'Great Ice Age." "-Episcopal Register.

"' The Great Ice Age' is a work of extraordinary interest and value. The subject is peculiarly attractive in the immensity of its scope, and exercises a fascination over the imagination so absorbing that it can scarcely find expression in words. It has all the charms of wonder-tales, and excites scientific and unscientific minds alike."-Boston Gazette.

"Mr. Geikie has succeeded in writing one of the most charming volumes in the library of popularized science."-Utica Herald.

"We cannot too heartily commend the style of this book, which is scientific and yet popular, and yet not so popular as to dispense with the necessity of the reader's putting his mind to work in order to follow out the author in his forcible yet lucid arguments. Nor can the attentive reader fail to leave the work with the same enthusiasm over the subject as is shown in every page by the talented author."-Portland Press.

"Although Mr. Geikie's position in the scientific world is such as to indicate that he is a pretty safe teacher, some of his views are decidedly original, and he does not make a point of sticking to the beaten path."-Springfield Union.

"Prof. Geikie's book is one that may well engage thoughtful students other than geologists, bearing as it does on the absorbing question of the unwritten history of our race. The closing chapter of his work, in which, reviewing his analytical method, he constructs the story of the checkered past of the last 200,000 years, can scarcely fail to give food for thought even to the indifferent."-Buffalo Courier.

"Every step in the process is traced with admirable perspicuity and fullness by Mr. Geikie."-London Saturday Review.

"It offers to the student of geology by far the completest account of the period yet published, and is characterized throughout by refreshing vigor of diction and originality of thought." - Glasgow Herald.

\section{APPLETON \& CO., Publishers,}

549 \& 55I BROADWAY, N. Y. 
Eleventh Edition, Entirely Revised.

\section{PRINCiPles OF GEOLOGY; \\ OR,}

\section{THE MODERN CHANGES OF THE EARTH}

AND

ITS INHABITANTS CONSIDERED AS ILLUSTRATIVE OF GEOLOCX'.

In 2 Vols. 8vo. Cloth.

ILLUSTRATED WITH MAPS, PLATES, AND WOODCUTS.

By Sir CHARLES LYELL, BART., M.A., F.R.S. PRICE, \$8.00.

"I have followed the rule adopted in my first volume, of reprinting the Preface to the tenth edition, by which the reader will be directed to those numerous and important additions and corrections which I found necessary, in consequence of the progress of the science during the fifteen years which separated the ninth and tenth editions." Extract from Preface.

In this last edition of Principles of Geology, Sir Charles Lyell has set the seal of his matured experience and convictions upon a work which has for years held the position of a classic in the literature of science. Encyclopædic in its scope, and exhaustive in its treatment of every department of that study for which our language has no name exactly equivalent to the German Erdkunde, the Principles of Geology may be looked upon with pride, not only as a representative of English science, but as without a rival of its kind anywhere. Growing in fulness and accuracy with the growth of experience and observation in every region of the world, the work has incorporated with itself each established discovery, and has been modified by every hypothesis of value which has been brought to bear upon, or been envolved from, the most recent body of facts. Its successive editions thus stand as a series of landmarks, indicating the gradual expansion or rise of geological knowledge during a lifetime happily prolonged over at least two average generations. In the impression now before us, the veteran geologist might be expected to have comparatively little to add by way of novel matter to the thoroughly revised and largely rewritten edition, the tenth in order, which he put forth scarcely more than three years ago, separated as that edition was by an interval of fifteen years from that immediately preceding it. There are, notwithstanding, sundry points of importance which call for notice as contributing to the facts comprised within his general scope, as well as enhancing the unity and force of the argument which runs through the length and breadth of his system. These editions have reference in the main to three large questions which may be said just now to engross among them the most lively and active interest among students of Nature. The first of these questions is that of volcanic action, manifested especially in geysers, or as diversely affected by water. The second is the latest phase assumed by the discussion upon the Darwinian theory. And the third is the existence and distribution of oceanic life at great depths, as determined by recent dredging operations.

\section{APPLETON \& CO., Publishers,} 549 \& 55I BROADWAY, NEW YORK. 


\section{A New Magazine for Students and Cultivated Readers.}

\section{THE POPULAR SCIENCE MONTHLY, CONDUCTED BY}

Profescor E. L. YOUMANS.

THE growing importance of scientific knowledge to all classes of the community calls for more efficient means of diffusing it. THE PoPULAR SCIENCE MonTHLY has been started to promote this object, and supplies a want met by no other periodical in the United States.

It contains instructive and attractive articles, and abstracts of articles, original, selected, and illustrated, from the leading scientific men of different countries, giving the latest interpretations of natural phenomena, explaining the applications of science to the practical arts, and to the operations of domestic life.

It is designed to give especial prominence to those branches of science which help to a better understanding of the nature of man; to present the claims of scientific education; and the bearings of science upon questions of society and government. How the various subjects of current opinion are affected by the advance of scientific inquiry will also be considered.

In its literary character, this periodical aims to be popular, without being superficial, and appeals to the intelligent reading-classes of the community. It seeks to procure authentic statements from men who know their subjects, and who will address the non-scientific public for purposes of exposition and explanation.

It will have contributions from Herbert Spencer, Professor Huxley, Professor TyNDAll, Mr. DARwin, and other writers identified with speculative thought and scientific investigation.

THE POPULAR SCIENCE MONTHLY is published in a large octavo, handsomely printed on clear type. Terms, Five Dollars per annum, or Fifty Cents per copy.

\section{OPINIONS OF THE PRESS.}

"Just the publication needed at the present day."-Montreal Gazette.

"It is, beyond comparison, the best attempt at jourralism of the kind ever made in this country."-Home Fournal.

"The initial number is admirably constituted."-Evening Mail.

"In our opinion, the right idea has been happily hit in the plan of this new monthly." - Buffalo Courier.

"A journal which promises to be of eminent value to the cause of popular education in this country." $-N$. Y. Tribune.

\section{IMPORTANT TO CLUES.}

The Popular Science Monthly will be supplied at reduced rates with any periodical published in this country.

Any person remitting Twenty Dollars for four yearly subscriptions will receive an extra copy gratis, or five yearly subscriptions for $\$ 20$.

Thr POPUlar ScIENCE MIONThly and APpletons' Journal (weekly), per annum, $\$ 8 . \infty$ T. Payment, in all cases, must be in advance.

Remittances should be made by postal money-order or check to the Publishers,

$$
\text { D. APPLETON \& C0., } 549 \& 551 \text { Broadway, New York. }
$$








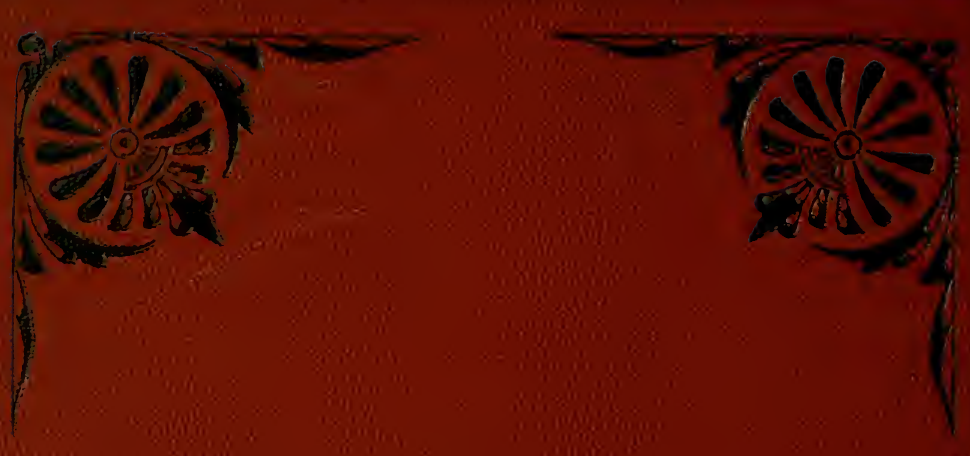

r

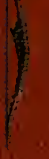

gen 